\title{
METAL COMPLEXES OF SCORPIONATE-LIKE POLYIMIDO SULPHUR PHOSPHANYL LIGANDS
}

\author{
Dissertation zur Erlangung des \\ mathematisch-naturwissenschaftlichen Doktorgrades \\ der Georg-August-Universität Göttingen
}

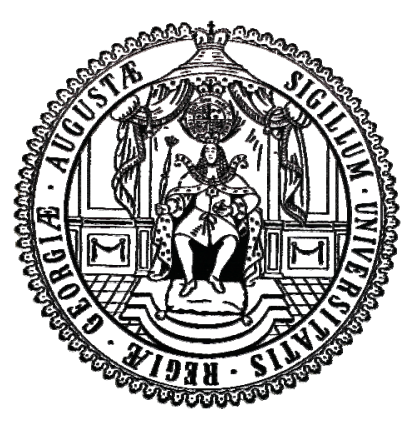

vorgelegt von

Margret Meinholz

aus Coesfeld

Göttingen 2011 

Eingereicht am:

28.03.2011

Referent:

Prof. Dr. D. Stalke

Co-Referenten:

Prof. Dr. F. Meyer

Prof. Dr. L. Ackermann

Datum der mündlichen Prüfung: $\quad$ 11.05.2011

Prüfer Anorganische Chemie: $\quad$ Prof. Dr. D. Stalke

Prüfer Makromolekulare Chemie: Prof. Dr. M. Buback

Prüferin Kristallographie: $\quad$ Prof. Dr. H. Sowa

Erweiterte Prüfungskommision: Prof. Dr. F. Meyer

Prof. Dr. L. Ackermann

Prof. Dr. O. Wenger 
"Oft bringt ein Tag,

worauf man sonst ein Jahr lang wartet."

Menander 


\section{CONTENTS}

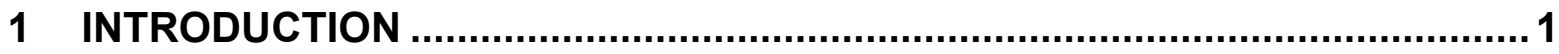

2 LIGANDS WITH PHOSPHORUS SIDE-ARM ........................................ 13

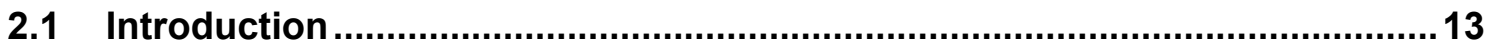

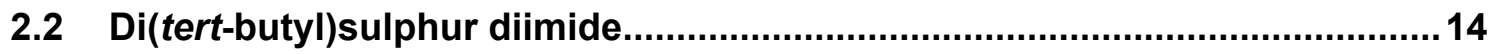

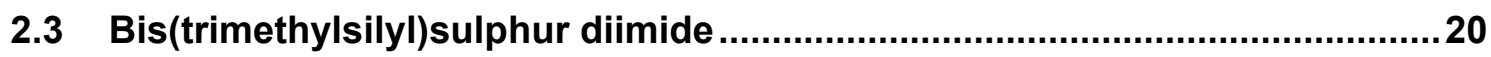

2.3.1 A Stereocentre on the connecting Carbon Atom ......................................... 24

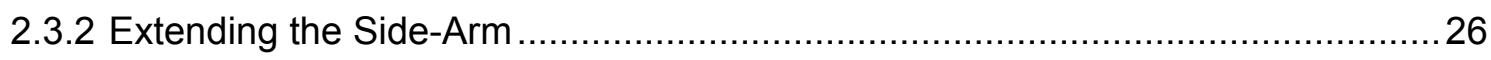

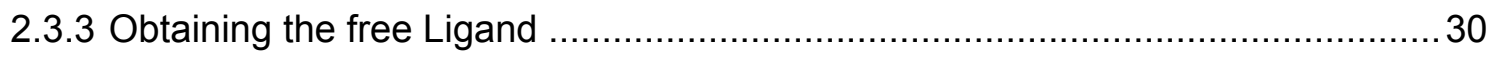

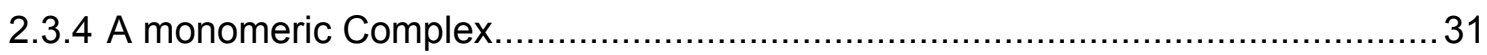

2.4 Complexes with the di(tert-butyl)phosphanyl Side-Arm ...............................

3 LIGANDS WITH NITROGEN SIDE-ARM .................................................... 42

3.1 Metalation and Reaction of Dimethylaniline............................................42

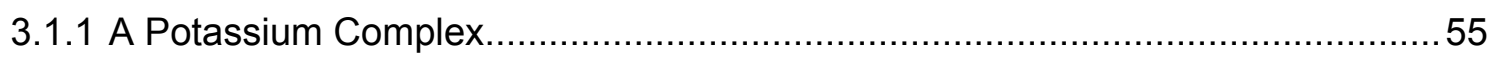

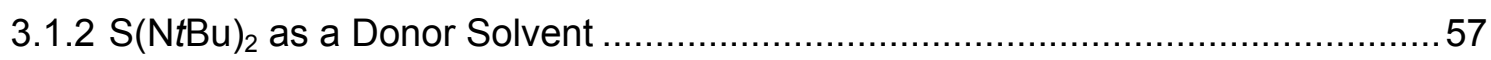

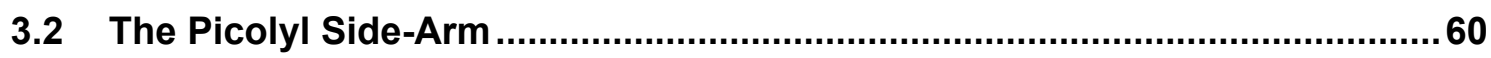

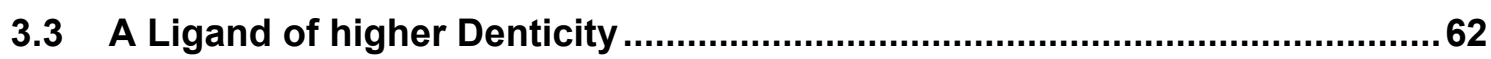

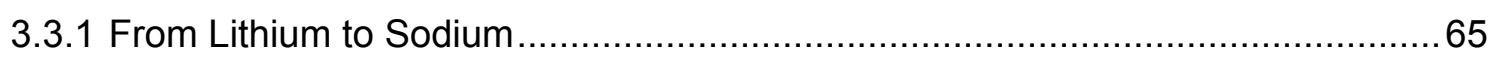

4 COMPLEXES WITH TWO SULPHUR DIIMIDO MOIETIES ...........................69

5 FROM MAIN GROUP TO TRANSITION METALS ................................... 80

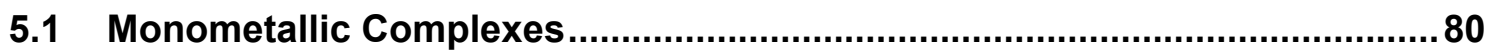

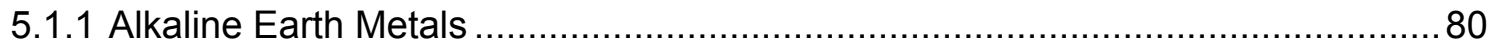

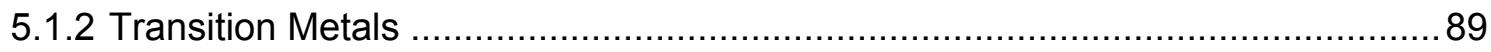

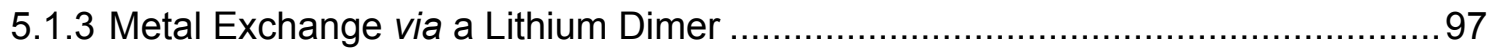

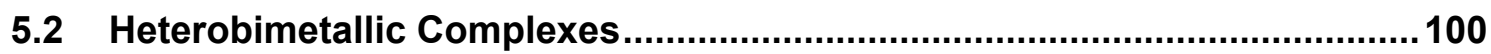

6 CONCLUSION AND OUTLOOK ............................................................ 105 
7 EXPERIMENTAL SECTION................................................................ 108

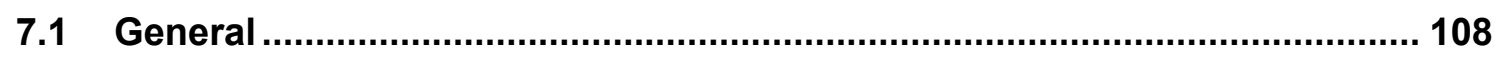

7.2 Analytical Methods.................................................................................. 108

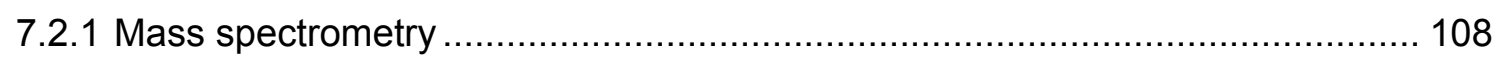

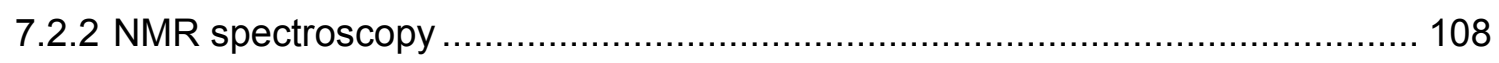

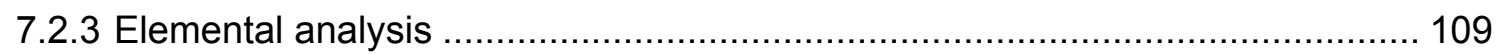

7.3 Syntheses and Characterizations .......................................................... 109

8 CRYSTALLOGRAPHIC SECTION ....................................................... 127

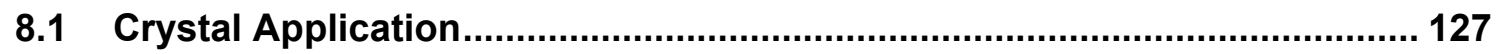

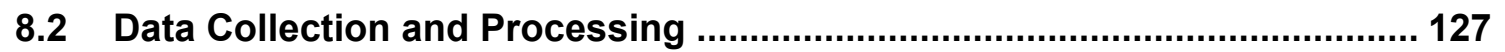

8.3 Structure Solution and Refinement .......................................................... 128

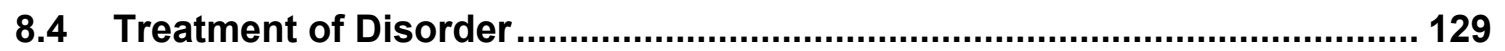

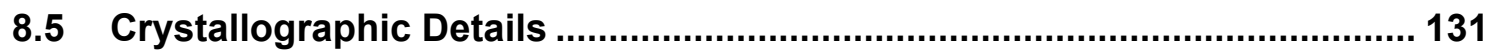

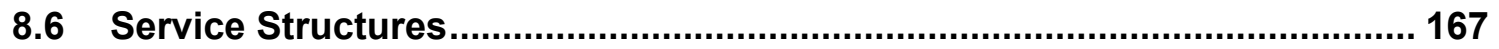

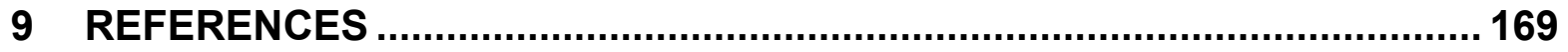




\section{ABBREVIATIONS}

\begin{tabular}{|c|c|}
\hline$\AA$ & Angstrom \\
\hline AMMM & alkali metal mediated metalation \\
\hline approx. & approximately \\
\hline av. & average \\
\hline calc. & calculated \\
\hline $\mathrm{cp}$ & cyclopentadienyl \\
\hline CVD & chemical vapour deposition \\
\hline decomp. & decomposition \\
\hline dme & dimethoxyethane \\
\hline $\mathrm{dmp}$ & 2,6-dimesitylphenyl \\
\hline DOSY & diffusion ordered spectroscopy \\
\hline e. $g$ & for example (lat.: exemplia gratia) \\
\hline Et & ethyl \\
\hline et al. & and others (lat.: et alii) \\
\hline GoF & goodness of fit \\
\hline $\mathrm{h}$ & hour(s) \\
\hline HMBC & heteronuclear multiple bond correlation \\
\hline HOESY & heteronuclear Overhauser effect spectroscopy \\
\hline HSAB & hard and soft acids and bases \\
\hline HSQC & Heteronuclear single quantum coherence \\
\hline i. e. & that is (lat.: id est) \\
\hline $1 \mu S$ & Incoatec Microfocus Source \\
\hline $\operatorname{iPr}$ & iso-propyl \\
\hline LDA & lithium diisopropyl amide \\
\hline M & molar \\
\hline $\mathrm{Me}$ & methyl \\
\hline$n \mathrm{Bu}$ & $n$-butyl \\
\hline NMR & nuclear magnetic resonance \\
\hline NOESY & nuclear Overhauser effect spectroscopy \\
\hline $\mathrm{Ph}$ & phenyl \\
\hline pmdeta & pentamethyldiethylenetriamine \\
\hline pic & picolyl \\
\hline ppm & parts per million \\
\hline
\end{tabular}


$\mathrm{pz}$

rt

tBu

thf

thp

tmcda

tmeda

tmmda

tmp

trmeda

vs.

pyrazolyl

room temperature

tert-butyl

tetrahydrofurane

tetrahydropyrane

tetramethylcyclohexane-1,2-diamine

tetramethylethylenediamine

tetramethylmethylenediamine

tetramethylpiperidine

trimethylethylenediamine

versus 


\section{LIST OF COMPOUNDS}

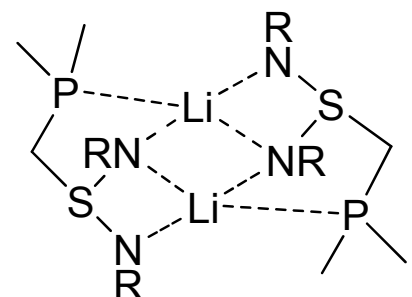

1: $\mathrm{R}=t \mathrm{Bu} ; 4: \mathrm{R}=\mathrm{SiMe}_{3}$

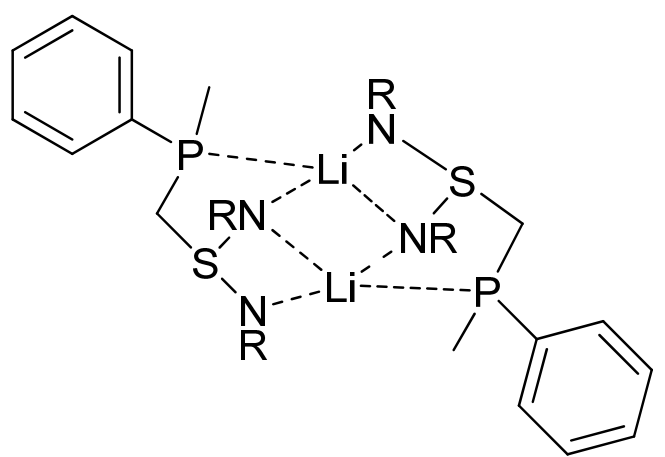

3: $\mathrm{R}=t \mathrm{Bu} ; \mathbf{6}: \mathrm{R}=\mathrm{SiMe}_{3}$

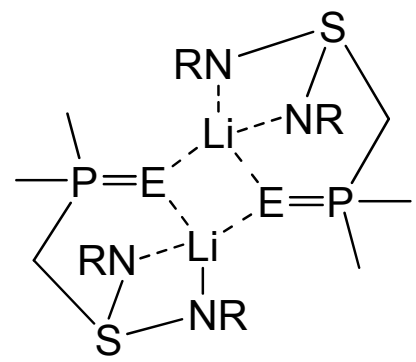

8: $\mathrm{E}=\mathrm{S}, \mathrm{R}=\mathrm{SiMe}_{3} ;$ 9: $\mathrm{E}=\mathrm{Se}, \mathrm{R}=\mathrm{SiMe}_{3}$

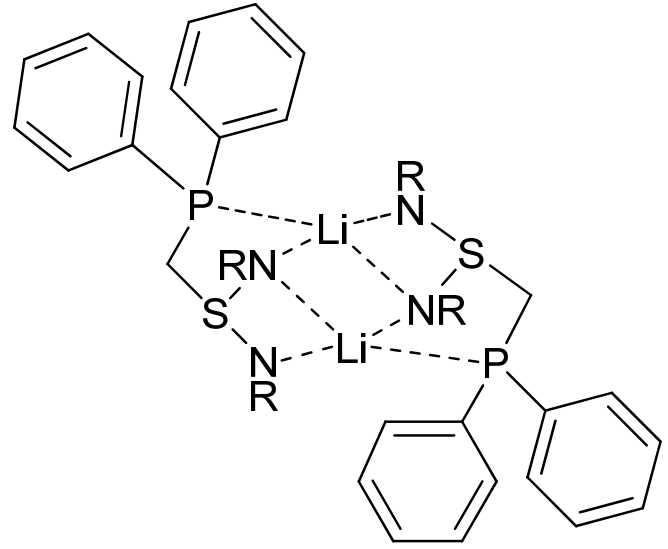

2: $\mathrm{R}=t \mathrm{Bu} ; \mathbf{5}: \mathrm{R}=\mathrm{SiMe}_{3}$

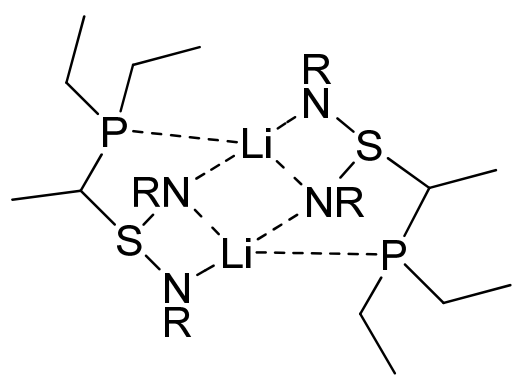

7: $\mathrm{R}=\mathrm{SiMe}_{3}$<smiles>C[SiH3]N=[SH](CP(c1ccccc1)c1ccccc1)=N[SiH3]C</smiles>

10 


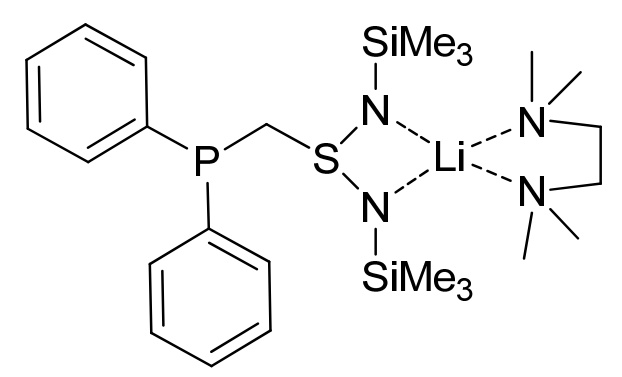

11

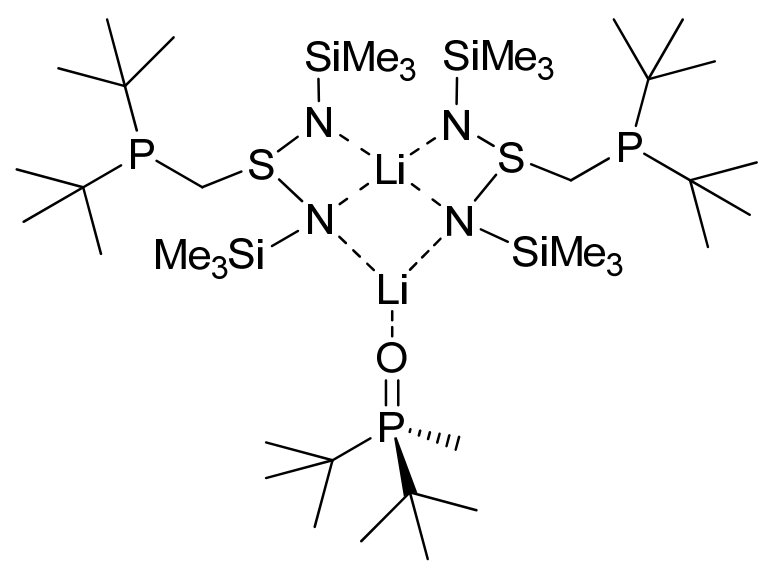

13

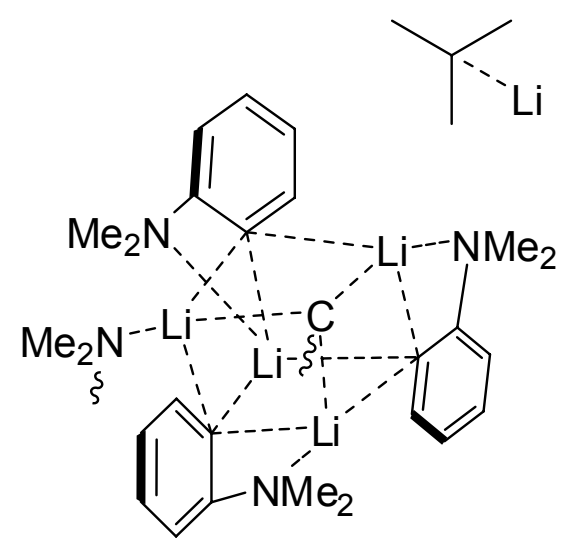

15: one phenyl ring has been omitted for clarity

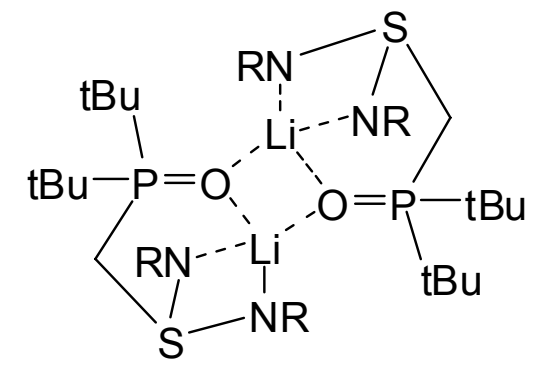

12: $\mathrm{R}=\mathrm{SiMe}_{3}$

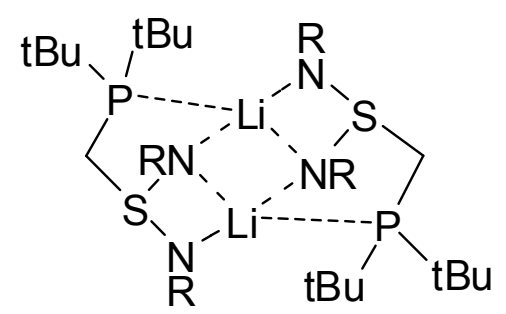

14: $\mathrm{R}=\mathrm{SiMe}_{3}$

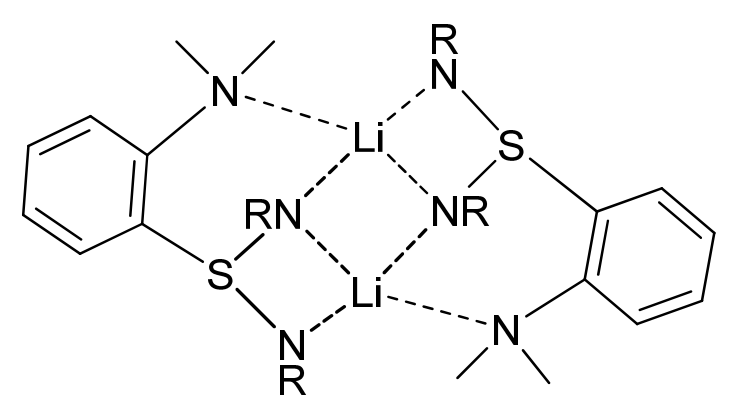

16: $\mathrm{R}=\mathrm{SiMe}_{3}$ 


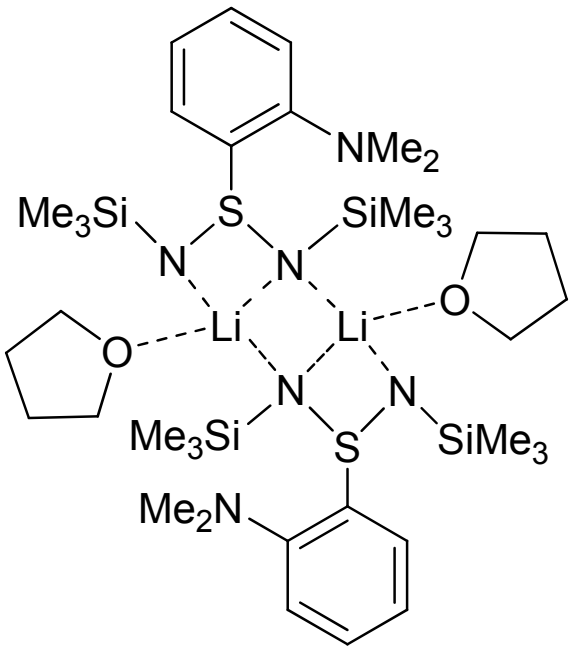

17

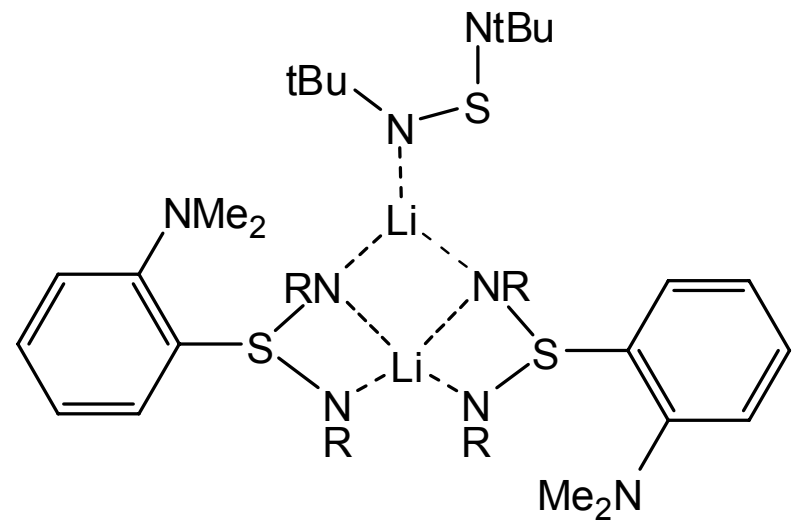

19: $R=t B u$

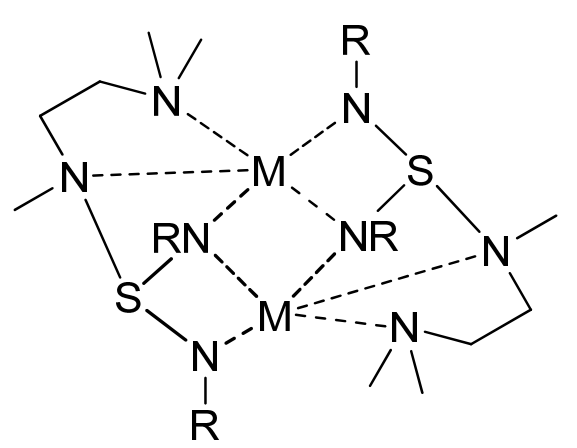

21: $\mathrm{R}=\mathrm{SiMe}_{3}, \mathrm{M}=\mathrm{Li} ; \mathrm{22}: \mathrm{R}=\mathrm{SiMe}_{3}, \mathrm{M}=\mathrm{Na}$

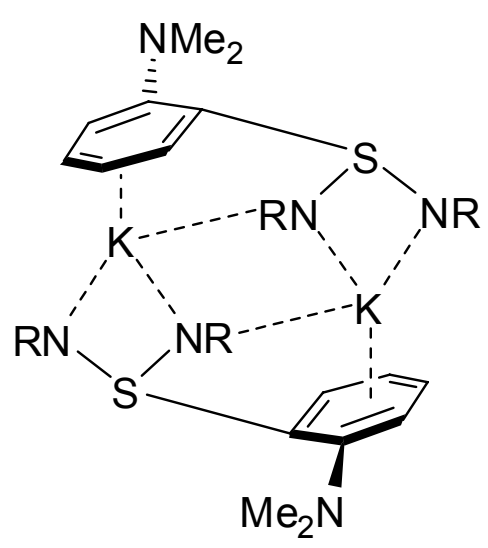

18: $\mathrm{R}=\mathrm{SiMe}_{3}$

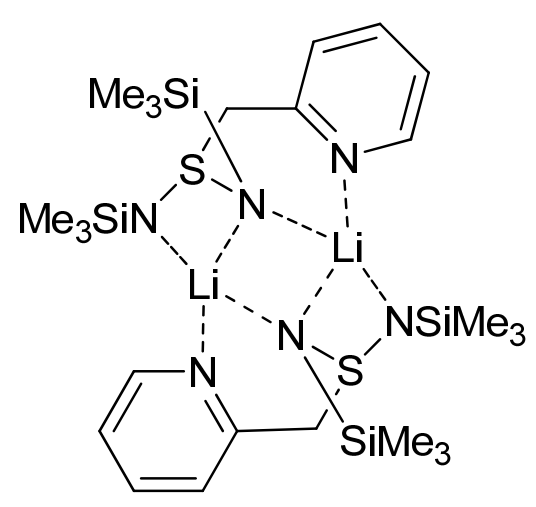

20

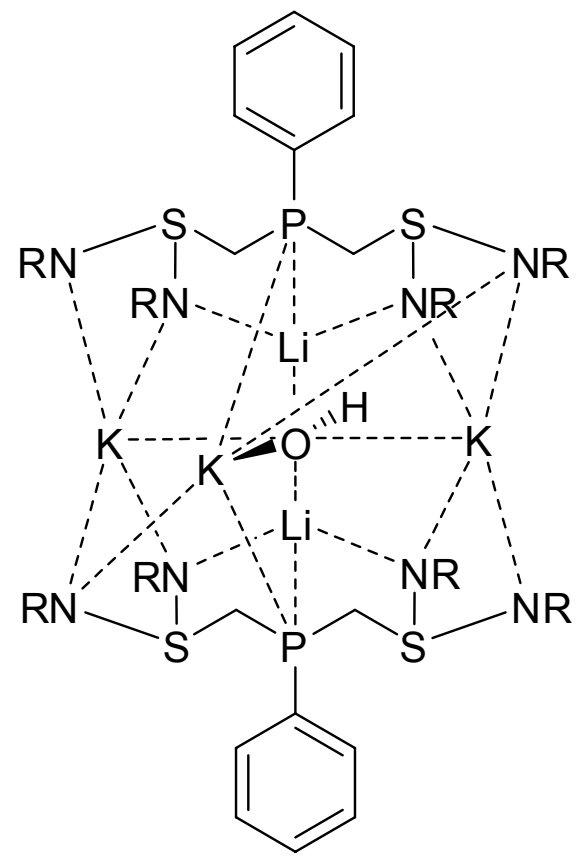

23: $\mathrm{R}=\mathrm{SiMe}_{3}$ 


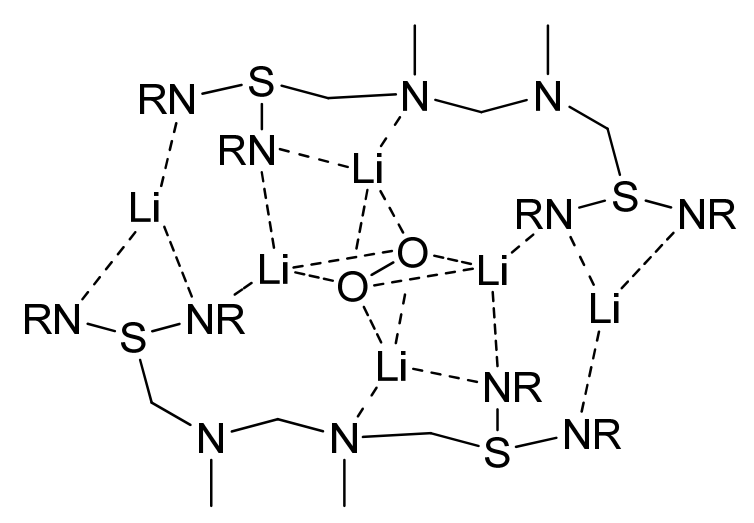

24: $R=t B u$

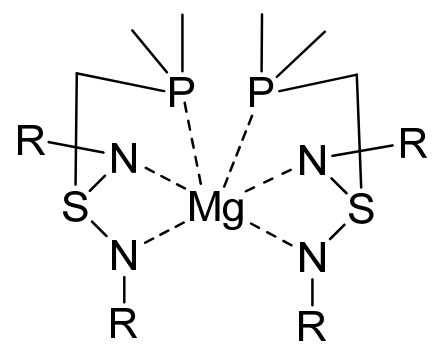

26: $\mathrm{R}=t \mathrm{Bu} ; 2$ 27: $\mathrm{R}=\mathrm{SiMe}_{3}$

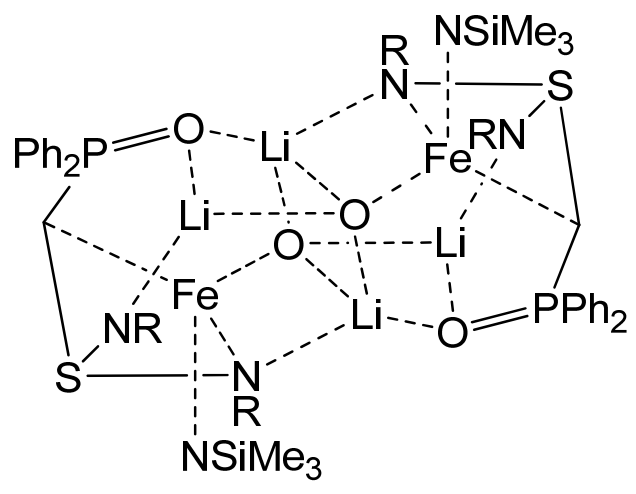

32: $\mathrm{R}=\mathrm{SiMe}_{3}$

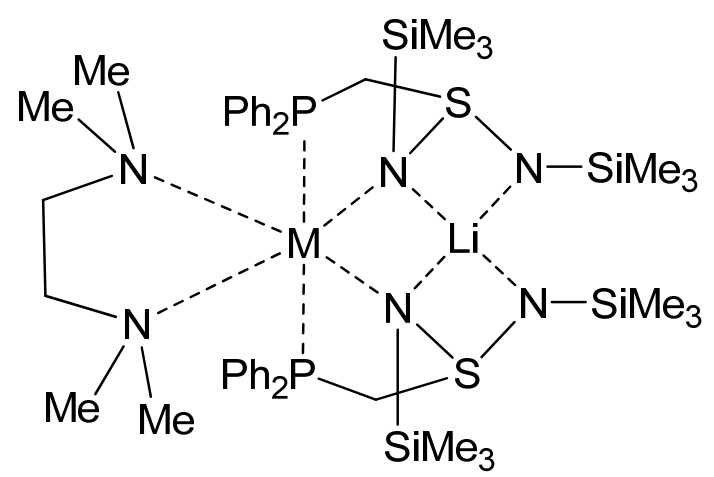

34: $M=R b^{+} ; 35: M=K^{+}$

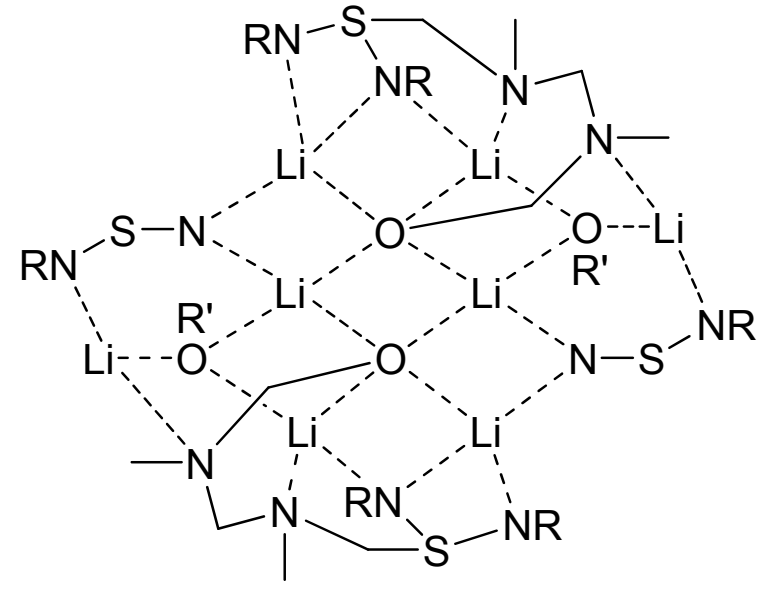

25: $\mathrm{R}=\mathrm{SiMe}_{3}, \mathrm{R}^{\prime}=t \mathrm{Bu}$

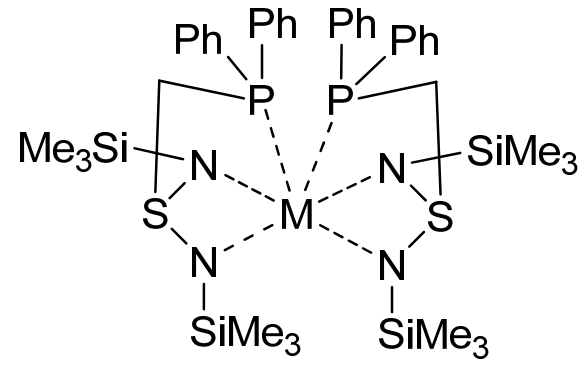

28: $\mathrm{M}=\mathrm{Ca}^{2+} ; \mathbf{2 9}: \mathrm{M}=\mathrm{Sr}^{2+} ; \mathbf{3 0}: \mathrm{M}=\mathrm{Co}^{2+} ; 31: \mathrm{M}$

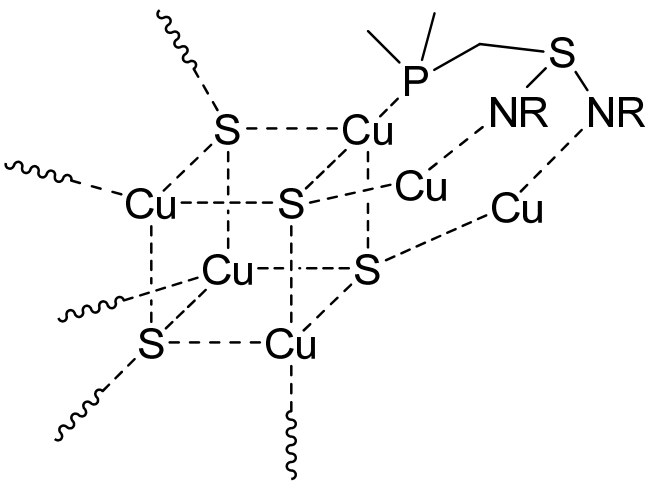

33: $\mathrm{R}=\mathrm{SiMe}_{3}$ 



\section{INTRODUCTION}

A prominent example for ligand design are poly(pyrazolyl)borates which Trofimenko introduced in 1966 as a new class of chelating ligands (Figure 1-1). ${ }^{[1]}$ They are prepared by heating an alkali metal borohydride with pyrazole at different temperatures, thus adding subsequent equivalents of pyrazole to the boron atom. Their stability towards air and moisture increases with the number of pyrazolyl groups bonded to the central boron atom. Tris(pyrazolyl)borate for instance is storable for years in the solid state even if exposed to air and light. Most of the poly(pyrazolyl)borate transition metal complexes are stable in water and air as well. ${ }^{[2]}$
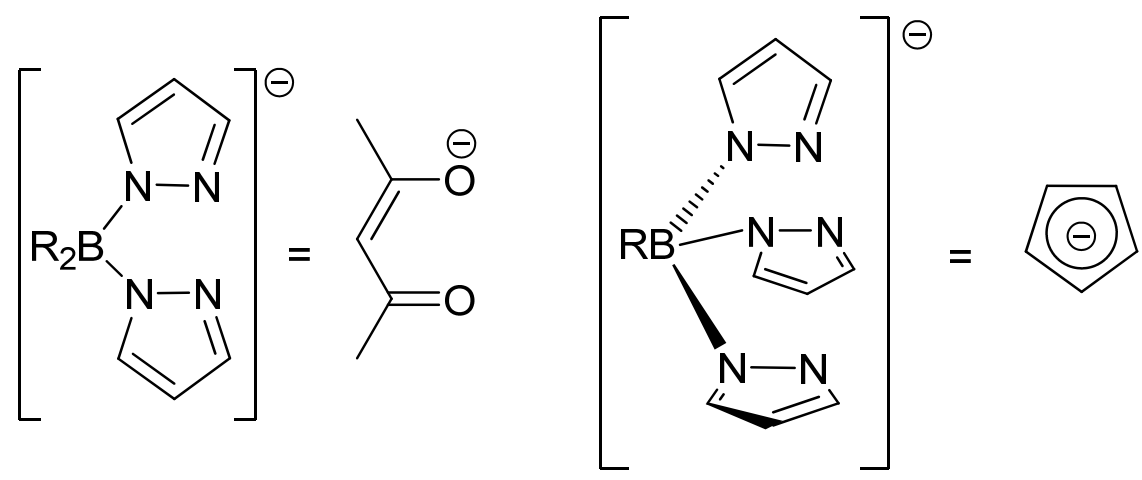

Figure 1-1: Analogies between bis(pyrazolyl)borate and $\beta$-diketonates (left); tris(pyrazolyl)borates and cyclopentadienyl (right); $\mathrm{R}=\mathrm{H}$, alkyl, aryl, ... .

The tris(pyrazolyl)borates in particular show very interesting complexation properties. They are often described as being analogues to $\mathrm{Cp}$ or $\mathrm{Cp}^{*}$ (Figure 1-1) as they are also six-electron donors, monoanionic and coordinate in a facial way, but this description does not take into account their unique complexation behaviour. ${ }^{[3,4]}$ With this ligand it was even possible to synthesise a homologue series of complexes with the hapticity of the ligand changing from $\kappa^{3}$ to $\kappa^{0} \cdot{ }^{[5]} \mathrm{A} \kappa^{5}$ Ir-complex ${ }^{[6]}$ and a $\eta^{5}$ compound ${ }^{[7]}$, where one of the pyrazole rings is coordinating a potassium cation, were described, too. However, these are special cases.

In general, the most important features of poly(pyrazolyl)borates are:

- formation of a six-membered, boat-shaped ring with a coordinated metal (Figure 1-2)

- tridentate, tripodal

- monoanionic

- facial coordinating

- "spectator ligands" (do not take part in reactions at the metal centre) 
The two pz groups ( $p z=1$-pyrazolyl or substituted 1-pyrazolyl) that are in plain chelate the metal in a bidentate way. The third pseudoaxial pz group acts as a sidearm that bends towards the metal. Therefore, the term "scorpionates" was coined with the two in-plane pyrazolyl groups being the claws and the third pz group being the sting of the scorpion.

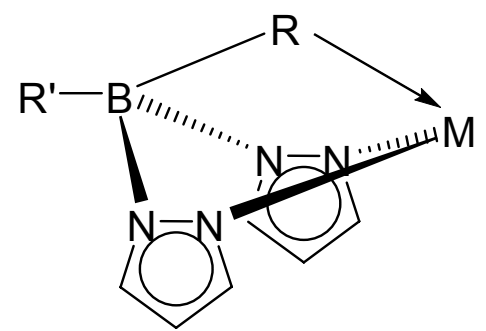

Figure 1-2: Boat conformation in metal complexes of poly(pyrazolyl)borates. $\mathrm{R}^{\prime}=\mathrm{H}$, alkyl, aryl, ...; $\mathrm{R}=\mathrm{H}, \mathrm{NR}_{2}, \mathrm{pz}, \mathrm{OR}, \mathrm{SR}$, agostic $\mathrm{C}-\mathrm{H}, \ldots$.

Over the years, the poly(pyrazolyl)borates triggered significant development in terms of ligands design and shaping of the complexation properties. Until today, there are four generations of poly(pyrazolyl)borate ligands. The first generation has been described above, where each donor site is a pz group.

The second generation came up in the 1980s and was developed by Trofimenko and co-workers as well. ${ }^{[8]}$ In this ligand type, the pyrazole rings bear bulky substituents at the 3-position and thus increased control is gained on the coordination behaviour. By choice of the substituents $(t \mathrm{Bu}, \mathrm{Ph}, \ldots)$, a coordination pocket of desired size can be created to fit certain metals. To be precise, it was then possible to synthesise monomeric complexes of transition metals $(M L(X)$, $\mathrm{L}=$ scorpionate, $\mathrm{X}=$ monodentate ligand) rather than dimeric octahedral complexes $\left(\mathrm{ML}_{2}\right)$. In terms of catalytic applications, the $\mathrm{ML}(\mathrm{X})$ form is preferred as it is more reactive. Additionally, the second generation scorpionate ligands prevent dissociation into $\mathrm{ML}_{2}$ and $\mathrm{MX}_{2}{ }^{[9]}$ and access of substrates can be controlled by the size of the coordination pocket. ${ }^{[8 a]}$

The third generation scorpionates are tuned by substituting the noncoordinating ligand R' (Figure 1-2). ${ }^{[10]}$ This leads to different packing of the molecules in the crystal structure and can alter the spin state of the coordinated metal. In addition, the introduction of a further donor site paves the way for heterobimetallic complexes. Finally, the term "fourth generation scorpionates" was introduced in 2010 for linked pyrazolylborates that can bind in a meridional way to metal ions. ${ }^{[11,12,13]}$ Consequently, they offer different coordination modes in comparison to the classical 
scorpionate ligands, however their stability is sometimes limited. Examples for the four generations of scorpionate ligands are depicted in Figure 1-3.

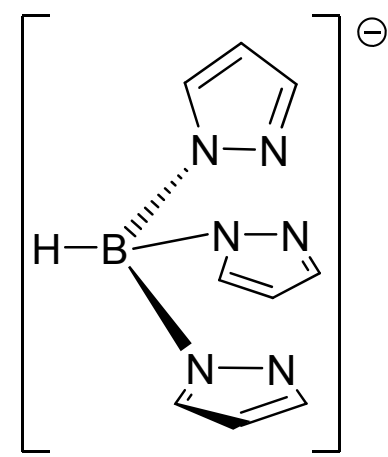

1. generation

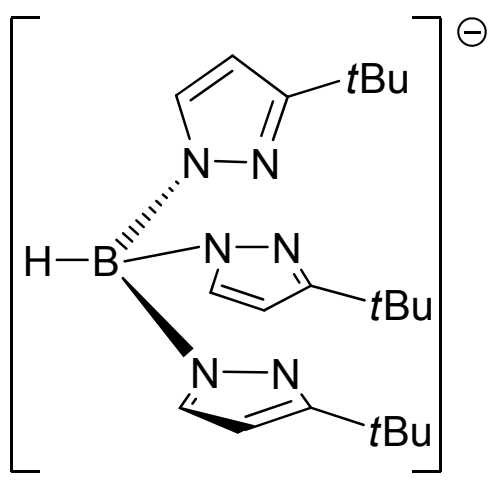

2. generation

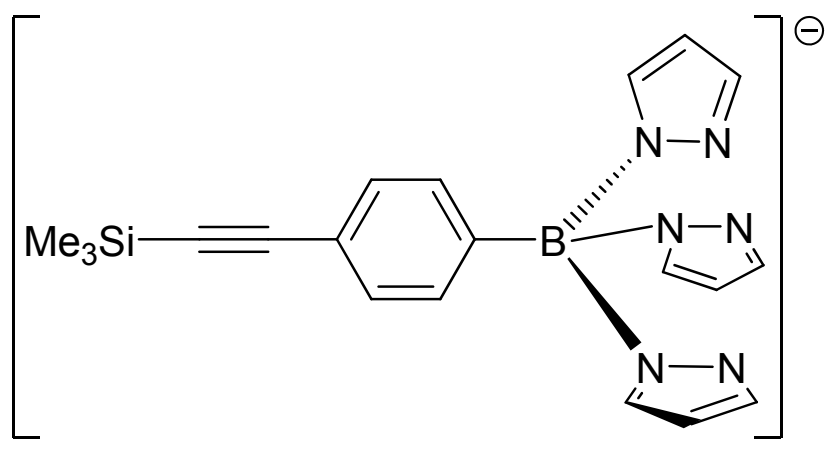

3. generation

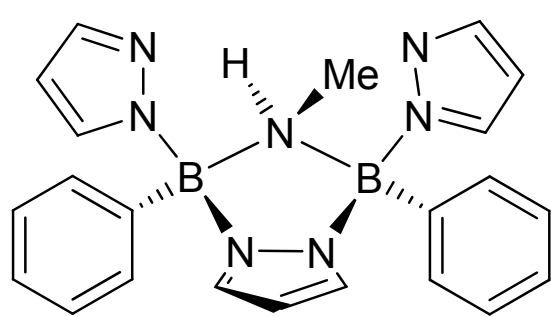

4. generation

Figure 1-3: Four generations of scorpionate ligands.

Further classification into two different classes of scorpionate ligands is possible. Homoscorpionates have three identical coordinating groups, usually pyrazole. Heteroscorpionates consist of two identical chelating claws (pyrazole) and a sting that is different from pyrazole. Thus, it is possible to introduce softer donor sites into the ligand periphery. Alternatively, all pz groups can be replaced by substituents with other donor atoms like sulphur, selenium or phosphorus. Interesting examples can be found in the phosphinoborate family, namely $\left[\mathrm{PhB}\left(\mathrm{CH}_{2} \mathrm{PiPr}_{2}\right)_{3}\right]^{-[14]}$ or $\left[\mathrm{PhB}\left(\mathrm{CH}_{2} \mathrm{PPh}_{2}\right)_{3}\right]^{-[15]}$. The boron atom can also be replaced by carbon, leading to poly(pyrazolyl)methanes ${ }^{[16]}$ which are neutral analogues of poly(pyrazolyl)borates and are also important in coordination chemistry. ${ }^{[17]}$

One of the most important features of scorpionate ligands is their applicability in biomimetical complexes as the pyrazole group is histidine-like. By the introduction of other donor atoms in the side-arms, the coordination by different amino-acids can be modelled. Important examples come from the group of Lippard who succeeded in 
modelling the diiron centre of the oxygen transport protein hemerythrin. ${ }^{[18]}$ This dinuclear oxo-bridged iron complex contains histidine and oxygen donors around the iron atoms and could be modelled with the complex $\left[\mathrm{Fe}_{2} \mathrm{O}\left(\mathrm{O}_{2} \mathrm{CCH}_{3}\right)_{2}\left(\mathrm{HBpz}_{3}\right)_{2}\right]$ (Figure 1-4).

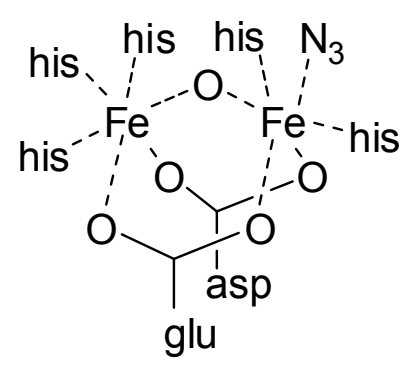

(a)

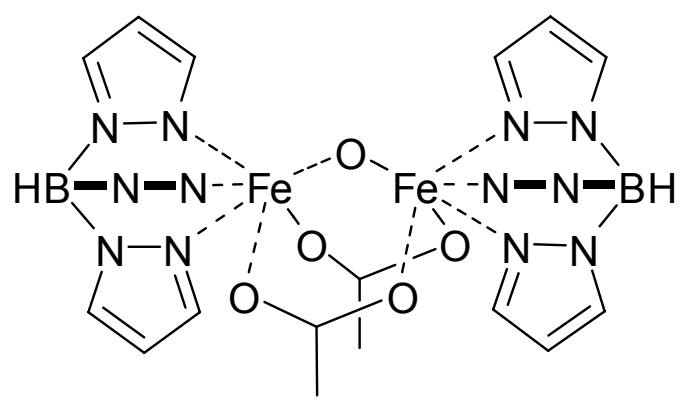

(b)

Figure 1-4: Diiron site of hemerythrin ( $\mathrm{a}$, his = histidine, glu = glutamate, asp = aspartate $)$ and structural model (b, B-N-N = pyrazole).

Kitajima et al. worked on dinuclear copper complexes which could serve as models for the oxygen binding in hemocyanin which also is an oxygen transport protein. ${ }^{[19]}$ The compound $\left[\mathrm{Cu}\left(\mathrm{HB}\left(3,5-\mathrm{Pr}_{2} \mathrm{pz}\right)_{3}\right)\right]_{2}(\mathrm{O})_{2}$ is a dimer where both copper atoms are coordinated facially by the tris(pyrazolyl)borate ligands and are bridged side-on by a peroxide molecule. The steric bulk of the employed second generation scorpionate made this dinuclear complex feasible.

In 1997 Higgs and Carrano introduced (2-hydroxyphenyl)bis(pyrazolyl)methanes as biomimetically relevant heteroscorpionates. ${ }^{[20]}$ These ligands can stabilise cobalt(II) in an octahedral or a tetrahedral environment thereby showing their flexibility.

A heteroditopic approach was undertaken by Holthausen, Wagner and coworkers. ${ }^{[21]}$ They wanted to model the coordination environment of the copper atoms in dopamine $\beta$-monooxygenase and peptidylglycine $\alpha$-hydroxylating monooxygenase which catalyse the stereo specific hydroxylation of $\mathrm{C}-\mathrm{H}$ bonds in certain peptides. In the dinuclear reactive centre of the enzymes one copper atom is surrounded by three histidine ligands $\left(\mathrm{Cu}_{\mathrm{A}}\right)$, the other one by two imidazolyl and one methionine-thioether group $\left(\mathrm{Cu}_{\mathrm{B}}\right){ }^{\left[{ }^{[22]}\right.}$ Therefore, two scorpionates with pyrazolyl and thioether substituents were linked together via a $p$-phenylene bridge (Figure 1-5). Thus, both copper atoms would be held at a distance of $11 \AA$, which had also been found in the enzymes mentioned above. 


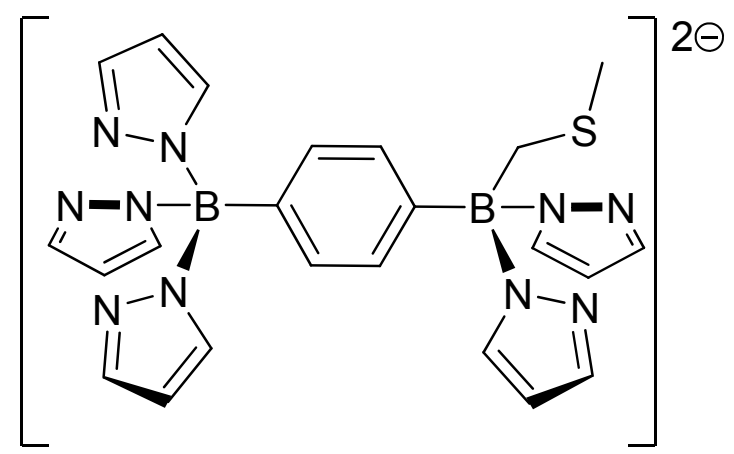

Figure 1-5: Structural model of the active site in dopamine $\beta$-monooxygenase and peptidylglycine $\alpha$ hydroxylating monooxygenase.

In general, the steric demand, ligand field strength and the complexation behaviour of scorpionate ligands can nowadays be controlled. Scorpionate ligands are used in polymerisation reactions ${ }^{[23]}$, chemical vapour deposition $(C V D)^{[24]}$ and bioinorganic chemistry, just to name a few applications. They have one drawback, though: it is very difficult to synthesise homogeneous series of heteroscorpionate ligands because of selectivity problems and substituent scrambling on the borate ion. ${ }^{[11]}$ This is important, however, if the ligand properties are to be reliably tuned.

Instead of a boron atom as bridgehead, other elements can be used in order to create scorpionate-like tripodal ligands. One example, which was already mentioned above, is the carbon atom in poly(pyrazolyl)methanes. However, softer elements like silicon $^{[25]}$ and phosphorus ${ }^{[26]}$ or even metals like germanium ${ }^{[27]}$ tin $^{[27]}$ and lead ${ }^{[28]}$ can serve as bridgehead atoms.

In our group, the sulphurimide chemistry is a well investigated field. Therefore, the idea of using sulphur as a bridgehead atom was obvious. It is well known that in sulphur diimides $\mathrm{S}(\mathrm{NR})_{2}$, the $\mathrm{S}-\mathrm{N}$ bonds can be described as $\mathrm{S}^{\delta+}-\mathrm{N}^{\delta-}$ polar bonds, which has been proven by theoretical and experimental charge density studies. ${ }^{[29,30]}$

$$
\begin{aligned}
2 \mathrm{~S}(\mathrm{NtBu})_{2}+4[\mathrm{Li}(\mathrm{HNtBu})] \stackrel{\text { hexane, rt }}{\longrightarrow}\left[\mathrm{Li}_{4}\left\{(\mathrm{NtBu})_{3} \mathrm{~S}\right\}_{2}\right]+2 \mathrm{H}_{2} \mathrm{NtBu} \\
\quad\left[\mathrm{Li}_{4}\left\{(\mathrm{NtBu})_{3} \mathrm{~S}\right\}_{2}\right]+2 \mathrm{Br}_{2} \frac{\text { hexane/thf }}{\stackrel{-78^{\circ} \mathrm{C}}{\longrightarrow}} \mathrm{S}(\mathrm{NtBu})_{3}+4 \mathrm{LiBr}
\end{aligned}
$$

Equation 1-1: Preparation of $\mathrm{S}(\mathrm{NtBu})_{3}$.

Therefore, it is possible to add nucleophiles to the central sulphur atom in order to synthesise potentially tripodal ligands. One very interesting example which has been extensively studied is tris(tert-butyl)sulphur triimide, $\mathrm{S}(\mathrm{N} t \mathrm{Bu})_{3}$. 
The third coordinating imido group is added via reaction of $\mathrm{S}(\mathrm{NtBu})_{2}$ with [ $\mathrm{Li}$ $(\mathrm{HNtBu})]$ and subsequent oxidation with bromine (Equation 1-1). ${ }^{[31]}$ However, there are certain disadvantages in the synthesis and the final product. The intermediate $\left[\mathrm{Li}_{4}\left\{(\mathrm{NtBu})_{3} \mathrm{~S}\right\}_{2}\right]$ is highly oxygen sensitive and immediately turns blue if it is not handled with the greatest care. ${ }^{[32]}$ In addition, the tris(tert-butyl)sulphur triimide is not very flexible regarding its coordination properties. The $\mathrm{S}-\mathrm{N}$ bonds are rather short and rigid and the substituents on the nitrogen atoms are bulky. This could be overcome, however, by the introduction of an additional, more flexible side-arm. As the molecule is planar, the attack of a nucleophile from above or beneath the $\mathrm{N}-\mathrm{S}-\mathrm{N}$ plane seems feasible.

However, this is hindered by electronic reasons, because exactly in these positions there is an accumulation of electron density (Figure 1-6). The attack of a nucleophile is only possible directly between two NtBu groups, where a charge depletion can be found. ${ }^{[29]}$ Therefore, only reagents that are quite slim i. e. small and planar can

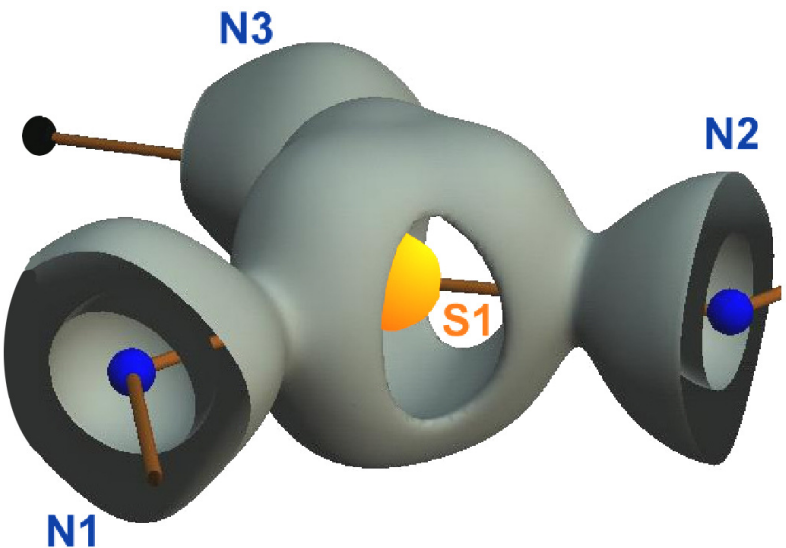

Figure 1-6: Laplacian of $\mathrm{S}(\mathrm{NtBu})_{3 .}{ }^{[29]}$ be used because of the bulky tertbutyl groups that shield the sulphur atom. In another approach, Schulz employed Grignard reagents that are softer and thereby more reactive towards the sulphur atom. ${ }^{[33]}$ He succeeded in bonding phenyl and benzyl groups to the central atom. However, these substituents do not have additional donor functionalities.

For those reasons, the functionalization of sulphur diimides seemed more rewarding as they already show a great variety of coordination motives ${ }^{[34]}$ (Figure 1-7) and the introduction of a side-arm is straightforward. Thus, heteroscorpionate type ligands can be created. 


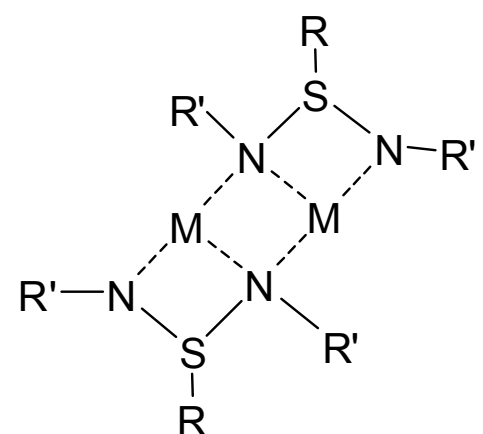

I<smiles>[R]N([R])[Si]([R])N([R])[M]N([R])[SH]([R])N([R])[M]</smiles>

IV

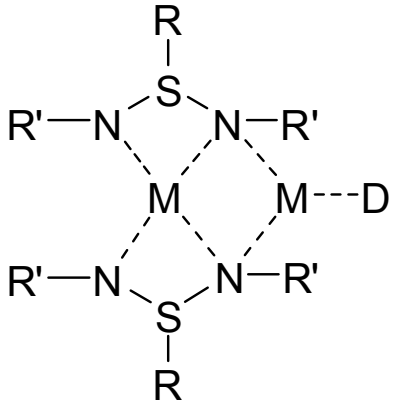

II<smiles>[R]C(N([R])[R])N([R])S1([R])N([R])C([R])N([R])N1[R]</smiles>

III

Figure 1-7: Coordination motives of diimidosulfinates $\left(M=\right.$ metal, $D=$ donor, $R / R^{\prime}=$ organic group).

Side-arms that have already been added to sulphur diimides include carbon, silicon, nitrogen and sulphur functionalities. ${ }^{[35,36,37]}$

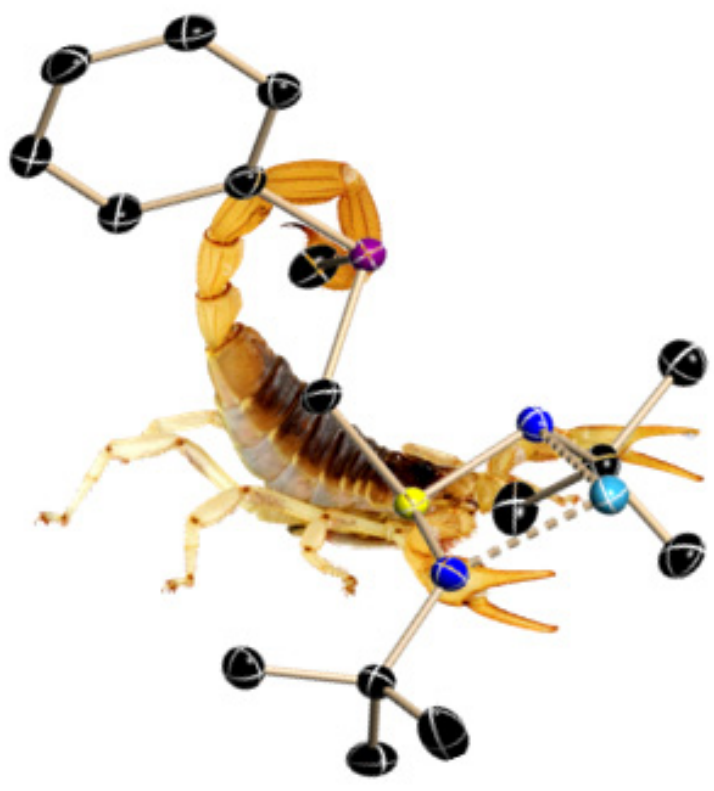

Figure 1-8: The scorpion is ready to sting.
In 2007 Deuerlein presented the synthesis of the phosphorusfunctionalized sulphur diimide $\left[\mathrm{Li}\left\{\mathrm{Me}_{2} \mathrm{PCH}_{2} \mathrm{~S}(\mathrm{~N} t \mathrm{Bu})_{2}\right\}\right]_{2}$ (1) ${ }^{[38,39]}$ This molecule is reminiscent of heteroscorpionates which also have the $(N, N, P)$ form. ${ }^{[40]}$

Its claws are the two diimido groups (dark blue) whereas the sting is represented by the phosphorus sidearm (purple) which can swing out and coordinate to the metal (Figure 1-8). Thereby potentially tridentate ligands with different donor sites can be created. This is of great 
importance for the synthesis of heterobimetallic complexes with metals of different HSAB hardness. ${ }^{[41]}$

Heterobimetallic complexes gain ever increasing attention in preparative chemistry, above all in deprotonation reactions. Usually, lithium organic reagents like BuLi or LDA are used for such purposes. However, they suffer from insufficient functional group tolerance, low selectivity and the reactions have to be conducted at low temperatures (usually below $0^{\circ} \mathrm{C}$ ) to avoid side-reactions. This is where so-called complex metalators consisting of two or more metal components are used. In these compounds the metal atoms interact synergistically because they are held in close spatial proximity. Thereby, unusual (for lithium organics) deprotonation reactions are feasible and selectivities can greatly be enhanced. Prominent examples are the LiCKOR superbases of Lochmann and Schlosser ${ }^{[42]}$, zincate complexes ${ }^{[43]}$, turboGrignard reagents ${ }^{[44]}$ or inverse crown reagents for alkali metal mediated metalations $(\mathrm{AMMMs})^{[45]}$. These four types of metalating agents will be described briefly and some examples are presented (Figure 1-9). A more detailed discussion can be found in the literature and partly in upcoming chapters of this thesis.

In the 1960's, Lochmann and Schlosser observed independently, that the interaction of a lithium organic reagent ( $\mathrm{LiC}$ ) and a potassium alkoxyde (KOR) lead to a more reactive species (LiCKOR). Therefore, these systems were called superbases, as their reactivity is enhanced in comparison to $n B$ BuLi although is below that of pure $n$ BuK. Until today, however, the structures of most of these superbases are not clear.

Zincate complexes have been investigated by Kondo and Uchiyama since 1999. They paired lithium-TMP (TMP = tetramethylpiperidine) with $\mathrm{Zn}(t \mathrm{Bu})_{2}$ to produce a TMP-zincate. ${ }^{[43 a]}$ This reagent proved to be highly reactive in the ortho-metalation of arenes. Also the metalation of heteroaromatic systems was possible with excellent selectivity. By the change of the substituents on the zinc atom, the stereo selectivity can be controlled. ${ }^{[43 \mathrm{~b}]}$ However, again no crystal structure was presented. Stalke et al. studied the aggregation and deaggregation of parent lithium trimethylzincate with different donor bases and presented crystal structures of a contact ion pair and a solvens separated ion pair. ${ }^{[46]}$ 
Turbo-Grignard reagents are linked to the name of Knochel and obey the general formula $\mathrm{RMgCl} \cdot \mathrm{LiCl}(\mathrm{R}=$ alkyl). Such mixed lithium/magnesium complexes are more reactive than the original, monometallic Grignard reagents (RMgX). When an equimolar amount of $\mathrm{LiCl}$ is added to $i \mathrm{PrMgCl}$, its reactivity in $\mathrm{Br} / \mathrm{Mg}$ exchange reactions is greatly increased. ${ }^{[44 a, 47]}$ The reagent was prepared for the first time by adding $\mathrm{PrCl}$ to magnesium turnings and $\mathrm{LiCl}$ in $\mathrm{THF}$ and was used as this solution. Today it is even commercially available. ${ }^{[48]}$ Knochel suggested that the high reactivity of this turbo-Grignard base was due to the fact that $\mathrm{LiCl}$ breaks up the oligomeric $(i \mathrm{PrMgCl})_{\mathrm{n}}$ aggregates.

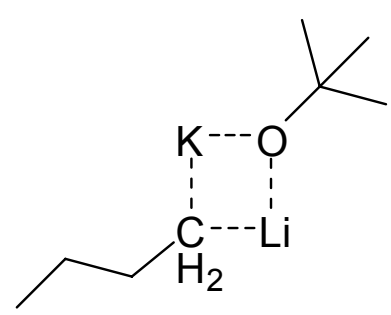

a<smiles></smiles>

C

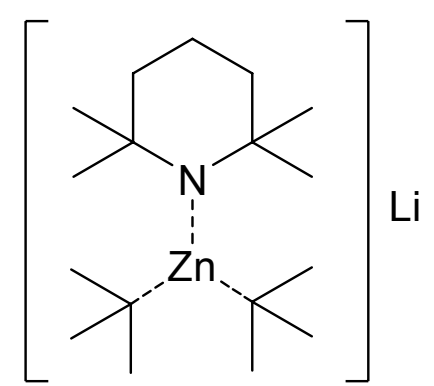

b

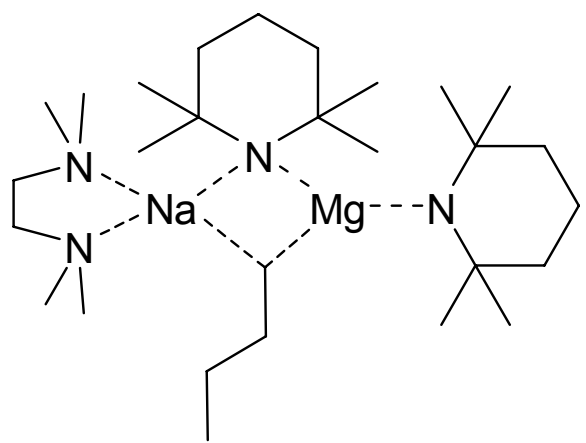

d

Figure 1-9: Heterobimetallic complexes for metalation reactions; a: LiCKOR, b: Zincate, c: turboGrignard, d: AMMM.

In subsequent reactions it became evident that derivatives of $\mathrm{PrMgCl} / \mathrm{LiCl}$ display an enhanced stereo selectivity in the magnesiation of arenes and heteroarenes. ${ }^{[49]}$ The turbo-Grignard reagents for this reactions were prepared by mixing $i \mathrm{PrMgCl} \cdot \mathrm{LiCl}$ with an amine (TMP, $\mathrm{HNiPr}_{2}$ ) and the resulting turbo-Hauser ${ }^{[50]}$ base (which can be regarded as a special case of turbo-Grignards) was then reacted with an arene or heteroarene (Equation 1-2). 


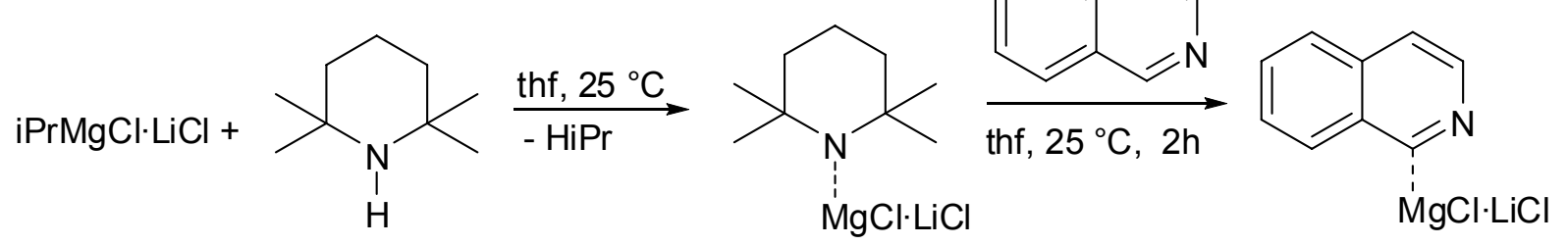

Equation 1-2: Preparation and reaction of turbo-Grignard reagents.

Recently, the structure of one of these reagents has been elucidated (Figure $1-9, \mathbf{c}) \cdot{ }^{[51]}$ This is very important because with the knowledge of the structure, deductions regarding the reactivity can be made. In turn, this could lead to a better understanding of the mechanism of these deprotonation reactions and the development of tailor-made bases.

In another approach, Mulvey and co-workers put considerable effort into the research of alkali metal mediated metalations (AMMMs). For these reactions an alkali metal is combined with another divalent metal in a heterobimetallic organometallic compound. To achieve this, a metal amide, a metal alkyl reagent and a donor base are mixed. It is, however, the divalent metal which effects the deprotonation in the end. This is surprising as the alkali metal is usually more reactive but there seems to be a strong synergistic effect when both metals are in close spatial proximity. Thus, the metadeprotonation of toluene was achieved with a mixed sodium/magnesium reagent (Figure 1-9, d). ${ }^{[45,52]}$
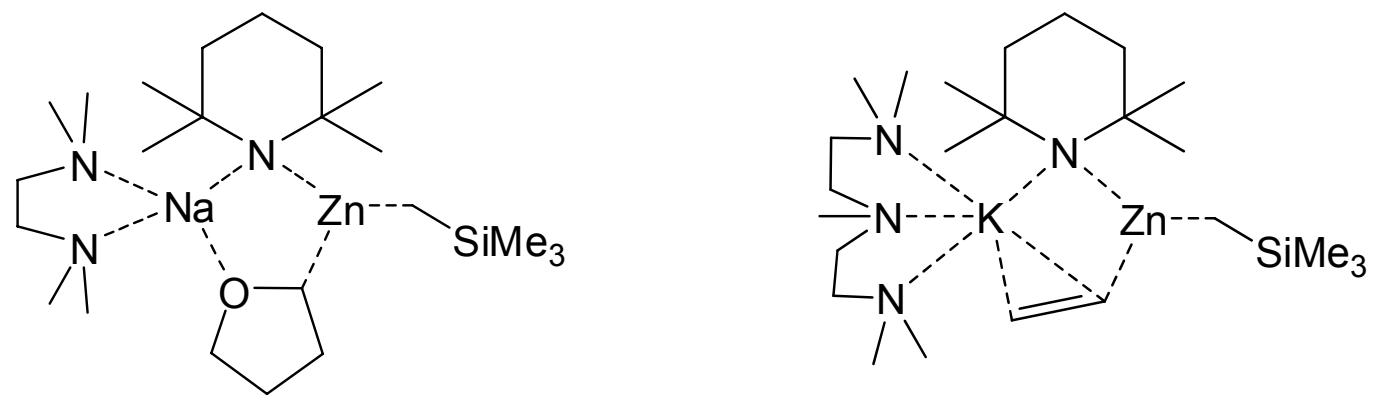

Figure 1-10: Products of the deprotonation of THF (right) and ethene (left) with heterobimetallic bases.

In another approach, ferrocene was fourfold deprotonated with a similar reagent. ${ }^{[53]}$ Apart from unusual stereoselectivities, those compounds can even deprotonate THF, THP (tetrahydropyrane) or ethene. ${ }^{[54]}$ The abstraction of a hydrogen atom adjacent to oxygen in cyclic ethers usually leads to ether cleavage reactions. However, with the heterobimetallic base $\left[(\right.$ tmeda $\left.) \mathrm{Na}(\mu-\operatorname{tmp})\left(\mu-\mathrm{CH}_{2} \mathrm{SiMe}_{3}\right) \mathrm{Zn}\left(\mathrm{CH}_{2} \mathrm{SiMe}_{3}\right)\right]$, the 
$\alpha$-deprotonation of THF is possible and the reaction product has been characterised by X-ray crystallography. Likewise, the deprotonation of ethene was achieved with the mixed potassium/zinc complex [(pmdeta) $\left.\mathrm{K}(\mu-\mathrm{tmp})\left(\mu-\mathrm{CH}_{2} \mathrm{SiMe}_{3}\right) \mathrm{Zn}\left(\mathrm{CH}_{2} \mathrm{SiMe}_{3}\right)\right]$ and the product was structurally characterised (Figure 1-10).

\section{Scope of this Thesis}

As the introduction of nucleophiles at the sulphur atom in sulphur diimides has been well established over the years, the goal of this thesis was to develop new sulphur diimido ligands with functionalized side-arms in order to generate potentially tripodal ligands. As it is also established so far that the sulphur atom does not take part in metal coordination, an additional donor site should be soft. With this approach, potentially hemilabile ligands are accessible that are reminiscent of heteroscorpionates. Hemilability means, that in one coordination compound, some metal-donor bonds are weaker than others and can easily be cleaved. ${ }^{[55]}$ In lithium complexes of $(N, N, P)$ ligands for example, this would be the P-Li bond because of the unsuitable soft/hard interaction.

Furthermore, a side-arm should be flexible enough to bind small and large metal atoms and make the synthesis of heterobimetallic complexes feasible. Phosphorus was chosen as an additional donor site, because of the good availability of the starting materials and the already established synthesis. ${ }^{[38,39]}$ The resulting ligands were called NSCP ligands because a sulphur diimide (NS) is linked to a phosphane via a carbon-bridge (CP). As the side-arm of a ligand should be flexible in order to achieve variable binding modes, phosphanes with methyl groups were to be employed. These represent potential $\mathrm{CH}_{2}$-bridges between the sulphur and the phosphorus atom. For comparison, the corresponding nitrogen analogues of the NSCP-ligands were to be synthesised as well. It would be interesting to elucidate the differences between the period one and two elements in their coordination behaviour and compare their binding modes.

The development of a whole set of building blocks (i. e. sulphur diimides on the one hand - nucleophile side-arms on the other hand) that may be combined in many different ways was the main goal. Thereby, a modular synthesis of side-arm donating, tripodal ligands for the desired application would become possible. It should be feasible to alter the ligand at need for the complexation of the metals of choice and to change the steric and electronic properties in a straightforward way. In 
addition, it should be possible to complex both hard and soft metals and stabilise them in low oxidation states.

First, a set of ligands had to be synthesised that differed on the one hand in their sulphur diimido moiety and on the other hand in the coordinating side-arm. Second, the complexation of various metal cations was to be tested. Thereby, different oxidation states, coordination modes as well as transition and main group metals could be employed in metalation reactions and the behaviour of the ligand could be analysed. It was also of interest to compare different starting materials for transmetalation reactions regarding their reactivity. In the end, it should be possible to synthesise heterobimetallic complexes as well.

To fully understand and characterise the new compounds in the solid state as well as in solution, X-ray crystallography and NMR spectroscopy should become the analytical methods of choice. 


\section{LIGANDS WITH PHOSPHORUS SIDE-ARM}

\subsection{Introduction}

As the sulphur atom in the sulphur diimides does not take part in metal coordination, a different soft donor site in the ligand would be of great interest. Therefore, a phosphorus containing side-arm was connected to the sulphur atom. Such a sidearm donation has the advantage of increased flexibility and complexation versatility.

In upcoming chapters, the exchange of the phosphorus side-arm by a nitrogen containing one in order to compare the different possible coordination modes is described. In addition, the connection of two sulphur diimides by donor containing bridges is shown. Thus, even more diverse coordination modes are gained. In the end, metal exchange reactions were carried out to fully explore the complexation properties of the new ligand system. Therefore, main group and transition metals were employed in different oxidation states.

In this chapter, the design of different sulphur diimide centred lithium complexes is described. Additionally, the access to a metal free derivative is shown as well as the synthesis of an ideal starting material for metal exchange reactions.

In 2007, Deuerlein reported the synthesis of a novel diimidosulfinate with phosphorus side-arm. ${ }^{[38]}$ In a first attempt, he reacted the lithiated sulphur ylide $\left[(\text { thf }) \mathrm{Li}\left\{\mathrm{H}_{2} \mathrm{CS}(\mathrm{N} t \mathrm{Bu})_{2}\right\}\right]_{2}$ with $\mathrm{Me}_{2} \mathrm{PCl}, \mathrm{Me}(\mathrm{Ph}) \mathrm{PCl}$ or $\mathrm{Ph}_{2} \mathrm{PCl}$ in a salt elimination reaction. Unfortunately, this route led to decomposition of the ligand with unpredictable products as Equation 2-1 points out. A similar reaction had also earlier been described by Hänssgen et al. in 2001. ${ }^{[56]}$
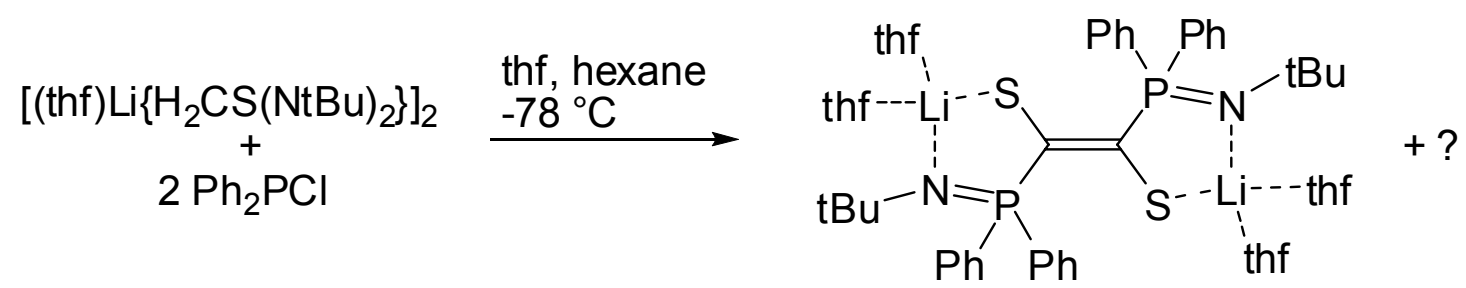

Equation 2-1: Reaction of $\left[(\text { thf }) \mathrm{Li}\left\{\mathrm{H}_{2} \mathrm{CS}(\mathrm{N} t \mathrm{Bu})_{2}\right\}\right]_{2}$ with $\mathrm{Ph}_{2} \mathrm{PCl}$.

The sulphur ylides and other similar sulphur nitrogen compounds are too redox active ${ }^{[38,57,58]}$ and the addition of metal halogenides leads to $\mathrm{S}-\mathrm{N}$ and $\mathrm{S}-\mathrm{C}$ bond cleavage reactions. This phenomenon had already been reported by Hänssgen and Steffens for sulphur diimide derivatives in the 1980's. ${ }^{[59]}$ Therefore, the reaction 
had to be conducted differently. $\mathrm{PMe}_{3}$ was lithiated - a procedure that has been well described in the literature ${ }^{[60,61,62]}$ - and reacted with $\mathrm{S}(\mathrm{N} t \mathrm{Bu})_{2}$ (general Equation 2-2). The structure of the obtained lithium complex is shown in Figure 2-1.

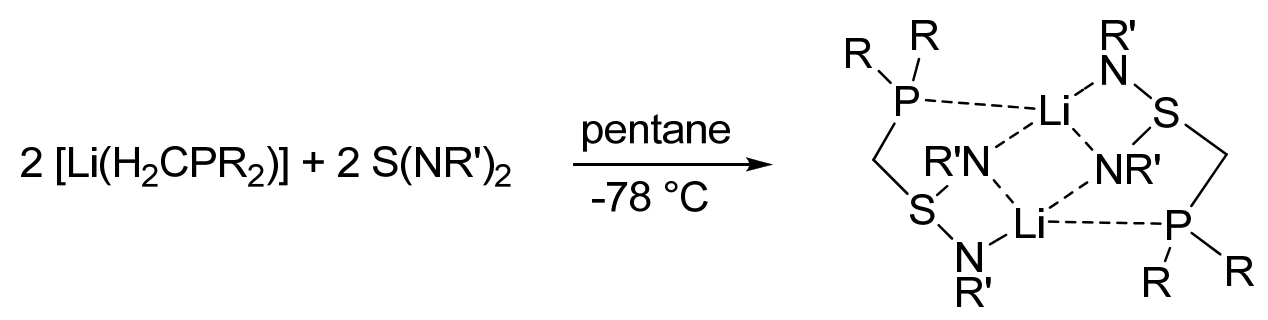

Equation 2-2: Preparation of $\left[\mathrm{Li}\left\{\mathrm{R}_{2} \mathrm{PCH} \mathrm{S}_{2}\left(\mathrm{NR}^{\prime}\right)_{2}\right\}\right]_{2}$.

There exists a patent of a nickel complex with the related ligand $\left\{t \mathrm{Bu}_{2} \mathrm{PCH}_{2} \mathrm{~S}\left(\mathrm{NSiMe}_{3}\right)_{2}\right\}$ for olefin polymerization ${ }^{[63]}$ and Deuerlein started to pursue this topic. He was able to show that the phosphane-functionaliziation of a sulphur diimide is easily possible. This reaction - which was mentioned above - should in principle be applicable to any phosphane with a methyl group.

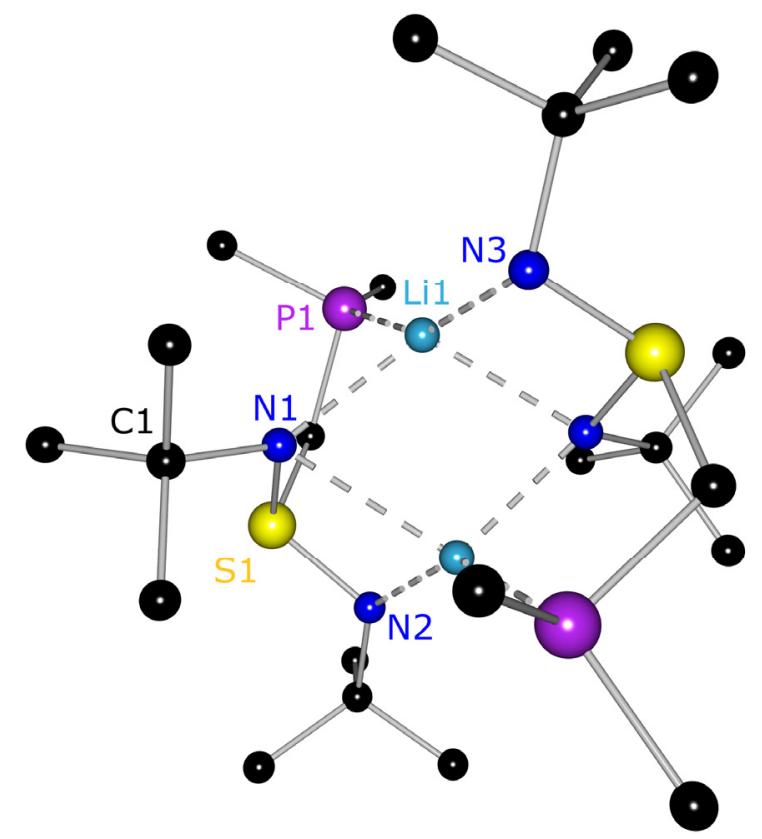

Figure 2-1: Molecular structure of $\left[\mathrm{Li}\left\{\mathrm{Me}_{2} \mathrm{PCH}_{2} \mathrm{~S}(\mathrm{~N} t \mathrm{Bu})_{2}\right\}\right]_{2}$ (1). Hydrogen atoms are omitted for clarity.

\subsection{Di(tert-butyl)sulphur diimide}

As already mentioned above, the linkage of sulphur diimide and phosphane was achieved by an equimolar reaction of lithium dialkyl phosphanyl methanide and di(tert-butyl)sulphur diimide, $\mathrm{S}(\mathrm{N} t \mathrm{Bu})_{2}$. This reaction had to be improved further, as the lithiation of $\mathrm{PMe}_{3}$ by the mentioned literature methods was not satisfying because 
the yield was too low and the instructions contradictory. ${ }^{[60,61,62]}$ Eventually, a modified procedure was established: a solution of $t \mathrm{BuLi}$ in pentane $(1.5 \mathrm{M})$ was reduced to approx. half of its volume and the phosphane was added drop wise at room temperature. After $30 \mathrm{~min}$ a white precipitate could be observed. After stirring over night, the reaction was complete, the white powder was filtered off and thoroughly washed with pentane. With this rather drastic method a yield of up to $75 \%$ $\left[\mathrm{Li}\left(\mathrm{H}_{2} \mathrm{CPMe}_{2}\right)\right]$ can be obtained.

Deuerlein had also reacted $\mathrm{S}(\mathrm{N} t \mathrm{Bu})_{2}$ with [(tmeda) $\left.\mathrm{Li}_{(}\left(\mathrm{H}_{2} \mathrm{CPPh}_{2}\right)\right]$ in pentane and observed a beige powder which he characterised by ${ }^{1} \mathrm{H}$ and ${ }^{31} \mathrm{P}\left\{{ }^{1} \mathrm{H}\right\}$ NMR spectroscopy. A full characterisation of $\left[\mathrm{Li}\left\{\mathrm{Ph}_{2} \mathrm{PCH}_{2} \mathrm{~S}(\mathrm{~N} t \mathrm{Bu})_{2}\right\}\right]_{2}$ (2) including the crystal structure is given in this thesis. Different to $\mathrm{PMe}_{3}, \mathrm{Ph}_{2} \mathrm{PMe}$ can only be deprotonated by $\mathrm{tBuLi}$ in moderate yield. Therefore, a $1: 1$ equimolar mixture of $n \mathrm{BuLi} / \mathrm{TMEDA}$ has to be used. This gives [(tmeda) $\left.L i\left(\mathrm{H}_{2} \mathrm{CPPh}_{2}\right)\right]$ as a white powder in $80 \%$ yield. ${ }^{[64,65,66]}$ Complex 2 was synthesised by equimolar reaction of lithio(diphenylphosphino)methane-tetramethylethylenediamine with $\mathrm{S}(\mathrm{NtBu})_{2}$ in pentane, according to Equation 2-2.

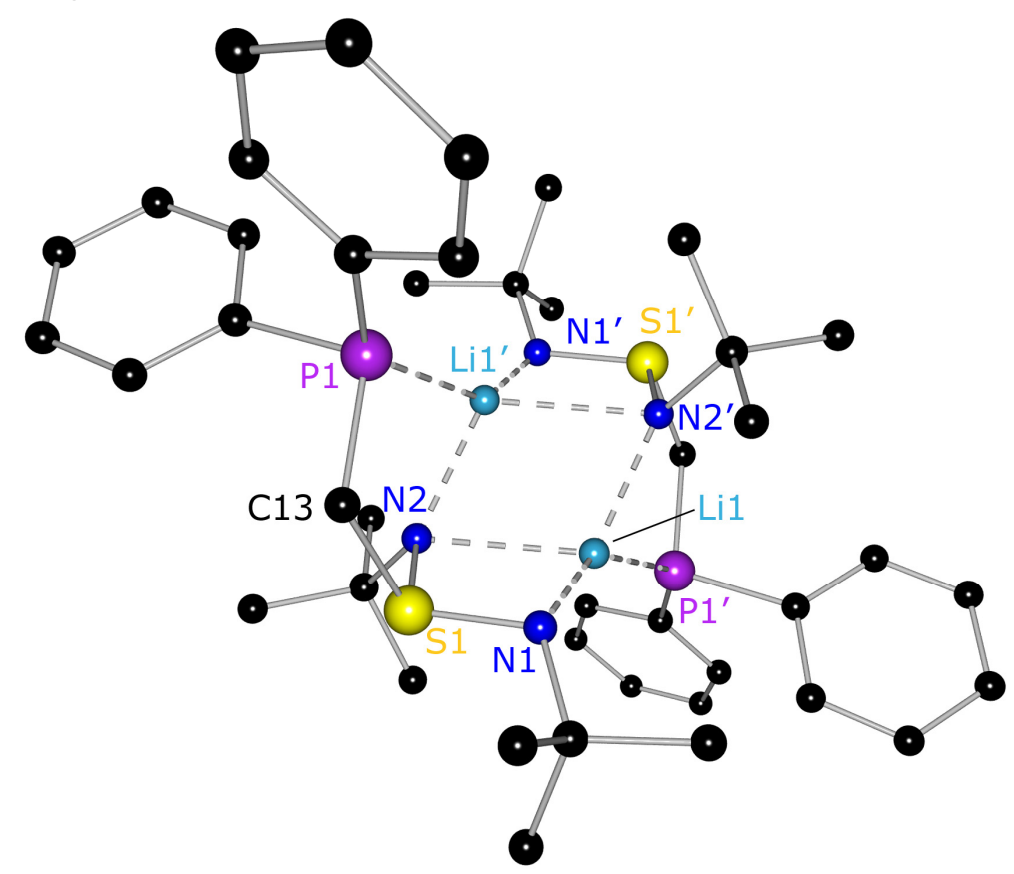

Figure 2-2: Molecular structure of $\left[\mathrm{Li}\left\{\mathrm{Ph}_{2} \mathrm{PCH}_{2} \mathrm{~S}(\mathrm{NtBu})_{2}\right\}\right]_{2}$ (2). Hydrogen atoms are omitted for clarity.

The resulting beige powder was dissolved in toluene and stored at $-25^{\circ} \mathrm{C}$, yielding colourless crystals in the space group $P \overline{1}$ after several days with half a dimer in the asymmetric unit. The inadequate bite of the tridentate ligand with respect to the small lithium cation in addition to a missing donor solvent results in a dimeric complex (Figure 2-2). The main core of the system is consisting of a $(\mathrm{LiN})_{2}$ 
heteroatomic ring in which both the lithium cations are fourfold coordinated by the donor atoms of each ligand. The structural characteristics of $\mathbf{2}$ are thus akin to complex 1. The bond lengths and angles of 2 are within the expected range, being not very different to 1 . One nitrogen atom of each ligand unit (N2 and N2') is coordinating to both lithium atoms while the other nitrogen atoms coordinate to the lithium atom of just one half $\left(\mathrm{Li} 1-\mathrm{N} 1 / \mathrm{Li} 1^{\prime}-\mathrm{N} 1^{\prime}\right)$. It is important to note that the phosphorus atom coordinates to the lithium atom of the other half of the dimer (Li1$\left.\mathrm{P} 11^{\prime} / \mathrm{Li1}-\mathrm{P} 1\right)$. This arrangement is responsible for the good stability of the system. All S-N distances $(1.6120(14) \AA-1.6295(14) \AA$ ) are marginally shorter than an average sulphur-nitrogen single-bond $(1.69 \AA) .{ }^{[67]}$ However, these $\mathrm{S}-\mathrm{N}$ bond lengths are in the range of other alkyl diimidosulfinates (1.598-1.657 A). ${ }^{[29]}$

Table 2-1: Selected bond lengths $[\AA]$ and angles $\left[{ }^{\circ}\right]$ of 2 and 5

\begin{tabular}{|c|c|c|c|c|c|}
\hline & 2 & 5 & & 2 & 5 \\
\hline S1-N1 & $1.6120(14)$ & $1.6238(15)$ & $\mathrm{N} 1-\mathrm{S} 1-\mathrm{N} 2$ & $104.15(7)$ & $106.34(8)$ \\
\hline $\mathrm{S} 1-\mathrm{N} 2$ & $1.6295(14)$ & $1.6060(15)$ & S1-C13-P1 & $113.51(9)$ & $114.43(9)$ \\
\hline$S 1-C 13$ & $1.8412(17)$ & $1.8381(18)$ & S1-N1-Li1 & $98.12(11)$ & $83.35(10)$ \\
\hline$P 1-C 13$ & $1.8404(17)$ & $1.8402(19)$ & C13-P1-Li1' & $102.33(8)$ & $90.73(9)$ \\
\hline P1-Li1' & $2.657(3)$ & $2.588(3)$ & N1-Li1-N2 & $72.88(10)$ & $73.93(12)$ \\
\hline N1-Li1 & $1.959(3)$ & $2.303(4)$ & Li1-N2-Li1'/Li1-N1-Li1' & $69.88(13)$ & $77.27(14)$ \\
\hline N2-Li1 & $2.318(3)$ & $1.974(3)$ & N2-Li1-N2'/N1-Li1-N1' & $110.12(13)$ & $102.72(14)$ \\
\hline Li1'-N2/N1 & $2.044(3)$ & $2.028(4)$ & P1-Li1'-N2/N1 & $76.78(9)$ & $79.97(11)$ \\
\hline N1-C14/Si1 & $1.485(2)$ & $1.7394(16)$ & S1-N1-C14/Si1 & $114.75(11)$ & $118.40(9)$ \\
\hline
\end{tabular}

The longer Li-N2 distances (Li1-N2 2.318(3) $\AA$ and Li1'-N2 2.044(3) $\AA$ ) compared to Li1-N1 (1.959(3) $\AA$ ) are due to the shared lithium coordination of N2. $\mathrm{Li} 1-\mathrm{N} 1$ and Li1'-N2 are in the typical range of Li-N bonds $(1.905-2.202 \AA),{ }^{[68]}$ but Li1 seems to be weakly coordinated to N2. The Li1'-P1 distance of 2.657(3) $\AA$ is in the normal range for $\mathrm{Li}(\mathrm{P}-\mathrm{C}-\mathrm{C}=\mathrm{N})$ systems $(2.365-2.824 \AA)$ which are similar to the ligand described here. ${ }^{[34,69]}$ The N1-S1-N2 $\left(104.15(7)^{\circ}\right)$, N1-S1-C13 $\left(106.45(8)^{\circ}\right)$ and $\mathrm{N} 2-\mathrm{S} 1-\mathrm{C} 13\left(101.29(7)^{\circ}\right)$ bond angles are more acute than the ideal tetrahedral angle of $109.5^{\circ}$. This is a result of the stereochemically active lone pair of the sulphur atom which takes up more space than a normal substituent. The acute N2-Li1'-P1 angle of $79.63(7)^{\circ}$ is typical for $\mathrm{Li}(\mathrm{P}-\mathrm{C}-\mathrm{C}=\mathrm{N})$ systems though $\left(73.10-87.35^{\circ}\right) .^{[69]}$ 
Selected bond lengths and angles of $\mathbf{2}$ and its silicon analogue $\mathbf{5}$ can be found in Table 2-1.

From the NMR spectra of $\mathbf{2}$ in solution it is obvious that the complex shows a dynamic behaviour different to the solid state. The ${ }^{7} \mathrm{Li}\left\{{ }^{1} \mathrm{H}\right\}$ NMR spectrum reveals a coupling between one lithium atom and two phosphorus atoms (triplet in the ${ }^{7} \mathrm{Li}\left\{{ }^{1} \mathrm{H}\right\}$ NMR, ${ }^{1} J_{P-L i}=12.8 \mathrm{~Hz}$ ). This can only be rationalized with a flipping Li-P-bond and on average the contact of a single phosphorus atom to two lithium atoms and vice versa in solution (Figure 2-3). This phenomenon was as well observed by lzod et al. for $\left[\mathrm{MeP}\left(\mathrm{C}_{6} \mathrm{H}_{4}-2-\mathrm{CH}_{2} \mathrm{NMe}_{2}\right)\left\{\mathrm{C}_{6} \mathrm{H}_{4}-2-\mathrm{CH}(\mathrm{Li}) \mathrm{NMe}_{2}\right\}\right]_{2} \cdot{ }^{[70]}$

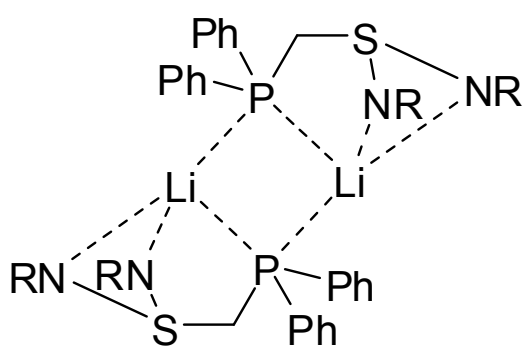

Figure 2-3: Proposed average structure of 2 in solution, $R=t B u$.

This hypothesis can also be proven by the ${ }^{13} \mathrm{C}\left\{{ }^{1} \mathrm{H}\right\}$ NMR spectra of 2 (Figure 2-4). The phenyl carbon atoms show various multiplets whit structures that can only be explained if both phosphorus atoms are coupled to each other over the bridging lithium atom and thereby influence the carbon atoms in the rings. With phosphorus decoupling, those multiplets change into singlets. The solution structure according to Figure 2-3 gets even more plausible by simulation of the spin system (Figure 2-4).
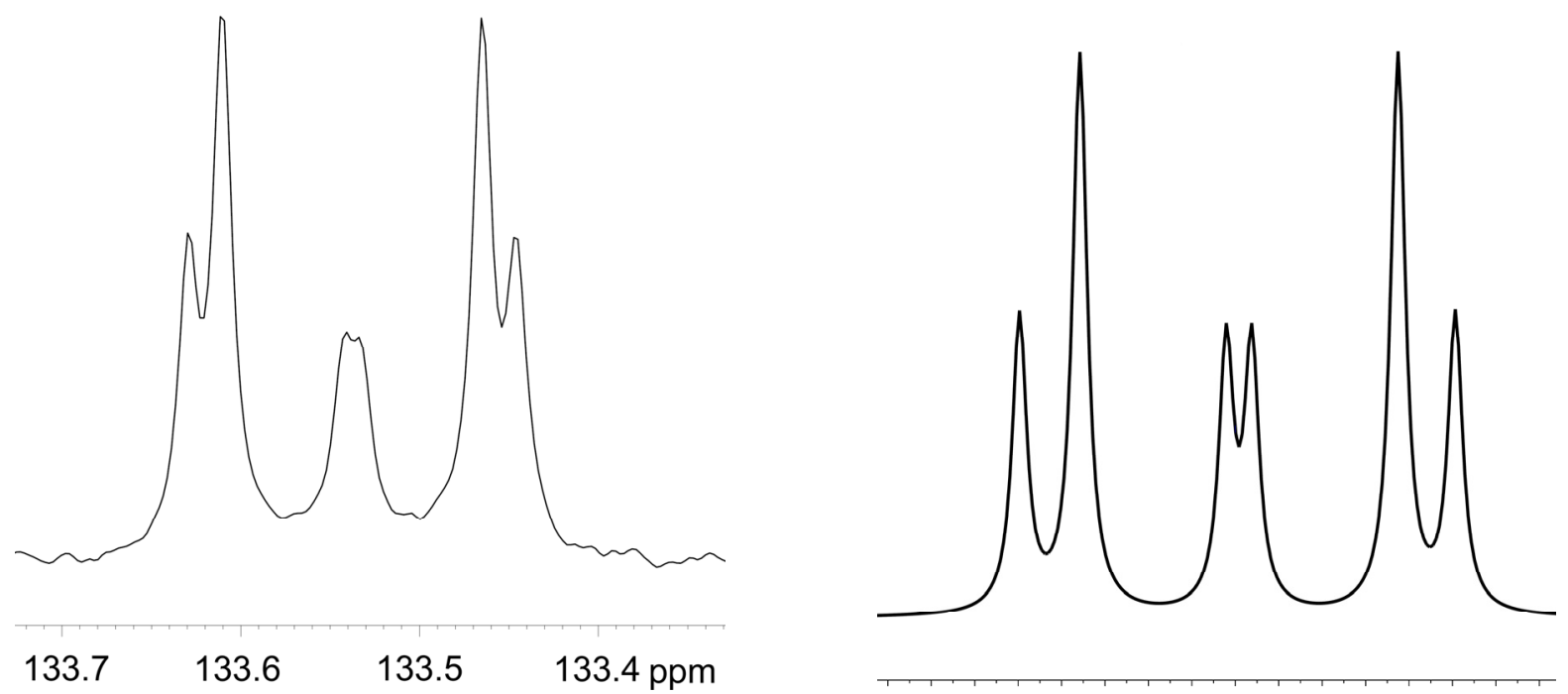

Figure 2-4: ${ }^{13} \mathrm{C}\left\{{ }^{1} \mathrm{H}\right\}$ NMR signal of the meta carbon atom in 2 (right, no ${ }^{31} \mathrm{P}$ decoupling); simulation of the signal (left) ${ }^{[71]}$. 
As a part of the strategy to create a structural variety of new multidentate ligands, modifications in the phosphane moiety were made to get $\left[\mathrm{Li}\left\{\mathrm{Me}(\mathrm{Ph}) \mathrm{PCH}_{2} \mathrm{~S}(\mathrm{NtBu})_{2}\right\}\right]_{2}$ (3). It crystallises from pentane in the monoclinic space group $P 2_{1} / C$. 3 is also obtained as a dimer and the main core of the system is the known $(\mathrm{LiN})_{2}$ fourmembered ring with both lithium atoms being fourfold coordinated by the nitrogen and phosphorus atoms of each ligand. Most of the overall structural features are like in $\mathbf{1}$ and $\mathbf{2}$, but differently to them, chirality is introduced at the phosphorus atoms P1 and $\mathrm{P} 1$ ' of the donating side-arm. Due to the centre of inversion in the middle of the $(\mathrm{LiN})_{2}$ four-membered ring, 3 crystallizes as a centrosymmetric structure. Consequently, both phosphorus atoms have different absolute configurations. The solid state structure is shown in Figure 2-5.

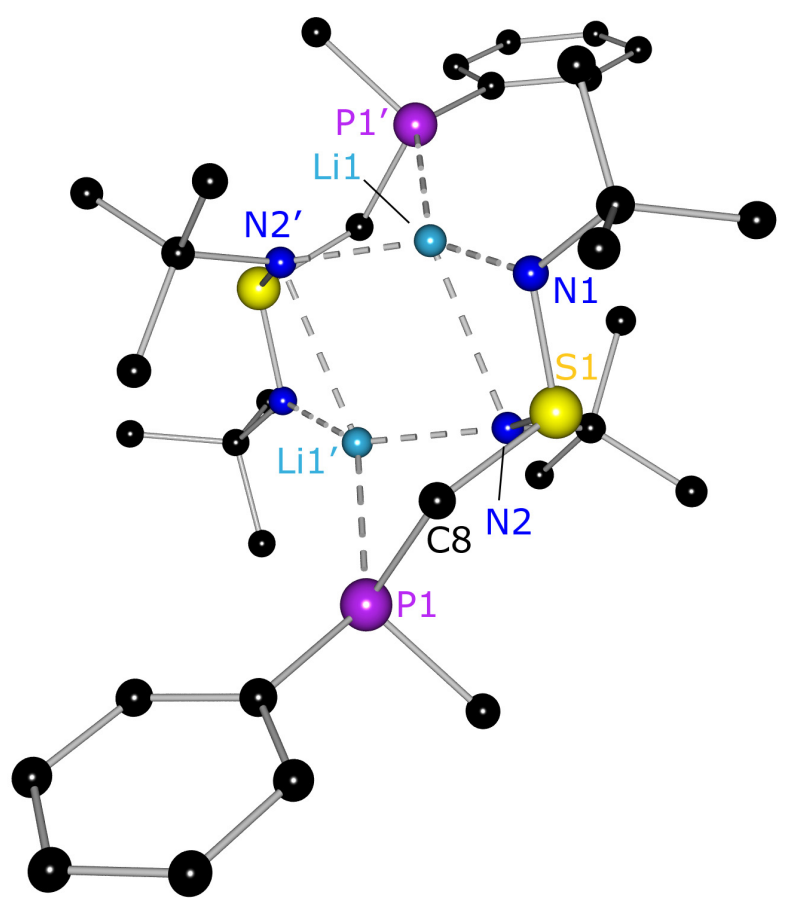

Figure 2-5: Molecular structure of $\left[\mathrm{Li}\left\{\mathrm{Me}(\mathrm{Ph}) \mathrm{PCH}_{2} \mathrm{~S}(\mathrm{NtBu})_{2}\right\}\right]_{2}(\mathbf{3})$. Hydrogen atoms are omitted for clarity.

The $\mathrm{S}-\mathrm{N}$ bond distances are almost equal and lie in the range of 1.6107(11)$1.6278(11) \AA$. The two $\left(\mathrm{SN}_{2}\right)$ units are tilted by $134.4^{\circ}$ with respect to the $(\mathrm{LiN})_{2}$ ring with the phosphane moiety residing on opposite sides of the $\left(\mathrm{SN}_{2}\right)$ planes. The N1S1-N2 $\left(105.68(6)^{\circ}\right)$ and N1-S1-C8 $\left(104.97(6)^{\circ}\right)$ angles are almost in the same range as for compounds 1 and 2 . However, the $\mathrm{N} 2-\mathrm{S} 1-\mathrm{C} 8$ angle of $98.81(6)^{\circ}$ is slightly more acute than in 1 and 2. The Li1-P1 distance is 2.644(2) $\AA$, which is slightly longer than the average $(2.520 \AA)$ of the Li-P bonds. ${ }^{[68]}$ The acute N2-Li1-P1 angle of $76.66(7)^{\circ}$ is known for such systems $\left(73.10-87.35^{\circ}\right),{ }^{[72]}$ however, this angle 
is the most acute among the compounds 1-3. Selected bond lengths and angles are compared to the silicon analogue $\left[\mathrm{Li}\left\{\mathrm{Me}(\mathrm{Ph}) \mathrm{PCH}_{2} \mathrm{~S}\left(\mathrm{NSiMe}_{3}\right)_{2}\right\}\right]_{2}(\mathbf{6})$ in Table 2-3.

The NMR spectra show a signal doubling that is due to two diastereomers which are present. In solution the phenyl rings can be arranged 'trans' to each other like in the solid state or 'cis'. The resulting diastereomers have very similar chemical shifts and their NMR signals are therefore overlapping. Thus, it is impossible to assign specific shifts to one specific diastereomer. Nevertheless, it can be conjectured that the 'trans' isomer prevails as it is also the preferred arrangement in the solid state and displays the least steric strain. Integration of the $\mathrm{PCH}_{3}$ signals shows a ratio of 1 to 0.75 for 'trans' to 'cis'. To get a rough estimate of the conversion times from the 'trans' to the 'cis' isomer, a NOESY spectrum was recorded. With the knowledge of the mixing time $\tau_{\text {mix }}\left(d_{8}=0.5 \mathrm{~s}\right)$ the velocity constants $k_{1} / k_{-1}$ can be calculated: $\mathrm{k}_{1}=0.34 \mathrm{~s}^{-1}$ (trans to cis) and $\mathrm{k}_{-1}=0.49 \mathrm{~s}^{-1}$ (cis to trans).

As in compounds 1 and $\mathbf{2}$ a $\mathrm{P}-\mathrm{Li}-\mathrm{P}$ system seems to be present. It is obvious not only through the ${ }^{31} \mathrm{P}\left\{{ }^{1} \mathrm{H}\right\}$ and ${ }^{7} \mathrm{Li}\left\{{ }^{1} \mathrm{H}\right\}$ spectra but as well through the ${ }^{13} \mathrm{C}\left\{{ }^{1} \mathrm{H}\right\}$ spectrum. The nuclei are coupled to both phosphorus atoms over the Li-bridge. Thus the resulting multiplets can be explained. In ${ }^{31} \mathrm{P}$ decoupled spectra the couplings disappear just like in 2. The $\mathrm{P}-\mathrm{CH}_{2}-\mathrm{S}$ signal in the ${ }^{1} \mathrm{H}$ NMR spectrum (Figure 2-6) is a good example for this.

In the upper half of the figure a rather complicated coupling pattern can be seen. This is due to the two diastereomers and the coupling of the protons to the neighbouring phosphorus atom as well as the phosphorus atom on the other side of the bridging lithium ion. When the ${ }^{1} \mathrm{H}$ spectrum is recorded with ${ }^{31} \mathrm{P}$ decoupling, the picture gets somewhat clearer. It can now be distinguished between two sets of signals which are expected for two diastereomers $\mathrm{A}$ and $\mathrm{B}$. In addition, the protons in the $\mathrm{CH}_{2}$ bridge are coupled to each other because they are diastereotopic $\left({ }^{2} \mathrm{~J}_{\mathrm{H}-\mathrm{H}}=\right.$ $\left.13.3 \mathrm{~Hz}(\mathrm{~A}),{ }^{2} \mathrm{~J}_{\mathrm{H}-\mathrm{H}}=13.4 \mathrm{~Hz}(\mathrm{~B})\right)$ and a roof effect becomes visible. This phenomenon always occurs if two atoms that are coupling to each other differ very little in their chemical environment. ${ }^{[73]}$ 

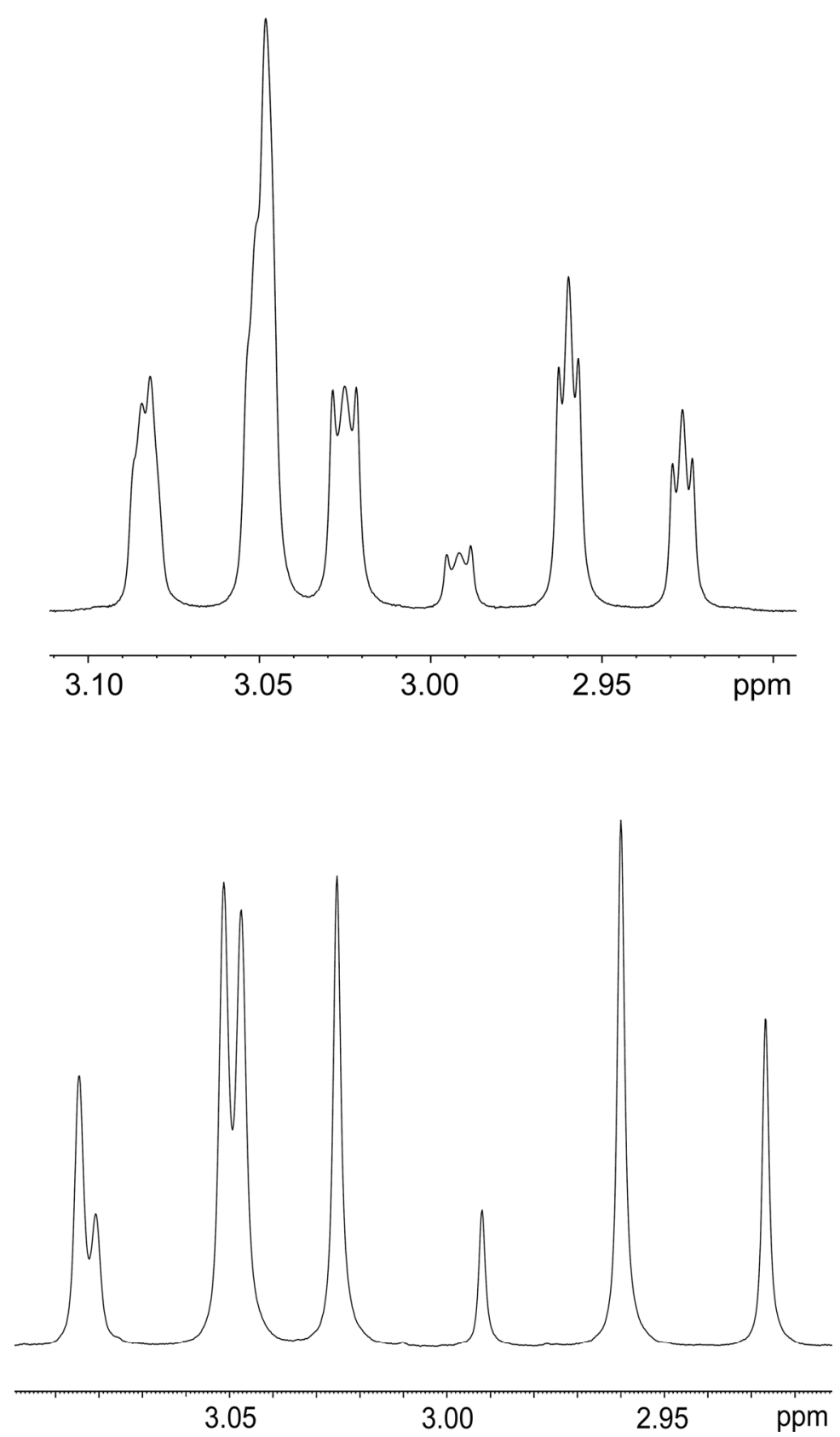

Figure 2-6: ${ }^{1} \mathrm{H}$ NMR signals of $\mathrm{P}-\mathrm{CH}_{2}-\mathrm{S}$ in $\left[\mathrm{Li}\left\{\mathrm{Me}(\mathrm{Ph}) \mathrm{PCH}_{2} \mathrm{~S}(\mathrm{~N} t \mathrm{Bu})_{2}\right\}\right]_{2}(3)$; above: ${ }^{31} \mathrm{P}$ coupled, below: ${ }^{31} \mathrm{P}$ decoupled.

\subsection{Bis(trimethylsilyl)sulphur diimide}

For ligand design, it is desirable to modify not only the substituents on the phosphorus atom but also the imido groups at the sulphur atom. $\mathrm{S}\left(\mathrm{NSiMe}_{3}\right)_{2}$ is easily accessible by the reaction of $\mathrm{SOCl}_{2}$ with $\left[\mathrm{Li}\left\{\mathrm{N}\left(\mathrm{SiMe}_{3}\right)_{2}\right\}\right]{ }^{[74]}$ It was chosen because it only differs from $\mathrm{S}(\mathrm{NtBu})_{2}$ in one atom bound to nitrogen. Silicon is softer and larger than carbon and has lower electronegativity, giving rise to a different electronic 
situation. The reaction of $\left[\mathrm{Li}\left(\mathrm{CH}_{2} \mathrm{PMe}_{2}\right)\right]$ with $\mathrm{S}\left(\mathrm{NSiMe}_{3}\right)_{2}$ in pentane gave $\left[\mathrm{Li}\left\{\mathrm{Me}_{2} \mathrm{PCH}_{2} \mathrm{~S}\left(\mathrm{NSiMe}_{3}\right)_{2}\right\}\right]_{2}$ (4) as a white powder. Crystallization from pentane at $-25^{\circ} \mathrm{C}$ yielded colourless crystals in the space group $P \overline{1}$. The structural characteristics are the same as in compounds 1-3 (Figure 2-7). A comparison with $\left[\mathrm{Li}\left\{\mathrm{Me}_{2} \mathrm{PCH}_{2} \mathrm{~S}(\mathrm{NtBu})_{2}\right\}\right]_{2}$ (1) can be found in Table 2-2.

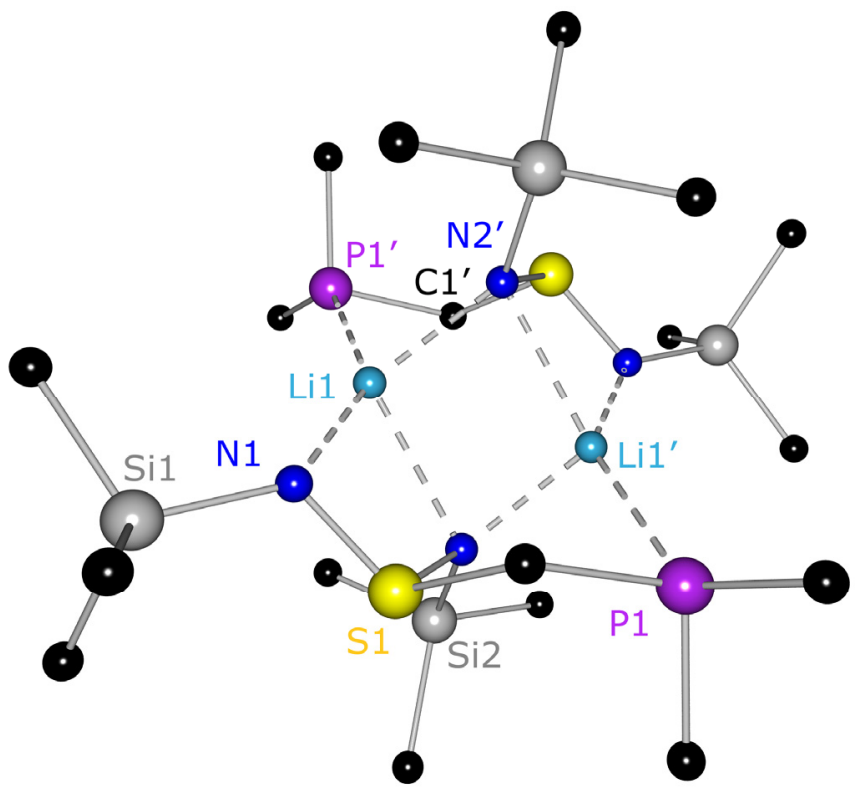

Figure 2-7: Molecular structure of $\left[\mathrm{Li}\left\{\mathrm{Me}_{2} \mathrm{PCH}_{2} \mathrm{~S}\left(\mathrm{NSiMe}_{3}\right)_{2}\right\}\right]_{2}(4)$. Hydrogen atoms are omitted for clarity.

The introduction of the silicon atom does not change the overall structural characteristics of the complex. However, the bond angles - especially around the sulphur atom - are affected.

Table 2-2: Selected bond lengths $[\AA]$ and angles $\left[^{\circ}\right]$ of 1 and 4

\begin{tabular}{llllll}
\hline \multicolumn{1}{c}{$\mathbf{1}$} & \multicolumn{2}{c}{$\mathbf{4}$} & & \multicolumn{1}{c}{$\mathbf{1}$} & \multicolumn{1}{c}{$\mathbf{4}$} \\
\hline S1-N1 & $1.6144(9)$ & $1.6031(10)$ & N1-S1-N2 & $104.74(5)$ & $105.89(5)$ \\
S1-N2 & $1.6351(9)$ & $1.6221(10)$ & S1-C9-P1/S1-C1-P1 & $116.24(6)$ & $113.96(6)$ \\
S1-C9/C1 & $1.8406(11)$ & $1.8286(12)$ & S1-N1-Li1 & $100.05(7)$ & $95.76(8)$ \\
P1-C9/C1 & $1.8403(11)$ & $1.8406(13)$ & C9-P1-Li2/C1-P1-Li1' & $96.36(5)$ & $86.45(6)$ \\
N1-Li1 & $1.939(2)$ & $1.989(2)$ & N1-Li1-N2 & $71.93(7)$ & $73.00(8)$ \\
N2-Li1 & $2.398(2)$ & $2.315(2)$ & Li1-N2-Li2/Li1' & $69.23(7)$ & $80.96(9)$ \\
N2-Li2/Li1' & $2.059(2)$ & $2.029(2)$ & N2-Li1-N3/N2' & $103.61(9)$ & $99.04(9)$ \\
P1-Li2/Li1' & $2.6425(19)$ & $2.655(2)$ & P1-Li2-N2/P1-Li1'-N2 & $76.79(6)$ & $79.63(7)$ \\
N1-C1/Si1 & $1.4792(13)$ & $1.7138(10)$ & S1-N1-C1/Si1 & $116.43(7)$ & $119.57(6)$ \\
\hline
\end{tabular}


The N1-S1-N2 angle is wider by approx. one degree; on the other hand the S1-C1-P1 angle of $113.96(6)^{\circ}$ is considerably more acute and approaches the value for an ideal tetrahedron. The angles inside the $(\mathrm{LiN})_{2}$ heteroatomic ring are also closer to $90^{\circ}$, which is the expected value for a square planar environment. The bond lengths are not affected much by the different electronic situation in the ligand and only deviate slightly from the values reported for 1 . It seems obvious that an electronic change in the ligand causes structural changes as well. This indicates a different reactivity of the di(tert-butyl)sulphur diimides compared to the bis(trimethylsilyl)sulphur diimides which might become useful for future work.

In order to synthesise a lithium complex with $\mathrm{S}\left(\mathrm{NSiMe}_{3}\right)_{2}$ similar to $2, \mathrm{Ph}_{2} \mathrm{PMe}$ was deprotonated with $t \mathrm{BuLi}$ to give $\left[\mathrm{Li}\left(\mathrm{CH}_{2} \mathrm{PPh}_{2}\right)\right]$. When this lithiated phosphane was reacted with $\mathrm{S}\left(\mathrm{NSiMe}_{3}\right)_{2}$ (Equation 2-3) and the solution stored at $-25{ }^{\circ} \mathrm{C}$ for several days, $\left[\mathrm{Li}\left\{\mathrm{Ph}_{2} \mathrm{PCH}_{2} \mathrm{~S}\left(\mathrm{NSiMe}_{3}\right)_{2}\right\}\right]_{2}$ (5) crystallised as colourless needles in the monoclinic space group $P 2_{1} / n$.

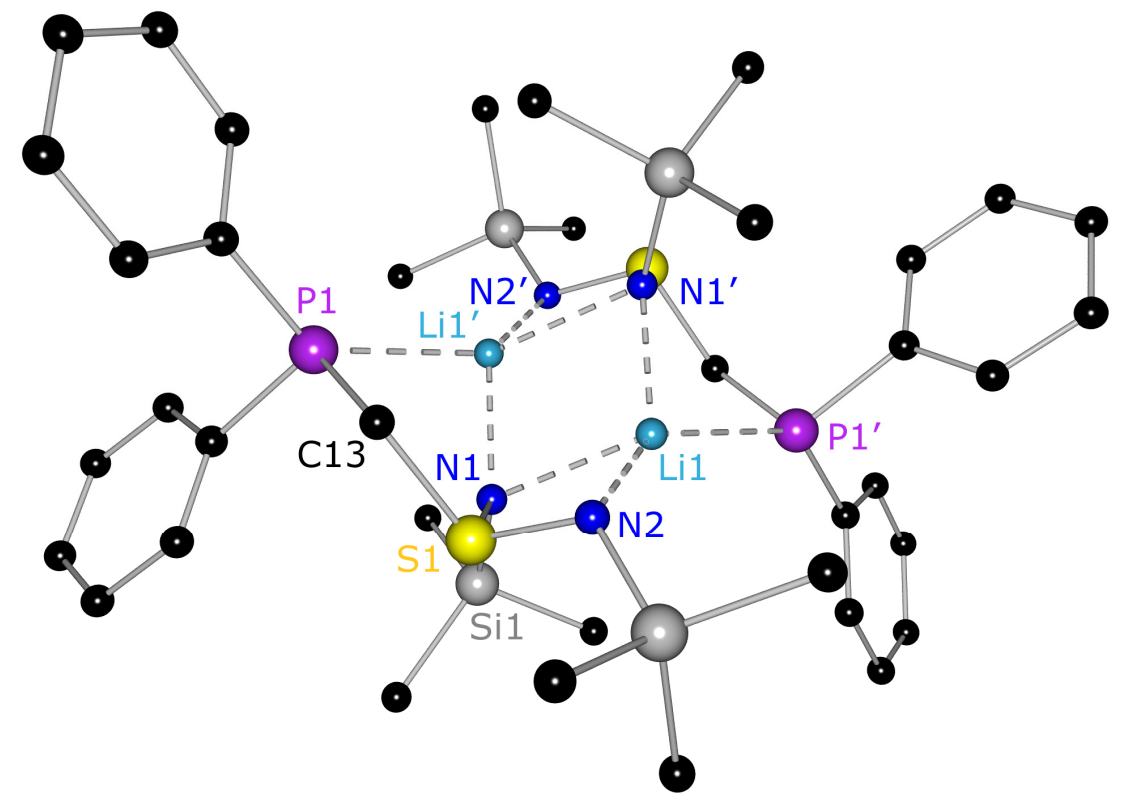

Figure 2-8: Molecular structure of $\left[\mathrm{Li}\left\{\mathrm{Ph}_{2} \mathrm{PCH}_{2} \mathrm{~S}\left(\mathrm{NSiMe}_{3}\right)_{2}\right\}\right]_{2}$ (5). Hydrogen atoms are omitted for clarity.

The structural features are similar to those of $\mathbf{2}$. There is a centre of inversion in the middle of the structure and the bond lengths are virtually the same. However, the angles differ notably, as could be observed for $\mathbf{1}$ and $\mathbf{4}$ already. The structure is shown in Figure 2-8, selected bond lengths and angles of $\mathbf{2}$ and $\mathbf{5}$ can be found in Table 2-1. 


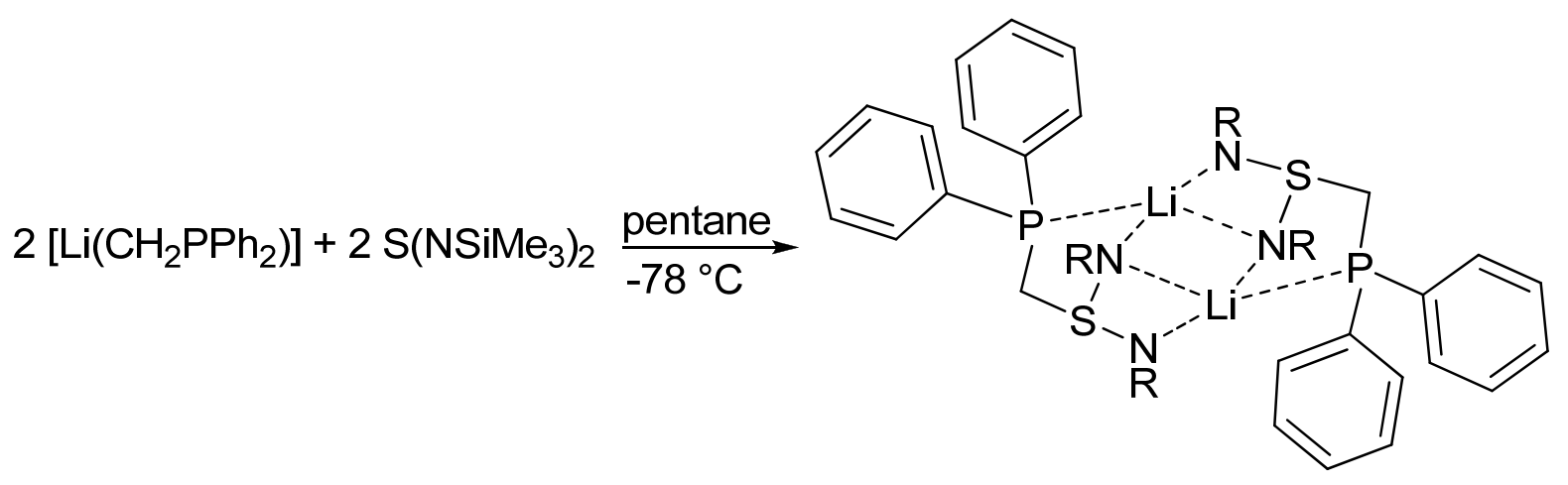

Equation 2-3: Preparation of $\left[\mathrm{Li}\left\{\mathrm{Ph}_{2} \mathrm{PCH}_{2} \mathrm{~S}\left(\mathrm{NSiMe}_{3}\right)_{2}\right\}\right]_{2}(\mathbf{5}) ; \mathrm{R}=\mathrm{SiMe}_{3}$.

The analogue to 3, [ $\left.\mathrm{Li}\left\{\mathrm{Me}(\mathrm{Ph}) \mathrm{PCH}_{2} \mathrm{~S}\left(\mathrm{NSiMe}_{3}\right)_{2}\right\}\right]_{2}$ (6), was prepared according to Equation 2-2 and crystallises in the triclinic space group $P \overline{1}$ with one half of the dimer in the asymmetric unit. Due to poor data quality the residual electron density of $1.32 \mathrm{eA}^{-3}$ ) cannot be assigned sensibly. The structure is shown and discussed nevertheless for comparison reasons although the bond lengths and angles might have bigger standard deviations.

The geometrical features are similar to $\left[\mathrm{Li}\left\{\mathrm{Me}(\mathrm{Ph}) \mathrm{PCH}_{2} \mathrm{~S}(\mathrm{~N} t \mathrm{Bu})_{2}\right\}\right]_{2}$ (3). Both have an inversion centre in the middle of the $(\mathrm{LiN})_{2}$ ring, the bond lengths are almost the same and the angles differ a little. The molecular structure of $\mathbf{6}$ is shown in Figure 2-9. Selected bond lengths and angles in comparison to 3 can be found in Table 2-3.

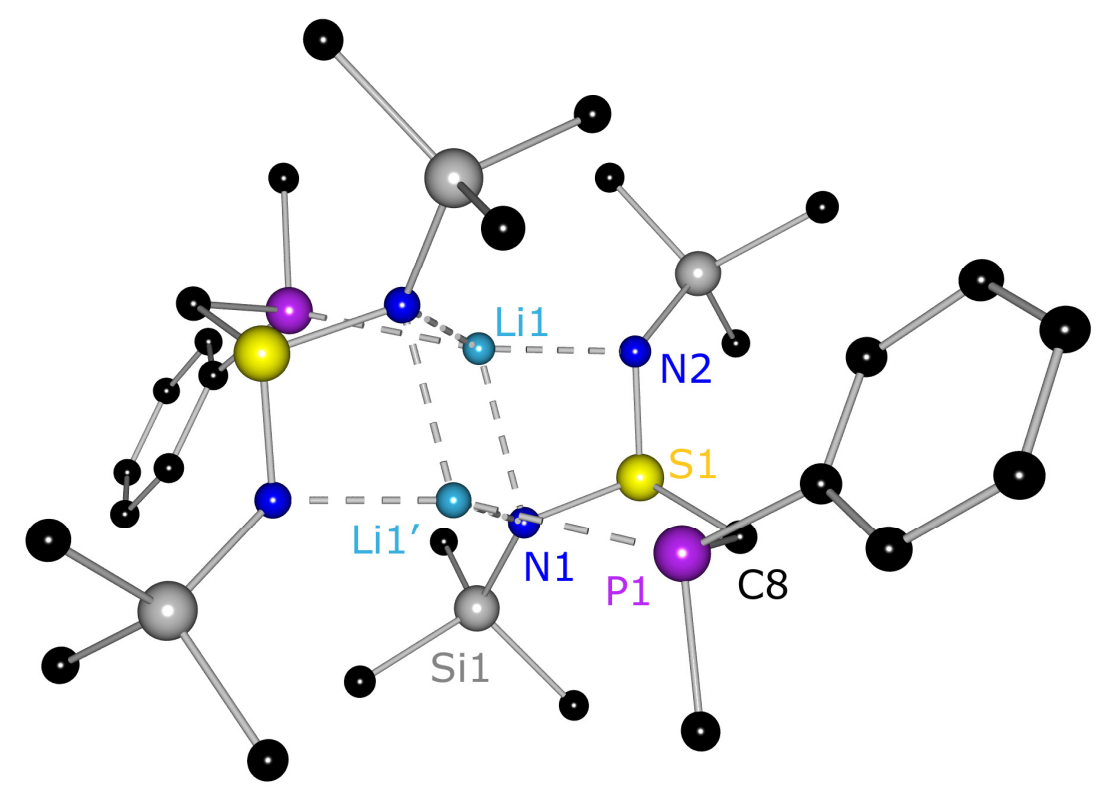

Figure 2-9: Molecular structure of $\left[\mathrm{Li}\left\{\mathrm{Me}(\mathrm{Ph}) \mathrm{PCH}_{2} \mathrm{~S}\left(\mathrm{NSiMe}_{3}\right)_{2}\right\}\right]_{2}(6)$. Hydrogen atoms are omitted for clarity. 
Table 2-3: Selected bond lengths $[\AA]$ and angles $\left[{ }^{\circ}\right]$ of 3 and 6

\begin{tabular}{llllll}
\hline & \multicolumn{1}{c}{$\mathbf{3}$} & $\mathbf{6}$ & & \multicolumn{1}{c}{$\mathbf{3}$} & \multicolumn{1}{c}{$\mathbf{6}$} \\
\hline S1-N1 & $1.6107(11)$ & $1.626(3)$ & N1-S1-N2 & $105.68(6)$ & $104.59(14)$ \\
S1-N2 & $1.6278(11)$ & $1.594(3)$ & S1-C8-P1 & $114.41(7)$ & $112.94(19)$ \\
S1-C8 & $1.8398(13)$ & $1.814(4)$ & S1-N1-Li1 & $101.81(9)$ & $85.55(19)$ \\
P1-C8 & $1.8463(14)$ & $1.840(4)$ & C8-P1-Li1' & $89.37(7)$ & $101.80(17)$ \\
N1-Li1 & $1.957(3)$ & $2.224(7)$ & N1-Li1-N2 & $69.41(8)$ & $74.3(2)$ \\
N2-Li1 & $2.506(3)$ & $1.984(6)$ & Li1-N2-Li1'/Li1-N1-Li1' & $76.86(11)$ & $69.2(3)$ \\
Li1'-N2/N1 & $2.008(3)$ & $2.049(6)$ & N2-Li1-N2'/N1-Li1-N1' & $103.14(11)$ & $110.8(3)$ \\
P1-Li1' & $2.644(2)$ & $2.591(6)$ & P1-Li1'-N2/N1 & $76.66(8)$ & $80.4(2)$ \\
N1-C9/Si1 & $1.4820(17)$ & $1.741(3)$ & S1-N1-C9/Si1 & $116.96(9)$ & $112.73(15)$ \\
\hline
\end{tabular}

\subsubsection{A Stereocentre on the connecting Carbon Atom}

When $\mathrm{PEt}_{3}$ was lithiated with $t \mathrm{BuLi}$, $\left[\mathrm{Li}\left(\mathrm{HCP}(\mathrm{Me}) \mathrm{Et}_{2}\right)\right]$ was produced. The $\mathrm{CH}_{2}$ group was rather deprotonated than the $\mathrm{CH}_{3}$ group because of the higher acidity of the hydrogen atoms as the electron-withdrawing phosphorus atom is in closer proximity. Thus, is could be shown that the deprotonation does not take place at the sterically unprotected methyl group. When this lithiated phosphane was reacted with $\mathrm{S}\left(\mathrm{NSiMe}_{3}\right)_{2}$, chirality was introduced at the connecting carbon atom and the resulting product has the formula $\left[\mathrm{Li}\left\{\mathrm{Et}_{2} \mathrm{PCH}(\mathrm{Me}) \mathrm{S}\left(\mathrm{NSiMe}_{3}\right)_{2}\right\}\right]_{2}(7)$.

Due to the centre of inversion in the $(\mathrm{LiN})_{2}$ four membered ring both connecting carbon atoms have different absolute configurations (Figure 2-10). The S-N bond distances are almost equal to 4 and lie at 1.5906(10) $\AA$ for S1-N1 and $1.6235(10) \AA$ for $S 1-N 2$, respectively. The two $\left(\mathrm{SN}_{2}\right)$ units are inclined by $116.9^{\circ}$ with respect to the $(\mathrm{LiN})_{2}$ ring and the ethyl phosphane moieties reside on opposite sides of the $\left(\mathrm{SN}_{2}\right)$ planes. Thus, the steric strain between the trimethylsilyl groups is minimized. It is worthy to note that the $\mathrm{Li}-\mathrm{N}$ bond distances in 7 differ less from each other than in 4 . The N2-Li1'-P1 angle of $83.25(7)^{\circ}$ is less acute in 7 compared to 4 due to the bulkier groups on the phosphorus atom. Selected bond lengths and angles can be found in Table 2-4. 


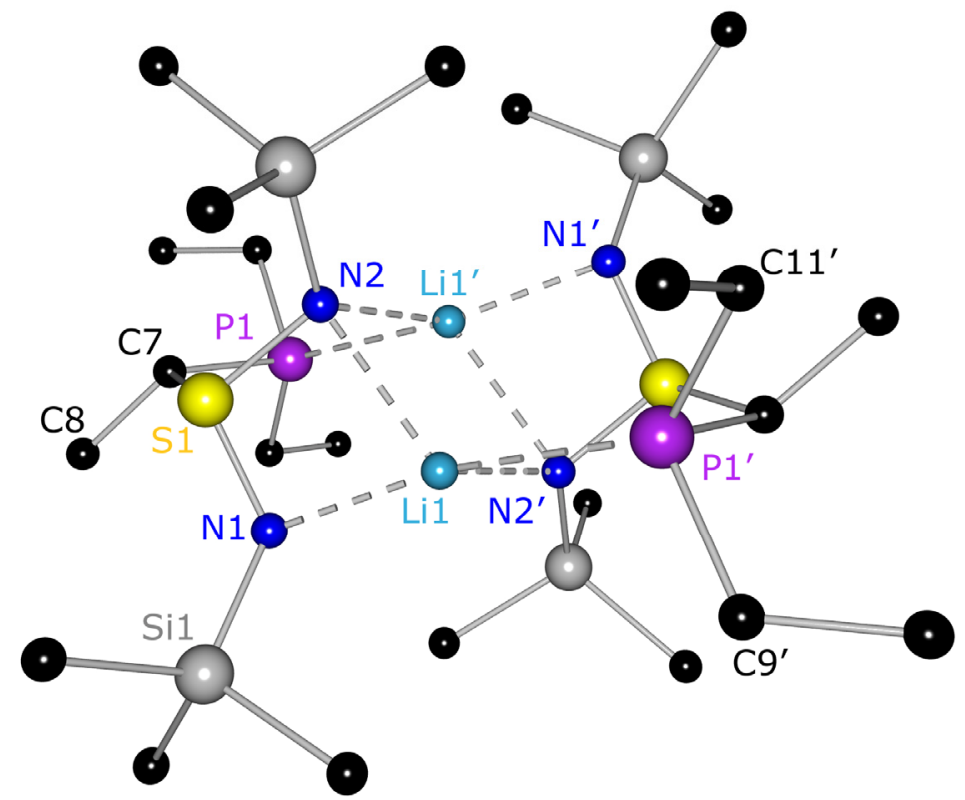

Figure 2-10: Molecular structure of $\left[\mathrm{Li}\left\{\mathrm{Et}_{2} \mathrm{PCH}(\mathrm{Me}) \mathrm{S}\left(\mathrm{NSiMe}_{3}\right)_{2}\right\}\right]_{2}(7)$. Hydrogen atoms are omitted for clarity.

Table 2-4: Selected bond lengths $[\AA]$ and angles $\left[{ }^{\circ}\right]$ in 7

\begin{tabular}{llll}
\hline S1-N1 & $1.5906(10)$ & N1-S1-N2 & $104.22(5)$ \\
S1-N2 & $1.6235(10)$ & S1-C7-P1 & $111.63(6)$ \\
S1-C7 & $1.8300(12)$ & S1-N1-Li1 & $94.40(8)$ \\
P1-C7 & $1.8682(13)$ & C7-P1-Li1' & $99.18(6)$ \\
P1-Li1' & $2.622(2)$ & N1-Li1-N2 & $73.19(8)$ \\
N1-Li1 & $2.028(2)$ & Li1-N2-Li1' & $69.46(10)$ \\
N2-Li1 & $2.219(2)$ & N2-Li1-N2' & $110.54(10)$ \\
N2-Li1' & $2.037(2)$ & P1-Li1'-N2 & $114.22(9)$ \\
N1-Si1 & $1.7122(11)$ & S1-N1-Si1 & $123.87(6)$ \\
\hline
\end{tabular}

From the NMR spectra, the presence of two diastereomers due to the stereocentre on $\mathrm{C} 7$ becomes obvious. This observation is comparable to complex 3 . However, in the case of 7 , the two compounds are clearly separated in the ${ }^{31} \mathrm{P}\left\{{ }^{1} \mathrm{H}\right\}$ spectrum $(\delta(A)=-30.74, \delta(B)=-27.34 \mathrm{ppm}$, see Figure 2-11), showing two septets due to the coupling of one phosphorus atom to two lithium atoms as discussed in chapter 2.2. Again, it can be speculated that the 'trans' isomer is the preferred arrangement in solution (i. e. the methyl groups are on opposite sides of the $(\mathrm{LiN})_{2}$ plane). 


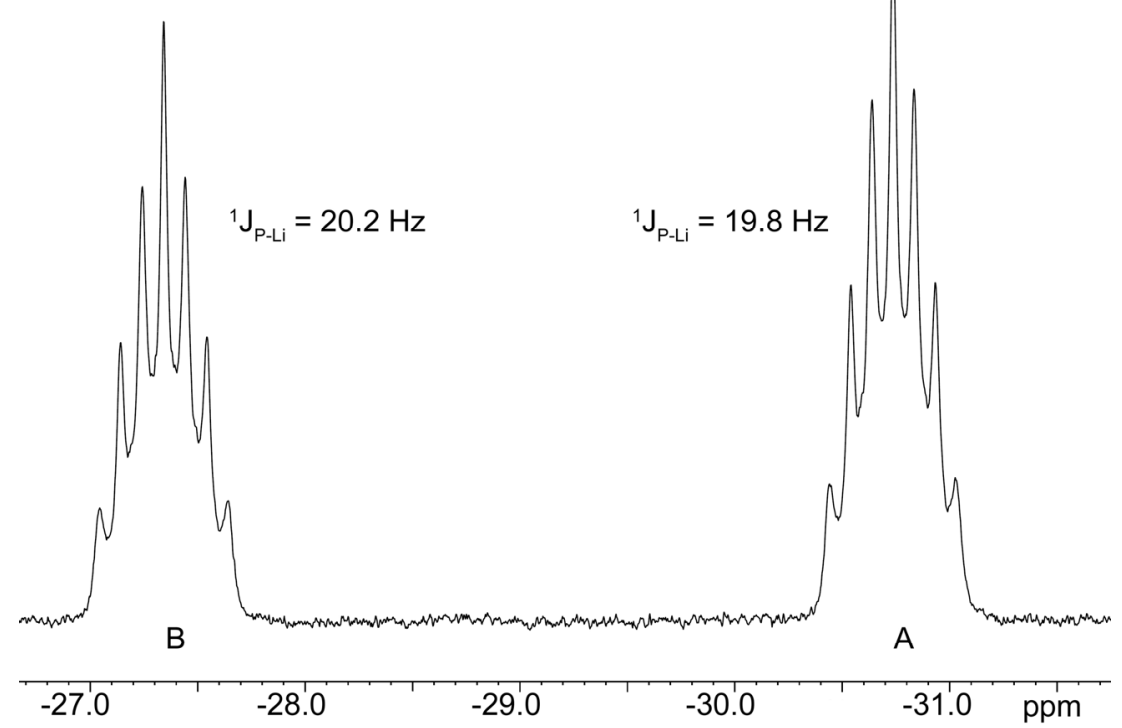

Figure 2-11: ${ }^{31} \mathrm{P}\left\{{ }^{1} \mathrm{H}\right\}$ NMR spectrum of 7 showing the signals for two diastereomers $A$ and $B$.

The formation of the equilibrium between the two diastereomers seems to be very fast. Even a frozen sample which is allowed to warm up in the spectrometer shows the same ratio of $A$ to $B$ which does not change during the measurement. In the ${ }^{1} \mathrm{H}$ spectrum, the signals are not as clearly separated as in the ${ }^{31} \mathrm{P}\left\{{ }^{1} \mathrm{H}\right\}$ spectrum and complicate the interpretation.

\subsubsection{Extending the Side-Arm}

In order to further enhance the flexibility and adaptability of the new ligand system, the length of the side-arm can be changed. One way would be to use a phosphane with longer alkane substituents like ethane or butane. It is a problem though, that those groups are deprotonated at the $\mathrm{CH}_{2}$ group next to the phosphorus atom as those hydrogen atoms are the most acidic. This was clearly demonstrated by the synthesis of $\left[\mathrm{Li}\left\{\mathrm{Et}_{2} \mathrm{PCH}(\mathrm{Me}) \mathrm{S}\left(\mathrm{NSiMe}_{3}\right)_{2}\right\}\right]_{2}$ (7). Therefore, another synthetic route had to be explored. Morrow et al. reported the preparation of the diphenyl-1alkinylphosphane $\mathrm{Ph}_{2} \mathrm{PCCCH}_{3}$ in 1969 (Equation 2-4), which should be a good starting material. ${ }^{[75]}$ The absence of $\mathrm{CH}_{2}$ groups should prevent side-reactions.

In order to lithiate the phosphane, a solution of $t \mathrm{BuLi}$ in pentane was reduced in volume and $\mathrm{Ph}_{2} \mathrm{PCCCH}_{3}$ added drop wise at room temperature. The orange precipitate was filtered and washed with pentane. Although the substance was poorly soluble, the NMR spectra showed to expected signals. The equimolar reactions with 
$\mathrm{S}(\mathrm{NtBu})_{2}$ or $\mathrm{S}\left(\mathrm{NSiMe}_{3}\right)_{2}$ did not yield crystals or other uniform products even after months, therefore this route was abandoned.

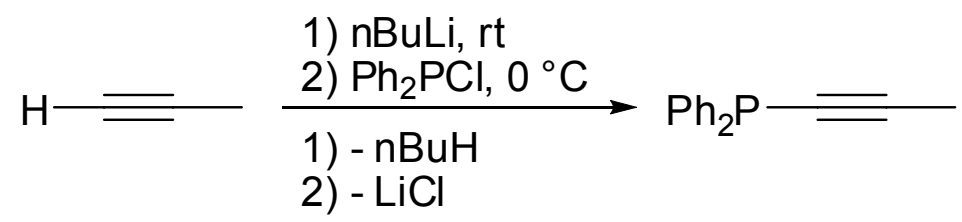

Equation 2-4: Preparation of $\mathrm{Ph}_{2} \mathrm{PCCCH}_{3}$.

Another way to elongate the donating side-arm would be to oxidise the phosphorus atom. This reaction is well known in our work group from the field of phosphanyl anthracenes. This substance class can be oxidised at the phosphorus atom with $\left[\mathrm{H}_{2} \mathrm{O}_{2} \cdot\left(\mathrm{NH}_{2}\right)_{2} \mathrm{CO}\right]$, elemental sulphur and selenium. ${ }^{[76]}$ The reaction is of importance because some of the resulting phosphoryl anthracenes show solid state fluorescence when aromatic guest molecules are present in the crystal lattice and can therefore be employed as chemosensors.

For the oxidation of $\left[\mathrm{Li}\left\{\mathrm{Me}_{2} \mathrm{PCH}_{2} \mathrm{~S}\left(\mathrm{NSiMe}_{3}\right)_{2}\right\}\right]_{2}$ (4) elemental sulphur was suspended in pentane and a solution of 4 in pentane was added slowly at $-78^{\circ} \mathrm{C}$.

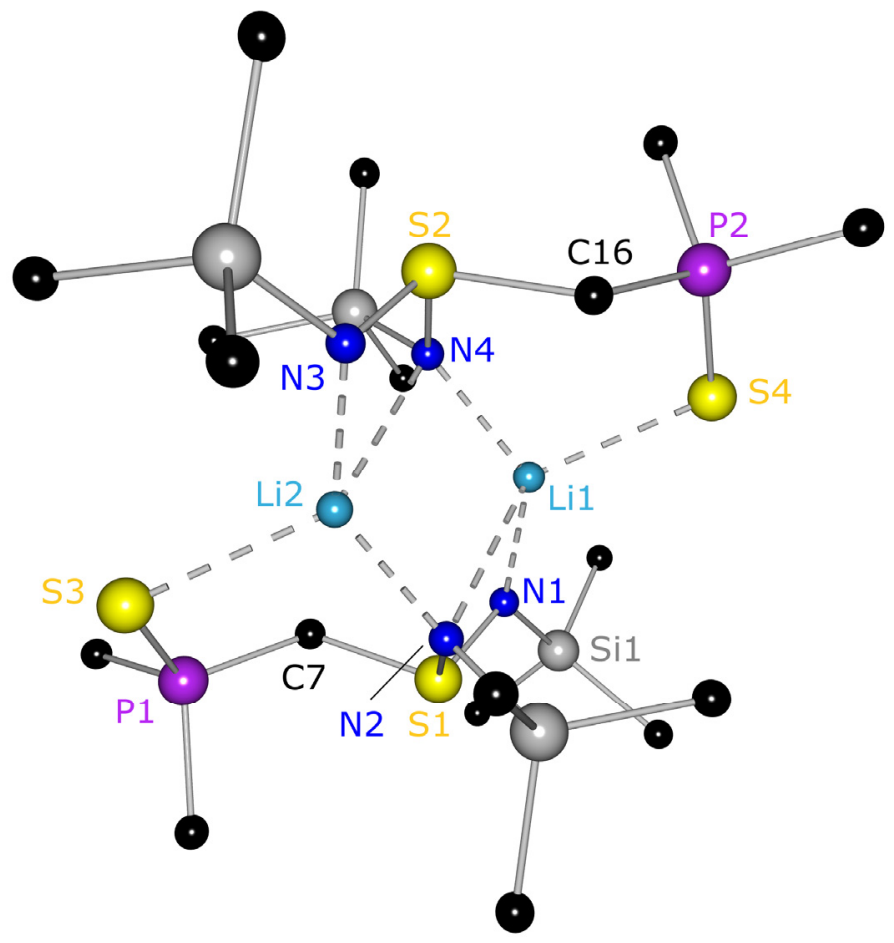

Figure 2-12: Molecular structure of $\left[\mathrm{Li}\left\{\mathrm{Me}_{2} \mathrm{P}(\mathrm{S}) \mathrm{CH}_{2} \mathrm{~S}\left(\mathrm{NSiMe}_{3}\right)_{2}\right\}\right]_{2}(\mathbf{8})$. Hydrogen atoms are omitted for clarity.

After warming to room temperature and stirring over night, insoluble material was filtered off, the solution reduced in volume and stored at $-25^{\circ} \mathrm{C}$ for 
crystallization. The product $\left[\mathrm{Li}\left\{\mathrm{Me}_{2} \mathrm{P}(\mathrm{S}) \mathrm{CH}_{2} \mathrm{~S}\left(\mathrm{NSiMe}_{3}\right)_{2}\right\}\right]_{2}$ (8) crystallises in the monoclinic space group $P 2_{1} / n$ as colourless blocks (Figure 2-12). There is one dimer in the asymmetric unit which displays the same geometrical characteristics as all the other structures of that type. The lithium atoms are coordinated by three nitrogen and one sulphur atom, thus the side-arm is indeed elongated. The S4-Li1 bond length is 2.495(7) $\AA$ which is slightly shorter than the P1-Li1' length of 2.665(2) $\AA$ in 4 . First of all this is due to the fact that the sulphur atom is not as sterically hindered as the phosphorus atom because of the missing methyl groups. Second, it is the better donor for lithium because of its greater HSAB hardness. ${ }^{[41]}$ In addition, it can get in closer proximity because of the greater flexibility of the side-arm. The side-arm in $\mathbf{8}$ forms a six-membered ring in a boat conformation when it is coordinating to the lithium cation vs. a five-membered ring in $\mathbf{4}$, thereby reducing the steric strain in the system. It can also be seen that the central $(\mathrm{LiN})_{2}$ ring and the diimido moieties intersect at a much smaller angle $\left(42.2^{\circ}\right)$ than all other structures of this type.

The P1-S3 bond of 1.9526(14) $\AA$ matches that of related structures like $\left[(\text { thf }) L i\left\{S P(N i P r)(N H i P r)_{2}\right\}\right]_{2} \quad(P-S: \quad 1.9927(8) \AA)^{[77]}, \quad[($ tmeda $) L i\{t \operatorname{BuN}(\mathrm{S}) P(\mu-$ $\left.\left.\mathrm{N} t \mathrm{Bu})_{2} \mathrm{P}(\mathrm{S}) \mathrm{NH} t \mathrm{Bu}\right\}\right] \quad(\mathrm{P}-\mathrm{S} \text { : } 1.978(2) \AA)^{[78]}$ and the predicted value of $1.92 \AA .{ }^{[67]}$ However it is slightly elongated due to the coordination of the lithium atom. Selected bond lengths and angles can be found in Table 2-5.

Table 2-5: Selected bond lengths $[\AA]$ and angles $\left[{ }^{\circ}\right]$ in 8 and $\mathbf{9}$

\begin{tabular}{llllll}
\hline & $\mathbf{8}$ & $\mathbf{9}$ & & \multicolumn{1}{c}{$\mathbf{8}$} & \multicolumn{1}{c}{$\mathbf{9}$} \\
\hline S1-N1 & $1.599(3)$ & $1.595(2)$ & N1-S1-N2 & $107.56(16)$ & $107.49(12)$ \\
S1-N2 & $1.602(3)$ & $1.614(2)$ & S1-C7-P1 & $118.6(2)$ & $119.80(16)$ \\
S1-C7 & $1.828(4)$ & $1.831(3)$ & S3-P1-C7/Se1-P1-C7 & $116.29(14)$ & $114.75(10)$ \\
P1-C7 & $1.819(4)$ & $1.822(3)$ & P1-S3-Li2/P1-Se1-Li1 & $94.30(16)$ & $91.28(11)$ \\
P1-S3/Se1 & $1.9526(14)$ & $2.1196(8)$ & N1-Li1-N2/N1-Li2-N2 & $67.9(2)$ & $68.25(16)$ \\
Li1-N1/N3 & $1.982(7)$ & $1.994(5)$ & N2-Li1-N4 & $132.7(4)$ & $99.0(2)$ \\
N2-Li1 & $2.560(7)$ & $2.018(5)$ & Li1-N2-Li2 & $82.5(3)$ & $80.8(2)$ \\
N2-Li2 & $1.989(7)$ & $2.554(5)$ & S3-Li2-N2/Se1-Li1-N2 & $104.7(3)$ & $105.6(2)$ \\
S3-Li2/Se1-Li1 & $2.470(7)$ & $2.614(5)$ & S3-Li2-N3/Se1-Li1-N3 & $115.4(3)$ & $115.0(2)$ \\
\hline
\end{tabular}

All signals in the ${ }^{1} \mathrm{H}$ NMR spectrum of 8 show a downfield shift of approx. $0.4 \mathrm{ppm}$ in comparison to the starting material 4 . This could be due to the electron withdrawing effect of the sulphur atom at the phosphorus atom and the resulting 
deshielding of the hydrogen atoms. Interestingly, a ${ }^{2} J_{\mathrm{Li}-\mathrm{P}}$ coupling is not detected. The ${ }^{31} \mathrm{P}\left\{{ }^{1} \mathrm{H}\right\}$ shift of $27.05 \mathrm{ppm}$ is in the expected region for oxidised phosphorus atoms although not very near to the reported value of $83 \mathrm{ppm}$ for the olefin polymerisation catalyst $\left[\left(\mathrm{C}_{3} \mathrm{H}_{5}\right) \mathrm{Ni}\left\{t \mathrm{Bu}_{2} \mathrm{PCH}_{2} \mathrm{~S}\left(\mathrm{NSiMe}_{2}\right)\right\}\right]$ which was already mentioned in the introduction of this chapter ${ }^{[63]}$ Regarding the chemical shift of this catalyst, it is thinkable that is was oxidised during the reaction. This finding will be discussed in more detail in chapter 2.4 .

The selenium analogue of $\mathbf{8}$ was synthesised in the same way, using grey selenium as a starting material. $\left[\mathrm{Li}\left\{\mathrm{Me}_{2} \mathrm{P}(\mathrm{Se}) \mathrm{CH}_{2} \mathrm{~S}\left(\mathrm{NSiMe}_{3}\right)_{2}\right\}\right]_{2}(\mathbf{9})$ also crystallises in the monoclinic space group $P 2_{1} / n$ with the whole molecule in the asymmetric unit (Figure 2-13). The structure is isostructural to $\mathbf{8}$. The coordination of the lithium cations is similar to 8 , with the selenium atoms taking part in the coordination.

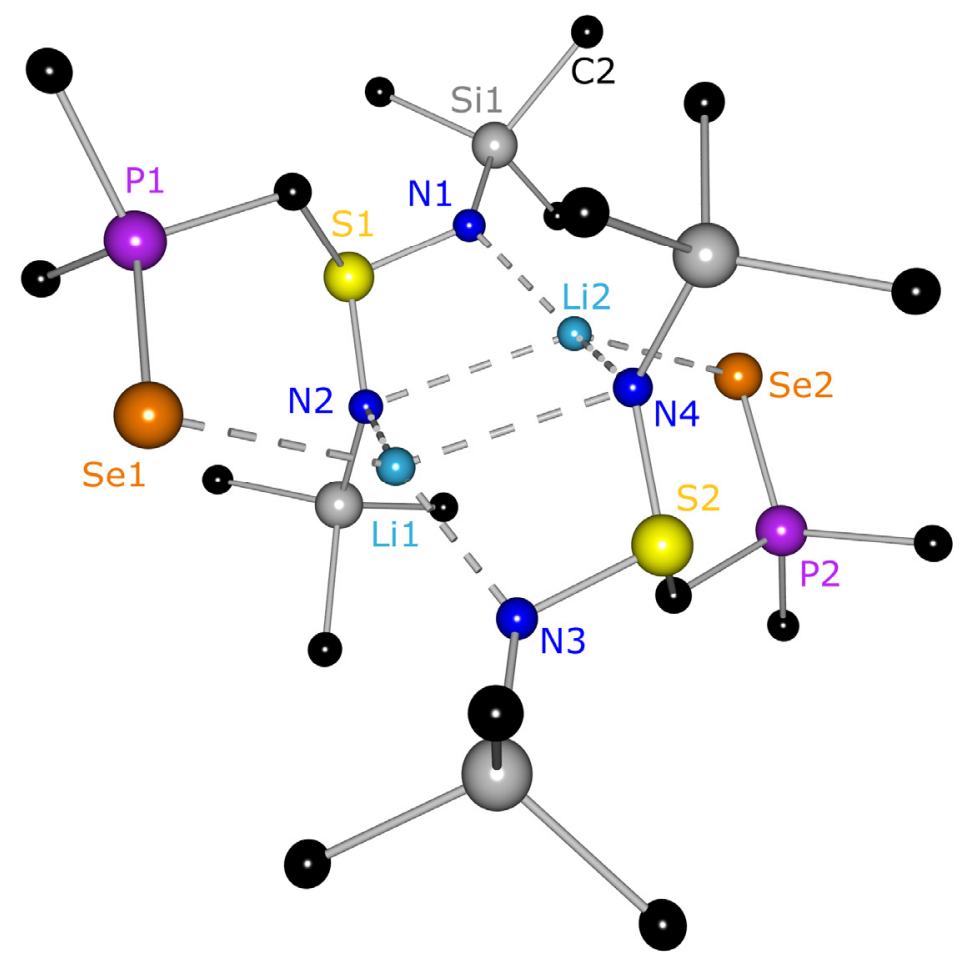

Figure 2-13: Molecular structure of $\left[\mathrm{Li}\left\{\mathrm{Me}_{2} \mathrm{P}(\mathrm{Se}) \mathrm{CH}_{2} \mathrm{~S}\left(\mathrm{NSiMe}_{3}\right)_{2}\right\}\right]_{2}(\mathbf{9})$. Hydrogen atoms are omitted for clarity.

The central $(\mathrm{LiN})_{2}$ four-membered ring shows similar values for the bond lengths and angles. Nevertheless, the coordination of the $\mathrm{SePCH}_{2}$ side-arm is even weaker than in the corresponding sulphur compound with $\mathrm{Li}-\mathrm{Se}$ bond lengths of 2.614(5) $\AA$ (Se1-Li1) and 2.593(5) $\AA$ (Se2-Li2) which are quite similar to the values found for $\left[(\text { thf })_{2} \mathrm{Li}\left\{t \mathrm{BuN}(\mathrm{Se}) \mathrm{P}(\mu-\mathrm{N} t \mathrm{Bu})_{2} \mathrm{PNH} t \mathrm{Bu}\right\}\right]$ (Se-Li: $\left.2.605(10) \AA\right)^{[78]}$. Interestingly, 
these bond distances are almost the same as the P1-Li1' bond of 2.655(2) $\AA$ in the non-oxidised starting material $\left[\mathrm{Li}\left\{\mathrm{Me}_{2} \mathrm{PCH}_{2} \mathrm{~S}\left(\mathrm{NSiMe}_{3}\right)_{2}\right\}\right]_{2}$ (4).

The ${ }^{31} \mathrm{P}\left\{{ }^{1} \mathrm{H}\right\}$ signal of $6.23 \mathrm{ppm}$ is shifted less downfield in comparison to 8 because of the lower electronegativity of selenium compared to sulphur. On the contrary this effect is not visible in the ${ }^{1} \mathrm{H}$ spectrum where the signals are shifted to even lower fields.

By oxidizing the phosphorus atom it was possible to extend the side-arm by one atom. It could be shown that the oxidation of phosphorus in the NSCP ligands with elemental sulphur or selenium is possible if the right conditions are chosen, which represents an additional possibility for ligand design. By this synthesis the coordinating side-arm can be lengthened which is essential if larger metal atoms are to be coordinated.

\subsubsection{Obtaining the free Ligand}

The reaction of [(tmeda) $\left.L i\left(\mathrm{H}_{2} \mathrm{CPPh}{ }_{2}\right)\right]$ and $\mathrm{S}(\mathrm{NtBu})_{2}$ in toluene proceeded to give $\left[\mathrm{Li}\left\{\mathrm{Ph}_{2} \mathrm{PCH}_{2} \mathrm{~S}(\mathrm{NtBu})_{2}\right\}\right]_{2}(2)$ as a lithium dimer. However, when the same reaction was carried out with $\mathrm{S}\left(\mathrm{NSiMe}_{3}\right)_{2}$ in toluene, protonation of the ligand occurred, resulting in the formation of $\mathrm{Ph}_{2} \mathrm{PCH}_{2} \mathrm{~S}\left(\mathrm{NSiMe}_{3}\right)\left(\mathrm{HNSiMe}_{3}\right)$ (10) in nearly quantitative yield. Currentyl it is proposed that this is due to the $\mathrm{C}-\mathrm{H}$ bond activation reaction described in Equation 2-5. Thus, a TMEDA molecule is deprotonated, resulting in the formation of 10 and lithiated TMEDA. This lithium organic compound has already been described by Strohmann et al. ${ }^{[79]}$ but could until now not be accounted for in the present reaction.

$\left[(\right.$ tmeda $\left.) L i\left(\mathrm{CH}_{2} \mathrm{PPh}_{2}\right)\right]+\mathrm{S}\left(\mathrm{NSiMe}_{3}\right)_{2} \frac{\text { toluene }}{-78^{\circ} \mathrm{C}}$

Equation 2-5: Preparation of $\mathrm{Ph}_{2} \mathrm{PCH}_{2} \mathrm{~S}\left(\mathrm{NSiMe}_{3}\right)\left(\mathrm{HNSiMe}_{3}\right)($ (10).

Compound $\mathbf{1 0}$ crystallises from toluene layered with pentane in the monoclinic space group $P 2_{1} / n$ as a monomer. The solid state structure is shown in Figure 2-14. The bond distances for P1-C1 (1.8404(13) $\AA$ ) and P1-C13 (1.8526(11) $\AA$ ) are similar to those of 1-6. The $\mathrm{S} 1-\mathrm{C} 13$ bond distance of $1.8092(12) \AA$ is also slightly shorter 
than in complexes 1-6. The N1-S1-N2 $\left(109.26(5)^{\circ}\right)$ as well as the S1-C13-P1 angle $\left(113.54(6)^{\circ}\right)$ are widened compared to the lithiated species. The S-N bond distances of $1.6520(9) \AA(\mathrm{S} 1-\mathrm{N} 1)$ and $1.5698(10) \AA(\mathrm{S} 1-\mathrm{N} 2)$ are very close to the predicted values for a single and a double bond. ${ }^{[67]}$ They also match the bond lengths of methyl(diimido)sulfinic acid $\mathrm{H}(\mathrm{N} t \mathrm{Bu})_{2} \mathrm{SMe}$ and methylene-bis(triimido)sulfonic acid $\mathrm{H}_{2} \mathrm{C}\left\{\mathrm{S}(\mathrm{N} t \mathrm{Bu})_{2}(\mathrm{NH} t \mathrm{Bu})\right\}_{2}$, which have $\mathrm{S}-\mathrm{N}$ bond distances of 1.52 and $1.68 \AA^{[30,80]}$ Both six-membered rings are inclined by $99.1^{\circ}$ with respect to each other. In addition, two molecules are linked with each other via a hydrogen bond between $\mathrm{H} 1$ and N2. This behaviour is similar to $\mathrm{PhS}\left(\mathrm{HNSiMe}_{3}\right)\left(\mathrm{NSiMe}_{3}\right)$, where the protonated nitrogen atom has a trigonal planar environment. ${ }^{[81]}$ In 10 , the nitrogen atom N1 only deviates by $7.2^{\circ}$ from the $\mathrm{H} 1-\mathrm{S} 1-\mathrm{Si} 1$ plane which is in accordance with $\mathrm{PhS}\left(\mathrm{HNSiMe}_{3}\right)\left(\mathrm{NSiMe}_{3}\right)$ where the corresponding angle is $7.3^{\circ}$. The $\mathrm{S}-\mathrm{N}$ bond lengths of $1.662(1) \AA$ and $1.572(1) \AA$ are also very similar to 10 . Selected bond lengths and angles can be found in Table 2-6.

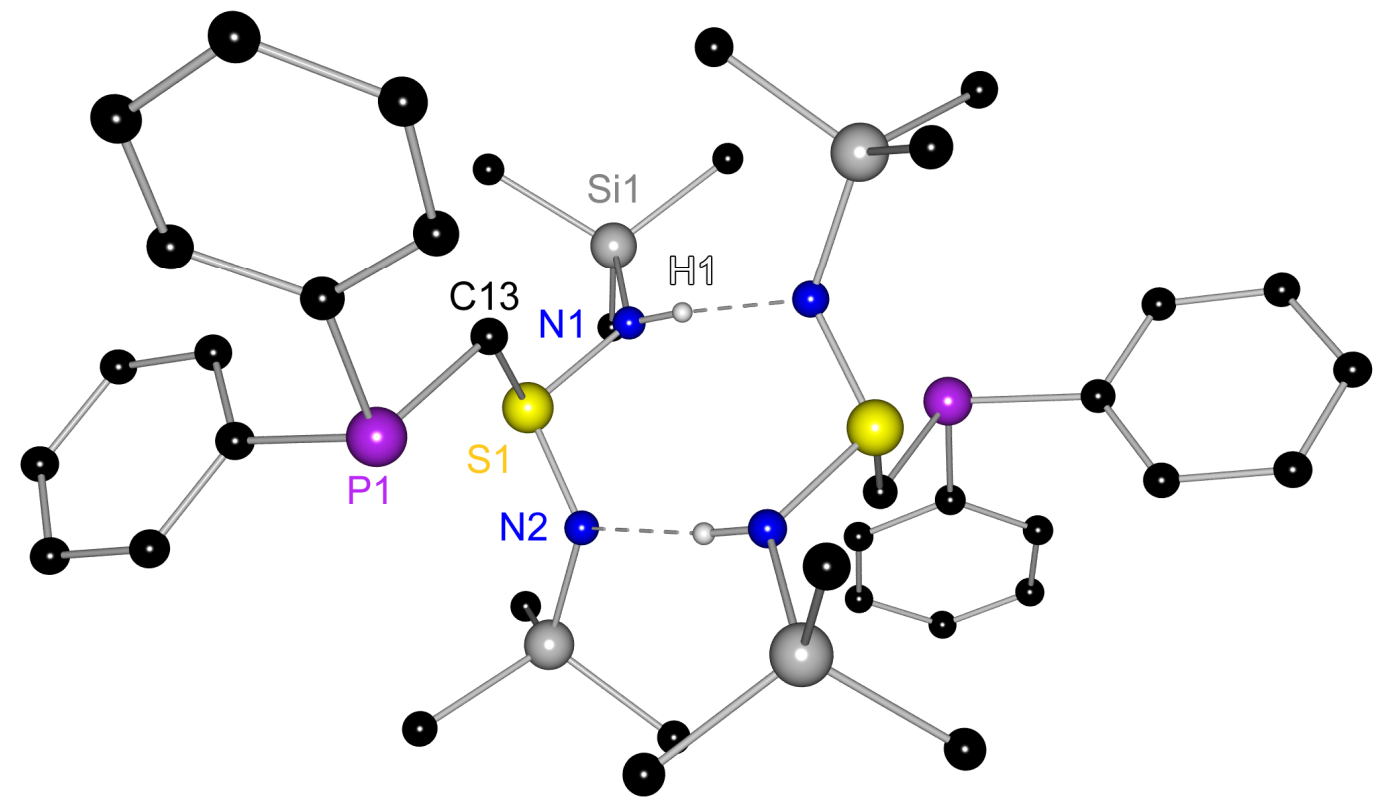

Figure 2-14: Molecular structure of $\mathrm{Ph}_{2} \mathrm{PCH}_{2} \mathrm{~S}\left(\mathrm{NSiMe}_{3}\right)\left(\mathrm{HNSiMe}_{3}\right)$ (10) including the connecting hydrogen bonds. Hydrogen atoms (except $\mathrm{H} 1$ ) are omitted for clarity.

\subsubsection{A monomeric Complex}

To identify the source of the hydrogen atom, several experiments were carried out. They show that toluene cannot be the source of the hydrogen atom. After stirring the reaction mixture for $20 \mathrm{~h}$, there was evidence of a compound which gave a very broad signal at $-39 \mathrm{ppm}$ in the ${ }^{31} \mathrm{P}\left\{{ }^{1} \mathrm{H}\right\}$ NMR spectrum. From this intermediate compound the reaction to the final product $\left(\delta_{31 \mathrm{P}}=-28.8 \mathrm{ppm}\right)$ proceeded very slowly 
at $-25^{\circ} \mathrm{C}$. From the NMR spectrum it was concluded that the intermediate compound probably is some kind of lithium complex. When the same reaction (according to Equation 2-5) was carried out in pentane instead of toluene it was possible to crystallise the intermediate lithium complex [(tmeda) $\left.L i\left\{\mathrm{Ph}_{2} \mathrm{PCH}_{2} \mathrm{~S}\left(\mathrm{NSiMe}_{3}\right)_{2}\right\}\right]$ (11) (Equation 2-6). The ${ }^{31} \mathrm{P}\left\{{ }^{1} \mathrm{H}\right\}$ NMR spectrum of the crystals shows a very broad signal at $-39 \mathrm{ppm}$. This indicates $\mathbf{1 1}$ to be the intermediate in the synthesis of $\mathbf{1 0}$.

These results were unexpected regarding the strategy and are probably due to the different electronic situation in the $\mathrm{S}\left(\mathrm{NSiMe}_{3}\right)_{2}$ moiety. Compound 11 crystallises from pentane as a monomer in the monoclinic space group $C 2 / c$ with half a pentane molecule in the asymmetric unit (Figure 2-15). A comparison of the bond lengths and angles with $\mathrm{Ph}_{2} \mathrm{PCH}_{2} \mathrm{~S}\left(\mathrm{NSiMe}_{3}\right)\left(\mathrm{HNSiMe}_{3}\right)$ (10) can be found in Table 2-6.

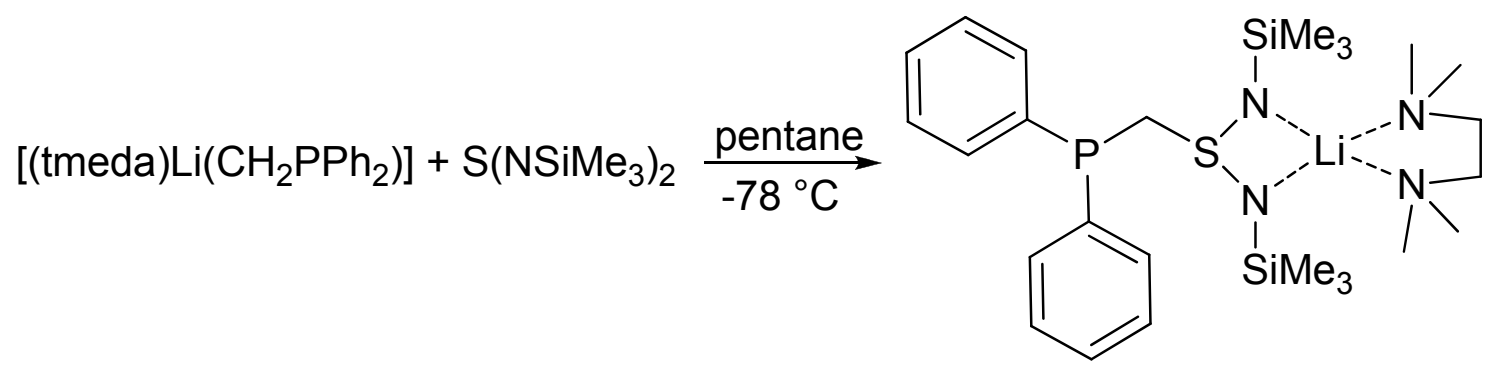

Equation 2-6: Preparation of [(tmeda)Li $\left.\left\{\mathrm{Ph}_{2} \mathrm{PCH}_{2} \mathrm{~S}\left(\mathrm{NSiMe}_{3}\right)_{2}\right\}\right]$ (11).

The coordination mode in this compound is new compared to the complexes 1-8. The lithium cation is fourfold $\mathrm{N}$-coordinated and the phosphorus atom is not taking part in the coordination as the Li-P distance of $3.23 \AA$ is too long to be regarded a bond. Nevertheless, an orientation towards the lithium ion can be observed which is due to electrostatic attraction. Furthermore, the S1-C13-P1 angle of $108.79(9)^{\circ}$ indicates the inclination of the phosphorus atom towards the lithium cation. This finding is confirmed by the ${ }^{31} \mathrm{P}\left\{{ }^{1} \mathrm{H}\right\}$ NMR spectrum which shows a very broad signal at $-39 \mathrm{ppm}$. The line broadening can only be explained with a (weak) Li$P$ contact in solution. The significant quadropolar moment of the lithium nucleus broadens the phosphorus signal. This long-range interaction might also be the reason for the protonation of the ligand when the reaction is conducted in toluene. 


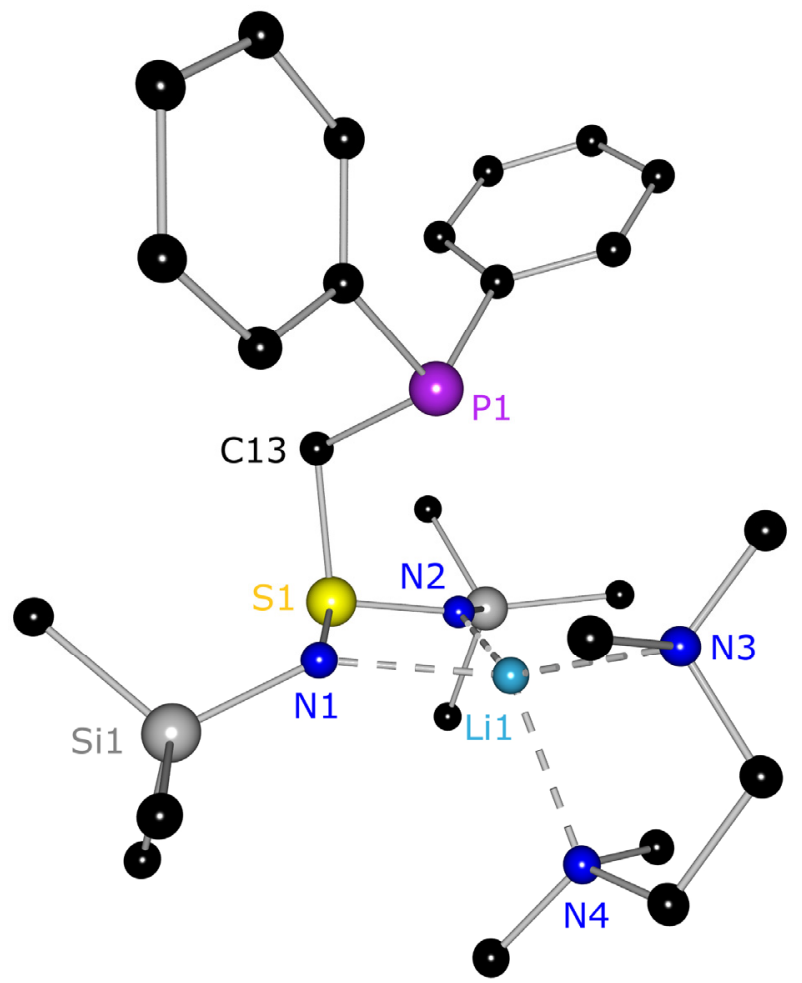

Figure 2-15: Molecular structure of [(tmeda) $\left.L i\left\{\mathrm{Ph}_{2} \mathrm{PCH}_{2} \mathrm{~S}\left(\mathrm{NSiMe}_{3}\right)_{2}\right\}\right]$ (11). Hydrogen atoms are omitted for clarity.

In the solid state both phenyl rings are twisted by $90^{\circ}$ with respect to each other, facilitating close packing of the molecules in the crystal. The central $\left(\mathrm{SN}_{2} \mathrm{Li}\right)$ ring is almost perfectly planar with the phosphorus atom residing above this plane. It is aligned with $\mathrm{C} 13, \mathrm{~S} 1, \mathrm{Li} 1$ and both nitrogen atoms of the TMEDA molecule with respect to the N1-S1-N2 bisection.

Table 2-6: Selected bond lengths $[\AA]$ and angles $\left[^{\circ}\right]$ in 10 and 11

\begin{tabular}{lcclcc}
\hline & $\mathbf{1 0}$ & $\mathbf{1 1}$ & & $\mathbf{1 0}$ & $\mathbf{1 1}$ \\
\hline S1-N1 & $1.6520(9)$ & $1.6070(15)$ & N1-S1-N2 & $109.26(5)$ & $103.72(8)$ \\
S1-N2 & $1.7184(10)$ & $1.6032(16)$ & S1-C13-P1 & $113.54(6)$ & $108.79(9)$ \\
S1-C13 & $1.8092(12)$ & $1.8338(18)$ & S1-N1-Li1 & --- & $89.41(12)$ \\
P1-C13 & $1.8526(11)$ & $1.8557(18)$ & S1-N2-Li & --- & $90.63(12)$ \\
N1-Si1 & $1.7421(10)$ & $1.7150(16)$ & S1-N1-Si1 & $123.18(6)$ & $117.55(9)$ \\
N1-Li1 & --- & $2.071(4)$ & N1-Li1-N2 & --- & $75.80(12)$ \\
N2-Li1 & --- & $2.039(4)$ & N3-Li1-N4 & --- & $83.19(13)$ \\
N3-Li1 & --- & $2.150(4)$ & N1-Li1-N3 & --- & $132.61(18)$ \\
N4-Li1 & --- & $2.129(4)$ & & & \\
\hline
\end{tabular}


The N1-S1-N2 angle of $103.72(8)^{\circ}$ is slightly more acute than in the lithium complexes 1-8. The Li-N distances range from 2.039(4) $\AA$ (Li1-N2) to 2.150(4) $\AA$ (Li1-N3) with the bonds from the TMEDA molecule being marginally longer than the bonds from the diimido moiety. As the phosphorus side-arm is not donating to the $\mathrm{Li}$ cation, it is free for binding to any other soft metal, thus providing the opportunity to generate heterobimetallic complexes just like the earlier reported $\left[(\text { thf })_{2} \mathrm{Li}\left\{(\mathrm{NtBu})_{3} \mathrm{SMe}\right\} \mathrm{ZnMe}_{2}\right]^{\left[{ }^{[82]}\right.}$

To check whether or not the solvent toluene was the source of the hydrogen atom in 10, a sample of crystalline [(tmeda) $\left.\mathrm{Li}\left\{\mathrm{Ph}_{2} \mathrm{PCH}_{2} \mathrm{~S}\left(\mathrm{NSiMe}_{3}\right)_{2}\right\}\right]$ (11) was dissolved in toluene- $\mathrm{d}^{8}$ and the NMR tube was melted off. The idea behind this was that the incorporation of deuterium into $\mathrm{Ph}_{2} \mathrm{PCH}_{2} \mathrm{~S}\left(\mathrm{NSiMe}_{3}\right)\left(\mathrm{HNSiMe}_{3}\right)$ (10) would be detectable in the NMR spectra. Curiously, the spectra did not change at all, i. e. pure 11 could not be converted into 10 by this method. Consequently, it could not be resolved why the deprotonation of TMEDA only occurs in toluene and not in pentane. The different polarity of the two solvents and therefore a distinct activation of the lithium complex 11 could be a reason. When the synthesis of $\left[\mathrm{Li}\left\{\mathrm{Ph}_{2} \mathrm{PCH}_{2} \mathrm{~S}\left(\mathrm{NSiMe}_{3}\right)_{2}\right\}\right]_{2}(\mathbf{5})$ is carried out in toluene, the outcome is the same as with pentane. However, if $\mathbf{5}$ is dissolved in pentane together with two equivalents of TMEDA and stored at room temperature for several weeks, the protonated species $\mathrm{Ph}_{2} \mathrm{PCH}_{2} \mathrm{~S}\left(\mathrm{NSiMe}_{3}\right)\left(\mathrm{HNSiMe}_{3}\right)(10)$ is isolated.

\section{Conclusion}

With the free ligand at hand, it should now be easily possible to obtain a great variety of mono- and bimetallic complexes directly rather than following the metathesis or salt elimination route. This can be problematic as some sulphur diimido compounds undergo ligand scrambling with metal halogenides as was already discussed at the beginning of this chapter. Now the reaction of $\mathbf{1 0}$ with metal amides or metal hydrides will hopefully give new metal complexes. 10 would be an excellent starting material for such reactions as it can be prepared in nearly quantitative yield and great purity. However, the reaction has to be further investigated to prove the source of the hydrogen.

However, 11 could also be a very good starting material for metal exchange reactions. As the phosphorus atom does not take part in the complexation of lithium, it is free to coordinate to other metals. Thereby, a precoordination is possible that 
brings the metal in close proximity to the nitrogen atoms. Lithium could then leave the complex as a TMEDA/ligand adduct and the metal exchange would be complete.

In conclusion, it can be stated that the phosphorus side-arm on the sulphur diimide can be modified in a straightforward way. The NSCP ligands are indeed tridentate, containing hard nitrogen and soft phosphorus donor sites. Although the bite of the ligand system is not optimized for lithium cations, the complexes formed are quite stable. Even the softer phosphorus site coordinates the hard lithium cation, yet in solution. It seems that the $\left\{\mathrm{R}_{2} \mathrm{PCH}_{2} \mathrm{~S}\left(\mathrm{NR}^{\prime}\right)_{2}\right\}^{-}$anions are indeed the ligands which are complexing as good as envisaged. Further, the formation of dimers seems to be favoured as it helps to balance the electron deficiency of the metal cations.

There is a wide range of methyl phosphanes which can be deprotonated and reacted with a sulphur diimide. Thus, the steric properties of the obtained lithium complexes can be tuned. It is even possible to introduce a stereocentre at the phosphorus atom $(3,6)$ or at the carbon atom $(7)$ of the connecting $\mathrm{CH}_{2}$ bridge. In addition, different sulphur diimides can be used which are responsible for the distinct electronic properties of the compounds. In addition, the side-arm can be extended by oxidation of the phosphorus atom without loosing the soft donor site.

It has been shown, that it is possible to generate a complex of choice by choosing the appropriate phosphane, diimide and solvent. Thereby, a metal-free ligand (10) and a monomeric complex (11) were synthesised. There is now a library of different building blocks that can be combined in order to synthesise the appropriate compound for the desired application. The yields are good and $\mathbf{1 0}$ and $\mathbf{1 1}$ are excellent starting materials for subsequent metalation or metal exchange reactions. The new ligand system can thereby be fitted to the needs of the synthetic chemist, giving the opportunity to choose from a variety of possible derivatisations.

Besides, the phosphorus side-arm is in general flexible in solution and can bind to both lithium atoms. This process is fast on the NMR time scale and cannot be frozen out even at very low temperatures $(120 \mathrm{~K})$. 


\subsection{Complexes with the di(tert-butyl)phosphanyl Side-Arm}

As already mentioned above, in 2005 a patent was granted for $\left[\left(\mathrm{C}_{3} \mathrm{H}_{7}\right) \mathrm{Ni}\left\{t \mathrm{Bu}_{2} \mathrm{PCH}_{2} \mathrm{~S}\left(\mathrm{NSiMe}_{3}\right)_{2}\right\}\right]$ which was said to be a catalyst for the polymerization of olefins. ${ }^{[63]}$

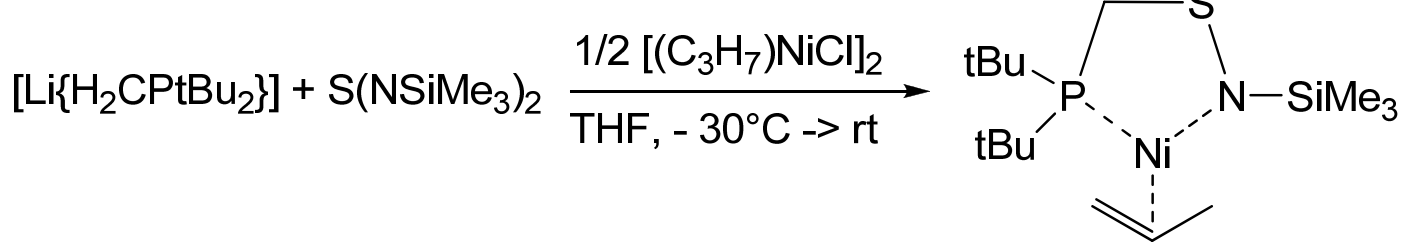

Equation 2-7: Preparation of $\left[\left(\mathrm{C}_{3} \mathrm{H}_{7}\right) \mathrm{Ni}\left\{t \mathrm{Bu}_{2} \mathrm{PCH}_{2} \mathrm{~S}\left(\mathrm{NSiMe}_{3}\right)_{2}\right\}\right]^{[63]}$

The only analysis given was a ${ }^{31} \mathrm{P}$ NMR spectrum of $\delta=+83 \mathrm{ppm}$ chemical shift. This is quite striking when we take into account that all the other lithium dimers of that type described in this thesis show ${ }^{31} \mathrm{P}$ signals between -68 and $-27 \mathrm{ppm}$. Although one might argue this shift difference could be due to the different central metal or the substituents on the phosphorus atom this is highly doubtful. It is much more probable that the compound described in the patent was oxidised during the reaction or a chlorine substituent of the transmetalation reagent $\left[\left(\mathrm{C}_{3} \mathrm{H}_{7}\right) \mathrm{NiCl}\right]_{2}$ was present in the molecule. The described reaction pathway also suggests that. In order to prove this hypothesis it was tried to synthesise the complex $\left[\left(\mathrm{C}_{3} \mathrm{H}_{7}\right) \mathrm{Ni}\left\{t \mathrm{Bu}_{2} \mathrm{PCH}_{2} \mathrm{~S}\left(\mathrm{NSiMe}_{3}\right)_{2}\right\}\right]$. The first step is the lithiation of $t \mathrm{Bu}_{2} \mathrm{PMe}$ which is quite difficult and has to be conducted under harsh conditions. ${ }^{[60,83,84]}$ The product $\left[\mathrm{Li}\left(\mathrm{H}_{2} \mathrm{CPtBu} \mathrm{Bu}_{2}\right)\right]$ is even more reactive than $\left[\mathrm{Li}\left(\mathrm{H}_{2} \mathrm{CPMe}_{2}\right)\right]$ and has to be handled with great care.

After the reaction with $\mathrm{S}\left(\mathrm{NSiMe}_{3}\right)_{2}$, three different products from three different reaction flasks could be structurally characterized. Two of them were indeed oxidised. As it proved impossible to get a uniform product in reasonable yield, the transmetalation with $\left[\left(\mathrm{C}_{3} \mathrm{H}_{7}\right) \mathrm{NiCl}\right]_{2}$ was not attempted.

The compound from the first experiment has the formula $\left[\mathrm{Li}\left\{t \mathrm{Bu}_{2} \mathrm{P}(\mathrm{O}) \mathrm{CH}_{2} \mathrm{~S}\left(\mathrm{NSiMe}_{3}\right)_{2}\right\}\right]_{2}$ (12) and crystallises in the triclinic space group $P \overline{1}$ with half a dimer in the asymmetric unit. The centre of the structure is a $(\mathrm{LiO})_{2}$ heteroatomic ring with both lithium atoms being additionally coordinated by two nitrogen atoms of one diimido moiety. Therefore two six-membered rings are connected to the central four-membered ring and are perfectly aligned and planar. The phosphorus side-arms are in that plane but point to opposite sides of the 
molecule. The sulphur atoms are in that plane as well with the nitrogen atoms bent somewhat downwards/upwards by $7.5^{\circ}$ to either side. The structure is depicted in Figure 2-16.

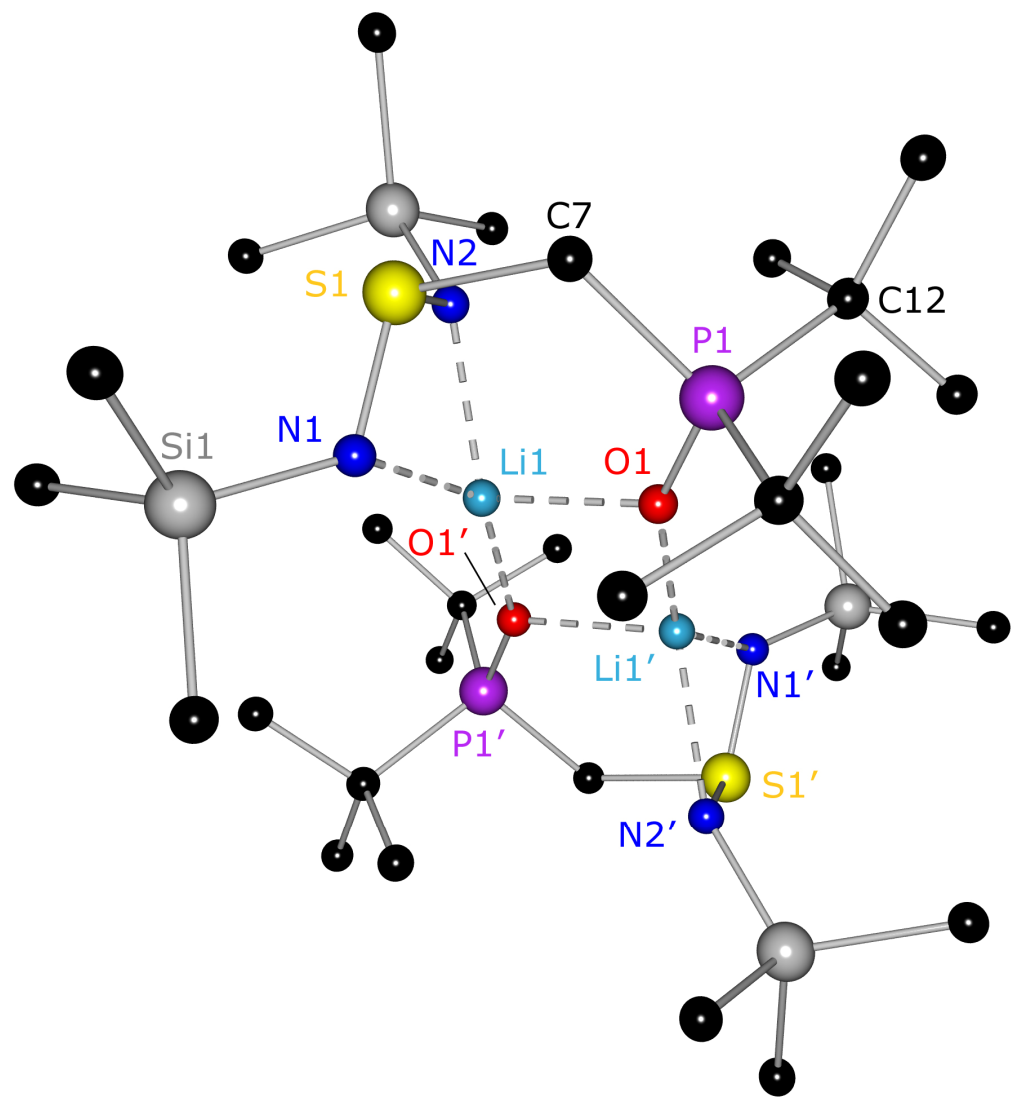

Figure 2-16: Molecular structure of $\left[\mathrm{Li}\left\{t \mathrm{Bu}{ }_{2} \mathrm{P}(\mathrm{O}) \mathrm{CH}_{2} \mathrm{~S}\left(\mathrm{NSiMe}_{3}\right)_{2}\right\}\right]_{2}($ 12). Hydrogen atoms are omitted for clarity.

The $\mathrm{S}-\mathrm{N}$ bonds have almost the same length and are slightly shorter than a typical $\mathrm{S}-\mathrm{N}$ single bond. The $\mathrm{Li}-\mathrm{O}$ distances are shorter than the $\mathrm{Li}-\mathrm{N}$ distances which is expected because oxygen is the better donor for the hard lithium cation.

Table 2-7: Selected bond lengths $[\AA]$ and angles $\left[{ }^{\circ}\right]$ in 12

\begin{tabular}{llll}
\hline S1-N1 & $1.5985(17)$ & N1-S1-N2 & $105.71(9)$ \\
S1-N2 & $1.5951(6)$ & S1-C7-P1 & $117.60(10)$ \\
S1-C7 & $1.860(2)$ & O1-Li1-O1' & $95.04(15)$ \\
C7-P1 & $1.8314(19)$ & Li1-O1-Li1' & $84.96(15)$ \\
N1-Li1 & $2.065(4)$ & O1-Li1-N1 & $99.10(15)$ \\
N2-Li1 & $2.075(4)$ & N1-Li1-N2 & $75.88(13)$ \\
O1'-Li1 & $1.884(4)$ & S1-N1-Li1 & $86.73(12)$ \\
O1-Li1 & $1.983(3)$ & P1-O1-Li1 & $120.87(12)$ \\
P1-O1 & $1.5067(13)$ & Li1-N2-Si2 & $140.54(13)$ \\
\hline
\end{tabular}


The $\mathrm{P}-\mathrm{O}$ bond length of $1.5067(13) \AA$ is slightly elongated, a phenomenon that was already observed for the $\mathrm{P}-\mathrm{S}$ bond in $\left[\mathrm{Li}\left\{\mathrm{Me}_{2} \mathrm{P}(\mathrm{S}) \mathrm{CH}_{2} \mathrm{~S}\left(\mathrm{NSiMe}_{3}\right)_{2}\right\}\right]_{2}(8)$. From the angles Li1-O1-Li1' $\left(84.96(15)^{\circ}\right)$ and O1-Li1-O1' $\left(95.04(15)^{\circ}\right)$ it is obvious that the central four-membered ring is almost planar but slightly distorted in direction of the oxygen atoms. The bond lengths and angles can be found in Table 2-8.

The crystal structure of 13 (Figure 2-17) contains a $t \mathrm{Bu}_{2} \mathrm{P}(\mathrm{O}) \mathrm{Me}$ molecule as free donor emphasising yet again that the starting material is easy to oxidise. The lithium cations are additionally coordinated by two $\left\{\mathrm{BH}_{2} \mathrm{PCH}_{2} \mathrm{~S}\left(\mathrm{NSiMe}_{3}\right)_{2}\right\}^{-}$ligands.

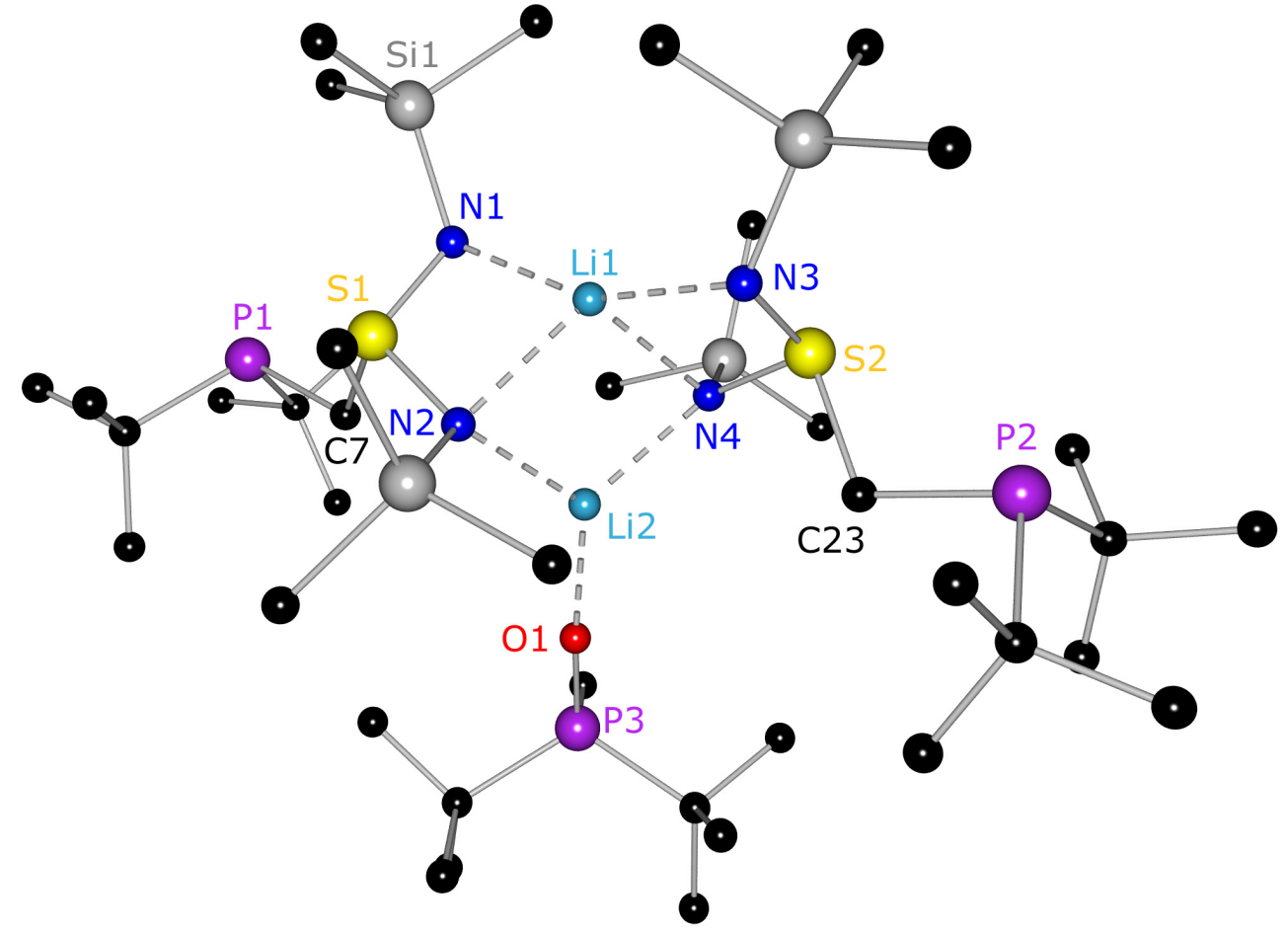

Figure 2-17: Molecular structure of $\left[\mathrm{Li}_{2}\left\{\mathrm{Bu}_{2} \mathrm{PCH}_{2} \mathrm{~S}\left(\mathrm{NSiMe}_{3}\right)_{2}\right\}_{2}(\mathrm{Bu} 2 \mathrm{P}(\mathrm{O}) \mathrm{Me})\right](13)$. Hydrogen atoms are omitted for clarity.

It is remarkable that the phosphorus atoms do not take part in the coordination at all because the binding site is blocked by $t \mathrm{Bu}_{2} \mathrm{P}(\mathrm{O}) \mathrm{Me}$. Both lithium atoms rather have different coordination environments. Li1 is distorted tetrahedrally surrounded by four nitrogen atoms of the diimido moieties. Li2 is trigonal planar coordinated by the two nitrogen atoms $\mathrm{N} 2$ and $\mathrm{N} 4$ and the oxygen atom of the $\mathrm{BBu}_{2} \mathrm{P}(\mathrm{O}) \mathrm{Me}$ molecule which is not aligned with the lithium atoms but bent slightly to one side. The phosphane side-arms point to opposite sides of the complex, thereby reducing the steric strain. They are free to rotate about the $\mathrm{P}-\mathrm{CH}_{2}$ bond and could bind another metal atom, thus opening the way to heterobimetallic complexes. It might also be 
possible to exchange the $t \mathrm{Bu}_{2} \mathrm{P}(\mathrm{O}) \mathrm{Me}$ ligand to generate heterotrimetallic complexes. The major problem for the preparative use of this compound is the uncertain outcome of the reaction. Selected bond lengths and angles can be found in Table 2-8. They do not show any unusual values and the bond lengths in both halves of the dimer a virtually the same. 13 still shows a low electron density peak which can not be accounted for and which is probably due to insufficient crystal quality.

The binding motif of a dimeric sulphur-nitrogen lithium complex with a fourfold/threefold mixed nitrogen/oxygen coordination is well known in the literature and has been reported e.g. for $\left[(\right.$ thf $\left.) \mathrm{Li}_{2}\left\{\left(\mathrm{H}_{3} \mathrm{CCNC}_{4} \mathrm{H}_{3}\right) \mathrm{S}(\mathrm{N} t \mathrm{Bu})_{2}\right\}_{2}\right],{ }^{[35]}$ $\left[\left(\mathrm{Et}_{2} \mathrm{O}\right)\left\{\mathrm{Li}\left(\mathrm{C}_{6} \mathrm{H}_{5}\right) \mathrm{S}\left(\mathrm{NSiMe}_{3}\right)_{2}\right\}_{2}\right]$ or $\left[\left(\mathrm{Et}_{2} \mathrm{O}\right)\left\{\mathrm{Li}\left(\mathrm{C}_{6} \mathrm{H}_{5}\right) \mathrm{S}(\mathrm{NtBu})\left(\mathrm{SNiMe}_{3}\right)\right\}_{2}\right]{ }^{[85]}$ It is also a typical structural feature in organolithium compounds with side-arm donation. ${ }^{[86]}$ $t \mathrm{Bu}_{2} \mathrm{P}(\mathrm{O}) \mathrm{Me}$ has so far only once been reported as a donor molecule in dichlorobis(di-tert-butylmethylphosphineoxide- $\kappa$ O)diphenyltin(IV) which was just structurally characterised but not further investigated. ${ }^{[87]}$

Table 2-8: Selected bond lengths $[\AA]$ and angles $\left[{ }^{\circ}\right]$ in 13 and 14

\begin{tabular}{lllllc}
\hline & \multicolumn{1}{c}{13} & 14 & \multicolumn{1}{c}{13} & 14 \\
\hline S1-N1 & $1.599(2)$ & $1.628(2)$ & N1-S1-N2 & $104.06(11)$ & $104.73(13)$ \\
S1-N2 & $1.632(2)$ & $1.605(2)$ & N3-S2-N4 & $104.03(10)$ & --- \\
S1-C7 & $1.832(3)$ & $1.831(3)$ & S1-C7-P1 & $114.50(14)$ & $115.06(16)$ \\
P1-C7 & $1.856(3)$ & $1.851(3)$ & N1-Li1-N2 & $74.67(15)$ & $74.39(19)$ \\
N1-Li1 & $2.076(4)$ & $2.183(5)$ & N3-Li1-N4 & $74.75(15)$ & --- \\
N1-Li1' & --- & $2.062(6)$ & N1-Li1-N3/N1' & $155.5(2)$ & $110.8(2)$ \\
N2-Li1 & $2.123(5)$ & $2.048(6)$ & P1'-Li1-N2 & --- & $153.8(2)$ \\
P1-Li1' & --- & $2.887(5)$ & N2-Li2-N4/N1'-Li1-N2 & $107.5(2)$ & $123.2(3)$ \\
N2-Li2 & $2.063(5)$ & -- & N2-Li2-O1 & $125.2(2)$ & --- \\
O1-Li2 & $1.831(4)$ & --- & Li2-O1-P3 & $168.7(2)$ & --- \\
O1-P3 & $1.4913(19)$ & --- & Li2-N2-Li1 & $75.54(17)$ & -- \\
N1-Si1 & $1.717(2)$ & $1.741(2)$ & & & \\
\hline
\end{tabular}

After several attempts, it was finally possible to crystallise the non-oxidised form of the lithium complex $\left[\mathrm{Li}\left\{t \mathrm{Bu}_{2} \mathrm{PCH}_{2} \mathrm{~S}\left(\mathrm{NSiMe}_{3}\right)_{2}\right\}\right]_{2}$ (14). It is a dimer with the well known $(\mathrm{LiN})_{2}$ four-membered ring in the centre. The geometry of $\mathbf{1 4}$ is therefore the same as in all the other complexes of this type which have been described in the preceding 
chapters. The structure is depicted in Figure 2-18, selected bond lengths and angles in comparison with 13 can be found in Table 2-8.

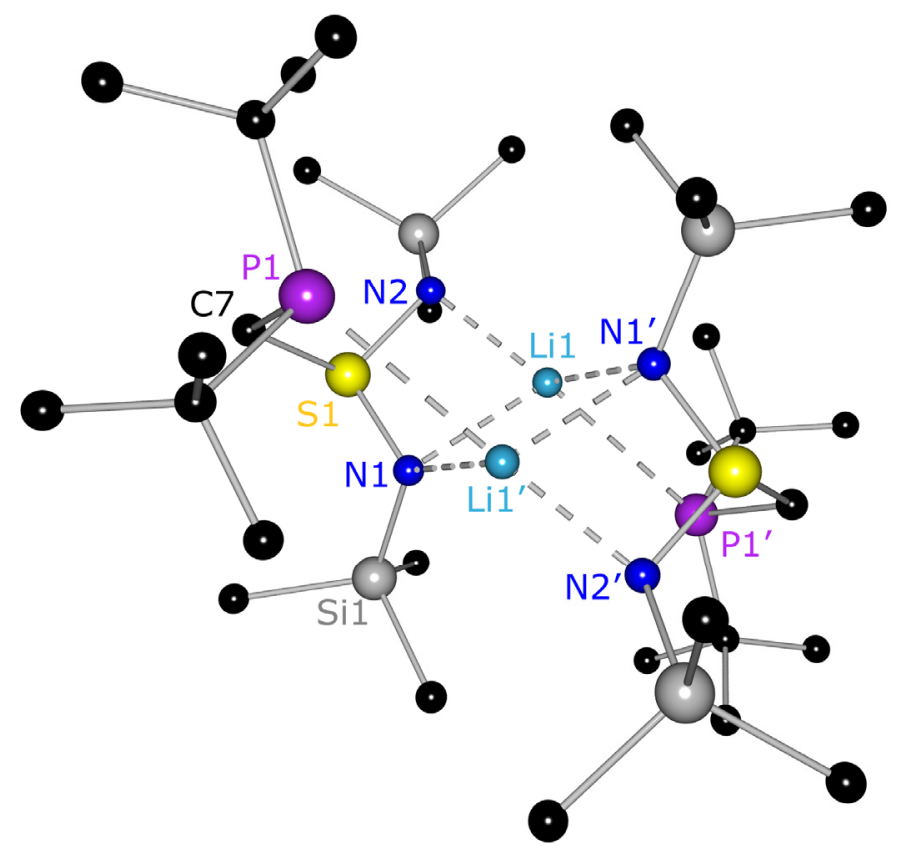

Figure 2-18: Molecular structure of $\left[\mathrm{Li}\left\{\mathrm{BBu}_{2} \mathrm{PCH}_{2} \mathrm{~S}\left(\mathrm{NSiMe}_{3}\right)_{2}\right\}\right]_{2}($ (14). Hydrogen atoms are omitted for clarity.

The Li-P bond length of $2.887(5) \AA$ is considerably longer than in the other dimeric structures 1-8, where values of about $2.60 \AA$ were found. This observation can be explained with the tert-butyl groups at the phosphorus atom which exhibit a considerable steric strain, although they are good $\sigma$-donors that increase the negative charge on the phosphorus atom which should strengthen the Li-P bond. Thus, steric reasons seem to be more important. This finding is very interesting in terms of ligand design. It could be shown that the substituents at the phosphorus atom have an influence on the bond lengths and therefore could as well have an influence on the structure of the complex. With even more sterically shielding groups it would be possible to synthesise complexes which are not dimeric but form larger aggregates. 14 could also be a good starting material for transmetalation reactions as the phosphorus side-arm seems to be bonding even weaker than in the other complexes discussed so far.

The sensitivity towards oxygen is a problem. Therefore, the synthesis of $\mathbf{1 4}$ should probably be conducted in an argon glove box and the starting material $t \mathrm{Bu}_{2} \mathrm{PMe}$ should be thoroughly dried. Due to these obstacles, an application for this type of ligand in homogenous catalysis does not seem very likely. The ${ }^{31} \mathrm{P}\left\{{ }^{1} \mathrm{H}\right\}$ chemical shift of $\mathbf{1 4}$ is $+8.75 \mathrm{ppm}$ and the signal is shifted to higher field when the ligand is oxidised (around $65 \mathrm{ppm}$, from the reaction solution). Therefore, it is even 
more likely that the supposed polymerization catalyst $\left[\left(\mathrm{C}_{3} \mathrm{H}_{7}\right) \mathrm{Ni}\left\{t \mathrm{Bu}_{2} \mathrm{PCH}_{2} \mathrm{~S}\left(\mathrm{NSiMe}_{3}\right)_{2}\right\}\right]$ with a reported chemical shift of $+83 \mathrm{ppm}$ was oxidised as well. 


\section{LIGANDS WITH NITROGEN SIDE-ARM}

\subsection{Metalation and Reaction of Dimethylaniline}

Since the reactions of sulphur diimides with lithiated phosphanes proceeded smoothly and give very good yields the analogous lithium amides were employed in the synthesis. Although the softer coordination site is sacrificed other binding modes become more important. It also was of interest to compare the complexes that only differ in one heteroatom. For these reasons and also because it is analogous to $\mathrm{Me}_{2} \mathrm{PPh}$, dimethylaniline became the first starting material. In addition, its deprotonation is well established in the literature. ${ }^{[88]}$ However, refluxing the in situ reaction mixture for $20 \mathrm{~h}$ with $n \mathrm{BuLi}$ as described was modified to a lithiation with tBuLi just like for the phosphanes mentioned above. The advantages are that the lithiated product precipitates partly from pentane, it can be obtained very pure and the yield can be determined unequivocally.

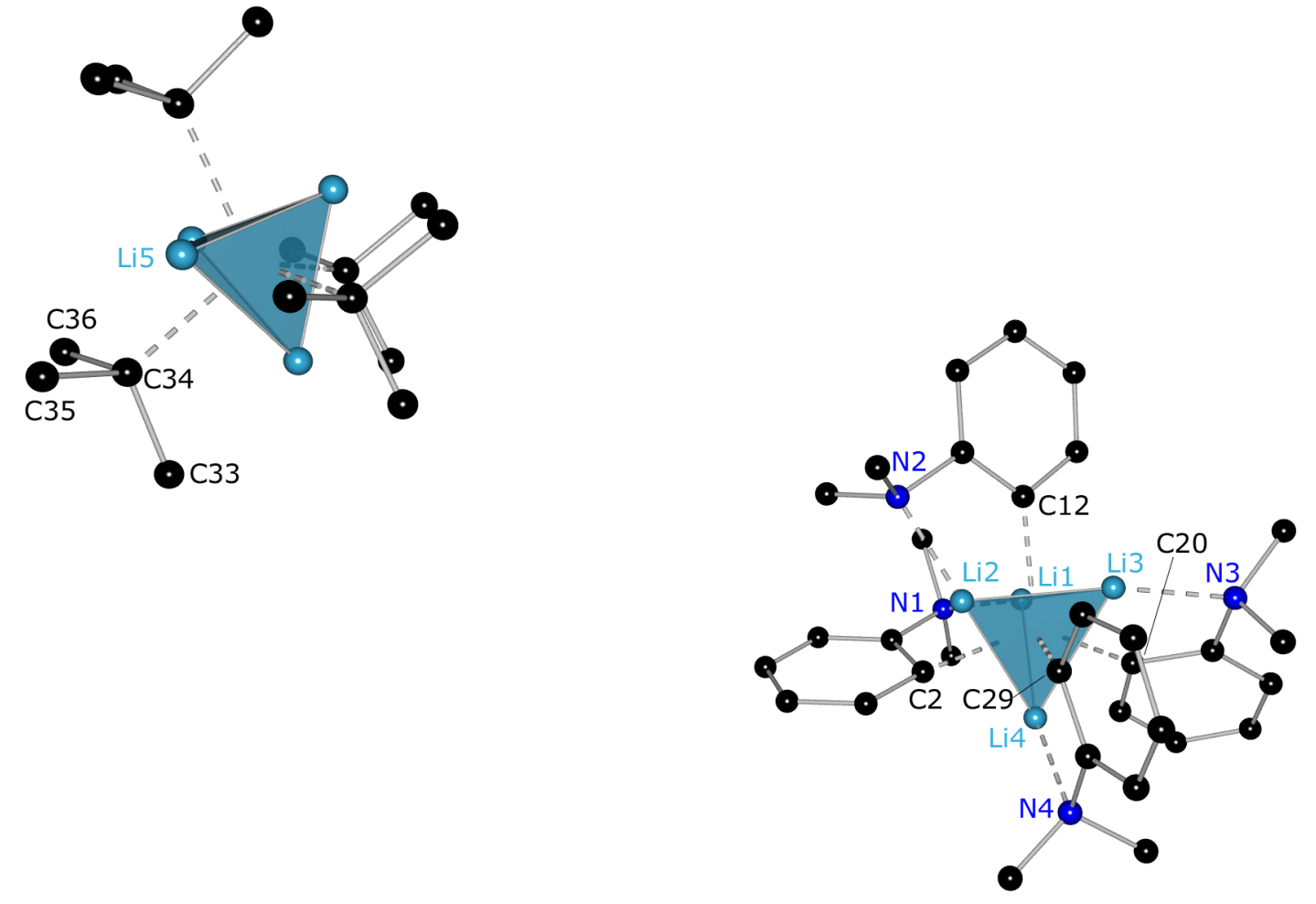

Figure 3-1: Molecular structure of $\left[\mathrm{Li}\left\{\left(\mathrm{C}_{6} \mathrm{H}_{4}\right) \mathrm{NMe}_{2}\right\}_{4}[t \mathrm{BuLi}]\right.$ (15). Hydrogen atoms are omitted for clarity and two $\mathrm{Me}_{2} \mathrm{NPh}$ moieties are shown transparent; the tBuLi tetramer is shown completely.

When the orange filtrate was stored at room temperature for one day, colourless needles crystallised. Unexpectedly, they were quite stable and could be 
mounted onto the diffractometer without cooling and haste. The structure of $\mathbf{1 5}$ is shown in Figure 3-1, selected bond lengths and angles can be found in Table 3-1.

Surprisingly, the unit cell contains two different lithium organic molecules which is quite rare. One is a tetrameric $\left[\mathrm{Li}\left\{\left(\mathrm{C}_{6} \mathrm{H}_{4}\right) \mathrm{NMe}_{2}\right\}\right]_{4}$ cluster, the other one is a $t \mathrm{BuLi}$ molecule that is part of a tetramer as well. This structural motif is quite unique. There is only one other example in the literature. ${ }^{[89]}$ In 2007 Mitzel et al. crystallised 2-lithio1,3-dimethyl-1,3-diazacyclohexane as a tetramer with one tBuLi molecule in the unit cell. The structural motif is similar to 15 and both compounds crystallise in the tetragonal space group $\overline{\overline{4}}$. The $[\mathrm{tBuLi}]_{4}$ units are located on four edges of the unit cell as well as on two faces. Eight $\left[\mathrm{Li}\left\{\left(\mathrm{C}_{6} \mathrm{H}_{4}\right) \mathrm{NMe}_{2}\right\}\right]_{4}$ tetramers fill the spaces in between. The remarcable stability of the crystals probably has its origin in the good shielding of the lithium cations by the ligand periphery. In both tetramers the lithium cations form triangles which are $\mu_{3}$-capped by a carbanionic $C_{\alpha}$ atom. This arrangement is the most efficient structure building principle in lithium organic chemistry and can further be aggregated to build different lithium deltahedra. The $\mathrm{Li}_{4}$ tetrahedron is found in various lithium organic tetramers while the $\mathrm{Li}_{6}$ octahedron is present in many hexamers. ${ }^{[86,90]}$

The nature of the $\mathrm{Li}-\mathrm{C}$ bond was an issue of constant research and was debated to be predominantly ionic ${ }^{[91]}$ or mainly covalent. ${ }^{[92]}$ Currently, the $\mathrm{Li}-\mathrm{C}$ bond nature again is revisited, mainly by theoretical investigations. ${ }^{[3]}$ However, the presence of a direct $\mathrm{Li}-\mathrm{Li}$ metal bond has never been proven in the tetrameric or hexameric aggregates. Assuming a covalent contribution, the $\mathrm{Li}_{3} \mathrm{C}_{\alpha}$ moieties should be held together by $4 \mathrm{c}-2 \mathrm{e}$ bonds. ${ }^{[72]}$ The tetrameric lithium organics $[\mathrm{MeLi}]_{4},{ }^{\left[{ }^{[9]}\right]}$ $[\mathrm{EtLi}]_{4},{ }^{[95]}$ and $\left[\mathrm{tBuLi}_{4}{ }_{4}{ }^{[96]}\right.$ are white pyrophoric powders. While methyllithium is soluble only in polar solvents like diethyl ether, the two others are soluble in nonpolar hydrocarbons like hexane. Even in the solid-state none of the three tetrameric structures adopts ideal $\mathrm{T}_{d}$ symmetry, but the $\mathrm{Li} \cdots \mathrm{Li}$ distances fit reasonably well. While they are $284 \mathrm{pm}$ in $[\mathrm{LiF}]_{\infty}$, they cover the range from 241 to $256 \mathrm{pm}$ in the $[R L i]_{4}$ tetramers. The crystallographically independent $\mathrm{Li} \ldots \mathrm{Li}$ distances of the individual tetramers are similar within the estimated standard deviations. They decrease from $256 \mathrm{pm}$ in $[\mathrm{MeLi}]_{4}$, to $253 \mathrm{pm}$ in [EtLi $]_{4}$, and $241 \mathrm{pm}$ in [tBuLi$]_{4}$. Interestingly, the Li$\mathrm{C}_{\alpha}$ bond lengths are almost the same at 226 $\pm 2 \mathrm{pm}$ and close to the mean $\mathrm{Li}-\mathrm{C}$ bond distance of $230 \mathrm{pm} .{ }^{[68]}$ In addition, $[\mathrm{EtLi}]_{4}$ and $\left[\mathrm{tBuLi}_{4}\right.$ display relatively short $\mathrm{Li} \ldots \mathrm{C}_{\beta}$ distances. In the latter they are only $10 \mathrm{pm}$ longer than the $\mathrm{Li}-\mathrm{C}_{\alpha}$ bonds. 
Addition of neutral donor bases like $\mathrm{Et}_{2} \mathrm{O}$, THF, DME, TMEDA or PMDETA to aggregated lithium organics usually decreases their degree of aggregation. ${ }^{[97]}$ Multiple $\mathrm{Li}-\mathrm{C}_{\alpha}$ and additional $\mathrm{Li} \cdots \mathrm{C}_{\beta}$ interactions are partly substituted by $\mathrm{N} \rightarrow \mathrm{Li}$ or $\mathrm{O} \rightarrow \mathrm{Li}$ donor bonds. This deaggregation commonly results in increased reactivity because the rate determining step in deprotonation reactions is normally the reaction of the monomer. ${ }^{[98]}$

In lithium aryls like $\left[\mathrm{Li}\left\{\left(\mathrm{C}_{6} \mathrm{H}_{4}\right) \mathrm{NMe}_{2}\right\}\right]_{4}$ two structure building principles are opperating: (i) the haptotropic $\eta^{6}$-coordination of the lithium cation to the $\pi$ charge density of the aromatic carbanion and (ii) the $\mathrm{Li}_{2} \mathrm{C}_{2}$ four-membered ring built upon donorbase-induced dimer formation. On the addition of donorbases or implementation of donating side-arms it is the $\pi$-bonding that is given up first. It is the predetermined breaking point of the infinite solid-state structure if molecular fractions are cut out in the deaggregation process.

Table 3-1: Selected bond lengths $[\AA]$ and angles $\left[^{\circ}\right]$ in 15

\begin{tabular}{llll}
\hline Li1-N1 & $2.042(4)$ & N1-Li1-C2 & $68.70(13)$ \\
Li3-N3 & $2.051(4)$ & N1-Li1-C20 & $131.17(19)$ \\
Li1-C2 & $2.274(4)$ & C12-Li1-C20 & $107.04(17)$ \\
Li1-C12 & $2.277(4)$ & C2-Li1-C12 & $103.84(15)$ \\
Li1-C20 & $2.254(4)$ & N3-Li3-C29 & $117.23(17)$ \\
Li3-C12 & $2.244(4)$ & N3-Li3-C12 & $132.70(19)$ \\
Li3-C20 & $2.218(4)$ & C12-Li3-C20 & $109.53(17)$ \\
Li3-C29 & $2.234(4)$ & C12-Li3-C29 & $108.65(16)$ \\
Li5-C34 & $2.267(5)$ & Li1-C20-Li3 & $69.15(14)$ \\
Li1…i2 & $2.630(6)$ & & \\
Li1‥Li4 & $2.499(6)$ & & \\
\hline
\end{tabular}

In $\left[\mathrm{Li}\left\{\left(\mathrm{C}_{6} \mathrm{H}_{4}\right) \mathrm{NMe}_{2}\right\}\right]_{4}$ a single dimethylamino group in ortho-position to the ipsocarbon atom causes a structural motif reminiscent to the $\left[\left(\mathrm{Et}_{2} \mathrm{O}\right) \mathrm{LiPh}\right]_{4}{ }^{[99]}$ tetramer. The amino nitrogen atoms act as the diethyl ether molecules at the apexes of the metal deltahedron. In addition, each of the four $\mathrm{Li}_{3}$ triangles is $\mu_{3}$-capped by a $\mathrm{C}_{\alpha}$ atom above the center of the equilateral metal triangle. Thus $\mathbf{1 5}$ is comparable to $\left[(\text { tmeda })\left\{\left(\mathrm{LiC}_{6} \mathrm{H}_{4} \mathrm{OMe}\right)_{4}\right\}_{2}\right]^{[100]}$ and $\left[\mathrm{Li}\left\{\left(\mathrm{C}_{6} \mathrm{H}_{3}\right)\left(\mathrm{NMe}_{2}\right)_{2}\right\}\right]_{3 .}{ }^{[101]}$ The $\mathrm{Li}-\mathrm{C}_{. \alpha}$ bond lengths in 15 range from $2.218 \AA$ (Li3-C20) to $2.277 \AA$ (Li1-C12) compared to $2.30 \AA$ in [(tmeda) $\left.\left\{\left(\mathrm{LiC}_{6} \mathrm{H}_{4} \mathrm{OMe}\right)_{4}\right\}_{2}\right]$. The average $\mathrm{Li}-\mathrm{N}$ bond lengths of $2.14 \AA$ and $2.12 \AA$ are 
slightly elongated in comparison to 15 (on average $2.040 \AA$ ). The average $\mathrm{Li} \cdots \mathrm{Li}$ distance in 15 is 2.562(6) $\AA$ and is closer to the reported value for $\left[(\right.$ tmeda $\left.)\left\{\left(\mathrm{LiC}_{6} \mathrm{H}_{4} \mathrm{OMe}\right)_{4}\right\}_{2}\right] \quad(2.64 \AA)$. The corresponding distance in $\left[\mathrm{Li}\left\{\left(\mathrm{C}_{6} \mathrm{H}_{3}\right)\left(\mathrm{NMe}_{2}\right)_{2}\right\}\right]_{3}$ is $3.08 \AA$.

It is worthy to note that the coordination angles for $\mathrm{Li} 1 / \mathrm{Li} 2$ and $\mathrm{Li} 3 / \mathrm{Li} 4$ are different. Li3 is almost in plane with $\mathrm{C} 29, \mathrm{~N} 3$ and $\mathrm{C} 12$ resulting in a distorted trigonal pyramidal coordination. The N3-Li3-C29 and $\mathrm{C} 29-\mathrm{Li} 3-\mathrm{C} 12$ planes only deviate by $11.9^{\circ}$ from each other. Li1 on the other hand is distorted tetrahedrally coordinated $\left(\mathrm{C} 2-\mathrm{Li1}-\mathrm{C} 20\right.$ : $109.59(16)^{\circ}$, C12-Li1-N1: 120.99(17) ${ }^{\circ}$. As a result, two $(\mathrm{LiC})_{2}$ rhombuses that are turned by $90^{\circ}$ against each other make up the centre of the structure. The methyl groups of two neighbouring $\mathrm{Me}_{2} \mathrm{NPh}$ moieties point into opposite directions and the phenyl rings are inclined by $64.3^{\circ}$ although this is only the case for the pairs Li1/Li2 and Li3/Li4.

The $[t \mathrm{BuLi}]_{4}$ subunit in $\mathbf{1 5}$ has the same structural features as the donor-free parent material in the solid state. ${ }^{[96]}$ The methyl groups are arranged ecliptically with respect to the lithium atoms of the capped metal triangle. The $\mathrm{Li}-\mathrm{C}_{\alpha}$ bond length of 2.267(5) $\AA$ is in the expected range. The average $L i-C_{\beta}$ distance is $2.410(8) \AA$ while the $\mathrm{Li}$... Li distance is $2.424(8) \AA$.

The NMR spectra of the complex are very interesting and illustrative about the equilibriae present in solution. In the $400 \mathrm{MHz}{ }^{7} \mathrm{Li}\left\{{ }^{1} \mathrm{H}\right\}$ spectrum in toluene- $\mathrm{d}^{8}$, twelve signals with different intensities can be identified in the region from approx. 0 to 4 ppm (Figure 3-2).

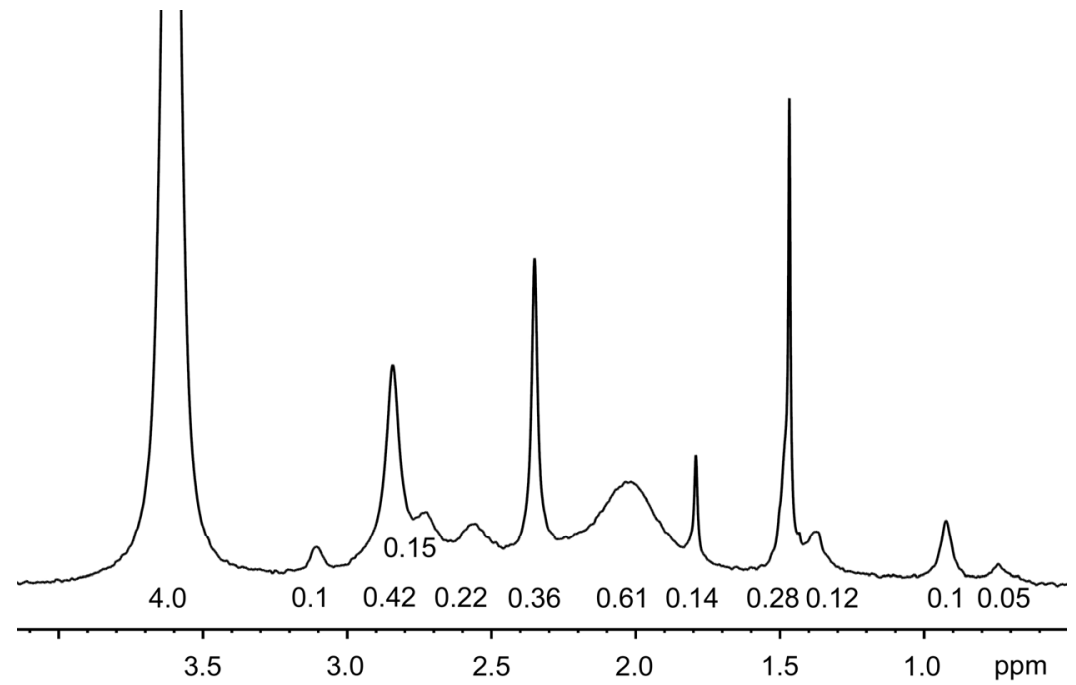

Figure 3-2: ${ }^{7} \mathrm{Li}\left\{{ }^{1} \mathrm{H}\right\} \mathrm{NMR}$ spectrum of $\left[\mathrm{Li}\left\{\left(\mathrm{C}_{6} \mathrm{H}_{4}\right) \mathrm{NMe}_{2}\right\}\right]_{4}[\mathrm{BBLLi}](15)$ in toluene-d $\mathrm{d}^{8}$, including integrals. 
However, if the complexes would have the same composition in solution as in the solid state, one would expect only two signals - one for the almost $T_{d}$-symmetric $\left[t_{\mathrm{BuLi}}\right]_{4}$ and one for $\left[\mathrm{Li}\left\{\left(\mathrm{C}_{6} \mathrm{H}_{4}\right) \mathrm{NMe}_{2}\right\}\right]_{4}$. Therefore, the conclusion can be drawn that probably different aggregates exist in solution. With the stochiometry in mind, five different arrangements for tetramers can ab initio be envisaged: $\left[\mathrm{Li}\left\{\left(\mathrm{C}_{6} \mathrm{H}_{4}\right) \mathrm{NMe}_{2}\right\}\right]_{4}$, $\left[\mathrm{Li}\left\{\left(\mathrm{C}_{6} \mathrm{H}_{4}\right) \mathrm{NMe}_{2}\right\}\right]_{3}[t \mathrm{BuLi}], \quad\left[\mathrm{Li}\left\{\left(\mathrm{C}_{6} \mathrm{H}_{4}\right) \mathrm{NMe}_{2}\right\}\right]_{2}[t \mathrm{BuLi}]_{2}, \quad\left[\mathrm{Li}\left\{\left(\mathrm{C}_{6} \mathrm{H}_{4}\right) \mathrm{NMe}_{2}\right\}\right][t \mathrm{BuLi}]_{3}$ and $\left[t_{B u L i}\right]_{4}$. In addition, the formation of dimers and other species is also possible. Therefore, several questions arose:

- Are there mixed aggregates?

- Are there other aggregates than tetramers?

- Are the aggregates interconvertible?

- What exactly are the different aggregates?

In order to answer those questions, DOSY NMR spectra were recorded among others. DOSY is the abbreviation for Diffusion-Ordered NMR Spectroscopy and its basic principles were first introduced by Stejskal and Tanner as a onedimensional experiment in the 1960's. ${ }^{[102]}$ In 1992, Johnson went one step further and developed the corresponding two-dimensional experiment. ${ }^{[103]}$ With this pulse gradient spin-echo (PGSE) method, the diffusion of molecules in the NMR tube can be observed and a plot of the diffusion coefficient vs. the chemical shift is generated. Thereby, different components of a mixture can be identified via their hydrodynamic radii according to the Stokes-Einstein equation (Equation 3-1). ${ }^{[104]}$ These are correlated to their formula weights and at the same time to their degrees of aggregation. Of course, this is only strictly true, if the molecules are spherical and considerably larger than the solvent. For the discussed tetrahedra with an average diameter of $7.50 \AA$ for $[t \mathrm{BuLi}]_{4}$ and $10.17 \AA$ for $\left[\mathrm{Li}\left\{\left(\mathrm{C}_{6} \mathrm{H}_{4}\right) \mathrm{NMe}_{2}\right\}\right]_{4}$ this is valid (the values are estimated from the crystal structure).

$$
\begin{array}{ll}
\mathrm{D}=\text { diffusion coefficient } \\
\mathrm{k}=\text { Boltzmann constant } \\
\mathrm{T}=\frac{\mathrm{T}}{6 \pi \eta R_{H}} \quad \text { temperature } \\
\eta=\text { viscosity } \\
\mathrm{R}_{\mathrm{H}}=\text { hydrodynamic radius }
\end{array}
$$

Equation 3-1: Stokes-Einstein equation. 
The individual spectra of every component can also be obtained from the DOSY experiment. Thus, DOSY represents an excellent method for the analysis of complex mixtures (e.g. enzymes), systems containing different aggregates or for polymer analysis. In addition, the molecular masses of the distinct molecules can be extrapolated if an internal reference is present. ${ }^{[105]}$

In 2000, Williard et al. used DOSY spectroscopy for the first time for the analysis of different THF/nBuLi aggregates in solution. ${ }^{[106]}$ From such an experiment, lots of information can be drawn: ${ }^{[107]}$

- determination of the aggregation number of organometallic compounds

- determination of the solvation state

- identification of new aggregates in solution (i. e. which are not present in the solid state)

- extrapolation of the molecular weight of the different components by using an internal reference with known weight

- determination of relative diffusion coefficients

- individual 1D spectra of every component that is present in the mixture (if the spectrum is not too complex)

To take full advantage of the method it is vital that the signals are well separated. Relative diffusion coefficients can either be directly read from the spectrum or the peak areas are fitted to the Stejskal-Tanner equation (Equation 3-2). ${ }^{[102]}$

$$
\begin{aligned}
& \mathrm{I}=\begin{array}{c}
\text { peak area, } \mathrm{I}_{0}=\text { peak area in the } \\
\text { absence of gradients }
\end{array} \\
& \gamma=\text { gyromagnetic ratio } \\
& \ln \frac{I}{I_{0}}=-\left(\gamma^{2} \delta^{2} G^{2}\left(\Delta-\frac{\delta}{3}\right)\right) D \quad \text { gradient duration } \\
& \mathrm{G}=\text { strength of the gradient pulse } \\
& \Delta=\text { diffusion time, } \mathrm{D}=\text { diffusion coef- } \\
& \text { ficient }
\end{aligned}
$$

Equation 3-2: Stejskal-Tanner equation.

In the resulting plots, the slope of the straight line is directly proportional to the diffusion coefficient and thereby the particle size. ${ }^{[106]}$ 
The ${ }^{1} \mathrm{H}$ DOSY ${ }^{[108]}$ spectrum of 15 shows four to five different tetrameric aggregates in the aromatic region (Figure 3-3) which are associated to the peaks between 7.8 and $8.2 \mathrm{ppm}$. The tBuLi tetramer can be identified as well because it has a similar diffusion coefficient to the solvent toluene.

The largest peak at $8.22 \mathrm{ppm}$ belongs to the ring-proton next to the lithium cation in the $\left[\mathrm{Li}\left\{\left(\mathrm{C}_{6} \mathrm{H}_{4}\right) \mathrm{NMe}_{2}\right\}\right]_{4}$ tetramer which is believed to be the main isomer in solution. The smaller signals at $7.89,7.96,8.01$ and $8.08 \mathrm{ppm}$ belong to other tetramers which contain the $\left[\mathrm{Li}\left\{\left(\mathrm{C}_{6} \mathrm{H}_{4}\right) \mathrm{NMe}_{2}\right\}\right]$ moiety. Most likely, the broad singlet at $8.08 \mathrm{ppm}$ is just the result of exchange between different aggregates. The same could be observed in the ${ }^{7} \mathrm{Li}\left\{{ }^{1} \mathrm{H}\right\}$ spectrum (Figure 3-2).

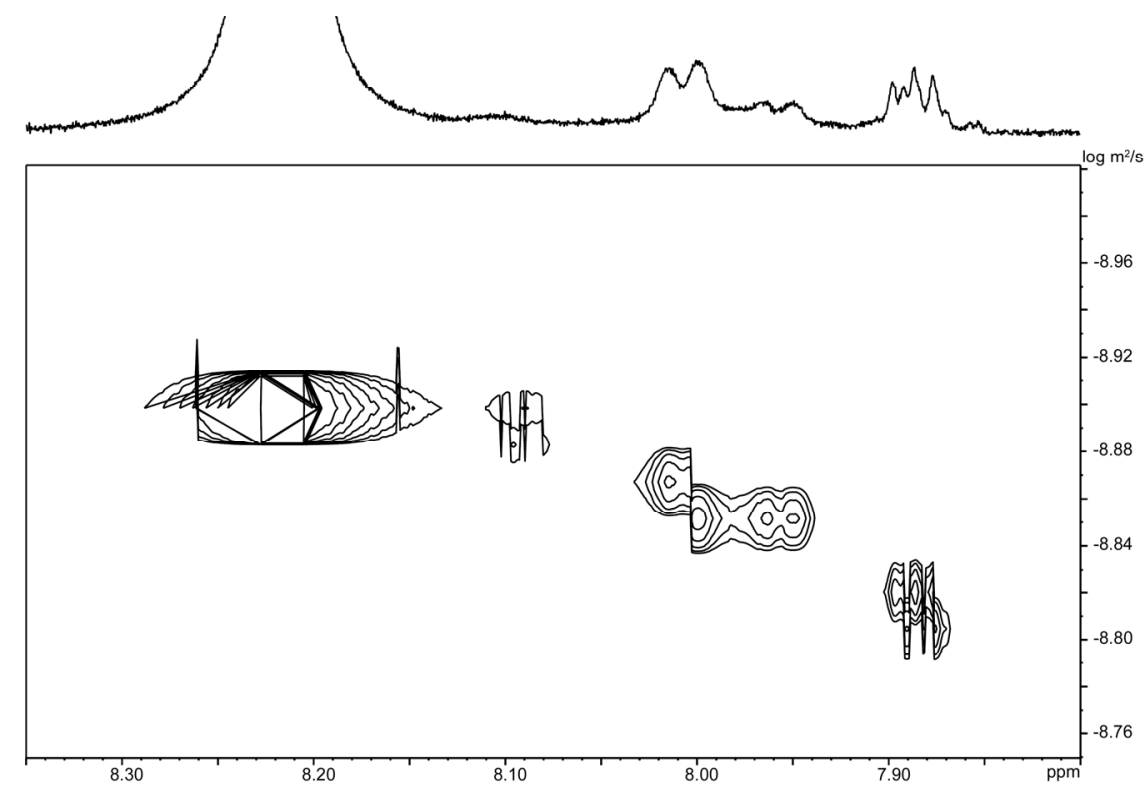

Figure 3-3: ${ }^{1} \mathrm{H}$ DOSY spectrum of $\left[\mathrm{Li}\left\{\left(\mathrm{C}_{6} \mathrm{H}_{4}\right) \mathrm{NMe}_{2}\right\}\right]_{4}[t \mathrm{BuLi}](15)$ in toluene-d ${ }^{8}$.

Because of the exchange of the different molecules in solution, the aggregates contain chemically inequivalent lithium ions. Thus, the sharp peaks would belong to defined aggregates and the broad peaks are exchange peaks which are not visible in a $300 \mathrm{MHz}$ spectrum but become sharper when the sample is cooled to $-50{ }^{\circ} \mathrm{C}$. Upon cooling of the sample to $-80^{\circ} \mathrm{C}$, only two peaks at 3.61 and $1.47 \mathrm{ppm}$ remain, which are associated to $\left[\mathrm{Li}\left\{\left(\mathrm{C}_{6} \mathrm{H}_{4}\right) \mathrm{NMe}_{2}\right\}\right]_{4}$ and $[t \mathrm{BuLi}]_{4}$, respectively. Thus, the arrangement of the solid state is also achieved in solution at very low temperatures.

With this knowledge, one problem arises for the assignment of the aggregates in the ${ }^{1} \mathrm{H}$ DOSY spectrum: because the spectrum has an acquisition time of approx. one hour, peaks for exchange products are visible that can be mistaken for additional 
aggregates. As a consequence, a ${ }^{7} \mathrm{Li}$ DOSY spectrum was recorded because the exchange peaks can be determined easier in the ${ }^{7} \mathrm{Li}$ spectrum (broad peaks).

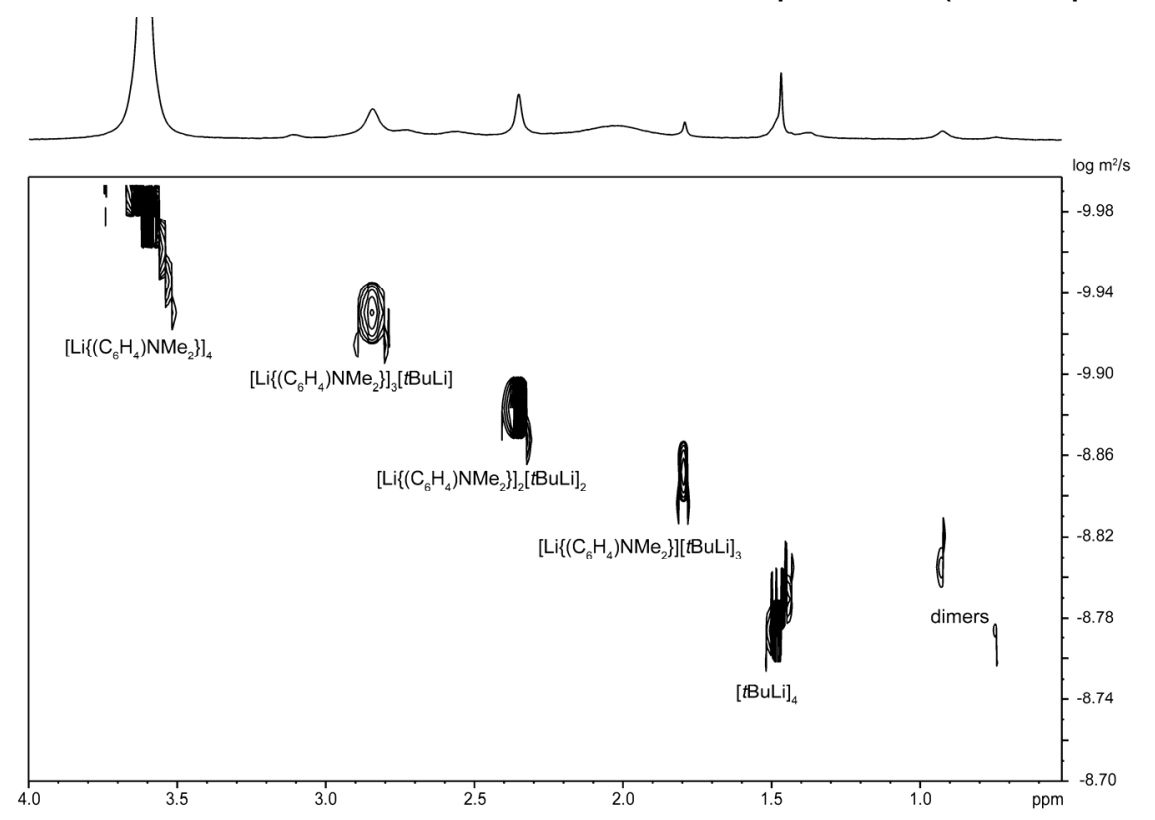

Figure 3-4: ${ }^{7} \mathrm{Li}$ DOSY spectrum of $\left[\mathrm{Li}\left\{\left(\mathrm{C}_{6} \mathrm{H}_{4}\right) \mathrm{NMe}_{2}\right\}\right]_{4}[t \mathrm{BuLi}](15)$ in toluene- $\mathrm{d}^{8}$.

In Figure 3-4 clearly separated diffusion peaks for the five main aggregates in solution (see above) are visible. From left to right the diffusion coefficient (as well as the molecular weight) of the tetramers decreases stepwise by the same amount because one $\left[\mathrm{Li}\left\{\left(\mathrm{C}_{6} \mathrm{H}_{4}\right) \mathrm{NMe}_{2}\right\}\right]$ moiety is consecutively substituted with a tBuLi molecule. Two additional peaks at around $1.00 \mathrm{ppm}$ could be dimers their composition, however, is unresolved. From the diffusion coefficient a mixed $\left[\mathrm{Li}\left\{\left(\mathrm{C}_{6} \mathrm{H}_{4}\right) \mathrm{NMe}_{2}\right\}\right] / t \mathrm{BuLi}$ dimer could be rationalised.

The exchange between the five tetramers was further verified with ${ }^{1} \mathrm{H}$ and ${ }^{7} \mathrm{Li}$ NOESY spectra that show definite exchange peaks between $t \mathrm{Bu}$ and aromatic signals. In the ${ }^{7} \mathrm{Li}$ NOESY spectrum the exchange between $\left[\mathrm{Li}\left\{\left(\mathrm{C}_{6} \mathrm{H}_{4}\right) \mathrm{NMe}_{2}\right\}\right]_{4}$ and the other $\left[\mathrm{Li}\left\{\left(\mathrm{C}_{6} \mathrm{H}_{4}\right) \mathrm{NMe}_{2}\right\}\right]$-containing tetramers (and vice versa) is clearly visible (Figure 3-5).

The assignment of peaks to the two main aggregates $[t \mathrm{BuLi}]_{4}$ and $\left.\left[\mathrm{Li}\left(\mathrm{C}_{6} \mathrm{H}_{4}\right) \mathrm{NMe}_{2}\right\}\right]_{4}$ was achieved by a combination of HSQC, HMBC, ${ }^{7} \mathrm{Li}$ HOESY as well as ${ }^{13} \mathrm{C}\left\{{ }^{1} \mathrm{H}\right\}$ room temperature and low temperature spectra. In $\left.\left[\mathrm{Li}\left(\mathrm{C}_{6} \mathrm{H}_{4}\right) \mathrm{NMe}_{2}\right\}\right]_{4}$, all lithium ions are chemically equivalent. A shift of $3.61 \mathrm{ppm}$ is assigned to them because of a cross peak between that signal and the signal of the neighbouring $\mathrm{H}$-atom. The shifts for $[\text { [BuLi }]_{4}$ were compared to the literature. ${ }^{[109]}$ When the sample is cooled to $-50{ }^{\circ} \mathrm{C}$, a coupling between the lithium atoms and the $\mathrm{CH}_{3}$ groups in $[\mathrm{BBLi}]_{4}$ becomes visible 
$\left({ }^{2} J_{\mathrm{Li}-\mathrm{C}}=14.22 \mathrm{~Hz}\right)$. As the resolution is not high enough, it can be speculated if ten or thirteen lines are present, corresponding to a coupling of the carbon atom with three or four ${ }^{7} \mathrm{Li}$ cores. This fluxionality of $t \mathrm{BuLi}$ tetramers in solution was already observed by Thomas et al. in 1986 for [tBu$u^{6} \mathrm{Li}_{4}$. Depending on the temperature, the carbon atom can couple to four lithium atoms, when the temperature is high, or only three lithium ions when the temperature is lower because the movement is frozen. ${ }^{[110]}$

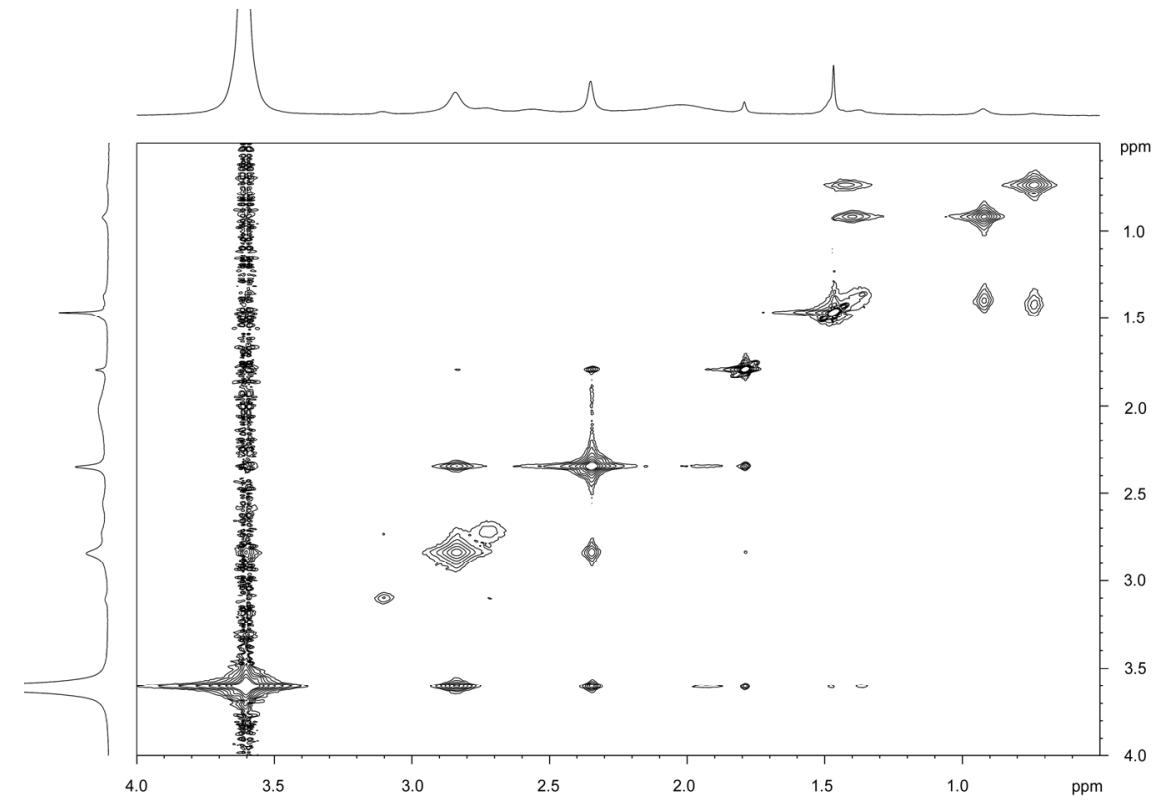

Figure 3-5: ${ }^{7} \mathrm{Li}$ NOESY spectrum of $\left[\mathrm{Li}\left\{\left(\mathrm{C}_{6} \mathrm{H}_{4}\right) \mathrm{NMe}_{2}\right\}\right]_{4}[t \mathrm{BuLi}](15)$ in toluene-d ${ }^{8}$.

To summarize, the questions posed above can be answered as follows:

- Are there mixed aggregates?: Yes. There definitely is exchange between $t B u$ and $\mathrm{Ph}$ signals as well as different lithiated species $\left({ }^{1} \mathrm{H}\right.$ and ${ }^{7} \mathrm{Li}$ NOESY) therefore there are mixed aggregates. The different species in the aromatic region of the ${ }^{1} \mathrm{H}$ DOSY spectrum also suggest that.

- Are there other aggregates than tetramers?: Most probable yes. All species that contain the $\mathrm{Me}_{2} \mathrm{NPh}$ moiety seem to be tetrameric $\left({ }^{1} \mathrm{H}\right.$ DOSY), the [tBuLi] $]_{4}$ tetramer is also visible. In the ${ }^{7} \mathrm{Li}$ DOSY two peaks are visible that could be mixed dimers.

- Are the aggregates interconvertible?: Yes. There is exchange between different aggregates ( ${ }^{1} \mathrm{H}$ and ${ }^{7} \mathrm{Li}$ NOESY).

- What exactly are the different aggregates?: The tetramers are $\left.\left[\mathrm{Li}\left(\mathrm{C}_{6} \mathrm{H}_{4}\right) \mathrm{NMe}_{2}\right\}\right]_{4}, \quad\left[\mathrm{Li}\left\{\left(\mathrm{C}_{6} \mathrm{H}_{4}\right) \mathrm{NMe}_{2}\right\}\right]_{3}[t \mathrm{BuLi}], \quad\left[\mathrm{Li}\left\{\left(\mathrm{C}_{6} \mathrm{H}_{4}\right) \mathrm{NMe}_{2}\right\}\right]_{2}[t \mathrm{BuLi}]_{2}$, $\left[\mathrm{Li}\left\{\left(\mathrm{C}_{6} \mathrm{H}_{4}\right) \mathrm{NMe}_{2}\right\}\right][t \mathrm{BuLi}]_{3}$ and $[t \mathrm{BuLi}]_{4}$. This can be rationalized by the ${ }^{7} \mathrm{Li}$ DOSY as well as ${ }^{1} \mathrm{H}$ DOSY, NOESY, HSQC, HMBC and ${ }^{1} \mathrm{H}$ spectra. The exact nature of the dimeric aggregates is still under investigation. 
Interestingly, deprotonation of $\mathrm{Me}_{2} \mathrm{NPh}$ does not occur at one of the methyl groups but at the phenyl ring in ortho position to the dimethylamino group. This effect is known as 'directed ortho metalation' (DoM) and has been thoroughly explored by Snieckus. ${ }^{[111]}$ According to this concept, tBuLi is precoordinated by the dimethylamino side-arm and gets in close spatial proximity to the ortho-hydrogen atom, facilitating deprotonation at that position.

The case of $\mathrm{Me}_{2} \mathrm{PPh}$ is different because deprotonation is only possible at the methyl groups. Strangely, when considering the electronegativities of nitrogen (3.0) and phosphorus $(2.1)^{[112]}$, methyl deprotonation should be favoured in the nitrogen compound as the protons are thermodynamically more acidic.

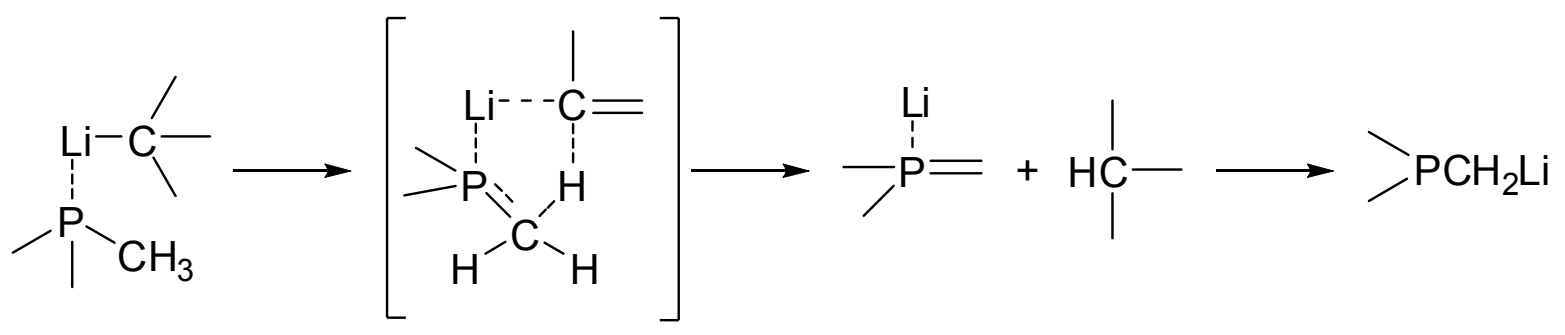

Figure 3-6: Suggested mechanism of the methyl-metalation in tertiary phosphanes.

The phenomenon is well known in the literature ${ }^{[113]}$ and can be rationalized with the different stabilization of the intermediate carbanion. Peterson et al. ${ }^{[113 c]}$ suggested d-orbital resonance stabilization of the carbanion via a cyclic transition state in tertiary phosphanes (Figure 3-6).

Unlike phosphorus, nitrogen does not have a high polarizability or empty orbitals of low energy to stabilise the transition state. In addition, the lone pair at the nitrogen atom would have a repulsive force on the carbanion at the methyl group and deprotonation of the ring is therefore favoured. Deuterium exchange studies have also shown that the relative kinetic acidity of $\alpha-C$ hydrogen atoms in nitrogen containing compounds is much lower than in the corresponding phosphorus or sulphur analogues. ${ }^{[114]}$

Generation of unactivated or unstabilised lithiomethyl(amines) can only be achieved by metal-lithium exchange (where the metal predominantly is tin) ${ }^{[113 c, 115]}$, reductive carbon-sulphur ${ }^{[116]}$ or carbon-tellurium bond cleavage ${ }^{[117]}$. Another alternative is the precoordination of the lithium organyl by a donor site which is in close proximity to the $\alpha-C$ hydrogen atoms. Known examples are the lithiation of TMEDA, ${ }^{[79,118]}$ PMDTA, ${ }^{[119]}$ TMCDA $^{[120]}$ or TMMDA ${ }^{[121]}$. Generally speaking, it is not 
possible to $\alpha$-deprotonate tertiary amines without carbanion stabilizing groups or an additional chelating site.

Upon reaction of an equimolar amount of 15 with $\mathrm{S}\left(\mathrm{NSiMe}_{3}\right)_{2}$ a dimer with the formula $\left[\mathrm{Li}\left\{\mathrm{Me}_{2} \mathrm{~N}\left(\mathrm{C}_{6} \mathrm{H}_{4}\right) \mathrm{S}\left(\mathrm{NSiMe}_{3}\right)_{2}\right\}\right]_{2}$ (16) was formed. There had obviously been no reaction with tert-butyllithium although one could argue that only one product crystallised.

Compound 16 crystallises as a dimer in the monoclinic space group $P 2_{1} / C$ with the whole dimer in the asymmetric unit. It shows the already well known $(\mathrm{LiN})_{2}$ fourmembered planar ring with bond distances similar to the corresponding phosphorus compound (6). Due to the different deprotonation of the starting material, 16 shows different connectivity from $\mathbf{6}$, though. The sulphur diimide moiety is directly bonded to the phenyl ring and not to the methyl group of the dimethylamino substituent. Thereby, a larger bite angle of the nitrogen side-arm is created. Nevertheless, the coordination of the lithium ion is the same. One lithium atom is coordinated by one sulphur diimide moiety (Li1) whereas the other lithium atom is complexed by the $\mathrm{Me}_{2} \mathrm{~N}$ side-arm (Li2) of the same ligand, providing the dimeric link (see Figure 3-7).

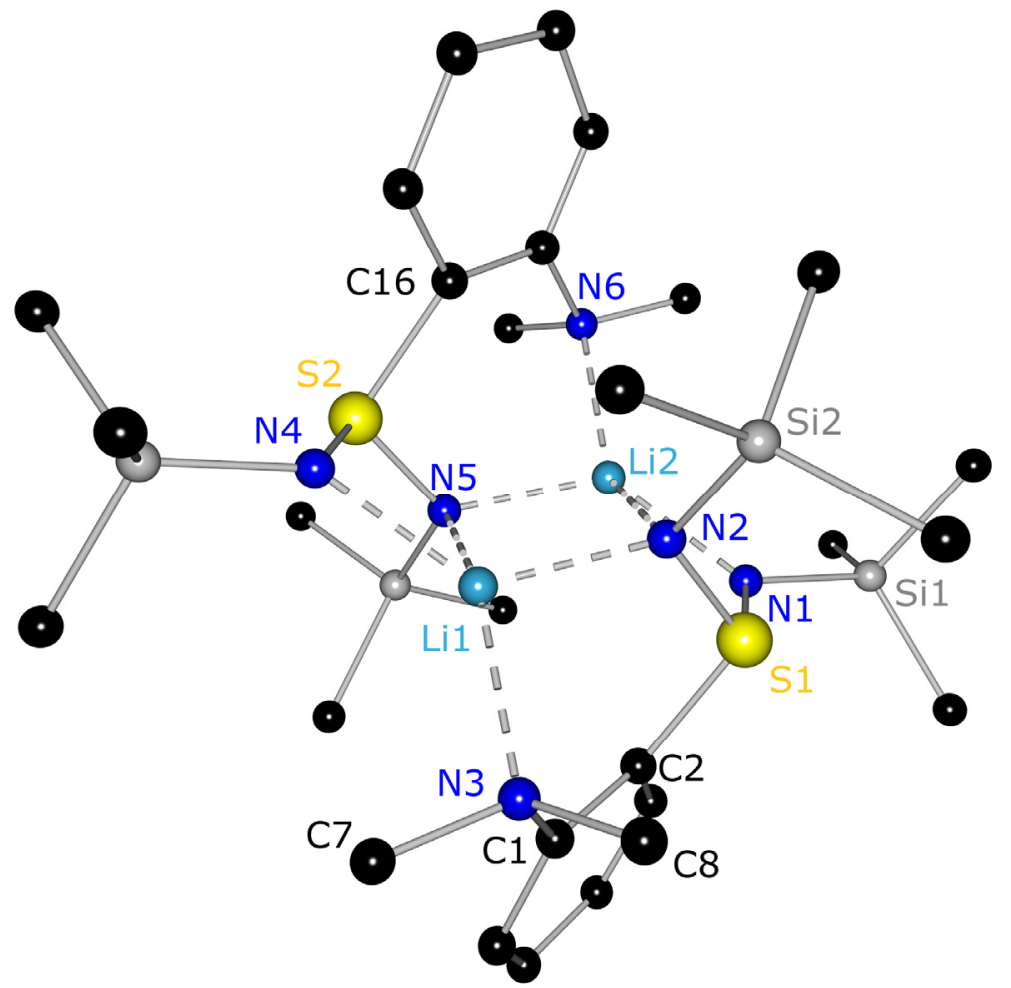

Figure 3-7: Molecular structure of $\left[\mathrm{Li}\left\{\mathrm{Me}_{2} \mathrm{~N}\left(\mathrm{C}_{6} \mathrm{H}_{4}\right) \mathrm{S}\left(\mathrm{NSiMe}_{3}\right)_{2}\right\}\right]_{2}$ (16). Hydrogen atoms are omitted for clarity.

The $\mathrm{N}-\mathrm{S}-\mathrm{N}$ angle is widened compared to the phosphorus compound 6 $\left(106.54(4)^{\circ}\right.$ vs. $\left.105.68(6)^{\circ}\right)$. This is due to the sterically slightly more demanding 
nitrogen side-arm. The methyl groups of the dimethylamino substituent are not aligned with the phenyl ring but are pointing away from the centre of the molecule, thus reducing steric strain and bringing the lone pair in the right position to coordinate the metal. The bond lengths and angles are all in the expected range. Selected bond lengths and angles for $\left[\mathrm{Li}\left\{\mathrm{Me}(\mathrm{Ph}) \mathrm{PCH}_{2} \mathrm{~S}\left(\mathrm{NSiMe}_{3}\right)_{2}\right\}\right]_{2}(6)$ and 16 can be found in Table 3-2.

Table 3-2: Selected bond lengths $[\AA]$ and angles $\left[{ }^{\circ}\right]$ in 6 and 16

\begin{tabular}{|c|c|c|c|c|c|}
\hline & 6 & 16 & & 6 & 16 \\
\hline $\mathrm{S} 1-\mathrm{N} 1$ & $1.6107(11)$ & $1.6053(10)$ & $\mathrm{N} 1-\mathrm{S} 1-\mathrm{N} 2$ & $105.68(6)$ & $106.54(5)$ \\
\hline $\mathrm{S} 1-\mathrm{N} 2$ & $1.6278(11)$ & $1.6139(10)$ & $\mathrm{S} 1-\mathrm{C} 8-\mathrm{P} 1 / \mathrm{S} 1-\mathrm{C} 2-\mathrm{C} 1$ & $114.41(7)$ & $126.70(9)$ \\
\hline $\mathrm{S} 1-\mathrm{C} 8 / \mathrm{C} 2$ & $1.8398(13)$ & $1.8431(12)$ & Li1-N2-Li1'/Li2 & $76.86(11)$ & $85.74(9)$ \\
\hline $\mathrm{C} 7-\mathrm{P} 1 / \mathrm{C} 1-\mathrm{N} 3$ & $1.8330(15)$ & $1.4388(15)$ & N1-Li1-N2/N1-Li2-N2 & $69.41(8)$ & $72.53(7)$ \\
\hline N1-Li1/Li2 & $1.957(3)$ & $2.068(2)$ & N2-Li1-N2'/N5 & $103.14(11)$ & $94.38(9)$ \\
\hline N2-Li1'/Li1 & $2.008(3)$ & $1.968(2)$ & N2'-Li1-N1/N2-Li1-N4 & $138.96(14)$ & $129.89(12)$ \\
\hline N2-Li1/Li2 & $2.506(3)$ & $2.284(2)$ & P1'-Li1-N2/N3-Li1-N5 & $122.84(10)$ & $136.21(11)$ \\
\hline P1-Li1'/N3-Li1 & $2.644(2)$ & $2.193(2)$ & & & \\
\hline
\end{tabular}

To further test if the $\mathrm{Me}_{2} \mathrm{~N}$ side-arm is as flexible and easily cleavable in solution as the $\mathrm{R}_{2} \mathrm{P}$ side-arm in corresponding complexes, two equivalents of $\mathrm{THF}$ were added to $\left[\mathrm{Li}\left\{\mathrm{Me}_{2} \mathrm{~N}\left(\mathrm{C}_{6} \mathrm{H}_{4}\right) \mathrm{S}\left(\mathrm{NSiMe}_{3}\right)_{2}\right\}\right]_{2}$ (16). As expected, the $\mathrm{Me}_{2} \mathrm{~N}$ side-arm coordination was replaced by one THF donor molecule each as the oxygen atom in THF is a better donor for lithium than nitrogen. Thereby the lability of the $\mathrm{Li}-\mathrm{NMe}_{2}$ bond could be proved. The dimethylamino group should now be easily approached by a second metal to give heterobimetallic complexes. The structure of $\left[(\text { thf }) \mathrm{Li}\left\{\mathrm{Me}_{2} \mathrm{~N}\left(\mathrm{C}_{6} \mathrm{H}_{4}\right) \mathrm{S}\left(\mathrm{NSiMe}_{3}\right)_{2}\right\}\right]_{2}$ (17) is depicted in Figure 3-8.

The structure shows the typical four-membered $(\mathrm{LiN})_{2}$ ring and the overall structural features are similar to other compounds of this type, e. $g$. $\left[(\text { thf }) \mathrm{Li}\left(\mathrm{C}_{6} \mathrm{H}_{5}\right) \mathrm{S}\left(\mathrm{NSiMe}_{3}\right)_{2}\right]_{2}{ }^{[85]}$ The lithium cations are each coordinated by three nitrogen atoms of the two ligands and one oxygen atom of the THF molecule. Both phenyl rings are on opposite sides of the central $\mathrm{N}_{2} \mathrm{Li}$-plane and are arranged almost parallel to each other with the $\mathrm{NMe}_{2}$ groups pointing away from the centre. Therefore, the coordination of a second metal seems feasible, as the nitrogen atoms $\mathrm{N} 1$ and $\mathrm{N} 1$ ' are sterically not protected. 


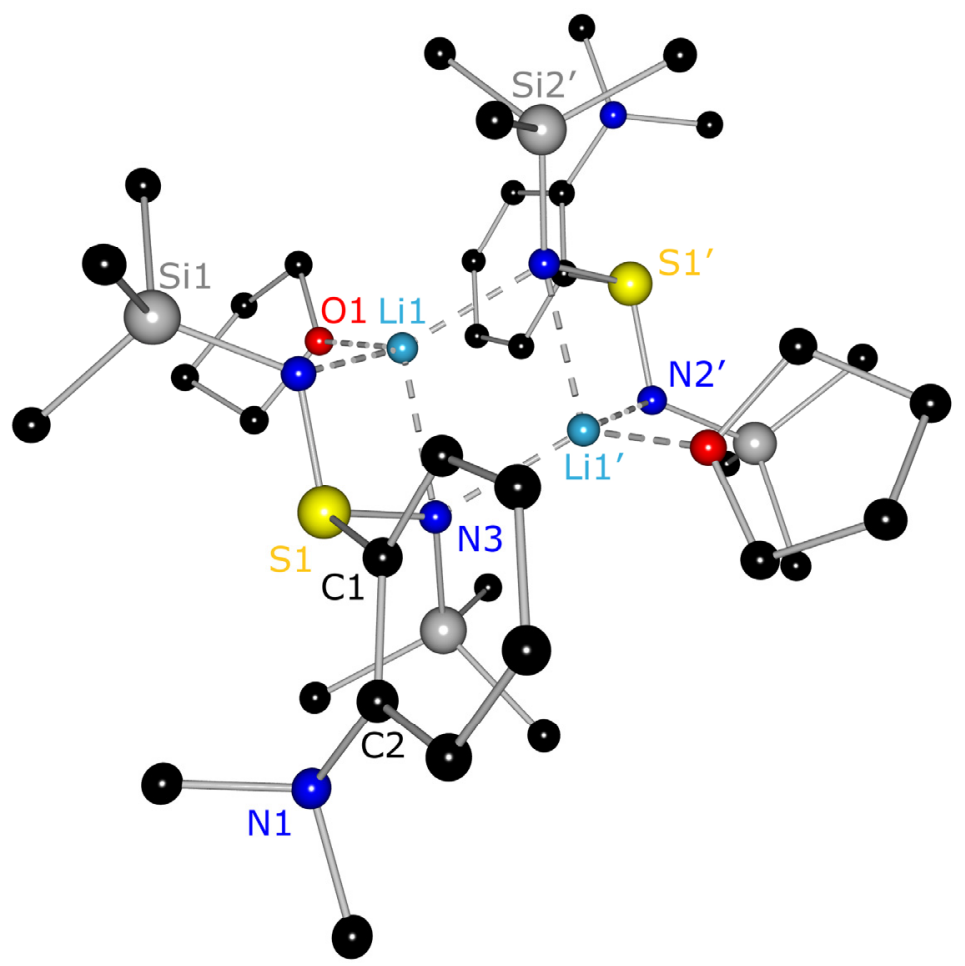

Figure 3-8: Molecular structure of $\left[(\text { thf }) L i\left\{\mathrm{Me}_{2} \mathrm{~N}\left(\mathrm{C}_{6} \mathrm{H}_{4}\right) \mathrm{S}\left(\mathrm{NSiMe}_{3}\right)_{2}\right\}\right]_{2}($ (17). Hydrogen atoms are omitted for clarity.

The $\mathrm{S}-\mathrm{N}, \mathrm{S}-\mathrm{C}$ and $\mathrm{C}-\mathrm{N}$ bond lengths are all quite similar to 16 . The $\mathrm{N}-\mathrm{Li}$ contacts differ very little, too. Nevertheless, the angles vary. The $\mathrm{N}-\mathrm{S}-\mathrm{N}$ angle is more acute as well as the S1-C1-C2 angle $\left(120.28(10)^{\circ}, 126.70(9)^{\circ}\right.$ in 16). This is clearly due to the non-coordinating side-arm. The oxygen atoms of the THF molecules deviate by $40.6^{\circ}$ from the central $(\mathrm{LiN})_{2}$ plane. The NSN moiety is located at an angle of $91.6^{\circ}$ to the N3-Li1-O1 plane. Selected bond lengths and angles can be found in Table 3-3.

Table 3-3: Selected bond lengths $[\AA]$ and angles $\left[{ }^{\circ}\right]$ in 17

\begin{tabular}{llll}
\hline S1-N2 & $1.5994(10)$ & N2-S1-N3 & $103.19(5)$ \\
S1-N3 & $1.6252(10)$ & C1-S1-N3 & $104.21(6)$ \\
S1-C1 & $1.8325(13)$ & N1-C2-C1 & $119.16(12)$ \\
C2-N1 & $1.4263(18)$ & S1-C1-C2 & $120.28(10)$ \\
O1-Li1 & $1.946(2)$ & N2-Li1-N3 & $72.33(8)$ \\
N3-Li1 & $2.231(2)$ & N2-Li1-N3' & $121.16(11)$ \\
N2-Li1 & $2.043(2)$ & N3-Li1-O1 & $115.10(11)$ \\
N3-Li1' & $2.091(2)$ & Li1-N3-Li1' & $72.55(10)$ \\
\hline
\end{tabular}


The NMR spectra of 16 and 17 differ only slightly. The signals for the ring hydrogen atoms in 17 are shifted to lower field because of the missing $\mathrm{Li}$ coordination. Interestingly, this does not seem to influence the $\mathrm{NMe}_{2}$ shift. The signal just gets very broad, probably because the group can rotate freely due to the missing coordination.

\subsubsection{A Potassium Complex}

In the 1960s Lochmann and Schlosser presented an excellent method for the deprotonation of unacidic substances. ${ }^{[42]}$ Following this concept, Ott was able to synthesise a homologues series of alkaline metal functionalized picolines; he even succeeded to crystallise the first Cs-picolines. ${ }^{[122]}$ In 2007 Izod et al. successfully employed $\mathrm{NaOtBu}$ and $\mathrm{KO}$ Bu for the transmetalation of lithium amino phosphanide complexes. $^{[123]}$

With these successes in mind, KOtBu was used for the deprotonation of $\mathrm{Me}_{2} \mathrm{NPh}$. KOtBu and the amine were suspended in hexane und tBuLi was added drop wise with stirring at room temperature. After several hours, the brown slurry was filtered, thoroughly washed with hexane to remove LiOtBu and dried in vacuo. The resulting powder is highly pyrophoric and even in an argon glove box it was only storable for about one week before it degraded into a white powder. NMR spectroscopy clearly showed that $\left[\mathrm{K}\left\{\left(\mathrm{C}_{6} \mathrm{H}_{4}\right) \mathrm{NMe}_{2}\right\}\right]$ was the obtained product. Thereby, the transmetalation step had already been effected during the synthesis of the starting material, thus omitting the difficult metal exchange in the final compound.

When $\left[\mathrm{K}\left\{\left(\mathrm{C}_{6} \mathrm{H}_{4}\right) \mathrm{NMe}_{2}\right\}\right]$ was reacted with an equimolar amount of $\mathrm{S}\left(\mathrm{NSiMe}_{3}\right)_{2}$ at $-78^{\circ} \mathrm{C}$ and the solution stored at $-20^{\circ} \mathrm{C}$, colourless crystals were obtained after one week (Equation 3-3). The complex $\left.\left[K\left\{\mathrm{Me}_{2} \mathrm{~N}\left(\mathrm{C}_{6} \mathrm{H}_{4}\right) \mathrm{S}\left(\mathrm{NSiMe}_{3}\right)_{2}\right\}\right]_{2}\right]$ (18) crystallises in the monoclinic space group $\mathrm{C} 2 / \mathrm{c}$ with two dimers in the asymmetric unit. The potassium ions are bonded by two nitrogen atoms of one diimido moiety (N1/N2, $\left.\mathrm{N} 1^{\prime} / \mathrm{N} 2^{\prime}\right)$, one nitrogen atom of the other diimido moiety (N1'/N1) and $\eta^{6}$ by the phenyl ring of that half. 


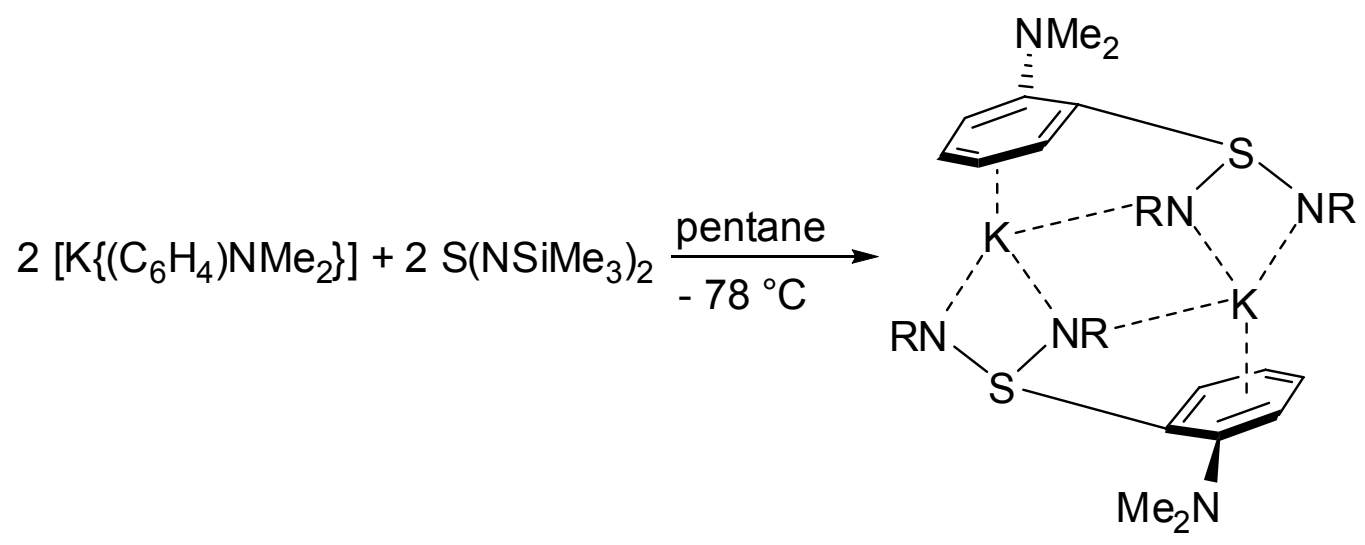

Equation 3-3: Preparation of $\left.\left[K\left\{\mathrm{Me}_{2} \mathrm{~N}\left(\mathrm{C}_{6} \mathrm{H}_{4}\right) \mathrm{S}\left(\mathrm{NSiMe}_{3}\right)_{2}\right\}\right]_{2}\right]$ (18), $\mathrm{R}=\mathrm{SiMe}_{3}$.

This is very different in comparison to the corresponding lithium complex 16 (Figure 3-7) and is due to the lower HSAB hardness of potassium. In the case of lithium, the dimethylamino group takes part in the coordination rather than the $\mathrm{C}_{6^{-}}$ perimeter. Despite of the $\eta^{6}$-coordination of the phenyl ring, the connecting $S-C$ bond is virtually not affected (1.832(2) $\AA$ in 18 vs. 1.8431(12) $\AA$ in 16).

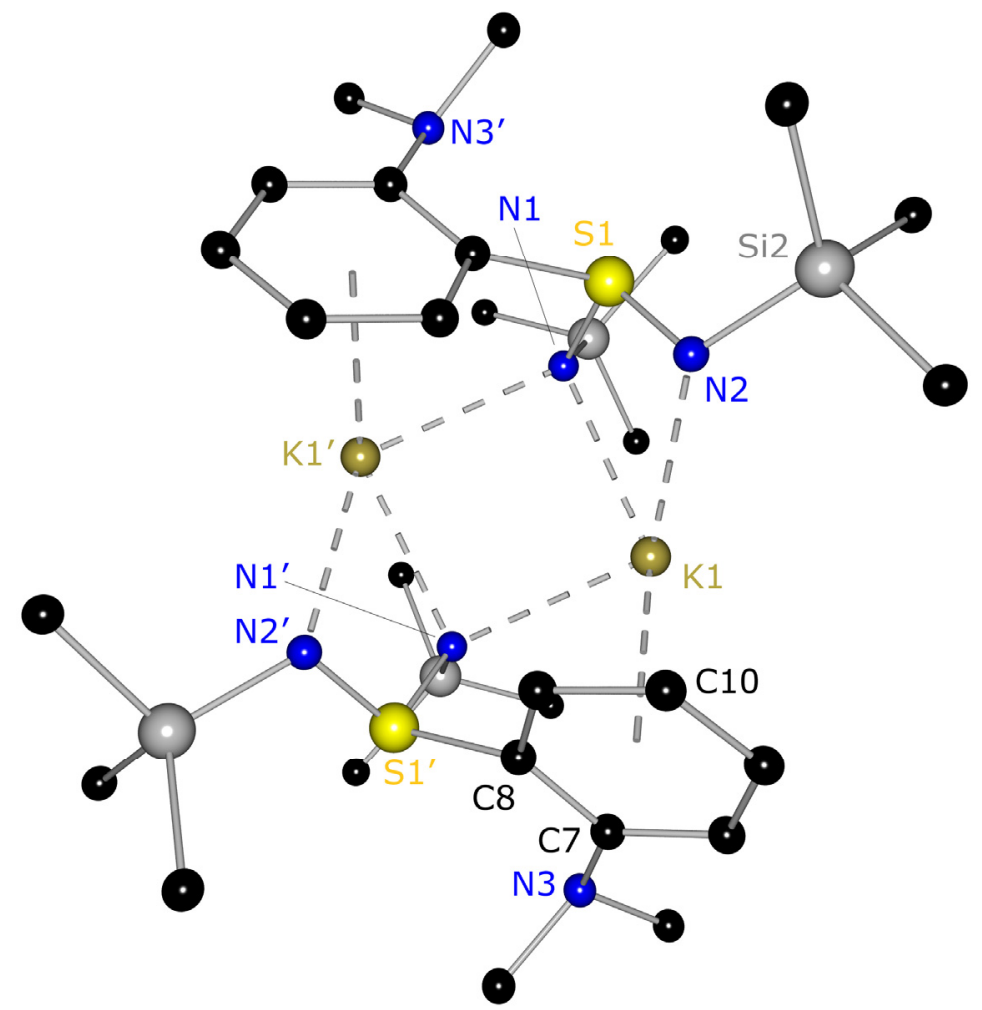

Figure 3-9: Molecular structure of $\left.\left[\mathrm{K}\left\{\mathrm{Me}_{2} \mathrm{~N}\left(\mathrm{C}_{6} \mathrm{H}_{4}\right) \mathrm{S}\left(\mathrm{NSiMe}_{3}\right)_{2}\right\}\right]_{2}\right]$ (18). Hydrogen atoms are omitted for clarity.

In 18, the amino arm is free to rotate and may bind to other metal atoms. The $\mathrm{N}-\mathrm{K}$ bond lengths range from 2.7656(18) $\AA$ (N2-K1) to 2.8923(17) $\AA$ (N1-K1') and are therefore in the expected range. ${ }^{[68]}$ They are similar to the diimido potassium complex $\left[(\mathrm{dme}) \mathrm{K}\left\{\left(\mathrm{Me}_{3} \mathrm{SiN}\right)_{2} \mathrm{SPh}\right\}\right]_{2}$ which displays $\mathrm{N}-\mathrm{K}$ distances of $2.725(2) \AA$ and 
2.823(2) $\AA_{.}^{[81]}$ The distance of the potassium cation from the coordinating phenyl ring is on average $3.3 \AA$ which is in the usual range ${ }^{[124]}$ and comparable to $\left[\left\{(t \mathrm{BuO}){ }_{2} \mathrm{Sb}_{3}(\mu-\mathrm{NCy})_{3}\left(\mu^{3}-\mathrm{NCy}\right)\right\} \mathrm{K}\left(\eta^{6}-\mathrm{C}_{6} \mathrm{H}_{5} \mathrm{Me}\right)\right]^{[125]} \quad\left[\mathrm{Ph}_{3} \mathrm{CK}(\mathrm{thf})(\mathrm{pmdta})\right]{ }^{[126]}$ $\left[\mathrm{PyPh}_{2} \mathrm{CK}(\mathrm{thf})(\mathrm{pmdta})\right]^{[127]}$ or $\left(\eta^{3}-(\mathrm{PNtBu})_{2}(\mathrm{NtBu})_{2}\right)\left[\eta^{2}-(\mathrm{NtBu})_{2} \mathrm{P}\right] \mathrm{ZrCl}{ }^{[128]}$. The phenyl rings are oriented $95.5^{\circ}$ with respect to each other (Figure 3-9). Important bond lengths and angles of $\mathbf{1 8}$ and $\mathbf{1 6}$ are compared in Table 3-4.

Table 3-4: Selected bond lengths $[\AA]$ and angles $\left[^{\circ}\right]$ in 18 and 16

\begin{tabular}{lllllc}
\hline & 16 & \multicolumn{1}{c}{18} & & 16 & 18 \\
\hline S1-N1 & $1.6053(10)$ & $1.6140(17)$ & N1-S1-N2 & $106.54(5)$ & $107.55(9)$ \\
S1-N2 & $1.6139(10)$ & $1.6067(17)$ & S1-C2-C1/S1'-C8-C7 & $126.70(9)$ & $119.76(16)$ \\
S1-C2/C8' & $1.8431(12)$ & $1.832(2)$ & Li1-N2-Li2/K1-N1-K1' $^{\prime}$ & $85.74(9)$ & $85.39(5)$ \\
N3-C1/C7 & $1.4388(15)$ & $1.419(3)$ & N1-Li2-N2/N1-K1-N2 & $72.53(7)$ & $55.95(5)$ \\
N1-Li2/K1 & $2.068(2)$ & $2.7726(17)$ & N2-Li1-N5/N1-K1-N1' & $94.38(9)$ & $88.23(5)$ \\
N2-Li1/K1 & $1.968(2)$ & $2.7656(18)$ & N2-Li1-N4/N2-K1-N1' & $129.89(12)$ & $125.93(5)$ \\
N2-Li2/N1-K1' & $2.284(2)$ & $2.8923(17)$ & N2-K1-C7 & -- & $127.71(5)$ \\
N3-Li1/C10-K1 & $2.193(2)$ & $3.375(2)$ & N3-Li1-N5 & $136.21(11)$ & -- \\
C7-K1 & --- & $3.361(2)$ & & & \\
\hline
\end{tabular}

With the complexation of potassium by the $\left\{\mathrm{Me}_{2} \mathrm{~N}\left(\mathrm{C}_{6} \mathrm{H}_{4}\right) \mathrm{S}\left(\mathrm{NSiMe}_{3}\right)_{2}\right\}^{-}$ligand, compounds with softer metals come into focus and the versatility of the ligand system is displayed. Not only the nitrogen atoms can act as donors but the phenyl ring as well because it is in spatial proximity to the diimido moiety.

\subsection{2 $\mathrm{S}(\mathrm{NtBu})_{2}$ as a Donor Solvent}

As the reaction of lithiated dimethylaniline and $\mathrm{S}\left(\mathrm{NSiMe}_{3}\right)_{2}$ proceeded smoothly and in excellent yield, $\mathrm{S}(\mathrm{N} t \mathrm{Bu})_{2}$ was employed to generate a ligand analogous to 16 but with different substituents at the sulphur atom. Surprisingly, the conversion is not equimolar and proceeds according to Equation 3-4. It is striking that $\left[(t \mathrm{BuN})_{2} \mathrm{~S} \cdot\left\{\mathrm{LiMe}_{2} \mathrm{~N}\left(\mathrm{C}_{6} \mathrm{H}_{4}\right) \mathrm{S}(\mathrm{NtBu})_{2}\right\}_{2}\right]$ (19) always crystallises with one equivalent of $\mathrm{S}(\mathrm{N} t \mathrm{Bu})_{2}$ as a donor solvent, even when the reaction is conducted with equimolar amounts of $\mathrm{S}(\mathrm{NtBu})_{2}$ and $\left[\mathrm{Li}\left\{\left(\mathrm{C}_{6} \mathrm{H}_{4}\right) \mathrm{NMe}_{2}\right\}\right]$. This behaviour is not observed when $\mathrm{S}\left(\mathrm{NSiMe}_{3}\right)_{2}$ is used instead. 


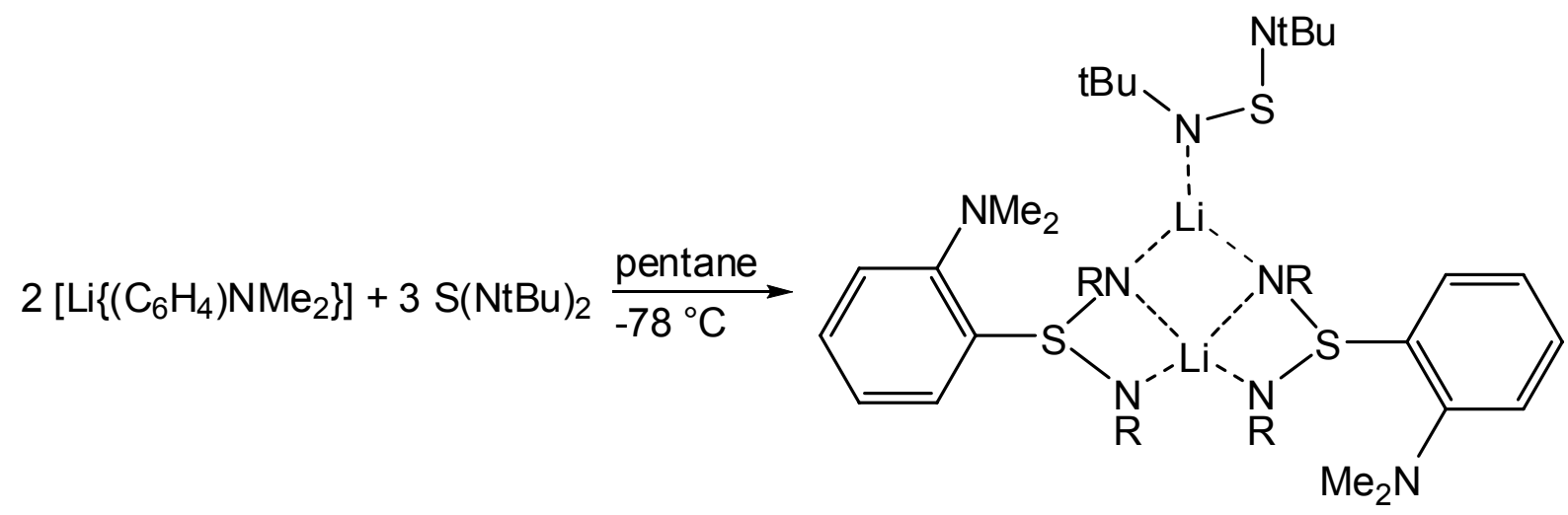

Equation 3-4: Preparation of $\left[(t B u N)_{2} S \cdot\left\{\mathrm{LiMe}_{2} \mathrm{~N}\left(\mathrm{C}_{6} \mathrm{H}_{4}\right) \mathrm{S}(\mathrm{N} t \mathrm{Bu})_{2}\right\}_{2}\right]($ 19), $\mathrm{R}=t \mathrm{Bu}$.

The reaction product crystallises in the monoclinic space group $P 2_{1} / n$ with the whole molecule in the asymmetric unit (Figure 3-10). One lithium atom (Li1) is tetrahedrally coordinated by four nitrogen atoms of the two $\left\{\mathrm{Me}_{2} \mathrm{~N}\left(\mathrm{C}_{6} \mathrm{H}_{4}\right) \mathrm{S}(\mathrm{NtBu})_{2}\right\}^{-}$ ligands. Different to 16, the dimethylamino groups do not take part in the coordination. The $\mathrm{Li}-\mathrm{N}$ bond lengths are in the expected range between 1.955(3) $\AA$ (Li1-N2) and 2.338(3) (Li1-N3) A. Two of the diimido nitrogen atoms (N3 and N5) additionally coordinate a second lithium cation, giving rise to the longer $\mathrm{Li}-\mathrm{N}$ distances. $\mathrm{Li} 2$ has a trigonal planar coordination geometry with all $\mathrm{N}-\mathrm{Li} 2-\mathrm{N}$ angles close to $120^{\circ}$ (N3-Li2-N5: 115.74(14) $)^{\circ}$ N3-Li2-N8: 124.27(14) ${ }^{\circ}$, N5-Li2-N8: $\left.119.73(14)^{\circ}\right)$. The third coordination site is occupied by a free, non-disordered $\mathrm{S}(\mathrm{N} t \mathrm{Bu})_{2}$ molecule, acting as a donor solvent.

The diimide molecule is almost perfectly aligned which can be rationalized with the torsion angle C37-N8-S3-N7 of $0.81(16)^{\circ}$. The $\mathrm{S}-\mathrm{N}$ distances of the coordinating diimido moieties are in the expected range for diimido sulfinates. In contrast, the $\mathrm{S}-\mathrm{N}$ distances in the free $\mathrm{S}(\mathrm{NtBu})_{2}$ are considerably shorter (1.5331(15) $\AA$ and $1.5396(14) \AA)$, which is well in the range of the uncoordinating starting material. ${ }^{[129]}$ The distance between S3 and N8 is slightly longer (1.5396 $\AA$ ) because of the coordination to the lithium atom. All $\mathrm{S}-\mathrm{N}$ bond lengths suit the concept of polar reinforced $\mathrm{S}^{\delta+}-\mathrm{N}^{\delta-}$ bonds deduced from experimental and theoretical charge density investigations. ${ }^{[130]}$ Nevertheless, the centre of the structure consists of the well known ( $\mathrm{LiN})_{2}$ four-membered ring with the $\mathrm{Li}-\mathrm{N}$ distances being in the same range as for all the other structures. The diimido moieties are inclined by $42.7^{\circ}$ and $44.3^{\circ}$ from the central $\mathrm{Li}-\mathrm{N}-\mathrm{Li}$ plane. Both $\mathrm{S}(\mathrm{N} t \mathrm{Bu})_{2}$ groups are twisted by $62.0^{\circ}$ with respect to each other, thus promoting the tetrahedral environment around Li1. Selected bond lengths and angles are shown in Table 3-5. 


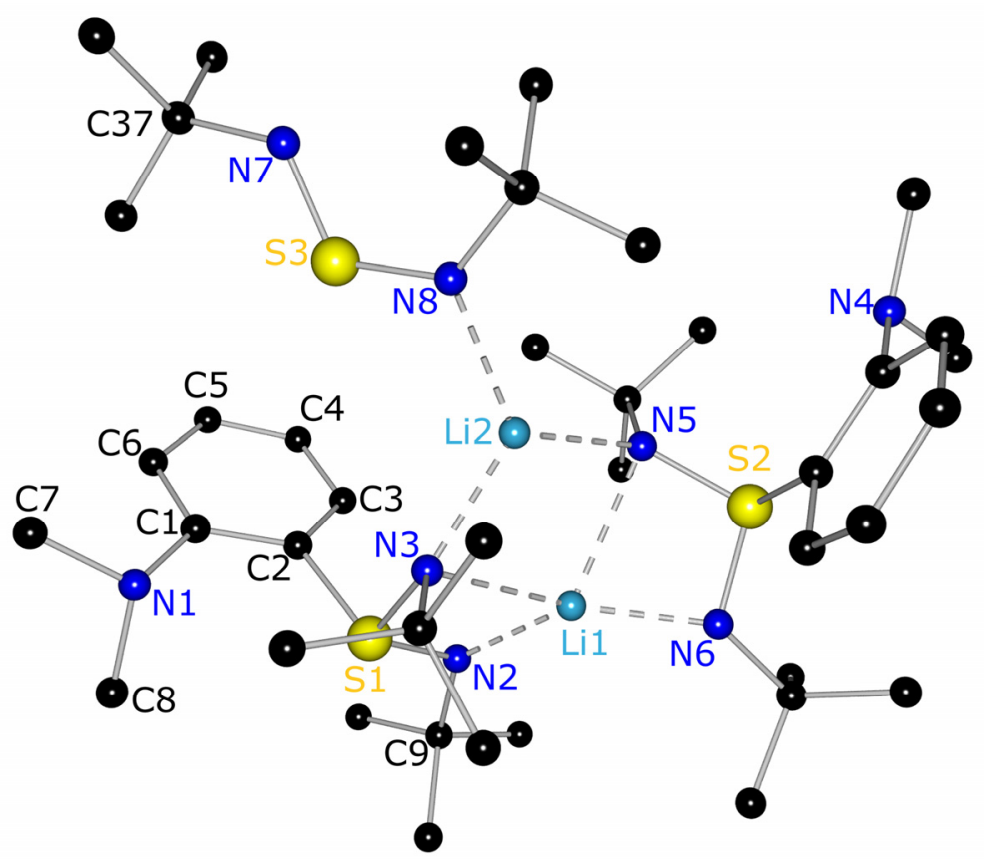

Figure 3-10: Molecular structure of $\left[(t \mathrm{BuN})_{2} \mathrm{~S} \cdot\left\{\mathrm{LiMe}_{2} \mathrm{~N}\left(\mathrm{C}_{6} \mathrm{H}_{4}\right) \mathrm{S}(\mathrm{NtBu})_{2}\right\}_{2}\right](19)$. Hydrogen atoms are omitted for clarity.

The threefold/fourfold binding motif of lithium is well known - not only in diimido complexes ${ }^{[36,131]}$ but also with other ligands ${ }^{[132]}$ and is one of the preferred coordination geometries for sulphur diimido complexes with donor solvents. It is interesting though, that the coordination is not similar to 17 and the two diimido moieties are bridging both lithium atoms. This could be due to the increased steric demand of $\mathrm{S}(\mathrm{NtBu})_{2}$ in comparison to THF. Consequently, a control of the coordination motif seems feasible just by choosing the right solvent.

Table 3-5: Selected bond lengths $[\AA]$ and angles $\left[{ }^{\circ}\right]$ in 19

\begin{tabular}{llll}
\hline S1-N2 & $1.617(13)$ & N2-S1-N3 & $104.15(7)$ \\
S1-N3 & $1.6350(13)$ & N7-S3-N8 & $114.98(8)$ \\
S3-N7 & $1.5331(15)$ & C1-C2-S1 & $121.65(12)$ \\
S3-N8 & $1.5396(14)$ & N2-Li1-N6 & $143.34(16)$ \\
S1-C2 & $1.8267(16)$ & N6-Li1-N5 & $72.74(10)$ \\
C1-N1 & $1.422(2)$ & N2-Li1-N3 & $72.63(10)$ \\
N1-Li1 & $1.955(3)$ & N5-Li1-N3 & $96.20(11)$ \\
N3-Li2 & $2.051(3)$ & N5-Li2-N3 & $115.74(14)$ \\
N8-Li2 & $2.127(3)$ & N5-Li2-N8 & $119.73(14)$ \\
N3-Li1 & $2.338(3)$ & N3-Li2-N8 & $124.27(14)$ \\
\hline
\end{tabular}




\section{Conclusion}

The very different structural characteristics in 19 compared to 16 might have their origin in electronic reasons, as the silicon atom in $\mathrm{S}\left(\mathrm{NSiMe}_{3}\right)_{2}$ is the only difference in the reactions leading to both lithium complexes. It is striking that 19 always crystallises with one equivalent of $\mathrm{S}(\mathrm{NtBu})_{2}$ as a donor solvent, even if the reaction is conducted with equimolar amounts of $\mathrm{S}(\mathrm{NtBu})_{2}$ and $\left[\mathrm{Li}\left\{\left(\mathrm{C}_{6} \mathrm{H}_{4}\right) \mathrm{NMe}_{2}\right\}\right]$. This behaviour is not observed when $\mathrm{S}\left(\mathrm{NSiMe}_{3}\right)_{2}$ is used instead.

During the course of this research, it became obvious that most of the reactions proceeded much better with $\mathrm{S}\left(\mathrm{NSiMe}_{3}\right)_{2}$ than with $\mathrm{S}(\mathrm{NtBu})_{2}$. Some do not even work at all with di(tert)butyl sulphur diimide. A reason for this could be the different activation of the sulphur atom by the different substituents. In both cases the $\mathrm{S}-\mathrm{N}$ bond is polarized in direction of the nitrogen atom. However, the better polarizability and lower electronegativity of silicon compared to carbon allows for a better distribution of the negative charge into the ligand. Consequently, the positive charge at the sulphur atom is augmented. For nucleophiles (just like the employed carbanions), the addition becomes easier $i$. e. faster. It can be speculated that the complete addition of $\mathrm{S}(\mathrm{NtBu})_{2}$ to $\left[\mathrm{Li}\left\{\left(\mathrm{C}_{6} \mathrm{H}_{4}\right) \mathrm{NMe}_{2}\right\}\right]$ to form $\left[(t B u N)_{2} \mathrm{~S} \cdot\left\{\mathrm{LiMe}_{2} \mathrm{~N}\left(\mathrm{C}_{6} \mathrm{H}_{4}\right) \mathrm{S}(\mathrm{N} t \mathrm{Bu})_{2}\right\}_{2}\right]$ proceeds slowly, so that 19 is already being formed in the reaction flask and complete conversion cannot be achieved. This effec is likely to be minimal, as it has no influence on the $\mathrm{S}-\mathrm{N}$ bond lengths.

\subsection{The Picolyl Side-Arm}

As has already been discussed in chapter 3.1, dimethylaniline can only be deprotonated with tert-butyllithium directly at the ring. In order to synthesise a compound that has a nitrogen-functionalized side-arm which is connected to the sulphur atom via a $\mathrm{CH}_{2}$ bridge 2-picoline was employed in the synthesis. The deprotonation and reactivity of this heterocycle has been extensively studied by Ott in our workgroup. ${ }^{[122]}$ One of the most convenient ways is the deprotonation with $n \mathrm{BuLi}$ and TMEDA at $-78^{\circ} \mathrm{C}{ }^{[133]}[$ (tmeda)Li(2-Pic)] crystallises as dark red needles that can be filtered, washed and stored in an argon drybox without being too reactive.

The equimolar reaction with $\mathrm{S}\left(\mathrm{NSiMe}_{3}\right)_{2}$ yields colourless crystals of space group $P \overline{1}$. Compound 20 is a dimer (see Figure 3-11) which is isosteric to the 
previously reported $\left[\mathrm{Li}\left\{2-\mathrm{PiCS}(\mathrm{N} t \mathrm{Bu})_{2}\right\}\right]_{2}$ which crystallises in the monoclinic space group $C 2 / c{ }^{[36]}$ There are no unusual bond lengths and angles. A selection is shown in Table 3-6.

Table 3-6: Selected bond lengths $[\AA]$ and angles $\left[{ }^{\circ}\right]$ in 20 and $\left.\left[\mathrm{Li}\left\{2-\mathrm{PicS}(\mathrm{N} t \mathrm{Bu})_{2}\right)\right\}\right]_{2}$

\begin{tabular}{|c|c|c|c|c|c|}
\hline & 20 & $\begin{array}{l}\text { [Li }\{2-\mathrm{PicS}- \\
\left.\left.\left.(\mathrm{NtBu})_{2}\right)\right\}\right]_{2}\end{array}$ & & 20 & $\begin{array}{l}{[\mathrm{Li}\{2-\mathrm{PicS}-} \\
\left.\left.\left.(\mathrm{N} t \mathrm{Bu})_{2}\right)\right\}\right]_{2}\end{array}$ \\
\hline S1-N3 & $1.6140(9)$ & $1.6253(17)$ & N2-S1-N3 & $106.66(5)$ & $103.48(9)$ \\
\hline $\mathrm{S} 1-\mathrm{N} 2$ & $1.6018(9)$ & $1.6101(17)$ & $\mathrm{C} 6-\mathrm{C} 1-\mathrm{N} 1$ & $116.21(10)$ & $115.96(19)$ \\
\hline S1-C6 & $1.8442(11)$ & $1.859(2)$ & $\mathrm{S} 1-\mathrm{C} 6-\mathrm{C} 1$ & $114.01(8)$ & $113.26(15)$ \\
\hline $\mathrm{C} 1-\mathrm{C} 6$ & $1.4901(15)$ & $1.487(3)$ & Li1-N3-Li1' & $81.09(9)$ & $81.54(16)$ \\
\hline Li1-N1' & $2.052(2)$ & $2.118(4)$ & N3-Li1-N3' & $98.91(9)$ & $98.46(16)$ \\
\hline Li1-N2 & $2.046(2)$ & $1.979(4)$ & N2-Li1-N3 & $74.69(7)$ & $126.8(2)$ \\
\hline Li1-N3 & $2.201(2)$ & $2.281(4)$ & N1-Li1'-N3 & $94.44(9)$ & $94.55(16)$ \\
\hline Li1-N3' & $2.091(2)$ & $2.074(4)$ & C1-N1-Li1' & $114.58(9)$ & $110.43(17)$ \\
\hline
\end{tabular}

The compound shows the same structural features as [Li\{2-PicS $\left.\left.\left.(\mathrm{NtBu})_{2}\right)\right\}\right]_{2}$. In the centre of the structure is the typical $(\mathrm{LiN})_{2}$ four-membered heteroatomic ring. Both lithium atoms are coordinated by four nitrogen atoms in a distorted tetrahedral manner. The N2-S1-N3 angle of $106.66(5)^{\circ}$ is wider than in the corresponding

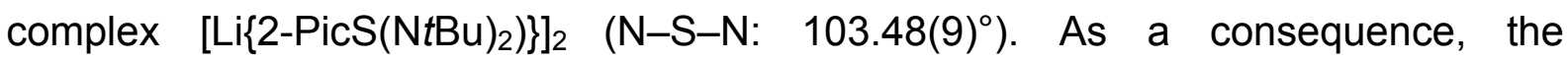
corresponding $\mathrm{Li}-\mathrm{N}$ bond distances are elongated: N2-Li1 2.046(2) $\AA$ in 20 vs. 1.979(4) $\AA$ and N3'-Li1 2.091(2) $\AA$ vs. 2.074(4) $\AA$. The C6-C1-N1 (116.21(10 $\left.{ }^{\circ}\right)$ and S1-C6-C1 $\left(114.01(8)^{\circ}\right)$ angles are also widened compared to [Li\{2-PicS $\left.\left.\left.(\mathrm{N} t \mathrm{Bu})_{2}\right)\right\}\right]_{2}$ $\left(115.96(19)^{\circ}\right.$ and $113.26(15)^{\circ}$, respectively). Interestingly, this larger bite of the ligand brings the two lithium cations into closer proximity. They are $2.791 \AA$ apart in $\mathbf{2 0}$, compared to $2.848 \AA$ in the di(tert-butyl)sulphur diimido complex. 


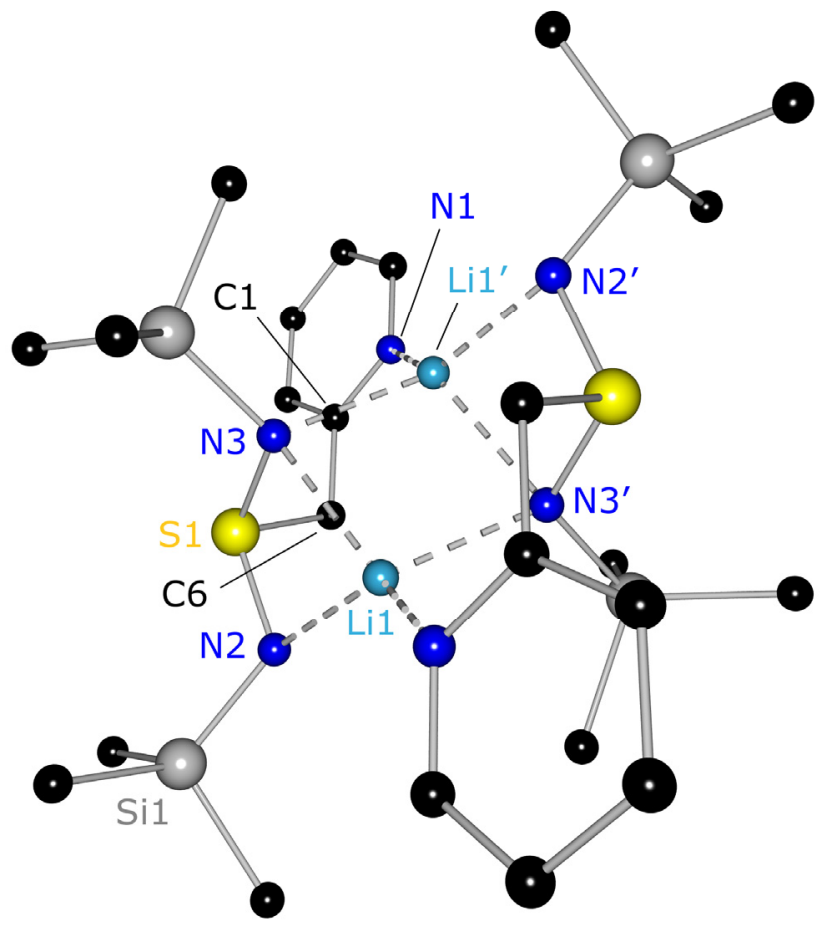

Figure 3-11: Molecular structure of $\left[\mathrm{Li}\left\{2-\mathrm{PicS}\left(\mathrm{NSiMe}_{3}\right)_{2}\right\}\right]_{2}(20)$. Hydrogen atoms are omitted for clarity.

\subsection{A Ligand of higher Denticity}

To generate a ligand with more than three binding sites, trimethylethylenediamine (TrMEDA) was lithiated and reacted with bis(trimethylsilyl)sulphur diimide in a one pot synthesis. This particular amine was chosen because it can be metalated very easily, it has two additional donor sites and should have the required flexibility. ${ }^{[134]}$ In addition, it is already being used as a bidentate ligand in many metal complexes ${ }^{[135]}$ and should therefore have the desired properties.

After lithiation of the amine, the reaction mixture was stirred for two hours and the diimide was added. The solution was then stirred for several hours, reduced in volume and stored at $-25^{\circ} \mathrm{C}$ for crystallization. The molecular structure of $\left[\mathrm{Li}\left\{\mathrm{Me}_{2} \mathrm{~N}\left(\mathrm{CH}_{2}\right)_{2} \mathrm{~N}(\mathrm{Me}) \mathrm{S}\left(\mathrm{NSiMe}_{3}\right)_{2}\right\}\right]_{2}(\mathbf{2 1})$ is shown in Figure 3-12.

All four nitrogen atoms of one ligand take part in the coordination, proving the anticipated flexibility. Consequently, the lithium cations are fivefold coordinated in a very distorted way and the coordination polyhedron seems arbitrary to assign. 


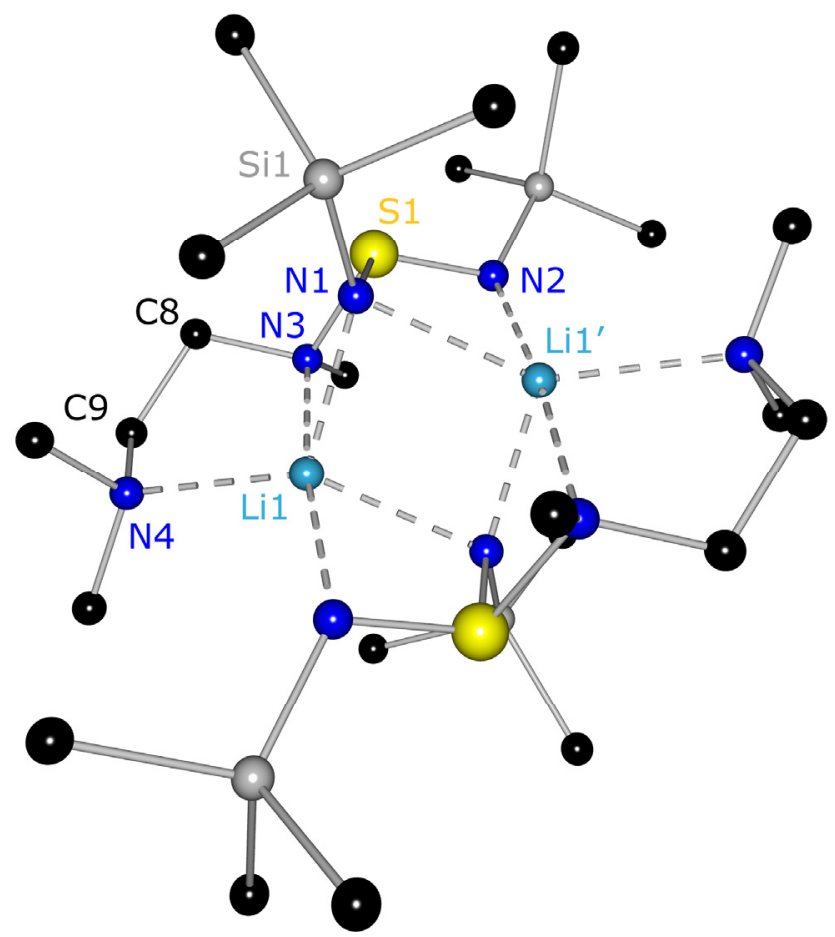

Figure 3-12: Molecular structure of $\left[\mathrm{Li}\left\{\mathrm{Me}_{2} \mathrm{~N}\left(\mathrm{CH}_{2}\right)_{2} \mathrm{~N}(\mathrm{Me}) \mathrm{S}\left(\mathrm{NSiMe}_{3}\right)_{2}\right\}\right]_{2}$ (21). Hydrogen atoms are omitted for clarity.

If the two largest bond angles around Li1 (N3-Li1-N2': 171.77(9) and N4Li1-N1': $\left.143.11(9)^{\circ}\right)$ are taken into account, the geometry index $\tau_{5}$ can be calculated, where the angle $\beta$ is larger than the angle $\alpha$ (Equation 3-5). ${ }^{[136]}$

$$
\tau_{5}=\frac{\beta-\alpha}{60}
$$

Equation 3-5: Definition of $\tau_{5}$.

This value was introduced by Addison and Reedijk in 1984 and represents an easy method to distinguish between a square pyramidal and a trigonal bipyramidal coordination geometry. This is especially handy for cases where the geometry is not clearly visible. Thus, for a square pyramidal coordination $\tau_{5}=0$ and for a trigonal bipyramid $\tau_{5}=1$. In the case of $\mathbf{2 1}$ it is optically almost impossible to discern the coordination geometry around the lithium atoms. The value of $\tau_{5}=0.48$ proves this but hints to a probably heavily distorted square pyramid.

It could be stated that in the ligand the nitrogen side-arm acts as an intramolecular TMEDA molecule. The $\mathrm{N}-\mathrm{Li}$ distances range from 2.0989(19) $\AA$ (N1Li1) to $2.442(2) \AA$ (N3-Li1) and are comparable to the other structures with nitrogen side-arm although N3-Li1 is near to the upper limit for N-Li bonds. ${ }^{[68]}$ The N1-S1-N2 angle of $107.75(4)^{\circ}$ is somewhat wider than in the other structures reported so far. This is due to the third nitrogen atom bonded to the diimido moiety and the arising 
fivefold coordination of the lithium cation. The trigonal bipyramidal environment could only be achieved if $\mathrm{N} 1$ and $\mathrm{N} 2$ were further apart from each other. The $\mathrm{S}-\mathrm{N}$ distances of 1.6009(8) $\AA(\mathrm{S} 1-\mathrm{N} 1)$ and 1.5847(8) $\AA$ (S1-N2) are on average shorter than in similar complexes but S1-N3 (1.7770(9) $\AA$ ) is even longer than an average $\mathrm{S}-\mathrm{N}$ single bond. This is due to the complexation of Li1. Selected bond lengths and angles, compared with the corresponding sodium complex, can be found in Table 3-7.

There seems to be a certain dynamic in solution. The $\mathrm{N}\left(\mathrm{CH}_{2}\right)_{2} \mathrm{~N}$ signals in the ${ }^{1} \mathrm{H}$ NMR spectrum are very broad at room temperature, indicating that the whole side-arm is moving. This is only possible if the N4- Li bond is cleaved and the sidearm is free to rotate.

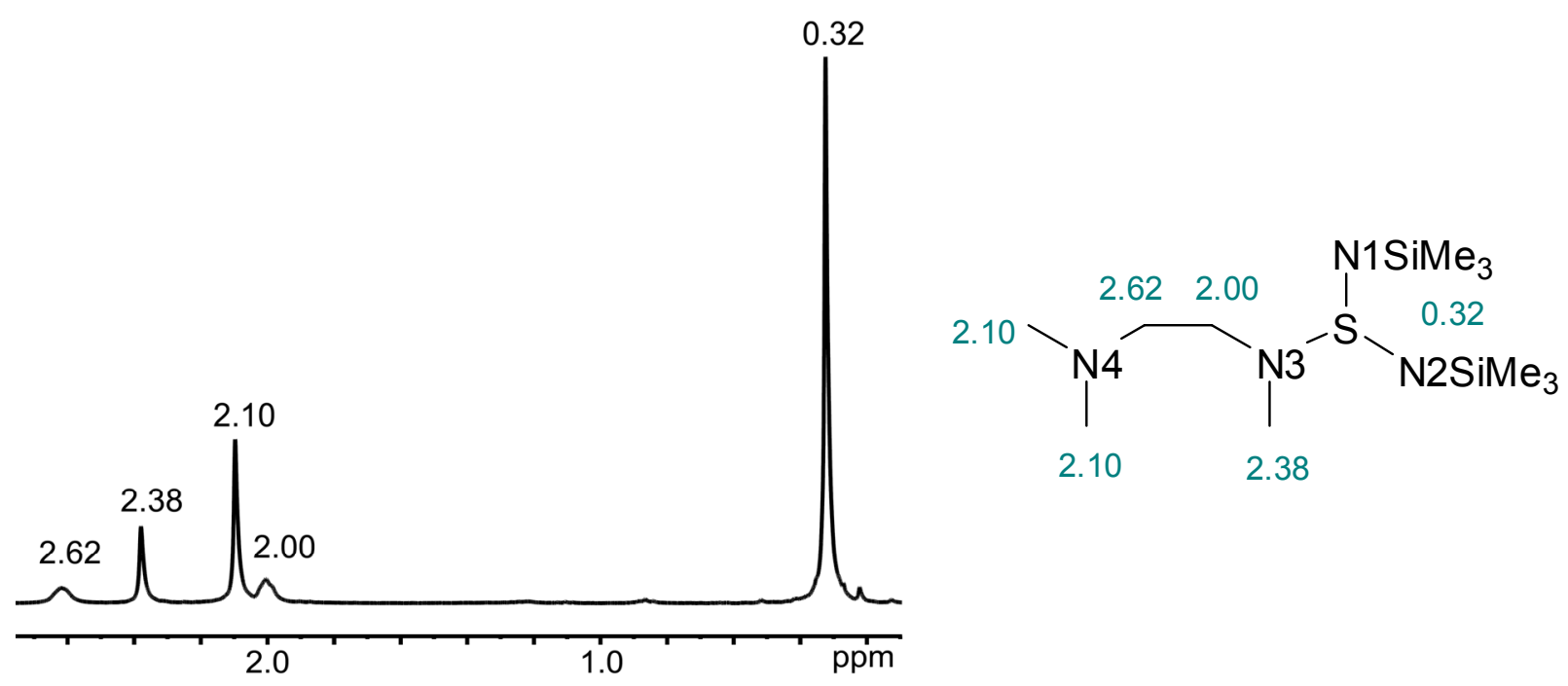

Figure 3-13: ${ }^{1} \mathrm{H}$ NMR spectrum of 21 in $\mathrm{C}_{6} \mathrm{D}_{6}$.

The fivefold $\mathrm{N}$-coordination of lithium is not very common. $\mathrm{Li}^{+}$rather prefers the coordination numbers four and six. When coordinated by a matching hemiporphyrizinato ligand however, a donor solvent can occupy the fifth coordination site, leading to a square pyramidal geometry around lithium. ${ }^{[137]}$ There are also amidinate complexes that show the fivefold coordination motif. ${ }^{[138]}$ Amidinates of the general form $\left[R^{1} N C\left(R^{2}\right) N R^{3}\right]^{-}$have nearly the same complexation potential as sulphur diimides resulting from the same geometry. Nevertheless, their coordination modes are limited. 


\subsubsection{From Lithium to Sodium}

When deprotonating TrMEDA with $n \mathrm{BuLi}$ in the presence of $\mathrm{NaOtBu}$, the sodium intermediate is obtained which forms the dimer 22 upon reaction with $\mathrm{S}\left(\mathrm{NSiMe}_{3}\right)_{2}$ which is analogous to 21 (see Equation 3-6). The structure of 22 is shown in Figure 3-14.

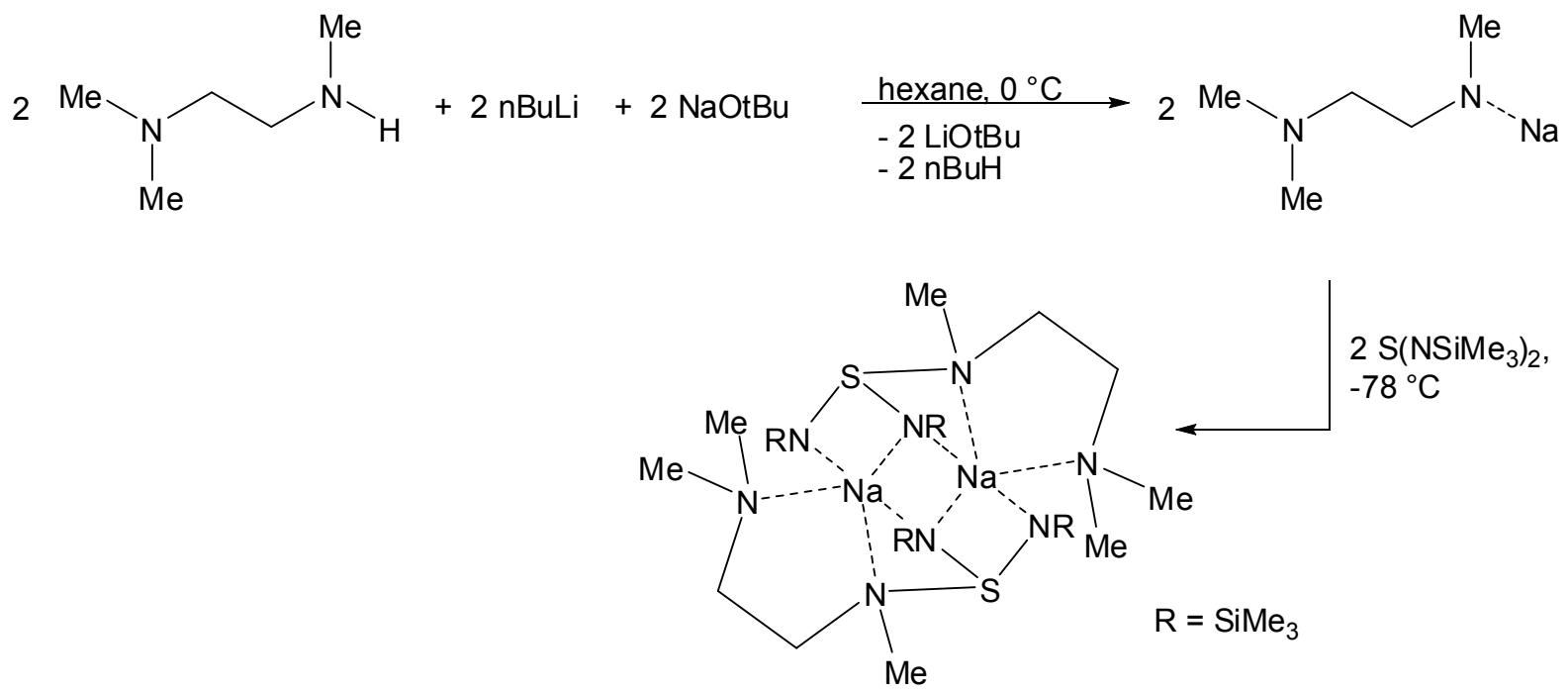

Equation 3-6: Preparation of $\left[\mathrm{Na}\left\{\mathrm{Me}_{2} \mathrm{~N}\left(\mathrm{CH}_{2}\right)_{2} \mathrm{~N}(\mathrm{Me}) \mathrm{S}\left(\mathrm{NSiMe}_{3}\right)_{2}\right\}\right]_{2}$ (22).

The sodium cation is fivefold coordinated by nitrogen atoms, similar to the lithium atom in the related complex. The resulting trigonal bipyramidal environment of the sodium atoms is more distorted than in the corresponding lithium complex (N1-Na1N3: $167.53(4)^{\circ}$ vs. N2'-Li1-N3: $\left.171.77(9)^{\circ}\right)$. This is also evident if the geometry index $\tau_{5}$ is calculated. The two largest angles around Na1 are N1-Na1-N3 (167.53(4) $)^{\circ}$ and N4-Na1-N2' $\left(144.69(4)^{\circ}\right)$ and $\tau_{5}=0.38$. Therefore, it can be deduced that 22 has a rather distorted square pyramidal geometry around the sodium cations. This is probably due to the fact that sodium is larger than lithium and the ligand in 22 is moved further away from the metal. Thereby, the coordinating nitrogen atoms can easier get into the plane of $\mathrm{Na1}$ and $\mathrm{Na} 1$ '.

Selected bond lengths and angles of $\mathbf{2 2}$ compared to the lithium complex $\mathbf{2 1}$ can be found in Table 3-7. 


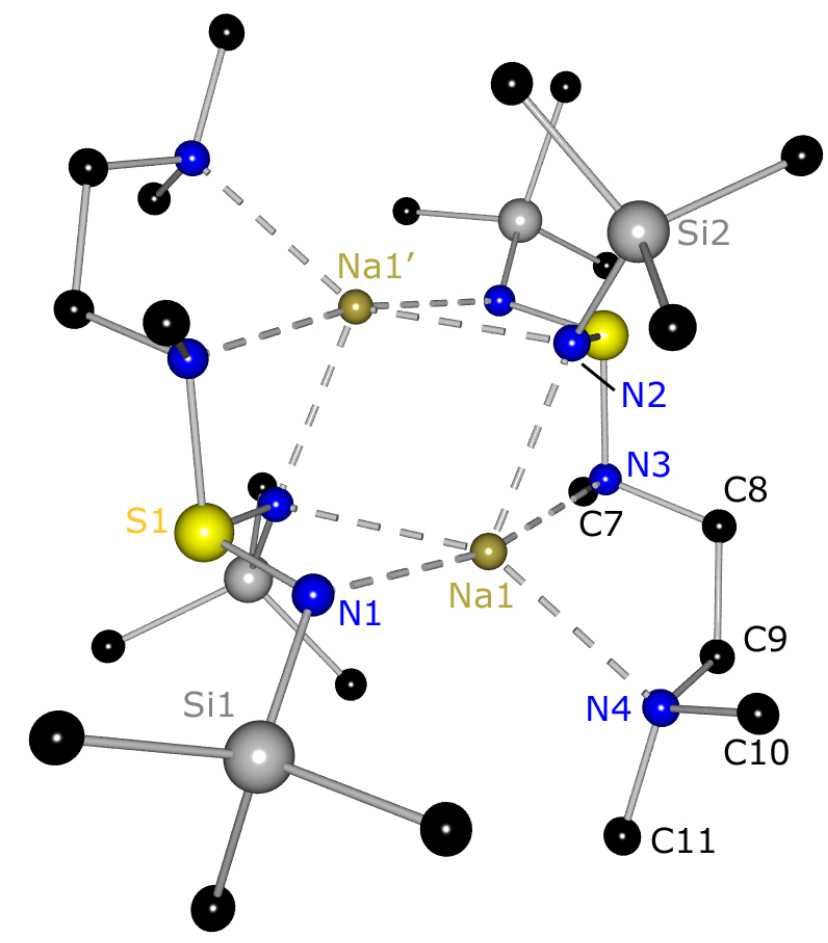

Figure 3-14: Molecular structure of $\left[\mathrm{Na}\left\{\mathrm{Me}_{2} \mathrm{~N}\left(\mathrm{CH}_{2}\right)_{2} \mathrm{~N}(\mathrm{Me}) \mathrm{S}\left(\mathrm{NSiMe}_{3}\right)_{2}\right\}\right]_{2}$ (22). Hydrogen atoms are omitted for clarity.

Table 3-7: Selected bond lengths $[\AA]$ and angles $\left[{ }^{\circ}\right]$ in 21 and 22

\begin{tabular}{|c|c|c|c|c|c|}
\hline & 21 & 22 & & 21 & 22 \\
\hline $\mathrm{S} 1-\mathrm{N} 1$ & $1.6009(8)$ & $1.5836(11)$ & $\mathrm{N} 1-\mathrm{S} 1-\mathrm{N} 2 / \mathrm{N} 2$ & $107.75(4)$ & $108.69(6)$ \\
\hline S1-N2/N2' & $1.5847(8)$ & $1.5889(11)$ & N1-S1-N3/N3' & $96.08(4)$ & $102.37(5)$ \\
\hline S1-N3/N3' & $1.7770(9)$ & $1.7892(11)$ & C8-N3-S1/S1' & $108.17(6)$ & $107.95(8)$ \\
\hline N1-Li1/Na1 & $2.0989(19)$ & $2.4256(12)$ & N1-Li1'-N2/N1-Na1-N2' & $114.89(8)$ & $62.83(4)$ \\
\hline N1-Li1'/N2-Na1 & $2.2768(19)$ & $2.4173(12)$ & N1-Li1-N1'/N2-Na1-N2' & $98.81(7)$ & $100.06(4)$ \\
\hline N2-Li1'/Na1' & $2.1934(19)$ & $2.5173(12)$ & Li1-N1-Li1'l & $81.19(7)$ & \\
\hline N3-Li1/Na1 & $2.442(2)$ & $2.5784(12)$ & Na1-N2-Na1' & & $79.95(4)$ \\
\hline N4-Li1/Na1 & $2.2534(19)$ & $2.5051(12)$ & N1-Li1-N3/N2-Na1-N3 & $66.76(6)$ & $60.68(4)$ \\
\hline N1-Si1 & $1.7268(8)$ & $1.7208(11)$ & N3-Li1-N4/N3-Na1-N4 & $78.89(6)$ & $74.46(4)$ \\
\hline \multirow[t]{2}{*}{ C8-C9 } & $1.5201(14)$ & $1.5244(18)$ & N2'-Li1-N3/N1-Na1-N3 & $171.77(9)$ & $167.53(4)$ \\
\hline & & & N3-C8-C9 & $110.11(8)$ & $111.68(1)$ \\
\hline
\end{tabular}

The S1-N1 and S1-N2 bond lengths are in the expected range for diimido sulfinates. The S1-N3' bond of 1.7892(11) $\AA$, on the other hand, is considerably elongated in comparison to a standard $\mathrm{S}-\mathrm{N}$ single bond of $1.69 \AA$. This is due to the complexation of Na1' and the complexing TrMEDA side-arm. The ligands are less strained and occupy more space around the central metals in comparison to 21 . This 
is also obvious if the angles around the sulphur atoms are taken into account. The TrMEDA sidearm is not bent inwards as much (N1-S1-N3': 102.37(5) ${ }^{\circ}$ vs. 96.08(4) in 21). As a result, all nitrogen-metal bond lengths are on average $0.3 \AA$ longer than in the lithium derivative. This is of course also due to the fact that sodium has a larger ionic radius. All $\mathrm{Na}-\mathrm{N}$ bonds are in the expected range for diimido-sodium compounds. ${ }^{[139,140]}$ Interestingly, the N3-Na1-N4 angle of $74.46(4)^{\circ}$ is more acute than the corresponding angle in the lithium complex $\left(78.89(6)^{\circ}\right)$. That is only possible because the ligand in $\mathbf{2 2}$ is bonding weaker to the metal, thereby leaving more space at the centre of the structure where the TrMEDA side-arm can get closer. The distances in the central four-membered ring support this observation: Li1 ...Li1': $2.851 \AA$ and $\mathrm{Na} 1 \ldots \mathrm{Na1}$ ': $3.171 \AA$.

The ${ }^{1} \mathrm{H}$ NMR spectrum also shows a dynamic behaviour which is even more pronounced than in the corresponding lithium complex. The $\mathrm{N}\left(\mathrm{CH}_{2}\right)_{2} \mathrm{~N}$ signals only become visible at $-30^{\circ} \mathrm{C}$. Thus, the presumption that the whole side-arm moves in solution is confirmed. As the N4-Na1 bond is longer than the N4-Li1 bond, it can be cleaved easier and the movement of the side-arm becomes faster. Consequently, the signals get broader and eventually disappear.
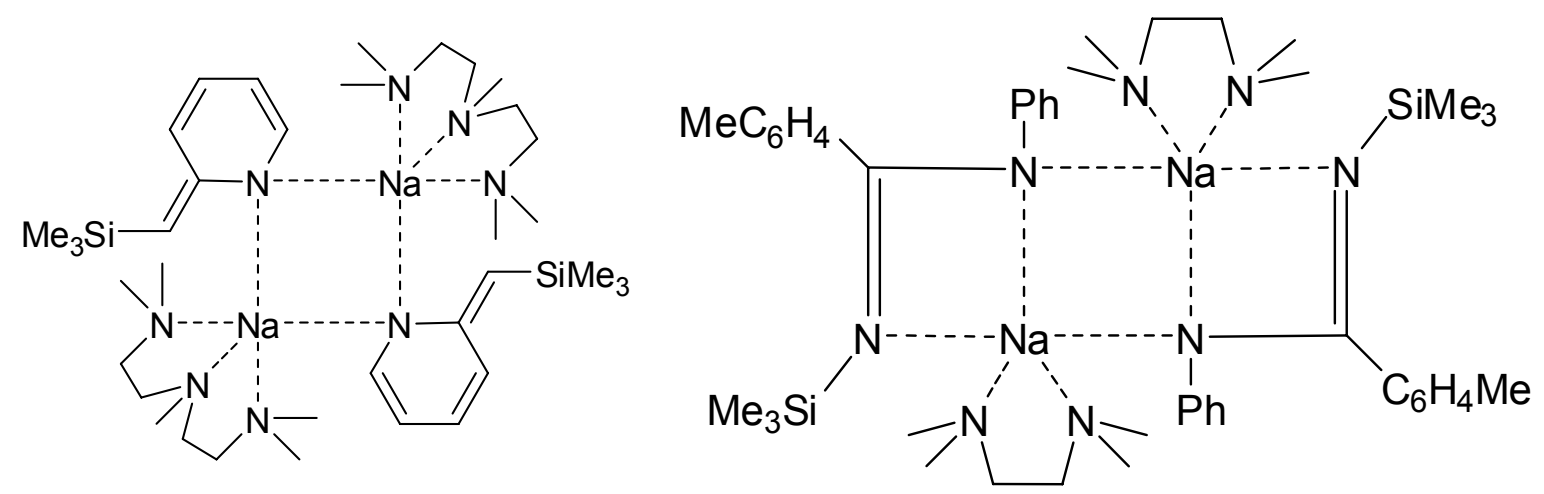

Figure 3-15: Examples for fivefold $\mathrm{N}$-coordinated sodium cations.

The coordination number five is also not preferred by sodium as is the same case for lithium. There are only a few examples reported in the literature. Raston et al. synthesised a dimeric sodium complex with a monosilylated picolyl ligand and PMDETA with the formula [(pmdeta)Na\{2-Pic(SiMe 3$) \mathrm{CH}\}]_{2}$ (Figure 3-15, left). ${ }^{[140]}$ The sodium cation is fivefold coordinated by nitrogen atoms resulting in the formation of a central planar $(\mathrm{NaN})_{2}$ four-membered ring which is similar to complex 22. Lappert et al. reported on fivefold coordinated sodium in a benzamidinato/TMEDA complex (Figure 3-15, right) in 2007 that also shows the central $(\mathrm{NaN})_{2}$ ring ${ }^{[141]}$ Apparently, 
this is a preferred arrangement with such a bidentate ligand which is quite similar to sulphur diimides.

\section{Conclusion}

To summarize the results, it can be stated that the functionalization of sulphur diimides with metalated amines is a straightforward method to generate a great variety of new ligands. They show flexibility just like the corresponding phosphorus compounds, although the amine backbone in 16 and 19 is more rigid than the $\mathrm{SCH}_{2} \mathrm{P}$ bridge in chapter 1-12. This slight disadvantage is compensated by the introduction of the TrMEDA side-arm in $\mathbf{2 1}$ which has an additional binding site for metal cations and provides a bigger coordination claw than $\mathrm{S}(\mathrm{NR})_{2}$. This result should be encouraging for the use of similar phosphorus compounds to regain the advantage of a softer donor site. The donor exchange reaction at the lithium cation in $\mathbf{1 6}$ leaves it very clear that the nitrogen side-arm is - like the phosphorus side-arms - bonding weakly. It can therefore easily be replaced by better donors for lithium metal. Thus, a free donor site in the ligand is generated, opening up the route to further coordination compounds and heterobimetallic complexes. In addition, the THF molecule itself may also be interchangeable. Interestingly, the addition of THF to a solution of $\left[\mathrm{Li}\left\{\mathrm{Me}_{2} \mathrm{PCH}_{2} \mathrm{~S}(\mathrm{~N} t \mathrm{Bu})_{2}\right\}\right]_{2}$ (1) does not lead to the replacement of the phosphorus sidearm. ${ }^{[38]}$ This is indeed surprising as the phosphorus-lithium bond in 1 (2.6425(19) $\AA$ ) is significantly longer than the N3-Li bond in $16(2.193(2) \AA)$. It has to be further investigated what the reason might be, hence the role of the substituents on the nitrogen atoms of the sulphur diimido moiety has not been determined yet.

It has also been shown that a transmetalation step does not necessarily have to be carried out with the final lithium complexes. A more elegant way is to metalate the starting materials and subsequently react them with a sulphur diimide. It has been proven that alkali metal complexes of the different ligands can be obtained by this route. It has to be further investigated now, which other metals can be introduced via this reaction pathway. Finally, it was also possible to synthesise [Li\{2$\left.\left.\mathrm{PicS}\left(\mathrm{NSiMe}_{3}\right)_{2}\right\}\right]_{2}(20)$, the analogue of $\left[\mathrm{Li}\left\{2-\mathrm{PiCS}(\mathrm{NtBu})_{2}\right\}\right]_{2}$. This ligand preserves the $\mathrm{CH}_{2}$ bridge between the sulphur atom and the side-arm. 


\section{Complexes WITH TWO SulPhUR DIIMIDO MOIETIES}

A ligand with two donating diimido groups would be a beneficial addition to this new class of compounds because it would exhibit even more donor atoms and increased flexibility as well as complexation versatility. $\mathrm{Me}_{2} \mathrm{PPh}$ was chosen as a starting material because it offers two possible $\mathrm{CH}_{2}$ bridges. However, direct metalation of both methyl groups is difficult which is due to the fact that deprotonation at one methyl group deactivates the second methyl group and the reaction gets too slow. ${ }^{[142]}$ Usually, metal-lithium exchange reactions are conducted in order to obtain $\left[\mathrm{RE}\left(\mathrm{CH}_{2} \mathrm{Li}\right)_{2}\right]$ compounds ( $\mathrm{E}=$ main group element). By this method $\left[\mathrm{MeN}\left(\mathrm{CH}_{2} \mathrm{Li}\right)_{2}\right]$ and $\left[\mathrm{Me}_{2} \mathrm{C}\left(\mathrm{CH}_{2} \mathrm{Li}\right)_{2}\right]^{[143]}$ have been prepared via tin-lithium and mercury-lithium exchange, respectively. [ $\left.\mathrm{S}\left(\mathrm{CH}_{2} \mathrm{Li}\right)_{2}\right]$ can be synthesised by tellurium-lithium exchange but is highly explosive. ${ }^{[144]}$ Strohmann et al. reported in 2010 the double deprotonation of dimethylphenylphosphine borane with $t \mathrm{BuLi}$ and $(R, R)-\mathrm{TMCDA}^{\left[{ }^{[45]}\right.}$ This reaction readily proceeds at $-30{ }^{\circ} \mathrm{C}$ which is due to stabilizing $\mathrm{Li}-\mathrm{H}$ interactions with the borane that lower the barrier for the second deprotonation to only $92 \mathrm{~kJ} / \mathrm{mol}$.

Considering all this, it was obvious that a stronger base than tBuLi had to be used if the hazardous organo-tin and organo-mercury compounds were to be avoided. Lochmann and Schlosser presented independently in the late 1960s the use and preparation of so-called superbasic mixtures. ${ }^{[42]}$ They consist of an alkali metal alkoxyde (e. g. KOR) and a lithium organic reagent $(\mathrm{Li}-\mathrm{C})$ and were therefore called LiCKOR.

To facilitate dual metalation of $\mathrm{Me}_{2} \mathrm{PPh}$, the phosphane was mixed with $\mathrm{KOtBu}$ and $t$ BuLi was slowly added drop wise at room temperature. Thereby, a superbase formed in situ, promoting deprotonation of both methyl groups. The precipitated powder was filtered, washed, suspended in pentane and $\mathrm{S}\left(\mathrm{NSiMe}_{3}\right)_{2}$ was slowly added at $-78{ }^{\circ} \mathrm{C}$. After some time several crystals, suitable for structural analysis, were obtained. Unfortunately, the yield was very low, so that no NMR spectra could be recorded. The double deprotonation probably had not completed or the ligand was partly decomposed by the superbase. The molecular structure of $\mathbf{2 3}$ is shown in Figure 4-1. The compound crystallises in the monoclinic space group $P 2_{1} / c$ with the whole molecule and one equivalent of pentane in the asymmetric unit. 


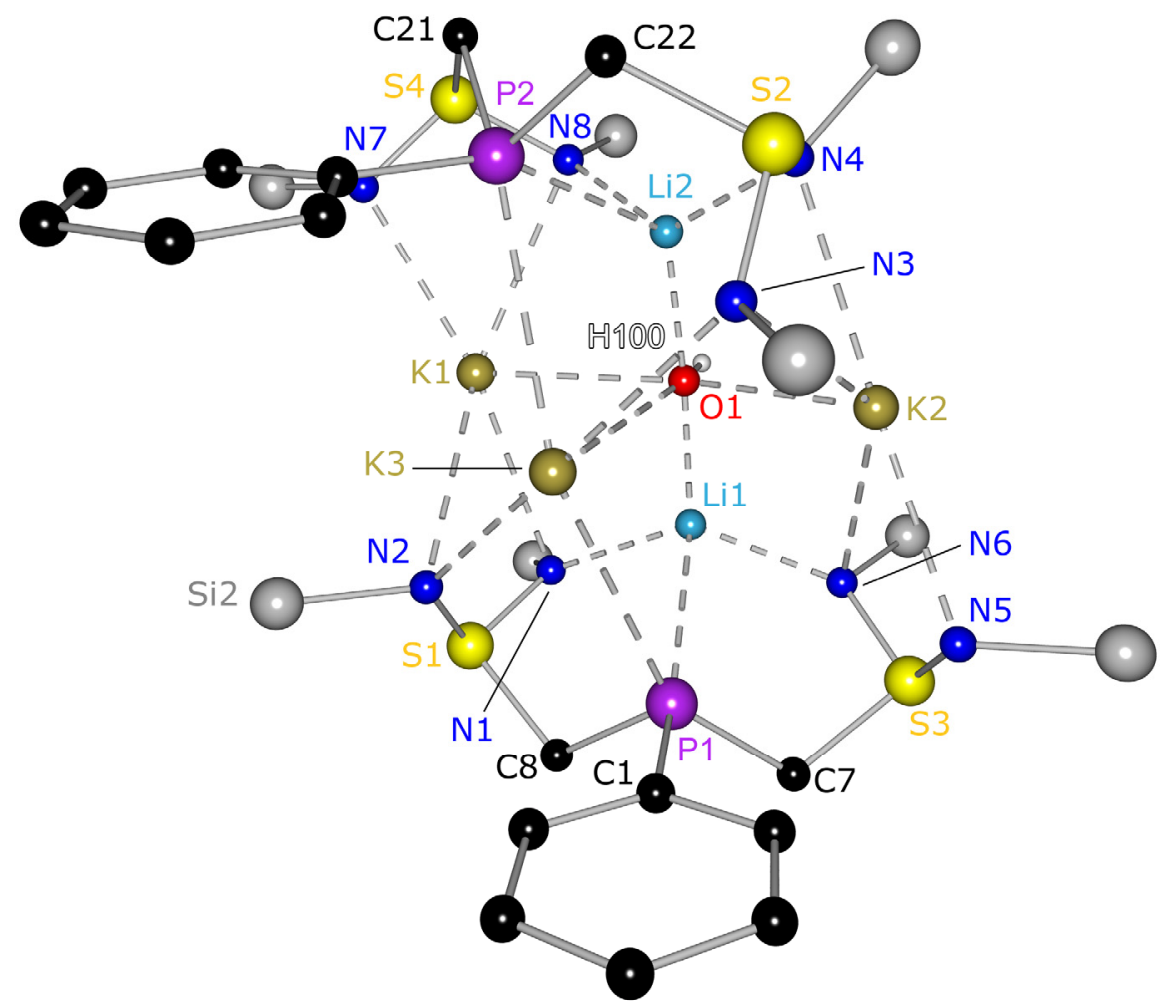

Figure 4-1: Molecular structure of $\left[\mathrm{Li}_{2} \mathrm{~K}_{3}\left\{\mathrm{PhP}\left(\mathrm{CH}_{2} \mathrm{~S}\left(\mathrm{NSiMe}_{3}\right)_{2}\right\}_{2} \mathrm{OH}\right]\right.$ (23). Hydrogen atoms and the methyl groups of the trimethylsilyl substituents are omitted for clarity.

The complex is a dimer formed by two $\left.\left\{\mathrm{PhP}\left\{\mathrm{CH}_{2} \mathrm{~S}\left(\mathrm{NSiMe}_{3}\right)_{2}\right)\right\}_{2}\right\}^{2-}$ ligands, two lithium atoms, three potassium cations and one hydroxide ion. The hydrogen position was taken from the difference Fourier map and refined freely. The two lithium monocations have the same coordination sphere. They are bound to two nitrogen atoms of two different diimido moieties, one phosphorus atom of the same ligand and the central $(\mathrm{OH})^{-}$ion. The coordination polyhedron can be describes as distorted tetrahedron with angles of $120.54(17)^{\circ}$ (P1-Li1-O1) and 133.08(19) ${ }^{\circ}$ (N1-Li1-N6).

The potassium cations have different coordination geometries. $\mathrm{K} 1$ and $\mathrm{K} 2$ are fivefold coordinated by four nitrogen atoms of two diimido moieties of both ligands and the $(\mathrm{OH})^{-}$ion in a distorted square pyramidal manner (N2-K1-01: 88.77(5) ${ }^{\circ}$, N1-K1-N7: $\left.168.82(5)^{\circ}\right)$ with the oxygen atom at the apex of the pyramid. The N5$\mathrm{K} 2-\mathrm{N} 6$ and N4-K2-N3 planes are inclined by $49.6^{\circ}$, thereby promoting the distortion. $\mathrm{K} 3$ is complexed by two nitrogen atoms, both phosphorus atoms and the hydroxide ion in a distorted square pyramidal manner. The N2-K3-N3 $\left(167.90(6)^{\circ}\right)$ and N2$\mathrm{K} 3-\mathrm{O} 1\left(84.80(5)^{\circ}\right)$ angles point that out. The oxygen atom is bridging all the metal ions in the structure with bond lengths of O1-Li1 1.920(4) $\AA$, O1-K1 2.7438(16) $\AA$ and $01-K 33.2473(18) \AA$. The bond to $K 3$ is rather long and is in the upper range for such distances. ${ }^{[68]}$ Selected bond lengths and angles can be found in Table 4-1. 
The two ligands act as pentadentate chelates with all four nitrogen and the phosphorus atom taking part in the metal coordination. Interestingly, both the hard and the soft donor sites coordinate the lithium and the potassium ions at the same time. Just N2/N7 and N3/N5 bind to potassium cations only, with bond lengths of N2K1 3.0646(18) $\AA$ and N2-K3 2.7638(18) A. N1, which is bonding to Li1 and K1, has bond lengths of $2.110(4) \AA(\mathrm{Li} 1-\mathrm{N} 1)$ and $2.8888(18) \AA(\mathrm{K} 1-\mathrm{N} 1)$, respectively. As expected, the $\mathrm{N}-\mathrm{Li}$ bond is considerably shorter than the $\mathrm{N}-\mathrm{K}$ bond. The phosphorus atoms $\mathrm{P} 1$ and $\mathrm{P} 2$ are connected to one lithium and one potassium cation, each showing bond distances of 2.655(4) $\AA$ (P1-Li1) and 3.3326(8) $\AA$ (P1-K3). Both ligand units are only slightly strained as can be seen from the angles around $C 8$ and $P 1$, which do not deviate much from the ideal tetrahedral angle, for example S1-C8-P1: 110.69(11) and C8-P1-C1: 103.58(10) .

Table 4-1: Selected bond lengths $[\AA]$ and angles $\left[^{\circ}\right]$ in 23

\begin{tabular}{llll}
\hline S1-N1 & $1.6182(18)$ & N1-S1-N2 & $108.22(9)$ \\
S1-N2 & $1.6110(17)$ & S1-C8-P1 & $110.69(11)$ \\
S1-C8 & $1.817(2)$ & C8-P1-C1 & $103.58(10)$ \\
P1-C7 & $1.841(2)$ & C1-P1-Li1 & $151.41(10)$ \\
P1-C8 & $1.849(2)$ & N1-Li1-P1 & $85.18(13)$ \\
N1-K1 & $2.8888(18)$ & N6-Li1-O1 & $114.08(18)$ \\
N2-K1 & $3.0646(18)$ & P1-Li1-O1 & $120.54(17)$ \\
N2-K3 & $2.7638(18)$ & N1-K1-N2 & $52.03(5)$ \\
N1-Li1 & $2.110(4)$ & N2-K1-O1 & $88.77(5)$ \\
N6-Li1 & $2.094(4)$ & N1-K1-N7 & $168.82(5)$ \\
O1-Li1 & $1.920(4)$ & P1-K3-P2 & $148.72(2)$ \\
P1-Li1 & $2.655(4)$ & N2-K3-N3 & $167.90(6)$ \\
P1-K3 & $3.3326(8)$ & N2-K3-O1 & $84.80(5)$ \\
O1-K3 & $3.2473(18)$ & K1-O1-K2 & $153.95(7)$ \\
O1-K1 & $2.7438(16)$ & Li1-O1-Li2 & $173.52(18)$ \\
N2-Si2 & $1.7250(18)$ & Li1-O1-K3 & $86.59(12)$ \\
\hline
\end{tabular}

It can be concluded that it is indeed possible to deprotonate $\mathrm{Me}_{2} \mathrm{PPh}$ twice with the help of the superbase $t \mathrm{BuLi} / \mathrm{KOtBu}$. This reaction still has to be investigated further to make use of it on a preparative scale. In addition, a donor base should probably be added for the crystallization in order to obtain monomeric complexes and 
to make the hydroxide ion dispensable as a crystallization template. It seems plausible that the discussed complex was only stable because of that capping ligand, which probably originates from traces of water or $(\mathrm{OtBu})^{-}$. This would also explain the very low yield in crystals. Nevertheless, a compound like $\left[\mathrm{PhP}\left(\mathrm{CH}_{2} \mathrm{~S}\left(\mathrm{NSiMe}_{3}\right)_{2} \mathrm{M}\right)_{2}\right]$ (with $\mathrm{M}=$ any alkali metal) is only feasible if donor bases are present to saturate the coordination sphere of the metal.

Known complexes in the literature with different alkaline metals in the same crystal structure are usually approaches towards novel superbases and therefore contain the $(\mathrm{OtBu})^{-}$ligand. ${ }^{[146,147]}$

In an attempt to synthesise other ligands with two diimido moieties like $\mathbf{2 3}$ with better yields, TMMDA (tetramethylmethylenediamine) was deprotonated with tBuLi according to a published procedure. ${ }^{[121]}$ The double $\alpha$-lithiation of this tertiary amine is possible because of the precoordination of $t \mathrm{BuLi}$ by the substrate as already discussed in chapter 3.1. The lithiated product was suspended in pentane and two equivalents of $\mathrm{S}(\mathrm{N} t \mathrm{Bu})_{2}$ were slowly added at $-78^{\circ} \mathrm{C}$ (Equation $\left.4-1\right)$.

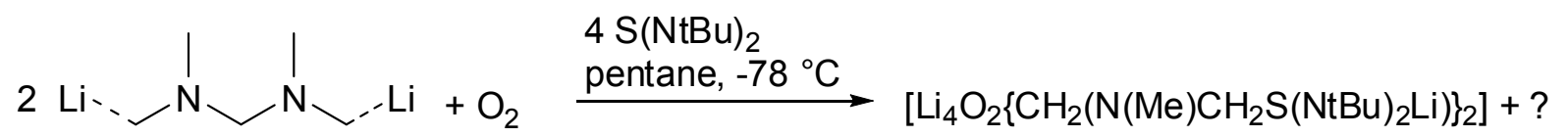
Equation 4-1: Possible preparation of $\left[\mathrm{Li}_{4} \mathrm{O}_{2}\left\{\mathrm{CH}_{2}\left(\mathrm{~N}(\mathrm{Me}) \mathrm{CH}_{2} \mathrm{~S}(\mathrm{NtBu})_{2} \mathrm{Li}\right)\right\}_{2}\right]$ (24).

After stirring over night, the suspension was filtered and the resulting light yellow solution stored at $-25^{\circ} \mathrm{C}$ for crystallization. The molecular structure of 24 is shown in Figure 4-2. Interestingly, there was oxygen incorporated into the compound. Most likely it was $\mathrm{O}_{2}$ which was still dissolved in the TMMDA as the starting material was only shortly degassed prior to use. With the same batch of amine and diimide the structure was successfully reproduced. The presence of water would probably have led to the incorporation of $\mathrm{OH}^{-}$rather than $\mathrm{O}_{2}{ }^{2-}$. However, the exact source of the oxygen remains uncertain.

The compound crystallises in the monoclinic space group $P 2_{1} / c$ as a dimeric structure with an $\mathrm{O}_{2}{ }^{2-}$ anion in the centre. The anticipated ligand $\left\{\left(\mathrm{CH}_{2}\left(\mathrm{~N}(\mathrm{Me}) \mathrm{CH}_{2} \mathrm{~S}(\mathrm{~N} t \mathrm{Bu})_{2}\right)_{2}\right\}^{2-}\right.$ has formed, with six nitrogen atoms as possible donor sites. Interestingly, there was no formation of lithium oxide, which could have been expected when $\mathrm{O}_{2}$ or moisture are present. 


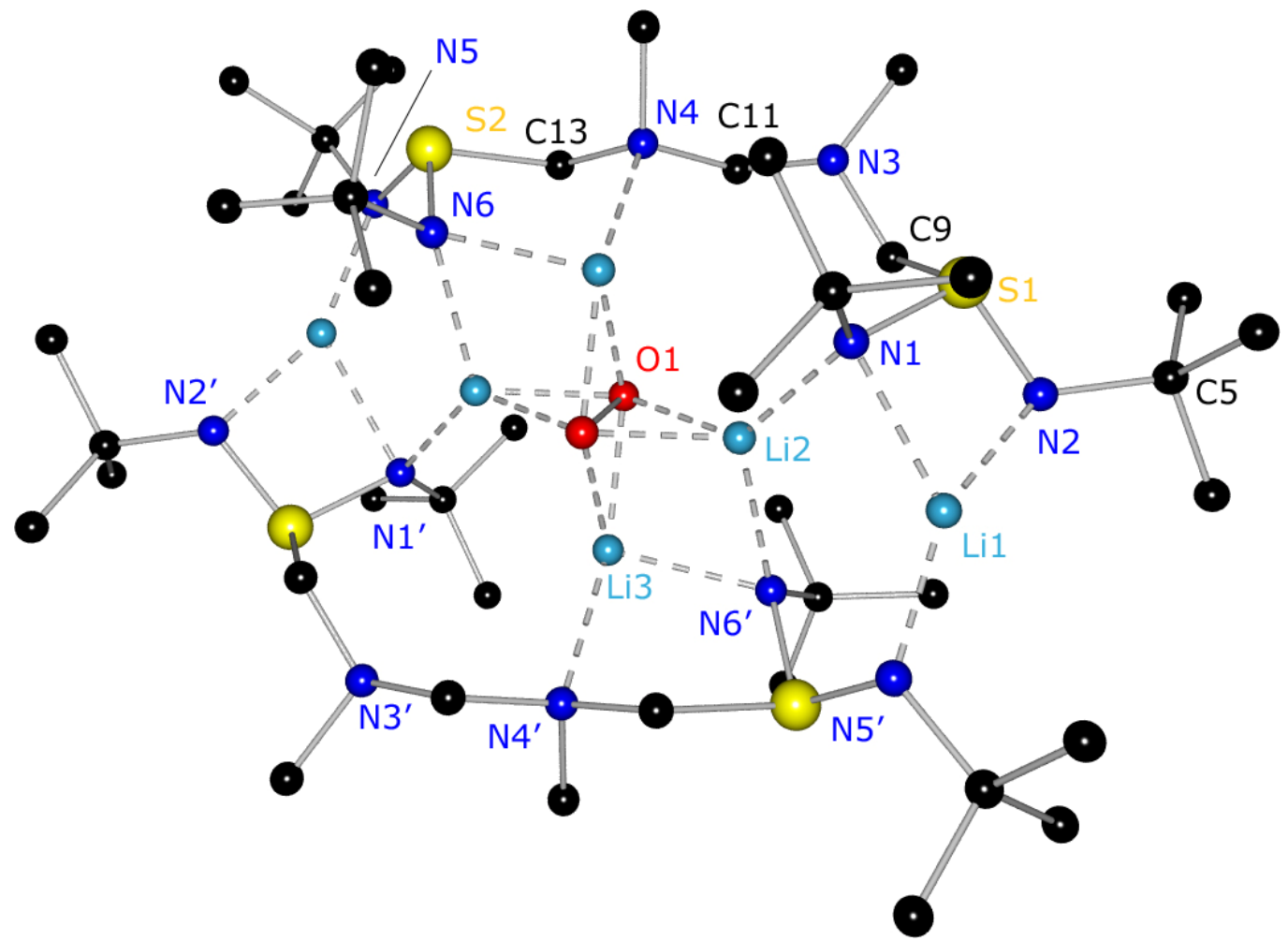

Figure 4-2: Molecular structure of $\left[\mathrm{Li}_{4} \mathrm{O}_{2}\left\{\mathrm{CH}_{2}\left(\mathrm{~N}(\mathrm{Me}) \mathrm{CH}_{2} \mathrm{~S}(\mathrm{NtBu})_{2} \mathrm{Li}\right)\right\}_{2}\right](24)$. Hydrogen atoms are omitted for clarity.

The oxygen molecule in the centre of the structure has a bond length of 1.559(3) $\AA$ and can therefore be regarded as a peroxide anion. ${ }^{[148]}$ Both oxygen atoms are connected to four lithium cations and form a star in the centre of the structure which is surrounded by two ligands and two additional lithium ions. Li2, Li2', Li3 and Li3' are coordinated by both oxygen donors with an average bond length of 1.936(4) $\AA$. This matches the value reported for $\left[\mathrm{Ph}_{4} \mathrm{Si}_{2} \mathrm{O}(\mathrm{OLiPy})_{2}\right]_{2}$ which displays $\mathrm{Li}-\mathrm{O}$ bonds of $1.943 \AA{ }^{[149]} \mathrm{Li} 2$ and Li2' are additionally coordinated by two nitrogen atoms (N1/N1', N6/N6') of two diimido substituents in two ligands. Li3 is also coordinated by N6' and by N4' which is part of the TMMDA bridge. The third lithium atom, Li1, at the edge of the complex, is only threefold coordinated by N1, N2 and N3'. There is no interconnection to neighbouring molecules. All $\mathrm{Li}-\mathrm{N}$ bond lengths range from $1.961(5) \AA$ to $2.175(9) \AA$ which is in the expected range. ${ }^{[68]}$ Thus 24 is yet another example of threefold/fourfold lithium coordination in the same structure. The N1-S1-N2 angle of $102.21(11)^{\circ}$ is more acute than in the other structures described in this thesis. In addition, the tetrahedral angle N1-S1-C9 of $100.13(11)^{\circ}$ is quite acute. Selected bond lengths and angles in comparison with the similar complex 25 can be found in Table 4-2. 
Table 4-2: Selected bond lengths $[\AA]$ and angles $\left[^{\circ}\right]$ in 24 and 25

\begin{tabular}{|c|c|c|c|c|c|}
\hline & 24 & 25 & & 24 & 25 \\
\hline $\mathrm{S} 1-\mathrm{N} 1$ & $1.643(2)$ & $1.6004(16)$ & $\mathrm{N} 1-\mathrm{S} 1-\mathrm{N} 2$ & $102.21(11)$ & $104.61(8)$ \\
\hline $\mathrm{S} 1-\mathrm{N} 2$ & $1.620(2)$ & $1.6158(15)$ & N5-S2-N6 & --- & $114.51(9)$ \\
\hline S2-N5 & --- & $1.5551(16)$ & $\mathrm{N} 1-\mathrm{S} 1-\mathrm{C} 9 / \mathrm{N} 1-\mathrm{S} 1-\mathrm{C} 7$ & $100.13(11)$ & $105.23(9)$ \\
\hline S2-N6 & --- & $1.4924(16)$ & N3-C11-N4/N3-C9-N4 & $112.36(18)$ & $112.16(14)$ \\
\hline $\mathrm{S} 1-\mathrm{C} 9 / \mathrm{S} 1-\mathrm{C} 7$ & $1.845(3)$ & $1.8337(19)$ & N1-Li1-N2/N1-Li4'-N2 & $75.57(16)$ & $75.37(12)$ \\
\hline $01-01$ & $1.557(5)$ & --- & Li1-N1-Li2/Li1-N2-Li4' & $76.82(19)$ & $75.09(13)$ \\
\hline $\mathrm{C} 11-\mathrm{O} 2$ & --- & $1.388(2)$ & N4-Li3'-N6/N2-Li1-N3 & $90.60(17)$ & $90.42(13)$ \\
\hline Li1-O1 & --- & $1.865(3)$ & O1-Li2-N1/O1-Li2-N5 & $131.0(2)$ & $136.80(18)$ \\
\hline Li2-O1 & $1.922(5)$ & $1.886(3)$ & Li2-O1-Li2‘/Li3-O2-Li3’ & $131.9(2)$ & $80.65(13)$ \\
\hline Li3-O1 & $1.987(5)$ & $1.942(3)$ & O1-Li2-O1'/O1-Li1-O2 & $48.08(13)$ & $94.19(14)$ \\
\hline Li1-N1/Li4'-N1 & $2.175(9)$ & $2.019(3)$ & Li2-O1-Li3' & $86.8(2)$ & --- \\
\hline Li1-N2/Li4'-N2 & $1.961(5)$ & $2.141(3)$ & Li2-N6'-Li3/Li3-N6-Li4 & $67.62(16)$ & $79.68(13)$ \\
\hline Li1-N5'/Li1-N3 & $1.965(5)$ & $2.101(3)$ & $\mathrm{S} 1-\mathrm{C} 9-\mathrm{N} 3 / \mathrm{S} 1-\mathrm{C} 7-\mathrm{N} 3$ & $112.46(15)$ & $113.89(12)$ \\
\hline Li2-N1/Li2-N4 & $2.021(4)$ & $2.146(3)$ & $\mathrm{S} 2-\mathrm{C} 13-\mathrm{N} 4 / \mathrm{N} 4-\mathrm{C} 11-\mathrm{O} 2$ & $114.43(15)$ & $112.86(14)$ \\
\hline Li3-N4'/Li3-O2 & $2.119(5)$ & $1.999(3)$ & S1-N2-C5/S2-N6-Li4 & $117.86(17)$ & $130.31(13)$ \\
\hline Li3-N6'/Li3-N6 & $2.128(4)$ & $2.084(3)$ & & & \\
\hline
\end{tabular}

The coordination of $\mathrm{O}_{2}{ }^{2-}$ by four metal cations in a star formation is not unknown in the literature. In 1998, Mulvey et al. presented a mixed lithium/magnesium hexamethyldisilazid that can stabilise peroxide in the centre of a four-membered ring. ${ }^{[150]}$ The resulting structural motif is the same as in $\mathbf{2 4}$, nevertheless the yield of 1-5 \% was very poor. In addition, the peroxide ion was disordered with an oxide ion. Compounds of that sort were dubbed 'inverse crown complexes' in comparison to crown ethers. ${ }^{[151]}$ These molecules contain various oxygen donor sites and are cyclic ethers which can accommodate metal cations of the appropriate shape in the centre. 24 as well as the lithium/magnesium hexamethyldisilazide act with inverted sign. They are cyclic compounds with metal ions bonded in the ring periphery which can coordinate matching anions like peroxide, oxide, ${ }^{[150]}$ hydrides ${ }^{[152]}$ or even larger molecules like ferrocene. ${ }^{[53]}$ In essence, the Lewis basic sites have been exchanged for Lewis acids. With this substance class, the stabilization of unusual anions as well as deprotonation reactions are feasible that are otherwise thermodynamically hindered. One example is the 2,5-deprotonation of toluene to form $\left(\mathrm{C}_{6} \mathrm{H}_{3} \mathrm{CH}_{3}\right)^{2-}$ where the more acidic methyl group is left intact (Figure 4-3). ${ }^{[153]}$ 


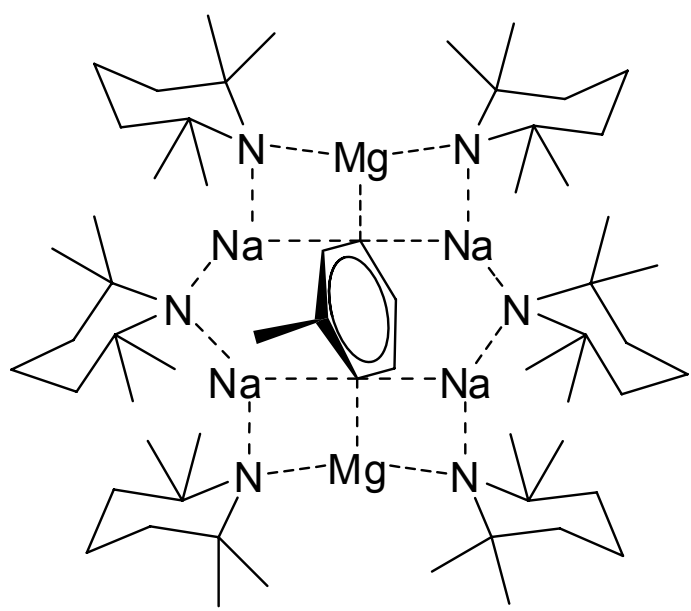

Figure 4-3: Structure of $\left[\mathrm{Na}_{4} \mathrm{Mg}_{2}(\operatorname{tmp})_{6}\left(\mathrm{C}_{6} \mathrm{H}_{3} \mathrm{CH}_{3}\right)\right]$, (tmp = 2,2,6,6-tetramethylpiperidine). ${ }^{[153]}$

This phenomenon is probably due to the position of the magnesium atoms in the ring and presents a great advantage over $n$ BuLi/TMEDA. This mixture is only able to deprotonate toluene twice in a random and unpredictable way. ${ }^{[154]}$ It has to be considered, however, that most of the reported structures of 'inverse crowns' so far contain two different metals in the ring which leads to synergistic effects and the ring itself is only held together by amides.

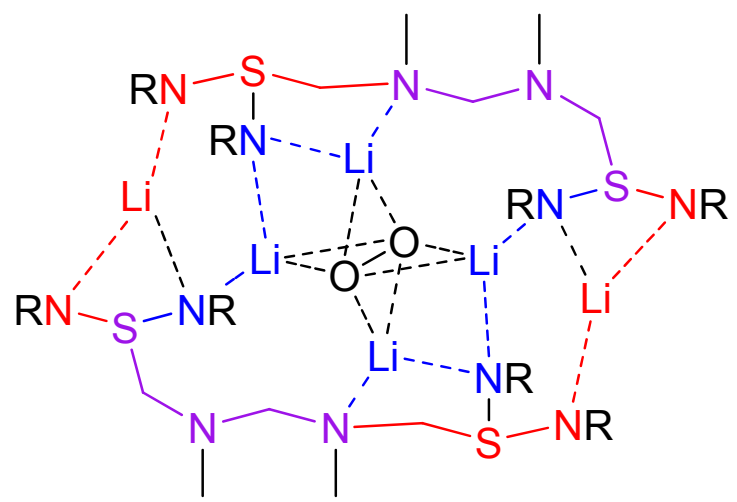

Figure 4-4: 'Ring in the ring' structure; blue: inner ring, red: outer ring, purple: part of both rings.

With this concept in mind it is noteworthy that 24 contains different heteroatoms in the ring and can be regarded as a 'ring in the ring' system. There is an outer 20-membered ring of the two ligands which are connected by two lithium atoms, Li1 and Li1'. The inner ring is consisting of 18 atoms and is directly coordinating the peroxide dianion (Figure 4-4).

In analogy to 24, the reaction of lithiated TMMDA with $\mathrm{S}\left(\mathrm{NSiMe}_{3}\right)_{2}$ was performed to yield $\left[\mathrm{Li}_{4}\left\{\left(\mathrm{NSiMe}_{3}\right)_{2} \mathrm{SCH}_{2} \mathrm{~N}(\mathrm{Me}) \mathrm{CH}_{2} \mathrm{~N}(\mathrm{Me}) \mathrm{CO}\right\}\left\{\mathrm{NSN}\left(\mathrm{SiMe}_{3}\right)\right\}(\mathrm{OtBu})\right]_{2}$ (25). In this 
reaction, the desired ligand was only formed in small yield as heavy ligand scrambling occurred. One ligand can be described with the formula $\left\{\left(\mathrm{Me}_{3} \mathrm{SiN}\right)_{2} \mathrm{SCH}_{2} \mathrm{~N}(\mathrm{Me}) \mathrm{CH}_{2} \mathrm{~N}(\mathrm{Me}) \mathrm{CH}_{2}(\mathrm{O})\right\}^{2-}$ (L1). Another ligand is $\left\{\mathrm{Me}_{3} \mathrm{SiNSN}\right\}^{-}$(L2) which originates from a sulphur diimide after $\mathrm{N}-\mathrm{Si}$ bond cleavage. The third ligand is $\{\mathrm{OtBu}\}^{-}$(L3) which is disordered with $\left\{\mathrm{OSiMe}_{3}\right\}^{-}(27 \%$ vs. $73 \%)$, with the trimethylsilyl group originating from the cleaved diimide and the tert-butyl group from the utilized tBuLi. It becomes clear with this structure in mind that the starting material was indeed contaminated with oxygen (see Figure 4-5).

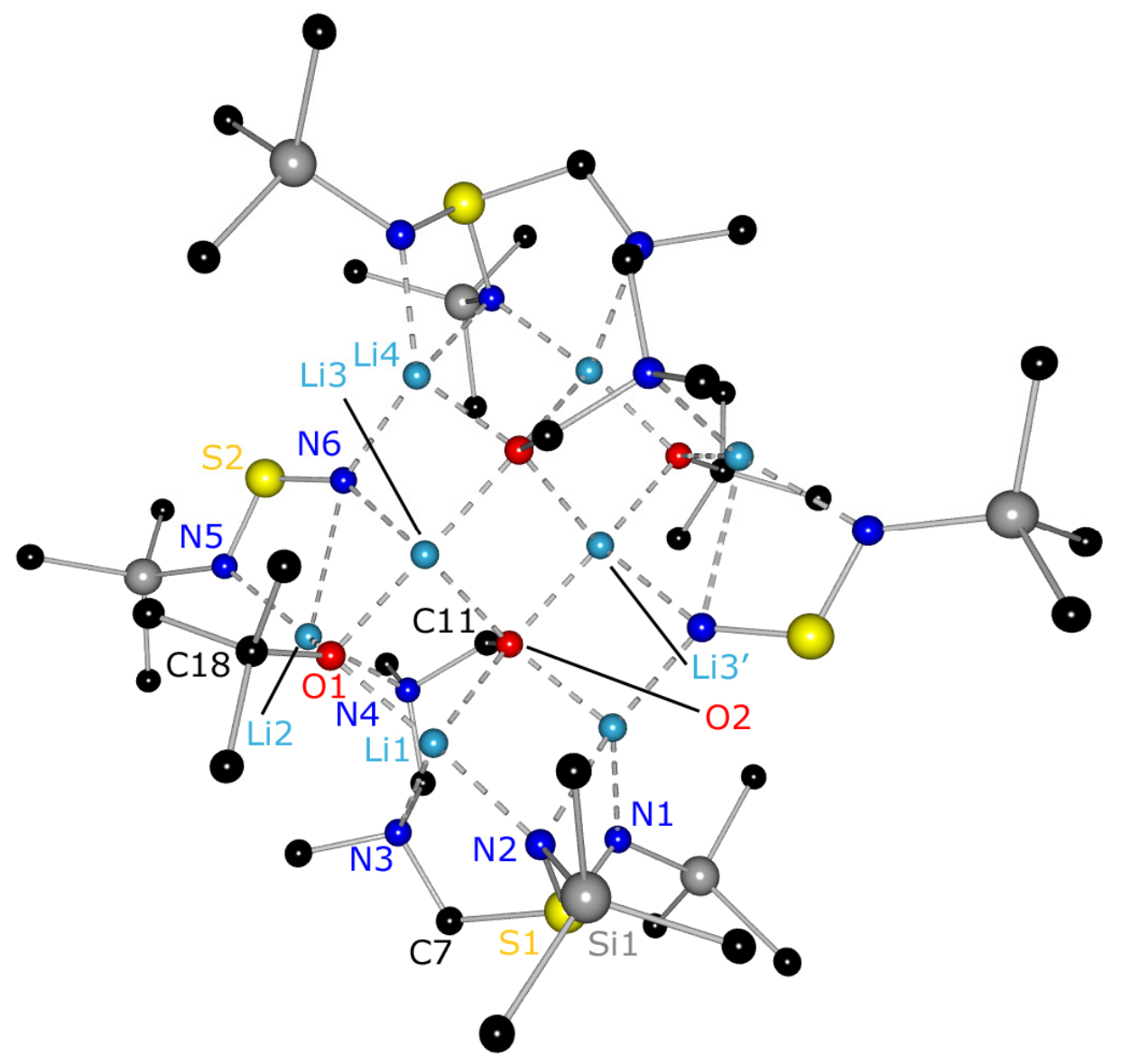

Figure 4-5: Molecular structure of $\left[\mathrm{Li}_{4}\left\{\left(\mathrm{NSiMe}_{3}\right)_{2} \mathrm{SCH}_{2} \mathrm{~N}(\mathrm{Me}) \mathrm{CH}_{2} \mathrm{~N}(\mathrm{Me}) \mathrm{CO}\right\}\left\{\mathrm{NSN}\left(\mathrm{SiMe}_{3}\right)\right\}(\mathrm{OtBu})\right]_{2}$ (25). Hydrogen atoms are omitted for clarity.

In addition, the reactivity of the lithiated amine seems to be too high for $\mathrm{S}\left(\mathrm{NSiMe}_{3}\right)_{2}$ as it is partially cleaved during the reaction. Even lower temperatures than $-78^{\circ} \mathrm{C}$ should be employed during the synthesis to avoid this.

There are eight lithium cations in the structure that are coordinated in four different ways. Li1 is distorted tetrahedrally coordinated by two nitrogen atoms and one oxygen atom of $\mathbf{L} 1$ as well as by the $\mathrm{OtBu}^{-}$anion. The $\mathrm{N}-\mathrm{Li}$ and $\mathrm{O}-\mathrm{Li}$ bonds do not show any unusual values. Both the N2-Li1-N3 $\left(90.42(13)^{\circ}\right)$ and O1-Li1-O2 
$\left(94.19(14)^{\circ}\right)$ angles are close to $90^{\circ}$. The coordination geometry of Li2 can be described as a trigonal pyramid. The base is formed by O1, N4 and N5 (O1-Li2-N5: $136.80(18)^{\circ}$ ) with $\mathrm{N} 6$ at the apex. Li3 is distorted tetrahedrally coordinated by three oxygen atoms $\mathrm{O} 1, \mathrm{O} 2$ and $\mathrm{O} 2$ ' and by N6. Consequently, it is interconnecting both halves of the dimer. Li4 on the other hand is coordinated by the diimido nitrogen atoms N1' and N2' of L1, N6 and O2' in a distorted tetrahedral manner. In that way, the centre of the structure is consisting of seven four-membered rings which are interconnected.

The bond lengths in the two diimido ligands L1 and L2 differ considerably. While N1-S1 (1.6004(16) $\AA$ ) and N2-S1 (1.6158(15) $\AA$ ) are in the typical range for diimido sulfinates, N5-S2 (1.5551(16) $\AA$ ) and N6-S2 (1.4924(16) $\AA$ ) are significantly shorter. Generally speaking, the bond lengths and angles in L1 are almost the same as in the corresponding ligand in $\mathbf{2 4}$.

To summarize the results, it has to be acknowledged that it is possible to link two sulphur diimides by a diamino bridge. Nevertheless, if the synthetic route according to Equation 4-1 is employed, anions are needed to balance the electron deficiency. Especially 24 seems to be an excellent oxygen scavenger as even the degassing of the reactants leads to high yields of the peroxide containing complex. However, these new ligands show the versatility of the sulphur diimido moiety and its value in ligand design.

\section{Conclusion}

All new complexes that have been presented so far, arranged in their different categories, are depicted in Figure 4-6. The functionalization of sulphur diimides with donor-containing side-arms was achieved. These can be modified regarding their steric bulk and the HSAB hardness of the donor. The electronic properties of the ligand can be tuned by the choice of the sulphur diimide. Thus, the different building units can be combined to synthesise the ligand of choice. Through this modularity different coordination modes can be achieved, e. g. $\left[\mathrm{Li}\left\{\mathrm{Me}_{2} \mathrm{~N}\left(\mathrm{C}_{6} \mathrm{H}_{4}\right) \mathrm{S}\left(\mathrm{NSiMe}_{3}\right)_{2}\right\}\right]_{2}$ (16) and [(tBuN $\left.)_{2} \mathrm{~S} \cdot\left\{\mathrm{LiMe}_{2} \mathrm{~N}\left(\mathrm{C}_{6} \mathrm{H}_{4}\right) \mathrm{S}(\mathrm{N} t \mathrm{Bu})_{2}\right\}_{2}\right]$ (19). Additionally, the phosphorus atom can be oxidised with oxygen $(12,13)$, sulphur $(8)$ or selenium $(9)$ in order to modify the coordination claw. By choice of the right reaction conditions, the free ligand (10) and a monomeric complex (11) can be synthesised which are promising precursors for metalation reactions. It could also be shown that the side-arms are weakly 
bonding in solution and can be exchanged by better donors (17), proving the hemilability of the system.

The connection of two sulphur diimides with TMMDA yields multidentate complexes that are reminiscent of inverse crown complexes.

Metal exchange reactions of the lithiated amines with alkali metal tertbutoxides give access to interesting coordination compounds. It seems that the adaption of the ligands to different ionic radii is unproblematic and stable complexes of lithium, sodium and potassium are formed. 


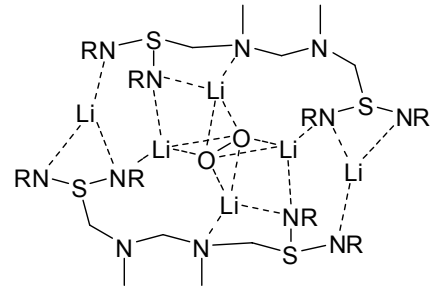

(24)

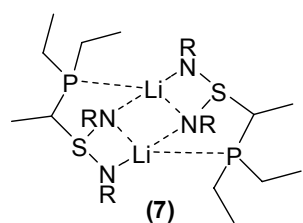

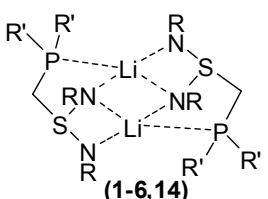

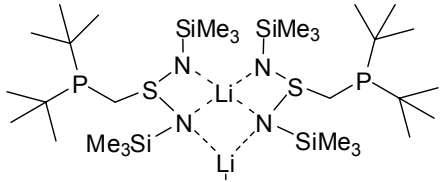<smiles>CC(C)(C)P(C)(=O)C(C)(C)C</smiles>

(13)

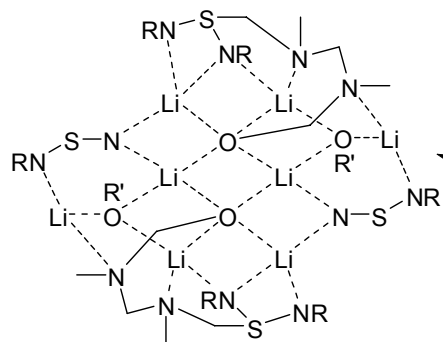

(25)
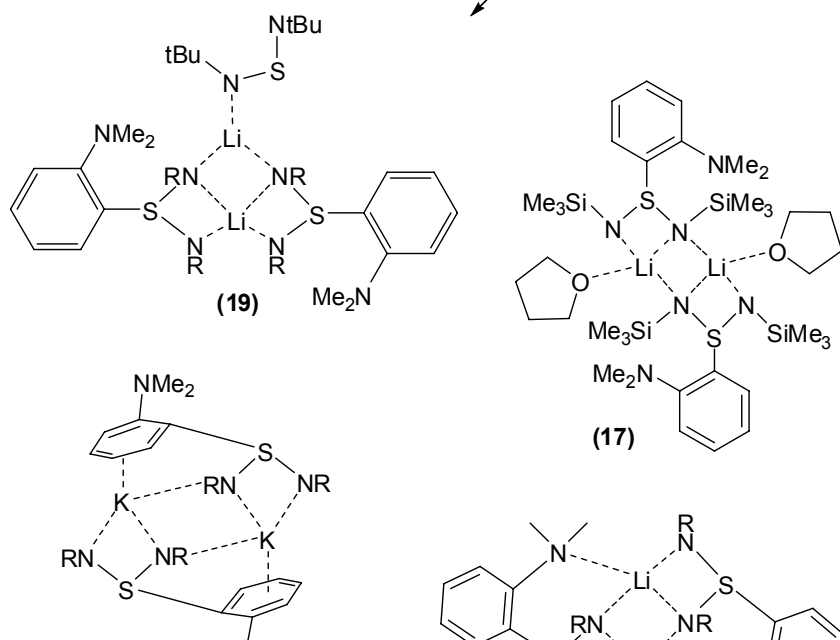

(18) $\mathrm{Me}_{2} \mathrm{~N}$

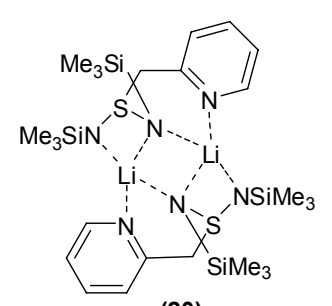

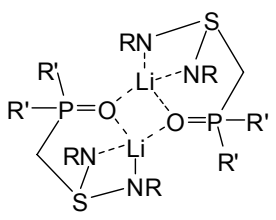

(12)

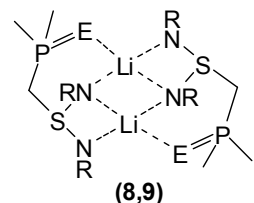

$(8,9)$

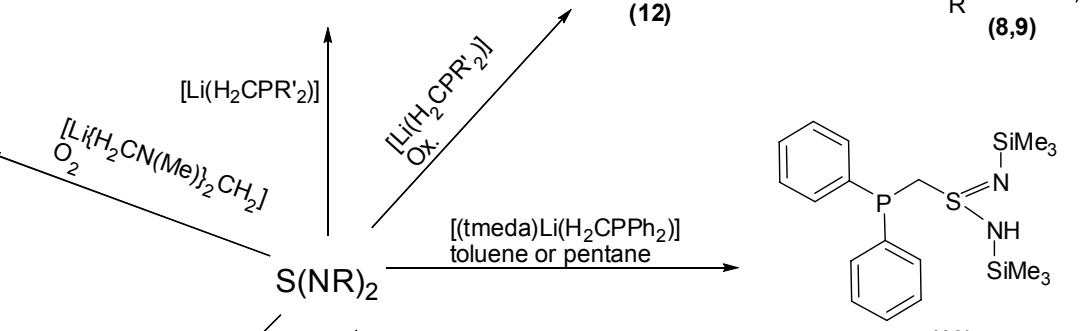

(10)

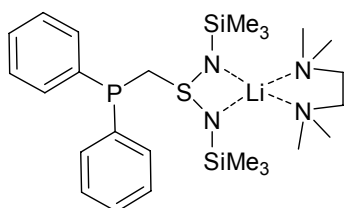

(11)
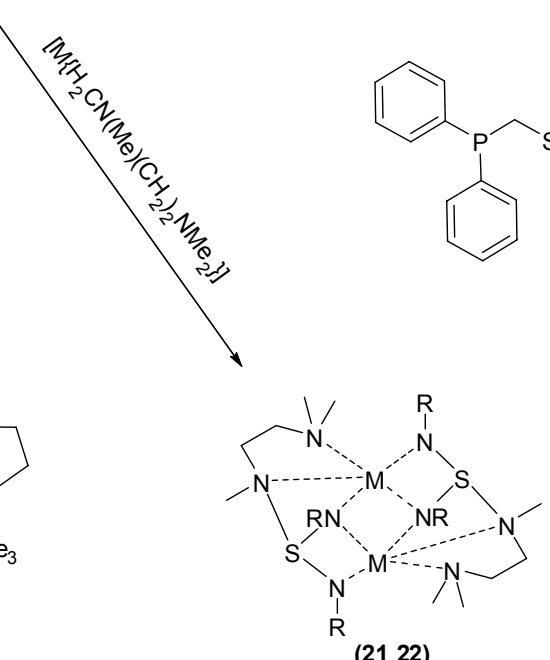

(17)

$(21,22)$

(20)

Figure 4-6: Novel sulphur diimido complexes with (potential) side-arm donation; $R=t \mathrm{Bu}, \mathrm{SiMe}_{3} ; \mathrm{R}^{\prime}=$ $\mathrm{Me}, \mathrm{Ph}$. 


\section{From main Group to Transition Metals}

\subsection{Monometallic Complexes}

The lithium complexes discussed in the previous chapters have demonstrated the flexibility and versatility of this class of new hemilabile Janus head ligands. It would now be of interest to promote metal exchange reactions to explore their full complexation potential. Cations, dications as well as main group and transition metals were employed in order to get a broad overview.

Direct transmetalation of the lithium dimers with metal halides was successful in the case of $\mathrm{MgCl}_{2}$ only. The ineptness for metal halides in general for such reactions with sulphur diimido compounds has already been discussed above. The use of $\mathrm{MgCl}_{2}$ was probably successful because of the diagonal relationship to lithium.

Unfortunately, $\mathrm{Ph}_{2} \mathrm{PCH}_{2} \mathrm{~S}\left(\mathrm{NSiMe}_{3}\right)\left(\mathrm{HNSiMe}_{3}\right)$ has a long crystallization time of months rather than weeks. Therefore, it is not a good starting material. A substance would be preferred that can be synthesised in reasonable time. Therefore, another method or starting material had to be found. As already discussed concerning the NSCP ligands, another reaction to obtain the desired metal-free ligands is not feasible - transmetalation is inevitable. It should be possible to transmetalate lithium diimido complexes if the lithium metal is already precoordinated by another donor. This principle is quite intuitive as the lithium cation is not coordinated as firmly and can be removed easier. With this in mind, [(tmeda) $\left.L i\left\{\mathrm{Ph}_{2} \mathrm{PCH}_{2} \mathrm{~S}\left(\mathrm{NSiMe}_{3}\right)_{2}\right\}\right]$ (11) should be a good starting point, as the lithium atom is not only complexed by the diimido nitrogen atoms but as well by a TMEDA molecule. In addition, 11 can be prepared in high purity as well as in reasonable yield and time.

\subsubsection{Alkaline Earth Metals}

Because of the diagonal relationship to lithium, magnesium was the first metal to be employed in a salt elimination reaction. Although the use of metal halides for such syntheses is sometimes problematic with sulphur diimide derivatives because of their redox-activity, ${ }^{[58]}$ the reaction of 1 with $\mathrm{MgCl}_{2}$ in a 1:1 molar ratio afforded the spirocyclic species [Mg\{ $\left.\left.\mathrm{Me}_{2} \mathrm{PCH}_{2} \mathrm{~S}(\mathrm{~N} t \mathrm{Bu})_{2}\right\}_{2}\right]$ (26) according to Equation 5-1. 


$$
\mathrm{MgCl}_{2}+\left[\mathrm{Li}\left\{\mathrm{Me}_{2} \mathrm{PCH}_{2} \mathrm{~S}(\mathrm{NR})_{2}\right\}\right]_{2} \stackrel{\text { pentane, }-78{ }^{\circ} \mathrm{C}}{-2 \mathrm{LiCl}}
$$

Equation 5-1: Preparation of $\left[\mathrm{Mg}\left\{\mathrm{Me}_{2} \mathrm{PCH} \mathrm{CH}_{2} \mathrm{~S}(\mathrm{NR})_{2}\right\}_{2}\right] ; \mathrm{R}=t \mathrm{Bu}(\mathbf{2 6}), \mathrm{R}=\mathrm{SiMe}_{3}(27)$.

The formation of this magnesium complex demonstrates that the new Janus head ligands are valuable multidentate chelating ligands due to the intramolecular phosphane donor site held in close spatial proximity to the functional imido groups. Complex 26 crystallises at $4{ }^{\circ} \mathrm{C}$ from pentane as colourless plates in the orthorhombic space group Fdd2 (Figure 5-1) with half a molecule in the asymmetric unit.

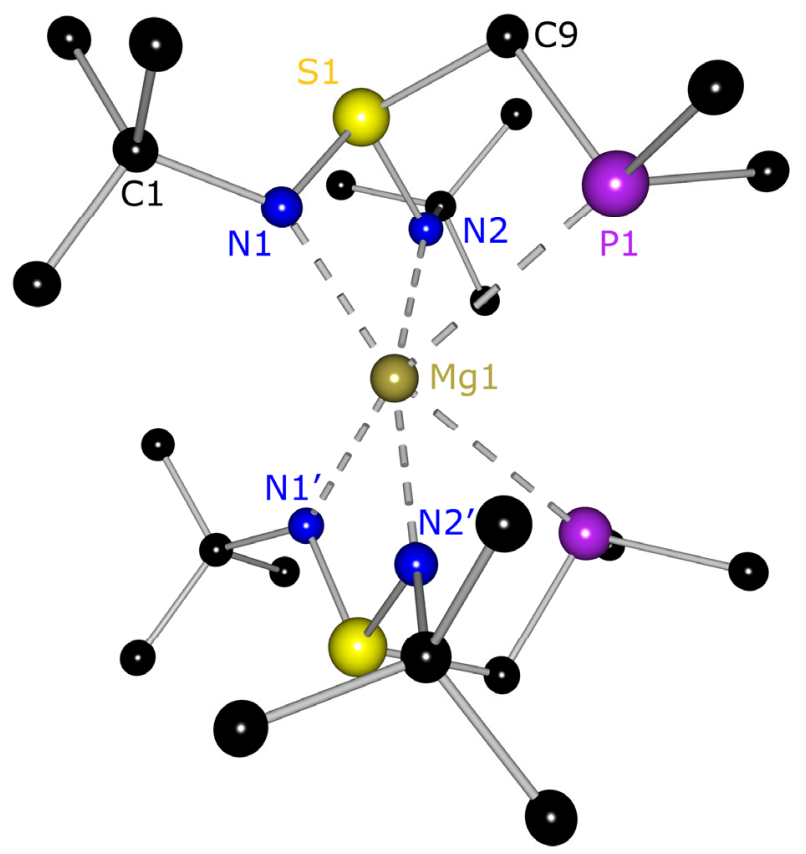

Figure 5-1: Molecular structure of $\left[\mathrm{Mg}\left\{\mathrm{Me}_{2} \mathrm{PCH}_{2} \mathrm{~S}(\mathrm{NtBu})_{2}\right\}_{2}\right]$ (26). Hydrogen atoms are omitted for clarity.

As the compound undergoes a destructive phase transition at about $220 \mathrm{~K}$ the X-ray data set had to be collected at $-23^{\circ} \mathrm{C}$ (Figure 5-2). The marked reflex clearly indicates a splitting of the crystal between 219 and $207 \mathrm{~K}$. In order to get a data set that would be resolved better, it should be tried to crystallise the compound at a temperature which lies below the phase transition barrier. 

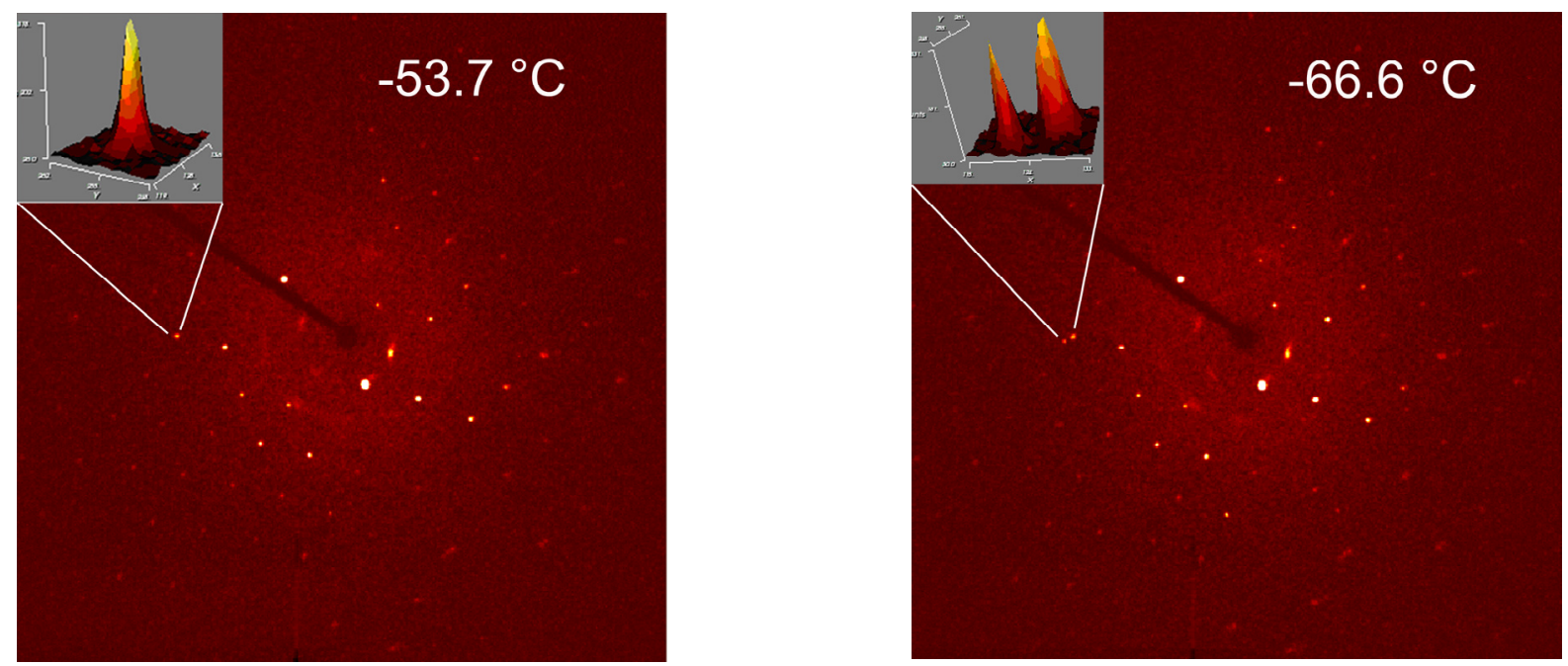

Figure 5-2: Diffraction pattern of a single crystal of $\left[\mathrm{Mg}\left\{\mathrm{Me}_{2} \mathrm{PCH}_{2} \mathrm{~S}(\mathrm{NtBu})_{2}\right\}_{2}\right](26)$ at different temperatures and in the same orientation.

The monomeric structure shows a distorted octahedral geometry at the central magnesium dication. The molecule has a crystallographically imposed twofold symmetry with the magnesium atom located at the twofold axis. It is coordinated by two nitrogen atoms and one phosphorus atom of each phosphane side-arm as a five membered chelating ring with bite angles of $74.24(8)^{\circ}(\mathrm{N} 1-\mathrm{Mg} 1-\mathrm{P} 1)$ to $70.82(8)^{\circ}$ (N2-Mg1-P1). This means that the NSCP ligand behaves in a tridentate manner, thus demonstrating tripodal donation by means of two terminal nitrogen atoms and side-arm donation by the phosphorus atom.

Coordination of the magnesium atom shows $\mathrm{Mg}-\mathrm{N}$ distances in the range of $2.102(2) \AA$ to $2.138(2) \AA$. These values are similar to those reported for compounds containing a sulphur-bonded imido nitrogen donor $(2.035-2.295 \AA){ }^{[34,69]}$ The $\mathrm{Mg}-\mathrm{N}$ bond distances are marginally longer than in $\left[\mathrm{Mg}\left\{\left(\mathrm{NSiMe}_{3}\right)_{2} \mathrm{SN}\left(\mathrm{SiMe}_{3}\right)_{2}\right\}_{2}\right]$ (2.0592(6) $\AA$ ), probably because in that complex side-arm donation is hindered due to steric reasons. ${ }^{[155]}$ The Mg-P bond length is not consistent with the predicted covalent value $(2.65 \AA)$. The distance of $2.9855(13) \AA$ is elongated in comparison to $\mathrm{Mg}-\mathrm{P}$ distances in mononuclear and dinuclear magnesium phosphanides e. $g$. $\left[\mathrm{BuMg}\left\{\mathrm{P}\left(\mathrm{CH}\left(\mathrm{SiMe}_{3}\right)_{2}\right)\left(\mathrm{C}_{6} \mathrm{H}_{4}-2-\mathrm{OMe}\right)\right\}\right]_{2} \quad(2.5760(8) \AA$ and $2.5978(8) \AA) \quad$ or $\left[\mathrm{Mg}\left\{\mathrm{P}\left(\mathrm{CH}\left(\mathrm{SiMe}_{3}\right)_{2}\right)\left(\mathrm{C}_{6} \mathrm{H}_{4}-2-\mathrm{CH}_{2} \mathrm{NMe}_{2}\right)\right\}\right]_{2}(2.556(1) \AA) .{ }^{[156]}$ This elongation of the Mg$\mathrm{P}$ bond distance is attributed to the side-arm donation of a phosphane rather than coordination of a phosphanide. $\mathbf{2 6}$ is therefore closer related to $\left[\mathrm{Mg}\left\{\left(\mathrm{C}_{6} \mathrm{H}_{3}\right)\left(\mathrm{H}_{2} \mathrm{CPMe}_{2}\right)_{2}\right\}_{2}\right]$ which displays $\mathrm{Mg}-\mathrm{P}$ bond lengths of $2.770(1) \AA$ and 2.761(1) $\AA .{ }^{[157]}$ With a different central metal, it would be possible to reversibly cleave the metal-phosphorus-bond to generate a pendent donor site for other softer metal 
cations. The $\mathrm{N}-\mathrm{S}-\mathrm{N}$ bond angle $\left(97.43(12)^{\circ}\right)$ is more acute than in 1 and those in alkali metal derivatives $\left(104.2-110.7^{\circ}\right)$, but covers almost the same range as in comparable compounds with $\mathrm{Mg}^{2+}$ or other dicationic metals $\left(97.6-98.9^{\circ}\right) .{ }^{[82,155,158]}$ This can be attributed to the higher charge of the magnesium dication, leading to a stronger repulsion between the positively charged sulphur atom and the metal ion. Selected bond lengths and angles of 26 compared to [ $\left.\mathrm{Mg}\left\{\mathrm{Me}_{2} \mathrm{PCH}_{2} \mathrm{~S}\left(\mathrm{NSiMe}_{3}\right)_{2}\right\}_{2}\right]$ (27) can be found in Table 5-1.

Table 5-1: Selected bond lengths $[\AA]$ and angles $\left[^{\circ}\right]$ in 26 and 27

\begin{tabular}{|c|c|c|c|c|c|}
\hline & 26 & 27 & & 26 & 27 \\
\hline S1-N1 & $1.617(2)$ & $1.6123(8)$ & $\mathrm{N} 1-\mathrm{S} 1-\mathrm{N} 2$ & $97.43(12)$ & $100.44(4)$ \\
\hline $\mathrm{S} 1-\mathrm{N} 2$ & $1.622(2)$ & $1.6111(8)$ & $\mathrm{S} 1-\mathrm{C} 9 / \mathrm{P} 1-\mathrm{C} 7$ & $108.24(16)$ & $107.75(5)$ \\
\hline $\mathrm{P} 1-\mathrm{C} 9 / \mathrm{C} 7$ & $1.838(4)$ & $1.8481(10)$ & N1-Mg1-N2 & $70.07(9)$ & $70.81(3)$ \\
\hline $\mathrm{S} 1-\mathrm{C} 9 / \mathrm{C} 7$ & $1.838(4)$ & $1.8263(10)$ & N1-Mg1-P1 & $74.24(8)$ & $72.54(2)$ \\
\hline Mg1-N1 & $2.102(2)$ & $2.1481(8)$ & N1-Mg1-P1'/P2 & $163.71(8)$ & $100.47(2)$ \\
\hline $\mathrm{Mg} 1-\mathrm{N} 2$ & $2.138(2)$ & $2.1276(8)$ & N2-Mg1-P1'/P2 & $98.35(8)$ & $163.15(2)$ \\
\hline Mg1-P1 & $2.9855(13)$ & $2.8570(4)$ & N2-Mg1-N2' & $164.93(17)$ & --- \\
\hline N1-C1/Si1 & $1.481(4)$ & $1.7237(8)$ & N1-Mg1-N4 & --- & $169.95(3)$ \\
\hline
\end{tabular}

The magnesium complex [Mg\{ $\left.\left.\mathrm{Me}_{2} \mathrm{PCH}_{2} \mathrm{~S}\left(\mathrm{NSiMe}_{3}\right)_{2}\right\}_{2}\right]$ (27) was equally isolated from a transmetalation reaction of 4 with $\mathrm{MgCl}_{2}$ in equimolar ratio. Unlike compound 26 which undergoes a phase transition at about $220 \mathrm{~K}, 27$ is stable when cooled to $100 \mathrm{~K}$. The complex crystallises at $-25^{\circ} \mathrm{C}$ from pentane as colourless blocks in the monoclinic space group $P 2_{1} / n$ and the structure is monomeric. The phosphane diimido moiety is attached to the magnesium atom in a tripodal fashion involving donation from two terminal nitrogen atoms and the side-arm donation from the phosphorus atom (Figure 5-3). In the solid state the central magnesium atom in 27 approximately adopts an octahedral coordination polyhedron, consisting of two phosphorus and four nitrogen atoms of two ligands. The structural motif is the same as in the magnesium compound 26 . Selected bond lengths and angles in comparison with the latter can be found in Table 5-1. 


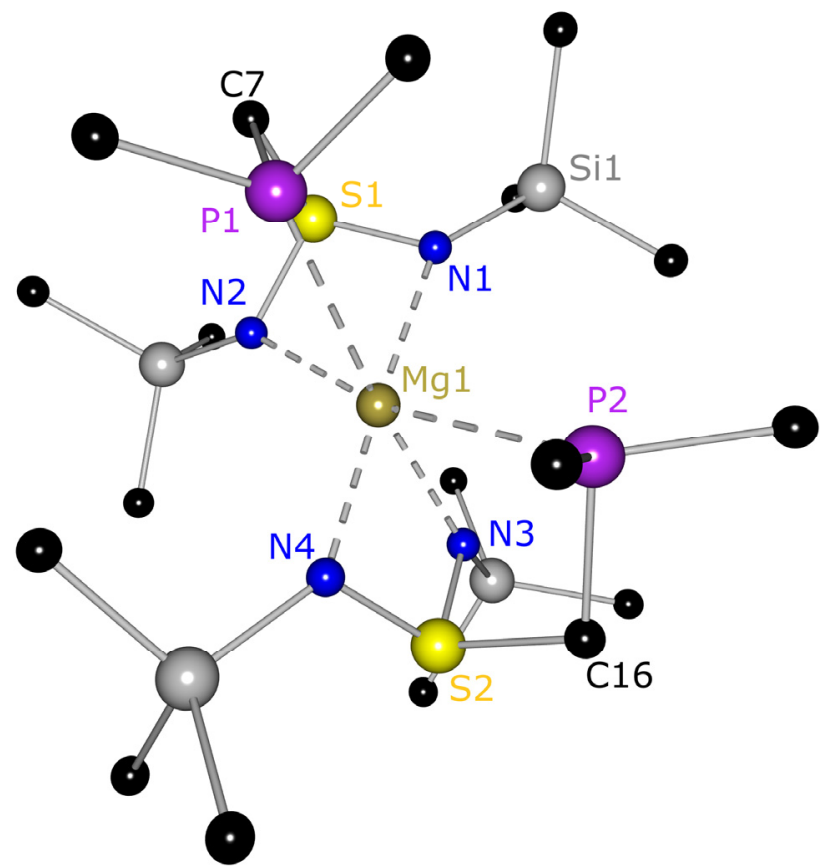

Figure 5-3: Molecular structure of $\left[\mathrm{Mg}\left\{\mathrm{Me}_{2} \mathrm{PCH}_{2} \mathrm{~S}\left(\mathrm{NSiMe}_{3}\right)_{2}\right\}_{2}\right](27)$. Hydrogen atoms are omitted for clarity.

The synthesis of the magnesium complexes 26 and 27 has proven that two NSCP ligands have the ability to complex small dications in a hexadentate manner. Consequently, it was of interest what coordination geometry would be adapted by a larger dication. For comparison reasons, the heavier homologues calcium and strontium were employed. Unfortunately, it was only possible to obtain crystals of the two magnesium complexes via the salt elimination route. The use of other metal halides did not yield the desired products. Therefore the second route transmetalation of $\mathbf{1 1}$, where the lithium atom is already precoordinated - was pursued.

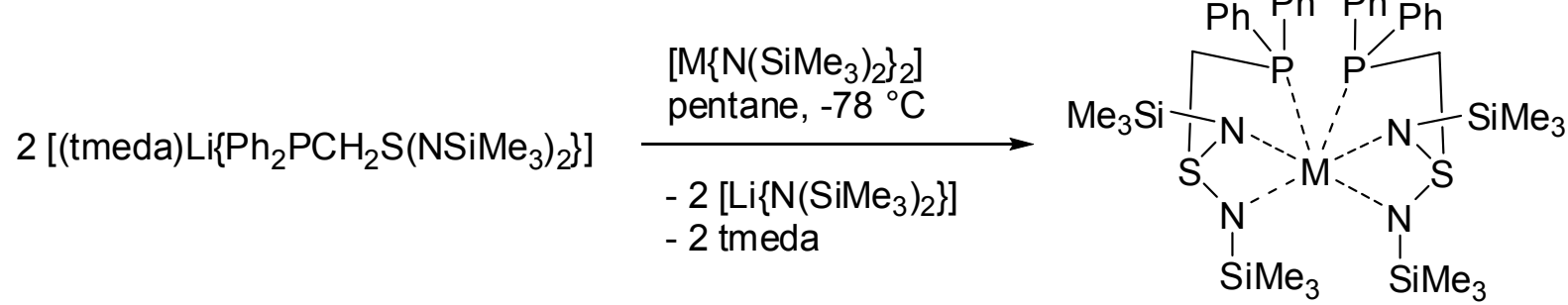

Equation 5-2: Preparation of metal complexes $\left[\mathrm{M}\left\{\mathrm{Ph}_{2} \mathrm{PCH}_{2} \mathrm{~S}\left(\mathrm{NSiMe}_{3}\right)_{2}\right\}_{2}\right], \mathrm{M}=\mathrm{Ca}, \mathrm{Sr}, \mathrm{Co}, \mathrm{Fe}$.

$\beta$-diketiminato-calcium complexes are known to catalyse hydroamination and hydrophosphination reactions of alkenes and alkynes or carbodiimides. ${ }^{[159]}$ This addition of the $\mathrm{P}-\mathrm{H}$ bond of a primary or a secondary phosphane can also be promoted by trivalent lanthanide catalysts or transition metals. The catalytic activity of alkaline earth metals is thus not unknown in the literature. Benzyl alkaline earth 
metals are precatalysts for the hydrosilylation of alkenes. ${ }^{[160]}$ Calcium has the advantage over many other metals to be readily available, cheap and non-toxic which is most advantageous if it is to be used in polymerization reactions. This has e. $g$. been studied by Souter et al. for 2-vinylpyridine. ${ }^{[161]}$

The reaction of $\left[\mathrm{Ca}\left\{\mathrm{N}\left(\mathrm{SiMe}_{3}\right)_{2}\right\}_{2}\right]$ with [(tmeda) $\left.\left.\mathrm{Li}_{2} \mathrm{Ph}_{2} \mathrm{PCH}_{2} \mathrm{~S}\left(\mathrm{NSiMe}_{3}\right)_{2}\right\}\right]$ proceeded with a complete metal exchange according to Equation 5-2. It could have been speculated that the large calcium atom would be coordinated by the pendent phosphorus side-arm and the smaller lithium cation would remain between the nitrogen atoms yielding a heterobimetallic complex. This was not observed; a dimer of formula [Ca\{ $\left.\left.\mathrm{Ph}_{2} \mathrm{PCH}_{2} \mathrm{~S}\left(\mathrm{NSiMe}_{3}\right)_{2}\right\}_{2}\right]$ (28) was formed instead, with the calcium dication being coordinated by the four nitrogen and two phosphorus atoms of two ligands (Figure 5-4) in a tridentate, cap-shaped manner. The coordination of the SNCP ligand resembles the coordination of $\mathrm{S}(\mathrm{N} t \mathrm{Bu})_{3}{ }^{2-}$ in $\left[(\operatorname{thf})_{2} \mathrm{Li}_{2} \mathrm{Ca}\left\{(\mathrm{NtBu})_{3} \mathrm{~S}\right\}_{2}\right]^{[58]}$ and 28 could be regarded as a monometallic analogue of that complex. The coordination cannot be described as an octahedron as it is too distorted. One could rather speak of two NNPCa tetrahedra that are linked via their apexes over the central calcium dication.

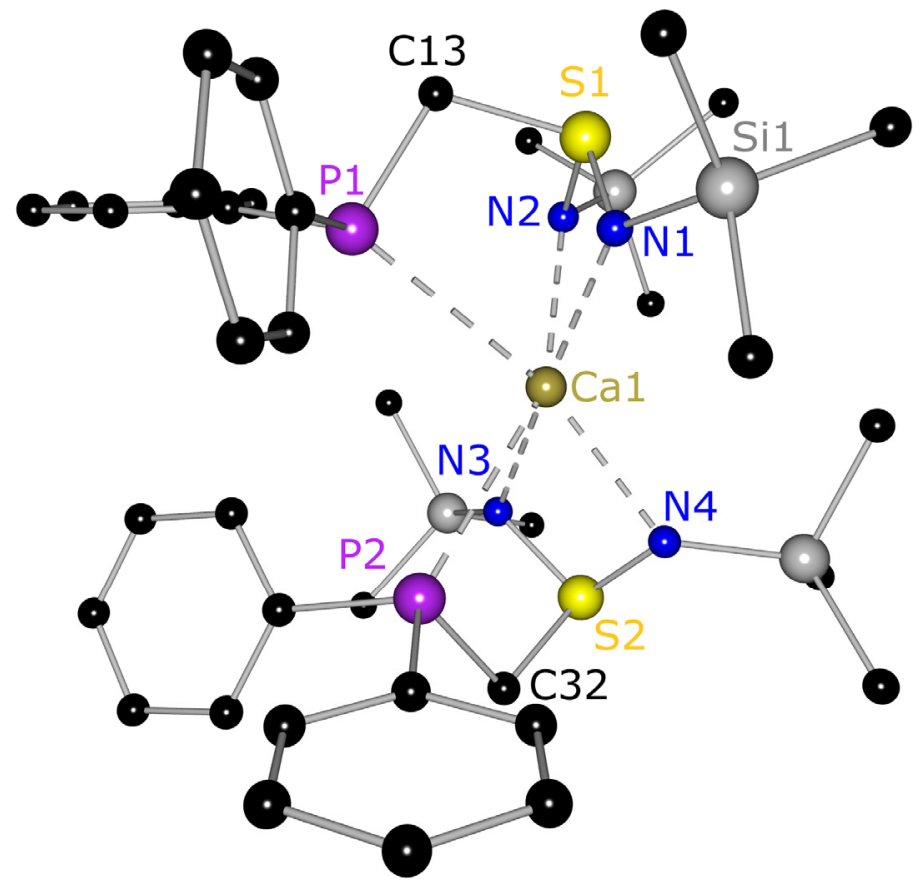

Figure 5-4: Molecular structure of $\left[\mathrm{Ca}\left\{\mathrm{Ph}_{2} \mathrm{PCH}_{2} \mathrm{~S}\left(\mathrm{NSiMe}_{3}\right)_{2}\right\}_{2}\right](28)$. Hydrogen atoms are omitted for clarity.

The angles of N1-Ca1-N2 63.47(6) ${ }^{\circ}$ and N2-Ca1-P1 71.20(5) ${ }^{\circ}$ around the calcium atom make that clear. Both tetrahedra are twisted by $55^{\circ}$ with respect to each other, inhibiting an alignment of the two phosphorus donor atoms. Despite of 
the different ligand, the structure is very similar to the magnesium complexes $\mathbf{2 6}$ and 27. Selected bond lengths compared with other metal complexes can be found in Table 5-2, angles in Table 5-3.

Table 5-2: Selected bond lengths $[\AA]$ in 28 to 31

\begin{tabular}{lllll}
\hline & $\mathbf{2 8}(\mathrm{Ca})$ & $\mathbf{2 9}(\mathrm{Sr})$ & $\mathbf{3 0}(\mathrm{Co})$ & $\mathbf{3 1}(\mathrm{Fe})$ \\
\hline $\mathrm{S} 1-\mathrm{N} 1$ & $1.6078(19)$ & $1.6056(12)$ & $1.6051(17)$ & $1.606(2)$ \\
$\mathrm{S} 1-\mathrm{N} 2$ & $1.6076(17)$ & $1.6013(13)$ & $1.6177(17)$ & $1.6151(19)$ \\
$\mathrm{N} 1-\mathrm{Si} 1$ & $1.7223(18)$ & $1.7138(13)$ & $1.7251(16)$ & $1.7276(19)$ \\
$\mathrm{S} 1-\mathrm{C} 13$ & $1.831(2)$ & $1.8254(15)$ & $1.834(2)$ & $1.836(2)$ \\
$\mathrm{P} 1-\mathrm{C} 13$ & $1.847(2)$ & $1.8454(15)$ & $1.849(2)$ & $1.846(2)$ \\
$\mathrm{N} 1-\mathrm{M} 1$ & $2.4198(18)$ & $2.5495(12)$ & $2.1228(16)$ & $2.1523(18)$ \\
$\mathrm{N} 2-\mathrm{M} 1$ & $2.3909(19)$ & $2.5517(14)$ & $2.1402(16)$ & $2.1697(19)$ \\
$\mathrm{N} 3-\mathrm{M} 1$ & $2.4378(18)$ & $2.5374(13)$ & $2.1245(15)$ & $2.1785(19)$ \\
$\mathrm{N} 4-\mathrm{M} 1$ & $2.3960(18)$ & $2.5698(12)$ & $2.1429(16)$ & $2.1475(18)$ \\
$\mathrm{P} 1-\mathrm{M} 1$ & $3.0815(7)$ & $3.1804(5)$ & $2.8421(6)$ & $2.7569(7)$ \\
$\mathrm{P} 2-\mathrm{M} 1$ & $3.0219(7)$ & $3.1608(5)$ & $2.7409(6)$ & $2.8279(7)$ \\
\hline
\end{tabular}

Table 5-3: Selected angles [ $\left.{ }^{\circ}\right]$ in 28 to 31

\begin{tabular}{lllll}
\hline & $\mathbf{2 8}(\mathrm{Ca})$ & $\mathbf{2 9}(\mathbf{S r})$ & $\mathbf{3 0}(\mathrm{Co})$ & $\mathbf{3 1}(\mathrm{Fe})$ \\
\hline N1-S1-N2 & $103.80(9)$ & $104.73(7)$ & $99.75(8)$ & $99.95(10)$ \\
S1-C13-P1 & $107.70(11)$ & $108.20(8)$ & $105.95(10)$ & $105.68(12)$ \\
S1-N1-Si1 & $121.71(11)$ & $122.93(8)$ & $121.80(10)$ & $122.12(11)$ \\
C1-P1-C7 & $105.86(10)$ & $106.36(7)$ & $102.65(9)$ & $101.22(10)$ \\
N1-M1-N2 & $63.47(6)$ & $59.71(4)$ & $70.63(6)$ & $69.59(7)$ \\
N2-M1-P1 & $71.20(5)$ & $66.70(3)$ & $70.60(5)$ & $71.19(5)$ \\
N3-M1-N4 & $63.37(6)$ & $59.77(4)$ & $70.18(6)$ & $69.88(7)$ \\
N4-M1-P2 & $71.88(4)$ & $60.91(3)$ & $71.66(5)$ & $77.33(5)$ \\
P1-M1-Nx & $158.40(5)(\mathrm{N} 4)$ & $154.03(3)(\mathrm{N} 3)$ & $172.27(4)(\mathrm{N} 3)$ & $170.87(5)(\mathrm{N} 4)$ \\
N1-M1-Nx & $175.82(6)(\mathrm{N} 3)$ & $176.82(4)(\mathrm{N} 4)$ & $110.39(6)(\mathrm{N} 3)$ & $109.86(7)(\mathrm{N} 3)$ \\
\hline
\end{tabular}

It is striking that the phosphorus atoms are on the same side of the molecule and not on opposite sides as one could expect to reduce steric strain. When taking a closer look this assumption is not the case. If the phenyl rings would be arranged on opposite sides of the molecule the hydrogen atoms of the trimethylsilyl groups and 
the rings would come too close to each other. In the arrangement that exists in the crystal, the four phenyl rings are twisted by approximately $90^{\circ}$ with respect to each other, thereby evading that problem. In addition, it has already been established by theoretical investigations that the heavier alkaline earth metals show not only ionic but also covalent bonding properties. This is achieved by contribution of the d-orbitals and the high polarisability of the sub-valence shells, making the atom nonspherical. ${ }^{[162]}$ Therefore, the heavier alkaline earth metal halides and hydrides have bent rather than linear structures.

It is thinkable that the arrangement of the phosphorus atoms in $\mathbf{2 8}$ is also controlled by these facts, which is underlined by the geometry of the complex. Thus, $\sigma$-bonding character between the phosphorus p-orbital and the calcium d-orbital could be responsible for the cis-arrangement of the phosphorus side-arms as well as the polarisation of $\mathrm{Ca}^{2+}$ by the ligand. A similar cisoid arrangement of ligands was found in $\left[(\text { thf }) \mathrm{Ca}\left\{\left(\mathrm{NSiMe}_{3}\right)_{2} \mathrm{PPh}_{2}\right\}_{2}\right]^{[163]}$ and $\left[(\mathrm{N} \text {-carbazolyl })_{2} \mathrm{Ba}(\mathrm{dme})_{3}\right]^{[164]}$ and discussed accordingly.

The bond lengths in $\mathbf{2 8}$ are all in the expected range and are comparable to other similar phosphorus-calcium or nitrogen-calcium complexes, although the phosphorus-calcium bonds are somewhat elongated. ${ }^{[165]}$

The reaction of 11 with $\left[\mathrm{Sr}\left\{\mathrm{N}\left(\mathrm{SiMe}_{3}\right)_{2}\right\}_{2}\right]$ afforded the strontium complex 29 as colourless crystals. The structure which is depicted in Figure 5-5 is isosteric to the calcium complex 28.

The nitrogen-strontium and phosphorus-strontium bond distances are elongated in comparison to the calcium complex which is due to the larger ionic radius of strontium. They are in the range of the bis(diphosphanylamido) complex $\left[(\text { thf })_{3} \operatorname{Sr}\left\{\left(\mathrm{Ph}_{2} \mathrm{P}\right)_{2} \mathrm{~N}\right\}_{2}\right]^{[165 \mathrm{~b}]}$ and aminotroponiminate complexes ${ }^{[165 \mathrm{c}]}$ that have comparable steric requirements. The $\mathrm{N} 1-\mathrm{S} 1-\mathrm{N} 2$ angle is slightly widened in comparison to the calcium complex $\left(104.73(7)^{\circ}\right.$ vs. $\left.103.80(9)^{\circ}\right)$ as well as the S1C13-P1 angle $\left(108.20(8)^{\circ}\right.$ vs. $\left.107.70(11)^{\circ}\right)$.

On the other hand, the angles around the strontium dication are considerably more acute than in the calcium complex. This could be due to the fact that the bond lengths to the donor atoms are longer because of the increased ionic radius and the ligand is located further away from the central metal. Consequently the angles have to become more acute. The arrangement of the phosphorus side-arms is the same as in the corresponding calcium complex, however the bending of the ligand is 
reduced (S1-Ca1-S2: 158.103(19) $\left.)^{\circ}, \mathrm{S} 1-\mathrm{Sr} 1-\mathrm{S} 2: 162.896(10)^{\circ}\right)$ which might be due to the larger cation size.

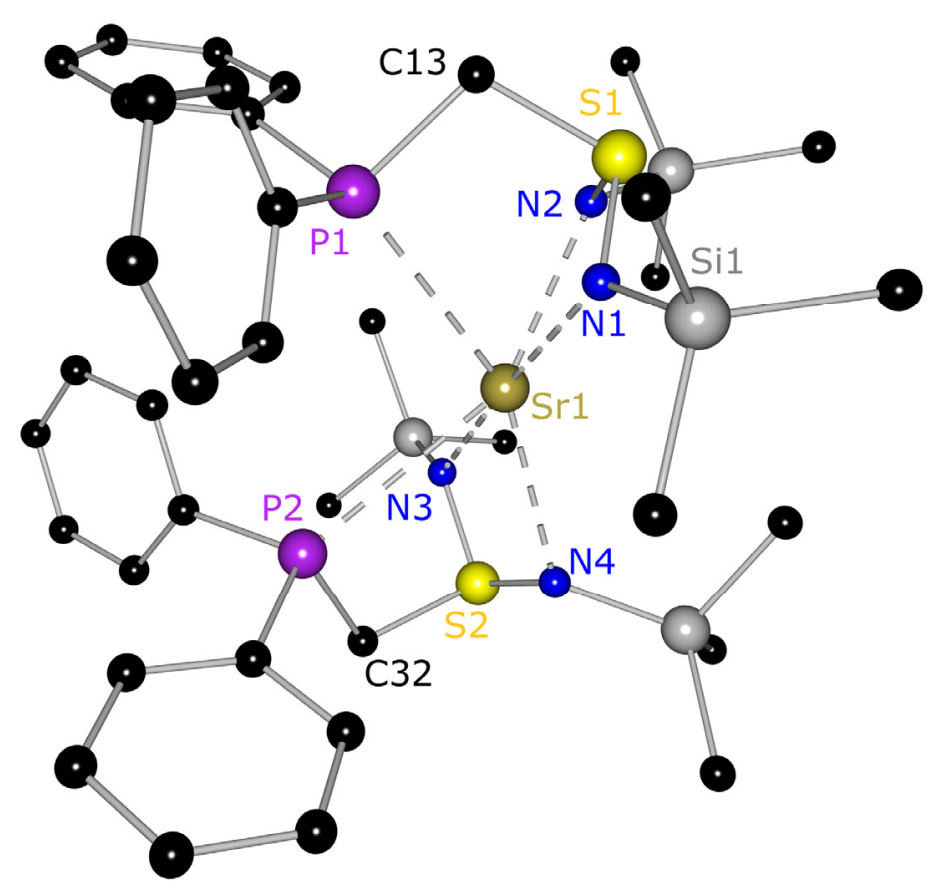

Figure 5-5: Molecular structure of $\left[\mathrm{Sr}\left\{\mathrm{Ph}_{2} \mathrm{PCH}_{2} \mathrm{~S}\left(\mathrm{NSiMe}_{3}\right)_{2}\right\}_{2}\right]$ (29). Hydrogen atoms are omitted for clarity.

In essence, it could be shown that the new ligand $\left\{\mathrm{R}_{2} \mathrm{PCH}_{2} \mathrm{~S}\left(\mathrm{NSiMe}_{3}\right)_{2}\right\}$ is indeed very flexible and versatile as it can form stable complexes of the lower and higher homologues of the alkaline earth metals. In the cases described here the ionic radii range from $72 \mathrm{pm}\left(\mathrm{Mg}^{2+}\right)$ to $121 \mathrm{pm}\left(\mathrm{Sr}^{2+}\right)$ for the coordination number six. The connectivity is always the same with all nitrogen and phosphorus atoms taking part in the coordination, regardless of the HSAB hardness of the central metal. There is no formation of aggregates, which usually is a known property of the heavier alkaline earth metals because of their very large ionic radii. ${ }^{[166]}$ It can be concluded that the ligand employed is sterically demanding enough to block certain coordination sites and prevent the formation of aggregates. This is a great advantage regarding possible catalytic applications as it ensures the complex to remain intact during and after the reaction.

It is also known that the coordination behaviour and the chemistry of the alkaline earth metals is comparable to certain lanthanides. ${ }^{[167]}$ This becomes evident if the ionic radii of $\mathrm{Ca}^{2+}$ and $\mathrm{Sr}^{2+}$ are contrasted with those of $\mathrm{Yb}^{2+}$ and $\mathrm{Sm}^{2+}$ or $\mathrm{Eu}^{2+}: 106$ and 121 vs. 108,122 and $120 \mathrm{pm}$ (for coordination number six). ${ }^{[168,169]}$ For the future it would therefore be very interesting to employ metal amides of some lanthanides in 
the metal exchange reactions discussed above and compare them to their alkaline earth metal counterparts.

\subsubsection{Transition Metals}

To further investigate the complexation potential of the new ligand, bivalent transition metals were employed in the synthesis. Cobalt was chosen as a central metal because it is easily accessible and has two stable oxidation states that should be well interconvertible. It would be of great interest to compare the coordination of the same metal in different oxidation states by the same ligand. Cobalt complexes are being employed as catalysts for the release of hydrogen from ammonia borane, $\mathrm{NH}_{3} \mathrm{BH}_{3}$, which is a very good hydrogen storage material. ${ }^{[170]}$ This is desirable because the combustion of hydrogen produces no toxic by-products and thus is a favourable source of energy. In contrast to methane, there is no formation of $\mathrm{CO}_{2}$ after release of the hydrogen from ammonia borane. It contains a high hydrogen percentage (19.6 wt\%) and possesses good stability because it is solid at room temperature and therefore does not have to be stored under pressure like hydrogen gas. ${ }^{[171]}$

Cobalt(II) compounds with tridentate bispyridyl-based nitrogen ligands are highly active catalysts for the oligomerization of ethylene. ${ }^{[172]}$ There also exists an application of $\mathrm{Co}$ (II) phosphane complexes in the hydrovinylation of styrene with excellent chemoselectivity. ${ }^{[173]}$

From the experience gained with the alkaline earth metal complexes it was clear that bivalent metals form very stable compounds with the ligand $\left\{\mathrm{Ph}_{2} \mathrm{PCH}_{2} \mathrm{~S}\left(\mathrm{NSiMe}_{3}\right)_{2}\right\}^{-}$. Therefore [Co $\left.\left\{\mathrm{N}\left(\mathrm{SiMe}_{3}\right)_{2}\right\}_{2}\right]$ was reacted with 11 according to the general reaction scheme (Equation 5-2). After storing the solution at $4{ }^{\circ} \mathrm{C}$ for several hours, blue to purple crystals suitable for X-ray crystallography could be obtained. The structure crystallises in the orthorhombic space group Pna2 ${ }_{1}$. It has the same characteristics as the other complexes discussed above and is shown in Figure 5-6. The bond lengths and angles can be found in Table 5-2 and Table 5-3, respectively. 


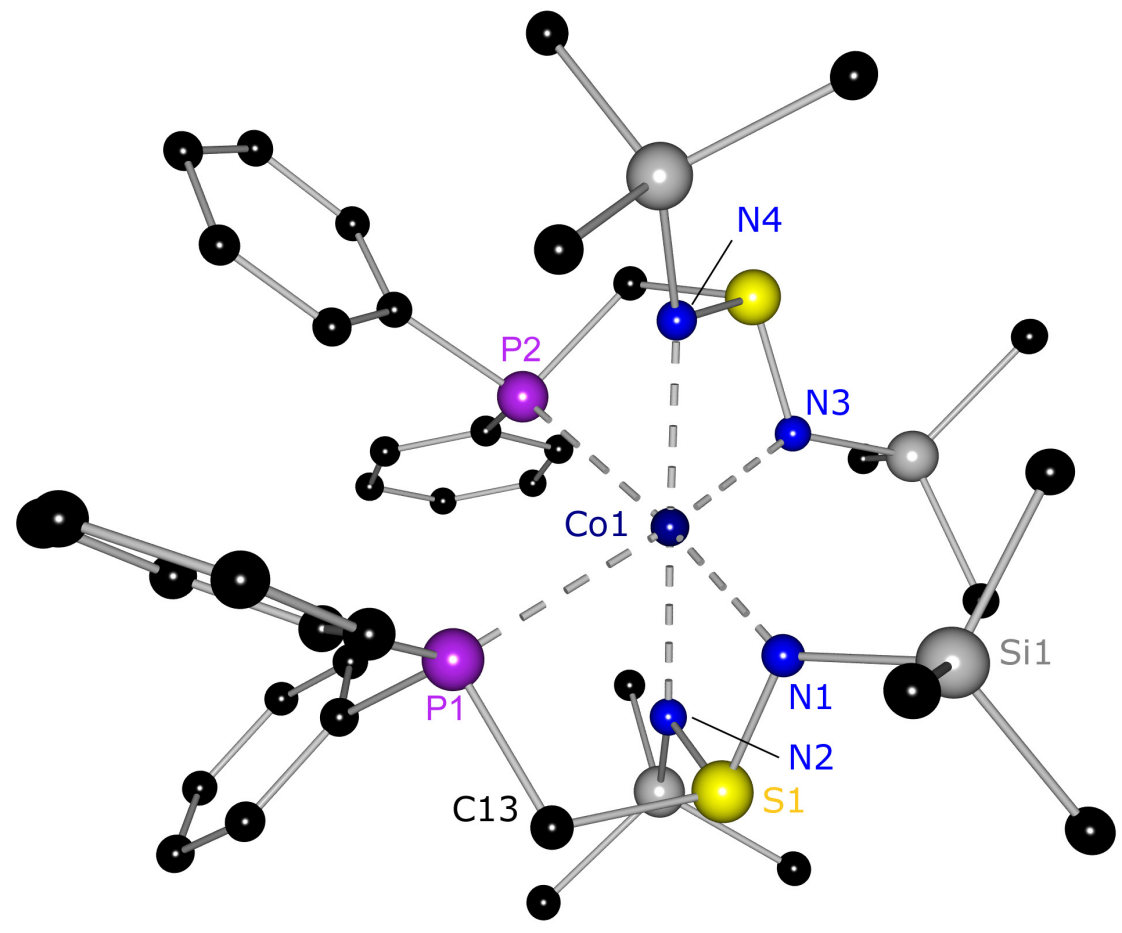

Figure 5-6: Molecular structure of $\left[\mathrm{Co}\left\{\mathrm{Ph}_{2} \mathrm{PCH}_{2} \mathrm{~S}\left(\mathrm{NSiMe}_{3}\right)_{2}\right\}_{2}\right](\mathbf{3 0})$. Hydrogen atoms are omitted for clarity.

Interestingly, the coordination of the central cobalt dication can be described as a distorted octahedron which is in contrast to the calcium and the strontium complexes. N3 and P1 can be regarded as the apexes of the polyhedron. The N3Co1-N4 and N1-Co1-N2 angles of $70.18(6)^{\circ}$ and $70.63(6)^{\circ}$, respectively underline that view. They are not very close to $90^{\circ}$ but closer than the corresponding values of the strontium complex $\left(63.37(6)^{\circ}\right.$ and $\left.59.71(4)^{\circ}\right)$. P1 and N3 are almost aligned straight which is demonstrated by the P1-Co1-N3 angle of $172.27(4)^{\circ}$. The corresponding value in the strontium complex is $154.03(3)^{\circ}$ and therefore much smaller. It is remarkable that the N1-S1-N2 angle of $99.75(8)^{\circ}$ is much more acute than in the two complexes described earlier. It is comparable to the magnesium complexes 26 and 27 that show values of $97.43(12)^{\circ}$ and $100.44(4)^{\circ}$. This decrease of the $\mathrm{N}-\mathrm{S}-\mathrm{N}$ angle could be due to the small cation size of $\mathrm{Co}$ (II) (65 pm low-spin, $74.5 \mathrm{pm}$ high-spin) which is comparable to $\mathrm{Mg}(\mathrm{II})(72 \mathrm{pm}){ }^{[169]}$

The ligand is able to get closer to the central metal, getting twisted stronger as a result. The S-C-P angle $\left(105.95(10)^{\circ}\right)$ is reduced as well. The Co-N and Co-P bond lengths range from 2.1228(16) $\AA$ (N1-Co1) to 2.1429(16) $\AA$ (N4-Co1) and $2.7409(6) \AA$ to $2.8421(6) \AA$ (P2/P1-Co1). Particularly the cobalt-phosphorus bonds are much longer than in comparable octahedral structures of cobalt(III). ${ }^{[174,175]}$ In 2006, Salem and co-workers presented a hexadentate $\mathrm{P}_{3} \mathrm{~N}_{3}$ ligand which forms an 
octahedral complex with cobalt(III). ${ }^{[176]}$ The Co-P and Co-N bond lengths in those complexes are around $2.2067 \AA$ and $2.024 \AA$. The question remains wether $\mathbf{3 0}$ is a high-spin or a low-spin complex. $\mathrm{PR}_{3}$ is known to be a strong $\sigma$-donor ligand and a good $\pi$-acceptor so that the ligand field splitting is large. $\mathrm{Co}^{2+}$ probably is in a lowspin state and the phosphorus side-arms form $\sigma$-bonds with the $d_{z 2}$ and the $d_{x 2-y 2}$ orbitals. Consequently, their cisoid arrangement gets obvious. However, the spinstate has still to be further investigated.

A search for similar cobalt(II) complexes in the CCDC clearly shows that there are none. There is a great variety of cobalt(III) compounds involving the NioxH or similar ligands ( $\mathrm{NioxH}_{2}=1,2$-cyclohexanedione dioxime). The coordination sphere is then widened to six by $\mathrm{PPh}_{3}$ ligands, resulting in an octahedral geometry of the complexes. ${ }^{[177]}$ Another class of nitrogen and phosphorus bonded cobalt complexes is made with PNNP pincer ligands like $\left\{\mathrm{Ph}_{2} \mathrm{P}\left(\mathrm{CH}_{2}\right)_{2} \mathrm{~N}\left(\mathrm{CH}_{2}\right)_{2} \mathrm{~N}\left(\mathrm{CH}_{2}\right)_{2} \mathrm{PPh}_{2}\right\}$ or derivatives thereof. These are closely related to the ligand employed during this work. However, cobalt(II) complexes of this type are very rare which is probably due to the easy oxidation to cobalt(III). This brings the new ligand presented here into the focus as it is able to stabilise that oxidation state and paves the way to metal complexes that are in general not easily accessible.

As a second example for transition metals, iron(II) was chosen. It is known to catalyse all sorts of reactions, e. $g$. hydrogenations ${ }^{[178]}$, hydrosilylations ${ }^{[179]}$, olefinpolymerizations ${ }^{[180]}$, cross-couplings ${ }^{[181]}$, bond-cleavages ${ }^{[182]}$ and many more. ${ }^{[183]}$ Catalysts based on iron are desirable because of their low cost and low toxicity in comparison to other transition metals. Morris et al. described in 2008 an iron(II) complex with a tetradentate PNNP ligand for the asymmetric hydrogenation of polar bonds with hydrogen at relatively low temperatures. ${ }^{[184]}$ Their goal was to synthesise enantiopure alcohols and amines from prochiral molecules which was only efficiently possible with ruthenium and rhodium catalysts until that time. ${ }^{[185]}$

In 2010, Morris et al. presented iron(II) complexes with tridentate phosphorus/nitrogen based ligands that could be active in hydrogenation reactions. ${ }^{[186]}$ These ligands form octahedral complexes with $\mathrm{Fe}(\mathrm{II})$ where iron is complexed by two ligands and coordinated by two phosphorus and four nitrogen atoms or vice versa. Unfortunately, those compounds could not be characterised by X-ray crystallography due to poor solubility. NMR spectra were recorded however, 
showing no paramagnetism. These PNP or NPN ligands therefore seem to generate a strong ligand field, leading to low-spin iron(II). Other examples for NPN ligands come from the group of Braunstein. They used bis(2-picolyl)phenylphosphane and related systems for the complexation of divalent transition metals. ${ }^{[187]} \mathrm{Fe}(\mathrm{II})$ is coordinated as well by two ligands with all three donor atoms taking part in the coordination to form a distorted octahedral coordination geometry. Kirchner et al. use similar ligands of the PNP form on the basis of N-heterocyclic diamines. ${ }^{[188]}$ Some tridentate ligands which have already been employed in the complexation of $\mathrm{Fe}$ (II) are depicted in Figure 5-7 and Figure 5-10 [189].

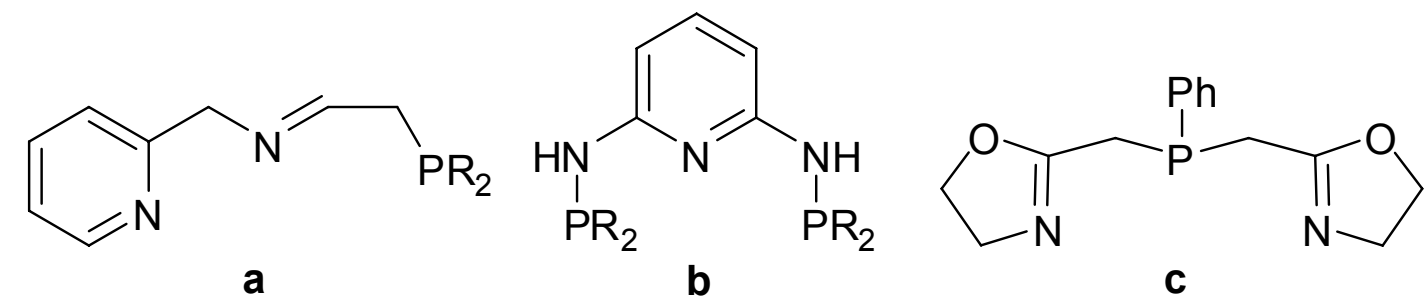

Figure 5-7: Examples for tridentate phosphorus/nitrogen ligands: $a^{[186]}, b^{[188]}, c^{[187]}$.

[Fe $\left.\left\{\mathrm{Ph}_{2} \mathrm{PCH}_{2} \mathrm{~S}\left(\mathrm{NSiMe}_{3}\right)_{2}\right\}_{2}\right]$ (31) was synthesised just like the cobalt complex $\mathbf{3 0}$. After storing the reaction solution for two weeks at $4{ }^{\circ} \mathrm{C}$, colourless crystals could be obtained. The complex crystallises in the orthorhombic space group Pna2 ${ }_{1}$ with the whole molecule in the asymmetric unit. A picture of compound 31 can be found in Figure 5-8. The structure is analogous to $\left[\mathrm{Co}\left\{\mathrm{Ph}_{2} \mathrm{PCH}_{2} \mathrm{~S}\left(\mathrm{NSiMe}_{3}\right)_{2}\right\}_{2}\right](\mathbf{3 0})$ which is due to the similar ionic radii of $\mathrm{Co}(\mathrm{II})$ and $\mathrm{Fe}(\mathrm{II})$. The angles in the ligand as well as around the iron dication have almost the same values as in the cobalt analogue. The bond lengths are also very similar. Selected bond lengths and angles, compared to the calcium, strontium and cobalt complexes can be found in Table 5-2 and Table 5-3. The similarity of the structures $\mathbf{2 6}$ to $\mathbf{3 1}$ is certainly due to the flexibility of the ligand which is able to accommodate ions of very different radii. In addition, all the metal complexes presented here so far show excellent solubility in all sorts of hydrocarbons.

Unfortunately, it was not possible until now to gather enough substance for NMR spectroscopic measurements or other analytics because the complex seemed to decompose partially. It would be of great interest to confirm if the iron(II) dication is low-spin as well (like in Morris' case) because this would allow to draw conclusions about the behaviour of the ligand. 


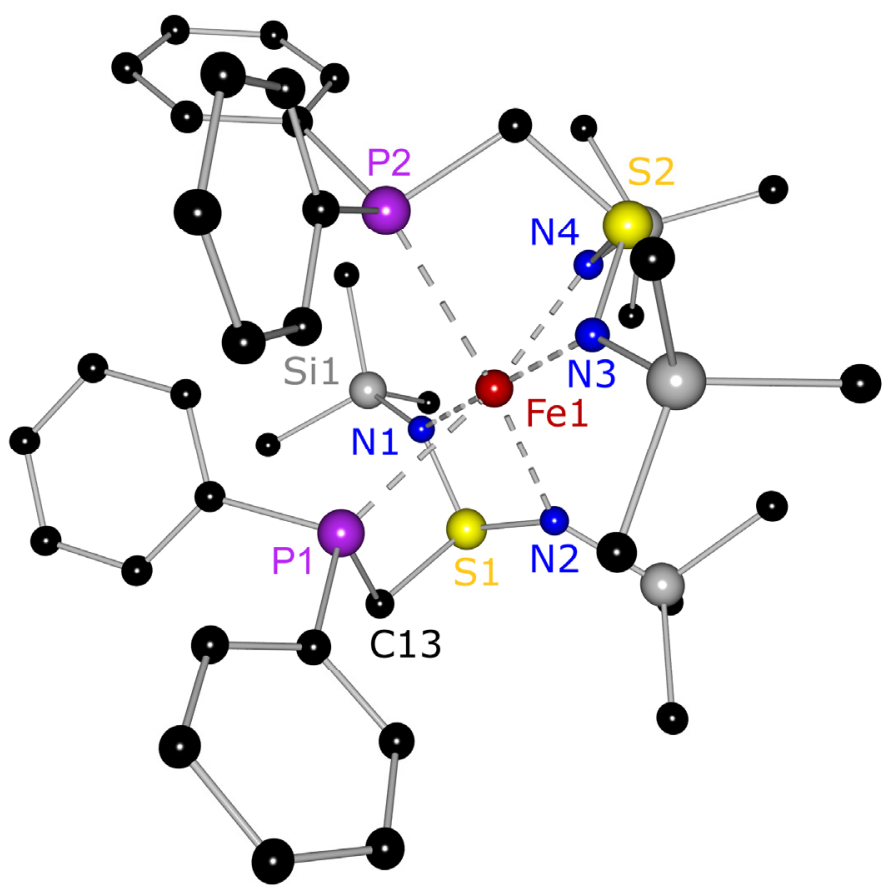

Figure 5-8: Molecular structure of $\left[\mathrm{Fe}\left\{\mathrm{Ph}_{2} \mathrm{PCH}_{2} \mathrm{~S}\left(\mathrm{NSiMe}_{3}\right)_{2}\right\}_{2}\right]$ (31). Hydrogen atoms are omitted for clarity.

It is possible that the iron complex $\left[\mathrm{Fe}\left\{\mathrm{Ph}_{2} \mathrm{PCH}_{2} \mathrm{~S}\left(\mathrm{NSiMe}_{3}\right)_{2}\right\}_{2}\right]$ can promote $\mathrm{H}_{2}$ hydrogenation reactions as well. The phosphorus side-arm seems to be bonded weakly and could easily dissociate to form an amine-hydrido complex. The synthesis of $\mathrm{Ph}_{2} \mathrm{PCH}_{2} \mathrm{~S}\left(\mathrm{NSiMe}_{3}\right)\left(\mathrm{HNSiMe}_{3}\right)$ (10) shows, that the nitrogen atoms can be protonated. A possible reaction mechanism is described in the literature for a related Ru system. ${ }^{[185 b, 190,191]}$

The reaction of [(tmeda) $\left.\mathrm{Li}\left\{\mathrm{Ph}_{2} \mathrm{PCH}_{2} \mathrm{~S}\left(\mathrm{NSiMe}_{3}\right)_{2}\right\}\right]$ (11) with $\left[\mathrm{Fe}\left\{\mathrm{N}\left(\mathrm{SiMe}_{3}\right)_{2}\right\}_{2}\right]$ afforded a second product from the same reaction vessel which was obtained as red plates. The molecular structure is shown in Figure 5-9.

The phosphorus atom in the starting material 11 was oxidised and two $\mathrm{O}^{-}$ions were incorporated into the structure. There was no metal exchange but the formation of a heterobimetallic complex of $\mathrm{Li}^{+}$and $\mathrm{Fe}^{2+}$ instead. A similar case was described by Kempe et al. when they tried to transmetalate lithiated 4-methyl$2\left[\right.$ (trimethylsilyl)amino]pyridine with $\mathrm{FeCl}_{2}{ }^{[192]}$ They obtained a mixed metal lithium/iron(II) complex with a central $\mathrm{O}^{2-}$ dianion (Figure 5-10, right). 


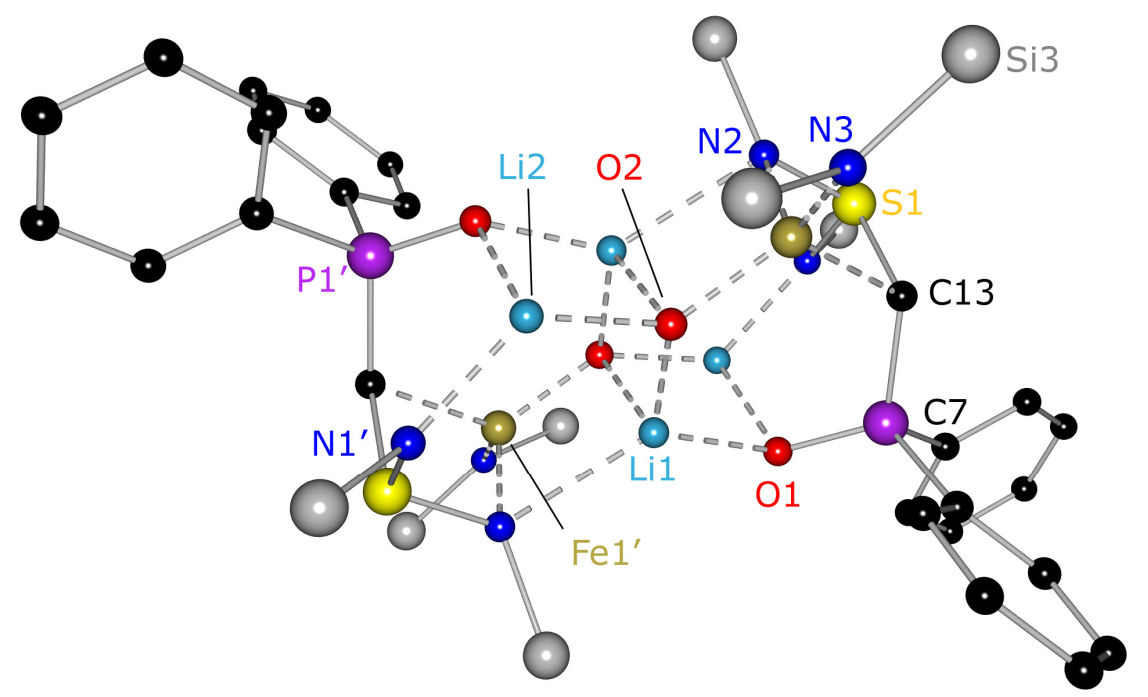

Figure 5-9: Molecular structure of $\left[\left\{\mathrm{FeN}\left(\mathrm{SiMe}_{3}\right)_{2}\right\}\left\{\mathrm{Li}\left(\mathrm{NSiMe}_{3}\right)_{2} \mathrm{SCHP}(\mathrm{O}) \mathrm{Ph}_{2}\right\}(\mathrm{LiO})\right]_{2}($ (32). Hydrogen atoms and the methyl substituents of the $\mathrm{SiMe}_{3}$ groups are omitted for clarity.

In 32, the $\mathrm{PCH}_{2} \mathrm{~S}$ bridge was deprotonated by the iron bis(hexamethyl)silylamide, creating a carbocation which is taking part in the coordination of Fe(II). The reaction could be described according to Equation 5-3.

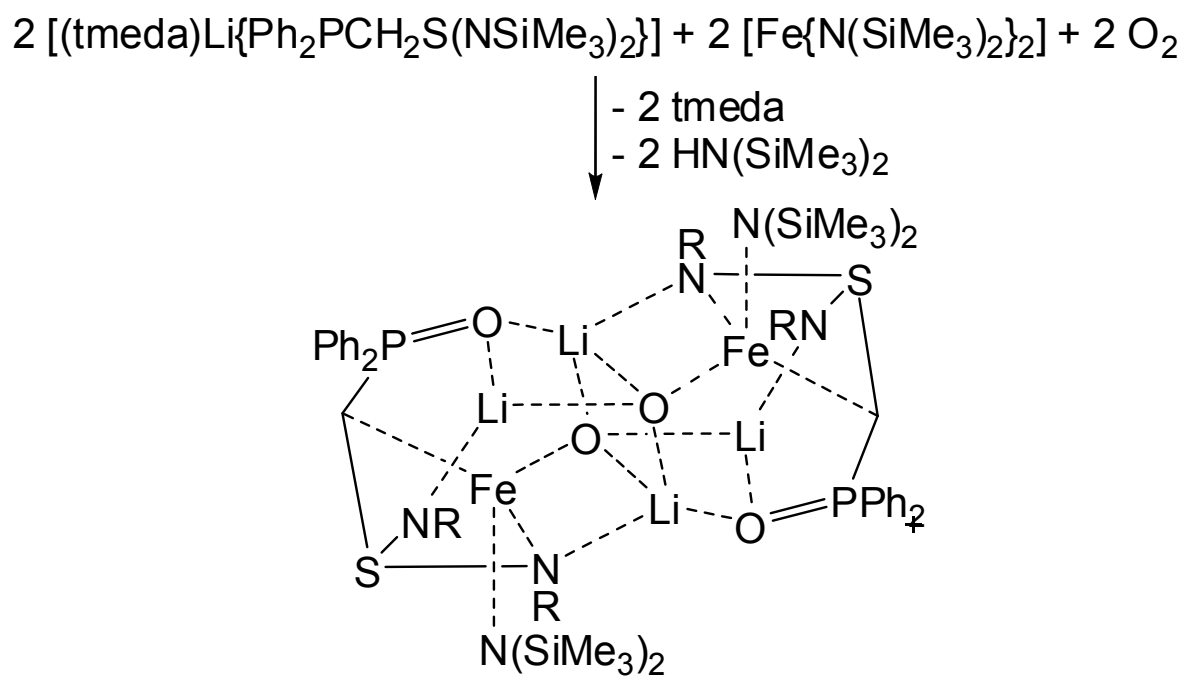

Equation 5-3: Possible formation of 32, $\mathrm{R}=\mathrm{SiMe}_{3}$.

The structure is dimeric with a four-membered planar $(\mathrm{LiO})_{2}$ ring in the centre. This central ring is connecting four six-membered rings which are as well interconnected. There are four lithium and two iron cations in the complex. The nitrogen atoms of the diimido moieties coordinate two lithium atoms (Li1 and Li2') of different halves of the dimer and one iron atom (Fe1) of the same half. The oxygen atoms on the phosphorus coordinate two lithium cations of both halves (Li1 and Li2'). 
The iron(II) dication is additionally coordinated by the carbocation C13, one oxygen atom of the central four-membered ring (O2) and a bis(trimethylsilyl)amido ligand.

Li1 is bonding to three oxygen atoms and one nitrogen atom. It adopts a distorted tetrahedral coordination geometry with angles between $101.46(11)^{\circ}(\mathrm{O} 2-$ Li1-O2') and $130.03(12)^{\circ}$ (N2'-Li1-O1). The nitrogen-lithium and oxygen-lithium bonds are in the expected range with the O-Li bonds being slightly shorter. Li2 is threefold coordinated by two oxygen atoms of different halves of the dimer and one nitrogen atom of a diimido moiety. The coordination around Li2 is not planar and can rather be described as trigonal pyramidal with Li2 being at the apex of the pyramid. The O2-Li2-O1' angle of $97.45(11)^{\circ}$ is closer to $90^{\circ}$ than to $120^{\circ}$. This is due to the fact that $\mathrm{Li} 2, \mathrm{O} 2$, $\mathrm{Li}_{1}$ ' and $\mathrm{O} 1$ ' form a square that is connected to the central fourmembered ring and encloses an angle of $110.4^{\circ}$.

Fe1 is distorted tetrahedrally coordinated by N2, N3, O2 and C13. The bond lengths are in accordance with the HSAB concept with Fe1-O2 (1.7850(10) $\AA$ ) being the shortest and Fe1-C13 (2.1601(13) $\AA$ ) the longest bond. Fe1-N2 however is rather short $(2.0352(12) \AA)$. This is probably due to the fact that the negative charge on $\mathrm{C} 13$ is partly delocalised into the diimido moiety. That explains the long Fe1-C13 as well as the short Fe1-N2 bond. This finding is further supported by the fact that the S1-C13-P1 angle of $117.41(7)^{\circ}$ is widened in comparison to the ideal tetrahedral angle and points to a $s p^{2}$-hybridised carbon atom. The $\mathrm{S}-\mathrm{N}$ bond lengths in the diimido moieties show an elongation of S1-N2 (1.6722(12) $\AA$ vs. 1.5961(12) $\AA$ for S1-N1) which is due to the coordination of two metals by N2. Selected bond lengths and angles in 32 can be found in Table 5-4. 

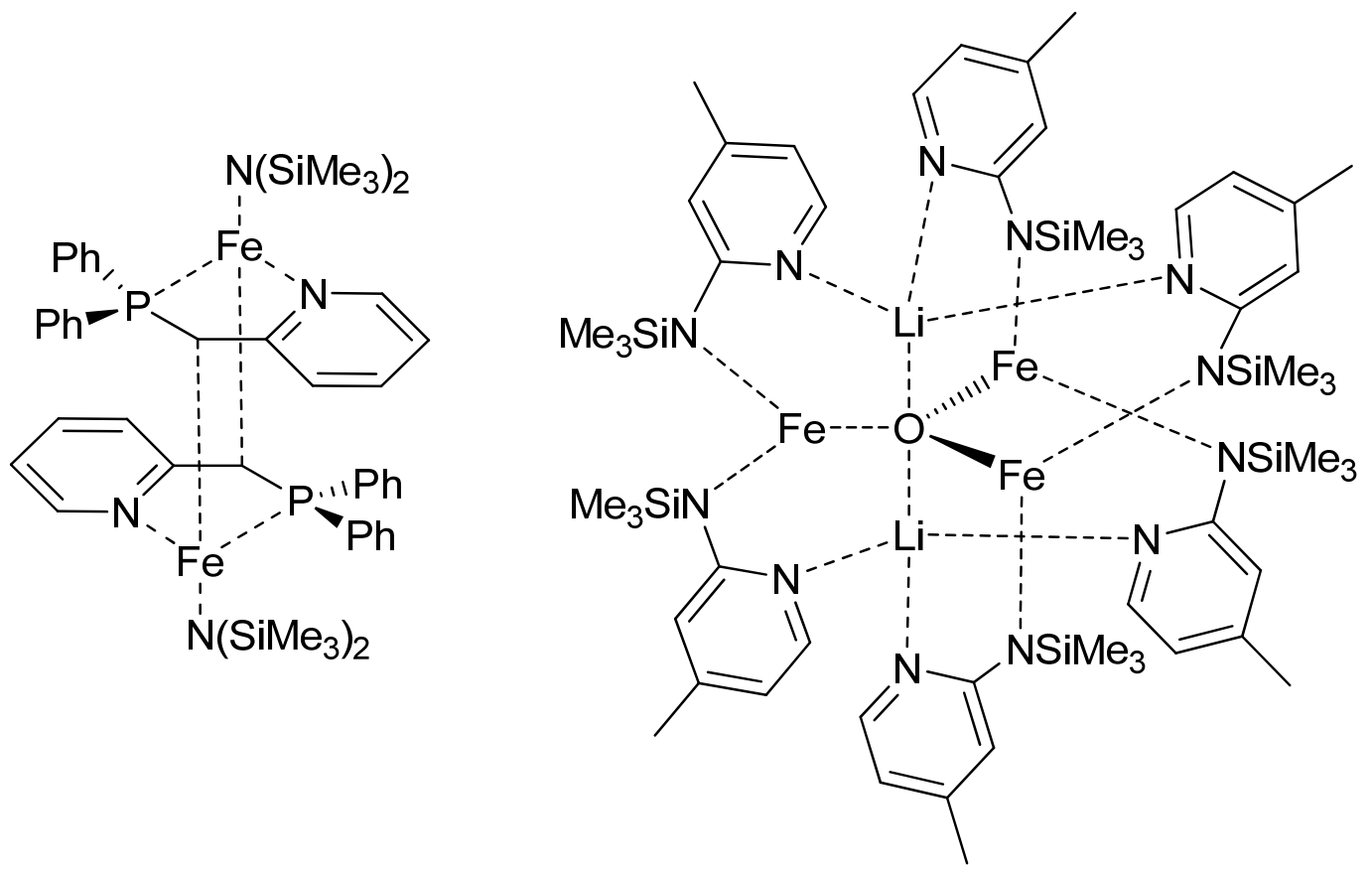

Figure 5-10: Iron(II) complexes related to $\left[\left\{\mathrm{FeN}\left(\mathrm{SiMe}_{3}\right)_{2}\right\}\left\{\mathrm{Li}\left(\mathrm{NSiMe}_{3}\right)_{2} \mathrm{SCH}_{2} \mathrm{P}(\mathrm{O}) \mathrm{Ph}_{2}\right\}(\mathrm{LiO})\right]_{2}(32)$.

Table 5-4: Selected bond lengths $[\AA]$ and angles $\left[{ }^{\circ}\right]$ in 32

\begin{tabular}{llll}
\hline S1-N1 & $1.5961(12)$ & N1-S1-N2 & $110.03(6)$ \\
S1-N2 & $1.6722(12)$ & S1-C13-P1 & $117.41(7)$ \\
S1-C13 & $1.8110(14)$ & C13-P1-O1 & $113.40(6)$ \\
P1-C13 & $1.7645(14)$ & O1-Li1-O2 & $109.34(13)$ \\
P1-O1 & $1.5148(10)$ & N2'-Li1-O1 & $130.03(12)$ \\
N1'-Li2 & $1.994(3)$ & O2-Li1-O2' & $101.46(11)$ \\
N2'-Li1 & $2.372(3)$ & N1'-Li2-O1' & $105.05(12)$ \\
N2-Fe1 & $2.0352(12)$ & O2-Li2-O1' & $97.45(11)$ \\
N3-Fe1 & $1.9343(12)$ & O2-Li2-N1' & $128.99(14)$ \\
C13-Fe1 & $2.1601(13)$ & N2-Fe1-N3 & $125.11(5)$ \\
O2-Fe1 & $1.7850(10)$ & N2-Fe1-C13 & $75.88(5)$ \\
O1-Li1 & $1.942(3)$ & N3-Fe1-O2 & $115.28(5)$ \\
O2-Li1 & $1.882(3)$ & O2-Fe1-C13 & $111.41(5)$ \\
N1-Si1 & $1.7345(12)$ & C7-P1-C13 & $115.07(7)$ \\
\hline
\end{tabular}

The coordination of iron(II) by oxygen, carbon and nitrogen in a fourfold geometry is not unknown. One example is $\left[\left\{\left(\mathrm{Ph}_{2} \mathrm{CN}\right)_{2} \mathrm{C}_{2} \mathrm{H}_{4}\right\} \mathrm{Fe}\left(\mathrm{CH}_{2} \mathrm{SiMe}_{3}\right)(\right.$ thf $\left.)\right]\left[\mathrm{BPh}_{4}\right]$ where the oxygen atom belongs to a coordinating THF molecule. ${ }^{[193]}$ Therefore the $\mathrm{Fe}-\mathrm{O}$ bond of 2.055(2) $\AA$ is considerably longer than in $\mathbf{3 2}$ where the O-donor is part of the ligand 
itself. Murso reported on the deprotonation of $\mathrm{Ph}_{2} \mathrm{PCH}_{2} \mathrm{Py}$ with $\left[\mathrm{Fe}\left\{\mathrm{N}\left(\mathrm{SiMe}_{3}\right)_{2}\right\}_{2}\right]$ at the $\mathrm{PCH}_{2}$ bridge yielding $\left[\mathrm{Fe}\left\{\mathrm{Ph}_{2} \mathrm{PC}(\mathrm{H}) \mathrm{Py}\right\}\left\{\mathrm{N}\left(\mathrm{SiMe}_{3}\right)_{2}\right\}\right]_{2} \cdot{ }^{[189]}$ In this complex, the $\mathrm{Fe}(\mathrm{II})$ dication is fourfold coordinated by two nitrogen and one phosphorus donor atoms as well as by a carbanion (Figure 5-10, left). Although there is no oxygen present, the coordination is quite similar to $\mathbf{3 2}$ and there is a $\mathrm{N}\left(\mathrm{SiMe}_{3}\right)_{2}$ ligand from the starting material as well. The reported average Fe-C bond length of 2.201(3) $\AA$ is almost the same as in 32 .

\subsubsection{Metal Exchange via a Lithium Dimer}

Metal exchange reactions with metal amides were conducted with the lithium dimer $\left[\mathrm{Li}\left\{\mathrm{Me}_{2} \mathrm{PCH}_{2} \mathrm{~S}\left(\mathrm{NSiMe}_{3}\right)_{2}\right\}\right]_{2}(4)$, too. The equimolar reaction of 4 and $\left[\mathrm{Cu}\left\{\mathrm{N}\left(\mathrm{SiMe}_{3}\right)_{2}\right\}\right]$ yielded colourless crystals after several days. The crystal structure revealed that the metal exchange did indeed proceed completely. Nevertheless, $S^{2-}$ ions are incorporated in the structure (Figure 5-11).

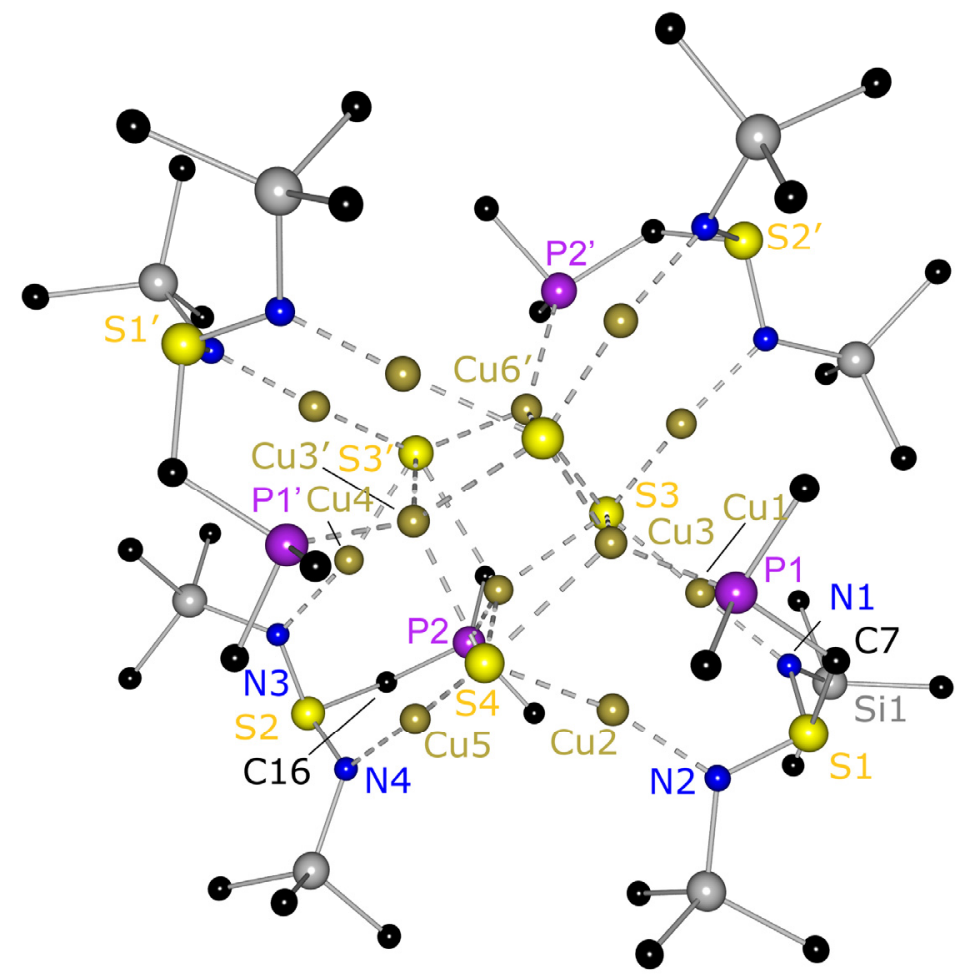

Figure 5-11: Molecular structure of $\left[\left\{\mathrm{Cu}\left(\mathrm{Me}_{2} \mathrm{PCH}_{2} \mathrm{~S}\left(\mathrm{NSiMe}_{3}\right)_{2}\right)\right\}_{4}\left\{\mathrm{Cu}_{2} \mathrm{~S}\right\}_{4}\right](33)$. Hydrogen atoms are omitted for clarity.

The compound crystallises in the monoclinic space group $\mathrm{C} 2 / \mathrm{c}$ with half of the cluster in the asymmetric unit. It consists of four $\left\{\mathrm{Me}_{2} \mathrm{PCH}_{2} \mathrm{~S}\left(\mathrm{NSiMe}_{3}\right)_{2}\right\}$ ligands which are bonding to two copper(I) ions each and a central $(\mathrm{Cu}(\mathrm{I}) \mathrm{S})_{4}$ distorted cube. Selected bond lengths and angles can be found in Table 5-5. 
It is remarkable that copper $(\mathrm{I})$ exhibits two different coordination geometries in the same complex. In sulphur diimido compounds the twofold linear coordination would usually be favoured. ${ }^{[1,35,194]}$ However, the formation of cubes or prisms between copper $(\mathrm{I})$ and chalcogens is a known coordination motif in cluster chemistry. ${ }^{[195]}$ Usually, the cluster formation can be controlled by varying the employed phosphane ligands and/or reaction conditions. ${ }^{[196]}$ The formation of such compounds according to the general reaction scheme (Equation 5-4) is very interesting. If the formation of clusters between copper $(\mathrm{I})$ and chalcogens is a stable and preferred arrangement, the source of $\mathrm{S}^{2-}$ in $\mathbf{3 3}$ thus could be explained as it is known that the $\mathrm{S}-\mathrm{N}$ and $\mathrm{N}-\mathrm{Si}$ bonds in $\mathrm{S}\left(\mathrm{NSiMe}_{3}\right)_{2}$ are easily cleaved. It could therefore act analogues to $E\left(\mathrm{SiMe}_{3}\right)_{2}$ according to Equation 5-4, releasing the $\mathrm{S}^{2-}$ dianion. This does not mean, however, that $\mathrm{S}\left(\mathrm{SiMe}_{3}\right)_{2}$ is formed in the reaction that leads to 33 .

$$
\begin{aligned}
& \text { 1. org. solvent } \\
& \begin{array}{cll}
\mathrm{CuX}+\mathrm{PR}_{2} \mathrm{R}^{\prime} & \left.\begin{array}{l}
2 . \mathrm{E}\left(\mathrm{SiMe}_{3}\right)_{2} \\
-\mathrm{SiMe}_{3} \mathrm{X}
\end{array} \mathrm{CU}_{2 n} \mathrm{E}_{\mathrm{n}}\left(\mathrm{PR}_{2} \mathrm{R}^{\prime}\right)_{m}\right] & \begin{array}{l}
\mathrm{X}=\mathrm{Cl}, \mathrm{OAc} \\
\mathrm{R}, \mathrm{R}^{\prime}=\text { org. group } \\
\mathrm{E}=\mathrm{S}, \mathrm{Se}
\end{array}
\end{array}
\end{aligned}
$$

Equation 5-4: General preparation of copper(I) chalcogen clusters; $n, m=$ integers. ${ }^{[197]}$

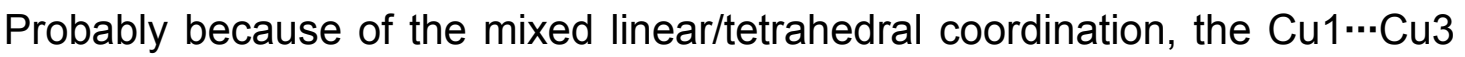
distance of $2.563 \AA$ is very short. However, this seems to be induced by the complex geometry and is not regarded a bond due to closed shell $d^{10}-d^{10}$ interactions. ${ }^{[198]}$

In contrast, Cu1 and Cu2 are $3.014 \AA$ apart, which is due to the wide bite of the sulphur diimido moiety and the coordination of the central $\mathrm{S}^{2-}$ ions to Cu1 and Cu2. Consequently, the N1-Cu1-S3 angle of $168.76(6)^{\circ}$ deviates considerably from $180^{\circ}$. This is different to other sulphur diimido copper complexes like $\left[\mathrm{Cu}\left\{\left(\mathrm{SC}_{8} \mathrm{H}_{5}\right) \mathrm{S}(\mathrm{NtBu})_{2}\right\}\right]_{2}(\mathrm{Cu} \cdots \mathrm{Cu}: 2.7852(6) \AA)^{[35]}$ and has its origin in the central (CuS $)_{4}$ cube which influences the coordination angles of the outer ligands.

Each ligand is binding to three different copper atoms. N1 and N2 are coordinating Cu1 and $\mathrm{Cu} 2$ in an almost linear fashion. The N1-Cu1-S3 and N2Cu2-S4 angles of $168.76(6)^{\circ}$ and $162.08(6)^{\circ}$, respectively, underline this very clearly. The N1-Cu1 (1.8902(17) $\AA$ ) and N2-Cu2 (1.9077(17) $\AA)$ bond lengths are comparable to the average values found in $\left[(\text { thf })_{2} \mathrm{Cu}_{3} \mathrm{Li}_{2} \mid\left\{(\mathrm{NtBu})_{3} \mathrm{~S}\right\}_{2}\right]$ (Cu-N:

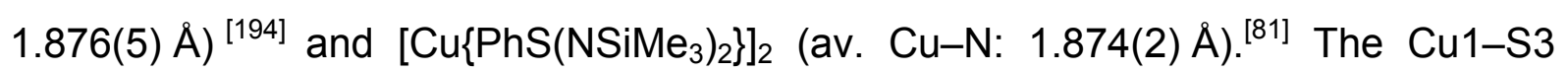
bond of 2.1299(5) $\AA$ is somewhat longer which is expected as sulphur is larger and easier to polarize than nitrogen. 
Table 5-5: Selected bond lengths $[\AA]$ and angles $\left[{ }^{\circ}\right]$ in 33

\begin{tabular}{llll}
\hline S1-N1 & $1.6089(19)$ & N1-S1-N2 & $109.59(10)$ \\
S1-N2 & $1.6131(19)$ & S1-C7-P1 & $118.46(12)$ \\
S1-C7 & $1.809(2)$ & N3-S2-N4 & $110.65(10)$ \\
P1-C7 & $1.864(2)$ & N1-Cu1-S3 & $168.76(6)$ \\
Cu1-N1 & $1.8902(17)$ & N2-Cu2-S4 & $162.08(6)$ \\
Cu1-S3 & $2.1299(5)$ & S3-Cu3-S4 & $112.471(17)$ \\
Cu2-N2 & $1.9077(17)$ & S4-Cu3-S4' & $85.44(2)$ \\
Cu2-S4 & $2.1630(5)$ & P1-Cu3-S3 & $124.94(2)$ \\
Cu3-P1 & $2.2950(6)$ & P1-Cu3-S4' & $102.98(2)$ \\
Cu3-S3 & $2.4384(6)$ & Cu2-S4-Cu3' & $131.82(2)$ \\
Cu3-S4 & $2.7265(6)$ & Cu5-S4-Cu3 & $125.92(2)$ \\
Cu3-S4' & $2.3390(5)$ & S1-N1-Si1 & $121.20(11)$ \\
N1-Si1 & $1.7323(19)$ & & \\
\hline
\end{tabular}

The copper(I) ions in the central (CuS $)_{4}$ cube are fourfold coordinated by three $\mathrm{S}^{2-}$ ions and one phosphorus atom of the ligand side-arm in a distorted tetrahedral manner. The angles around Cu3 for instance range from $85.44(2)^{\circ}$ to $124.94(2)^{\circ}$. The distortion is partly due to the different bond lengths inside the central cube; e. $g$. Cu3-S4 (2.7265(6) $\AA)$ is considerably longer than Cu3-S4' (2.3390(5) $\AA$ ). The bonds around Cu3, Cu3', Cu6 and Cu6' are also longer than the Cu-S bonds outside the cube.

$$
\begin{aligned}
& 2\left[\mathrm{Li}\left\{\mathrm{Me}_{2} \mathrm{PCH}_{2} \mathrm{~S}\left(\mathrm{NSiMe}_{3}\right)_{2}\right\}\right]_{2}+12\left[\mathrm{Cu}\left\{\mathrm{N}\left(\mathrm{SiMe}_{3}\right)_{2}\right\}\right]+4 \mathrm{~S} \\
& {\left[\left\{\mathrm{Cu}\left(\mathrm{Me}_{2} \mathrm{PCH}_{2} \mathrm{~S}\left(\mathrm{NSiMe}_{3}\right)_{2}\right)\right\}_{4}\left\{\mathrm{Cu}_{2} \mathrm{~S}\right\}_{4}\right]+4\left(\mathrm{Me}_{3} \mathrm{Si}\right)_{2} \mathrm{NN}\left(\mathrm{SiMe}_{3}\right)_{2}} \\
& 33
\end{aligned}
$$

Equation 5-5: Possible formation of 33.

Sulphur is always a minor contamination of the diimides employed in the reactions and could be the origin of the $S^{2-}$ ions. Otherwise, sulphur can be generated by decomposition of the ligand. Therefore, only a very small amount of crystals could be grown which were - apart from the X-ray structure and some NMR spectra - not further analysed. The reaction can probably be described according to Equation 5-5 although none of the by-products was verified. 
In summary, it has been shown in this work that copper(I) complexes of the new Janus head ligands are feasible even if the very stable lithium dimers are employed in the synthesis. For the future there are two possible routes: care must be taken to purify the starting materials even more thoroughly to prevent the formation of the copper/sulphur cluster 33. Alternatively, elemental sulphur could be added to the reaction in a stochiometric amount to synthesise $\mathbf{3 3}$ deliberately.

\subsection{Heterobimetallic Complexes}

As the copper complex $\mathbf{3 3}$ demonstrated, metal exchange with monovalent metals is possible, too. It was now of interest to prepare complexes of the ligand $\left\{\mathrm{Ph}_{2} \mathrm{PCH}_{2} \mathrm{~S}\left(\mathrm{NSiMe}_{3}\right)_{2}\right\}^{-}$and the heavier alkali metals to investigate the possible changes in coordination.

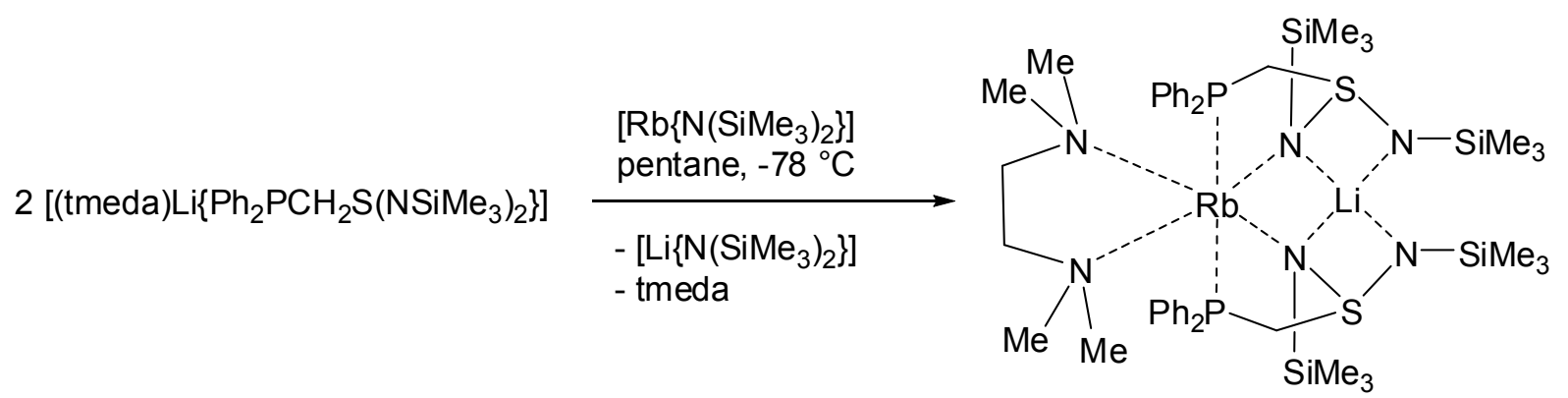

Equation 5-6: Preparation of [(tmeda) Rb $\left.\left\{\mathrm{Ph}_{2} \mathrm{PCH}_{2} \mathrm{~S}\left(\mathrm{NSiMe}_{3}\right)_{2}\right\}_{2} \mathrm{Li}\right]$ (34).

Compound 34 was prepared from reacting equimolar amounts of [(tmeda) $\left.L i\left\{\mathrm{Ph}_{2} \mathrm{PCH}_{2} \mathrm{~S}\left(\mathrm{NSiMe}_{3}\right)_{2}\right\}\right]$ (11) and $\left[\mathrm{Rb}\left\{\mathrm{N}\left(\mathrm{SiMe}_{3}\right)_{2}\right\}\right]$ at $-78{ }^{\circ} \mathrm{C}$ in pentane (Equation 5-6). Interestingly, the metal exchange was not complete. Only half an equivalent of lithium was exchanged with rubidium, resulting in the formation of a heterobimetallic dimeric complex with the molecular structure shown in Figure 5-12. As could have been expected, the lithium cation coordinated to four nitrogen atoms is persistent in the complex. In contrast, the rubidium cation is complexed by two nitrogen atoms of the diimido moieties, each of the phosphorus side-arms and the TMEDA molecule which completes the coordination. Consequently, both alkali metals have different coordination geometries and environments. The structure is bisected by a mirror plane which includes both metal ions. 


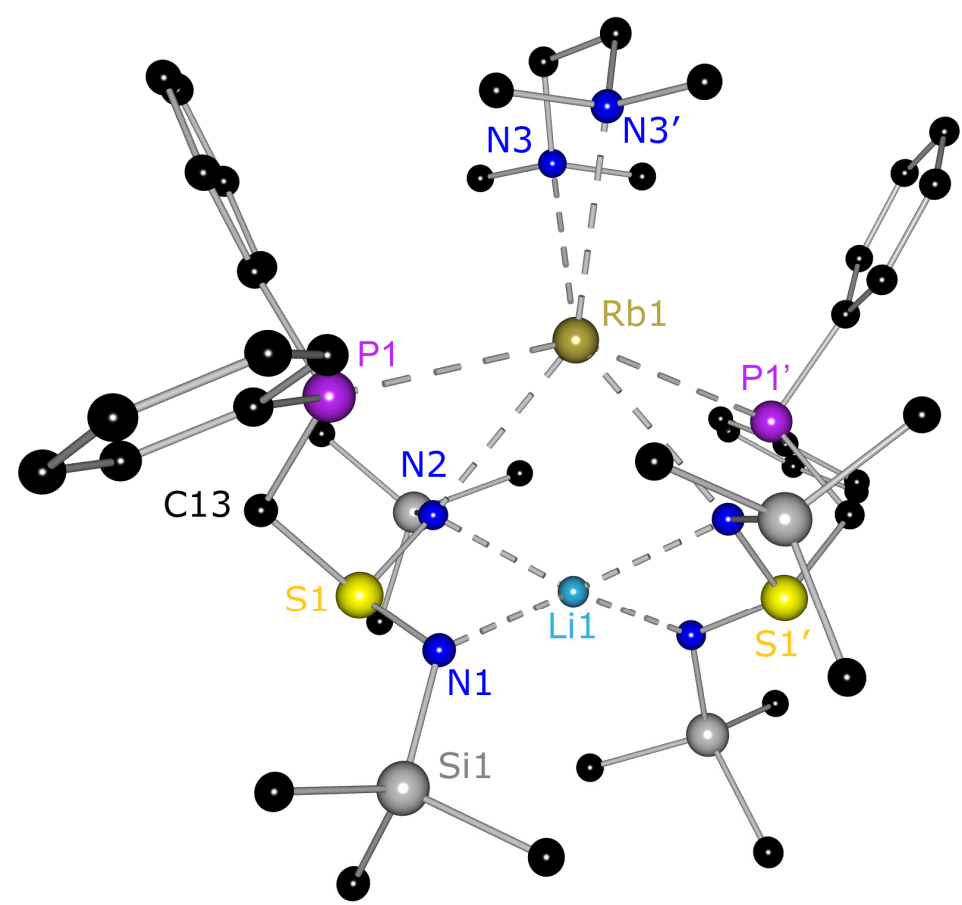

Figure 5-12: Molecular structure of $\left[(\operatorname{tmeda}) \mathrm{Rb}\left\{\mathrm{Ph}_{2} \mathrm{PCH}_{2} \mathrm{~S}\left(\mathrm{NSiMe}_{3}\right)_{2}\right\}_{2} \mathrm{Li}\right]$ (34). Hydrogen atoms are omitted for clarity.

Li1 has a distorted tetrahedral geometry with $\mathrm{Li}-\mathrm{N}$ bond lengths between 2.053(2) $\AA$ ( Li1-N1) and 2.262(2) $\AA$ (Li1-N2). The Li1-N2 bond is slightly elongated because $\mathrm{N} 2$ is also coordinating $\mathrm{Rb} 1$. The rubidium atom $\mathrm{Rb} 1$ is six fold coordinated in a severely distorted octahedral manner. It is interesting that one of the TMEDA molecules remains in the complex but has switched its coordination to rubidium. The $\mathrm{Rb}-\mathrm{N}$ and $\mathrm{Rb}-\mathrm{P}$ bonds are longer than $3.0 \AA$ which is normal and can be found in other complexes like $\left[\mathrm{Rb}(\text { thf }) \mathrm{P}\left(\mathrm{SiMe}_{3}\right)_{2}\right]_{\infty}{ }^{[199]},[\mathrm{RbP}(\mathrm{H})(\mathrm{dmp})]^{[200]}(\mathrm{dmp}=2,6-$ dimesitylphenyl) or $\left[\mathrm{Rb}\left\{\left(\left(\mathrm{Me}_{3} \mathrm{Si}\right)_{2} \mathrm{C}\right) \mathrm{P}\left(\mathrm{C}_{6} \mathrm{H}_{4}-2-\mathrm{CH}_{2} \mathrm{NMe}_{2}\right)_{2}\right\}\right]_{n}{ }^{[201]}$. Bond lengths and angles can be found in Table 5-6.

A CCDC search reveals that heterobimetallic complexes of lithium and rubidium are virtually unknown. There are only five examples of structurally characterised compounds of which three should be discussed. Mulvey et al. describe a heptalithium tetrarubidium mixed alkoxide peroxide wherein the clusters are linked by $\mathrm{Rb}-$ (TMEDA)-Rb bridges. ${ }^{[202]}$ The reported mean N-Rb bond length of $3.197 \AA$ is close to the value for Rb1-N3 (3.0458(16) $\AA$ ). Another compound with the constitution $\left[(t \mathrm{BuO})_{8} \mathrm{Li}_{4} \mathrm{Rb}_{4}\right]$ contains neither nitrogen nor phosphorus atoms. ${ }^{[203]}$ This is also the case in the third complex where lithium and rubidium are bridged by oxygen donors. $^{[204]}$ 
Table 5-6: Selected bond lengths $[\AA]]$ and angles $\left[^{\circ}\right]$ in 34 and 35

\begin{tabular}{llllll}
\hline \multicolumn{1}{c}{34} & \multicolumn{1}{c}{35} & & 34 & \multicolumn{1}{c}{35} \\
\hline S1-N1 & $1.6024(15)$ & $1.602(2)$ & N1-S1-N2 & $103.69(8)$ & $103.62(12)$ \\
S1-N2 & $1.6076(15)$ & $1.604(2)$ & S1-C13-P1 & $113.78(9)$ & $113.92(15)$ \\
S1-C13 & $1.8272(18)$ & $1.827(3)$ & N1-Li1-N2 & $71.43(6)$ & $71.07(9)$ \\
P1-C13 & $1.8515(18)$ & $1.853(3)$ & N1-Li1-N1' & $143.1(3)$ & $144.0(6)$ \\
N1-Li1 & $2.053(2)$ & $2.063(4)$ & N2-Li1-N2' & $130.4(2)$ & $128.2(5)$ \\
N2-Li1 & $2.262(2)$ & $2.263(5)$ & N2-M1-P1 & $59.15(3)$ & $60.43(5)$ \\
N2-M1 & $3.0646(15)$ & $2.934(2)$ & N2-M1-P1' & $97.97(3)$ & $101.35(5)$ \\
N3-M1 & $3.0458(16)$ & $2.936(3)$ & N2-M1-N2' & $84.11(6)$ & $87.87(9)$ \\
P1-M1 & $3.5996(5)$ & $3.5613(7)$ & N3-M1-N3' & $59.03(6)$ & $62.83(12)$ \\
N1-Si1 & $1.7106(16)$ & $1.712(2)$ & P1-M1-P1' & $150.818(18)$ & $156.23(4)$ \\
\hline
\end{tabular}

Interestingly, there are two signals in the ${ }^{7} \mathrm{Li}\left\{{ }^{1} \mathrm{H}\right\}$ NMR spectrum of 34 . The signal at $1.81 \mathrm{ppm}$ can be associated with the Rb/Li heterobimetallic complex 34 ; the other one at $1.02 \mathrm{ppm}$ seems to belong to the starting material [(tmeda) $\mathrm{Li}\left\{\mathrm{Ph}_{2} \mathrm{PCH}_{2} \mathrm{~S}\left(\mathrm{NSiMe}_{3}\right)_{2}\right.$ ] (11). This is certainly not due to contamination of the sample as crystals of $\mathbf{3 4}$ were dissolved for the NMR spectra and the sample was sealed airtight. In addition, the signal for the starting material is quite high. An impurity of such a high concentration should have been detected in the elemental analysis. However, this was not the case. When looking at the ${ }^{31} \mathrm{P}\left\{{ }^{1} \mathrm{H}\right\}$ spectrum the presence of the starting material in the sample gets even more obvious. There is a small broad signal at $-39 \mathrm{ppm}$, whereas the heterobimetallic complex $\mathbf{3 4}$ shows a signal at $-33 \mathrm{ppm}$. The integration reveals a ratio of 1 to 0.2 . All these analytical results indicate that the $\mathrm{Rb} / \mathrm{Li}$ complex is not retained completely in solution. Part of it seems to loose the rubidium. However, this is impossible because the charges would not be balanced anymore. Thus, another possibility has to be taken into account. The whole system is flexible in solution like the other structures discussed so far. Therefore, the TMEDA molecule is switching positions in solution and is also binding to the lithium cation. The shift of this new compound would then be very similar to 11 .

In essence, 34 represents the first heterobimetallic lithium/rubidium complex with nitrogen and phosphorus donor atoms. The coordination of phosphorus in such complexes is unprecedented. The compound is soluble in polar and unpolar organic solvents which is a great advantage and is due to the ligand periphery. Complexes of 
the heavier alkali metals usually tend to form larger aggregates which are poorly soluble. However, in the case of $\mathbf{3 4}$ this is averted by the ligand.

A reaction according to Equation 5-6 with $\left[\mathrm{K}\left\{\mathrm{N}\left(\mathrm{SiMe}_{3}\right)_{2}\right\}\right]$ yielded colourless crystals in the space group $C 2 / c$. The compound is the heterobimetallic lithium/potassium complex [(tmeda) $\left.\left.\mathrm{K}_{2} \mathrm{Ph}_{2} \mathrm{PCH}_{2} \mathrm{~S}\left(\mathrm{NSiMe}_{3}\right)_{2}\right\}_{2} \mathrm{Li}\right]$ (35) with the same structural features as 34. The molecular structure is shown in Figure 5-13.

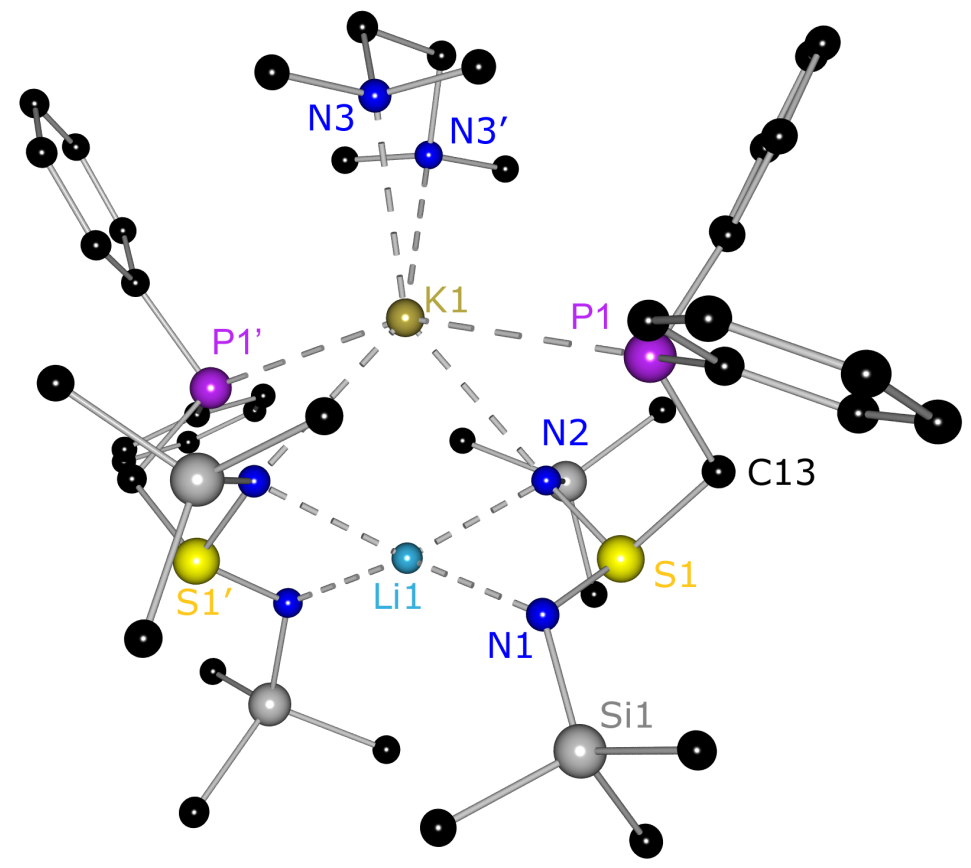

Figure 5-13: Molecular structure of [(tmeda) $\left.\left.\mathrm{K}_{2} \mathrm{Ph}_{2} \mathrm{PCH}_{2} \mathrm{~S}\left(\mathrm{NSiMe}_{3}\right)_{2}\right\}_{2} \mathrm{Li}\right]$ (35). Hydrogen atoms are omitted for clarity.

Unfortunately, the crystals were of poor quality and there still was some electron density unaccounted for in the refined model. The structure is shown here nevertheless for comparison reasons. Bond lengths and angles are discussed to give a general idea of their magnitude and the difference to [(tmeda)Rb $\left.\left\{\mathrm{Ph}_{2} \mathrm{PCH}_{2} \mathrm{~S}\left(\mathrm{NSiMe}_{3}\right)_{2}\right\}_{2} \mathrm{Li}\right](\mathbf{3 4})$.

The Li-N bond lengths are 2.069(4) $\AA$ (Li1-N1) and 2.254(4) $\AA$ (Li1-N2). The K1-P1 bond of $3.5613(7) \AA$ is almost the same as in the rubidium derivative (3.5996(5) $\AA$ ). This is probably due to the fact that the coordination of the lithium cation as a structural anchor already predetermines the position of the phosphorus side-arm. The potassium-nitrogen bond lengths almost have the same value (K1-N2: 2.933(2) $\AA$, K1-N3: $2.937(2) \AA$ ). The angles differ very little from the rubidium derivative. It is 
striking though, that the $\mathrm{P} 1-\mathrm{K} 1-\mathrm{P} 1 '$ angle of $156.23(4)^{\circ}$ is almost six degrees wider than in 34.

There are only a few examples of lithium/potassium heterobimetallic complexes. Several examples with butoxy ligands are supposed to be novel superbases; there are even $\mathrm{Li} / \mathrm{Na} / \mathrm{K}$ heterotrimetallic compounds. ${ }^{[146,147]}$ Westerhausen et al. synthesised mixed phosphanediide/silanolate heterotrimetallic aggregates with $\mathrm{Li} / \mathrm{K} / \mathrm{Sr}$ or $\mathrm{Li} / \mathrm{K} / \mathrm{Ba}{ }^{[205]}$ The average $\mathrm{K}-\mathrm{P}$ bond length of $3.365 \AA$ is shorter than in $\mathbf{3 5}$ though the structural features are also not very alike.

In 1998, our group presented a lithium/potassium heterobimetallic complex based on the $\left\{\mathrm{S}(\mathrm{N} t \mathrm{Bu})_{3}\right\}^{2-}$ ligand. ${ }^{[206]}$ The compound $\left[(\mathrm{thf})_{2} \mathrm{Li}_{4} \mathrm{~K}_{2}(\mathrm{OtBu})_{2}\left\{(\mathrm{~N} t \mathrm{Bu})_{3} \mathrm{~S}\right\}_{2}\right]$ was the first example of such a complex with a triazasulfite dianion. The metal ions are sandwiched between two $\left\{\mathrm{S}(\mathrm{N} t \mathrm{Bu})_{3}\right\}^{2-}$ caps with different coordination geometries. Thus, the arrangement is very different to 35 because there is no sidearm donation.

It would be interesting to see the results from metal exchange with $\left[\mathrm{Na}\left\{\mathrm{N}\left(\mathrm{SiMe}_{3}\right)_{2}\right\}\right]$ as it is not clear if this reaction would also be incomplete or if a monometallic compound could be obtained due to the smaller cation size. 


\section{CONCLUSION AND OUTLOOK}

In this thesis a new synthetic access to side-arm functionalized sulphur diimide ligands was developed. They can be tuned in their steric demand as well as in their electronic properties. Thus, this new ligand class shows outstanding performance in terms of ligand design. It can be adapted to accommodate the metal of choice and can stabilise metal cations like $\mathrm{Co}(\mathrm{II})$ and $\mathrm{Fe}$ (II) in low oxidation states. It became evident, that the side-arm has not as much influence on the coordination motif as the sulphur diimide moiety. As the $\mathrm{SN}_{2}$-chelating group is the structural anchor, the variation of the side-arm is almost without limits.

The coordination pattern can be changed by choosing the appropriate substituents or altering the sulphur diimido moiety. This became especially clear in $\left[\mathrm{Li}\left\{\mathrm{Me}_{2} \mathrm{~N}\left(\mathrm{C}_{6} \mathrm{H}_{4}\right) \mathrm{S}\left(\mathrm{NSiMe}_{3}\right)_{2}\right\}\right]_{2}$ (16) and [(tBuN $\left.)_{2} \mathrm{~S} \cdot\left\{\mathrm{LiMe}_{2} \mathrm{~N}\left(\mathrm{C}_{6} \mathrm{H}_{4}\right) \mathrm{S}(\mathrm{N} t \mathrm{Bu})_{2}\right\}_{2}\right]$ (19) which show a $(\mathrm{LiN})_{2}$ four-membered central ring (16) or a threefold/fourfold coordination (19) of the lithium ions. It would be of great interest to further investigate this phenomenon and tune the electronic properties in 16. For example the sulphur diimido moiety could be exchanged with $\mathrm{S}\left(\mathrm{NSiMe}_{3}\right)(\mathrm{N} t \mathrm{Bu}){ }^{[207]}$. Thus, an intermediate compound between 16 and 19 would be synthesised. To compare its coordination pattern to those of $\mathbf{1 6}$ and $\mathbf{1 9}$ would be of great interest because it is not clear which geometry would be favoured. In general, the introduction of different diimides into the complexes should be studied in order to gain more insight into the adaptability of the ligands which will be valuable for future work. The electronic and steric properties of the ligands were further altered by oxidising the phosphorus atom of the coordinating side-arm with oxygen (12), sulphur (8) and selenium (9). Thereby, the bite-angle of the ligand can be increased as well which will become important for the complexation of large metal cations in the future.

On the other hand, the choice of the diimide and the right reaction conditions yielded the metal-free ligand $\mathrm{Ph}_{2} \mathrm{PCH}_{2} \mathrm{~S}\left(\mathrm{NSiMe}_{3}\right)\left(\mathrm{HNSiMe}_{3}\right)$ (10). 10 represents an excellent starting material to introduce various metals because a salt elimination is no longer required. Thus, unwanted metal salts that could interfere with the final product are not formed. In addition, the versatility of possible metalating agents is greatly increased. The formation of $\mathbf{1 0}$ should be further investigated in order to fully understand the reaction. Unequivocally, a fast and more efficient access to this 
valuable starting material is required. It would be the basis of a vast range of various products. Not only bivalent metals but also metals with higher (or lower) valency could be coordinated by the ligand. If metal hexamethylsilylamides are used, the only by-product would be $\mathrm{HN}\left(\mathrm{SiMe}_{3}\right)_{2}$ which is easily removed. With the protonated ligand 10 , one of the key compounds of this thesis and for future reactions was synthesised.

The sulphur diimides with amine side-arm could be protonated as well in order to increase the choice of free ligands, which will play an important role in the synthesis of heterobimetallic complexes. This could be done by using either stochiometric amounts of water or $t \mathrm{BuNH}_{3} \mathrm{Cl}$, a reaction that has already been successfully employed with sulphur diimide derivatives. ${ }^{[30,80]}$

Protonation of the oxidised complexes $\left[\mathrm{Li}\left\{\mathrm{Me}_{2} \mathrm{P}(\mathrm{S}) \mathrm{CH}_{2} \mathrm{~S}\left(\mathrm{NSiMe}_{3}\right)_{2}\right\}\right]_{2}$ (8) and $\left[\mathrm{Li}\left\{\mathrm{Me}_{2} \mathrm{P}(\mathrm{Se}) \mathrm{CH}_{2} \mathrm{~S}\left(\mathrm{NSiMe}_{3}\right)_{2}\right\}\right]_{2}$ (9) should be tried as well. The unoxidised compounds of this type are not stable enough in hydrolysis reactions with water or $t B u N H_{3} \mathrm{Cl}$. However, the oxidation of the phosphorus atom probably stabilises the ligand.

During the course of this thesis it became obvious, that the precoordination of the lithium atom seems to be essential for transmetalation reactions. The dimeric complexes that are formed are too stable and undergo ligand scrambling in most cases, when they are reacted with metal halogenides, hydrides or amides. However, transmetalations were achieved with [(tmeda) $\left.L i\left\{\mathrm{Ph}_{2} \mathrm{PCH}_{2} \mathrm{~S}\left(\mathrm{NSiMe}_{3}\right)_{2}\right\}\right]$ (11). 11 is an excellent starting material for such reactions because the phosphorus side-arm is not coordinating to the lithium atom. It is therefore free to bind other metals and bring them into close spatial proximity of the two nitrogen chelating 'claws'. Lithium can then leave the complex as a stable TMEDA/ligand adduct. Via this route, a great variety of complexes with divalent metals was synthesised (26-31). The tripodal heteroscorpionate-like ligand is able to stabilise $s$ - and $d$-block metals in low oxidation states. When monovalent metals are employed, heterobimetallic complexes $(34,35)$ are generated, showing the great potential of this ligand class.

Another starting material for such reactions could be $\left[(\text { thf }) \mathrm{Li}\left\{\mathrm{Me}_{2} \mathrm{~N}\left(\mathrm{C}_{6} \mathrm{H}_{4}\right) \mathrm{S}\left(\mathrm{NSiMe}_{3}\right)_{2}\right\}\right]_{2}$ (17) which contains a free $\mathrm{NMe}_{2}$ side-arm. It would be very interesting to compare the metal complexes of the amino side-arm donating ligand with the phosphorus containing one. 
Alternatively, the transmetalation of the starting materials should be further pursued. The metal exchange with alkoxides works well which could be demonstrated by the synthesis of $\left[\mathrm{Na}\left\{\mathrm{Me}_{2} \mathrm{~N}\left(\mathrm{CH}_{2}\right)_{2} \mathrm{~N}(\mathrm{Me}) \mathrm{S}\left(\mathrm{NSiMe}_{3}\right)_{2}\right\}\right]_{2} \quad$ (22) and $\left[\mathrm{K}\left\{\mathrm{Me}_{2} \mathrm{~N}\left(\mathrm{C}_{6} \mathrm{H}_{4}\right)-\right.\right.$ $\left.\mathrm{S}\left(\mathrm{NSiMe}_{3}\right)_{2}\right]_{2}(18)$. By means of this method, the synthesis of a homologues series of alkali metal complexes is thinkable. Even a $\mathrm{Cu}(\mathrm{I})$ complex seems feasible as the syntheses of $\left[\mathrm{Cu}\left\{\left(\mathrm{C}_{6} \mathrm{H}_{4}\right) \mathrm{NMe}_{2}\right\}\right]^{[208]}$ and $\mathrm{CuOtBu}{ }^{[209]}$ have already been described in the literature.

More effort has also to be put into the transition metal complexes that were presented in this thesis. First of all, the yield has to be improved in order to make further analysis possible. Therefore, the whole reaction should probably be conducted in an argon glovebox. Especially the $\mathrm{Fe}(\mathrm{II})$ complex is of great interest because it can give insight into the donating properties of the ligand. By analysis of the spin state - which could be done via Mößbauer spectroscopy - the ligand field strength could be determined. In addition, the corresponding $\mathrm{Fe}$ (III) complex should be synthesised in order to compare the binding modes of the ligand.

For the future, the impact of the side-arm on the binding modes of the ligand should be further investigated. 3- and 4-picoline could yield different coordinations with a pendent side-arm. With such building blocks, the synthesis of polymeric structures would be possible. The use of side-arms with various donor sites is also intriguing. Thereby, the assembly of multimetallic systems or three-dimensional networks is feasible. These donor sites could be different in order to adapt to the coordination of various metals. 


\section{EXPERIMENTAL SECTION}

\subsection{General}

All experiments were carried out either in an atmosphere of purified dry nitrogen or argon, using modified Schlenk techniques ${ }^{[210]}$ or in an argon glovebox. Glassware was dried for several hours at $130^{\circ} \mathrm{C}$, assembled hot and cooled under vacuum. The solvents were freshly distilled from sodium-potassium alloy $\left(\mathrm{Et}_{2} \mathrm{O}\right.$, pentane), sodium (toluene) or potassium (THF, hexane) and degassed prior to use. $t$ BuLi in pentane and $n \mathrm{BuLi}$ in hexane were supplied by Chemetall $\mathrm{GmbH}$. The reactants were commercially available or synthesised according to published procedures $\left(\mathrm{S}(\mathrm{NtBu})_{2}{ }^{[211]}, \mathrm{S}\left(\mathrm{NSiMe}_{3}\right)_{2}{ }^{[212]},\left[(\mathrm{tmeda}) \mathrm{Li}\left(\mathrm{H}_{2} \mathrm{CPPh}_{2}\right)\right]^{[64,65,66]}\right)$.

\subsection{Analytical Methods}

\subsubsection{Mass spectrometry}

Mass spectra were recorded by electron ionization (El-MS: $75 \mathrm{eV}$ ) on a Finnigan MAT 95 spectrometer. The mass-to-charge ratios $(\mathrm{m} / \mathrm{z})$ of the fragment ions are based on the molecular masses of the isotopes with the highest natural abundance. The molecular peak $\mathrm{M}$ is defined as the compound without coordinating solvent.

\subsubsection{NMR spectroscopy}

All NMR spectra were recorded on Bruker Avance DPX 300 or DRX 500 spectrometers using TMS $\left({ }^{1} \mathrm{H},{ }^{13} \mathrm{C}\right.$ and $\left.{ }^{29} \mathrm{Si}\right), \mathrm{H}_{3} \mathrm{PO}_{4}\left({ }^{31} \mathrm{P}\right)$ and $\mathrm{LiCl}\left({ }^{7} \mathrm{Li}\right)$ as external reference and the protons of the deuterated solvents as internal standard. If not otherwise stated the spectra were recorded at room temperature and with ${ }^{1} \mathrm{H}$ or ${ }^{13} \mathrm{C}$ decoupling. The chemical shifts $\delta$ are given in ppm. Multiplicities are denominated $\mathrm{s}$ (singlet), d (doublet), tr (triplet), hept (heptet), br (broad signal). 


\subsubsection{Elemental analysis}

Elemental analyses were performed by the "Mikroanalytisches Labor des Instituts für Anorganische Chemie der Universität Göttingen" with an elementar Vario EL3 apparatus. The inclusion of argon, from canning in an argon drybox, led to systematic errors.

\subsection{Syntheses and Characterizations}

\subsubsection{General preparation of lithiated phosphanes}

A solution of $t \mathrm{BuLi}$ in pentane (1.5 M, 1.1 eq.) was reduced to half of its volume and the corresponding phosphane ( $\mathrm{PMe}_{3}, \mathrm{Me}_{2} \mathrm{PPh}, \mathrm{Ph}_{2} \mathrm{PMe}, \mathrm{PEt}_{3}, \mathrm{tBu}_{2} \mathrm{PMe} ; 1.0$ eq.) was added very slowly at rt. The solution was stirred over night and in the cases of $\mathrm{PEt}_{3}$ and $t \mathrm{Bu}_{2} \mathrm{PMe}$ refluxed for $1 \mathrm{~h}$. The white to light yellow precipitate was filtered and thoroughly washed with pentane several times.

a) $\left[\mathrm{Li}\left(\mathrm{H}_{2} \mathrm{CPMe}\right)\right]$ :

Yield: $75 \%$

${ }^{1} \mathrm{H}$-NMR (200.13 MHz, $\mathrm{d}_{8}$-THF): $\delta=-0.91\left(\mathrm{~s}, 2 \mathrm{H}, \mathrm{PCH} \mathrm{L}_{2} \mathrm{Li}\right), 0.76\left(\mathrm{~d}, 6 \mathrm{H},{ }^{2} \mathrm{JP}_{\mathrm{P}} \mathrm{H}\right.$ $\left.=1.64 \mathrm{~Hz}, \mathrm{P}\left(\mathrm{CH}_{3}\right)_{2}\right) ;{ }^{31} \mathbf{P}-\mathrm{NMR}\left(\mathbf{8 1 . 0 1} \mathbf{M H z}, \mathbf{d}_{\mathbf{8}}\right.$-THF): $\delta=-42.64$

b) $\left[\mathrm{Li}\left(\mathrm{H}_{2} \mathrm{CP}(\mathrm{Ph}) \mathrm{Me}\right)\right]$ :

Yield: $78 \%$

${ }^{1} \mathrm{H}-\mathrm{NMR}\left(200.13 \mathrm{MHz}, \mathrm{d}_{8}\right.$-THF): $\delta=-0.65\left(\mathrm{~d}, 2 \mathrm{H},{ }^{2} \mathrm{~J}_{\mathrm{P}-\mathrm{H}}=0.90 \mathrm{~Hz}, \mathrm{PCH}_{2} \mathrm{Li}\right)$, $1.02\left(\mathrm{~d}, 3 \mathrm{H},{ }^{2} \mathrm{~J}_{\mathrm{P}-\mathrm{H}}=2.41 \mathrm{~Hz}, \mathrm{PCH}_{3}\right), 6.82-6.89(\mathrm{~m}, 1 \mathrm{H}, \mathrm{p}-\mathrm{H}), 7.19-7.34(\mathrm{~m}, 4$ $\mathrm{H}, \mathrm{o}-\mathrm{H}, m-\mathrm{H}) ;{ }^{31} \mathrm{P}-\mathrm{NMR}\left(81.01 \mathrm{MHz}, \mathbf{d}_{8}-\mathrm{THF}\right): \delta=-20.48$

c) $\left[\mathrm{Li}\left(\mathrm{H}_{2} \mathrm{CPPh}\right)\right]$ :

Yield: $61 \%$, further analysis see ${ }^{[64,65,66]}$

d) $\left[\mathrm{Li}\left\{\mathrm{HC}\left(\mathrm{CH}_{3}\right) \mathrm{PEt}_{2}\right\}\right]$ :

Yield: $30 \%$

${ }^{1} \mathrm{H}-\mathrm{NMR}\left(200.13 \mathrm{MHz}, \mathrm{d}_{8}\right.$-THF): $\delta=-0.60-(-0.43)(\mathrm{m}, 1 \mathrm{H}, \mathrm{PCHLi}), 0.11(\mathrm{~s}, 3$ $\left.\mathrm{H}, \mathrm{PCH}_{3}\right), 0.95-1.09\left(\mathrm{~m}, 6 \mathrm{H}, \mathrm{PCH}_{2} \mathrm{CH}_{3}\right), 1.29-1.40\left(\mathrm{~m}, 4 \mathrm{H}, \mathrm{PCH}_{2} \mathrm{CH}_{3}\right) ;{ }^{31} \mathrm{P}-$ NMR (81.01 MHz, $\mathbf{d}_{8}$-THF): $\delta=-2.15$

e) $\left[\mathrm{Li}\left(\mathrm{H}_{2} \mathrm{CPtBu}\right)\right]$ :

Yield: $64 \%$, for further analysis see ${ }^{[60,84]}$ 


\subsection{2 $\left[\mathrm{Li}\left\{\mathrm{Me}_{2} \mathrm{PCH} \mathrm{CH}_{2} \mathrm{~S}(\mathrm{NtBu})_{2}\right\}\right]_{2}(1)$}

The product was synthesised according to Deuerlein ${ }^{[38]}$ and fully characterised.

Empirical formula: $\mathrm{C}_{22} \mathrm{H}_{52} \mathrm{Li}_{2} \mathrm{~N}_{4} \mathrm{P}_{2} \mathrm{~S}_{2}$

Molecular weight: $512.64 \mathrm{~g} / \mathrm{mol}$

Elemental analysis (found (calc.) [\%]): C 51.6 (51.6), H 10.9 (10.2), N 10.8 (10.9), S $12.3(12.5)$

${ }^{1} \mathrm{H}-N M R\left(500.13 \mathrm{MHz}, \mathbf{C}_{6} \mathrm{D}_{6}\right): \delta=0.896\left(\mathrm{~d}, 6 \mathrm{H},{ }^{2} J_{\mathrm{P}-\mathrm{H}}=0.55 \mathrm{~Hz}, \mathrm{P}\left(\mathrm{CH}_{3}\right)_{2}\right), 0.898(\mathrm{~d}$, $\left.6 \mathrm{H},{ }^{2} J_{\mathrm{P}-\mathrm{H}}=0.55 \mathrm{~Hz}, \mathrm{P}\left(\mathrm{CH}_{3}\right)_{2}\right), 1.44\left(\mathrm{~s}, 36 \mathrm{H}, \mathrm{C}\left(\mathrm{CH}_{3}\right)_{3}\right), 2.676\left(\mathrm{~d}, 2 \mathrm{H},{ }^{2} J_{\mathrm{P}-\mathrm{H}}=0.92\right.$ $\mathrm{Hz}, \mathrm{PCH}_{2} \mathrm{~S}$ ), 2.678 (d, $\left.2 \mathrm{H},{ }^{2} J_{\mathrm{P}-\mathrm{H}}=0.92 \mathrm{~Hz}, \mathrm{PCH}_{2} \mathrm{~S}\right)$

${ }^{7} \mathrm{Li}-N M R\left(194.37 \mathrm{MHz}, \mathrm{C}_{6} \mathrm{D}_{6}\right): \delta=2.22\left(\operatorname{tr},{ }^{1} J_{\mathrm{P}-\mathrm{Li}}=18.79 \mathrm{~Hz}, \mathrm{PLiP}\right)$

${ }^{13} \mathrm{C}-N M R\left(125.76 \mathrm{MHz}, \mathrm{C}_{6} \mathrm{D}_{6}\right): \delta=13.70\left(\mathrm{~d},{ }^{1} \mathrm{~J}_{\mathrm{P}-\mathrm{C}}=1.67 \mathrm{~Hz}, \mathrm{PCH}_{3}\right), 13.73\left(\mathrm{~d},{ }^{1} \mathrm{~J}_{\mathrm{P}-\mathrm{C}}=\right.$

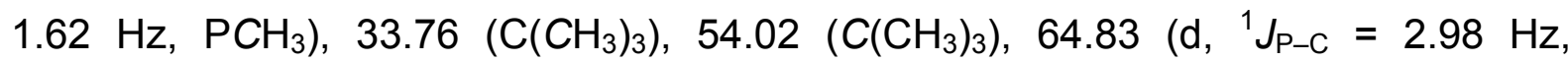
$\left.\mathrm{PCH}_{2} \mathrm{~S}\right), 64.92\left(\mathrm{~d},{ }^{1} \mathrm{~J}_{\mathrm{P}-\mathrm{C}}=3.00 \mathrm{~Hz}, \mathrm{PCH}_{2} \mathrm{~S}\right)$

${ }^{31}$ P-NMR (202.46 MHz, $\mathbf{C}_{6} \mathbf{D}_{6}$ ): $\delta=-67.00$ (hept, ${ }^{1} J_{\mathrm{P}-\mathrm{Li}}=18.17 \mathrm{~Hz}, \mathrm{Li} P \mathrm{Li}$ )

El-MS m/z [\%]: $235\left(\left\{\mathrm{Me}_{2} \mathrm{PCH}_{2} \mathrm{~S}(\mathrm{~N} t \mathrm{Bu})_{2}\right\}, 51\right), 178\left(\left\{\mathrm{Me}_{2} \mathrm{PCH}_{2} \mathrm{~S}(\mathrm{~N} t \mathrm{Bu})\right\}, 44\right), 162$ (\{MePCH$\left.\left.{ }_{2} \mathrm{~S}(\mathrm{~N} t \mathrm{Bu})_{2}\right\}, 30\right), 122\left(\left\{\mathrm{PCH}_{2} \mathrm{~S}(\mathrm{~N} t \mathrm{Bu})_{2}\right\}, 37\right), 75\left(\mathrm{Me}_{2} \mathrm{PCH}_{2}, 100\right), 57(t \mathrm{Bu})$

\subsection{3 $\left[\mathrm{Li}\left\{\mathrm{Ph}_{2} \mathrm{PCH}_{2} \mathrm{~S}(\mathrm{~N} t \mathrm{Bu})_{2}\right\}\right]_{2}(2)$}

The product was synthesised according to Deuerlein ${ }^{[38]}$ and fully characterised.

Empirical formula: $\mathrm{C}_{42} \mathrm{H}_{60} \mathrm{Li}_{2} \mathrm{~N}_{4} \mathrm{P}_{2} \mathrm{~S}_{2}$

Molecular weight: $760.93 \mathrm{~g} / \mathrm{mol}$

Elemental analysis, El-MS see ${ }^{[38]}$

${ }^{1} \mathrm{H}-\mathrm{NMR}\left(\mathbf{5 0 0 . 1 3} \mathbf{M H z}, \mathrm{C}_{6} \mathrm{D}_{6}\right): \delta=1.37$ (s, $\left.36 \mathrm{H}, \mathrm{C}\left(\mathrm{CH}_{3}\right)_{3}\right), 3.64\left(\mathrm{~s}, 4 \mathrm{H}, \mathrm{PCH}_{2} \mathrm{~S}\right), 6.98-$ $7.01(\mathrm{~m}, 4 \mathrm{H}, p-\mathrm{H}), 7.04-7.07(\mathrm{~m}, 8 \mathrm{H}, \mathrm{o}-\mathrm{H}), 7.56-7.59(\mathrm{~m}, 8 \mathrm{H}, m-\mathrm{H})$

${ }^{7}$ Li-NMR (194.37 MHz, $\left.\mathbf{C}_{6} \mathbf{D}_{6}\right): \delta=2.63\left(\operatorname{tr},{ }^{1} J_{\mathrm{P}-\mathrm{Li}}=12.80 \mathrm{~Hz}, \mathrm{PLiP}\right)$

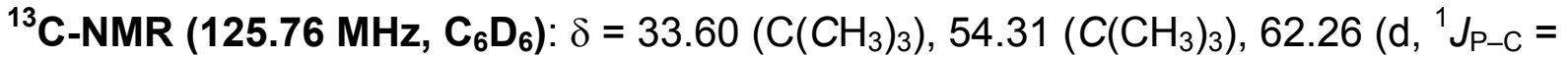
$\left.17.49 \mathrm{~Hz}, \mathrm{PCH}_{2} \mathrm{~S}\right), 128.63-128.76(\mathrm{~m}, \mathrm{o}-\mathrm{C}), 128.92(p-\mathrm{C}), 133.45-133.63\left(\mathrm{~m},{ }^{3} \mathrm{~J}_{\mathrm{P}-\mathrm{C}}=\right.$ 18.30 Hz, $m-\mathrm{C}), 137.79-137.82\left(\mathrm{~m},{ }^{1} J_{\mathrm{P}-\mathrm{C}}=3.76 \mathrm{~Hz}, i-\mathrm{C}\right)$

${ }^{31}$ P-NMR (202.46 MHz, $\mathrm{C}_{6} \mathrm{D}_{6}$ ): $\delta=-32.57$ (s br, LiPLi)

\subsection{4 $\left[\mathrm{Li}\left\{\mathrm{Me}(\mathrm{Ph}) \mathrm{PCH}_{2} \mathrm{~S}(\mathrm{~N} t \mathrm{Bu})_{2}\right\}\right]_{2}(3)$}

To a suspension of [Li $\left.\left\{\mathrm{H}_{2} \mathrm{CP}(\mathrm{Ph}) \mathrm{Me}\right\}\right](1.50 \mathrm{~g}, 11.4 \mathrm{mmol}, 2.0$ eq. $)$ in pentane $(30 \mathrm{~mL})$ was added $\mathrm{S}(\mathrm{NtBu})_{2}\left(1.98 \mathrm{~g}, 11.4 \mathrm{mmol}, 2.0 \mathrm{eq}\right.$.) very slowly at $-78{ }^{\circ} \mathrm{C}$. After $20 \mathrm{~min}$ at $-78^{\circ} \mathrm{C}$ the suspension was allowed to warm to $\mathrm{rt}$ and stirred for $24 \mathrm{~h}$. The yellow- 
orange solution was reduced to $2 / 3$ of its volume and stored at $-25^{\circ} \mathrm{C}$. After $3 \mathrm{~d}$ colourless crystals suitable for structural analysis were obtained.

Empirical formula: $\mathrm{C}_{32} \mathrm{H}_{56} \mathrm{Li}_{2} \mathrm{~N}_{4} \mathrm{P}_{2} \mathrm{~S}_{2}$

Yield: $2.65 \mathrm{~g}, 4.16 \mathrm{mmol}, 73 \%$
Molecular weight: $636.78 \mathrm{~g} / \mathrm{mol}$

Melting point: $125.5^{\circ} \mathrm{C}$ (decomp.)

Elemental analysis (found (calc.) [\%]): C 59.33 (60.36), H 8.75 (8.86), N 8.79 (8.80), S 10.26 (10.07)

${ }^{1} \mathrm{H}-\mathrm{NMR}\left(\mathbf{5 0 0 . 1 3} \mathbf{~ M H z}, \mathrm{C}_{6} \mathrm{D}_{6}\right): \delta=1.20\left(\mathrm{~s}, 3 \mathrm{H}, \mathrm{PCH}_{3}\right), 1.32\left(\mathrm{~s}, 3 \mathrm{H}, \mathrm{PCH}_{3}\right), 1.37(\mathrm{~s}$, $\left.9 \mathrm{H}, \mathrm{C}\left(\mathrm{CH}_{3}\right)_{3}\right), 1.38\left(\mathrm{~s}, 9 \mathrm{H}, \mathrm{C}\left(\mathrm{CH}_{3}\right)_{3}\right), 1.43\left(\mathrm{~s}, 9 \mathrm{H}, \mathrm{C}\left(\mathrm{CH}_{3}\right)_{3}\right), 1.45\left(\mathrm{~s}, 9 \mathrm{H}, \mathrm{C}\left(\mathrm{CH}_{3}\right)_{3}\right)$, 2.96-3.12 (m, $\left.4 \mathrm{H}, \mathrm{PCH}_{2} \mathrm{~S}\right)$, 7.02-7.05 (m, $\left.2 \mathrm{H}, p-\mathrm{H}\right)$, 7.08-7.12 (m, $\left.4 \mathrm{H}, \mathrm{o}-\mathrm{H}\right)$, 7.47$7.51(\mathrm{~m}, 4 \mathrm{H}, \mathrm{m}-\mathrm{H})$

${ }^{7}$ Li-NMR (194.37 MHz, $\mathrm{C}_{6} \mathrm{D}_{6}$ ): $\delta=2.41\left(\operatorname{tr},{ }^{1} \mathrm{~J}_{\mathrm{P}-\mathrm{Li}}=13.43 \mathrm{~Hz}, \mathrm{PLiP}\right)$

${ }^{13}$ C-NMR (125.76 MHz, $\left.\mathrm{C}_{6} \mathrm{D}_{6}\right): \delta=13.43\left(\mathrm{dd},{ }^{1} \mathrm{~J}_{\mathrm{P}-\mathrm{C}}=4.73 \mathrm{~Hz},{ }^{3} \mathrm{~J}_{\mathrm{P}-\mathrm{C}}=3.01 \mathrm{~Hz}\right.$, $\left.\mathrm{PLiPCH}_{3}\right), 13.60\left(\mathrm{dd},{ }^{1} \mathrm{JP}_{-\mathrm{C}}=5.02 \mathrm{~Hz},{ }^{3} \mathrm{~J}_{\mathrm{P}-\mathrm{C}}=2.44 \mathrm{~Hz}, \mathrm{PLiPCH}_{3}\right), 33.51-33.67(\mathrm{~m}$, $\left.\mathrm{C}\left(\mathrm{CH}_{3}\right)_{3}\right)$, 53.94-54.40 (m, $\left.\mathrm{C}\left(\mathrm{CH}_{3}\right)_{3}\right), 64.10-64.27\left(\mathrm{~m}, \mathrm{PCH}_{2} \mathrm{~S}\right), 128.56-128.70(\mathrm{~m}, \mathrm{o}-$ C), $131.89-132.27(\mathrm{~m}, p-\mathrm{C}), 139.65\left(\mathrm{dd},{ }^{3} \mathrm{~J}_{\mathrm{P}-\mathrm{C}}=3.49 \mathrm{~Hz},{ }^{5} \mathrm{~J}_{\mathrm{P}-\mathrm{C}}=1.99 \mathrm{~Hz}, m-\mathrm{C}\right)$, $139.97\left(\mathrm{dd},{ }^{1} \mathrm{~J}_{\mathrm{P}-\mathrm{C}}=3.16 \mathrm{~Hz},{ }^{3} \mathrm{~J}_{\mathrm{P}-\mathrm{C}}=2.24 \mathrm{~Hz}, i-\mathrm{C}\right)$

${ }^{31} \mathrm{P}$-NMR (202.46 MHz, $\left.\mathrm{C}_{6} \mathbf{D}_{6}\right): \delta=-51.77(\mathrm{~s} \mathrm{br}, \mathrm{Li} P \mathrm{Li})$

El-MS m/z [\%]: $312\left(\left\{\mathrm{Me}(\mathrm{Ph}) \mathrm{PCH}_{2} \mathrm{~S}(\mathrm{NtBu})_{2}\right\}, 7\right), 297\left(\left\{\mathrm{PhPCH}_{2} \mathrm{~S}(\mathrm{NtBu})_{2}\right\}, 93\right), 240$ ( $\left.\left\{\mathrm{Me}(\mathrm{Ph}) \mathrm{PCH}_{2} \mathrm{~S}(\mathrm{~N} t \mathrm{Bu})\right\}, 72\right), 184\left(\left\{\mathrm{Me}(\mathrm{Ph}) \mathrm{PCH}_{2} \mathrm{SN}\right\}, 39\right), 137\left(\left\{\mathrm{Me}(\mathrm{Ph}) \mathrm{PCH}_{2}\right\}, 100\right)$, 109 (PPh, 47), 77 (Ph, 7), 57 (tBu, 18)

\subsection{5 $\left[\mathrm{Li}\left\{\mathrm{Me}_{2} \mathrm{PCH}_{2} \mathrm{~S}\left(\mathrm{NSiMe}_{3}\right)_{2}\right\}\right]_{2}(4)$}

To a suspension of $\left[\mathrm{Li}\left(\mathrm{H}_{2} \mathrm{CPMe}\right) \mathrm{C}(0.60 \mathrm{~g}, 7.32 \mathrm{mmol}, 2.0\right.$ eq.) in pentane $(40 \mathrm{~mL})$ $\mathrm{S}\left(\mathrm{NSiMe}_{3}\right)_{2}\left(1.51 \mathrm{~g}, 7.32 \mathrm{mmol}, 2.0 \mathrm{eq}\right.$.) was added very slowly at $-78^{\circ} \mathrm{C}$. After $20 \mathrm{~min}$ at $-78^{\circ} \mathrm{C}$ the suspension was allowed to warm to $\mathrm{rt}$ and stirred for $24 \mathrm{~h}$. The green-yellow solution was filtered, reduced to $1 / 2$ of its volume and stored at $-25^{\circ} \mathrm{C}$. Colourless crystals, suitable for structural analysis were obtained after two days.

Empirical formula: $\mathrm{C}_{18} \mathrm{H}_{52} \mathrm{Li}_{2} \mathrm{~N}_{4} \mathrm{P}_{2} \mathrm{~S}_{2} \mathrm{Si}_{4}$

Yield: $1.64 \mathrm{~g}, 2.85 \mathrm{mmol}, 78 \%$
Molecular weight: $576.93 \mathrm{~g} / \mathrm{mol}$

Melting point: $147.3^{\circ} \mathrm{C}$ (decomp.)

Elemental analysis (found (calc.) [\%]): C 37.21 (37.47), H 9.00 (9.08), N 9.92 (9.71), S 11.14 (11.12)

${ }^{1} \mathrm{H}-\mathrm{NMR}\left(\mathbf{5 0 0 . 1 3} \mathbf{M H z}, \mathrm{C}_{6} \mathrm{D}_{6}\right): \delta=0.32\left(\mathrm{~s}, 36 \mathrm{H}, \mathrm{NSi}\left(\mathrm{CH}_{3}\right)_{3}\right), 0.83\left(\mathrm{~s}, 12 \mathrm{H}, \mathrm{P}\left(\mathrm{CH}_{3}\right)_{2}\right)$, $2.65\left(\mathrm{~s}, 4 \mathrm{H}, \mathrm{PCH}_{2} \mathrm{~S}\right)$

${ }^{7}$ Li-NMR (194.37 MHz, $\left.\mathrm{C}_{6} \mathrm{D}_{6}\right): \delta=2.19\left(\operatorname{tr},{ }^{1} \mathrm{JP}_{\mathrm{PLi}}=21.25 \mathrm{~Hz}, \mathrm{PLiP}\right)$ 
${ }^{13} \mathrm{C}-\mathrm{NMR}\left(125.77 \mathrm{MHz}, \mathrm{C}_{6} \mathrm{D}_{6}\right): \delta=2.92\left(\mathrm{NSi}\left(\mathrm{CH}_{3}\right)_{3}\right), 12.92\left(\mathrm{~d},{ }^{1} \mathrm{~J}_{\mathrm{P}-\mathrm{C}}=3.31 \mathrm{~Hz}\right.$, $\left.\mathrm{P}\left(\mathrm{CH}_{3}\right)_{2}\right), 66.51\left(\mathrm{~d},{ }^{1} \mathrm{~J}_{\mathrm{P}-\mathrm{C}}=10.94 \mathrm{~Hz}, \mathrm{PCH}_{2} \mathrm{~S}\right)$

${ }^{29} \mathrm{Si}-\mathrm{NMR}\left(99.36 \mathrm{MHz}, \mathrm{C}_{6} \mathrm{D}_{6}\right): \delta=-2.71$

${ }^{31}$ P-NMR (202.46 MHz, $\mathbf{C}_{6} \mathbf{D}_{6}$ ): $\delta=-67.87$ (hept, ${ }^{1} J_{\mathrm{P}-\mathrm{Li}}=20.84 \mathrm{~Hz}, \mathrm{Li} P \mathrm{Li}$ )

\subsection{6 $\left[\mathrm{Li}\left\{\mathrm{Ph}_{2} \mathrm{PCH}_{2} \mathrm{~S}\left(\mathrm{NSiMe}_{3}\right)_{2}\right\}\right]_{2}(5)$}

$\mathrm{S}\left(\mathrm{NSiMe}_{3}\right)_{2}(0.22 \mathrm{~g}, 1.06 \mathrm{mmol}, 2.0$ eq. $)$ was slowly added to a slurry of $\left[\mathrm{Li}\left(\mathrm{H}_{2} \mathrm{CPPh}_{2}\right)\right](0.22 \mathrm{~g}, 1.06 \mathrm{mmol}, 2.0$ eq. $)$ in pentane $(15 \mathrm{~mL})$ at $-78^{\circ} \mathrm{C}$. After stirring overnight at $\mathrm{rt}$ the clear solution was reduced in volume and kept at $-30{ }^{\circ} \mathrm{C}$ for four days, yielding colourless crystals.

Empirical formula: $\mathrm{C}_{38} \mathrm{H}_{60} \mathrm{Li}_{2} \mathrm{~N}_{4} \mathrm{P}_{2} \mathrm{~S}_{2} \mathrm{Si}_{4}$

Molecular weight: $825.21 \mathrm{~g} / \mathrm{mol}$

Yield (crystals): $0.25 \mathrm{~g}, 0.30 \mathrm{mmol}, 29 \%$

Elemental analysis (found (calc.) [\%]): C 54.79 (55.31), H 7.32 (7.33), N 7.36 (6.79), S 8.02 (7.77)

${ }^{1} \mathrm{H}-\mathrm{NMR}\left(\mathbf{5 0 0 . 1 3} \mathbf{M H z}, \mathrm{C}_{6} \mathrm{D}_{6}\right): \delta=0.28\left(\mathrm{~s}, 36 \mathrm{H}, \mathrm{NSi}\left(\mathrm{CH}_{3}\right)_{3}\right), 3.61\left(\mathrm{~s}, 4 \mathrm{H}, \mathrm{PCH}_{2} \mathrm{~S}\right)$, 6.97-7.06 (m, $12 \mathrm{H}, \mathrm{o}-\mathrm{H}, p-\mathrm{H}), 7.47-7.50(\mathrm{~m}, 8 \mathrm{H}, m-\mathrm{H})$

${ }^{7}$ Li-NMR (194.37 MHz, $\left.\mathrm{C}_{6} \mathrm{D}_{6}\right): \delta=2.62$

${ }^{13} \mathrm{C}-\mathrm{NMR}\left(125.76 \mathrm{MHz}, \mathrm{C}_{6} \mathrm{D}_{6}\right): \delta=2.74\left(\mathrm{NSi}\left(\mathrm{CH}_{3}\right)_{3}\right), 64.99\left(\mathrm{~d},{ }^{1} \mathrm{~J}_{\mathrm{P}-\mathrm{C}}=11.80 \mathrm{~Hz}\right.$, $\mathrm{PCH}_{2} \mathrm{~S}$ ), 128.84 (pseudo tr, o-C), $129.21(p-\mathrm{C}), 133.42-133.67\left(\mathrm{~m},{ }^{3} \mathrm{~J}_{\mathrm{P}-\mathrm{C}}=18.09 \mathrm{~Hz}\right.$, $m-\mathrm{C}), 136.57$ (i-C)

${ }^{29} \mathrm{Si}-\mathrm{NMR}\left(99.36 \mathrm{MHz}, \mathrm{C}_{6} \mathrm{D}_{6}\right): \delta=-1.78$

${ }^{31}$ P-NMR (202.46 MHz, $\left.\mathrm{C}_{6} \mathrm{D}_{6}\right): \delta=-33.19(\mathrm{~s} \mathrm{br})$

\subsection{7 $\left[\mathrm{Li}\left\{\mathrm{Me}(\mathrm{Ph}) \mathrm{PCH}_{2} \mathrm{~S}\left(\mathrm{NSiMe}_{3}\right)_{2}\right\}\right]_{2}(6)$}

To a suspension of [ $\left.\mathrm{Li}\left\{\mathrm{H}_{2} \mathrm{CP}(\mathrm{Ph}) \mathrm{Me}\right\}\right]$ ( $0.33 \mathrm{~g}, 2.5 \mathrm{mmol}, 2.0$ eq.) in pentane (15 mL) was added $\mathrm{S}\left(\mathrm{NSiMe}_{3}\right)_{2}\left(0.52 \mathrm{~g}, 2.5 \mathrm{mmol}, 2.0\right.$ eq.) very slowly at $-78^{\circ} \mathrm{C}$. After $20 \mathrm{~min}$ at $-78^{\circ} \mathrm{C}$ the suspension was allowed to warm to $\mathrm{rt}$ and stirred for $24 \mathrm{~h}$. The cleared yellow solution was reduced to $2 / 3$ of its volume and stored at $-25^{\circ} \mathrm{C}$. After two weeks, colourless crystals suitable for structural analysis, were obtained.

A: first diastereomer, B: second diastereomer, ratio 1:0.8

Empirical formula: $\mathrm{C}_{28} \mathrm{H}_{56} \mathrm{Li}_{2} \mathrm{~N}_{4} \mathrm{P}_{2} \mathrm{~S}_{2} \mathrm{Si}_{4}$

Molecular weight: $701.07 \mathrm{~g} / \mathrm{mol}$

${ }^{1} \mathrm{H}-\mathrm{NMR}\left(\mathbf{3 0 0 . 1 3} \mathrm{MHz}, \mathrm{C}_{6} \mathrm{D}_{6}\right): \delta=0.27$ (s, $\left.9 \mathrm{H}, \mathrm{NSi}\left(\mathrm{CH}_{3}\right)_{3}(\mathrm{~B})\right), 0.28(\mathrm{~s}, 9 \mathrm{H}$, $\left.\mathrm{NSi}\left(\mathrm{CH}_{3}\right)_{3}(\mathbf{A})\right), 0.33$ (s, $\left.9 \mathrm{H}, \mathrm{NSi}\left(\mathrm{CH}_{3}\right)_{3}(\mathbf{A})\right), 0.36$ (s, $\left.9 \mathrm{H}, \mathrm{NSi}\left(\mathrm{CH}_{3}\right)_{3}(\mathbf{B})\right), 1.13$ (s br, 
$\left.3 \mathrm{H}, \mathrm{PCH}_{3}(\mathbf{A})\right), 1.26$ (s br, $\left.3 \mathrm{H}, \mathrm{PCH}_{3}(\mathbf{B})\right)$, 2.91-3.09 (m, $\left.4 \mathrm{H}, \mathrm{PCH}_{2} \mathrm{~S}\right), 6.99-7.15$ (m, $6 \mathrm{H}, \mathrm{o}-\mathrm{H}, p-\mathrm{H}), 7.34-7.43(\mathrm{~m}, 4 \mathrm{H}, m-\mathrm{H})$

${ }^{7} \mathrm{Li}-\mathrm{NMR}\left(116.6 \mathrm{MHz}, \mathrm{C}_{6} \mathrm{D}_{6}\right): \delta=2.02\left(\mathrm{tr},{ }^{1} \mathrm{~J}_{\mathrm{P}-\mathrm{Li}}=17.62 \mathrm{~Hz}, \mathrm{PLiP}\right)$

${ }^{13} \mathrm{C}-\mathrm{NMR}\left(75.47 \mathrm{MHz}, \mathrm{C}_{6} \mathrm{D}_{6}\right): \quad \delta=2.74 \quad\left(\mathrm{NSi}\left(\mathrm{CH}_{3}\right)_{3}\right), \quad 2.78 \quad\left(\mathrm{NSi}\left(\mathrm{CH}_{3}\right)_{3}\right), \quad 2.81$ $\left(\mathrm{NSi}\left(\mathrm{CH}_{3}\right)_{3}\right), 2.84\left(\mathrm{NSi}\left(\mathrm{CH}_{3}\right)_{3}\right)$, 12.60-12.68 (m, PLiPCH$\left.)_{3}\right)$, 12.83-12.90 (m, PLiPCH$)_{3}$, 66.11-66.35 (m, $\left.\mathrm{PCH}_{2} \mathrm{~S}\right), 128.70-128.82$ (m, o-C), $128.99(p-\mathrm{C}), 131.70-132.13$ (m, $m-\mathrm{C}), 138.00(i-\mathrm{C}), 138.42(i-\mathrm{C})$

${ }^{29} \mathrm{Si}-N M R\left(59.63 \mathrm{MHz}, \mathrm{C}_{6} \mathrm{D}_{6}\right): \delta=-3.67,-2.66,-2.47,-1.79$

${ }^{31}$ P-NMR (121.49 MHz, $\left.\mathbf{C}_{6} \mathrm{D}_{6}\right): \delta=-(53.69-52.17)(\mathrm{m}, \mathrm{Li} P \mathrm{Li})$

\subsection{8 $\left.\left[\mathrm{Li}_{2} \mathrm{Et}_{2} \mathrm{PCH}(\mathrm{Me}) \mathrm{S}\left(\mathrm{NSiMe}_{3}\right)_{2}\right\}\right]_{2}(7)$}

To a suspension of $\left[\mathrm{Li}\left\{\mathrm{HC}\left(\mathrm{CH}_{3}\right) \mathrm{PEt}_{2}\right\}\right](0.13 \mathrm{~g}, 0.81 \mathrm{mmol}, 2.0 \mathrm{eq}$.$) in pentane$ $(10 \mathrm{~mL}) \mathrm{S}\left(\mathrm{NSiMe}_{3}\right)_{2}\left(0.17 \mathrm{~g}, 0.81 \mathrm{mmol}, 2.0\right.$ eq.) was added very slowly at $-78{ }^{\circ} \mathrm{C}$. After 20 min at $-78{ }^{\circ} \mathrm{C}$ the suspension was allowed to warm to rt and stirred for $24 \mathrm{~h}$. The yellow solution was reduced to $1 / 2$ of its volume and stored at $-25^{\circ} \mathrm{C}$. After one week, colourless crystals suitable for structural analysis were obtained.

A: first diastereomer, B: second diastereomer

Empirical formula: $\mathrm{C}_{24} \mathrm{H}_{64} \mathrm{Li}_{2} \mathrm{~N}_{4} \mathrm{P}_{2} \mathrm{~S}_{2} \mathrm{Si}_{4}$

Yield: $0.21 \mathrm{~g}, 0.32 \mathrm{mmol}, 80 \%$
Molecular weight: $661.09 \mathrm{~g} / \mathrm{mol}$

Melting point: $138.9^{\circ} \mathrm{C}$ (decomp.)

Elemental analysis (found (calc.) [\%]): C 42.96 (43.60), H 9.58 (9.76), N 8.70 (8.47), S 9.83 (9.70)

${ }^{1} \mathrm{H}-\mathrm{NMR}\left(500.13 \mathrm{MHz}, \mathbf{C}_{6} \mathbf{D}_{6}\right): \delta=0.36-0.37\left(\mathrm{~m}, 36 \mathrm{H}, \mathrm{NSi}\left(\mathrm{CH}_{3}\right)_{3}\right)$, 0.92-1.02 (m, $\left.12 \mathrm{H}, \mathrm{PCH}_{2} \mathrm{CH}_{3}\right), 1.09-1.16 / 1.24-1.32 / 1.43-1.54\left(\mathrm{~m}, 6 \mathrm{H}, \mathrm{PCH}\left(\mathrm{CH}_{3}\right) \mathrm{S}\right), 1.17-1.22$ (m, $8 \mathrm{H}, \mathrm{PCH}_{2} \mathrm{CH}_{3}$ )

The signals for the $\mathrm{PCH}\left(\mathrm{CH}_{3}\right) \mathrm{S}$ groups are overlaid by the signals of the $\mathrm{PCH}_{2} \mathrm{CH}_{3}$ groups, which is due to the two diastereomers. An unambiguous assignment is not possible.

${ }^{7}$ Li-NMR (194.37 MHz, $\left.\mathbf{C}_{6} \mathrm{D}_{6}\right): \delta=2.27\left(\operatorname{tr},{ }^{1} \mathrm{~J}_{\mathrm{P}-\mathrm{Li}}=17.84 \mathrm{~Hz}, \mathrm{PLiP}(\mathbf{A})\right), 2.37\left(\mathrm{tr},{ }^{1} \mathrm{~J}_{\mathrm{P}-\mathrm{Li}}\right.$ $=18.12 \mathrm{~Hz}, \mathrm{PLiP}(\mathrm{B}))$

${ }^{13} \mathrm{C}-\mathrm{NMR}\left(125.77 \mathrm{MHz}, \mathbf{C}_{6} \mathrm{D}_{6}\right): \delta=3.09-3.42\left(\mathrm{~m}, \mathrm{NSi}\left(\mathrm{CH}_{3}\right)_{3}\right), 10.46-11.21(\mathrm{~m}$, $\left.\mathrm{PCH}_{2} \mathrm{CH}_{3}, \mathrm{PCH}_{2} \mathrm{CH}_{3}\right), 13.66\left(\mathrm{~d},{ }^{2} J_{\mathrm{P}-\mathrm{C}}=5.86 \mathrm{~Hz}, \mathrm{PCH}\left(\mathrm{CH}_{3}\right) \mathrm{S}\right), 14.54\left(\mathrm{~d},{ }^{2} J_{\mathrm{P}-\mathrm{C}}=5.78\right.$ $\left.\mathrm{Hz}, \mathrm{PCH}\left(\mathrm{CH}_{3}\right) \mathrm{S}\right), 16.96\left(\mathrm{~d},{ }^{2} J_{\mathrm{P}-\mathrm{C}}=6.06 \mathrm{~Hz}, \mathrm{PCH}\left(\mathrm{CH}_{3}\right) \mathrm{S}\right), 17.53\left(\mathrm{~d},{ }^{2} J_{\mathrm{P}-\mathrm{C}}=7.19 \mathrm{~Hz}\right.$, $\left.\mathrm{PCH}\left(\mathrm{CH}_{3}\right) \mathrm{S}\right), 63.34\left(\mathrm{~d},{ }^{1} J_{\mathrm{P}-\mathrm{C}}=13.48 \mathrm{~Hz}, \mathrm{PCH}\left(\mathrm{CH}_{3}\right) \mathrm{S}(\mathbf{A})\right), 64.87\left(\mathrm{~d},{ }^{1} J_{\mathrm{P}-\mathrm{C}}=14.34\right.$ $\left.\mathrm{Hz}, \mathrm{PCH}\left(\mathrm{CH}_{3}\right) \mathrm{S}(\mathrm{B})\right)$

${ }^{29} \mathrm{Si}-N M R\left(99.36 \mathrm{MHz}, \mathrm{C}_{6} \mathrm{D}_{6}\right): \delta=-4.19,-3.65,-1.05,-0.55$ 
${ }^{31}$ P-NMR (202.46 MHz, $\mathbf{C}_{6} \mathbf{D}_{6}$ ): $\delta=-30.74$ (hept, ${ }^{1} J_{\mathrm{P}-L i}=19.78 \mathrm{~Hz}$, LiPLi (A)), -27.34 (hept, ${ }^{1} \mathrm{JP}_{\mathrm{PLi}}=20.19 \mathrm{~Hz}$, LiPLi (B))

\subsection{9 $\left[\mathrm{Li}\left\{\mathrm{Me}_{2} \mathrm{P}(\mathrm{S}) \mathrm{CH}_{2} \mathrm{~S}\left(\mathrm{NSiMe}_{3}\right)_{2}\right\}\right]_{2}(8)$}

To a suspension of sulphur $(0.02 \mathrm{~g}, 0.70 \mathrm{mmol}, 2.0$ eq. $)$ in pentane $(5 \mathrm{~mL})$ was added [Li\{ $\left.\left.\mathrm{Me}_{2} \mathrm{PCH}_{2} \mathrm{~S}\left(\mathrm{NSiMe}_{3}\right)_{2}\right\}\right]_{2}(4)(0.20 \mathrm{~g}, 0.35 \mathrm{mmol}, 1.0$ eq.) in pentane (10 mL) very slowly at $-78^{\circ} \mathrm{C}$. After $20 \mathrm{~min}$ at $-78^{\circ} \mathrm{C}$ the suspension was allowed to warm to rt and stirred for $24 \mathrm{~h}$. The resulting white precipitate was filtered and redissolved in pentane. Colourless crystals, suitable for structural analysis were obtained after one month.

Empirical formula: $\mathrm{C}_{18} \mathrm{H}_{52} \mathrm{Li}_{2} \mathrm{~N}_{4} \mathrm{P}_{2} \mathrm{~S}_{4} \mathrm{Si}_{4} \quad$ Molecular weight: $641.06 \mathrm{~g} / \mathrm{mol}$

Elemental analysis (found (calc.) [\%]): C 33.72 (33.72), H 7.94 (8.18), N 8.90 (8.74), S 20.87 (20.01)

${ }^{1} \mathrm{H}$-NMR (300.13 MHz, $\left.\mathrm{C}_{6} \mathrm{D}_{6}\right): \delta=0.47\left(\mathrm{~s}, 36 \mathrm{H}, \mathrm{NSi}\left(\mathrm{CH}_{3}\right)_{3}\right), 1.09\left(\mathrm{~d}, 12 \mathrm{H},{ }^{2} \mathrm{JP}_{\mathrm{P}-\mathrm{H}}=\right.$ $\left.13.03 \mathrm{~Hz}, \mathrm{P}\left(\mathrm{CH}_{3}\right)_{2}\right), 3.05\left(\mathrm{~d}, 4 \mathrm{H},{ }^{2} \mathrm{~J}_{\mathrm{P}-\mathrm{H}}=7.17 \mathrm{~Hz}, \mathrm{PCH}_{2} \mathrm{~S}\right)$

${ }^{7}$ Li-NMR (194.37 MHz, $\left.\mathrm{C}_{6} \mathrm{D}_{6}\right): \delta=2.23$

${ }^{13} \mathrm{C}-N M R\left(125.77 \mathrm{MHz}, \mathrm{C}_{6} \mathrm{D}_{6}\right): \delta=3.16\left(\mathrm{~N}\left(\mathrm{Si}\left(\mathrm{CH}_{3}\right)_{3}\right)\right), 20.74\left(\mathrm{~d},{ }^{1} \mathrm{~J}-\mathrm{C}=55.0 \mathrm{~Hz}\right.$, $\left.\mathrm{P}\left(\mathrm{CH}_{3}\right)_{2}\right), 66.18\left(\mathrm{~d},{ }^{1} \mathrm{~J}_{\mathrm{P}-\mathrm{C}}=38.94 \mathrm{~Hz}, \mathrm{PCH}_{2} \mathrm{~S}\right)$

${ }^{31}$ P-NMR (121.49 MHz, $\left.\mathbf{C}_{6} \mathbf{D}_{6}\right): \delta=27.05$

\subsubsection{0 $\left[\mathrm{Li}\left\{\mathrm{Me}_{2} \mathrm{P}(\mathrm{Se}) \mathrm{CH}_{2} \mathrm{~S}\left(\mathrm{NSiMe}_{3}\right)_{2}\right\}\right]_{2}(9)$}

To a suspension of selenium ( $0.082 \mathrm{~g}, 1.04 \mathrm{mmol}, 2.0$ eq.) in hexane $(5 \mathrm{~mL})$ was added $4(0.30 \mathrm{~g}, 0.52 \mathrm{mmol}, 1.0$ eq. $)$ in hexane $(10 \mathrm{~mL})$ very slowly at $-78^{\circ} \mathrm{C}$. After $20 \mathrm{~min}$ at $-78^{\circ} \mathrm{C}$ the suspension was allowed to warm to rt and stirred over night. The resulting white precipitate was filtered and redissolved in toluene. Colourless crystals, suitable for structural analysis were obtained after two months.

Empirical formula: $\mathrm{C}_{18} \mathrm{H}_{52} \mathrm{Li}_{2} \mathrm{~N}_{4} \mathrm{P}_{2} \mathrm{~S}_{2} \mathrm{Se}_{2} \mathrm{Si}_{4} \quad$ Molecular weight: $734.86 \mathrm{~g} / \mathrm{mol}$ ${ }^{1} \mathrm{H}$-NMR (300.13 MHz, $\left.\mathbf{C}_{6} \mathrm{D}_{6}\right): \delta=0.47\left(\mathrm{~s}, 36 \mathrm{H}, \mathrm{NSi}\left(\mathrm{CH}_{3}\right)_{3}\right), 1.24\left(\mathrm{~d}, 12 \mathrm{H},{ }^{2} \mathrm{JP}_{\mathrm{P}-\mathrm{H}}=\right.$ $\left.13.15 \mathrm{~Hz}, \mathrm{P}\left(\mathrm{CH}_{3}\right)_{2}\right), 3.15\left(\mathrm{~d}, 4 \mathrm{H},{ }^{2} \mathrm{~J}_{\mathrm{P}-\mathrm{H}}=7.59 \mathrm{~Hz}, \mathrm{PCH}_{2} \mathrm{~S}\right)$

${ }^{31}$ P-NMR (121.49 MHz, $\left.\mathrm{C}_{6} \mathrm{D}_{6}\right): \delta=6.23$ 


\subsubsection{1 $\left[\mathrm{Ph}_{2} \mathrm{PCH}_{2} \mathrm{~S}\left(\mathrm{NSiMe}_{3}\right)\left(\mathrm{HNSiMe}_{3}\right)\right](10)$}

To a slurry of [(tmeda) $\left.\mathrm{Li}\left(\mathrm{H}_{2} \mathrm{CPPh}_{2}\right)\right](0.88 \mathrm{~g}, 2.72 \mathrm{mmol}, 1.0$ eq. $)$ in pentane $(35 \mathrm{~mL})$ was slowly added $\mathrm{S}\left(\mathrm{NSiMe}_{3}\right)_{2}(0.56 \mathrm{~g}, 2.72 \mathrm{mmol}, 1.0$ eq. $)$ at $-78{ }^{\circ} \mathrm{C}$. After stirring at room temperature overnight, the solution was filtered over celite and the solvent removed in vacuo. The precipitate was dissolved in toluene $(30 \mathrm{~mL})$, layered with pentane $(5 \mathrm{~mL})$ and stored at $-25^{\circ} \mathrm{C}$. After two months crystals suitable for structural analysis were obtained.

Empirical formula: $\mathrm{C}_{19} \mathrm{H}_{31} \mathrm{~N}_{2} \mathrm{PSSi}_{2}$

Yield: $1.07 \mathrm{~g}, 2.63 \mathrm{mmol}, 97 \%$
Molecular weight: $406.67 \mathrm{~g} / \mathrm{mol}$

Melting point: $138.3^{\circ} \mathrm{C}$ (decomp.)

Elemental analysis (found (calc.) [\%]): C 55.94 (56.11), H 7.66 (7.68), N 7.00 (6.89), S 8.00 (7.88)

${ }^{1} \mathrm{H}-\mathrm{NMR}\left(500.13 \mathrm{MHz}, \mathbf{C}_{6} \mathrm{D}_{6}\right): \delta=0.22\left(\mathrm{~s}, 18 \mathrm{H}, \mathrm{NSi}\left(\mathrm{CH}_{3}\right)_{3}\right), 4.09\left(\mathrm{~d}, 2 \mathrm{H},{ }^{2} \mathrm{~J}_{\mathrm{P}-\mathrm{H}}=0.80\right.$ $\left.\mathrm{Hz}, \mathrm{PCH}_{2} \mathrm{~S}\right), 7.00-7.04(\mathrm{~m}, 2 \mathrm{H}, p-\mathrm{H}), 7.06-7.10(\mathrm{~m}, 4 \mathrm{H}, \mathrm{o}-\mathrm{H}), 7.49-7.52(\mathrm{~m}, 4 \mathrm{H}$, $m-\mathrm{H})$

${ }^{13} \mathrm{C}-\mathrm{NMR}\left(125.76 \mathrm{MHz}, \mathrm{C}_{6} \mathrm{D}_{6}\right): \delta=1.89\left(\mathrm{NSi}\left(\mathrm{CH}_{3}\right)_{3}\right), 63.59\left(\mathrm{~d},{ }^{1} \mathrm{~J}_{\mathrm{P}-\mathrm{C}}=24.61 \mathrm{~Hz}\right.$, $\left.\mathrm{PCH}_{2} \mathrm{~S}\right), 128.76\left(\mathrm{~d},{ }^{2} \mathrm{~J}_{\mathrm{P}-\mathrm{C}}=6.65 \mathrm{~Hz}, \mathrm{o}-\mathrm{C}\right), 129.00(p-\mathrm{C}), 133.34\left(\mathrm{~d},{ }^{3} J_{\mathrm{P}-\mathrm{C}}=19.71 \mathrm{~Hz}\right.$, $m-\mathrm{C}), 138.43\left(\mathrm{~d},{ }^{1} \mathrm{~J}_{\mathrm{P}-\mathrm{C}}=14.76 \mathrm{~Hz}, i-\mathrm{C}\right)$

${ }^{29} \mathrm{Si}-\mathrm{NMR}\left(99.36 \mathrm{MHz}, \mathrm{C}_{6} \mathrm{D}_{6}\right): \delta=2.59$

${ }^{31}$ P-NMR (202.46 MHz, $\left.\mathrm{C}_{6} \mathrm{D}_{6}\right): \delta=-28.81$

EI-MS m/z [\%]: 406 (M, 17), 318 (\{M - $\left.\left.\mathrm{HNSiMe}_{3}\right\}, 14\right), 286\left(\left\{\mathrm{Ph}_{2} \mathrm{PCH}_{2} \mathrm{SNSiMe}_{3}\right\}, 19\right)$, $272\left(\left\{\mathrm{Ph}_{2} \mathrm{PCH}_{2} \mathrm{SiMe}_{3}\right\}, 19\right), 207\left(\left\{\mathrm{M}-\mathrm{Ph}_{2} \mathrm{PCH}_{2}\right\}, 15\right), 199\left(\left\{\mathrm{Ph}_{2} \mathrm{PCH}_{2}\right\}, 100\right), 121$ $\left(\left\{\mathrm{SN}\left(\mathrm{HSiMe}_{3}\right)+\mathrm{H}\right\}, 100\right), 73\left(\mathrm{SiMe}_{3}, 20\right)$

\subsubsection{2 [(tmeda)Li $\left.\left\{\mathrm{Ph}_{2} \mathrm{PCH}_{2} \mathrm{~S}\left(\mathrm{NSiMe}_{3}\right)_{2}\right\}\right]$ (11)}

To a slurry of [(tmeda) $\left.\mathrm{Li}\left(\mathrm{H}_{2} \mathrm{CPPh}_{2}\right)\right](3.01 \mathrm{~g}, 9.30 \mathrm{mmol}, 1.0$ eq. $)$ in pentane $(50 \mathrm{~mL})$ $\mathrm{S}\left(\mathrm{NSiMe}_{3}\right)_{2}\left(1.92 \mathrm{~g}, 9.30 \mathrm{mmol}, 1.0\right.$ eq.) was slowly added at $-78{ }^{\circ} \mathrm{C}$. After stirring at rt overnight the solution was filtered over celite, reduced in volume and stored at $-25^{\circ} \mathrm{C}$, yielding colourless crystals after two days.

Empirical formula: $\mathrm{C}_{25} \mathrm{H}_{46} \mathrm{LiN}_{4} \mathrm{PSSi}_{2}$

Molecular weight: $528.29 \mathrm{~g} / \mathrm{mol}$

Yield: $4.44 \mathrm{~g}, 8.40 \mathrm{mmol}, 90 \%$

Elemental analysis (found (calc.) [\%]): C 56.08 (56.78), H 8.84 (8.77), N 10.37 (10.59), S 6.28 (6.06) 
${ }^{1} \mathrm{H}-\mathrm{NMR}\left(\mathbf{3 0 0 . 1 3} \mathbf{M H z}, \mathbf{C}_{6} \mathbf{D}_{6}\right): \delta=0.28\left(\mathrm{~s}, 18 \mathrm{H}, \mathrm{NSi}\left(\mathrm{CH}_{3}\right)_{3}\right), 1.77$ (s br, $4 \mathrm{H}$, $\left.\mathrm{N}\left(\mathrm{CH}_{2}\right)_{2} \mathrm{~N}\right), 2.07\left(\mathrm{~s}, 12 \mathrm{H},\left(\mathrm{CH}_{3}\right)_{2} \mathrm{~N}\right), 3.47$ (s br, $\left.2 \mathrm{H}, \mathrm{SCH}_{2} \mathrm{P}\right), 6.99-7.12(\mathrm{~m}, 6 \mathrm{H}, \mathrm{o}-\mathrm{H}$, $p-\mathrm{H}), 7.59-7.70(\mathrm{~m}, 4 \mathrm{H}, m-\mathrm{H})$

${ }^{7}$ Li-NMR (194.37 MHz, $\left.\mathbf{C}_{6} \mathrm{D}_{6}\right): \delta=1.00$

${ }^{13} \mathrm{C}-\mathrm{NMR}\left(125.76 \mathrm{MHz}, \mathbf{C}_{6} \mathrm{D}_{6}\right): \delta=3.19\left(\mathrm{NSi}\left(\mathrm{CH}_{3}\right)_{3}\right), 45.82\left(\left(\mathrm{CH}_{3}\right)_{2} \mathrm{~N}\right), 56.66$ $\left(\mathrm{N}\left(\mathrm{CH}_{2}\right)_{2}\right), 70.84$ (d, $\left.{ }^{1} \mathrm{~J}_{\mathrm{P}-\mathrm{C}}=23.99 \mathrm{~Hz}, \mathrm{PCH}_{2} \mathrm{~S}\right), 128.46\left(\mathrm{~d},{ }^{2} \mathrm{~J}_{\mathrm{P}-\mathrm{C}}=6.02 \mathrm{~Hz}, \mathrm{o}-\mathrm{C}\right)$, $132.41(p-C), 132.55(p-C), 133.90\left(\mathrm{~d},{ }^{3} J_{\mathrm{P}-\mathrm{C}}=19.50 \mathrm{~Hz}, m-\mathrm{C}\right), 142.04\left(\mathrm{~d},{ }^{1} J_{\mathrm{P}-\mathrm{C}}=\right.$ $14.98 \mathrm{~Hz}, i-\mathrm{C})$

${ }^{29} \mathrm{Si}-\mathrm{NMR}\left(99.36 \mathrm{MHz}, \mathrm{C}_{6} \mathrm{D}_{6}\right): \delta=-8.29$

${ }^{31}$ P-NMR (121.49 MHz, $\mathbf{C}_{6} \mathrm{D}_{6}$ ): $\delta=-38.78$ (s br)

\subsubsection{3 [ $\left[\mathrm{Li}\left\{t \mathrm{Bu}_{2} \mathrm{P}(\mathrm{O}) \mathrm{CH}_{2} \mathrm{~S}\left(\mathrm{NSiMe}_{3}\right)_{2}\right\}_{2}\right] \quad(12), \quad\left[\left(t \mathrm{Bu} \mathrm{H}_{2} \mathrm{P}(\mathrm{O}) \mathrm{Me}\right) \mathrm{Li}_{2}-\right.$ $\left.\left\{t \mathrm{Bu}_{2} \mathrm{PCH}_{2} \mathrm{~S}\left(\mathrm{NSiMe}_{3}\right)_{2}\right\}_{2}\right](13)$ and $\left[\mathrm{Li}\left\{\mathrm{tBu}_{2} \mathrm{PCH}_{2} \mathrm{~S}\left(\mathrm{NSiMe}_{3}\right)_{2}\right\}_{2}\right](14)$}

$\mathrm{S}\left(\mathrm{NSiMe}_{3}\right)_{2}(0.72 \mathrm{~g}, 3.49 \mathrm{mmol}, 2.0 \mathrm{eq}$.) was slowly added to a slurry of [Li $\left.\left(\mathrm{H}_{2} \mathrm{CPtBu} 2\right)\right](0.58 \mathrm{~g}, 3.49 \mathrm{mmol}, 2.0$ eq. $)$ in pentane $(25 \mathrm{~mL})$ at $-78{ }^{\circ} \mathrm{C}$. After stirring overnight at $r$ the suspension was filtered and the yellow solution stored at $-30{ }^{\circ} \mathrm{C}$ for eight days, yielding colourless crystals.

Empirical formula: $\mathrm{C}_{30} \mathrm{H}_{76} \mathrm{Li}_{2} \mathrm{~N}_{4} \mathrm{O}_{2} \mathrm{P}_{2} \mathrm{~S}_{2} \mathrm{Si}_{4}$

Molecular weight: $777.25 \mathrm{~g} / \mathrm{mol}$ (12)

Empirical formula: $\mathrm{C}_{44} \mathrm{H}_{109} \mathrm{Li}_{2} \mathrm{~N}_{4} \mathrm{OP}_{3} \mathrm{~S}_{2} \mathrm{Si}_{4}$

Molecular weight: $993.64 \mathrm{~g} / \mathrm{mol}$ (13)

Empirical formula: $\mathrm{C}_{30} \mathrm{H}_{76} \mathrm{Li}_{2} \mathrm{~N}_{4} \mathrm{P}_{2} \mathrm{~S}_{2} \mathrm{Si}_{4}$

Molecular weight: $745.25 \mathrm{~g} / \mathrm{mol}$ (14)

Analysis for 14:

Elemental analysis (found (calc.) [\%]): C 48.49 (48.35), H 10.80 (10.28), N 7.71 (7.52), S 8.55 (8.61)

${ }^{1} \mathrm{H}-\mathrm{NMR}\left(\mathbf{3 0 0 . 1 3} \mathbf{M H z}, \mathbf{C}_{6} \mathrm{D}_{6}\right): \delta=0.36-0.40\left(\mathrm{~m}, 36 \mathrm{H}, \mathrm{NSi}\left(\mathrm{CH}_{3}\right)_{3}\right), 1.11-1.19(\mathrm{~m}$, $36 \mathrm{H}, \mathrm{PC}\left(\mathrm{CH}_{3}\right)_{3}, 2.71-2.75\left(\mathrm{~m}, 4 \mathrm{H}, \mathrm{PCH}_{2} \mathrm{~S}\right)$

${ }^{7}$ Li-NMR (194.37 $\left.\mathrm{MHz}, \mathrm{C}_{6} \mathrm{D}_{6}\right): \delta=2.32$ (s)

${ }^{13} \mathrm{C}-\mathrm{NMR}\left(125.76 \mathrm{MHz}, \mathrm{C}_{6} \mathrm{D}_{6}\right): \quad \delta=3.15\left(\mathrm{NSi}\left(\mathrm{CH}_{3}\right)_{3}, \quad 30.32 \quad\left(\mathrm{PC}\left(\mathrm{CH}_{3}\right)_{3}\right), \quad 30.49\right.$ $\left(\mathrm{PC}\left(\mathrm{CH}_{3}\right)_{3}\right), 60.98\left(\mathrm{PC}\left(\mathrm{CH}_{3}\right)_{3}\right), 61.45\left(\mathrm{PCH}_{2} \mathrm{~S}\right)$

${ }^{29}$ Si-NMR (99.36 MHz, $\left.\mathrm{C}_{6} \mathrm{D}_{6}\right): \delta=-3.28$

${ }^{31}$ P-NMR (202.46 MHz, $\mathrm{C}_{6} \mathrm{D}_{6}$ ): $\delta=8.75$ (s br)

\subsubsection{4 $\left[\mathrm{Li}\left\{\left(\mathrm{C}_{6} \mathrm{H}_{4}\right) \mathrm{NMe}_{2}\right\}\right]_{4}[t \mathrm{BuLi}]$ (15)}

To $\mathrm{Me}_{2} \mathrm{NPh}$ ( $3.46 \mathrm{~g}, 30.0 \mathrm{mmol}, 4.0$ eq.) was added tBuLi in pentane $(1.5 \mathrm{M}, 25.0 \mathrm{~mL}$, $37.5 \mathrm{mmol}, 5.0$ eq.) at rt. After stirring over night the yellow solution was reduced in 
volume and stored at rt. After one day colourless crystals suitable for structural analysis were obtained.<smiles>Nc1ccccc1Cl</smiles>

numbering scheme

Empirical formula: $\mathrm{C}_{36} \mathrm{H}_{49} \mathrm{Li}_{5} \mathrm{~N}_{4}$

Molecular weight: $572.49 \mathrm{~g} / \mathrm{mol}$

Yield: $3.40 \mathrm{~g}, 5.94 \mathrm{mmol}, 79 \%$

Elemental analysis (found (calc.) [\%]): C 75.25 (75.52), H 8.99 (8.63), N 9.86 (9.79)

${ }^{1} \mathrm{H}-\mathrm{NMR}\left(\mathbf{3 0 0 . 1 3} \mathrm{MHz}, \mathrm{C}_{6} \mathrm{D}_{6}\right): \delta=0.84-1.26\left(\mathrm{~m}, 9 \mathrm{H}, \mathrm{C}\left(\mathrm{CH}_{3}\right)_{3}\right), 2.02-2.51(\mathrm{~m}, 24 \mathrm{H}$, $\left.\mathrm{N}\left(\mathrm{CH}_{3}\right)_{2}\right), 6.77-7.04\left(\mathrm{~m}, 4 \mathrm{H}, \mathrm{C}_{6} \mathrm{H}_{4}\right), 7.18-7.28\left(\mathrm{~m}, 8 \mathrm{H}, \mathrm{C}_{6} \mathrm{H}_{4}\right), 7.91-8.26(\mathrm{~m}, 4 \mathrm{H}$, $\mathrm{LiCCH})$; the shifts of the main isomer $\left[\mathrm{Li}\left\{\left(\mathrm{C}_{6} \mathrm{H}_{4}\right) \mathrm{NMe}_{2}\right\}\right]_{4}$, [tBuLi]: $\left(\mathbf{4 0 0 . 1 3} \mathbf{~ M H z}\right.$, tol-d $\left.\mathbf{d}^{8}\right)$ : $1.01\left(\mathrm{~s}, \mathrm{C}\left(\mathrm{CH}_{3}\right)_{3}\right), 2.06$ (s br, $\left.\mathrm{N}\left(\mathrm{CH}_{3}\right)_{2}\right), 7.01(\mathrm{~m}, 6-H), 7.22(\mathrm{~m}, 4-H, 5-H), 8.22$ (m, 3-H)

${ }^{7}$ Li-NMR (155.51 MHz, tol-d ${ }^{8}$ ): $\delta=0.74(\mathrm{br}, 0.05 \mathrm{Li}), 0.92(\mathrm{br}, 0.10 \mathrm{Li}), 1.38(\mathrm{br}, 0.12$ Li), 1.47 (0.28 Li), 1.79 (0.14 Li), 2.03 (br, $0.61 \mathrm{Li}), 2.35$ (0.36 Li), 2.56 (br, $0.22 \mathrm{Li})$, $2.73(\mathrm{br}, 0.15 \mathrm{Li}), 2.84(0.42 \mathrm{Li}), 3.11(\mathrm{br}, 0.10 \mathrm{Li}), 3.61\left(4 \mathrm{Li},\left[\mathrm{Li}\left\{\left(\mathrm{C}_{6} \mathrm{H}_{4}\right) \mathrm{NMe}_{2}\right\}\right]_{4}\right)$

${ }^{13} \mathrm{C}$-NMR (100.62 MHz, tol-d $\left.)^{8}\right): \delta=10.94\left(\mathrm{C}\left(\mathrm{CH}_{3}\right)_{3}\right), 32.30\left(\mathrm{C}\left(\mathrm{CH}_{3}\right)_{3}\right), 46.85$ $\left(\mathrm{N}\left(\mathrm{CH}_{3}\right)_{2}\right), 118.87$ (C6), 126.13 (C5), 127.97 (C4), 140.20 (C3), 166.21 (C1), 168.81 $(\mathrm{br}, \mathrm{C2})$

\subsubsection{5 $\left[\mathrm{Li}\left\{\mathrm{Me}_{2} \mathrm{~N}\left(\mathrm{C}_{6} \mathrm{H}_{4}\right) \mathrm{S}\left(\mathrm{NSiMe}_{3}\right)_{2}\right\}\right]_{2}(16)$}

To a suspension of $\left[\mathrm{Li}\left\{\left(\mathrm{C}_{6} \mathrm{H}_{4}\right) \mathrm{NMe}_{2}\right\}\right](1.00 \mathrm{~g}, 7.87 \mathrm{mmol}, 2.0$ eq.) in pentane $(30 \mathrm{~mL})$ was added $\mathrm{S}\left(\mathrm{NSiMe}_{3}\right)_{2}\left(1.62 \mathrm{~g}, 7.87 \mathrm{mmol}, 2.0 \mathrm{eq}\right.$.) very slowly at $-78{ }^{\circ} \mathrm{C}$. After $20 \mathrm{~min}$ at $-78^{\circ} \mathrm{C}$ the suspension was allowed to warm to rt and stirred for $24 \mathrm{~h}$. The solution was filtered, reduced to $1 / 2$ of its volume and stored at $-25{ }^{\circ} \mathrm{C}$. Colourless crystals, suitable for structural analysis were obtained after two days.<smiles>Nc1ccccc1S</smiles>

numbering scheme

Empirical formula: $\mathrm{C}_{28} \mathrm{H}_{56} \mathrm{~N}_{6} \mathrm{Si}_{4} \mathrm{~S}_{2} \mathrm{Li}_{2}$ Molecular weight: $667.15 \mathrm{~g} / \mathrm{mol}$

Yield (crystals): $2.21 \mathrm{~g}, 3.31 \mathrm{mmol}, 42 \%$

Elemental analysis (found (calc.) [\%]): C 50.25 (50.41), H 8.69 (8.46), N 12.56 (12.60), S 9.65 (9.61) 
${ }^{1} \mathrm{H}-\mathrm{NMR}\left(\mathbf{3 0 0 . 1 3} \mathrm{MHz}, \mathrm{C}_{6} \mathrm{D}_{6}\right): \delta=0.27\left(\mathrm{~s}, 36 \mathrm{H}, \mathrm{NSi}\left(\mathrm{CH}_{3}\right)_{3}\right), 2.62\left(\mathrm{~s}, 12 \mathrm{H}, \mathrm{N}\left(\mathrm{CH}_{3}\right)_{2}\right)$, $6.77\left(\mathrm{dd}, 2 \mathrm{H},{ }^{3} \mathrm{~J}_{\mathrm{H}-\mathrm{H}}=7.23 \mathrm{~Hz},{ }^{4} \mathrm{~J}_{\mathrm{H}-\mathrm{H}}=1.89 \mathrm{~Hz}, 6-H\right), 6.91-7.00(\mathrm{~m}, 4 \mathrm{H}, 4-H, 5-H)$, $7.94\left(\mathrm{dd}, 2 \mathrm{H},{ }^{3} \mathrm{~J}_{\mathrm{H}-\mathrm{H}}=6.80 \mathrm{~Hz},{ }^{4} \mathrm{~J}_{\mathrm{H}-\mathrm{H}}=2.51 \mathrm{~Hz}, 3-\mathrm{H}\right)$

${ }^{7}$ Li-NMR (116.64 MHz, $\mathbf{C}_{6} \mathrm{D}_{6}$ ): $\delta=2.34(\mathrm{~s} \mathrm{br})$

${ }^{13}$ C-NMR (75.47 MHz, $\left.\mathbf{C}_{6} \mathrm{D}_{6}\right): \delta=2.54\left(\mathrm{NSi}\left(\mathrm{CH}_{3}\right)_{3}\right), 47.20\left(\mathrm{~N}\left(\mathrm{CH}_{3}\right)_{2}\right), 120.14(\mathrm{C} 6)$, 124.58 (C5), 127.43 (C3), 130.25 (C4), 149.78 (C1), 150.24 (C2); $C 3$ is only visible in a hsqc spectrum, the signal is overlaid by $\mathrm{C}_{6} \mathrm{D}_{6}$

${ }^{29}$ Si-NMR (59.63 MHz, $\left.\mathrm{C}_{6} \mathrm{D}_{6}\right): \delta=-3.06$

\subsubsection{6 [(thf) $\left.\mathrm{Li}\left\{\mathrm{Me}_{2} \mathrm{~N}\left(\mathrm{C}_{6} \mathrm{H}_{4}\right) \mathrm{S}\left(\mathrm{NSiMe}_{3}\right)_{2}\right\}\right]_{2}(17)$}

$16(0.33 \mathrm{~g}, 0.50 \mathrm{mmol}, 1.0$ eq.) was dissolved in THF ( $5 \mathrm{~mL})$ and stirred for $15 \mathrm{~h}$. The solvent was removed in vacuo, the residue was dissolved in pentane $(20 \mathrm{~mL})$ and filtered. The colourless solution was stored at $4{ }^{\circ} \mathrm{C}$ for two days, yielding colourless crystals.

Empirical formula: $\mathrm{C}_{36} \mathrm{H}_{72} \mathrm{Li}_{2} \mathrm{~N}_{6} \mathrm{O}_{2} \mathrm{~S}_{2} \mathrm{Si}_{4} \quad$ Molecular weight: $811.36 \mathrm{~g} / \mathrm{mol}$ ${ }^{1} \mathrm{H}-\mathrm{NMR}\left(300.13 \mathrm{MHz}, \mathrm{C}_{6} \mathrm{D}_{6}\right): \delta=0.28\left(\mathrm{~s}, 18 \mathrm{H}, \mathrm{NSi}\left(\mathrm{CH}_{3}\right)_{3}\right), 0.30$ (s, $18 \mathrm{H}$, $\left.\mathrm{NSi}\left(\mathrm{CH}_{3}\right)_{3}\right), 1.35\left(\mathrm{~m}, 8 \mathrm{H}, \mathrm{OCH}_{2} \mathrm{CH}_{2}\right), 2.60$ (s br, $\left.12 \mathrm{H}, \mathrm{N}\left(\mathrm{CH}_{3}\right)_{2}\right), 3.45(\mathrm{~m}, 8 \mathrm{H}$, $\left.\mathrm{OCH}_{2} \mathrm{CH}_{2}\right), 6.78-6.79(\mathrm{~m}, 2 \mathrm{H}, 6-\mathrm{H}), 7.00-7.02(\mathrm{~m}, 4 \mathrm{H}, 4-\mathrm{H}, 5-\mathrm{H}), 8.20-8.28(\mathrm{~m}, 2 \mathrm{H}$, 3-H)

${ }^{7} \mathrm{Li}-\mathrm{NMR}\left(116.64 \mathrm{MHz}, \mathrm{C}_{6} \mathrm{D}_{6}\right): \delta=1.91(\mathrm{~s} \mathrm{br})$

${ }^{13}$ C-NMR $\left(75.47 \mathrm{MHz}, \mathrm{C}_{6} \mathrm{D}_{6}\right): \quad \delta=1.35\left(\mathrm{NSi}\left(\mathrm{CH}_{3}\right)_{3}\right), \quad 2.13\left(\mathrm{NSi}\left(\mathrm{CH}_{3}\right)_{3}\right), \quad 2.75$ $\left(\mathrm{NSi}\left(\mathrm{CH}_{3}\right)_{3}\right), 25.56\left(\mathrm{OCH}_{2} \mathrm{CH}_{2}\right), 45.80\left(\mathrm{~N}_{(}\left(\mathrm{CH}_{3}\right)_{2}\right), 46.44\left(\mathrm{~N}\left(\mathrm{CH}_{3}\right)_{2}\right), 67.84\left(\mathrm{OCH}_{2} \mathrm{CH}_{2}\right)$, 119.88 (C6), 124.32 (C5), 130.26 (s br, C3, C4), 135.46 (C1), 150.69 (C2)

${ }^{29}$ Si-NMR (99.36 MHz, $\left.\mathrm{C}_{6} \mathrm{D}_{6}\right): \delta=-2.56$

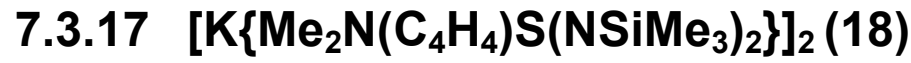

To a suspension of $\left[\mathrm{K}\left\{\left(\mathrm{C}_{6} \mathrm{H}_{4}\right) \mathrm{NMe}_{2}\right\}\right](1.00 \mathrm{~g}, 6.28 \mathrm{mmol}, 2.0$ eq.) in pentane (30 mL) was added $\mathrm{S}\left(\mathrm{NSiMe}_{3}\right)_{2}(1.30 \mathrm{~g}, 6.28 \mathrm{mmol}, 2.0 \mathrm{eq}$. $)$ very slowly at $-78^{\circ} \mathrm{C}$. After $20 \mathrm{~min}$ at $-78^{\circ} \mathrm{C}$ the suspension was allowed to warm to $\mathrm{rt}$ and stirred for $24 \mathrm{~h}$. The solution was filtered, reduced to $1 / 2$ of its volume and stored at $-25^{\circ} \mathrm{C}$. Colourless crystals, suitable for structural analysis were obtained after one week.

Empirical formula: $\mathrm{C}_{28} \mathrm{H}_{56} \mathrm{~N}_{6} \mathrm{Si}_{4} \mathrm{~S}_{2} \mathrm{~K}_{2}$

Molecular weight: $731.45 \mathrm{~g} / \mathrm{mol}$

Yield (crystals): $1.22 \mathrm{~g}, 1.66 \mathrm{mmol}, 53 \%$ 
Elemental analysis (found (calc.) [\%]): C 46.10 (45.98), H 8.01 (7.72), N 11.50 (11.49), S 8.85 (8.77)

${ }^{1} \mathrm{H}$-NMR (300.13 MHz, $\left.\mathrm{C}_{6} \mathrm{D}_{6}\right): \delta=0.24\left(\mathrm{~s}, 36 \mathrm{H}, \mathrm{NSi}\left(\mathrm{CH}_{3}\right)_{3}\right), 2.66\left(\mathrm{~s}, 12 \mathrm{H}, \mathrm{N}\left(\mathrm{CH}_{3}\right)_{2}\right)$, $6.60\left(\mathrm{dd}, 2 \mathrm{H},{ }^{3} \mathrm{~J}_{\mathrm{H}-\mathrm{H}}=7.82 \mathrm{~Hz},{ }^{4} \mathrm{~J}_{\mathrm{H}-\mathrm{H}}=1.01 \mathrm{~Hz}, 6-\mathrm{H}\right), 7.06$ (ddd, $2 \mathrm{H},{ }^{3} \mathrm{~J}_{\mathrm{H}-\mathrm{H}}=7.82 \mathrm{~Hz}$, $\left.{ }^{3} \mathrm{~J}_{\mathrm{H}-\mathrm{H}}=7.30 \mathrm{~Hz},{ }^{4} \mathrm{~J}_{\mathrm{H}-\mathrm{H}}=1.73 \mathrm{~Hz}, 5-\mathrm{H}\right), 7.37\left(\mathrm{ddd}, 2 \mathrm{H},{ }^{3} J_{\mathrm{H}-\mathrm{H}}=7.52 \mathrm{~Hz},{ }^{3} J_{\mathrm{H}-\mathrm{H}}=7.30\right.$ $\left.\mathrm{Hz},{ }^{4} \mathrm{~J}_{\mathrm{H}-\mathrm{H}}=1.01 \mathrm{~Hz}, 4-H\right), 8.60\left(\mathrm{dd}, 2 \mathrm{H},{ }^{3} \mathrm{~J}_{\mathrm{H}-\mathrm{H}}=7.52 \mathrm{~Hz},{ }^{4} \mathrm{~J}_{\mathrm{H}-\mathrm{H}}=1.73 \mathrm{~Hz}, 3-H\right)$

${ }^{13} \mathrm{C}-\mathrm{NMR}$ (75.47 MHz, $\left.\mathrm{C}_{6} \mathrm{D}_{6}\right): \delta=3.31\left(\mathrm{NSi}\left(\mathrm{CH}_{3}\right)_{3}\right), 45.16\left(\mathrm{~N}\left(\mathrm{CH}_{3}\right)_{2}\right), 117.71$ (C6), 122.31 (C3), 123.15 (C4), 129.24 (C5), 150.19 (C1), 152.46 (C2)

${ }^{29} \mathrm{Si}-\mathrm{NMR}\left(59.63 \mathrm{MHz}, \mathrm{C}_{6} \mathrm{D}_{6}\right): \delta=-7.32$

\subsubsection{8 [(tBuN $\left.)_{2} \mathrm{~S} \cdot\left\{\mathrm{LiMe}_{2} \mathrm{~N}\left(\mathrm{C}_{6} \mathrm{H}_{4}\right) \mathrm{S}(\mathrm{NtBu})_{2}\right\}_{2}\right](19)$}

To a suspension of $\left[\mathrm{Li}\left\{\left(\mathrm{C}_{6} \mathrm{H}_{4}\right) \mathrm{NMe}_{2}\right\}\right](1.00 \mathrm{~g}, 7.87 \mathrm{mmol}, 2.0$ eq.) in pentane $(30 \mathrm{~mL})$ was added $\mathrm{S}(\mathrm{NtBu})_{2}\left(2.06 \mathrm{~g}, 11.8 \mathrm{mmol}, 3.0\right.$ eq.) very slowly at $-78^{\circ} \mathrm{C}$. After $20 \mathrm{~min}$ at $-78{ }^{\circ} \mathrm{C}$ the suspension was allowed to warm to rt and stirred for $24 \mathrm{~h}$. The solution was filtered, reduced to $1 / 2$ of its volume and stored at $-25^{\circ} \mathrm{C}$. Colourless crystals, suitable for structural analysis were obtained after two weeks.

Empirical formula: $\mathrm{C}_{40} \mathrm{H}_{74} \mathrm{~N}_{8} \mathrm{~S}_{3} \mathrm{Li}_{2}$

Molecular weight: $777.15 \mathrm{~g} / \mathrm{mol}$

Yield (crystals): $2.08 \mathrm{~g}, 2.68 \mathrm{mmol}, 68 \%$

Elemental analysis (found (calc.) [\%]): C 61.63 (61.82), H 9.89 (9.60), N 14.42 (14.42), S 12.16 (12.38)

${ }^{1} \mathrm{H}-\mathrm{NMR}\left(\mathbf{5 0 0 . 1 3} \mathrm{MHz}, \mathrm{C}_{6} \mathrm{D}_{6}\right): \delta=1.36\left(\mathrm{~s} \mathrm{br}, 18 \mathrm{H}, \mathrm{S}(\mathrm{N} t \mathrm{Bu})_{2}\right), 1.42(\mathrm{~s}, 36 \mathrm{H}$, $\left.\mathrm{CS}\left(\mathrm{NC}\left(\mathrm{CH}_{3}\right)_{3}\right)_{2}\right), 2.66\left(\mathrm{~s}, 12 \mathrm{H}, \mathrm{N}\left(\mathrm{CH}_{3}\right)_{2}\right), 6.77\left(\mathrm{dd}, 2 \mathrm{H},{ }^{3} \mathrm{~J}_{\mathrm{H}-\mathrm{H}}=7.35 \mathrm{~Hz},{ }^{4} \mathrm{~J}_{\mathrm{H}-\mathrm{H}}=\right.$ $1.60 \mathrm{~Hz}, 6-H), 6.97-7.03(\mathrm{~m}, 4 \mathrm{H}, 4-H, 5-H), 8.33\left(\mathrm{dd}, 2 \mathrm{H},{ }^{3} \mathrm{~J}_{\mathrm{H}-\mathrm{H}}=7.15 \mathrm{~Hz},{ }^{4} \mathrm{~J}_{\mathrm{H}-\mathrm{H}}=\right.$ $2.10 \mathrm{~Hz}, 3-H)$

${ }^{7}$ Li-NMR (194.37 MHz, $\left.\mathrm{C}_{6} \mathrm{D}_{6}\right): \delta=2.37(\mathrm{~s} \mathrm{br})$

${ }^{13} \mathrm{C}$-NMR (125.76 MHz, $\left.\mathbf{C}_{6} \mathrm{D}_{6}\right): \delta=30.60\left(\mathrm{~S}\left(\mathrm{NC}\left(\mathrm{CH}_{3}\right)_{3}\right)_{2}\right), 33.54\left(\mathrm{CS}\left(\mathrm{NC}\left(\mathrm{CH}_{3}\right)_{3}\right)_{2}\right)$, $46.54\left(\mathrm{~N}\left(\mathrm{CH}_{3}\right)_{2}\right), 54.46\left(\mathrm{CS}\left(\mathrm{NC}\left(\mathrm{CH}_{3}\right)_{3}\right)_{2}\right), 60.62\left(\mathrm{~S}\left(\mathrm{NC}\left(\mathrm{CH}_{3}\right)_{3}\right)_{2}\right), 119.68(\mathrm{C} 6), 123.84$ (C5), 127.88 (C3), 139.37 (C4), 150.35 (C1), 150.43 (C2)

\subsubsection{9 [Li $\left.\left\{2-\mathrm{PyS}\left(\mathrm{NSiMe}_{3}\right)_{2}\right\}\right]_{2}(20)$}

To a solution of [(tmeda)Li(2-Py)] $(0.46 \mathrm{~g}, 2.07 \mathrm{mmol}, 2.0$ eq.) in pentane $(30 \mathrm{~mL})$ was added $\mathrm{S}\left(\mathrm{NSiMe}_{3}\right)_{2}(0.43 \mathrm{~g}, 2.07 \mathrm{mmol}, 2.0$ eq. $)$ at $-78{ }^{\circ} \mathrm{C}$ and the reaction mixture stirred over night. The red suspension was filtered over celite, reduced in 
volume and stored at $4{ }^{\circ} \mathrm{C}$. After $3 \mathrm{~h}$ colourless crystals suitable for structural analysis were obtained.

(12

6 numbering scheme

Empirical formula: $\mathrm{C}_{24} \mathrm{H}_{48} \mathrm{Li}_{2} \mathrm{~N}_{6} \mathrm{~S}_{2} \mathrm{Si}_{4}$

Molecular weight: $611.04 \mathrm{~g} / \mathrm{mol}$

Yield (crystals): $0.46 \mathrm{~g}, 0.75 \mathrm{mmol}, 72 \%$

Elemental analysis (found (calc.) [\%]): C 47.06 (47.02), H 8.04 (8.22), N 14.15 (13.71), S 10.83 (10.46)

$\left.{ }^{1} \mathrm{H}-\mathrm{NMR}\left(\mathbf{5 0 0 . 1 3} \mathrm{MHz}, \mathrm{C}_{6} \mathrm{D}_{6}, 343 \mathrm{~K}\right): \delta=0.25\left(\mathrm{~s}, 36 \mathrm{H}, \mathrm{NSi}\left(\mathrm{CH}_{3}\right)_{3}\right)\right), 3.99(\mathrm{~s}, 4 \mathrm{H}$, $\left.\mathrm{SCH}_{2} \mathrm{C}\right), 6.49\left(\mathrm{ddd}, 2 \mathrm{H},{ }^{3} \mathrm{~J}_{\mathrm{H}-\mathrm{H}}(\mathrm{H} 4 / \mathrm{H} 3)=7.60 \mathrm{~Hz},{ }^{3} \mathrm{~J}_{\mathrm{H}-\mathrm{H}}(\mathrm{H} 4 / \mathrm{H} 5)=5.00 \mathrm{~Hz}\right.$, $\left.{ }^{4} J_{\mathrm{H}-\mathrm{H}}(\mathrm{H} 4 / \mathrm{H} 2)=1.10 \mathrm{~Hz}, 4-H\right), 6.53$ (pseudo tr, $2 \mathrm{H},{ }^{3} J_{\mathrm{H}-\mathrm{H}}(\mathrm{H} 2 / \mathrm{H} 3)=7.70 \mathrm{~Hz}$, $\left.{ }^{4} J_{\mathrm{H}-\mathrm{H}}(\mathrm{H} 2 / \mathrm{H} 4)=1.10 \mathrm{~Hz}, 2-H\right), 6.88$ (ddd, $2 \mathrm{H},{ }^{3} J_{\mathrm{H}-\mathrm{H}}(\mathrm{H} 3 / \mathrm{H} 2)=7.70 \mathrm{~Hz}$, $\left.{ }^{3} J_{\mathrm{H}-\mathrm{H}}(\mathrm{H} 3 / \mathrm{H} 4)=7.60 \mathrm{~Hz},{ }^{4} \mathrm{~J}_{\mathrm{H}-\mathrm{H}}(\mathrm{H} 3 / \mathrm{H} 5)=1.75 \mathrm{~Hz}, 3-\mathrm{H}\right), 8.53$ (ddd, $2 \mathrm{H}$, $\left.{ }^{3} J_{H-H}(H 5 / H 4)=5.00 \mathrm{~Hz},{ }^{4} J_{H-H}(H 5 / H 3)=1.75 \mathrm{~Hz},{ }^{5} J_{H-H}(H 5 / H 2)=0.92 \mathrm{~Hz}, 5-H\right)$

${ }^{7}$ Li-NMR (116.64 MHz, $\mathrm{C}_{6} \mathrm{D}_{6}$ ): $\delta=2.66(\mathrm{~s} \mathrm{br})$

${ }^{13} \mathrm{C}$-NMR (125.48 MHz, $\left.\mathbf{C}_{6} \mathrm{D}_{6}\right): \delta=2.98\left(\mathrm{NSi}\left(\mathrm{CH}_{3}\right)_{3}\right), 72.40(\mathrm{C} 6), 121.88(\mathrm{C} 4), 124.51$ (C2), 137.38 (C3), 149.07 (C5), 154.74 (C1)

${ }^{29}$ Si-NMR (59.63 MHz, tol-d $\left.8,363 \mathrm{~K}\right): \delta=-2.57$

\subsubsection{0 $\left[\mathrm{Li}\left\{\mathrm{Me}_{2} \mathrm{~N}\left(\mathrm{CH}_{2}\right)_{2} \mathrm{~N}\left(\mathrm{CH}_{3}\right) \mathrm{S}\left(\mathrm{NSiMe}_{3}\right)_{2}\right\}\right]_{2}(21)$}

To a solution of [ $\left.\mathrm{Li}\left\{\mathrm{N}(\mathrm{Me})\left(\mathrm{CH}_{2}\right)_{2} \mathrm{NMe}_{2}\right\}\right](1.00 \mathrm{~g}, 9.25 \mathrm{mmol}, 2.0$ eq. $)$ in pentane $(20 \mathrm{~mL})$ was added $\mathrm{S}\left(\mathrm{NSiMe}_{3}\right)_{2}\left(1.91 \mathrm{~g}, 9.25 \mathrm{mmol}, 2.0 \mathrm{eq}\right.$.) very slowly at $-78{ }^{\circ} \mathrm{C}$. After $20 \mathrm{~min}$ at $-78{ }^{\circ} \mathrm{C}$ the reaction mixture was allowed to warm to rt and stirred for $24 \mathrm{~h}$. The solution was reduced to $1 / 2$ of its volume and stored at $-25^{\circ} \mathrm{C}$. Colourless crystals, suitable for structural analysis were obtained after three days.

Empirical formula: $\mathrm{C}_{22} \mathrm{H}_{62} \mathrm{~N}_{8} \mathrm{Si}_{4} \mathrm{~S}_{2} \mathrm{Li}_{2}$

Molecular weight: $629.18 \mathrm{~g} / \mathrm{mol}$

Yield (crystals): $0.76 \mathrm{~g}, 1.20 \mathrm{mmol}, 51 \%$

Elemental analysis (found (calc.) [\%]): C 41.81 (42.00), H 9.84 (9.93), N 18.10 (17.81), S 10.15 (10.19)

${ }^{1} \mathrm{H}-\mathrm{NMR}\left(300.13 \mathrm{MHz}, \mathrm{C}_{6} \mathrm{D}_{6}\right): \delta=0.32\left(\mathrm{~s}, 36 \mathrm{H}, \mathrm{NSi}\left(\mathrm{CH}_{3}\right)_{3}\right), 2.00(\mathrm{~s} \mathrm{br}, 4 \mathrm{H}$, $\left.\left(\mathrm{CH}_{3}\right)_{2} \mathrm{NCH}_{2} \mathrm{CH}_{2}\right), 2.10$ (s, $\left.12 \mathrm{H}, \mathrm{N}\left(\mathrm{CH}_{3}\right)_{2}\right), 2.38$ (s, $\left.6 \mathrm{H}, \mathrm{SN}\left(\mathrm{CH}_{3}\right)\right), 2.62$ (s br, $4 \mathrm{H}$, $\left.\left(\mathrm{CH}_{3}\right)_{2} \mathrm{NCH}_{2} \mathrm{CH}_{2}\right)$

${ }^{7}$ Li-NMR (116.64 MHz, $\left.\mathrm{C}_{6} \mathrm{D}_{6}\right): \delta=1.38(\mathrm{~s} \mathrm{br})$ 
${ }^{13}$ C-NMR (125.76 MHz, $\left.\mathbf{C}_{6} \mathbf{D}_{6}\right): \delta=3.64\left(\mathrm{NSi}\left(\mathrm{CH}_{3}\right)_{3}\right), 38.00\left(\mathrm{~N}\left(\mathrm{CH}_{3}\right)_{2}\right), 46.00$ $\left(\left(\mathrm{CH}_{3}\right)_{2} \mathrm{NCH}_{2} \mathrm{CH}_{2}\right), 49.26\left(\left(\mathrm{CH}_{3}\right)_{2} \mathrm{NCH}_{2} \mathrm{CH}_{2}\right), 58.96\left(\mathrm{SN}\left(\mathrm{CH}_{3}\right)\right)$

${ }^{29} \mathrm{Si}-\mathrm{NMR}\left(59.63 \mathrm{MHz}, \mathrm{C}_{6} \mathrm{D}_{6}\right): \delta=-3.59$

\subsubsection{1 $\left[\mathrm{Na}\left\{\mathrm{Me}_{2} \mathrm{~N}\left(\mathrm{CH}_{2}\right)_{2} \mathrm{~N}(\mathrm{Me}) \mathrm{S}\left(\mathrm{NSiMe}_{3}\right)_{2}\right\}\right]_{2}(22)$}

To a suspension of TrMEDA (0.25 g, $2.45 \mathrm{mmol}, 2.0$ eq.) and $\mathrm{NaOtBu}(0.24 \mathrm{~g}$, $2.45 \mathrm{mmol}, 2.0$ eq.) in hexane $(5 \mathrm{~mL})$ was added $n$ BuLi $(1.6 \mathrm{M}$ in hexane, $1.53 \mathrm{~mL}$, $2.45 \mathrm{mmol}, 2.0$ eq.) at $0{ }^{\circ} \mathrm{C}$. After stirring at rt over night $\mathrm{S}\left(\mathrm{NSiMe}_{3}\right)_{2}(0.51 \mathrm{~g}$, $2.45 \mathrm{mmol}, 2.0$ eq.) was added dropwise at $-78^{\circ} \mathrm{C}$ and the suspension stirred for $8 \mathrm{~h}$. After filtration and reduction of the volume the solution was stored at $4{ }^{\circ} \mathrm{C}$, resulting in colourless crystals after one day.

Empirical formula: $\mathrm{C}_{22} \mathrm{H}_{62} \mathrm{~N}_{8} \mathrm{Na}_{2} \mathrm{~S}_{2} \mathrm{Si}_{4}$

Molecular weight: $661.26 \mathrm{~g} / \mathrm{mol}$

Yield (crystals): $0.78 \mathrm{~g}, 1.18 \mathrm{mmol}, 96 \%$

Elemental analysis (found (calc.) [\%]): C 39.46 (39.96), H 9.33 (9.33), N 16.47 (16.95), S 10.01 (9.70)

${ }^{1} \mathrm{H}-\mathrm{NMR}(\mathbf{5 0 0 . 1 3} \mathbf{~ M H z}$, tol-d $8,243 \mathrm{~K}): \delta=0.36\left(\mathrm{~s}, 16 \mathrm{H}, \mathrm{NSi}\left(\mathrm{CH}_{3}\right)_{3}\right), 0.39(\mathrm{~s}, 16 \mathrm{H}$, $\left.\mathrm{NSi}\left(\mathrm{CH}_{3}\right)_{3}\right), 1.46$ (d br, $\left.4 \mathrm{H},{ }^{2} J_{\mathrm{H}-\mathrm{H}}=13.0 \mathrm{~Hz},\left(\mathrm{CH}_{3}\right)_{2} \mathrm{NCH}_{2} \mathrm{CH}_{2}\right), 1.84(\mathrm{~d} \mathrm{br}, 4 \mathrm{H}$, $\left.{ }^{2} J_{\mathrm{H}-\mathrm{H}}=13.5 \mathrm{~Hz},\left(\mathrm{CH}_{3}\right)_{2} \mathrm{NCH}_{2} \mathrm{CH}_{2}\right), 2.02\left(\mathrm{~s}, 12 \mathrm{H}, \mathrm{N}\left(\mathrm{CH}_{3}\right)_{2}\right), 2.39\left(\mathrm{~s}, 6 \mathrm{H}, \mathrm{SN}\left(\mathrm{CH}_{3}\right)\right)$ ${ }^{13} \mathrm{C}-\mathrm{NMR}(125.76 \mathrm{MHz}$, tol-d $8,243 \mathrm{~K}): \delta=3.10\left(\mathrm{NSi}\left(\mathrm{CH}_{3}\right)_{3}\right), 3.86\left(\mathrm{NSi}\left(\mathrm{CH}_{3}\right)_{3}\right)$, $37.55\left(\mathrm{~N}\left(\mathrm{CH}_{3}\right)_{2}\right), 43.34\left(\left(\mathrm{CH}_{3}\right)_{2} \mathrm{NCH}_{2} \mathrm{CH}_{2}\right), 47.88\left(\left(\mathrm{CH}_{3}\right)_{2} \mathrm{NCH}_{2} \mathrm{CH}_{2}\right), 49.77\left(\mathrm{SN}\left(\mathrm{CH}_{3}\right)\right)$

${ }^{29} \mathrm{Si}-\mathrm{NMR}(99.36 \mathrm{MHz}$, tol-d $8,243 \mathrm{~K}): \delta=-5.35,4.54$

\subsubsection{2 $\left[(\mathrm{OH}) \mathrm{Li}_{2} \mathrm{~K}_{3}\left\{\mathrm{PhP}\left(\mathrm{CH}_{2} \mathrm{~S}\left(\mathrm{NSiMe}_{3}\right)_{2}\right)_{2}\right\}_{2}\right](23)$}

$\mathrm{Me}_{2} \mathrm{PPh}(1.03 \mathrm{~mL}, 8.10 \mathrm{mmol}, 1.0$ eq.) was mixed with $\mathrm{KO} \mathrm{Bu}(0.91 \mathrm{~g}, 8.10 \mathrm{mmol}$, 1.0 eq.) and tBuLi ( $1.5 \mathrm{M}$ in pentane, $5.40 \mathrm{~mL}, 8.10 \mathrm{mmol}, 1.0$ eq.) was slowly added dropwise at it. The precipitated brown powder was filtered, washed with pentane $(3 \times 5 \mathrm{~mL})$, suspended in pentane and $\mathrm{S}\left(\mathrm{NSiMe}_{3}\right)_{2}(1.67 \mathrm{~g}, 8.10 \mathrm{mmol}, 1.0$ eq. $)$ was slowly added at $-78^{\circ} \mathrm{C}$. The orange-brown suspension was allowed to warm to $\mathrm{rt}$ and stirred over night. It was filtered over celite, washed with pentane and the solution stored at $-25^{\circ} \mathrm{C}$. Colourless crystals, suitable for structural analysis were obtained after one week.

Empirical formula: $\mathrm{C}_{45} \mathrm{H}_{103} \mathrm{~K}_{3} \mathrm{Li}_{2} \mathrm{~N}_{8} \mathrm{OP}_{2} \mathrm{~S}_{4} \mathrm{Si}_{8} \quad$ Molecular weight: $1318.48 \mathrm{~g} / \mathrm{mol}$ 


\subsubsection{3 $\left[\mathrm{Li}_{4} \mathrm{O}_{2}\left\{\mathrm{CH}_{2}\left(\mathrm{~N}(\mathrm{Me}) \mathrm{CH}_{2} \mathrm{~S}(\mathrm{~N} t \mathrm{Bu})_{2} \mathrm{Li}\right)\right\}_{2}\right](24)$}

[Li $\left.\left\{\mathrm{H}_{2} \mathrm{CN}(\mathrm{Me})\right\}_{2} \mathrm{CH}_{2}\right](0.20 \mathrm{~g}, 1.75 \mathrm{mmol}, 2.0$ eq.) was suspended in pentane $(8 \mathrm{~mL})$ and $\mathrm{S}(\mathrm{NtBu})_{2}\left(0.61 \mathrm{~g}, 3.50 \mathrm{mmol}, 4.0 \mathrm{eq}\right.$.) was slowly added at $-78^{\circ} \mathrm{C}$. The solution was allowed to warm to rt over night, filtered and reduced in volume. Upon storage at $-25^{\circ} \mathrm{C}$ colourless crystals were obtained after several hours.

Empirical formula: $\mathrm{C}_{42} \mathrm{H}_{96} \mathrm{Li}_{6} \mathrm{~N}_{12} \mathrm{O}_{2} \mathrm{~S}_{4} \quad$ Molecular weight: $971.20 \mathrm{~g} / \mathrm{mol}$

Yield: $0.62 \mathrm{~g}, 0.64 \mathrm{mmol}, 73 \%$

Elemental analysis (found (calc.) [\%]): C 51.86 (51.94), H 10.25 (9.96), N 17.34 (17.31), S 13.74 (13.21)

${ }^{1} \mathrm{H}-\mathrm{NMR}\left(\mathbf{3 0 0 . 1 3} \mathrm{MHz}, \mathrm{C}_{6} \mathrm{D}_{6}\right): \delta=1.40\left(\mathrm{~s}, 72 \mathrm{H}, \mathrm{NC}\left(\mathrm{CH}_{3}\right)_{3}\right), 2.10\left(\mathrm{~s}, 12 \mathrm{H}, \mathrm{NCH}_{3}\right)$, $2.97\left(\mathrm{~s}, 4 \mathrm{H}, \mathrm{NCH}_{2} \mathrm{~N}\right), 3.13\left(\mathrm{~s}, 8 \mathrm{H}, \mathrm{NCH}_{2} \mathrm{~S}\right)$

${ }^{13} \mathrm{C}$-NMR (125.76 MHz, $\left.\mathrm{C}_{6} \mathrm{D}_{6}\right): \delta=33.95\left(\mathrm{NC}\left(\mathrm{CH}_{3}\right)_{3}\right), 47.10\left(\mathrm{~N}\left(\mathrm{CH}_{3}\right)_{2}\right), 53.44$ $\left(\mathrm{C}\left(\mathrm{CH}_{3}\right)_{3}\right), 86.39\left(\mathrm{SCH}_{2} \mathrm{~N}\right), 88.15\left(\mathrm{NCH}_{2} \mathrm{~N}\right)$

${ }^{7}$ Li-NMR (116.46 MHz, $\left.\mathrm{C}_{6} \mathrm{D}_{6}\right): \delta=2.53$

\subsubsection{4 [ $\mathrm{Li}_{4}\left\{\left(\mathrm{NSiMe}_{3}\right)_{2} \mathrm{SCH}_{2} \mathrm{~N}(\mathrm{Me}) \mathrm{CH}_{2} \mathrm{~N}(\mathrm{Me}) \mathrm{CH}_{2}(\mathrm{O})\right\}\left\{\mathrm{NSN}\left(\mathrm{SiMe}_{3}\right)\right\}-$ $(\mathrm{OtBu})]_{2}(25)$}

[Li $\left.\left\{\mathrm{H}_{2} \mathrm{CN}(\mathrm{Me})\right\}_{2} \mathrm{CH}_{2}\right](0.20 \mathrm{~g}, 1.75 \mathrm{mmol}, 2.0$ eq. $)$ was suspended in pentane $(10 \mathrm{~mL})$ and $\mathrm{S}\left(\mathrm{NSiMe}_{3}\right)_{2}\left(0.72 \mathrm{~g}, 3.50 \mathrm{mmol}, 4.0 \mathrm{eq}\right.$.) was slowly added at $-78{ }^{\circ} \mathrm{C}$. The solution was allowed to warm to rt over night, filtered and reduced in volume. Upon storage at $-30{ }^{\circ} \mathrm{C}$ colourless crystals were obtained after four days.

Empirical formula: $\mathrm{C}_{35.44} \mathrm{H}_{96.02} \mathrm{Li}_{8} \mathrm{~N}_{12} \mathrm{O}_{4} \mathrm{Si}_{6.57}$ Molecular weight: $1122.87 \mathrm{~g} / \mathrm{mol}$

\subsubsection{5 $\left[\mathrm{Mg}\left\{\mathrm{Me}_{2} \mathrm{PCH}_{2} \mathrm{~S}(\mathrm{NtBu})_{2}\right\}_{2}\right](26)$}

$\mathrm{MgCl}_{2}(0.17 \mathrm{~g}, 1.80 \mathrm{mmol}, 1.1$ eq. $)$ was dissolved in THF $(5 \mathrm{~mL})$ and cooled to -10 ${ }^{\circ} \mathrm{C}$. $\quad\left[\mathrm{Li}\left\{\mathrm{Me}_{2} \mathrm{PCH}_{2} \mathrm{~S}(\mathrm{NtBu})_{2}\right\}\right]_{2}$ (1) $(0.84 \mathrm{~g}, 1.64 \mathrm{mmol}, 1.0$ eq.) was dissolved in pentane $(20 \mathrm{~mL})$, cooled with an ice bath and added dropwise to the solution of $\mathrm{MgCl}_{2}$. The suspension was allowed to warm to rt and stirred overnight. The solvent was removed in vacuo and the resulting yellow powder suspended in $20 \mathrm{~mL}$ pentane. The suspension was filtered over celite and the volume of the filtrate was reduced. Colourless crystals were obtained after storing the yellow solution for three days at $4{ }^{\circ} \mathrm{C}$.

Empirical formula: $\mathrm{C}_{22} \mathrm{H}_{52} \mathrm{MgN}_{4} \mathrm{P}_{2} \mathrm{~S}_{2}$

Molecular weight: $523.07 \mathrm{~g} / \mathrm{mol}$ 
Yield: $0.54 \mathrm{~g}, 1.03 \mathrm{mmol}, 64 \%$

Melting point: $165.5^{\circ} \mathrm{C}$ (decomp.)

Elemental analysis (found (calc.) [\%]): C 49.93 (50.52), H 9.96 (10.02), N 10.95 (10.71), S 12.21 (12.26)

${ }^{1} \mathrm{H}-\mathrm{NMR}\left(500.13 \mathrm{MHz}, \mathrm{C}_{6} \mathrm{D}_{6}\right): \delta=0.976\left(\mathrm{~d}, 6 \mathrm{H},{ }^{2} \mathrm{~J}_{\mathrm{P}-\mathrm{H}}=1.08 \mathrm{~Hz}, \mathrm{P}\left(\mathrm{CH}_{3}\right)_{2}\right), 0.978(\mathrm{~d}$, $\left.6 \mathrm{H},{ }^{2} J_{\mathrm{P}-\mathrm{H}}=1.10 \mathrm{~Hz}, \mathrm{P}\left(\mathrm{CH}_{3}\right)_{2}\right), 1.39$ (s br, $36 \mathrm{H}, \mathrm{C}\left(\mathrm{CH}_{3}\right)_{3}$ ), 2.51 (pseudo tr, $4 \mathrm{H}$, $\left.{ }^{2} J_{\mathrm{P}-\mathrm{H}}=1.65 \mathrm{~Hz}, \mathrm{PCH}_{2} \mathrm{~S}\right)$

${ }^{13} \mathrm{C}-N M R\left(125.76 \mathrm{MHz}, \mathrm{C}_{6} \mathrm{D}_{6}\right): \delta=14.67\left(\mathrm{~d},{ }^{1} \mathrm{~J}_{\mathrm{P}-\mathrm{C}}=4.06 \mathrm{~Hz}, \mathrm{P}\left(\mathrm{CH}_{3}\right)_{2}\right), 14.71$ (d, $\left.{ }^{1} J_{\mathrm{P}-\mathrm{C}}=4.06 \mathrm{~Hz}, \mathrm{P}\left(\mathrm{CH}_{3}\right)_{2}\right), 33.67\left(\mathrm{C}\left(\mathrm{CH}_{3}\right)_{3}\right), 53.08\left(\mathrm{C}\left(\mathrm{CH}_{3}\right)_{3}\right), 65.92\left(\mathrm{~d},{ }^{1} \mathrm{~J}_{\mathrm{P}-\mathrm{C}}=\right.$ $\left.1.85 \mathrm{~Hz}, \mathrm{PCH}_{2} \mathrm{~S}\right), 65.94\left(\mathrm{~d},{ }^{1} \mathrm{~J}_{\mathrm{P}-\mathrm{C}}=1.99 \mathrm{~Hz}, \mathrm{PCH}_{2} \mathrm{~S}\right.$ )

${ }^{31} \mathrm{P}$-NMR (202.46 MHz, $\left.\mathrm{C}_{6} \mathrm{D}_{6}\right): \delta=-82.69$ (s br)

\subsubsection{6 $\left[\mathrm{Mg}\left\{\mathrm{Me}_{2} \mathrm{PCH}_{2} \mathrm{~S}\left(\mathrm{NSiMe}_{3}\right)_{2}\right\}_{2}\right](27)$}

$\left[\mathrm{Li}\left\{\mathrm{Me}_{2} \mathrm{PCH}_{2} \mathrm{~S}\left(\mathrm{NSiMe}_{3}\right)_{2}\right\}\right]_{2}$ (4) (0.54 g, $0.94 \mathrm{mmol}, 1.0$ eq.) and $\mathrm{MgCl}_{2}(0.13 \mathrm{~g}, 1.4$ mmol, 1.5 eq.) were joined in an argon drybox and dissolved in THF (10 mL). After stirring for $24 \mathrm{~h}$ at $\mathrm{rt}$, the solvent was evaporated in vacuo and the resulting powder suspended in pentane $(10 \mathrm{~mL})$. The suspension was filtered and reduced in volume. After storing the colourless solution at $4{ }^{\circ} \mathrm{C}$ for four days, crystals suitable for structural analysis were obtained.

Empirical formula: $\mathrm{C}_{18} \mathrm{H}_{52} \mathrm{MgN}_{4} \mathrm{P}_{2} \mathrm{~S}_{2} \mathrm{Si}_{4}$

Yield: $0.53 \mathrm{~g}, 0.90 \mathrm{mmol}, 96 \%$
Molecular weight: $587.36 \mathrm{~g} / \mathrm{mol}$

Melting point: $206.5^{\circ} \mathrm{C}$ (decomp.)

Elemental analysis (found (calc.) [\%]): C 36.92 (36.81), H 9.27 (8.92), N 9.75 (9.54), S 11.11 (10.92)

${ }^{1} \mathrm{H}-\mathrm{NMR}\left(500.13 \mathrm{MHz}, \mathrm{C}_{6} \mathrm{D}_{6}\right): \delta=0.29\left(\mathrm{~s}, 36 \mathrm{H}, \mathrm{NSi}\left(\mathrm{CH}_{3}\right)_{3}\right), 0.91\left(\mathrm{~s}, 12 \mathrm{H}, \mathrm{P}\left(\mathrm{CH}_{3}\right)_{2}\right)$, $2.398\left(\mathrm{~d}, 2 \mathrm{H},{ }^{2} J_{\mathrm{P}-\mathrm{H}}=1.93 \mathrm{~Hz}, \mathrm{PCH}_{2} \mathrm{~S}\right), 2.402\left(\mathrm{~d}, 2 \mathrm{H},{ }^{2} J_{\mathrm{P}-\mathrm{H}}=1.93 \mathrm{~Hz}, \mathrm{PCH}_{2} \mathrm{~S}\right)$

${ }^{13} \mathrm{C}-\mathrm{NMR}\left(125.76 \mathrm{MHz}, \mathrm{C}_{6} \mathrm{D}_{6}\right): \delta=2.75\left(\mathrm{NSi}\left(\mathrm{CH}_{3}\right)_{3}\right), 13.77\left(\mathrm{~d},{ }^{1} \mathrm{~J}_{\mathrm{P}-\mathrm{C}}=2.30 \mathrm{~Hz}\right.$, $\left.\mathrm{P}\left(\mathrm{CH}_{3}\right)_{2}\right), 13.79\left(\mathrm{~d},{ }^{1} \mathrm{~J}_{\mathrm{P}-\mathrm{C}}=2.30 \mathrm{~Hz}, \mathrm{P}\left(\mathrm{CH}_{3}\right)_{2}\right), 67.57\left(\mathrm{PCH}_{2} \mathrm{~S}\right)$

${ }^{29}$ Si-NMR (99.36 MHz, $\left.\mathrm{C}_{6} \mathrm{D}_{6}\right): \delta=-4.05$

${ }^{31}$ P-NMR (202.46 MHz, $\left.\mathrm{C}_{6} \mathrm{D}_{6}\right): \delta=-84.63$

\subsubsection{7 $\left[\mathrm{Ca}\left\{\mathrm{Ph}_{2} \mathrm{PCH}_{2} \mathrm{~S}\left(\mathrm{NSiMe}_{3}\right)_{2}\right\}_{2}\right](28)$}

To a slurry of $\left[\mathrm{Ca}\left\{\mathrm{N}\left(\mathrm{SiMe}_{3}\right)_{2}\right\}_{2}\right](0.10 \mathrm{~g}, 0.29 \mathrm{mmol}, 1.0$ eq. $)$ in pentane $(25 \mathrm{~mL})$ a solution of [(tmeda) $\left.\left.\mathrm{Li}_{2} \mathrm{Ph}_{2} \mathrm{PCH}_{2} \mathrm{~S}\left(\mathrm{NSiMe}_{3}\right)_{2}\right\}\right]$ (11) $(0.30 \mathrm{~g}, 0.57 \mathrm{mmol}, 2.0$ eq.) in pentane $(10 \mathrm{~mL})$ was slowly added at $-78{ }^{\circ} \mathrm{C}$. After warming to $\mathrm{rt}$ and stirring 
overnight, the light yellow suspension was filtered over celite, reduced in volume and stored at $4{ }^{\circ} \mathrm{C}$, yielding colourless crystals after one day.

Empirical formula: $\mathrm{C}_{38} \mathrm{H}_{60} \mathrm{CaN}_{4} \mathrm{P}_{2} \mathrm{~S}_{2} \mathrm{Si}_{4}$

Molecular weight: $851.40 \mathrm{~g} / \mathrm{mol}$

Yield: $0.12 \mathrm{~g}, 0.14 \mathrm{mmol}, 48 \%$

Elemental analysis (found (calc.) [\%]): C 53.49 (53.61), H 7.13 (7.10), N 7.19 (6.58), S 8.19 (7.53)

${ }^{1} \mathrm{H}-N M R\left(300.13 \mathrm{MHz}, \mathbf{C}_{6} \mathrm{D}_{6}\right): \delta=0.19\left(\mathrm{~s}, 36 \mathrm{H}, \mathrm{NSi}\left(\mathrm{CH}_{3}\right)_{3}\right), 3.39\left(\mathrm{~d}, 4 \mathrm{H},{ }^{2} \mathrm{~J}_{\mathrm{P}-\mathrm{H}}=\right.$ 5.01 Hz, PCH $\left.\mathrm{P}_{2} \mathrm{~S}\right), 6.99-7.07(\mathrm{~m}, 12 \mathrm{H}, \mathrm{o}-\mathrm{H}, p-\mathrm{H}), 7.51-7.57(\mathrm{~m}, 8 \mathrm{H}, m-\mathrm{H})$

${ }^{13} \mathrm{C}-\mathrm{NMR}\left(125.76 \mathrm{MHz}, \mathrm{C}_{6} \mathrm{D}_{6}\right): \delta=2.39\left(\mathrm{NSi}\left(\mathrm{CH}_{3}\right)_{3}\right), 70.09\left(\mathrm{PCH}_{2} \mathrm{~S}\right), 128.75$ (pseudo $\operatorname{tr}, o-\mathrm{C}), 128.00(p-\mathrm{C}), 133.00\left(\mathrm{~m},{ }^{3} J_{\mathrm{P}-\mathrm{C}}=18.25 \mathrm{~Hz}, m-\mathrm{C}\right), 137.29(i-\mathrm{C})$

${ }^{29}$ Si-NMR (99.36 MHz, $\left.\mathrm{C}_{6} \mathrm{D}_{6}\right): \delta=-3.67$

${ }^{31}$ P-NMR (121.49 MHz, $\left.\mathrm{C}_{6} \mathrm{D}_{6}\right): \delta=-39.31$

\subsubsection{8 $\left[\mathrm{Sr}\left\{\mathrm{Ph}_{2} \mathrm{PCH}_{2} \mathrm{~S}\left(\mathrm{NSiMe}_{3}\right)_{2}\right\}_{2}\right](29)$}

To a slurry of $\left[\mathrm{Sr}\left\{\mathrm{N}\left(\mathrm{SiMe}_{3}\right)_{2}\right\}_{2}\right](0.15 \mathrm{~g}, 0.37 \mathrm{mmol}, 1.0$ eq. $)$ in pentane $(5 \mathrm{~mL})$ a solution of $11(0.39 \mathrm{~g}, 0.73 \mathrm{mmol}, 2.0$ eq. $)$ in pentane $(10 \mathrm{~mL})$ was slowly added at $78{ }^{\circ} \mathrm{C}$. After warming to $\mathrm{rt}$ and stirring overnight, the light yellow suspension was filtered over celite, reduced in volume and stored at $4{ }^{\circ} \mathrm{C}$, yielding colourless crystals after two days.

Empirical formula: $\mathrm{C}_{38} \mathrm{H}_{60} \mathrm{SrN}_{4} \mathrm{P}_{2} \mathrm{~S}_{2} \mathrm{Si}_{4}$

Molecular weight: $898.94 \mathrm{~g} / \mathrm{mol}$

Yield (crystals): $0.15 \mathrm{~g}, 0.17 \mathrm{mmol}, 45 \%$

Elemental analysis (found (calc.) [\%]): C 50.73 (50.77), H 7.04 (6.73), N 6.34 (6.23), S 7.44 (7.13)

${ }^{1} \mathrm{H}-\mathrm{NMR}\left(300.13 \mathrm{MHz}, \mathrm{C}_{6} \mathrm{D}_{6}\right): \delta=0.21\left(\mathrm{~s}, 36 \mathrm{H}, \mathrm{NSi}\left(\mathrm{CH}_{3}\right)_{3}\right), 3.41\left(\mathrm{~d},{ }^{2} \mathrm{~J}_{\mathrm{P}-\mathrm{H}}=5.15 \mathrm{~Hz}\right.$, $\left.\mathrm{PCH}_{2} \mathrm{~S}\right), 6.99-7.05(\mathrm{~m}, 12 \mathrm{H}, p-\mathrm{H}, 0-\mathrm{H}), 7.47-7.50(\mathrm{~m}, 8 \mathrm{H}, m-\mathrm{H})$

${ }^{13} \mathrm{C}-\mathrm{NMR}\left(125.76 \mathrm{MHz}, \mathrm{C}_{6} \mathrm{D}_{6}\right): \delta=2.42\left(\mathrm{NSi}\left(\mathrm{CH}_{3}\right)_{3}\right), 70.08\left(\mathrm{~d},{ }^{1} \mathrm{~J}_{\mathrm{P}-\mathrm{C}}=5.55 \mathrm{~Hz}\right.$, $\left.\mathrm{PCH}_{2} \mathrm{~S}\right), 128.76(\mathrm{~m}, o-\mathrm{C}), 128.95(p-\mathrm{C}), 133.66-133.88$ (m, $\left.m-\mathrm{C}\right), 137.46(\mathrm{~m}, i-\mathrm{C})$

${ }^{29} \mathrm{Si}-\mathrm{NMR}\left(99.36 \mathrm{MHz}, \mathrm{C}_{6} \mathrm{D}_{6}\right): \delta=-4.53$

${ }^{31}$ P-NMR (121.49 MHz, $\left.\mathrm{C}_{6} \mathrm{D}_{6}\right): \delta=-36.07$

\subsubsection{9 [Co $\left.\left\{\mathrm{Ph}_{2} \mathrm{PCH}_{2} \mathrm{~S}\left(\mathrm{NSiMe}_{3}\right)_{2}\right\}_{2}\right](30)$}

To a slurry of $\left[\mathrm{Co}\left\{\mathrm{N}\left(\mathrm{SiMe}_{3}\right)_{2}\right\}_{2}\right](0.11 \mathrm{~g}, 0.29 \mathrm{mmol}, 1.0$ eq.) in pentane $(5 \mathrm{~mL})$ a solution of $11(0.29 \mathrm{~g}, 0.57 \mathrm{mmol}, 2.0$ eq.) in pentane $(10 \mathrm{~mL})$ was slowly added at $-78{ }^{\circ} \mathrm{C}$. After warming to $\mathrm{rt}$ and stirring overnight, the blue-purple suspension was 
filtered over celite, reduced in volume and stored at $4{ }^{\circ} \mathrm{C}$, yielding blue crystals after two hours.

Empirical formula: $\mathrm{C}_{38} \mathrm{H}_{60} \mathrm{CoN}_{4} \mathrm{P}_{2} \mathrm{~S}_{2} \mathrm{Si}_{4}$ Molecular weight: $870.25 \mathrm{~g} / \mathrm{mol}$

Yield (crystals): $0.05 \mathrm{~g}, 0.06 \mathrm{mmol}, 21 \%$

Elemental analysis (found (calc.) [\%]): C 51.58 (52.44), H 7.17 (6.95), N 6.59 (6.44), S 7.59 (7.37)

\subsubsection{0 $\left[\mathrm{Fe}\left\{\mathrm{Ph}_{2} \mathrm{PCH}_{2} \mathrm{~S}\left(\mathrm{NSiMe}_{3}\right)_{2}\right\}_{2}\right]$ (31) and [\{FeN $\left.\left(\mathrm{SiMe}_{3}\right)_{2}\right\}-$ $\left.\left\{\mathrm{Li}\left(\mathrm{NSiMe}_{3}\right)_{2} \mathrm{SCHP}(\mathrm{O}) \mathrm{Ph}_{2}\right\}(\mathrm{LiO})\right]_{2}(32)$}

To a slurry of [ $\left.\mathrm{Fe}\left\{\mathrm{N}\left(\mathrm{SiMe}_{3}\right)_{2}\right\}_{2}\right](0.21 \mathrm{~g}, 0.55 \mathrm{mmol}, 1.0$ eq. $)$ in pentane $(10 \mathrm{~mL}) \mathrm{a}$ solution of $11(0.58 \mathrm{~g}, 1.10 \mathrm{mmol}, 2.0 \mathrm{eq}$.) in pentane $(20 \mathrm{~mL})$ was slowly added at $78^{\circ} \mathrm{C}$. After warming to $\mathrm{rt}$ and stirring overnight, the light brown suspension was filtered over celite, reduced in volume and stored at $4{ }^{\circ} \mathrm{C}$, yielding colourless and red crystals after one month.

Empirical formula: $\mathrm{C}_{38} \mathrm{H}_{60} \mathrm{FeN}_{4} \mathrm{P}_{2} \mathrm{~S}_{2} \mathrm{Si}_{4} \quad$ (colourless)

Molecular weight: $867.17 \mathrm{~g} / \mathrm{mol}$

Empirical formula: $\mathrm{C}_{50} \mathrm{H}_{94} \mathrm{Fe}_{2} \mathrm{Li}_{4} \mathrm{~N}_{6} \mathrm{O}_{4} \mathrm{P}_{2} \mathrm{~S}_{2} \mathrm{Si}_{8} \quad$ (red)

Molecular weight: $1333.57 \mathrm{~g} / \mathrm{mol}$

\subsubsection{1 [ $\left.\left\{\mathrm{Cu}\left(\mathrm{Me}_{2} \mathrm{PCH}_{2} \mathrm{~S}\left(\mathrm{NSiMe}_{3}\right)_{2}\right)\right\}_{4}\left\{\mathrm{Cu}_{2} \mathrm{~S}\right\}_{4}\right](33)$}

[Cu\{N(SiMe $\left.\left.)_{2}\right\}\right]$ ] $(0.20 \mathrm{~g}, 0.89 \mathrm{mmol}, 2.0$ eq.) was suspended in THF (15 mL). $4(0.26$ $\mathrm{g}, 0.45 \mathrm{mmol}, 1.0$ eq.) in pentane $(15 \mathrm{~mL})$ was slowly added at $-78{ }^{\circ} \mathrm{C}$. After stirring over night the solvent was removed in vacuo and the residue suspended in hexane (30 $\mathrm{mL}$ ) and filtered over celite. The orange solution was reduced in volume and stored at $4{ }^{\circ} \mathrm{C}$ for two weeks, yielding colourless crystals.

Empirical formula: $\mathrm{C}_{36} \mathrm{H}_{104} \mathrm{Cu}_{12} \mathrm{~N}_{8} \mathrm{P}_{4} \mathrm{~S}_{8} \mathrm{Si}_{8} \quad$ Molecular weight: $2016.83 \mathrm{~g} / \mathrm{mol}$ ${ }^{1} \mathrm{H}-\mathrm{NMR}\left(300.13 \mathrm{MHz}, \mathbf{C}_{6} \mathbf{D}_{6}\right): \delta=0.41\left(\mathrm{~s}, 18 \mathrm{H}, \mathrm{NSi}\left(\mathrm{CH}_{3}\right)_{3}\right), 0.42(\mathrm{~s}, 18 \mathrm{H}$, $\left.\mathrm{NSi}\left(\mathrm{CH}_{3}\right)_{3}\right), 1.46\left(\mathrm{~d}, 6 \mathrm{H},{ }^{2} \mathrm{~J}_{\mathrm{P}-\mathrm{H}}=4.95 \mathrm{~Hz}, \mathrm{P}\left(\mathrm{CH}_{3}\right)_{2}\right), 1.53\left(\mathrm{~d}, 6 \mathrm{H},{ }^{2} \mathrm{~J}_{\mathrm{P}-\mathrm{H}}=3.99 \mathrm{~Hz}\right.$, $\left.\mathrm{P}\left(\mathrm{CH}_{3}\right)_{2}\right), 2.12\left(\mathrm{dd}, 4 \mathrm{H},{ }^{2} \mathrm{~J}_{\mathrm{H}-\mathrm{H}}=13.50 \mathrm{~Hz},{ }^{2} \mathrm{~J}_{\mathrm{P}-\mathrm{H}}=4.15 \mathrm{~Hz}, \mathrm{PCH} \mathrm{S}_{2}\right), 2.28(\mathrm{dd}, 4 \mathrm{H}$, $\left.{ }^{2} \mathrm{~J}_{\mathrm{H}-\mathrm{H}}=13.50 \mathrm{~Hz},{ }^{2} \mathrm{~J}_{\mathrm{P}-\mathrm{H}}=6.04 \mathrm{~Hz}, \mathrm{PCH}_{2} \mathrm{~S}\right)$

${ }^{31}$ P-NMR (121.49 MHz, $\left.\mathrm{C}_{6} \mathrm{D}_{6}\right): \delta=-75.78$ 


\subsubsection{2 [(tmeda)Rb $\left.\left\{\mathrm{Ph}_{2} \mathrm{PCH}_{2} \mathrm{~S}\left(\mathrm{NSiMe}_{3}\right)_{2}\right\}_{2} \mathrm{Li}\right]$ (34)}

To a slurry of $\left[\mathrm{Rb}\left\{\mathrm{N}\left(\mathrm{SiMe}_{3}\right)_{2}\right\}\right](0.14 \mathrm{~g}, 0.57 \mathrm{mmol}, 1.0$ eq.) in pentane $(5 \mathrm{~mL})$ a solution of $11(0.30 \mathrm{~g}, 0.57 \mathrm{mmol}, 1.0 \mathrm{eq}$.) in pentane $(10 \mathrm{~mL})$ was slowly added at $78^{\circ} \mathrm{C}$. After warming to $\mathrm{rt}$ and stirring overnight, the light brown suspension was filtered over celite, reduced in volume and stored at $4{ }^{\circ} \mathrm{C}$, yielding yellow crystals after two hours.

Empirical formula: $\mathrm{C}_{44} \mathrm{H}_{76} \mathrm{LiN}_{6} \mathrm{P}_{2} \mathrm{RbS}_{2} \mathrm{Si}_{4}$ Molecular weight: $1019.94 \mathrm{~g} / \mathrm{mol}$ Yield (crystals): $0.26 \mathrm{~g}, 0.26 \mathrm{mmol}, 45 \%$

Elemental analysis (found (calc.) [\%]): C 51.60 (51.81), H 7.60 (7.51), N 8.32 (8.24), S 6.55 (6.29)

${ }^{1} \mathrm{H}-\mathrm{NMR}\left(\mathbf{3 0 0 . 1 3} \mathrm{MHz}, \mathrm{C}_{6} \mathrm{D}_{6}\right): \delta=0.30\left(\mathrm{~s}, 36 \mathrm{H}, \mathrm{NSi}\left(\mathrm{CH}_{3}\right)_{3}\right), 2.08\left(\mathrm{~s}, 12 \mathrm{H}, \mathrm{N}\left(\mathrm{CH}_{3}\right)_{2}\right)$, $3.43\left(\mathrm{~s}, 4 \mathrm{H}, \mathrm{PCH}_{2} \mathrm{~S}\right), 7.02-7.13(\mathrm{~m}, 12 \mathrm{H}, \mathrm{o}-\mathrm{H}, p-\mathrm{H}), 7.56(\mathrm{~s} \mathrm{br}, 8 \mathrm{H}, m-\mathrm{H})$; the $\mathrm{N}\left(\mathrm{CH}_{2}\right)_{2} \mathrm{~N}$ protons were not resolved from the baseline

${ }^{7}$ Li-NMR (194.37 MHz, $\mathrm{C}_{6} \mathrm{D}_{6}$ ): $\delta=1.81(\mathrm{~s} \mathrm{br})$

${ }^{13}$ C-NMR (125.76 MHz, $\left.\mathrm{C}_{6} \mathrm{D}_{6}\right): \delta=3.37\left(\mathrm{NSi}\left(\mathrm{CH}_{3}\right)_{3}\right), 45.85\left(\mathrm{~N}\left(\mathrm{CH}_{3}\right)_{2}\right), 57.53(\mathrm{br}$, $\left.\mathrm{N}\left(\mathrm{CH}_{2}\right)_{2} \mathrm{~N}\right), 67.99\left(\mathrm{br}, \mathrm{PCH}{ }_{2} \mathrm{~S}\right), 128.29(o-\mathrm{C}), 128.65(\mathrm{br}, p-\mathrm{C}), 132.47\left(\mathrm{~d},{ }^{3} \mathrm{JP}_{\mathrm{P}} \mathrm{C}=\right.$ $18.71 \mathrm{~Hz}, m-\mathrm{C}$ ), 133.53 (d, ${ }^{1} \mathrm{~J}_{\mathrm{P}-\mathrm{C}}=18.35 \mathrm{~Hz}, i-\mathrm{C}$ )

${ }^{29} \mathrm{Si}-\mathrm{NMR}$ (99.36 MHz, $\left.\mathrm{C}_{6} \mathrm{D}_{6}\right): \delta=-5.63(\mathrm{~s} \mathrm{br})$

${ }^{31}$ P-NMR (202.46 MHz, $\left.\mathrm{C}_{6} \mathrm{D}_{6}\right): \delta=-33.03(\mathrm{~s} \mathrm{br})$

\subsubsection{3 [(tmeda)K\{ $\left.\left.\mathrm{Ph}_{2} \mathrm{PCH}_{2} \mathrm{~S}\left(\mathrm{NSiMe}_{3}\right)_{2}\right\}_{2} \mathrm{Li}\right](35)$}

To a slurry of $\left[\mathrm{K}\left\{\mathrm{N}\left(\mathrm{SiMe}_{3}\right)_{2}\right\}\right](0.11 \mathrm{~g}, 0.57 \mathrm{mmol}, 1.0$ eq. $)$ in pentane $(5 \mathrm{~mL})$ a solution of 11 ( $0.30 \mathrm{~g}, 0.57 \mathrm{mmol}, 1.0 \mathrm{eq}$.) in pentane $(10 \mathrm{~mL})$ was slowly added at $-78{ }^{\circ} \mathrm{C}$. After warming to rt and stirring overnight, the yellow suspension was filtered over celite, reduced in volume and stored at $-25^{\circ} \mathrm{C}$, yielding yellow crystals after four days.

Empirical formula: $\mathrm{C}_{44} \mathrm{H}_{76} \mathrm{LiN}_{6} \mathrm{P}_{2} \mathrm{KS}_{2} \mathrm{Si}_{4}$

Molecular weight: $973.57 \mathrm{~g} / \mathrm{mol}$

Yield (crystals): $0.16 \mathrm{~g}, 0.16 \mathrm{mmol}, 29 \%$

${ }^{1} \mathrm{H}-\mathrm{NMR}\left(300.13 \mathrm{MHz}, \mathbf{C}_{6} \mathrm{D}_{6}\right): \delta=0.23\left(\mathrm{~s}, 18 \mathrm{H}, \mathrm{NSi}\left(\mathrm{CH}_{3}\right)_{3}\right), 0.30(\mathrm{~s}, 18 \mathrm{H}$, $\left.\mathrm{NSi}\left(\mathrm{CH}_{3}\right)_{2}\right), 2.04\left(\mathrm{~s} \mathrm{br}, 16 \mathrm{H},\left(\mathrm{CH}_{3}\right)_{2} \mathrm{~N}, \mathrm{~N}\left(\mathrm{CH}_{2}\right)_{2} \mathrm{~N}\right), 3.40\left(\mathrm{~s} \mathrm{br}, 4 \mathrm{H}, \mathrm{PCH}_{2} \mathrm{~S}\right), 6.98-7.13$ (m, $12 \mathrm{H}, o-\mathrm{H}, p-\mathrm{H}), 7.46-7.68(\mathrm{~m}, 8 \mathrm{H}, m-\mathrm{H})$

${ }^{7} \mathrm{Li}-\mathrm{NMR}\left(\mathbf{1 1 6 . 6 4} \mathrm{MHz}, \mathrm{C}_{6} \mathrm{D}_{6}\right): \delta=1.90(\mathrm{~s} \mathrm{br})$

${ }^{31}$ P-NMR (121.49 MHz, $\mathrm{C}_{6} \mathrm{D}_{6}$ ): $\delta=-33.99(\mathrm{~s} \mathrm{br}),-33.30$ (s br) 


\section{Crystallographic Section}

\subsection{Crystal Application}

The crystals were taken from the mother liquor using standard Schlenk techniques and placed in perfluorated polyether oil on a microscope slide. An appropriately sized crystal of high quality was selected under a polarization microscope with the help of the X-TEMP2 cooling device (Figure 8-1). ${ }^{[213]}$ Thereby a crystal can be chosen under a protective nitrogen atmosphere and a desired temperature can be determined. The crystal was then mounted on the tip of a glass fibre, fixed to a goniometer head and shock cooled by the open-flow crystal cooling device. The polyether oil froze to a glas around the crystal protecting it, along with the nitrogen gas flow, from oxygen and moisture.

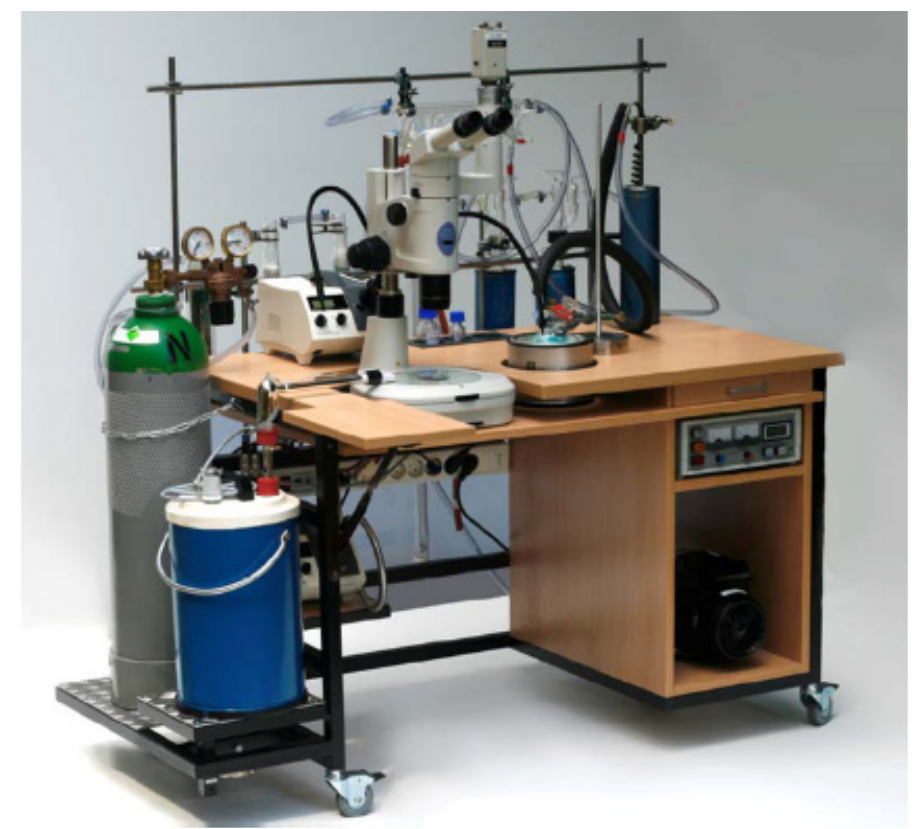

Figure 8-1: Mountig table with the X-TEMP2 cooling device. ${ }^{[214]}$

\subsection{Data Collection and Processing}

Data were collected on a Bruker SMART-APEXII rotating anode with D8 goniometer (Mo $\mathrm{K}_{\alpha}$ radiation, $\lambda=71.073 \mathrm{pm}$; INCOATEC Helios mirror optics) or an Incoatec microfocus source with Quazar mirror optics (Figure 8-2). ${ }^{[215]}$ All crystals were centered optically using a video camera after being mounted onto the diffractometer. 
Data collection was carried out with the APEX2 program package. ${ }^{[216]}$ Usually 48 frames in three different orientations were collected to check the crystal quality and determine the exposure time. The final measurement was then carried out in $\omega$-scan mode with a step-width of $0.3^{\circ}$.

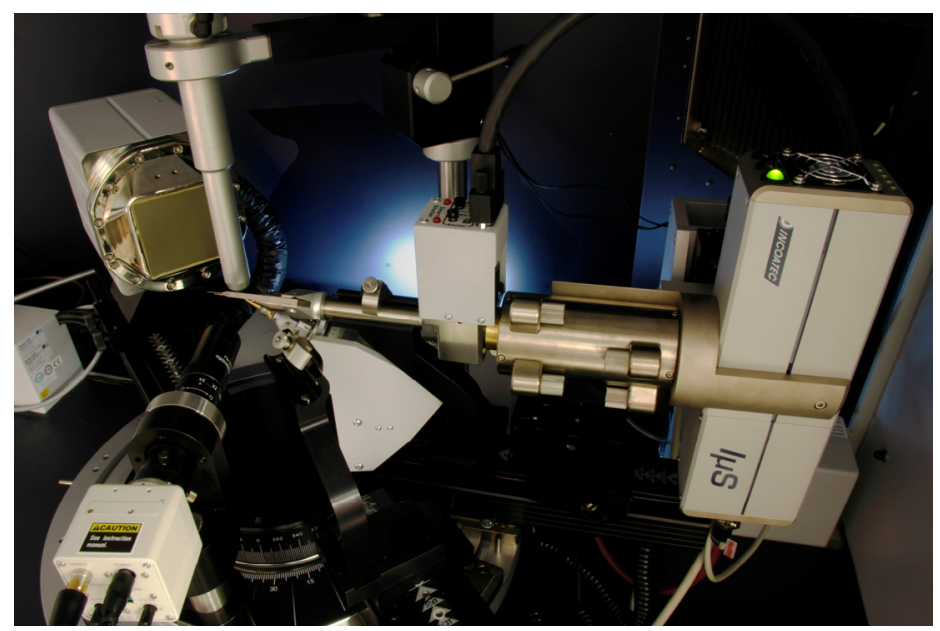

Figure 8-2: Setup of the INCOATEC micro focus source. ${ }^{[14]}$

The unit cell was searched and refined using APEX2. ${ }^{[216]}$ The data were integrated with SAINT ${ }^{[217]}$ and an empirical absorption correction with SADABS was applied. ${ }^{[218]}$ XPREP was used to determine the space group and for data merging. ${ }^{[219]}$

\subsection{Structure Solution and Refinement}

The structures were solved by direct methods with SHELXS and refined on $F^{2}$ using the full-matrix least-squares methods of SHELXL. ${ }^{[220]}$ From the integration the square of the structure factors $F_{0}^{2}$ was obtained which is directly proportional to the measured intensities. All non-hydrogen atoms were refined with anisotropic displacement parameters.

The results of the refinements were verified by comparison of the calculated $\left(F_{c}\right)$ and the observed $\left(F_{o}\right)$ structure factors. Commonly used criteria are the residuals $R 1$ (Equation 8-1) and $w R 2$ (Equation $8-2$ ). The value of $w R 2$ is thereby more significant because the model is refined against $F^{2}$. ${ }^{[21]}$

$$
R 1=\frac{\sum_{h k l}|| F_{o}-F_{c}||}{\sum_{h k l}\left|F_{0}\right|} \quad w R 2=\sqrt{\frac{\sum_{h k l} w\left(F_{o}^{2}-F_{c}^{2}\right)^{2}}{\sum_{h k l} w\left(F_{o}^{2}\right)^{2}}}
$$

Equation 8-1: Definition of $R 1 .^{[221]}$

Equation 8-2: Definition of $w R 2 .{ }^{[221]}$ 
Ideally, the residual densities at the end of the refinement should be low (i. e. below $1.00 \mathrm{e}^{-3}$ ). In addition, the deepest hole in the residual electron density map should be of comparable value. Due to model restrictions the residuals are normally found in the bonding regions. Higher residuals for heavy scatterers are acceptable as they arise mainly from absorption effects and Fourier truncation errors due to the limited recorded resolution range. The highest peak and deepest hole from difference Fourier analysis are listed in the crystallographic tables.

All hydrogen atoms bonded to $\mathrm{sp}^{2}\left(\mathrm{sp}^{3}\right)$ carbon atoms were assigned ideal positions and refined using a riding model with $\mathrm{U}_{\text {iso }}$ constrained to $1.2(1.5)$ times the $\mathrm{U}_{\text {eq }}$ value of the parent carbon atom. Hydrogen atoms bound to heteroatoms were located on the electron density map and refined using distance restraints. This is necessary because of the low electronegativity of hydrogen. Thus, its electron density is usually delocalised in direction of the heteroatom and only pseudo hydrogen positions can be found.

\subsection{Treatment of Disorder}

Especially $t \mathrm{Bu}$ groups or solvent molecules in the crystal can show thermal motion. Thus one given position cannot be unambiguously determined - the molecules or parts of them are disordered over different sites (positional disorder). This is often the case with ending groups which can rotate or tilt. In addition, atom positions can be occupied by different elements at the same time (site occupancy disorder).

To resolve disorder with the so-called split-atom model, the structure has to be refined as good as possible, thereby the disorder can be described more accurately. The main position of the disordered group is first described isotropically. Afterwards, the second position is assigned either by naming the corresponding Q-peaks or using the coordinates from the *.Ist file. Meanwhile, both sites are constrained to sum up to 1. Afterwards, the final refinement is undertaken as usual. Often it is helpful to assign disorder step by step in order to stabilise the refinement. ${ }^{[222]}$

In order to get physically sensible groups and to enhance the model it is often helpful or necessary to use constraints and restraints. A constraint is a mathematical operation fixing structural parameters on exact values (e. g. treatment of hydrogen atoms). Restraints introduce additional chemical or crystallographical information into the model. Restraints add to the data of the refinement and have to be observed within their standard deviations. Important restraints in SHELXL are SIMU and DELU 
(as well ISOR) which affect the anisotropic displacement parameters. ${ }^{[23]}$ DELU is the rigid bond restraint that fits the components of the anisotropic displacement parameters along the bonds resulting in uniform ADPs. SIMU is the similarity restraint which adjusts the ADPs of neighbouring atoms within a certain radius to be equal according to their esd's. ISOR forces the ADPs to adapt a more spherical, isotropic behavior, which is sometimes necessary to refine positions with minor occupation factors but should not be excessively used. 


\subsection{Crystallographic Details}

\subsection{1 $\left[\mathrm{Li}\left\{\mathrm{Ph}_{2} \mathrm{PCH}_{2} \mathrm{~S}(\mathrm{NtBu})_{2}\right\}\right]_{2}(2)$}

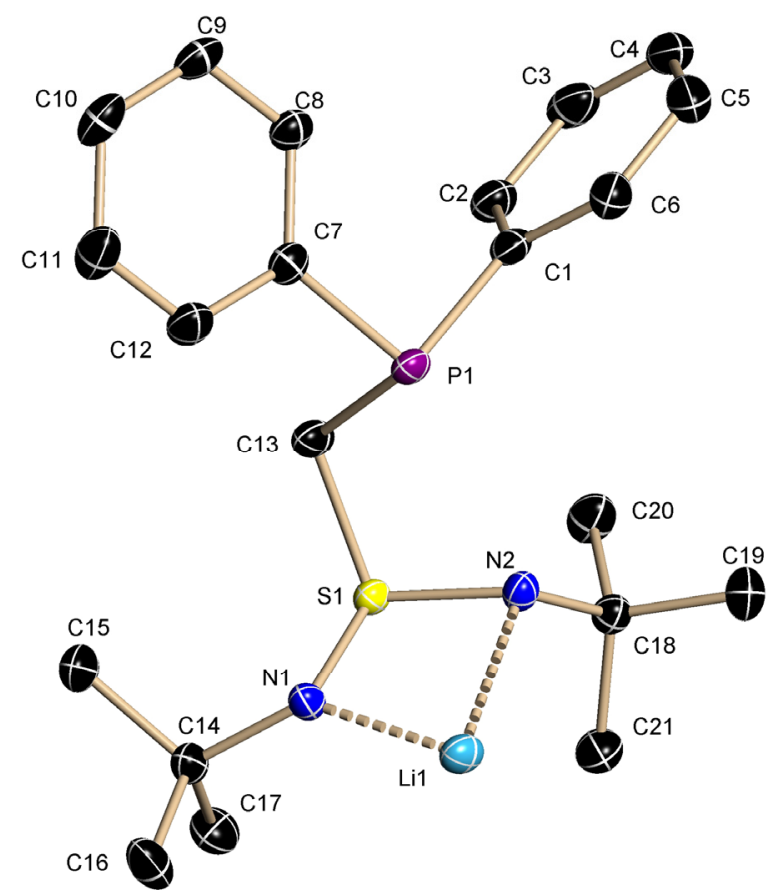

Asymmetric unit of 2. The anisotropic displacement parameters are shown at the $50 \%$ probability level, hydrogen atoms are omitted for clarity.

\begin{tabular}{|c|c|c|c|}
\hline identification code & Ph-Schnecke & $\mu\left[\mathrm{mm}^{-1}\right]$ & 0.235 \\
\hline empirical formula & $\mathrm{C}_{42} \mathrm{H}_{60} \mathrm{~N}_{4} \mathrm{P}_{2} \mathrm{~S}_{2} \mathrm{Li}_{2}$ & $F(000)$ & 408 \\
\hline molecular weight $[\mathrm{g} / \mathrm{mol}]$ & 760.93 & max./min. transmission & $0.8623 / 0.7544$ \\
\hline crystal size $[\mathrm{mm}]$ & $0.18 \times 0.1 \times 0.05$ & $\theta$ range $\left[{ }^{\circ}\right]$ & $1.88-28.28$ \\
\hline temperature $[\mathrm{K}]$ & $100(2)$ & completeness to $\theta_{\max }$ & 1.000 \\
\hline crystal system & triclinic & reflections collected & 25994 \\
\hline space group & $P \overline{1}$ & independent reflections & 5259 \\
\hline$a[\AA]$ & $9.6236(11)$ & $R_{\text {int }} / R_{\sigma}$ & $0.0399 / 0.0359$ \\
\hline$b[\AA]$ & $10.1512(12)$ & restraints/parameters & $0 / 241$ \\
\hline$c[\AA]$ & $11.3253(13)$ & GoF & 1.054 \\
\hline$\alpha\left[^{\circ}\right]$ & $73.936(2)$ & $R 1$ (all data) & 0.0564 \\
\hline$\beta\left[^{\circ}\right]$ & $84.728(2)$ & $R 1(1>2 \sigma(I))$ & 0.0391 \\
\hline$V\left[^{\circ}\right]$ & $88.960(2)$ & $w R 2$ (all data) & 0.1026 \\
\hline$V\left[\AA^{3}\right]$ & $1058.7(2)$ & $w R 2(1>2 \sigma(I))$ & 0.0976 \\
\hline$z$ & 1 & diff. peak/hole $\left[e \AA^{-3}\right]$ & $0.391 /-0.381$ \\
\hline$\rho_{\text {calc }}\left[\mathrm{g} \mathrm{cm}^{-3}\right]$ & 1.193 & $g 1 / g 2$ & $0.0518 / 0.3215$ \\
\hline
\end{tabular}




\subsection{2 $\left[\mathrm{Li}\left\{\mathrm{Me}(\mathrm{Ph}) \mathrm{PCH}_{2} \mathrm{~S}\left(\mathrm{NSiMe}_{3}\right)_{2}\right\}\right]_{2}(3)$}

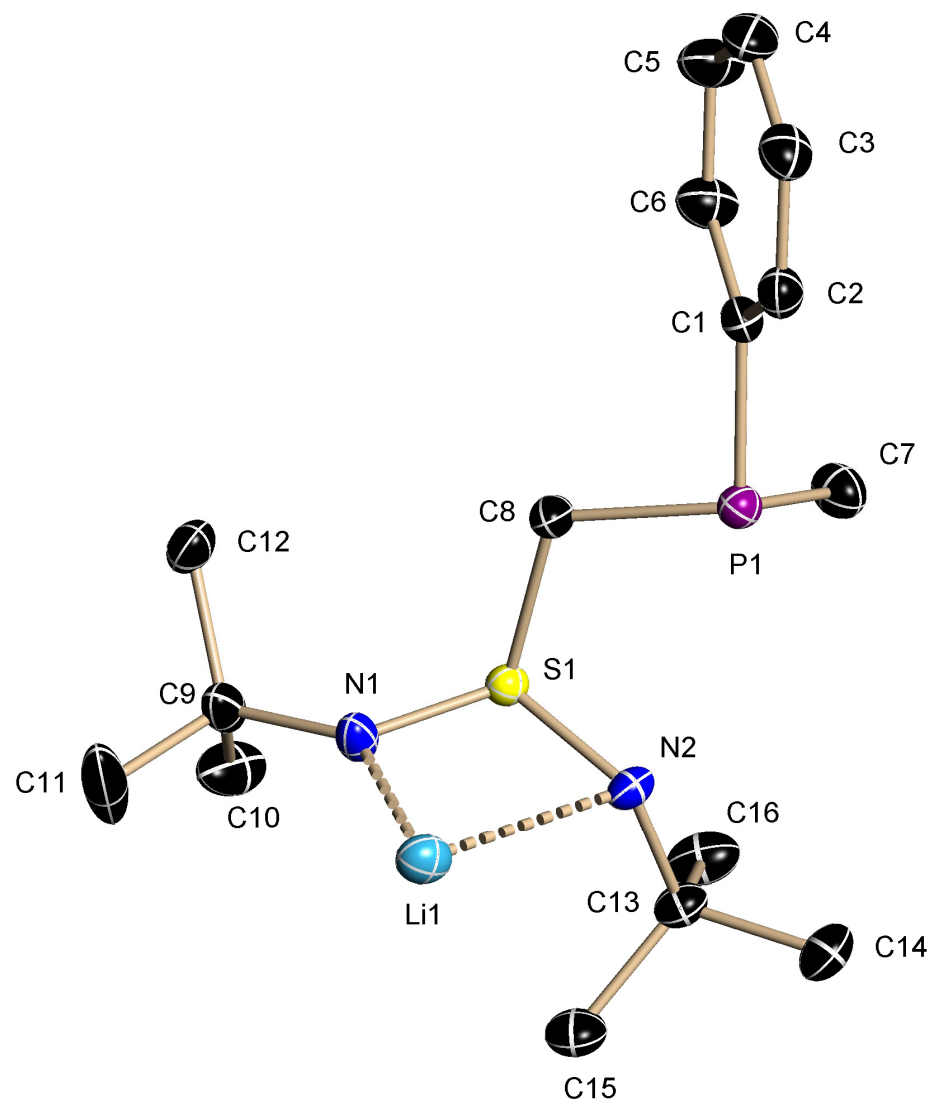

Asymmetric unit of 3. The anisotropic displacement parameters are shown at the $50 \%$ probability level, hydrogen atoms are omitted for clarity.

\begin{tabular}{ll|ll}
\hline identification code & Me-Ph-Schnecke & $F(000)$ & 688 \\
empirical formula & $\mathrm{C}_{32} \mathrm{H}_{56} \mathrm{~N}_{4} \mathrm{P}_{2} \mathrm{~S}_{2} \mathrm{Li}_{2}$ & max./min. transmission & $0.9703 / 0.9358$ \\
molecular weight $[\mathrm{g} / \mathrm{mol}]$ & 636.78 & $\theta$ range $\left[^{\circ}\right]$ & $1.96-26.37$ \\
crystal size $[\mathrm{mm}]$ & $0.16 \times 0.14 \times 0.08$ & completeness to $\theta_{\max }$ & 0.999 \\
temperature $[\mathrm{K}]$ & $100(2)$ & reflections collected & 39157 \\
crystal system & monoclinic & independent reflections & 3784 \\
space group & $P 2_{1} / c$ & $R_{\text {int }} / R_{\sigma}$ & $0.0274 / 0.0128$ \\
$a[\AA]$ & $10.5006(14)$ & restraints/parameters & $0 / 197$ \\
$b[\AA]]$ & $20.753(3)$ & GoF & 1.050 \\
$c[\AA]$ & $8.5699(11)$ & $R 1($ all data $)$ & 0.0325 \\
$\beta\left[^{\circ}\right]$ & $97.279(2)$ & $R 1(/>2 \sigma(I))$ & 0.0305 \\
$V\left[\AA^{3}\right]$ & $1852.5(4)$ & $w R 2($ all data $)$ & 0.0788 \\
$Z$ & 2 & $w R 2(>2 \sigma(I))$ & 0.0778 \\
$\rho_{\text {calc }}\left[\mathrm{g} \mathrm{cm}^{-3}\right]$ & 1.142 & diff. peak/hole $\left[\mathrm{e} \AA^{-3}\right]$ & $0.409 /-0.247$ \\
$\mu\left[\mathrm{mm}^{-1}\right]$ & 0.256 & g1/g2 & $0.0355 / 1.043$ \\
\hline
\end{tabular}




\subsection{3 $\left[\mathrm{Li}\left\{\mathrm{Me}_{2} \mathrm{PCH}_{2} \mathrm{~S}\left(\mathrm{NSiMe}_{3}\right)_{2}\right\}\right]_{2}(4)$}

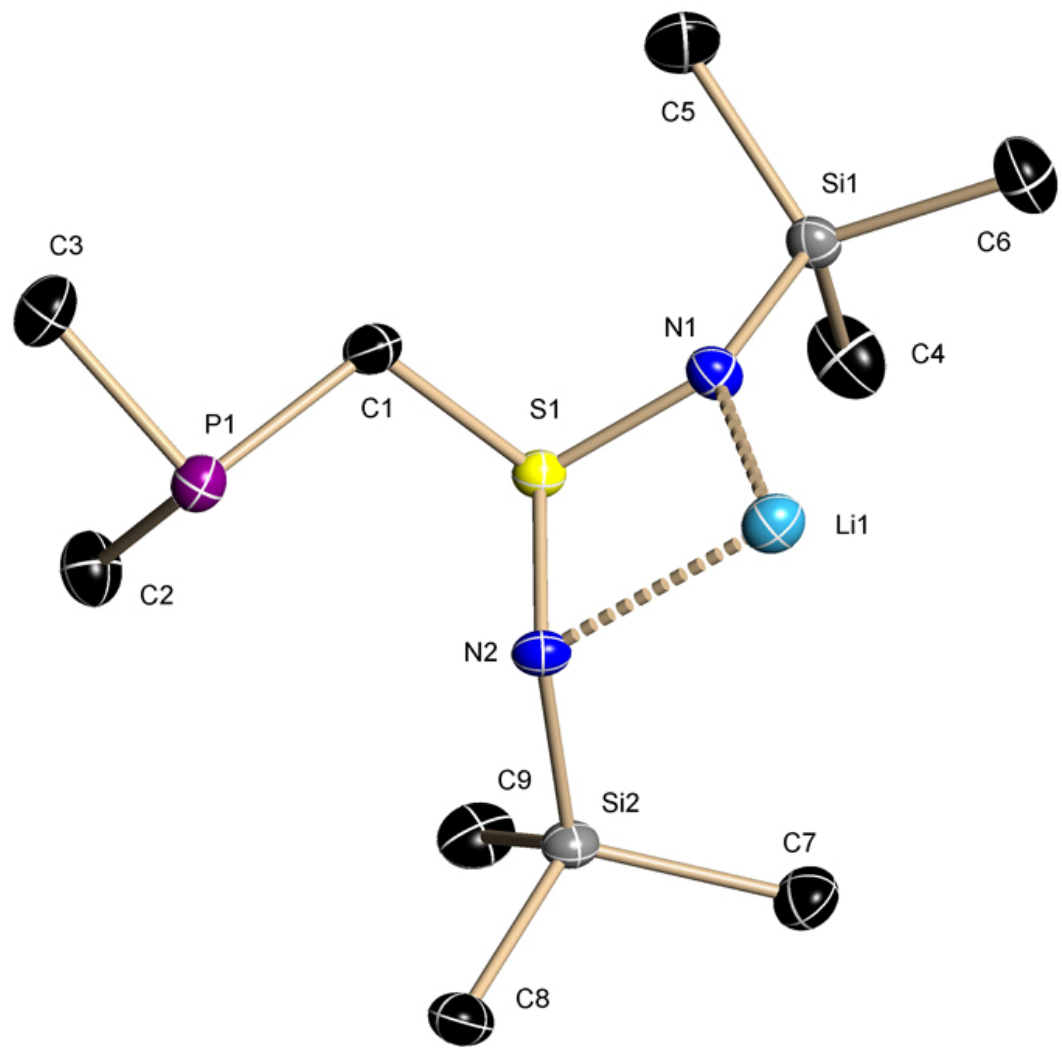

Asymmetric unit of 4 . The anisotropic displacement parameters are shown at the $50 \%$ probability level, hydrogen atoms are omitted for clarity.

\begin{tabular}{|c|c|c|c|}
\hline identification code & Krabbe & $\mu\left[\mathrm{mm}^{-1}\right]$ & 0.396 \\
\hline empirical formula & $\mathrm{C}_{18} \mathrm{H}_{52} \mathrm{~N}_{4} \mathrm{Si}_{4} \mathrm{P}_{2} \mathrm{~S}_{2} \mathrm{Li}_{2}$ & $F(000)$ & 312 \\
\hline molecular weight $[\mathrm{g} / \mathrm{mol}]$ & 576.93 & max./min. transmission & $0.9703 / 0.9262$ \\
\hline crystal size $[\mathrm{mm}]$ & $0.14 \times 0.12 \times 0.02$ & $\theta$ range $\left[{ }^{\circ}\right]$ & $2.18-26.37$ \\
\hline temperature $[\mathrm{K}]$ & $100(2)$ & completeness to $\theta_{\max }$ & 0.998 \\
\hline crystal system & triclinic & reflections collected & 21105 \\
\hline space group & $P \overline{1}$ & independent reflections & 3546 \\
\hline$a[\AA]]$ & $10.2715(11)$ & $R_{\text {int }} / R_{\sigma}$ & $0.0145 / 0.0148$ \\
\hline$b[\AA]$ & $10.3560(11)$ & restraints/parameters & $0 / 153$ \\
\hline$c[\AA]]$ & $10.4832(11)$ & GoF & 0.861 \\
\hline$\alpha\left[^{\circ}\right]$ & $68.6360(10)$ & $R 1$ (all data) & 0.0236 \\
\hline$\beta\left[^{\circ}\right]$ & $65.7280(10)$ & $R 1(I>2 \sigma(I))$ & 0.0216 \\
\hline$V\left[^{\circ}\right]$ & $60.9900(10)$ & $w R 2$ (all data) & 0.0619 \\
\hline$V\left[\AA^{3}\right]$ & $869.77(16)$ & $w R 2(I>2 \sigma(I))$ & 0.0607 \\
\hline$Z$ & 1 & diff. peak/hole $\left[\mathrm{e}^{-3}\right]$ & $0.314 /-0.223$ \\
\hline$\rho_{\text {calc }}\left[\mathrm{g} \mathrm{cm}^{-3}\right]$ & 1.101 & $g 1 / g 2$ & $0.0391 / 0.5002$ \\
\hline
\end{tabular}




\subsection{4 $\left[\mathrm{Li}\left\{\mathrm{Ph}_{2} \mathrm{PCH}_{2} \mathrm{~S}\left(\mathrm{NSiMe}_{3}\right)_{2}\right\}\right]_{2}(5)$}

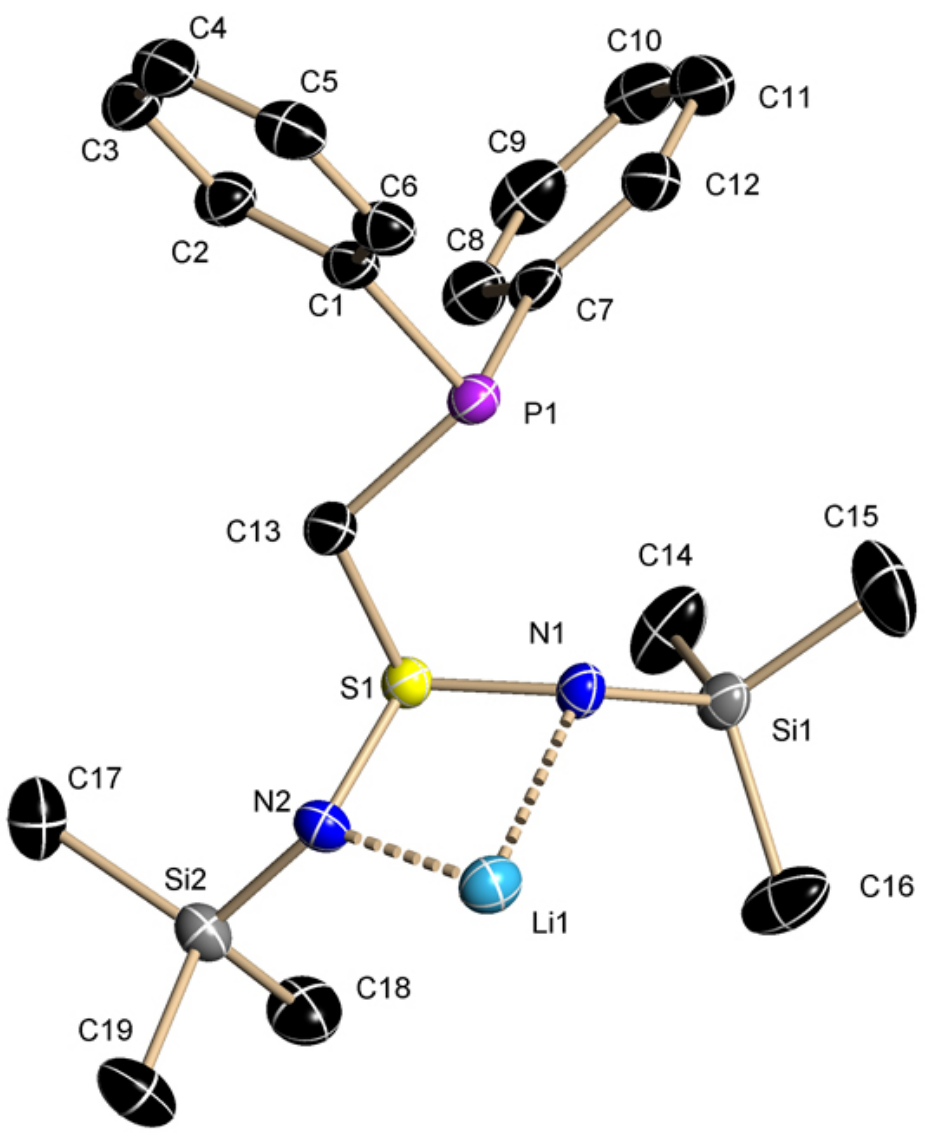

Asymmetric unit of $\mathbf{5}$. The anisotropic displacement parameters are shown at the $50 \%$ probability level, hydrogen atoms are omitted for clarity.

\begin{tabular}{ll|ll}
\hline identification code & MMP163 & $F(000)$ & 880 \\
empirical formula & $\mathrm{C}_{38} \mathrm{H}_{60} \mathrm{Li}_{2} \mathrm{~N}_{4} \mathrm{P}_{2} \mathrm{~S}_{2} \mathrm{Si}_{4}$ & max./min. transmission & $0.9422 / 0.5030$ \\
molecular weight [g/mol] & 825.20 & $\theta$ range $\left.{ }^{\circ}\right]$ & $1.83-26.74$ \\
crystal size $[\mathrm{mm}]$ & $0.20 \times 0.04 \times 0.02$ & completeness to $\theta_{\max }$ & 0.999 \\
temperature $[\mathrm{K}]$ & $100(2)$ & reflections collected & 28120 \\
crystal system & monoclinic & independent reflections & 5013 \\
space group & $P 2{ }_{1} / n$ & $R_{\text {int }} / R_{\sigma}$ & $0.0761 / 0.0550$ \\
$a[\AA]$ & $9.2956(18)$ & restraints/parameters & $0 / 241$ \\
$b[\AA]$ & $14.412(3)$ & GoF & 1.061 \\
$c[\AA]$ & $17.625(4)$ & $R 1($ all data $)$ & 0.0436 \\
$\beta\left[{ }^{\circ}\right]$ & $91.707(3)$ & $w 1(>2 \sigma(I))$ & 0.0373 \\
$V\left[\AA^{3}\right]$ & $2360.1(8)$ & $w R 2($ all data) & 0.1065 \\
$Z$ & 2 & diff. peak/hole $\left[\mathrm{e} \AA^{-3}\right]$ & 0.1016 \\
$\rho_{\text {calc }}\left[\mathrm{g} \mathrm{cm}^{-3}\right]$ & 1.161 & $\mathrm{~g} 1 / \mathrm{g} 2$ & $0.463 /-0.332$ \\
$\mu\left[\mathrm{mm}^{-1}\right]$ & 0.312 & $0.1325 / 3.7432$ \\
\hline
\end{tabular}




\subsection{5 $\left[\mathrm{Li}\left\{\mathrm{Me}(\mathrm{Ph}) \mathrm{PCH}_{2} \mathrm{~S}\left(\mathrm{NSiMe}_{3}\right)\right\}\right]_{2}(6)$}

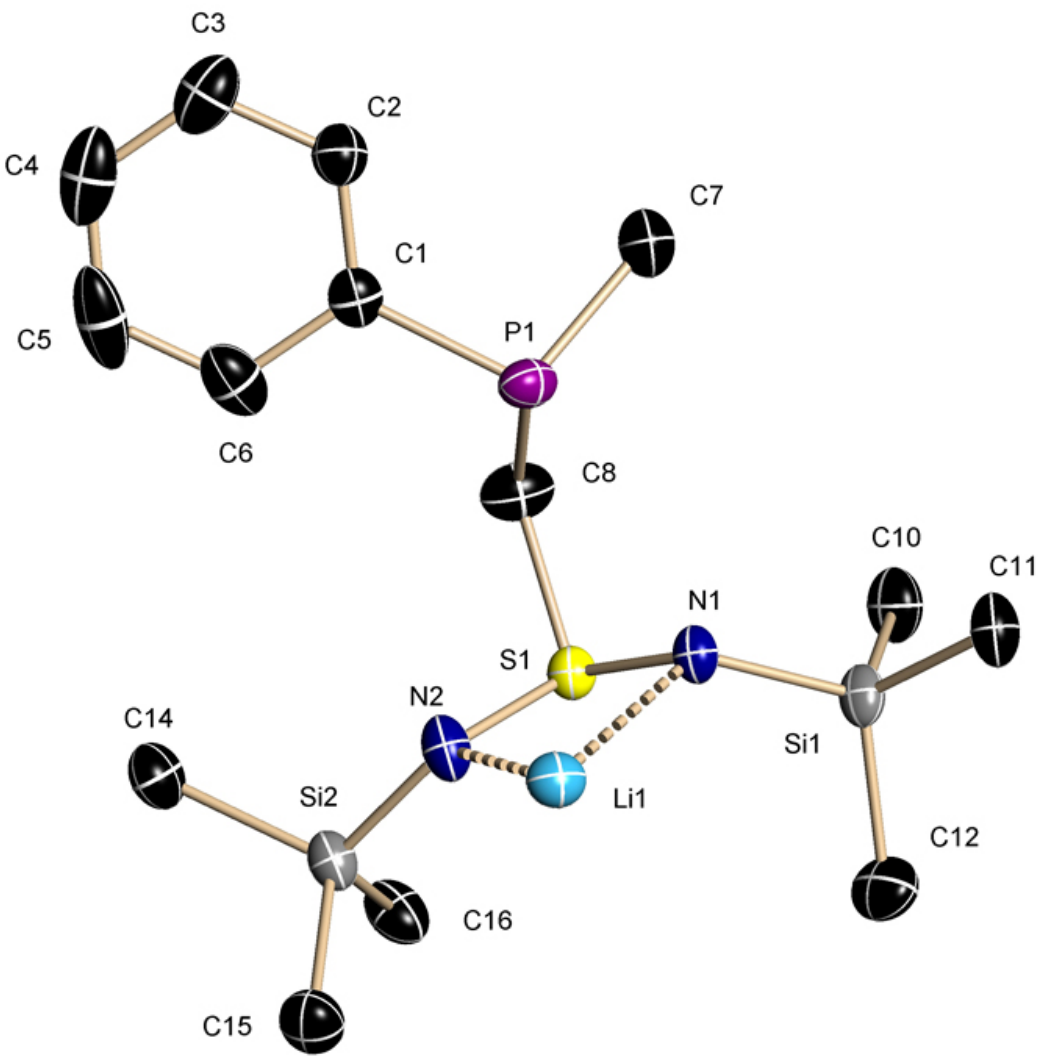

Asymmetric unit of 6 . The anisotropic displacement parameters are shown at the $50 \%$ probability level, hydrogen atoms are omitted for clarity. The residual density is above $1.00 \mathrm{e}^{-3}$ because the data quality is not sufficient.

\begin{tabular}{|c|c|c|c|}
\hline identification code & MMP103_1 & $\mu\left[\mathrm{mm}^{-1}\right]$ & 0.352 \\
\hline empirical formula & $\mathrm{C}_{28} \mathrm{H}_{56} \mathrm{Li}_{2} \mathrm{~N}_{4} \mathrm{P}_{2} \mathrm{~S}_{2} \mathrm{Si}_{4}$ & $F(000)$ & 376 \\
\hline molecular weight $[\mathrm{g} / \mathrm{mol}]$ & 701.07 & max./min. transmission & $0.9422 / 0.8182$ \\
\hline crystal size $[\mathrm{mm}]$ & $0.2 \times 0.2 \times 0.1$ & $\theta$ range $\left[{ }^{\circ}\right]$ & 2.363-26.5295 \\
\hline temperature $[\mathrm{K}]$ & $100(2)$ & completeness to $\theta_{\max }$ & 0.998 \\
\hline crystal system & triclinic & reflections collected & 17074 \\
\hline space group & $P \overline{1}$ & independent reflections & 3991 \\
\hline$a[\AA]]$ & $10.5602(12)$ & $R_{\text {int }} / R_{\sigma}$ & $0.0448 / 0.0369$ \\
\hline$b[\AA]]$ & $10.9235(13)$ & restraints/parameters & $0 / 198$ \\
\hline$c[\AA]$ & $10.9438(13)$ & GoF & 1.029 \\
\hline$\alpha\left[^{\circ}\right]$ & $79.480(2)$ & $R 1$ (all data) & 0.0749 \\
\hline$\beta\left[^{\circ}\right]$ & $66.032(2)$ & $R 1(I>2 \sigma(I))$ & 0.0539 \\
\hline$V\left[^{\circ}\right]$ & $61.491(2)$ & $w R 2$ (all data) & 0.1507 \\
\hline$V\left[\AA^{3}\right]$ & $1013.6(2)$ & $w R 2(I>2 \sigma(I))$ & 0.1375 \\
\hline Z & 1 & diff. peak/hole $\left[\mathrm{e}^{-3}\right]$ & $1.343 /-0.296$ \\
\hline$\rho_{\text {calc }}\left[\mathrm{g} \mathrm{cm}^{-3}\right]$ & 1.149 & $g 1 / g 2$ & $0.0756 / 1.6538$ \\
\hline
\end{tabular}




\subsection{6 $\left[\mathrm{Li}\left\{\mathrm{Et}_{2} \mathrm{PCH}\left(\mathrm{CH}_{3}\right) \mathrm{S}\left(\mathrm{NSiMe}_{3}\right)\right\}\right]_{2}(7)$}

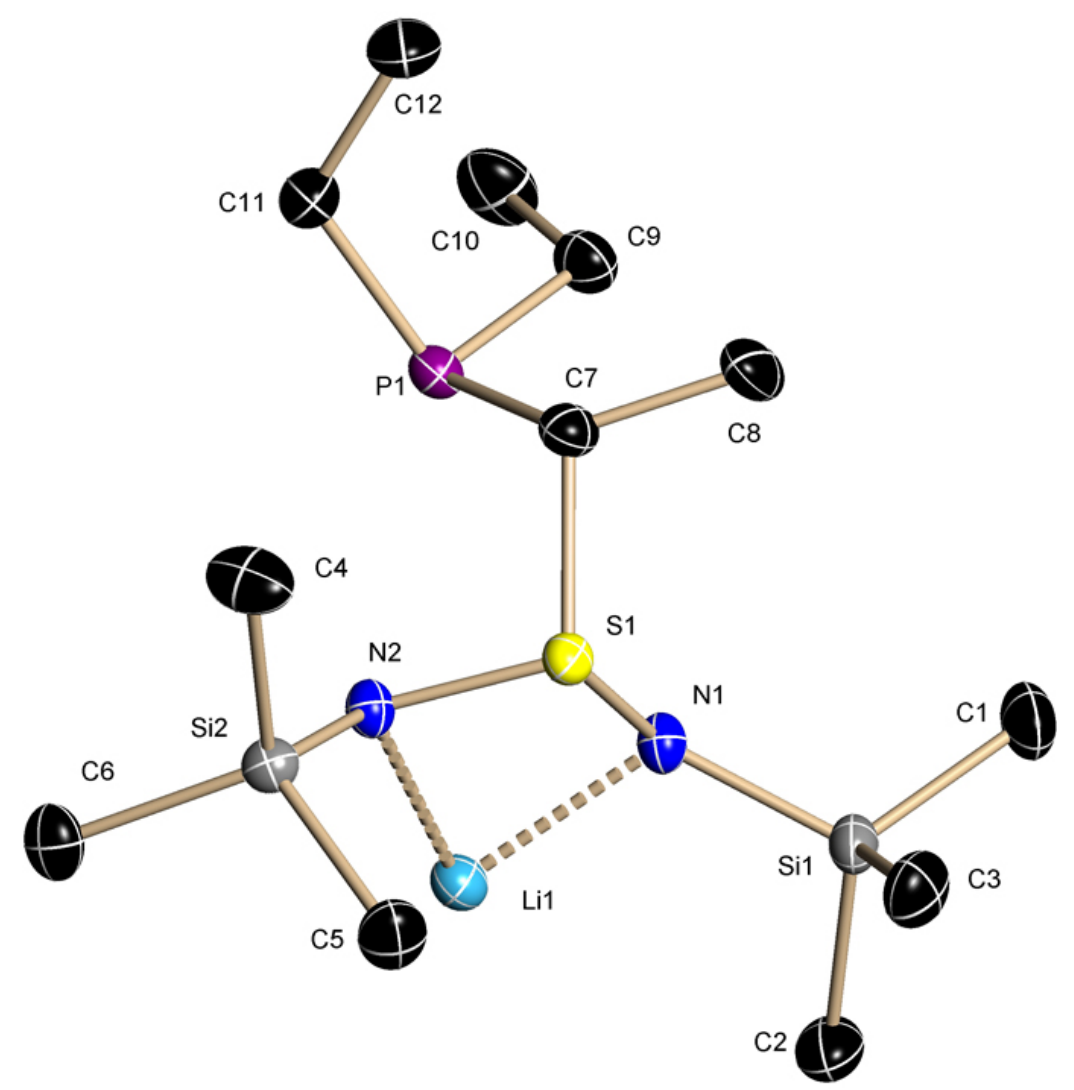

Asymmetric unit of 7 . The anisotropic displacement parameters are shown at the $50 \%$ probability level, hydrogen atoms are omitted for clarity.

\begin{tabular}{|c|c|c|c|}
\hline identification code & Spinne & $\mu\left[\mathrm{mm}^{-1}\right]$ & 0.357 \\
\hline empirical formula & $\mathrm{C}_{24} \mathrm{H}_{64} \mathrm{~N}_{4} \mathrm{Si}_{4} \mathrm{P}_{2} \mathrm{~S}_{2} \mathrm{Li}_{2}$ & $F(000)$ & 360 \\
\hline molecular weight $[\mathrm{g} / \mathrm{mol}]$ & 661.09 & max./min. transmission & $0.9422 / 0.8178$ \\
\hline crystal size $[\mathrm{mm}]$ & $0.8 \times 0.3 \times 0.04$ & $\theta$ range $\left[{ }^{\circ}\right]$ & $2.50-27.88$ \\
\hline temperature $[\mathrm{K}]$ & $100(2)$ & completeness to $\theta_{\max }$ & 0.996 \\
\hline crystal system & triclinic & reflections collected & 39887 \\
\hline space group & $P \overline{1}$ & independent reflections & 4676 \\
\hline$a[\AA]$ & $10.6002(6)$ & $R_{\text {int }} / R_{\sigma}$ & $0.0146 / 0.0074$ \\
\hline$b[\AA]$ & $10.6350(10)$ & restraints/parameters & $0 / 181$ \\
\hline$c[\AA]$ & $10.7744(6)$ & GoF & 1.068 \\
\hline$\alpha\left[^{\circ}\right]$ & $100.7850(10)$ & $R 1$ (all data) & 0.0299 \\
\hline$\beta\left[^{\circ}\right]$ & $117.3660(10)$ & $R 1(I>2 \sigma(I))$ & 0.0277 \\
\hline$V\left[^{\circ}\right]$ & $103.4460(10)$ & $w R 2$ (all data) & 0.0768 \\
\hline$V\left[\AA^{3}\right]$ & $986.48(12)$ & $w R 2(I>2 \sigma(I))$ & 0.0747 \\
\hline$z$ & 1 & diff. peak/hole $\left[\mathrm{e} \AA^{-3}\right]$ & $0.686 /-0.453$ \\
\hline$\rho_{\text {calc }}\left[\mathrm{g} \mathrm{cm}^{-3}\right]$ & 1.113 & $g 1 / g 2$ & $0.0396 / 0.456$ \\
\hline
\end{tabular}




\subsection{7 $\left[\mathrm{Li}\left\{\mathrm{Me}_{2} \mathrm{P}(\mathrm{S}) \mathrm{CH}_{2} \mathrm{~S}\left(\mathrm{NSiMe}_{3}\right)_{2}\right\}\right]_{2}(8)$}

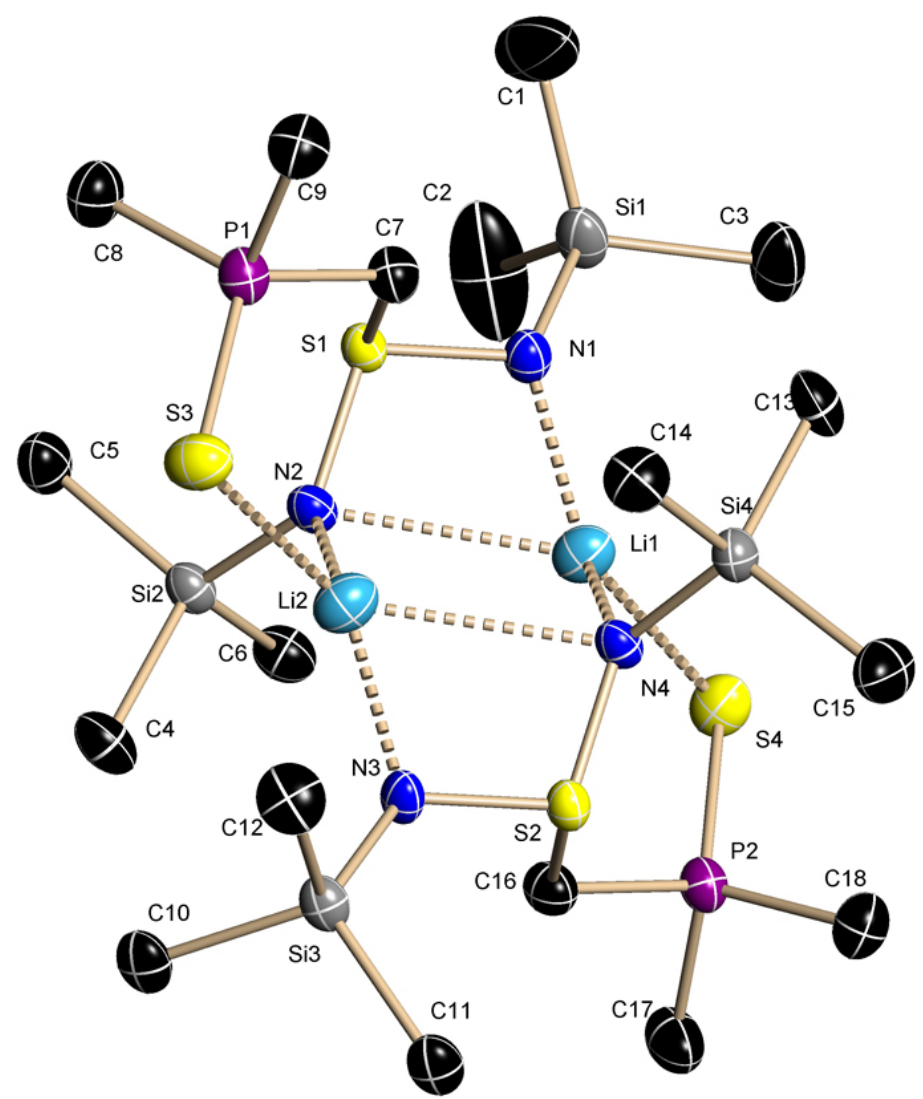

Asymmetric unit of 8. The anisotropic displacement parameters are shown at the $50 \%$ probability level, hydrogen atoms are omitted for clarity.

\begin{tabular}{ll|ll}
\hline identification code & $\mathrm{KrabbOx}$ & $F(000)$ & 1376 \\
empirical formula & $\mathrm{C}_{18} \mathrm{H}_{52} \mathrm{Li}_{2} \mathrm{~N}_{4} \mathrm{P}_{2} \mathrm{~S}_{4} \mathrm{Si}_{4}$ & max./min. transmission & $0.9799 / 0.9238$ \\
molecular weight [g/mol] & 641.06 & $\theta$ range [ $\left.{ }^{\circ}\right]$ & $1.30-25.68$ \\
crystal size $[\mathrm{mm}]$ & $0.12 \times 0.06 \times 0.04$ & completeness to $\theta_{\text {max }}$ & 1.0 \\
temperature $[\mathrm{K}]$ & $100(2)$ & reflections collected & 56599 \\
crystal system & monoclinic & independent reflections & 6870 \\
space group & $P 2{ }_{1} / n$ & $R_{\text {int }} / R_{\sigma}$ & $0.0824 / 0.0490$ \\
$a[\AA]$ & $18.3672(19)$ & restraints/parameters & $0 / 323$ \\
$b[\AA]$ & $11.7143(13)$ & GoF & 1.091 \\
$c[\AA]]$ & $18.699(2)$ & $R 1($ all data $)$ & 0.0837 \\
$\beta\left[^{\circ}\right]$ & $115.876(2)$ & $R 1(>2 \sigma(I))$ & 0.0517 \\
$V\left[\AA^{3}\right]$ & $3619.8(7)$ & $w R 2($ all data) & 0.1218 \\
$Z$ & 4 & $w R 2(>2 \sigma(I))$ & 0.1098 \\
$\rho_{\text {calc }}\left[\mathrm{g} \mathrm{cm}^{-3}\right]$ & 1.176 & diff. peak/hole $\left[\mathrm{e} \AA^{-3}\right]$ & $0.591 /-0.645$ \\
$\mu\left[\mathrm{mm}^{-1}\right]$ & 0.498 & $\mathrm{~g} 1 / \mathrm{g} 2$ & $0.0399 / 6.1868$ \\
\hline
\end{tabular}




\subsection{8 $\left[\mathrm{Li}\left\{\mathrm{Me}_{2} \mathrm{P}(\mathrm{Se}) \mathrm{CH}_{2} \mathrm{~S}\left(\mathrm{NSiMe}_{3}\right)_{2}\right\}\right]_{2}(9)$}

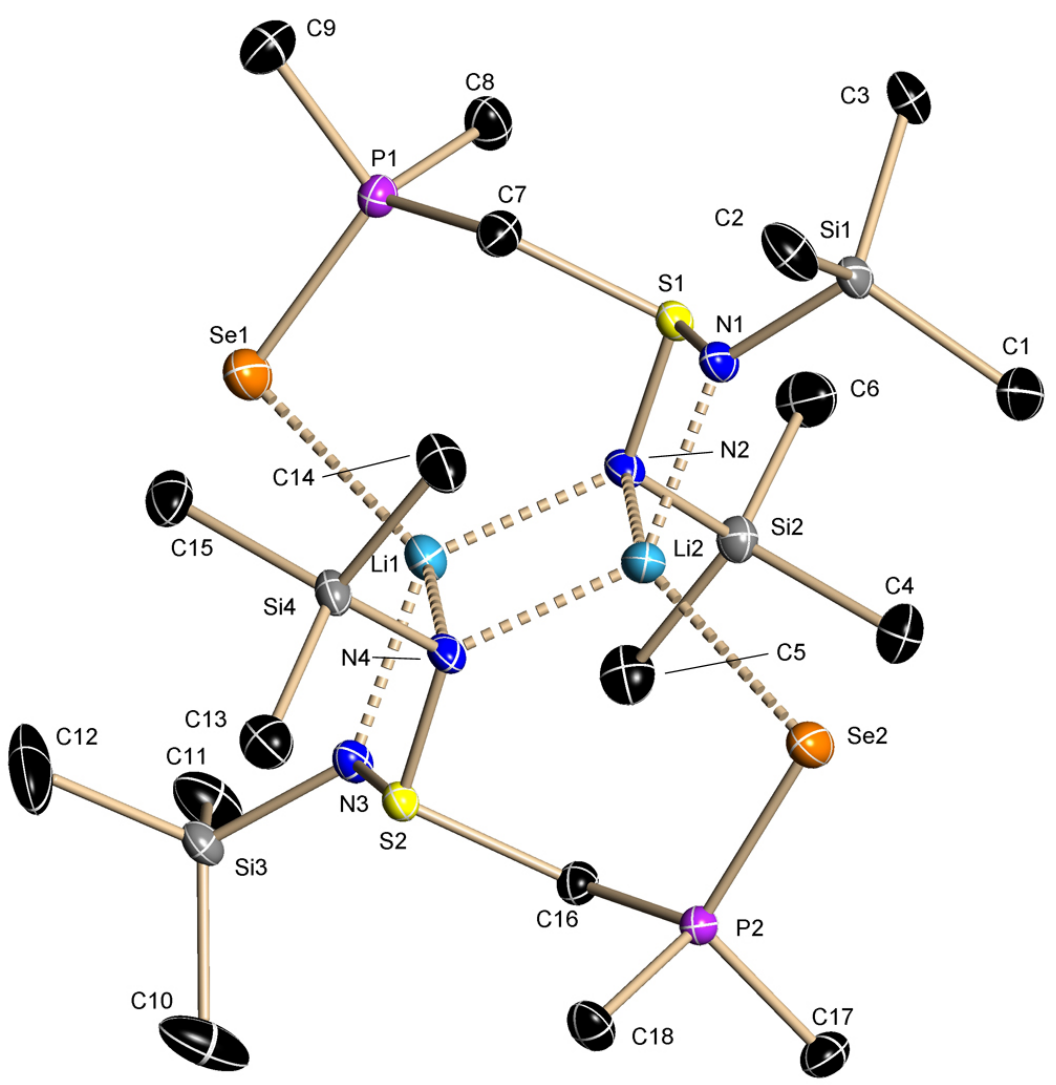

Asymmetric unit of 9. The anisotropic displacement parameters are shown at the $50 \%$ probability level, hydrogen atoms are omitted for clarity.

\begin{tabular}{ll|ll}
\hline identification code & MMP223_2 & $F(000)$ & 1520 \\
empirical formula & $\mathrm{C}_{18} \mathrm{H}_{52} \mathrm{Li}_{2} \mathrm{~N}_{4} \mathrm{P}_{2} \mathrm{~S}_{2} \mathrm{Se}_{2} \mathrm{Si}_{4}$ & max./min. transmission & $0.7080 / 0.9422$ \\
molecular weight $[\mathrm{g} / \mathrm{mol}]$ & 734.86 & $\theta$ range $\left[^{\circ}\right]$ & $2.169-26.269$ \\
crystal size $[\mathrm{mm}]$ & $0.22 \times 0.1 \times 0.1$ & completeness to $\theta_{\text {max }}$ & 1.000 \\
temperature $[\mathrm{K}]$ & $100(2)$ & reflections collected & 42058 \\
crystal system & monoclinic & independent reflections & 7260 \\
space group & $P 2 / n$ & $R_{\text {int }} / R_{\sigma}$ & $0.0553 / 0.0410$ \\
$a[\AA]$ & $18.734(3)$ & restraints/parameters & $0 / 323$ \\
$b[\AA]$ & $11.6198(18)$ & GoF & 1.023 \\
$c[\AA]$ & $18.839(3)$ & $R 1($ all data $)$ & 0.0495 \\
$\beta\left[^{\circ}\right]$ & $116.104(2)$ & $R 1(1>2 \sigma(I))$ & 0.0325 \\
$V\left[\AA^{3}\right]$ & $3682.5(10)$ & $w R 2($ all data $)$ & 0.0847 \\
$Z$ & 4 & $w R 2(/>2 \sigma(I))$ & 0.0782 \\
$\rho_{\text {calc }}\left[\mathrm{g} \mathrm{cm}^{-3}\right]$ & 1.325 & diff. peak/hole $\left[\mathrm{e} \AA^{-3}\right]$ & $0.462 /-0.713$ \\
$\mu\left[\mathrm{mm}^{-1}\right]$ & 2.353 & $\mathrm{~g} 1 / \mathrm{g} 2$ & $0.0352 / 3.5681$ \\
\hline
\end{tabular}




\subsection{9 $\quad \mathrm{Ph}_{2} \mathrm{PCH}_{2} \mathrm{~S}\left(\mathrm{NSiMe}_{3}\right)\left(\mathrm{HNSiMe}_{3}\right)(10)$}

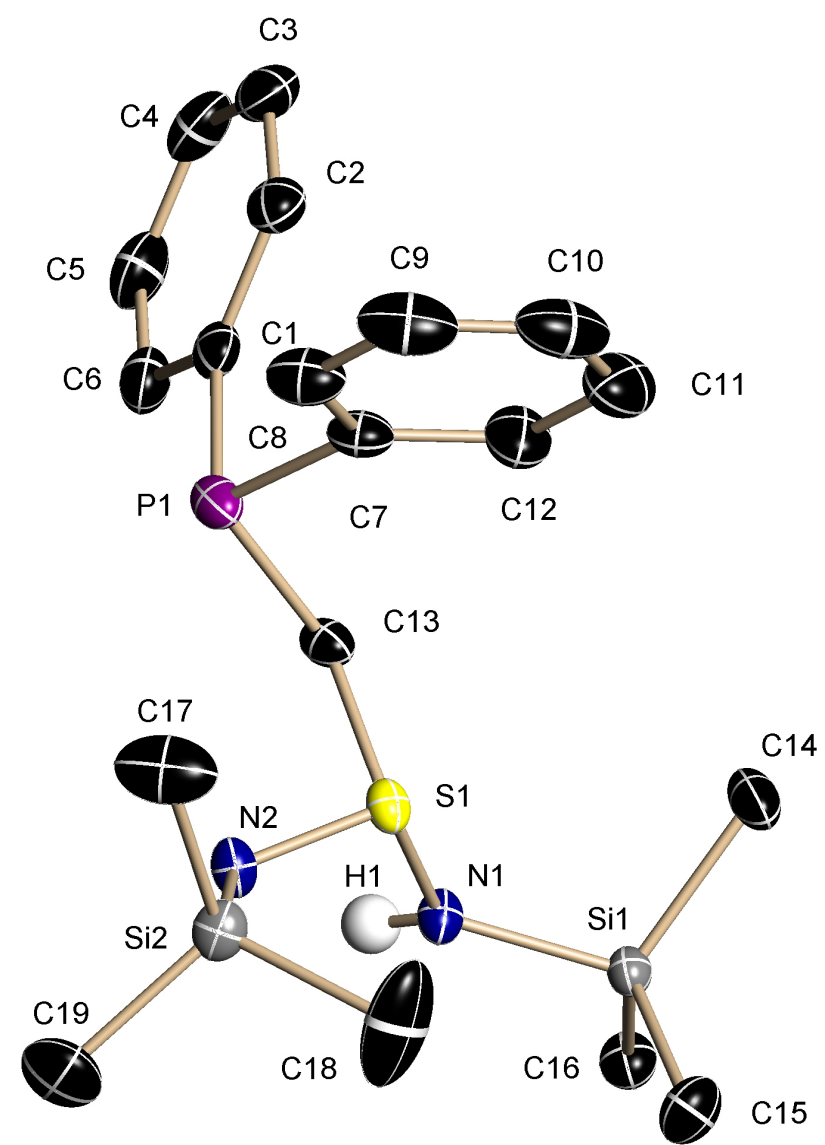

Asymmetric unit of 10. The anisotropic displacement parameters are shown at the $50 \%$ probability level, hydrogen atoms are omitted for clarity. $\mathrm{H} 1$ was freely refined using a distance restraint.

\begin{tabular}{ll|ll}
\hline identification code & Moskito & $F(000)$ & 872 \\
empirical formula & $\mathrm{C}_{19} \mathrm{H}_{31} \mathrm{Si}_{2} \mathrm{~N}_{2} \mathrm{PS}$ & max./min. transmission & $0.9422 / 0.8590$ \\
molecular weight $[\mathrm{g} / \mathrm{mol}]$ & 406.67 & $\theta$ range $\left[^{\circ}\right]$ & $2.59-27.88$ \\
crystal size $[\mathrm{mm}]$ & $0.54 \times 0.2 \times 0.12$ & completeness to $\theta_{\text {max }}$ & 0.999 \\
temperature $[\mathrm{K}]$ & $100(2)$ & reflections collected & 43786 \\
crystal system & monoclinic & independent reflections & 5491 \\
space group & $P 2_{1} / n$ & $R_{\text {int }} / R_{\sigma}$ & $0.016 / 0.0083$ \\
$a[\AA]$ & $12.9937(7)$ & restraints/parameters & $1 / 235$ \\
$b[\AA]$ & $9.9367(6)$ & GoF & 1.052 \\
$c[\AA]$ & $18.1145(10)$ & $R 1($ all data $)$ & 0.0289 \\
$\beta\left[^{\circ}\right]$ & $99.8430(10)$ & $R 1(>2 \sigma(I))$ & 0.0278 \\
$V\left[\AA^{3}\right]$ & $2304.4(2)$ & $w R 2($ all data $)$ & 0.0767 \\
$Z$ & 4 & $w R 2(/>2 \sigma(I))$ & 0.0757 \\
$\rho_{\text {calc }}\left[\mathrm{g} \mathrm{cm}^{-3}\right]$ & 1.172 & diff. peak/hole $\left[\mathrm{e} \AA^{-3}\right]$ & $0.596 /-0.340$ \\
$\mu\left[\mathrm{mm}^{-1}\right]$ & 0.319 & g1/g2 & $0.038 / 1.0873$ \\
\hline
\end{tabular}




\subsubsection{0 [(tmeda) $\left.\mathrm{Li}\left\{\mathrm{Ph}_{2} \mathrm{PCH}_{2} \mathrm{~S}\left(\mathrm{NSiMe}_{3}\right)_{2}\right\}\right]$ (11)}

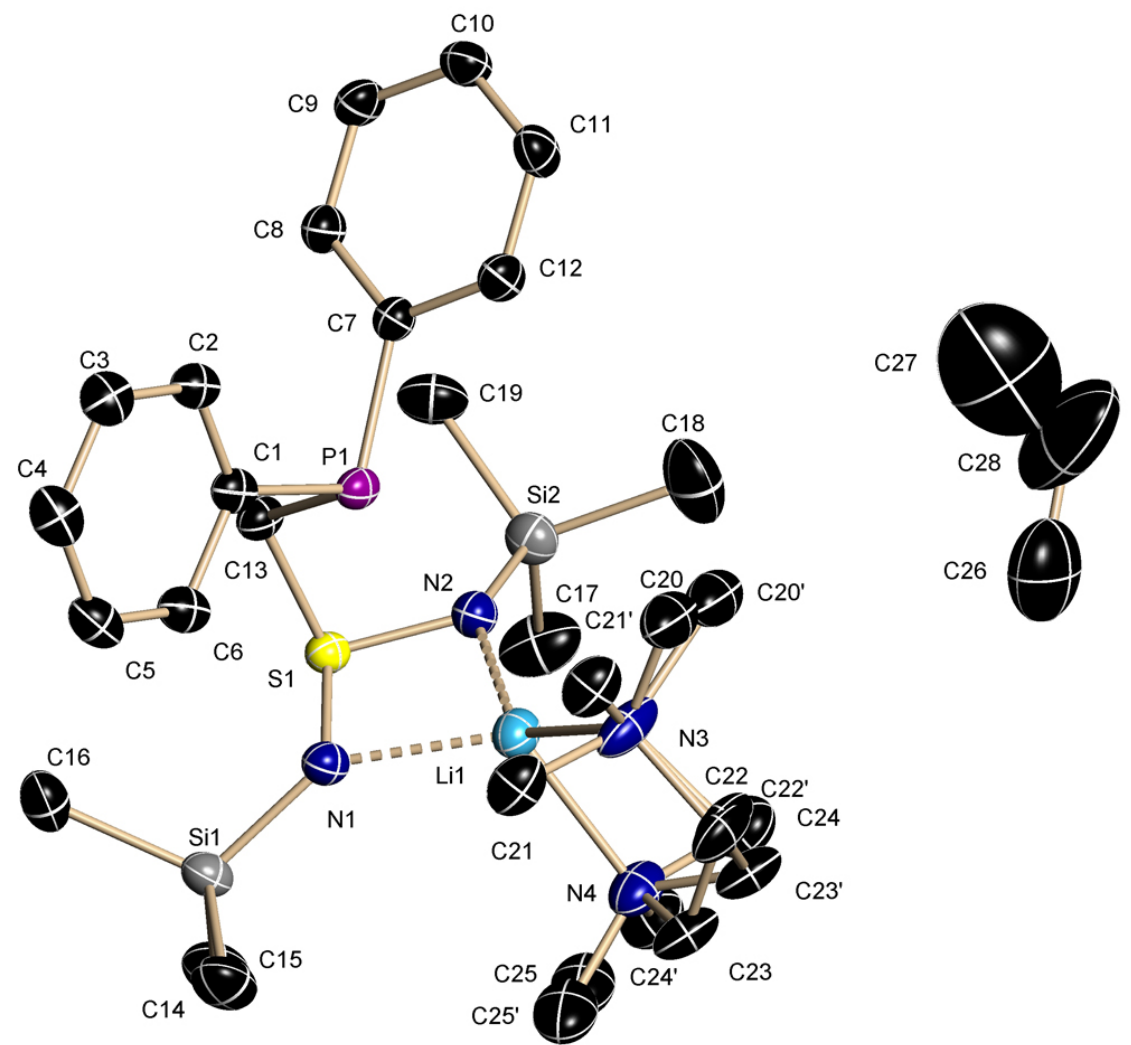

Asymmetric unit of 11 . The anisotropic displacement parameters are shown at the $50 \%$ probability level, hydrogen atoms are omitted for clarity. The pentane molecule is only half occupied as it is situated on a crystallographic mirror plane and was refined using PART -1. The TMEDA ligand is disordered over two sites with occupancies of 67 and $33 \%$, respectively.

\begin{tabular}{ll|ll}
\hline identification code & MMPIAN06 & $F(000)$ & 2456 \\
empirical formula & $\mathrm{C}_{28} \mathrm{H}_{53} \mathrm{LiN}_{4} \mathrm{PSSi}_{2}$ & max./min. transmission & $0.9422 / 0.8424$ \\
molecular weight $[\mathrm{g} / \mathrm{mol}]$ & 571.89 & $\theta$ range $\left.{ }^{\circ}\right]$ & $1.23-26.02$ \\
crystal size $[\mathrm{mm}]$ & $0.18 \times 0.04 \times 0.02$ & completeness to $\theta_{\max }$ & 0.999 \\
temperature $[\mathrm{K}]$ & $100(2)$ & reflections collected & 48696 \\
crystal system & monoclinic & independent reflections & 6847 \\
space group & $C 2 / c$ & $R_{\text {int }} / R_{\sigma}$ & $0.0632 / 0.0384$ \\
$a[\AA]$ & $33.944(5)$ & restraints/parameters & $0 / 387$ \\
$b[\AA]$ & $9.5352(13)$ & GoF & 1.071 \\
$c[\AA]$ & $21.921(3)$ & $R 1($ all data) & 0.0520 \\
$\beta\left[{ }^{\circ}\right]$ & $101.895(3)$ & $R 1(/>2 \sigma(I))$ & 0.0382 \\
$V\left[\AA^{3}\right]$ & $6942.4(17)$ & $w R 2($ all data) & 0.0974 \\
$Z$ & 8 & $w R 2(>2 \sigma(I))$ & 0.0903 \\
$\rho_{\text {calc }}\left[\mathrm{g} \mathrm{cm}^{-3}\right]$ & 1.081 & diff. peak/hole $\left[\mathrm{e} \AA^{-3}\right]$ & $0.344 /-0.244$ \\
$\mu\left[\mathrm{mm}^{-1}\right]$ & 0.229 & $\mathrm{~g} 1 / \mathrm{g} 2$ & $0.0288 / 8.9902$ \\
\hline
\end{tabular}




\subsubsection{1 $\left[\mathrm{Li}\left\{\mathrm{tBu}_{2} \mathrm{P}(\mathrm{O}) \mathrm{CH}_{2} \mathrm{~S}\left(\mathrm{NSiMe}_{3}\right)_{2}\right\}\right]_{2}(12)$}

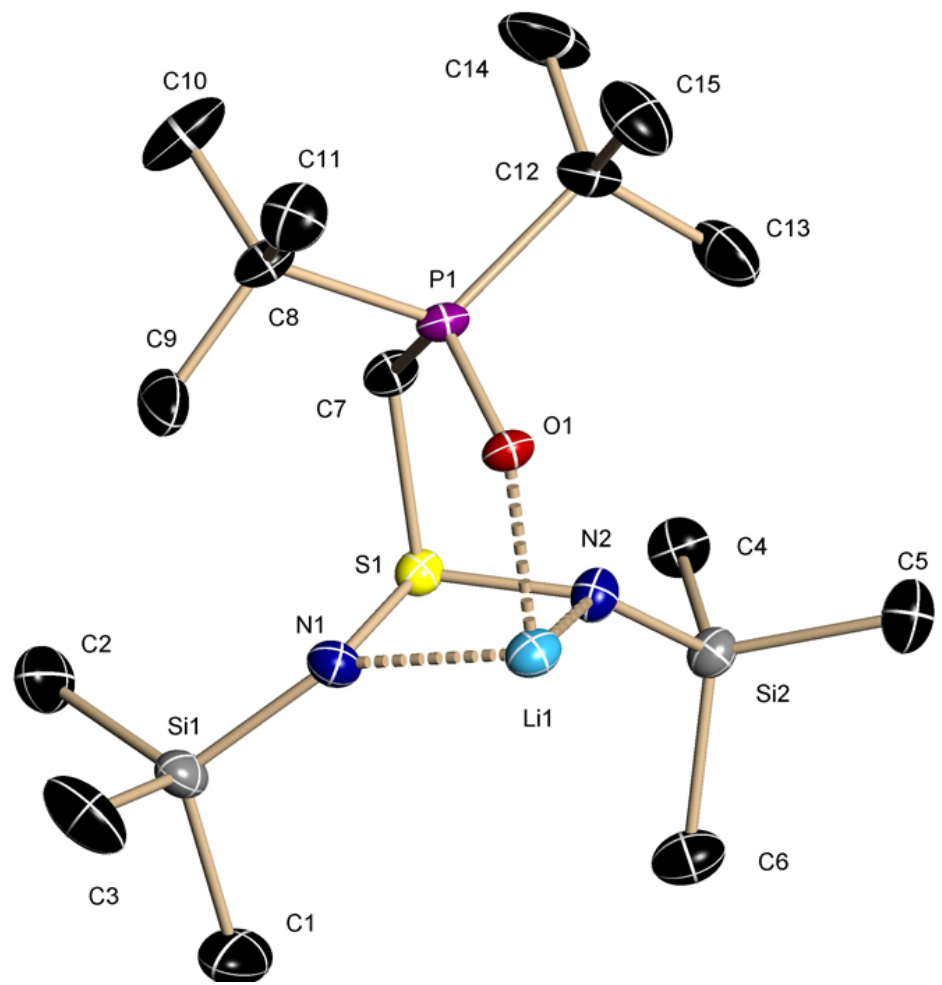

Asymmetric unit of 12. The anisotropic displacement parameters are shown at the $50 \%$ probability level, hydrogen atoms are omitted for clarity.

\begin{tabular}{|c|c|c|c|}
\hline identification code & MMP174 & $\mu\left[\mathrm{mm}^{-1}\right]$ & 0.311 \\
\hline empirical formula & $\mathrm{C}_{30} \mathrm{H}_{76} \mathrm{Li}_{2} \mathrm{~N}_{4} \mathrm{O}_{2} \mathrm{P}_{2} \mathrm{~S}_{2} \mathrm{Si}_{4}$ & $F(000)$ & 424 \\
\hline molecular weight $[\mathrm{g} / \mathrm{mol}]$ & 777.25 & max./min. transmission & $0.9422 / 0.8690$ \\
\hline crystal size $[\mathrm{mm}]$ & $0.14 \times 0.1 \times 0.01$ & $\theta$ range $\left[{ }^{\circ}\right]$ & $1.88-26.73$ \\
\hline temperature $[\mathrm{K}]$ & $100(2)$ & completeness to $\theta_{\max }$ & 0.999 \\
\hline crystal system & triclinic & reflections collected & 21034 \\
\hline space group & $P \overline{1}$ & independent reflections & 4985 \\
\hline$a[\AA]]$ & $10.2856(10)$ & $R_{\text {int }} / R_{\sigma}$ & $0.0386 / 0.0349$ \\
\hline$b[\AA]]$ & $11.4857(12)$ & restraints/parameters & $0 / 220$ \\
\hline$c[\AA]]$ & $11.7940(12)$ & GoF & 1.044 \\
\hline$\alpha\left[^{\circ}\right]$ & $70.915(2)$ & $R 1$ (all data) & 0.0536 \\
\hline$\beta\left[^{\circ}\right]$ & $70.929(2)$ & $R 1(I>2 \sigma(I))$ & 0.0391 \\
\hline$V\left[^{\circ}\right]$ & $66.854(2)$ & $w R 2$ (all data) & 0.1009 \\
\hline$V\left[\AA^{3}\right]$ & $1178.8(2)$ & $w R 2(1>2 \sigma(I))$ & 0.0936 \\
\hline Z & 1 & diff. peak/hole $\left[\mathrm{e}^{-3}\right]$ & $0.426 /-0.247$ \\
\hline$\rho_{\text {calc }}\left[\mathrm{g} \mathrm{cm}^{-3}\right]$ & 1.095 & $g 1 / g 2$ & $0.0508 / 0.5387$ \\
\hline
\end{tabular}




\subsubsection{2 [Li $\left.\left\{t \mathrm{Bu}_{2} \mathrm{PCH}_{2} \mathrm{~S}\left(\mathrm{NSiMe}_{3}\right)_{2}\right\}_{2}\left\{t \mathrm{Bu}{ }_{2} \mathrm{P}(\mathrm{O}) \mathrm{Me}\right\}\right](13)$}

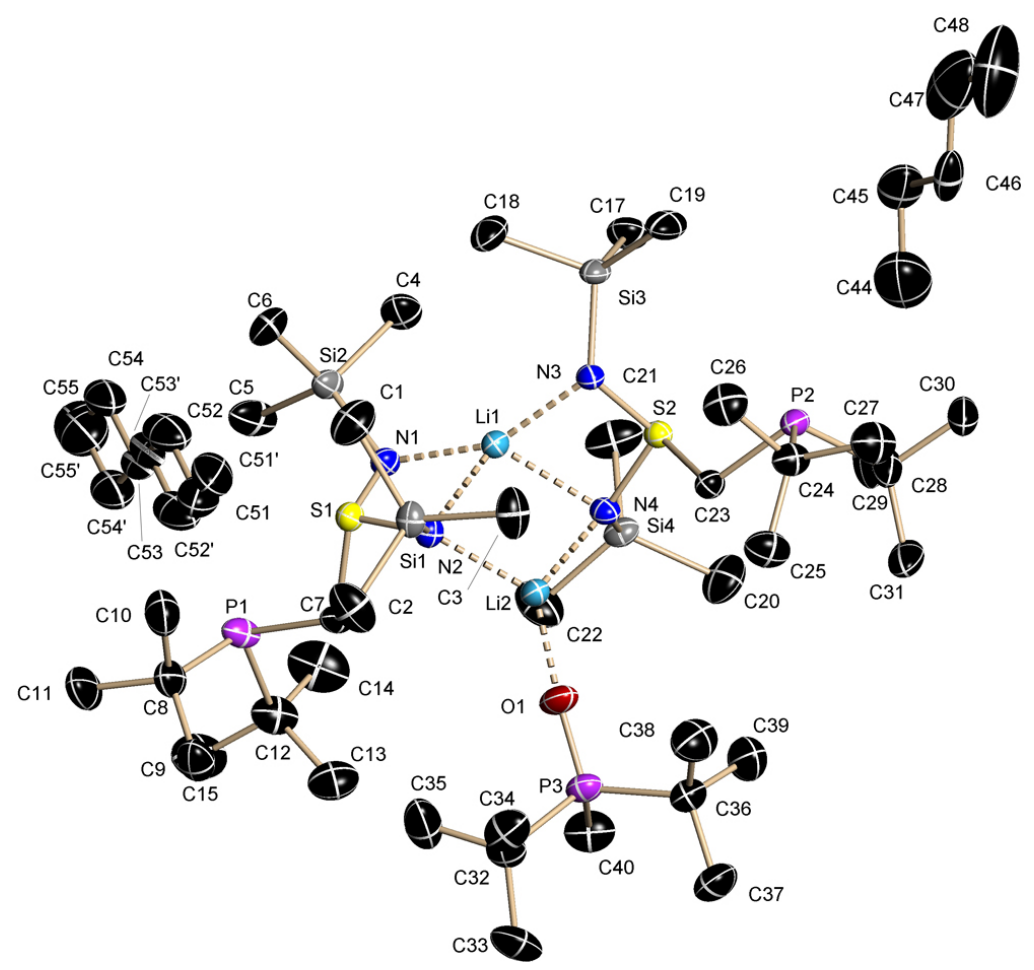

Asymmetric unit of 13. The anisotropic displacement parameters are shown at the $50 \%$ probability level, hydrogen atoms are omitted for clarity. The occupancy factors of the disordered pentane molecule on a special position refine to 63 and $37 \%$, respectively. The molecule was refined using SIMU, DELU and ISOR as well as EADP (C55/C55'), SADI and FLAT. As the pentane molecule lies on the mirror plane and because of the bad data quality it is complicated to assign the little electron density in a better way. When SQUEEZE of the PLATON ${ }^{[224]}$ program package is used, the esds of the bond lengths and angles in the $\left[\mathrm{Li}\left\{\mathrm{Bu}_{2} \mathrm{PCH}_{2} \mathrm{~S}\left(\mathrm{NSiMe}_{3}\right)_{2}\right\}_{2}\right]$ moiety do not improve.

\begin{tabular}{ll|ll}
\hline identification code & MMP197_2a & $F(000)$ & 2192 \\
empirical formula & $\mathrm{C}_{44} \mathrm{H}_{109} \mathrm{Li}_{2} \mathrm{~N}_{4} \mathrm{OP}_{3} \mathrm{~S}_{2} \mathrm{Si}_{4}$ & max./min. transmission & $0.9422 / 0.8927$ \\
molecular weight $[\mathrm{g} / \mathrm{mol}]$ & 993.64 & $\theta$ range $\left[^{\circ}\right]$ & $1.57-26.37$ \\
crystal size $[\mathrm{mm}]$ & $0.2 \times 0.2 \times 0.1$ & completeness to $\theta_{\max }$ & 1.000 \\
temperature $[\mathrm{K}]$ & $100(2)$ & reflections collected & 129001 \\
crystal system & monoclinic & independent reflections & 13114 \\
space group & $P 2_{1} / \mathrm{C}$ & $R_{\text {int }} / R_{\sigma}$ & $0.0342 / 0.0177$ \\
$a[\AA]$ & $27.929(3)$ & restraints/parameters & $121 / 659$ \\
$b[\AA]$ & $11.1729(13)$ & GoF & 1.043 \\
$c[\AA]$ & $22.139(3)$ & $R 1($ all data $)$ & 0.0653 \\
$\beta\left[{ }^{\circ}\right]$ & $111.563(2)$ & $R 1(/>2 \sigma(I))$ & 0.0564 \\
$V\left[\AA^{3}\right]$ & $6425.0(13)$ & $w R 2($ all data $)$ & 0.1553 \\
$Z$ & 4 & $w R 2(/>2 \sigma(I))$ & 0.1475 \\
$\rho_{c a l c}\left[\mathrm{~g} \mathrm{~cm}^{-3}\right]$ & 1.027 & diff. peak/hole $\left[\mathrm{e} \AA^{-3}\right]$ & $1.924 /-0.480$ \\
$\mu\left[\mathrm{mm}^{-1}\right]$ & 0.263 & g1/g2 & $0.0726 / 10.459$ \\
\hline
\end{tabular}




\subsubsection{3 $\left[\mathrm{Li}\left\{\mathrm{tBu}_{2} \mathrm{PCH}_{2} \mathrm{~S}\left(\mathrm{NSiMe}_{3}\right)_{2}\right\}\right]_{2}(14)$}

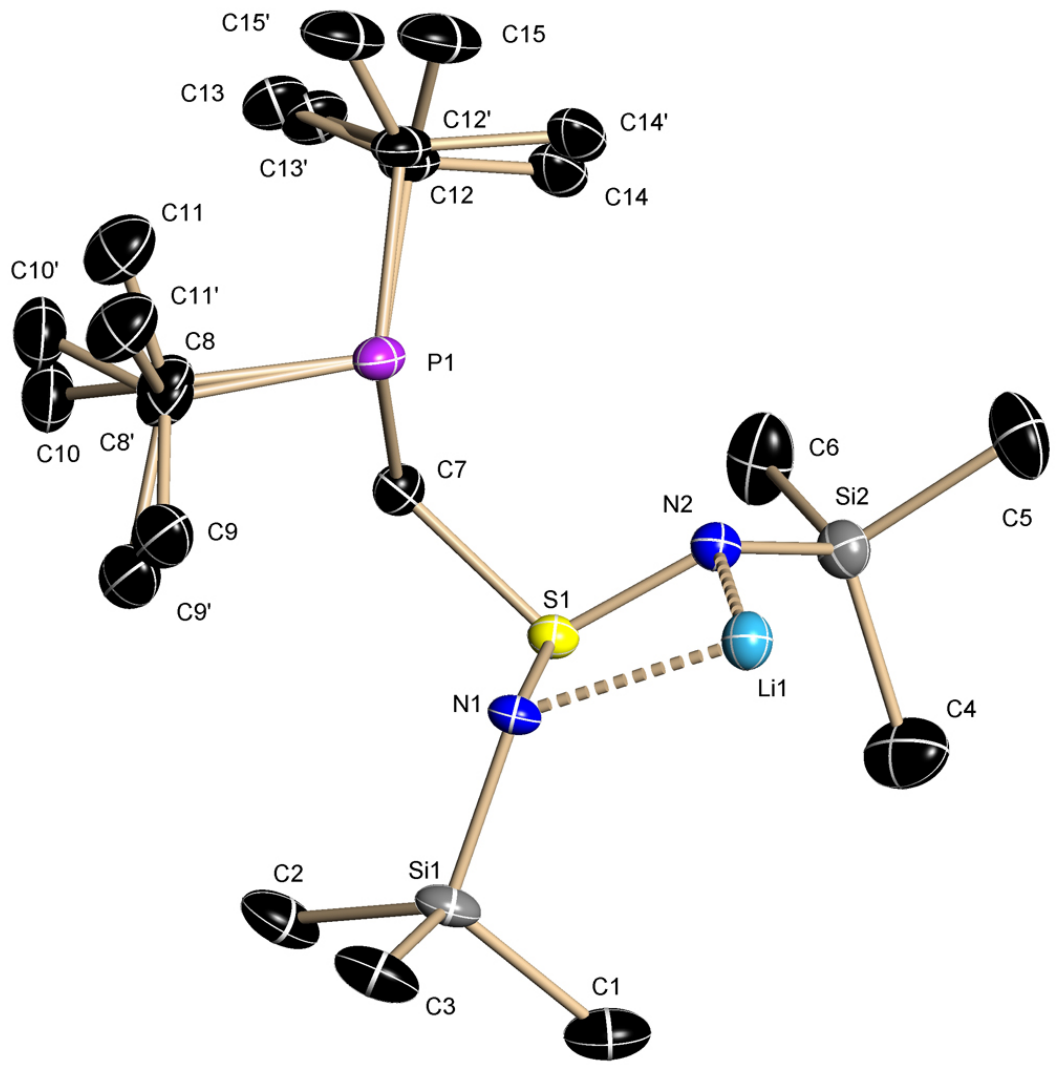

Asymmetric unit of 14. The anisotropic displacement parameters are shown at the $50 \%$ probability level, hydrogen atoms are omitted for clarity. The occupancy factors for the disordered $t \mathrm{Bu}$ groups refine to 87 and $13 \%$ for $\mathrm{C} 8-\mathrm{C} 11$ and 84 and $16 \%$ for $\mathrm{C} 12-\mathrm{C} 15$. The disorder was refined using

SADI and EADP.

\begin{tabular}{|c|c|c|c|}
\hline identification code & MMP256 & $F(000)$ & 816 \\
\hline empirical formula & $\mathrm{C}_{30} \mathrm{H}_{76} \mathrm{Li}_{2} \mathrm{~N}_{4} \mathrm{P}_{2} \mathrm{~S}_{2} \mathrm{Si}_{4}$ & max./min. transmission & $0.9422 / 0.7801$ \\
\hline molecular weight $[\mathrm{g} / \mathrm{mol}]$ & 745.25 & $\theta$ range $\left[{ }^{\circ}\right]$ & $2.05-26.13$ \\
\hline crystal size $[\mathrm{mm}]$ & $0.1 \times 0.1 \times 0.01$ & completeness to $\theta_{\max }$ & 0.997 \\
\hline temperature $[\mathrm{K}]$ & $100(2)$ & reflections collected & 34352 \\
\hline crystal system & monoclinic & independent reflections & 4460 \\
\hline space group & $P 2_{1} / c$ & $R_{\text {int }} / R_{\sigma}$ & $0.1313 / 0.0812$ \\
\hline$a[\AA]$ & $11.1544(19)$ & restraints/parameters & $14 / 243$ \\
\hline$b[\AA]$ & $19.906(3)$ & GoF & 1.037 \\
\hline$c[\AA]$ & $11.3602(19)$ & $R 1$ (all data) & 0.1000 \\
\hline$\beta\left[^{\circ}\right]$ & $117.149(3)$ & $R 1(I>2 \sigma(I))$ & 0.0527 \\
\hline$V\left[\AA^{3}\right]$ & $2244.5(6)$ & $w R 2$ (all data) & 0.1069 \\
\hline$Z$ & 2 & $w R 2(1>2 \sigma(I))$ & 0.0931 \\
\hline$\rho_{\text {calc }}\left[\mathrm{g} \mathrm{cm}^{-3}\right]$ & 1.103 & diff. peak/hole $\left[\mathrm{e} \AA^{-3}\right]$ & $0.356 /-0.294$ \\
\hline$\mu\left[\mathrm{mm}^{-1}\right]$ & 0.321 & $g 1 / g 2$ & $0.0351 / 1.2936$ \\
\hline
\end{tabular}




\subsubsection{4 $\left[\mathrm{Li}\left\{\left(\mathrm{C}_{6} \mathrm{H}_{4}\right) \mathrm{NMe}_{2}\right\}\right][t \mathrm{BuLi}](15)$}

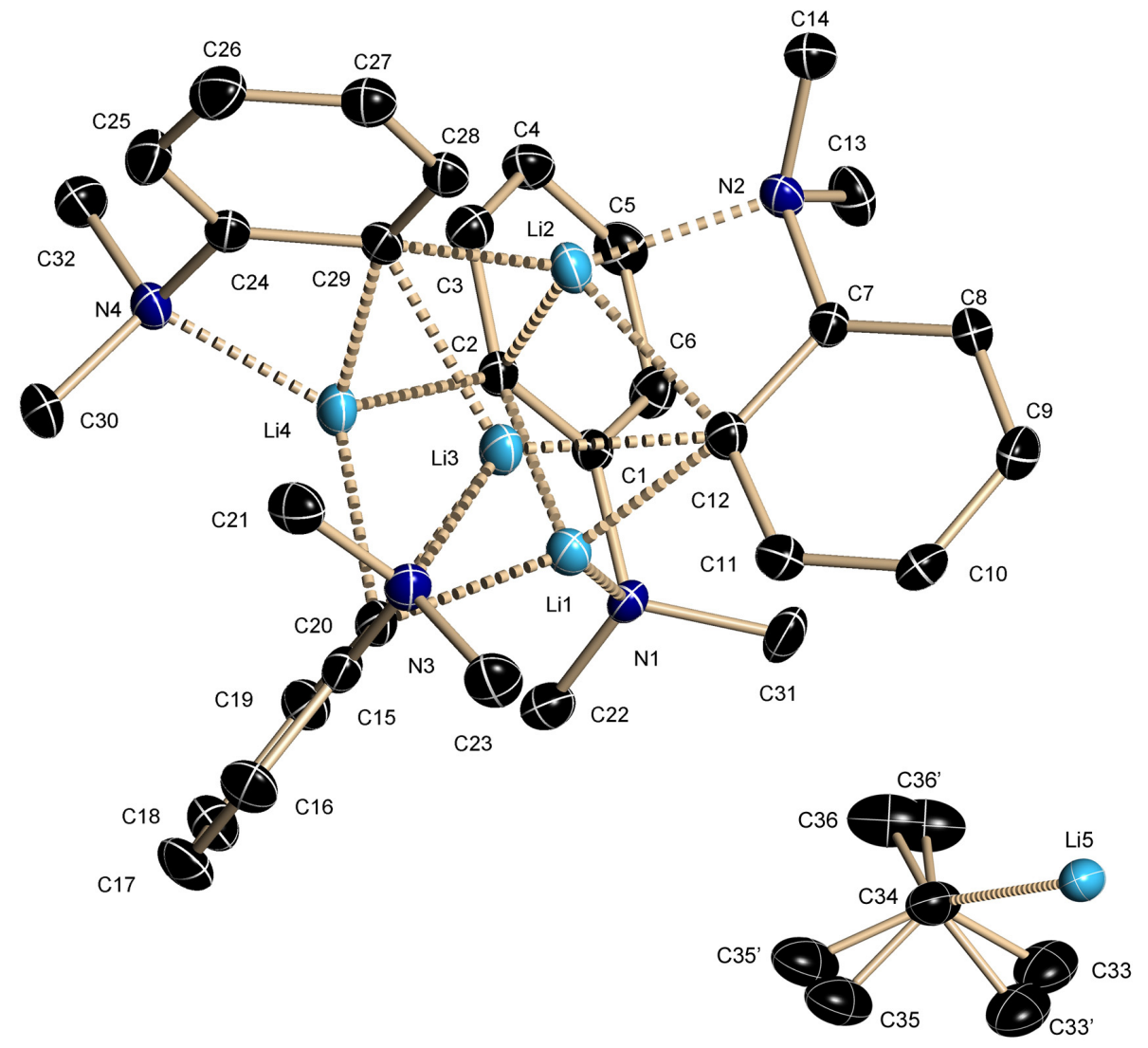

Asymmetric unit of 15 . The anisotropic displacement parameters are shown at the $50 \%$ probability level, hydrogen atoms are omitted for clarity. The $t$ Bu group of the $t$ BuLi molecule is disordered, the occupancy factors refine to 52 and $48 \%$, respectively.

\begin{tabular}{ll|ll}
\hline identification code & MMP182_L & max./min. transmission & $0.9422 / 0.7689$ \\
empirical formula & $\mathrm{C}_{36} \mathrm{H}_{49} \mathrm{Li}_{5} \mathrm{~N}_{8}$ & $\theta$ range $\left.{ }^{\circ}\right]$ & $1.45-26.76$ \\
molecular weight $[\mathrm{g} / \mathrm{mol}]$ & 572.49 & completeness to $\theta_{\max }$ & 0.999 \\
crystal size $[\mathrm{mm}]$ & $0.3 \times 0.04 \times 0.04$ & reflections collected & 40145 \\
temperature $[\mathrm{K}]$ & $100(2)$ & independent reflections & 3964 \\
crystal system & tetragonal & $R_{\text {int }} / R_{\sigma}$ & $0.0393 / 0.0402$ \\
space group & $\overline{4}$ & restraints/parameters & $6 / 429$ \\
$a[\AA]$ & $27.993(4)$ & GoF & 1.080 \\
$c[\AA]$ & $8.8744(12)$ & $R 1($ all data) & 0.0457 \\
$V\left[\AA^{3}\right]$ & $6954.3(16)$ & $R 1(I>2 \sigma(I))$ & 0.0379 \\
$Z$ & 2 & $w R 2($ all data $)$ & 0.0950 \\
$\rho_{\text {calc }}\left[\mathrm{g} \mathrm{cm}^{-3}\right]$ & 1.094 & $w R 2(>2 \sigma(I))$ & 0.0912 \\
$\mu\left[\mathrm{mm}^{-1}\right]$ & 0.061 & diff. peak/hole $\left[\mathrm{e} \AA^{-3}\right]$ & $0.258 /-0.183$ \\
$F(000)$ & 2464 & g1/g2 & $0.0428 / 3.3274$ \\
\hline
\end{tabular}




\subsubsection{5 $\left[\mathrm{Li}\left\{\mathrm{Me}_{2} \mathrm{~N}\left(\mathrm{C}_{6} \mathrm{H}_{4}\right) \mathrm{S}\left(\mathrm{NSiMe}_{3}\right)_{2}\right\}\right]_{2}(16)$}

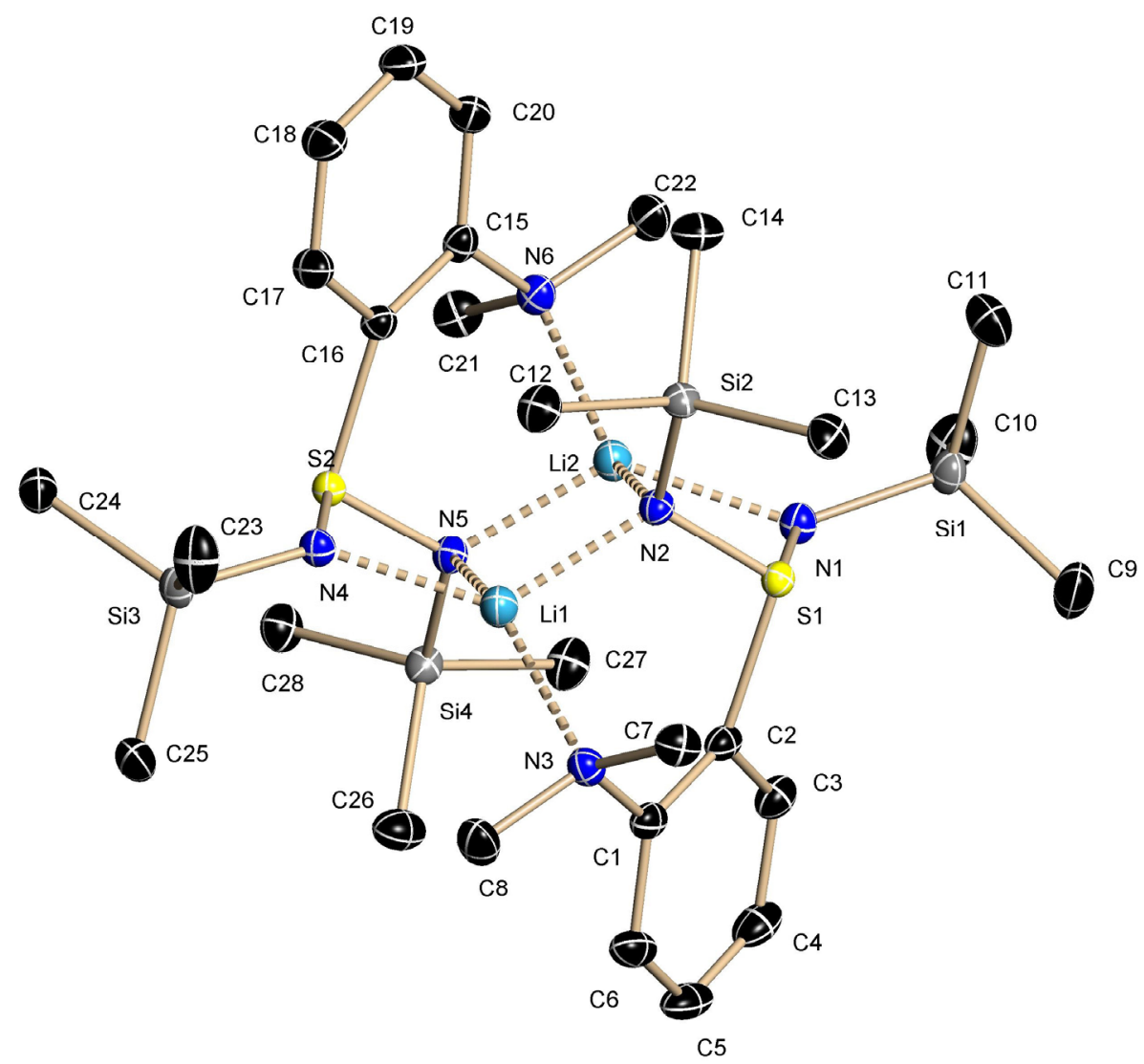

Asymmetric unit of 16 . The anisotropic displacement parameters are shown at the $50 \%$ probability level, hydrogen atoms are omitted for clarity.

\begin{tabular}{ll|ll}
\hline identification code & MMPMKLA20 & $F(000)$ & 1440 \\
empirical formula & $\mathrm{C}_{28} \mathrm{H}_{56} \mathrm{Li}_{2} \mathrm{~N}_{6} \mathrm{~S}_{2} \mathrm{Si}_{4}$ & max./min. transmission & $0.9893 / 0.9527$ \\
molecular weight $[\mathrm{g} / \mathrm{mol}]$ & 667.15 & $\theta$ range $\left[^{\circ}\right]$ & $2.44-27.88$ \\
crystal size $[\mathrm{mm}]$ & $0.2 \times 0.1 \times 0.04$ & completeness to $\theta_{\max }$ & 0.999 \\
temperature $[\mathrm{K}]$ & $100(2)$ & reflections collected & 67118 \\
crystal system & monoclinic & independent reflections & 9209 \\
space group & $P 2{ }_{1} / c$ & $R_{\text {int }} / R_{\sigma}$ & $0.0277 / 0.0167$ \\
$a[\AA]$ & $15.9924(18)$ & restraints/parameters & $0 / 395$ \\
$b[\AA]]$ & $11.9224(13)$ & GoF & 1.031 \\
$c[\AA]$ & $20.441(2)$ & $R 1($ all data $)$ & 0.0339 \\
$\beta\left[{ }^{\circ}\right]$ & $97.758(1)$ & $R 1(/>2 \sigma(I))$ & 0.0277 \\
$V\left[\AA^{3}\right]$ & $3861.7(7)$ & $w R 2($ all data) & 0.0760 \\
$Z$ & 4 & $w R 2(>2 \sigma(I))$ & 0.0720 \\
$\rho_{\text {calc }}\left[\mathrm{g} \mathrm{cm}^{-3}\right]$ & 1.147 & diff. peak/hole $\left[\mathrm{e} \AA^{-3}\right]$ & $0.350 /-0.244$ \\
$\mu\left[\mathrm{mm}^{-1}\right]$ & 0.288 & g1/g2 & $0.0356 / 1.7641$ \\
\hline
\end{tabular}




\subsubsection{6 [(thf)Li $\left.\left\{\mathrm{Me}_{2} \mathrm{~N}\left(\mathrm{C}_{6} \mathrm{H}_{4}\right) \mathrm{S}\left(\mathrm{NSiMe}_{3}\right)_{2}\right\}\right]_{2}(17)$}

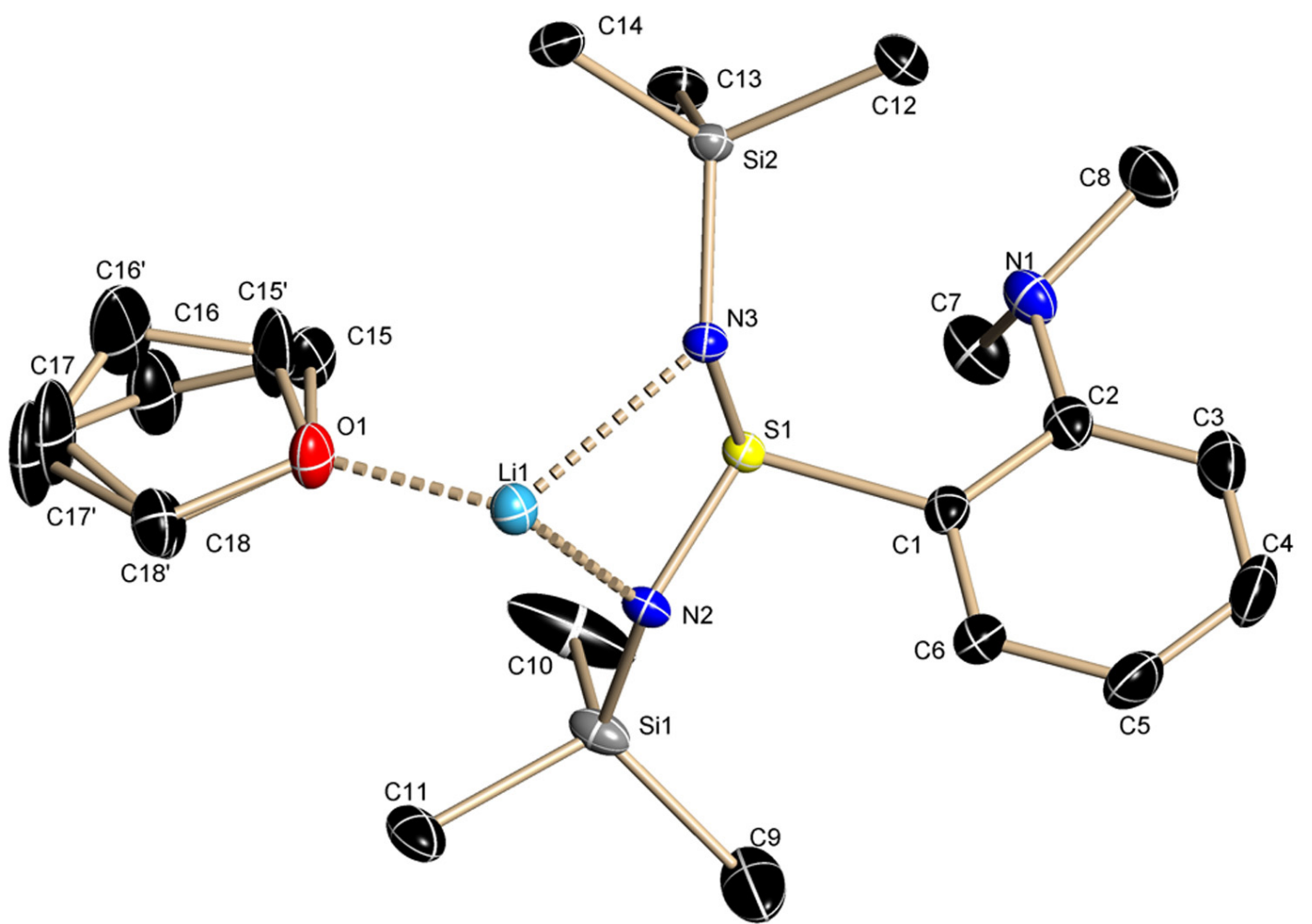

Asymmetric unit of 17 . The anisotropic displacement parameters are shown at the $50 \%$ probability level, hydrogen atoms are omitted for clarity. The THF molecule is disordered over two sites with occupancies of 79 and $21 \%$, respectively.

\begin{tabular}{ll|ll}
\hline identification code & MMP230_1 & $\mu\left[\mathrm{mm}^{-1}\right]$ & 0.251 \\
empirical formula & $\mathrm{C}_{36} \mathrm{H}_{72} \mathrm{Li}_{2} \mathrm{~N}_{6} \mathrm{O}_{2} \mathrm{~S}_{2} \mathrm{Si}_{4}$ & $F(000)$ & 440 \\
molecular weight $[\mathrm{g} / \mathrm{mol}]$ & 811.36 & max./min. transmission & $0.9422 / 0.8938$ \\
crystal size $[\mathrm{mm}]$ & $0.38 \times 0.24 \times 0.1$ & $\theta$ range $\left[^{\circ}\right]$ & $1.82-26.37$ \\
temperature $[\mathrm{K}]$ & $100(2)$ & completeness to $\theta_{\max }$ & 1 \\
crystal system & triclinic & reflections collected & 20312 \\
space group & $P 1$ & independent reflections & 4810 \\
$a[\AA]$ & $10.6363(7)$ & $R_{\text {int }} / R_{\sigma}$ & $0.0189 / 0.0151$ \\
$b[\AA]$ & $10.7789(7)$ & restraints/parameters & $0 / 268$ \\
$c[\AA]$ & $11.9504(7)$ & GoF & 1.077 \\
$\alpha\left[^{\circ}\right]$ & $74.373(1)$ & $R 1($ all data $)$ & 0.0309 \\
$\beta\left[^{\circ}\right]$ & $72.043(1)$ & $R 1(/>2 \sigma(I))$ & 0.0281 \\
$V\left[^{\circ}\right]$ & $66.036(1)$ & $w R 2($ all data) & 0.0750 \\
$V\left[\AA^{3}\right]$ & $1174.51(13)$ & $w R 2(I>2 \sigma(I))$ & 0.0728 \\
$Z$ & 1 & diff. peak/hole $\left[\mathrm{e} \AA^{-3}\right]$ & $0.340 /-0.283$ \\
$\rho_{\text {calc }}\left[\mathrm{g} \mathrm{cm}^{-3}\right]$ & 1.147 & $\mathrm{~g} 1 / \mathrm{g} 2$ & $0.0326 / 0.5806$ \\
\hline
\end{tabular}




\subsubsection{7 $\left[\mathrm{K}\left\{\mathrm{Me}_{2} \mathrm{~N}\left(\mathrm{C}_{6} \mathrm{H}_{4}\right) \mathrm{S}\left(\mathrm{NSiMe}_{3}\right)_{2}\right\}\right]_{2}(18)$}

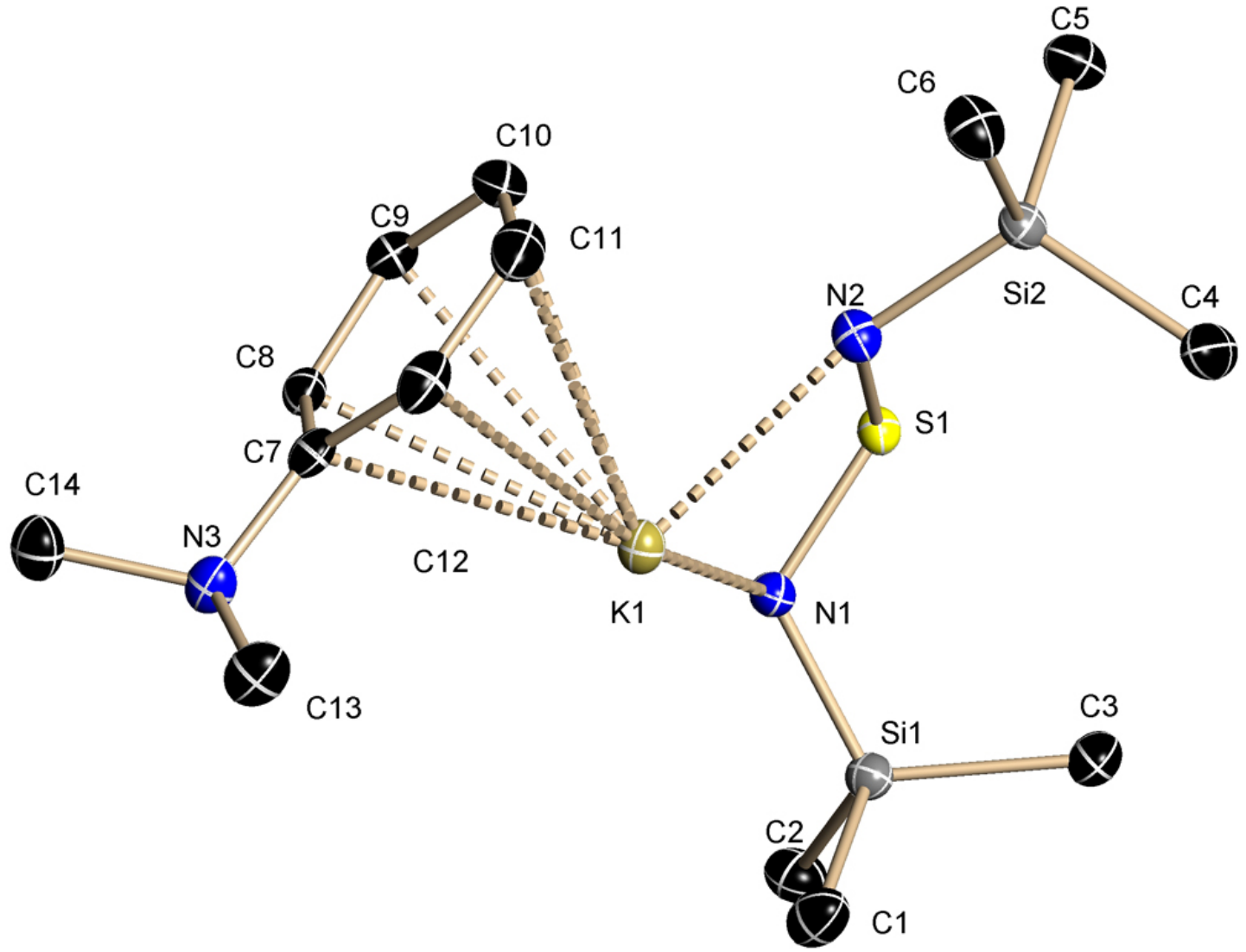

Asymmetric unit of 18 . The anisotropic displacement parameters are shown at the $50 \%$ probability level, hydrogen atoms are omitted for clarity.

\begin{tabular}{ll|ll}
\hline identification code & MMP213 & $F(000)$ & 1568 \\
empirical formula & $\mathrm{C}_{28} \mathrm{H}_{56} \mathrm{~K}_{2} \mathrm{~N}_{6} \mathrm{~S}_{2} \mathrm{Si}_{4}$ & max./min. transmission & $0.9422 / 0.7983$ \\
molecular weight [g/mol] & 731.47 & $\theta$ range $\left[^{\circ}\right]$ & $1.75-26.69^{\circ}$ \\
crystal size $[\mathrm{mm}]$ & $0.2 \times 0.2 \times 0.1$ & completeness to $\theta_{\text {max }}$ & 0.999 \\
temperature $[\mathrm{K}]$ & $100(2)$ & reflections collected & 22355 \\
crystal system & monoclinic & independent reflections & 4289 \\
space group & $C 2 / c$ & $R_{\text {int }} / R_{\sigma}$ & $0.0541 / 0.0438$ \\
$a[\AA]$ & $17.743(2)$ & restraints/parameters & $0 / 198$ \\
$b[\AA]]$ & $9.8015(10)$ & GoF & 1.030 \\
$c[\AA]$ & $23.866(3)$ & $R 1($ all data $)$ & 0.0565 \\
$\beta\left[^{\circ}\right]$ & $102.288(7)$ & $w R 2($ all data) & 0.0356 \\
$V\left[\AA^{3}\right]$ & $4055.3(8)$ & $w R 2(I>2 \sigma(I))$ & 0.0797 \\
$Z$ & 4 & diff. peak/hole $\left[\mathrm{e} \AA^{-3}\right]$ & 0.0725 \\
$\rho_{\text {calc }}\left[\mathrm{g} \mathrm{cm}^{-3}\right]$ & 1.198 & $\mathrm{~g} 1 / \mathrm{g} 2$ & $0.363 /-0.403$ \\
$\mu\left[\mathrm{mm}^{-1}\right]$ & 0.481 & & $0.0275 / 5.947$ \\
\hline
\end{tabular}




\subsubsection{8 $\left[(t \mathrm{BuN})_{2} \mathrm{~S} \cdot\left\{\mathrm{LiMe}_{2} \mathrm{~N}\left(\mathrm{C}_{6} \mathrm{H}_{4}\right) \mathrm{S}(\mathrm{NtBu})_{2}\right\}_{2}\right](19)$}

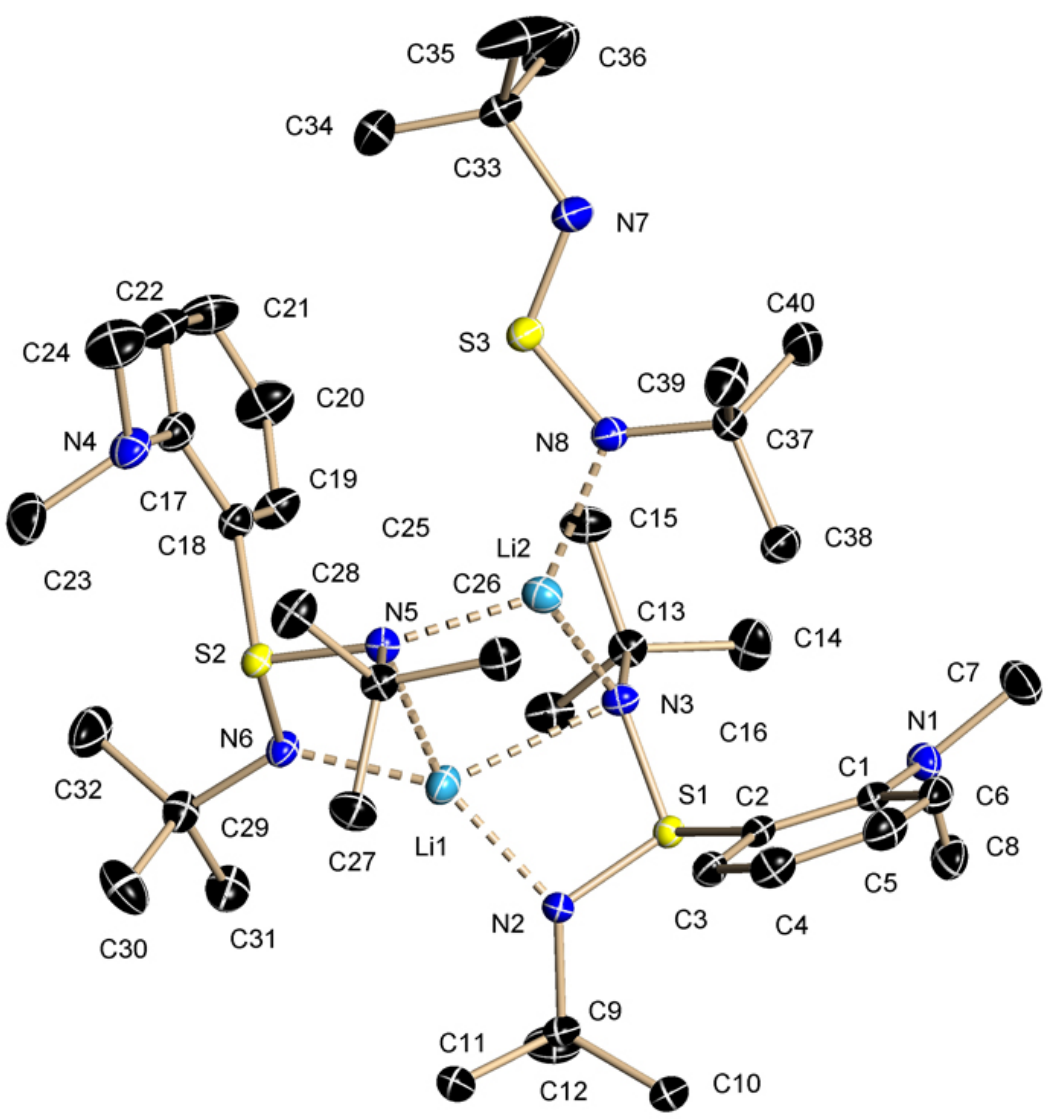

Asymmetric unit of 19 . The anisotropic displacement parameters are shown at the $50 \%$ probability level, hydrogen atoms are omitted for clarity.

\begin{tabular}{ll|ll}
\hline identification code & MMPMKLA18 & $F(000)$ & 1696 \\
empirical formula & $\mathrm{C}_{40} \mathrm{H}_{74} \mathrm{Li}_{2} \mathrm{~N}_{8} \mathrm{~S}_{3}$ & max./min. transmission & $0.9893 / 0.9119$ \\
molecular weight $[\mathrm{g} / \mathrm{mol}]$ & 777.13 & $\theta$ range $\left[^{\circ}\right]$ & $1.36-26.79$ \\
crystal size $[\mathrm{mm}]$ & $0.12 \times 0.06 \times 0.04$ & completeness to $\theta_{\max }$ & 0.998 \\
temperature $[\mathrm{K}]$ & $100(2)$ & reflections collected & 74676 \\
crystal system & monoclinic & independent reflections & 10263 \\
space group & $P 2_{1} / n$ & $R_{\text {int }} / R_{\sigma}$ & $0.0661 / 0.0382$ \\
$a[\AA]$ & $10.7028(15)$ & restraints/parameters & $0 / 500$ \\
$b[\AA]$ & $21.801(3)$ & GoF & 1.031 \\
$c[\AA]$ & $21.092(3)$ & $R 1($ all data $)$ & 0.0535 \\
$\beta\left[{ }^{\circ}\right]$ & $101.945(3)$ & $R 1(I>2 \sigma(I))$ & 0.0384 \\
$V\left[\AA^{3}\right]$ & $4814.8(12)$ & $w R 2($ all data) & 0.0933 \\
$Z$ & 4 & $w R 2(>2 \sigma(I))$ & 0.0917 \\
$\rho_{\text {calc }}\left[\mathrm{g} \mathrm{cm}^{-3}\right]$ & 1.072 & diff. peak/hole $\left[\mathrm{e} \AA^{-3}\right]$ & $0.289 /-0.408$ \\
$\mu\left[\mathrm{mm}^{-1}\right]$ & 0.188 & g1/g2 & $0.0383 / 2.6362$ \\
\hline
\end{tabular}




\subsubsection{9 $\left[\mathrm{Li}\left\{2-\mathrm{PyS}\left(\mathrm{NSiMe}_{3}\right)_{2}\right\}\right]_{2}(20)$}

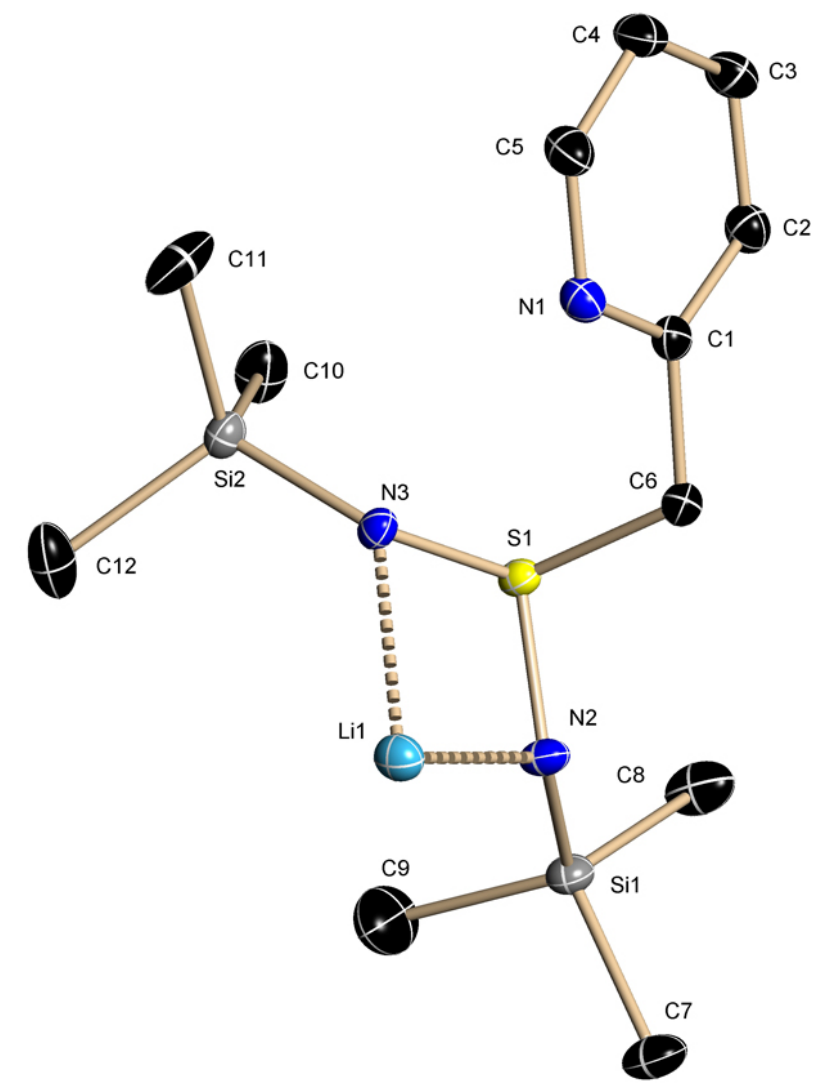

Asymmetric unit of 20. The anisotropic displacement parameters are shown at the $50 \%$ probability level, hydrogen atoms are omitted for clarity.

\begin{tabular}{|c|c|c|c|}
\hline identification code & MMP271 & $\mu\left[\mathrm{mm}^{-1}\right]$ & 0.310 \\
\hline empirical formula & $\mathrm{C}_{24} \mathrm{H}_{48} \mathrm{Li}_{2} \mathrm{~N}_{6} \mathrm{~S}_{2} \mathrm{Si}_{4}$ & $F(000)$ & 328 \\
\hline molecular weight $[\mathrm{g} / \mathrm{mol}]$ & 611.04 & max./min. transmission & $0.9422 / 0.8838$ \\
\hline crystal size $[\mathrm{mm}]$ & $0.18 \times 0.1 \times 0.01$ & $\theta$ range $\left[{ }^{\circ}\right]$ & $2.17-27.89$ \\
\hline temperature $[\mathrm{K}]$ & $100(2)$ & completeness to $\theta_{\max }$ & 0.999 \\
\hline crystal system & triclinic & reflections collected & 14695 \\
\hline space group & $P \overline{1}$ & independent reflections & 4187 \\
\hline$a[\AA]$ & $9.5103(9)$ & $R_{\text {int }} / R_{\sigma}$ & $0.0135 / 0.0120$ \\
\hline$b[\AA]$ & $10.5415(10)$ & restraints/parameters & $0 / 178$ \\
\hline$c[\AA]$ & $10.6013(10)$ & GoF & 1.047 \\
\hline$\alpha\left[^{\circ}\right]$ & $63.6220(10)$ & $R 1$ (all data) & 0.0272 \\
\hline$\beta\left[^{\circ}\right]$ & $68.6900(10)$ & $R 1(1>2 \sigma(I))$ & 0.0249 \\
\hline$V\left[^{\circ}\right]$ & $86.5790(10)$ & $w R 2$ (all data) & 0.0682 \\
\hline$V\left[\AA^{3}\right]$ & $880.43(14)$ & $w R 2(I>2 \sigma(I))$ & 0.0668 \\
\hline Z & 1 & diff. peak/hole $\left[\mathrm{e}^{-3}\right]$ & $0.373 /-0.248$ \\
\hline$\rho_{\text {calc }}\left[\mathrm{g} \mathrm{cm}^{-3}\right]$ & 1.152 & $\mathrm{~g} 1 / \mathrm{g} 2$ & $0.0317 / 0.4066$ \\
\hline
\end{tabular}




\subsubsection{0 $\left[\mathrm{Li}\left\{\mathrm{Me}_{2} \mathrm{~N}\left(\mathrm{CH}_{2}\right)_{2} \mathrm{~N}\left(\mathrm{CH}_{3}\right) \mathrm{S}\left(\mathrm{NSiMe}_{3}\right)_{2}\right\}\right]_{2}(21)$}

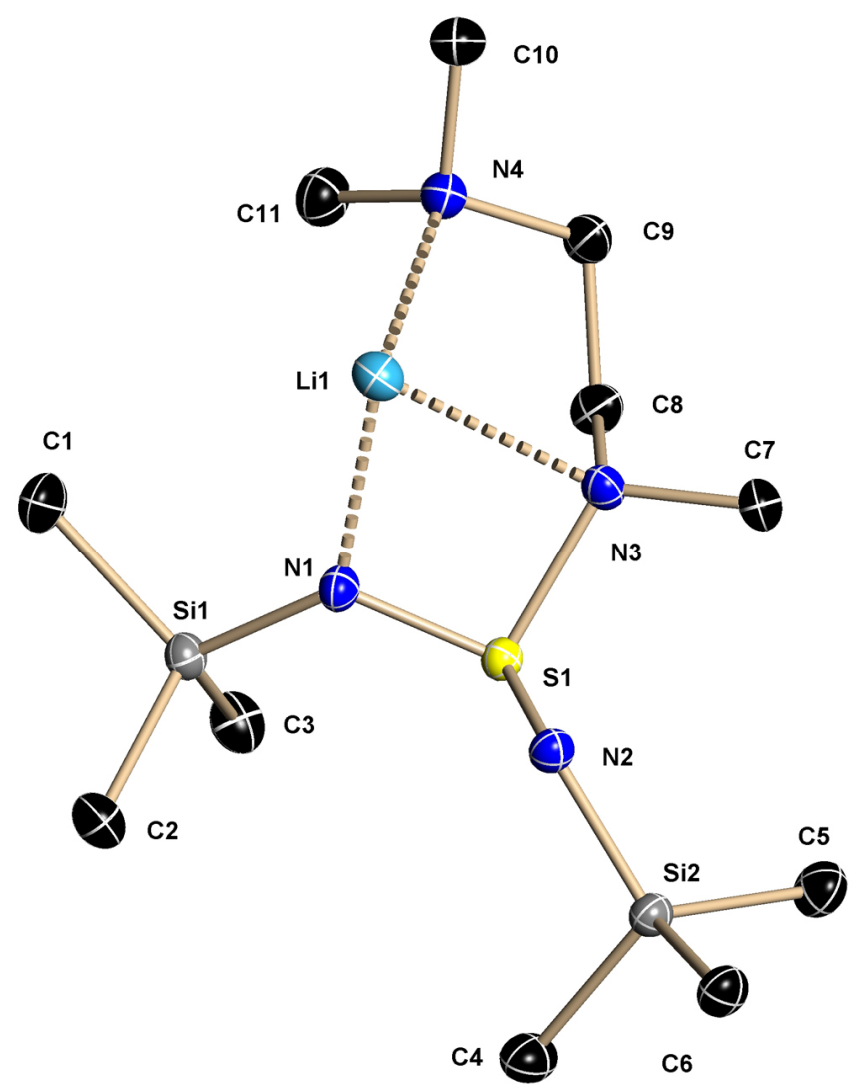

Asymmetric unit of 21. The anisotropic displacement parameters are shown at the $50 \%$ probability level, hydrogen atoms are omitted for clarity.

\begin{tabular}{|c|c|c|c|}
\hline identification code & MMPMKLA19 & $\mu\left[\mathrm{mm}^{-1}\right]$ & 0.287 \\
\hline empirical formula & $\mathrm{C}_{22} \mathrm{H}_{62} \mathrm{Li}_{2} \mathrm{~N}_{8} \mathrm{~S}_{2} \mathrm{Si}_{4}$ & $F(000)$ & 316 \\
\hline molecular weight $[\mathrm{g} / \mathrm{mol}]$ & 629.18 & max./min. transmission & $0.9422 / 0.8652$ \\
\hline crystal size $[\mathrm{mm}]$ & $0.4 \times 0.14 \times 0.08$ & $\theta$ range $\left[{ }^{\circ}\right]$ & $2.64-28.31$ \\
\hline temperature $[\mathrm{K}]$ & $100(2)$ & completeness to $\theta_{\max }$ & 0.994 \\
\hline crystal system & triclinic & reflections collected & 30141 \\
\hline space group & $P \overline{1}$ & independent reflections & 4620 \\
\hline$a[\AA \AA]$ & $10.0177(14)$ & $R_{\text {int }} / R_{\sigma}$ & $0.0166 / 0.0153$ \\
\hline$b[\AA]]$ & $10.2175(13)$ & restraints/parameters & $0 / 181$ \\
\hline$c[\AA ̊]$ & $10.7308(13)$ & GoF & 1.020 \\
\hline$\alpha\left[^{\circ}\right]$ & $95.461(1)$ & $R 1$ (all data) & 0.0257 \\
\hline$\beta\left[^{\circ}\right]$ & $108.065(1)$ & $R 1(I>2 \sigma(I))$ & 0.0240 \\
\hline$V\left[^{\circ}\right]$ & $112.888(1)$ & $w R 2$ (all data) & 0.0700 \\
\hline$V\left[\AA^{3}\right]$ & $932.4(2)$ & $w R 2(1>2 \sigma(I))$ & 0.0686 \\
\hline Z & 1 & diff. peak/hole $\left[\mathrm{e}^{-3}\right]$ & $0.372 /-0.286$ \\
\hline$\rho_{\text {calc }}\left[\mathrm{g} \mathrm{cm}^{-3}\right]$ & 1.120 & $\mathrm{~g} 1 / \mathrm{g} 2$ & $0.0382 / 0.3008$ \\
\hline
\end{tabular}




\subsubsection{1 $\left[\mathrm{Na}\left\{\mathrm{Me}_{2} \mathrm{~N}\left(\mathrm{CH}_{2}\right)_{2} \mathrm{~N}\left(\mathrm{CH}_{3}\right) \mathrm{S}\left(\mathrm{NSiMe}_{3}\right)_{2}\right\}\right]_{2}(22)$}

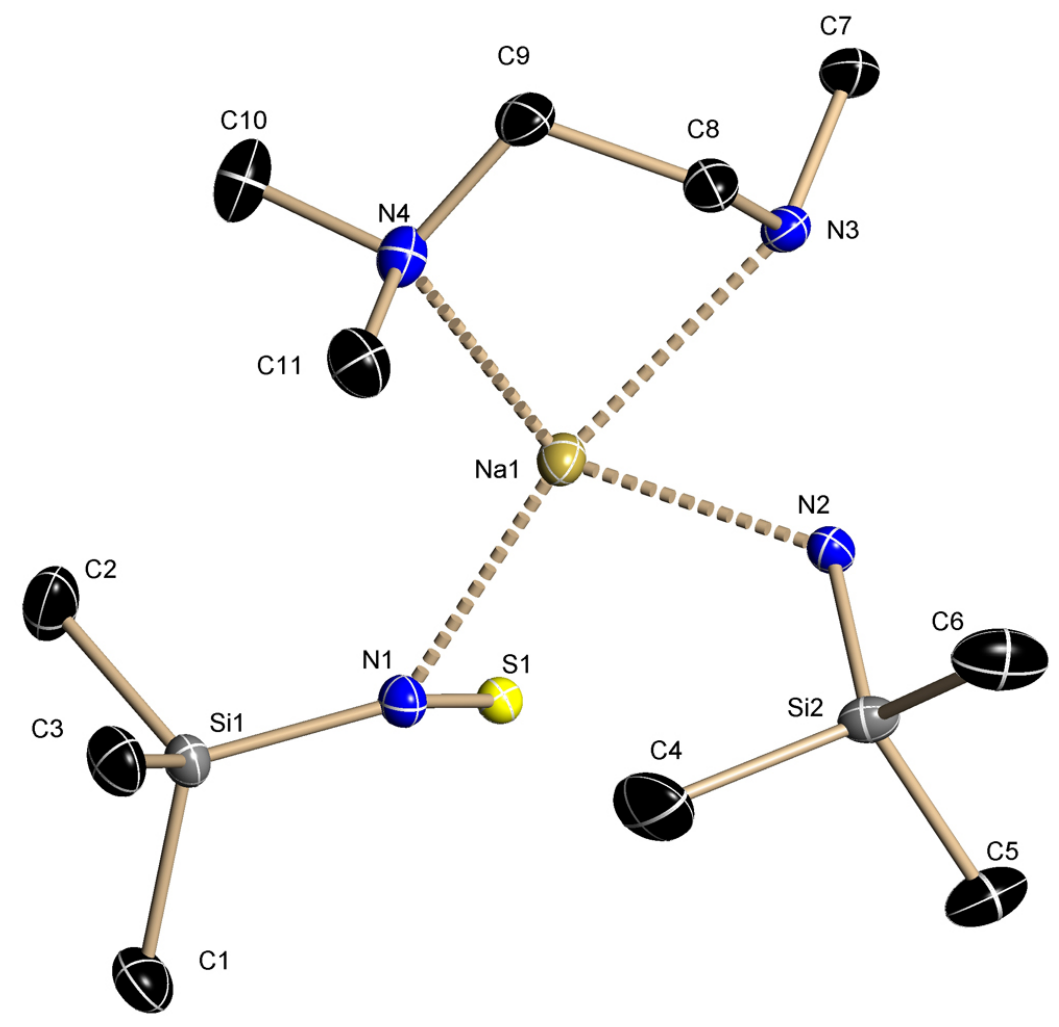

Asymmetric unit of 22. The anisotropic displacement parameters are shown at the $50 \%$ probability level, hydrogen atoms are omitted for clarity.

\begin{tabular}{|c|c|c|c|}
\hline identification code & MMPEK04 & $\mu\left[\mathrm{mm}^{-1}\right]$ & 0.306 \\
\hline empirical formula & $\mathrm{C}_{22} \mathrm{H}_{62} \mathrm{~N}_{8} \mathrm{Na}_{2} \mathrm{~S}_{2} \mathrm{Si}_{4}$ & $F(000)$ & 360 \\
\hline molecular weight $[\mathrm{g} / \mathrm{mol}]$ & 661.26 & max./min. transmission & $0.9422 / 0.8641$ \\
\hline crystal size $[\mathrm{mm}]$ & $0.2 \times 0.04 \times 0.04$ & $\theta$ range $\left[{ }^{\circ}\right]$ & $2.09-26.03$ \\
\hline temperature $[\mathrm{K}]$ & $100(2)$ & completeness to $\theta_{\max }$ & 0.996 \\
\hline crystal system & triclinic & reflections collected & 14548 \\
\hline space group & $P \overline{1}$ & independent reflections & 3831 \\
\hline$a[\AA \AA]$ & $10.1566(12)$ & $R_{\text {int }} / R_{\sigma}$ & $0.0177 / 0.0146$ \\
\hline$b[\AA]]$ & $10.7350(12)$ & restraints/parameters & $0 / 181$ \\
\hline$c[\AA]]$ & $10.9361(12)$ & GoF & 1.073 \\
\hline$\alpha\left[^{\circ}\right]$ & $90.997(2)$ & $R 1$ (all data) & 0.0272 \\
\hline$\beta\left[^{\circ}\right]$ & $114.202(1)$ & $R 1(I>2 \sigma(I))$ & 0.0250 \\
\hline$V\left[^{\circ}\right]$ & $113.399(1)$ & $w R 2$ (all data) & 0.0657 \\
\hline$V\left[\AA^{3}\right]$ & $974.73(19)$ & $w R 2(I>2 \sigma(I))$ & 0.0644 \\
\hline$z$ & 1 & diff. peak/hole $\left[\mathrm{e} \AA^{-3}\right]$ & $0.323 /-0.301$ \\
\hline$\rho_{\text {calc }}\left[\mathrm{g} \mathrm{cm}^{-3}\right]$ & 1.127 & $g 1 / g 2$ & $0.0263 / 0.5024$ \\
\hline
\end{tabular}




\subsubsection{2 $\left[\mathrm{Li}_{2} \mathrm{~K}_{3}\left\{\mathrm{PhP}\left(\mathrm{CH}_{2} \mathrm{~S}\left(\mathrm{NSiMe}_{3}\right)_{2}\right\}_{2}(\mathrm{OH})\right](23)\right.$}

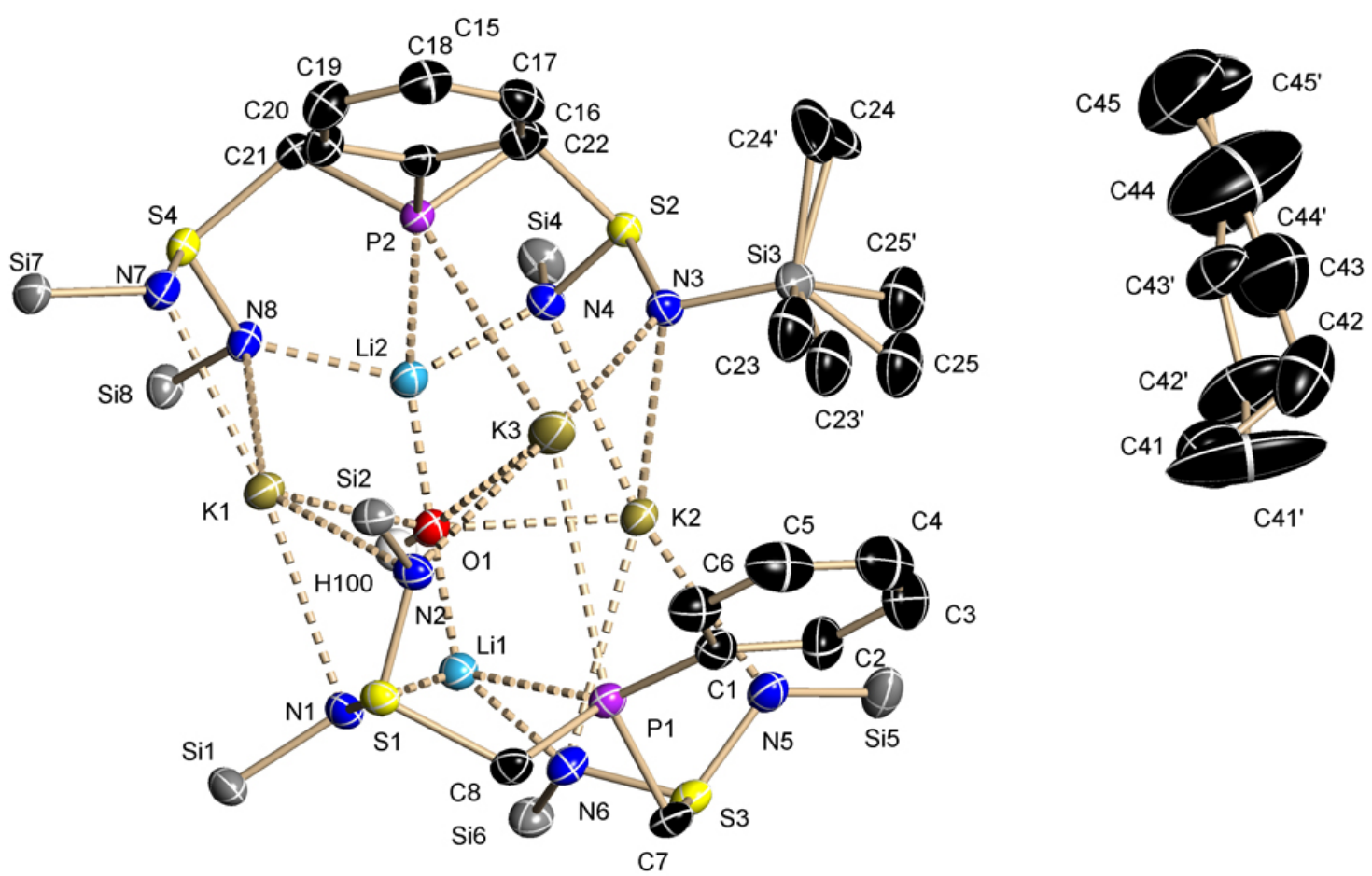

Asymmetric unit of 23. The anisotropic displacement parameters are shown at the $50 \%$ probability level, hydrogen atoms are omitted for clarity. The hydrogen atom on $\mathrm{O} 1$ was freely refined using distance restraints. The occupancy factors of the disordered pentane molecule refine to 57 and $43 \%$, respectively. The two solvent molecules were refined using SAME for the connectivities and SIMU, DELU and ISOR for the displacement parameters. Two of the $\mathrm{NSiMe}_{3}$ groups are disordered as well. The occupancy factors for $\mathrm{Si}(3) \mathrm{Me}_{3}$ refine to 72 and $28 \%$, respectively. The group was refined using

SADI restraints. For $\mathrm{Si}(4) \mathrm{Me}_{3}$ the values are 56 and $44 \%$, the group was refined using EADP.

\begin{tabular}{|c|c|c|c|}
\hline identification code & MMP218 & $F(000)$ & 2824 \\
\hline empirical formula & $\mathrm{C}_{45} \mathrm{H}_{103} \mathrm{~K}_{3} \mathrm{Li}_{2} \mathrm{~N}_{8} \mathrm{OP}_{2} \mathrm{~S}_{4} \mathrm{Si}_{8}$ & max./min. transmission & $0.9422 / 0.8702$ \\
\hline molecular weight $[\mathrm{g} / \mathrm{mol}]$ & 1318.48 & $\theta$ range $\left[{ }^{\circ}\right]$ & $0.96-26.80^{\circ}$ \\
\hline crystal size $[\mathrm{mm}]$ & $0.2 \times 0.2 \times 0.1$ & completeness to $\theta_{\max }$ & 0.999 \\
\hline temperature $[\mathrm{K}]$ & $100(2)$ & reflections collected & 184533 \\
\hline crystal system & monoclinic & independent reflections & 15896 \\
\hline space group & $P 2_{1} / c$ & $R_{\text {int }} / R_{\sigma}$ & $0.0474 / 0.0222$ \\
\hline$a[\AA]]$ & $21.5346(17)$ & restraints/parameters & $58 / 738$ \\
\hline$b[\AA]]$ & $14.3833(11)$ & GoF & 1.072 \\
\hline$c[\AA]]$ & $24.3506(19)$ & $R 1$ (all data) & 0.0509 \\
\hline$\beta\left[^{\circ}\right]$ & $99.826(1)$ & $R 1(/>2 \sigma(I))$ & 0.0388 \\
\hline$V\left[\AA^{3}\right]$ & $7431.7(10)$ & $w R 2$ (all data) & 0.0959 \\
\hline$Z$ & 4 & $w R 2(I>2 \sigma(I))$ & 0.0892 \\
\hline$\rho_{\text {calc }}\left[\mathrm{g} \mathrm{cm}^{-3}\right]$ & 1.178 & diff. peak/hole $\left[\mathrm{e} \AA^{-3}\right]$ & $0.853 /-0.830$ \\
\hline$\mu\left[\mathrm{mm}^{-1}\right]$ & 0.503 & $g 1 / g 2$ & $0.0354 / 8.0999$ \\
\hline
\end{tabular}




\subsubsection{3 $\left[\mathrm{Li}_{4} \mathrm{O}_{2}\left\{\mathrm{CH}_{2}\left(\mathrm{~N}(\mathrm{Me}) \mathrm{CH}_{2} \mathrm{~S}(\mathrm{NtBu})_{2} \mathrm{Li}\right)\right\}_{2}\right](24)$}

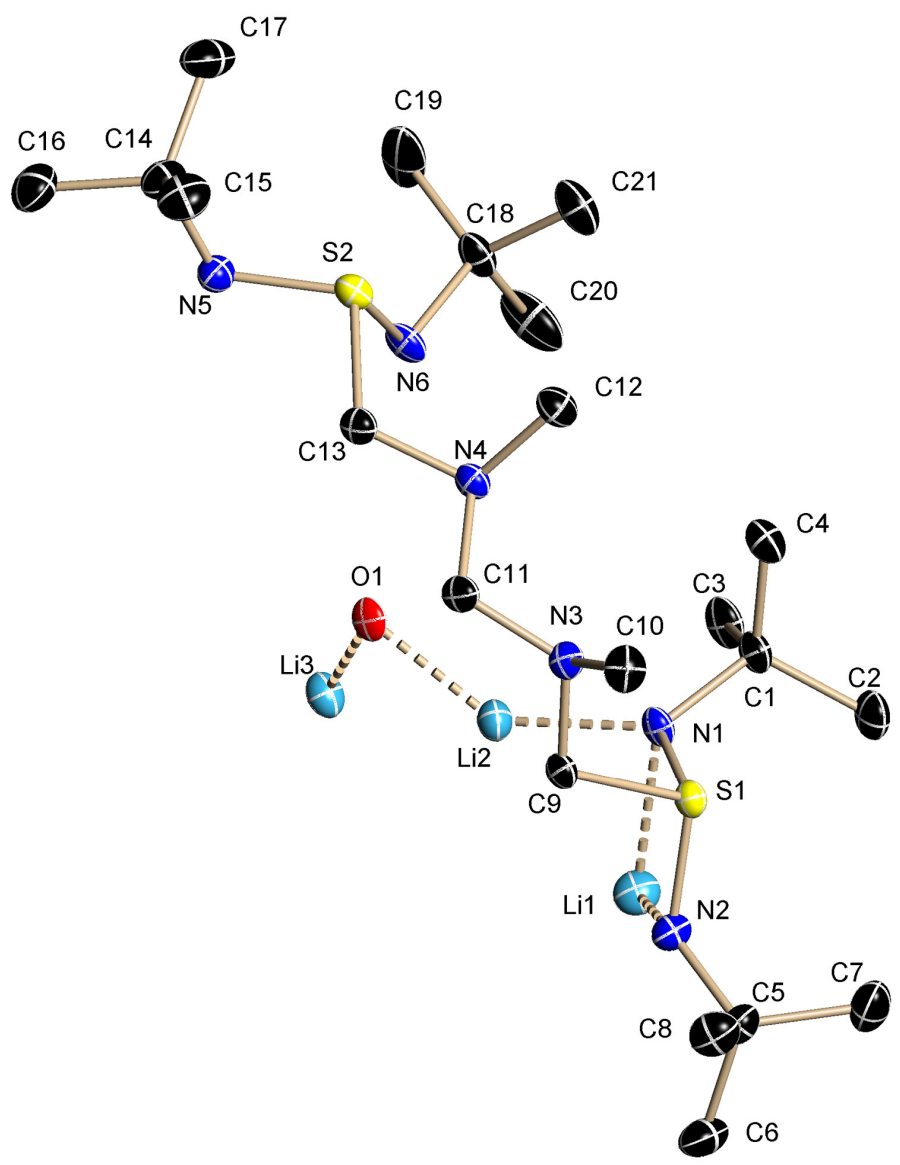

Asymmetric unit of 24. The anisotropic displacement parameters are shown at the $50 \%$ probability level, hydrogen atoms are omitted for clarity.

\begin{tabular}{ll|ll}
\hline identification code & MMPEK10 & $F(000)$ & 1056 \\
empirical formula & $\mathrm{C}_{42} \mathrm{H}_{96} \mathrm{Li}_{6} \mathrm{~N}_{12} \mathrm{O}_{2} \mathrm{~S}_{4}$ & max./min. transmission & $1.000 / 0.674$ \\
molecular weight $[\mathrm{g} / \mathrm{mol}]$ & 971.19 & $\theta$ range $\left[^{\circ}\right]$ & $1.68-25.72$ \\
crystal size $[\mathrm{mm}]$ & $0.15 \times 0.1 \times 0.1$ & completeness to $\theta_{\max }$ & 0.997 \\
temperature $[\mathrm{K}]$ & $100(2)$ & reflections collected & 56834 \\
crystal system & monoclinic & independent reflections & 5526 \\
space group & $P 2{ }_{1} / c$ & $R_{\text {int }} / R_{\sigma}$ & $0.0830 / 0.0401$ \\
$a[\AA]$ & $8.6080(9)$ & restraints/parameters & $0 / 312$ \\
$b[\AA]$ & $14.0907(14)$ & GoF & 1.073 \\
$c[\AA]$ & $24.267(3)$ & $R 1($ all data) & 0.0651 \\
$\beta\left[^{\circ}\right]$ & $99.829(2)$ & $R 1(I>2 \sigma(I))$ & 0.0491 \\
$V\left[\AA^{3}\right]$ & $2900.3(5)$ & $w R 2($ all data) & 0.1127 \\
$Z$ & 2 & $w R 2(I>2 \sigma(I))$ & 0.1056 \\
$\rho_{\text {calc }}\left[\mathrm{g} \mathrm{cm}^{-3}\right]$ & 1.110 & diff. peak/hole $\left[\mathrm{e} \AA^{-3}\right]$ & $0.623 /-0.419$ \\
$\mu\left[\mathrm{mm}^{-1}\right]$ & 0.206 & $g 1 / \mathrm{g} 2$ & $0.0294 / 3.8993$ \\
\hline
\end{tabular}




\subsubsection{4 $\left[\mathrm{Li}_{4}\left\{\left(\mathrm{NSiMe}_{3}\right)_{2} \mathrm{SCH}_{2} \mathrm{~N}(\mathrm{Me}) \mathrm{CH}_{2} \mathrm{~N}(\mathrm{Me}) \mathrm{CH}_{2}(\mathrm{O})\right\}\left\{\mathrm{NSN}\left(\mathrm{SiMe}_{3}\right)\right\}-\right.$ $(\mathrm{OtBu})]_{2}(25)$}

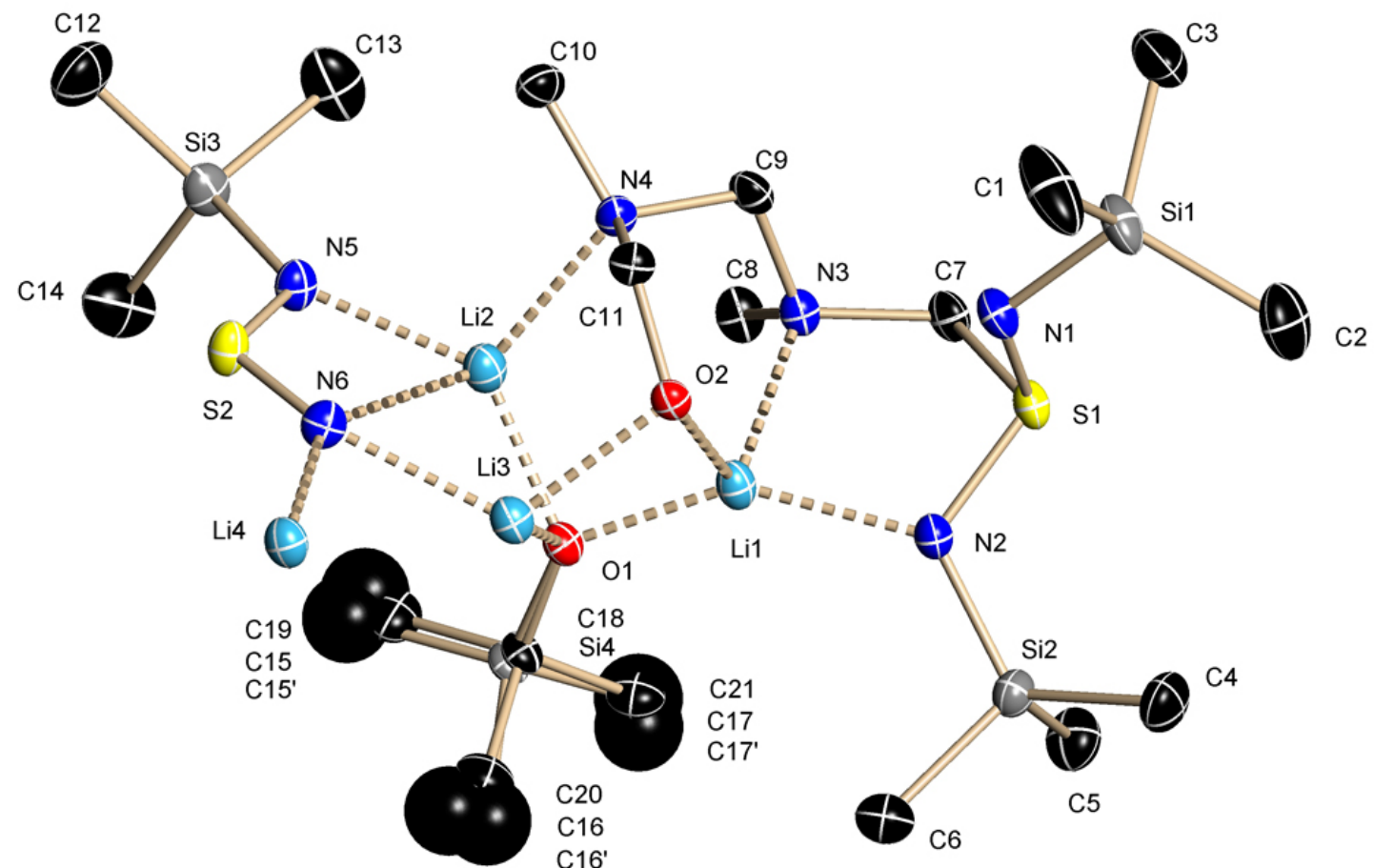

Asymmetric unit of 25. The anisotropic displacement parameters are shown at the $50 \%$ probability level, hydrogen atoms are omitted for clarity. The tBu group on $\mathrm{O} 1$ is disordered with a disordered $\mathrm{SiMe}_{3}$ group. The occupancy factors refine to 72 and $22 \%$ and $6 \%$ for the second site of the $\mathrm{SiMe}_{3}$ group. Because of the small occupancy, the second orientation of the $\mathrm{SiMe}_{3}$ group could not be refined anisotropically. The disorder was refined using DELU, ISOR and DFIX.

\begin{tabular}{ll|ll}
\hline identification code & MMPEK07 & $F(000)$ & 1209 \\
empirical formula & $\mathrm{C}_{35.44} \mathrm{H}_{96.02} \mathrm{Li}_{8} \mathrm{~N}_{12} \mathrm{O}_{4} \mathrm{~S}_{4} \mathrm{Si}_{6.57}$ & max./min. transmission & $0.9422 / 0.8318$ \\
molecular weight $[\mathrm{g} / \mathrm{mol}]$ & 1122.87 & $\theta$ range $\left[^{\circ}\right]$ & $1.64-26.37$ \\
crystal size $[\mathrm{mm}]$ & $0.2 \times 0.04 \times 0.04$ & completeness to $\theta_{\text {max }}$ & 1.000 \\
temperature $[\mathrm{K}]$ & $100(2)$ & reflections collected & 40145 \\
crystal system & monoclinic & independent reflections & 6806 \\
space group & $P 2{ }_{1} / n$ & $R_{\text {int }} / R_{\sigma}$ & $0.0568 / 0.0313$ \\
$a[\AA]$ & restraints/parameters & $18 / 366$ \\
$b[\AA]$ & GoF & 1.077 \\
$c[\AA]$ & $14.987(3)$ & $R 1($ all data $)$ & 0.0504 \\
$\beta\left[{ }^{\circ}\right]$ & $22.310(5)$ & $R 1(I>2 \sigma(I))$ & 0.0348 \\
$V\left[\AA^{3}\right]$ & 90 & $w R 2($ all data $)$ & 0.0874 \\
$Z$ & $3322.9(13)$ & $w R 2(I>2 \sigma(I))$ & 0.0806 \\
$\rho_{\text {calc }}\left[\mathrm{g} \mathrm{cm}^{-3}\right]$ & 2 & diff. peak/hole $\left[\mathrm{e} \AA^{-3}\right]$ & $0.386 /-0.312$ \\
$\mu\left[\mathrm{mm}^{-1}\right]$ & 1.122 & $\mathrm{~g} 1 / \mathrm{g} 2$ & $0.0348 / 1.8942$ \\
\hline
\end{tabular}




\subsubsection{5 $\left[\mathrm{Mg}\left\{\mathrm{Me}_{2} \mathrm{PCH}_{2} \mathrm{~S}(\mathrm{NtBu})_{2}\right\}_{2}\right](26)$}

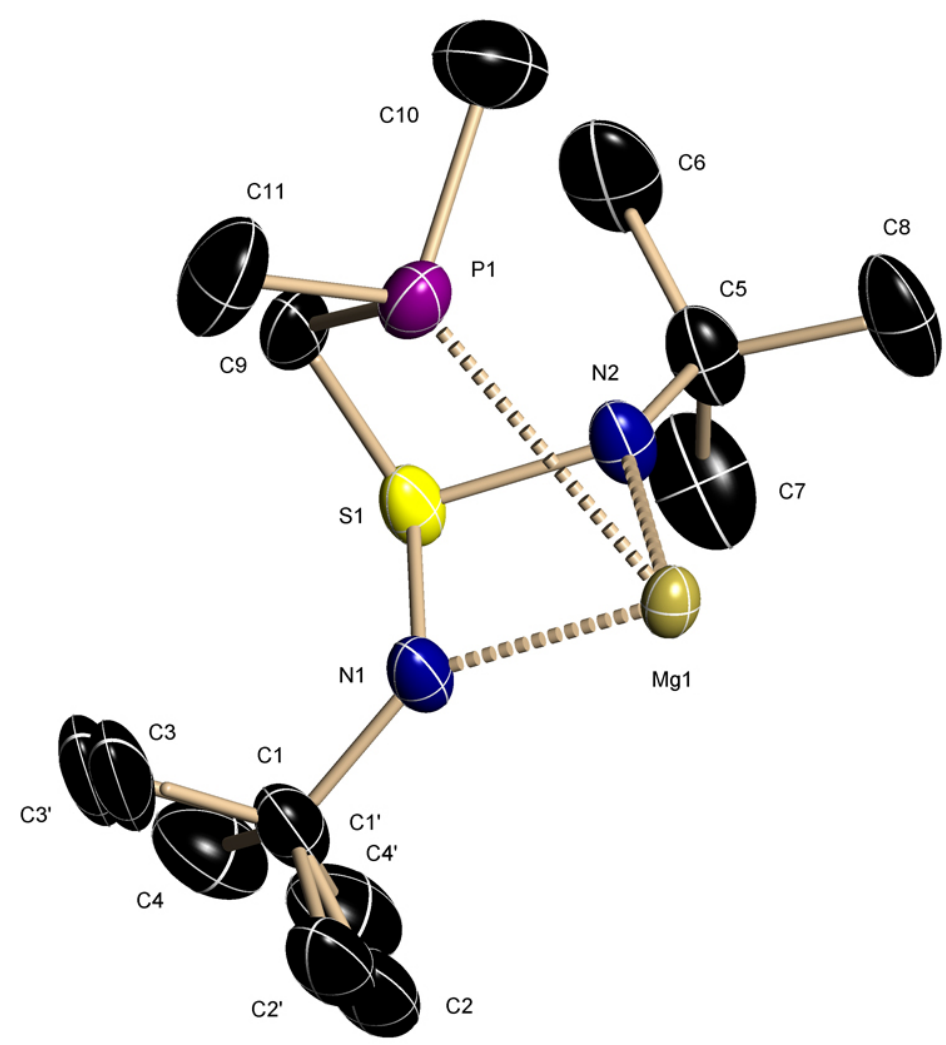

Asymmetric unit of 26. The anisotropic displacement parameters are shown at the $30 \%$ probability level, hydrogen atoms are omitted for clarity. One tBu group is disordered over two sites with occupancies of 60 and $40 \%$.

\begin{tabular}{ll|ll}
\hline identification code & Mücke & $F(000)$ & 2288 \\
empirical formula & $\mathrm{C}_{22} \mathrm{H}_{52} \mathrm{MgN}_{4} \mathrm{P}_{2} \mathrm{~S}_{2}$ & max./min. transmission & $0.98931 / 0.83307$ \\
molecular weight [g/mol] & 523.05 & $\theta$ range $\left[^{\circ}\right]$ & $2.19-26.40$ \\
crystal size $[\mathrm{mm}]$ & $0.2 \times 0.1 \times 0.02$ & completeness to $\theta_{\text {max }}$ & 0.999 \\
temperature $[\mathrm{K}]$ & $250(2)$ & reflections collected & 21122 \\
crystal system & orthorhombic & independent reflections & 3270 \\
space group & $F d d 2$ & $R_{\text {int }} / R_{\sigma}$ & $0.0407 / 0.0253$ \\
$a[\AA]$ & restraints/parameters & $31 / 162$ \\
$b[\AA]$ & GoF & 1.148 \\
$c[\AA]$ & $10.175(2)$ & $R 1($ all data $)$ & 0.0497 \\
$V\left[\AA^{3}\right]$ & $16.851(4)$ & $R 1(>2 \sigma(I))$ & 0.0462 \\
$Z$ & $6373(2)$ & $w R 2($ all data) & 0.1172 \\
$\rho_{\text {calc }}\left[\mathrm{g} \mathrm{cm}^{-3}\right]$ & 8 & $w R 2(>2 \sigma(I))$ & 0.1156 \\
$\mu\left[\mathrm{mm}^{-1}\right]$ & 1.090 & diff. peak/hole $\left[\mathrm{e} \AA^{-3}\right]$ & $0.227 /-0.227$ \\
& 0.303 & $g 1 / \mathrm{g} 2$ & $0.0553 / 7.7268$ \\
\hline
\end{tabular}




\subsubsection{6 $\left[\mathrm{Mg}\left\{\mathrm{Me}_{2} \mathrm{PCH}_{2} \mathrm{~S}\left(\mathrm{NSiMe}_{3}\right)_{2}\right\}_{2}\right](27)$}

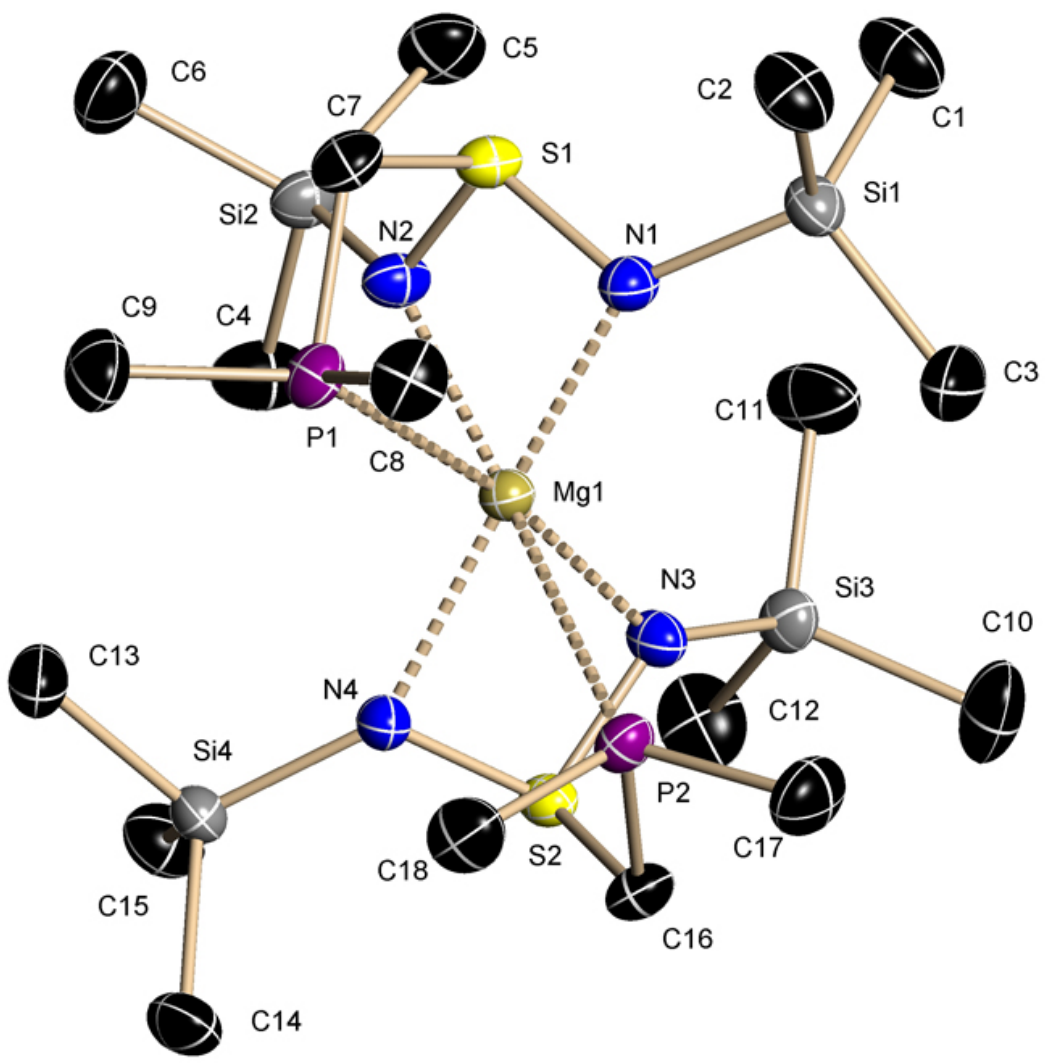

Asymmetric unit of 27 . The anisotropic displacement parameters are shown at the $50 \%$ probability level, hydrogen atoms are omitted for clarity.

\begin{tabular}{ll|ll}
\hline identification code & $\mathrm{MKP} 17$ & $F(000)$ & 1272 \\
empirical formula & $\mathrm{C}_{18} \mathrm{H}_{52} \mathrm{~N}_{4} \mathrm{Si}_{4} \mathrm{P}_{2} \mathrm{~S}_{2} \mathrm{Mg}$ & max./min. transmission & $0.9422 / 0.8698$ \\
molecular weight $[\mathrm{g} / \mathrm{mol}]$ & 587.36 & $\theta$ range $\left[^{\circ}\right]$ & $2.68-29.13$ \\
crystal size $[\mathrm{mm}]$ & $0.56 \times 0.52 \times 0.30$ & completeness to $\theta_{\max }$ & 0.998 \\
temperature $[\mathrm{K}]$ & $100(2)$ & reflections collected & 156125 \\
crystal system & monoclinic & independent reflections & 9326 \\
space group & $P 2_{1} / n$ & $R_{\text {int }} / R_{\sigma}$ & $0.0192 / 0.0072$ \\
$a[\AA]$ & $10.2563(5)$ & restraints/parameters & $0 / 296$ \\
$b[\AA]$ & $17.8142(8)$ & GoF & 1.019 \\
$c[\AA]$ & $19.2917(9)$ & $R 1($ all data $)$ & 0.0238 \\
$\beta\left[^{\circ}\right]$ & $99.2730(10)$ & $R 1(/>2 \sigma(I))$ & 0.0213 \\
$V\left[\AA^{3}\right]$ & $3478.7(3)$ & $w R 2($ all data) & 0.0630 \\
$Z$ & 4 & $w R 2(>2 \sigma(I))$ & 0.0612 \\
$\rho_{\text {calc }}\left[\mathrm{g} \mathrm{cm}^{-3}\right]$ & 1.122 & diff. peak/hole $\left[\mathrm{e} \AA^{-3}\right]$ & $0.286 /-0.263$ \\
$\mu\left[\mathrm{mm}^{-1}\right]$ & 0.415 & $\mathrm{~g} 1 / \mathrm{g} 2$ & $0.0374 / 0.6229$ \\
\hline
\end{tabular}




\subsubsection{7 $\left[\mathrm{Ca}\left\{\mathrm{Ph}_{2} \mathrm{PCH}_{2} \mathrm{~S}\left(\mathrm{NSiMe}_{3}\right)_{2}\right\}_{2}\right](28)$}

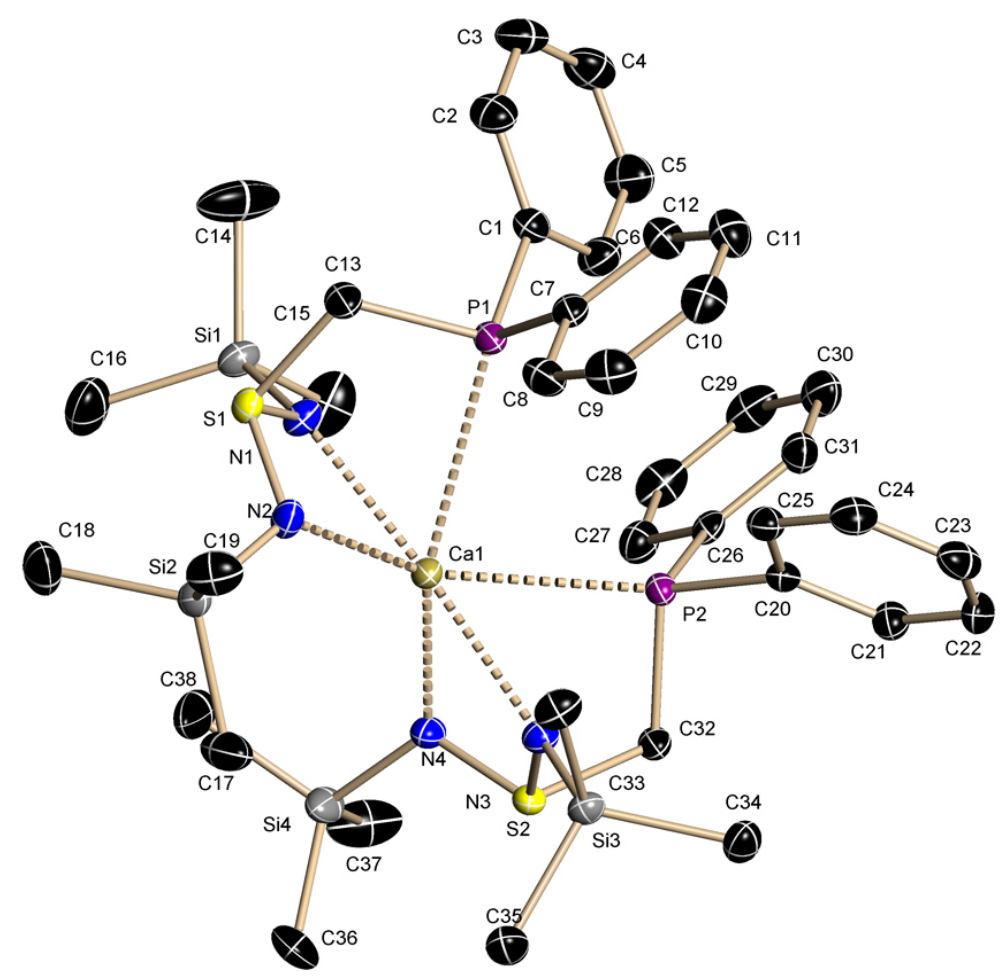

Asymmetric unit of $\mathbf{2 8}$. The anisotropic displacement parameters are shown at the $50 \%$ probability level, hydrogen atoms are omitted for clarity.

\begin{tabular}{|c|c|c|c|}
\hline identification code & MMP273 & $F(000)$ & 1816 \\
\hline empirical formula & $\mathrm{C}_{38} \mathrm{H}_{60} \mathrm{CaN}_{4} \mathrm{P}_{2} \mathrm{~S}_{2} \mathrm{Si}_{4}$ & max./min. transmission & $0.9422 / 0.8075$ \\
\hline molecular weight $[\mathrm{g} / \mathrm{mol}]$ & 851.40 & $\theta$ range $\left[{ }^{\circ}\right]$ & $1.34-26.02$ \\
\hline crystal size $[\mathrm{mm}]$ & $0.16 \times 0.02 \times 0.02$ & completeness to $\theta_{\max }$ & 0.999 \\
\hline temperature $[\mathrm{K}]$ & $100(2)$ & reflections collected & 46417 \\
\hline crystal system & orthorhombic & independent reflections & 9409 \\
\hline space group & $P 2_{1} 2_{1} 2_{1}$ & $R_{\text {int }} / R_{\sigma}$ & $0.0462 / 0.0305$ \\
\hline$a[\AA]$ & $10.2753(11)$ & restraints/parameters & $0 / 472$ \\
\hline$b[\AA]]$ & $20.867(2)$ & GoF & 1.050 \\
\hline$c[\AA]$ & $22.261(2)$ & $R 1$ (all data) & 0.0340 \\
\hline$V\left[\AA^{3}\right]$ & $4773.1(9)$ & $R 1(I>2 \sigma(I))$ & 0.0291 \\
\hline$z$ & 4 & $w R 2$ (all data) & 0.0691 \\
\hline$\rho_{\text {calc }}\left[\mathrm{g} \mathrm{cm}^{-3}\right]$ & 1.185 & $w R 2(I>2 \sigma(I))$ & 0.0668 \\
\hline$\mu\left[\mathrm{mm}^{-1}\right]$ & 0.416 & diff. peak/hole $\left[\mathrm{e}^{-3}\right]$ & $0.295 /-0.193$ \\
\hline Flack-x-parameter ${ }^{[225]}$ & $0.04(3)$ & $\mathrm{g} 1 / \mathrm{g} 2$ & $0.0343 / 1.346$ \\
\hline
\end{tabular}




\subsubsection{8 $\left[\mathrm{Sr}\left\{\mathrm{Ph}_{2} \mathrm{PCH}_{2} \mathrm{~S}\left(\mathrm{NSiMe}_{3}\right)_{2}\right\}_{2}\right](29)$}

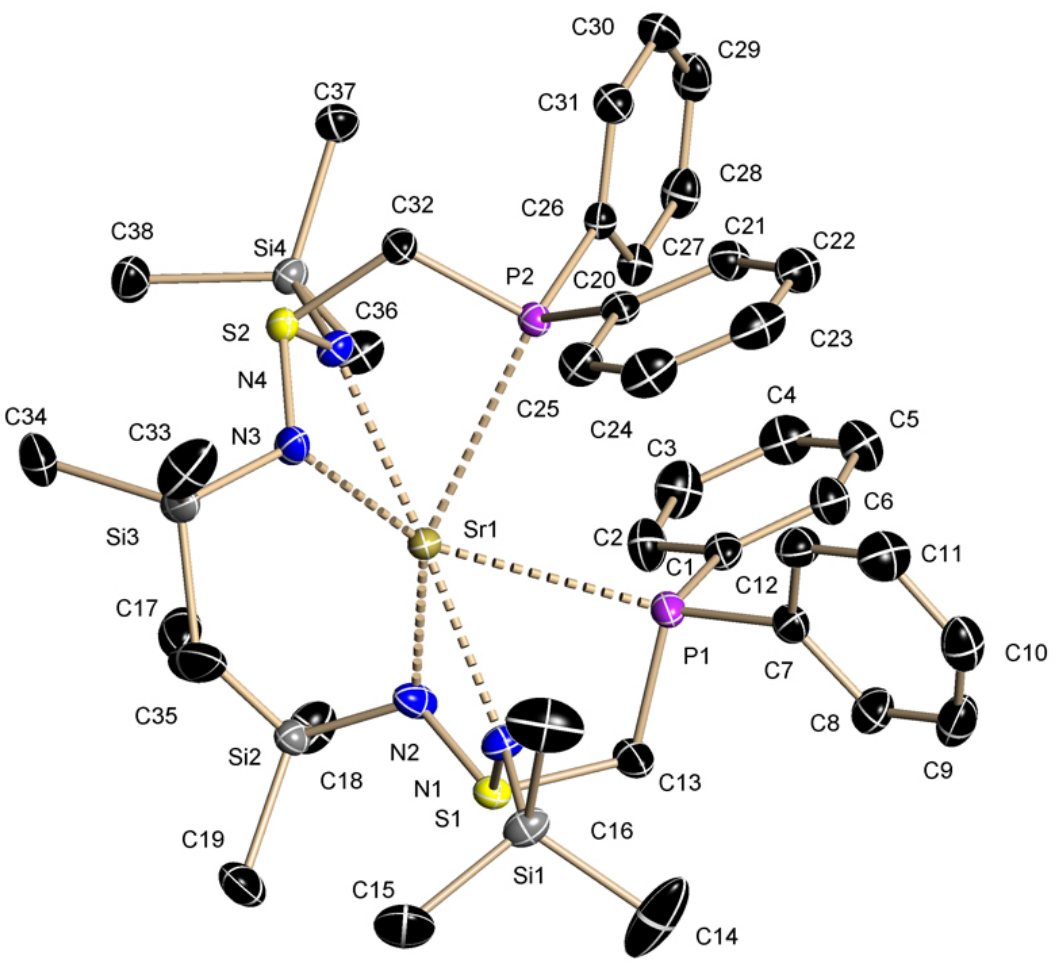

Asymmetric unit of 29. The anisotropic displacement parameters are shown at the $50 \%$ probability level, hydrogen atoms are omitted for clarity.

\begin{tabular}{|c|c|c|c|}
\hline identification code & MMP266 & $F(000)$ & 1888 \\
\hline empirical formula & $\mathrm{C}_{38} \mathrm{H}_{60} \mathrm{~N}_{4} \mathrm{P}_{2} \mathrm{~S}_{2} \mathrm{Si}_{4} \mathrm{Sr}$ & max./min. transmission & $0.9422 / 0.8426$ \\
\hline molecular weight $[\mathrm{g} / \mathrm{mol}]$ & 898.94 & $\theta$ range $\left[{ }^{\circ}\right]$ & $1.34-26.77$ \\
\hline crystal size $[\mathrm{mm}]$ & $0.2 \times 0.15 \times 0.1$ & completeness to $\theta_{\max }$ & 0.999 \\
\hline temperature $[\mathrm{K}]$ & $100(2)$ & reflections collected & 120179 \\
\hline crystal system & orthorhombic & independent reflections & 10269 \\
\hline space group & $P 2{ }_{1}{ }_{1} 2_{1}$ & $R_{\text {int }} / R_{\sigma}$ & $0.0262 / 0.0105$ \\
\hline$a[\AA]$ & $10.4329(17)$ & restraints/parameters & $0 / 472$ \\
\hline$b[\AA]$ & $20.842(3)$ & GoF & 1.053 \\
\hline$c[\AA]$ & $22.140(4)$ & $R 1$ (all data) & 0.0181 \\
\hline$V\left[\AA^{3}\right]$ & $4814.3(13)$ & $R 1(1>2 \sigma(I))$ & 0.0173 \\
\hline$Z$ & 4 & $w R 2$ (all data) & 0.0445 \\
\hline$\rho_{\text {calc }}\left[\mathrm{g} \mathrm{cm}^{-3}\right]$ & 1.240 & $w R 2(I>2 \sigma(I))$ & 0.0442 \\
\hline$\mu\left[\mathrm{mm}^{-1}\right]$ & 1.402 & diff. peak/hole $\left[\mathrm{e} \AA^{-3}\right]$ & $0.255 /-0.142$ \\
\hline Flack-x-parameter & $0.066(2)$ & $g 1 / g 2$ & $0.0232 / 1.356$ \\
\hline
\end{tabular}




\subsubsection{9 $\left[\mathrm{Co}\left\{\mathrm{Ph}_{2} \mathrm{PCH}_{2} \mathrm{~S}\left(\mathrm{NSiMe}_{3}\right)_{2}\right\}_{2}\right](30)$}

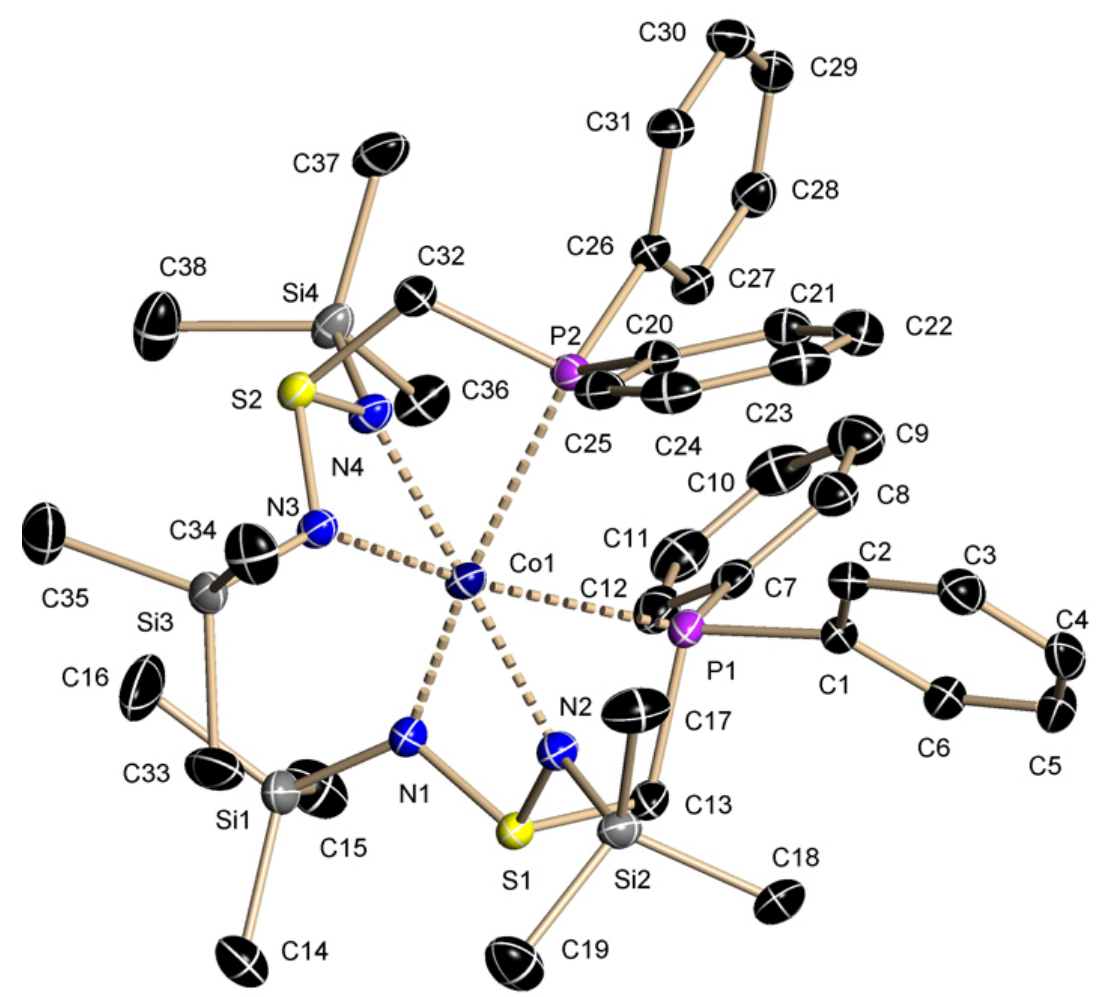

Asymmetric unit of 30. The anisotropic displacement parameters are shown at the $50 \%$ probability level, hydrogen atoms are omitted for clarity. The compound crystallises as a racemic twin with BASF values of 83 and $17 \%$, respectively.

\begin{tabular}{ll|ll}
\hline identification code & MMP266 & $F(000)$ & 1844 \\
empirical formula & $\mathrm{C}_{38} \mathrm{H}_{60} \mathrm{CoN}_{4} \mathrm{P}_{2} \mathrm{~S}_{2} \mathrm{Si}_{4}$ & max./min. transmission & $0.9422 / 0.8969$ \\
molecular weight $[\mathrm{g} / \mathrm{mol}]$ & 870.25 & $\theta$ range $\left[^{\circ}\right]$ & $1.82-28.29$ \\
crystal size $[\mathrm{mm}]$ & $0.2 \times 0.1 \times 0.02$ & completeness to $\theta_{\max }$ & 0.999 \\
temperature $[\mathrm{K}]$ & $100(2)$ & reflections collected & 95693 \\
crystal system & orthorhombic & independent reflections & 11283 \\
space group & $P$ na2 ${ }_{1}$ & $R_{\text {int }} / R_{\sigma}$ & $0.0385 / 0.0231$ \\
$a[\AA]$ & $22.4210(17)$ & restraints/parameters & $1 / 473$ \\
$b[\AA]$ & $10.7606(8)$ & GoF & 1.047 \\
$c[\AA]$ & $18.8363(14)$ & $R 1($ all data $)$ & 0.0275 \\
$V\left[\AA^{3}\right]$ & $4544.5(6)$ & $R 1(I>2 \sigma(I))$ & 0.0244 \\
$Z$ & 4 & $w R 2($ all data $)$ & 0.0602 \\
$\rho_{\text {calc }}\left[\mathrm{g} \mathrm{cm}{ }^{-3}\right]$ & 1.272 & $w R 2(I>2 \sigma(I))$ & 0.0584 \\
$\mu\left[\mathrm{mm}^{-1}\right]$ & 0.677 & diff. peak/hole $\left[\mathrm{e} \AA^{-3}\right]$ & $0.236 /-0.195$ \\
Flack-x-parameter & $0.170(7)$ & g1/g2 & $0.0284 / 1.288$ \\
\hline
\end{tabular}




\subsubsection{0 $\left[\mathrm{Fe}\left\{\mathrm{Ph}_{2} \mathrm{PCH}_{2} \mathrm{~S}\left(\mathrm{NSiMe}_{3}\right)_{2}\right\}_{2}\right](31)$}

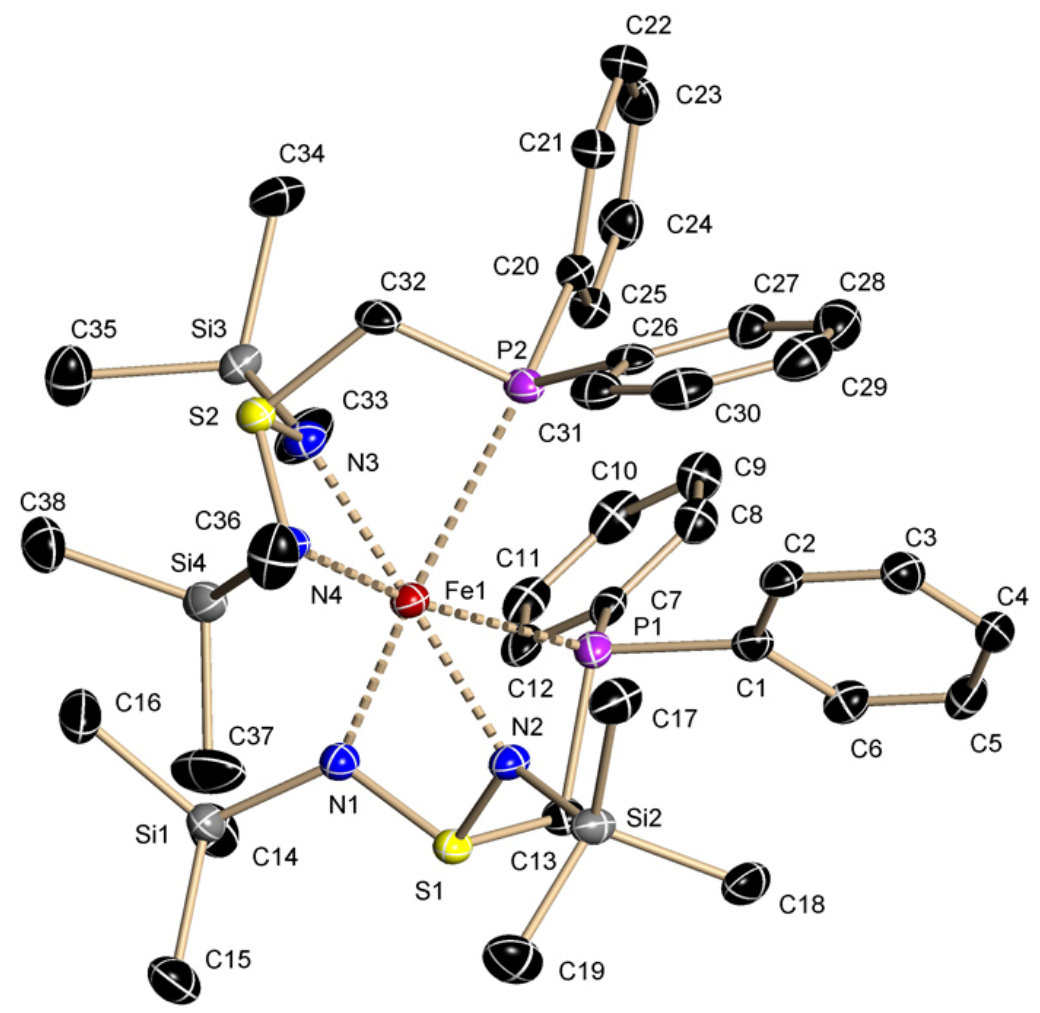

Asymmetric unit of 31. The anisotropic displacement parameters are shown at the $50 \%$ probability level, hydrogen atoms are omitted for clarity. The compound crystallises as a racemic twin with BASF values of 51 and $49 \%$, respectively. The Flack-x-parameter could not be determined.

\begin{tabular}{ll|ll}
\hline identification code & MMPEK23 & $F(000)$ & 1840 \\
empirical formula & $\mathrm{C}_{38} \mathrm{H}_{60} \mathrm{FeN}_{4} \mathrm{P}_{2} \mathrm{~S}_{2} \mathrm{Si}_{4}$ & max./min. transmission & $0.9422 / 0.8288$ \\
molecular weight $[\mathrm{g} / \mathrm{mol}]$ & 867.17 & $\theta$ range $\left.{ }^{\circ}\right]$ & $1.81-25.51$ \\
crystal size $[\mathrm{mm}]$ & $0.2 \times 0.1 \times 0.01$ & completeness to $\theta_{\max }$ & 0.974 \\
temperature $[\mathrm{K}]$ & $100(2)$ & reflections collected & 82204 \\
crystal system & orthorhombic & independent reflections & 8158 \\
space group & $P n a 2_{1}$ & $R_{\text {int }} / R_{\sigma}$ & $0.0423 / 0.0228$ \\
$a[\AA]$ & restraints/parameters & $1 / 473$ \\
$b[\AA]$ & $22.445(2)$ & GoF & 1.013 \\
$c[\AA]$ & $10.7778(10)$ & $R 1($ all data $)$ & 0.0256 \\
$V\left[\AA^{3}\right]$ & $18.8861(18)$ & $R 1(/>2 \sigma(I))$ & 0.0243 \\
$Z$ & $4568.8(7)$ & $w R 2($ all data) & 0.0621 \\
$\rho_{\text {calc }}\left[\mathrm{g} \mathrm{cm}^{-3}\right]$ & 4 & $w R 2(/>2 \sigma(I))$ & 0.0612 \\
$\mu\left[\mathrm{mm}^{-1}\right]$ & 1.261 & diff. peak/hole $\left[\mathrm{e} \AA^{-3}\right]$ & $0.453 /-0.244$ \\
& 0.627 & $\mathrm{~g} 1 / \mathrm{g} 2$ & $0.037 / 1.918$ \\
\hline
\end{tabular}




\subsubsection{1 $\left[\left\{\mathrm{FeN}\left(\mathrm{SiMe}_{3}\right)_{2}\right\}\left\{\mathrm{Li}\left(\mathrm{NSiMe}_{3}\right)_{2} \mathrm{SCHP}(\mathrm{O}) \mathrm{Ph}_{2}\right\}(\mathrm{LiO})\right]_{2}(32)$}

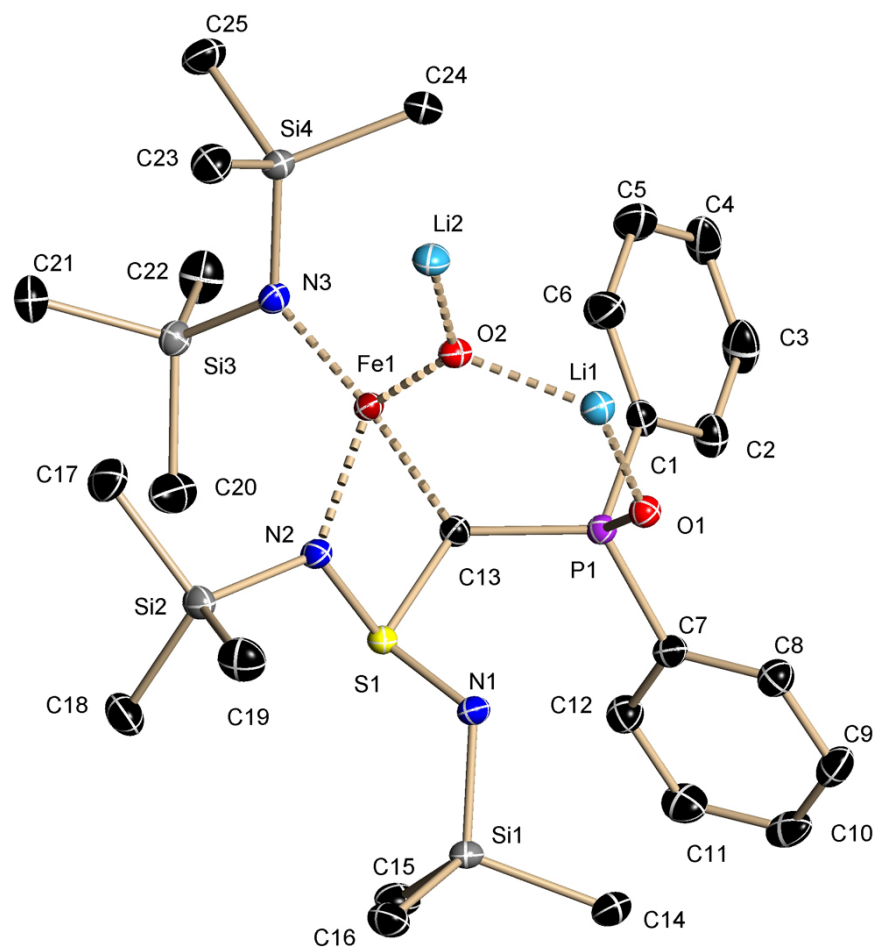

Asymmetric unit of 32. The anisotropic displacement parameters are shown at the $50 \%$ probability level, hydrogen atoms are omitted for clarity.

\begin{tabular}{|c|c|c|c|}
\hline identification code & MMPEK23_rot & $\mu\left[\mathrm{mm}^{-1}\right]$ & 0.688 \\
\hline empirical formula & $\mathrm{C}_{50} \mathrm{H}_{94} \mathrm{Fe}_{2} \mathrm{Li}_{4} \mathrm{~N}_{6} \mathrm{O}_{4} \mathrm{P}_{2} \mathrm{~S}_{2} \mathrm{Si}_{8}$ & $F(000)$ & 706 \\
\hline molecular weight $[\mathrm{g} / \mathrm{mol}]$ & 1333.57 & max./min. transmission & $0.9893 / 0.9409$ \\
\hline crystal size $[\mathrm{mm}]$ & $0.24 \times 0.2 \times 0.01$ & $\theta$ range $\left[{ }^{\circ}\right]$ & $1.59-26.77$ \\
\hline temperature $[\mathrm{K}]$ & $100(2)$ & completeness to $\theta_{\max }$ & 0.998 \\
\hline crystal system & triclinic & reflections collected & 33831 \\
\hline space group & $P \overline{1}$ & independent reflections & 7543 \\
\hline$a[\AA]]$ & $11.7823(13)$ & $R_{\text {int }} / R_{\sigma}$ & $0.0201 / 0.0153$ \\
\hline$b[\AA]$ & $12.6677(14)$ & restraints/parameters & $0 / 364$ \\
\hline$c[\AA]$ & $14.2318(16)$ & GoF & 1.047 \\
\hline$\alpha\left[^{\circ}\right]$ & $71.7790(10)$ & $R 1$ (all data) & 0.0246 \\
\hline$\beta\left[^{\circ}\right]$ & $66.2720(10)$ & $R 1(1>2 \sigma(I))$ & 0.0237 \\
\hline$V\left[^{\circ}\right]$ & $68.8660(10)$ & $w R 2$ (all data) & 0.0642 \\
\hline$V\left[\AA^{3}\right]$ & $1778.5(3)$ & $w R 2(I>2 \sigma(I))$ & 0.0627 \\
\hline Z & 1 & diff. peak/hole $\left[\mathrm{e} \AA^{-3}\right]$ & $0.404 /-0.249$ \\
\hline$\rho_{\text {calc }}\left[\mathrm{g} \mathrm{cm}^{-3}\right]$ & 1.245 & $g 1 / g 2$ & $0.0288 / 1.0845$ \\
\hline
\end{tabular}




\subsubsection{2 $\left[\left\{\mathrm{Cu}\left(\mathrm{Me}_{2} \mathrm{PCH}_{2} \mathrm{~S}\left(\mathrm{NSiMe}_{3}\right)_{2}\right)\right\}_{4}\left(\mathrm{Cu}_{2} \mathrm{~S}\right)_{4}\right](33)$}

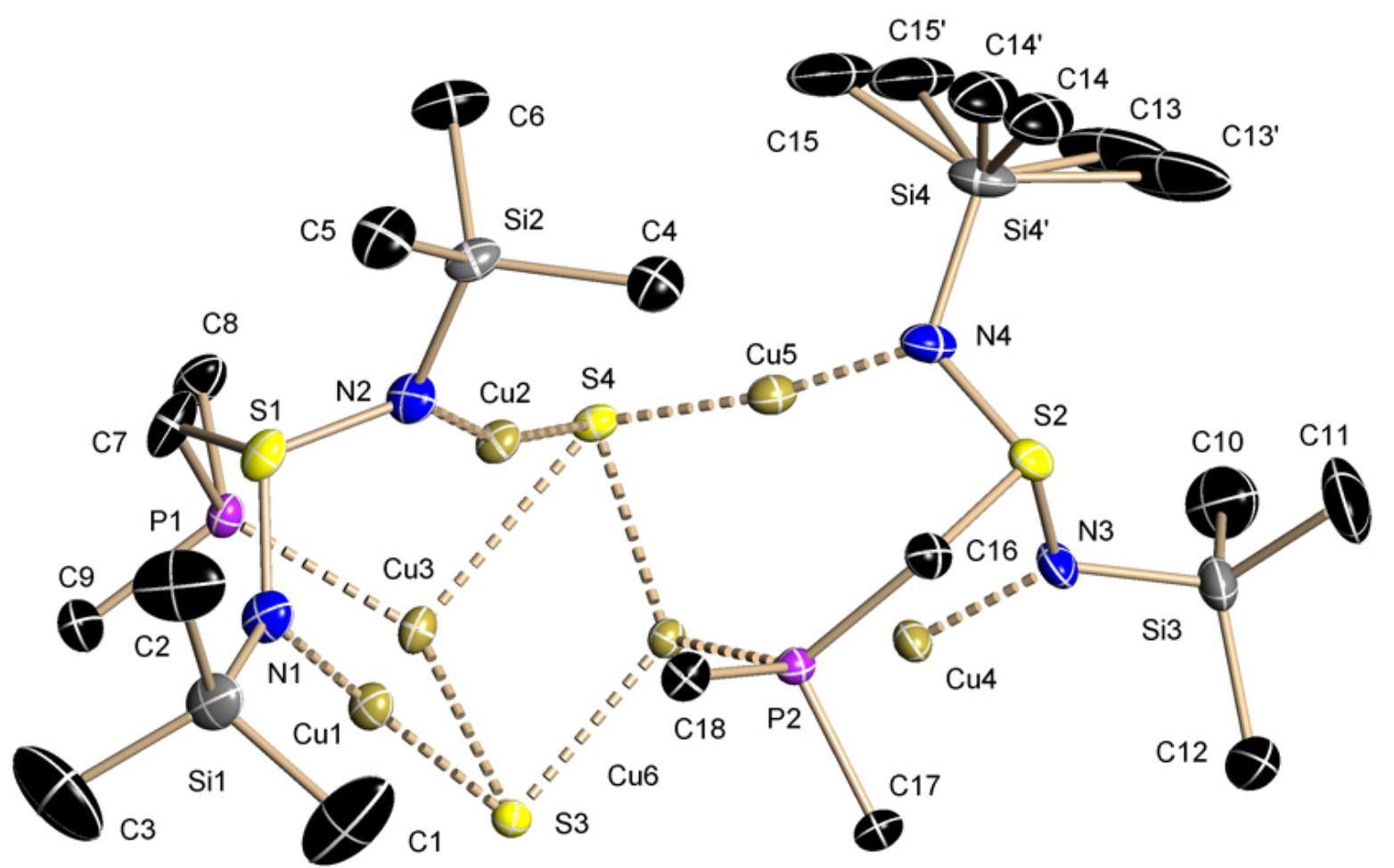

Asymmetric unit of 33. The anisotropic displacement parameters are shown at the $50 \%$ probability level, hydrogen atoms are omitted for clarity. The $\mathrm{NSiMe}_{3}$ group on $\mathrm{N} 4$ is disordered and was refined using SAME. The occupancy factors refine to 86 and $14 \%$, respectively.

\begin{tabular}{ll|ll}
\hline identification code & MMP236 & $F(000)$ & 4096 \\
empirical formula & $\mathrm{C}_{36} \mathrm{H}_{104} \mathrm{Cu}_{12} \mathrm{~N}_{8} \mathrm{P}_{4} \mathrm{~S}_{8} \mathrm{Si}_{8}$ & max./min. transmission & $0.9422 / 0.8205$ \\
molecular weight $[\mathrm{g} / \mathrm{mol}]$ & 2016.83 & $\theta$ range $\left[^{\circ}\right]$ & $1.42-26.37$ \\
crystal size $[\mathrm{mm}]$ & $0.18 \times 0.1 \times 0.02$ & completeness to $\theta_{\max }$ & 0.999 \\
temperature $[\mathrm{K}]$ & $100(2)$ & reflections collected & 40145 \\
crystal system & Monoclinic & independent reflections & 8166 \\
space group & $C 2 / c$ & $R_{\text {int }} / R_{\sigma}$ & $0.0393 / 0.0137$ \\
$a[\AA]$ & restraints/parameters & $9 / 372$ \\
$b[\AA]]$ & GoF & 1.020 \\
$c[\AA]$ & $91.087(3)$ & $R 1($ all data $)$ & 0.0236 \\
$\beta\left[^{\circ}\right]$ & $29.451(3)$ & $R 1(/>2 \sigma(I))$ & 0.0199 \\
$V\left[\AA^{3}\right]$ & $112.4610(10)$ & $w R 2($ all data) & 0.0499 \\
$Z$ & $7981.4(12)$ & $w R 2(>2 \sigma(I))$ & 0.0482 \\
$\rho_{\text {calc }}\left[\mathrm{g} \mathrm{cm}^{-3}\right]$ & 4 & diff. peak/hole $\left[\mathrm{e} \AA^{-3}\right]$ & $0.668 /-0.603$ \\
$\mu\left[\mathrm{mm}^{-1}\right]$ & 1.678 & $\mathrm{~g} 1 / \mathrm{g} 2$ & $0.0217 / 18.5376$ \\
\hline
\end{tabular}




\subsubsection{3 [(tmeda)Rb $\left.\left\{\mathrm{Ph}_{2} \mathrm{PCH}_{2} \mathrm{~S}\left(\mathrm{NSiMe}_{3}\right)_{2}\right\}_{2} \mathrm{Li}\right](34)$}

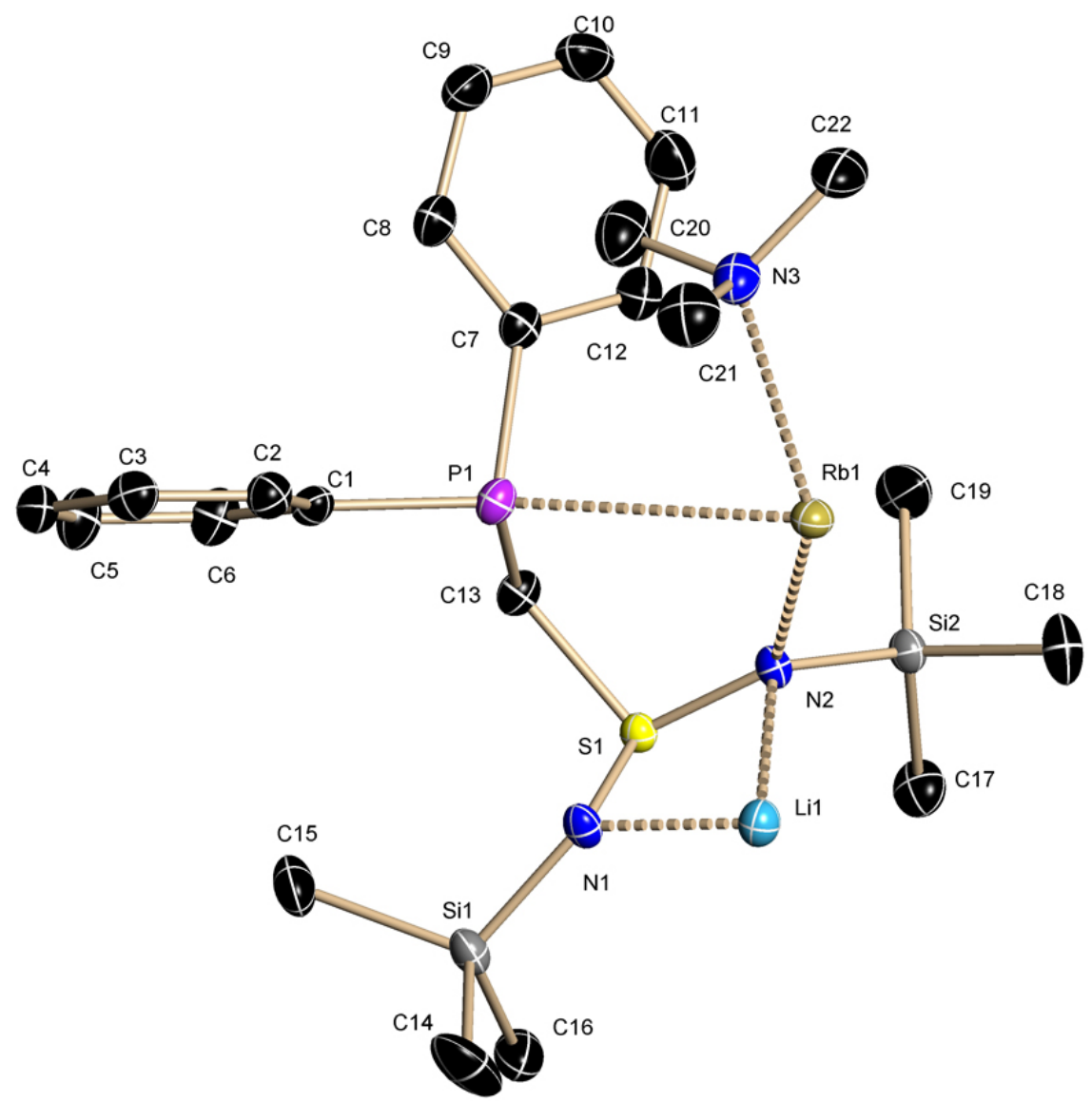

Asymmetric unit of 34. The anisotropic displacement parameters are shown at the $50 \%$ probability level, hydrogen atoms are omitted for clarity.

\begin{tabular}{|c|c|c|c|}
\hline identification code & MMP276 & $F(000)$ & 2160 \\
\hline empirical formula & $\mathrm{C}_{44} \mathrm{H}_{76} \mathrm{LiN}_{6} \mathrm{P}_{2} \mathrm{RbS}_{2} \mathrm{Si}_{4}$ & max./min. transmission & $0.942 / 0.8952$ \\
\hline molecular weight $[\mathrm{g} / \mathrm{mol}]$ & 1019.94 & $\theta$ range $\left[{ }^{\circ}\right]$ & $1.81-26.02$ \\
\hline crystal size $[\mathrm{mm}]$ & $0.2 \times 0.15 \times 0.1$ & completeness to $\theta_{\max }$ & 0.999 \\
\hline temperature $[\mathrm{K}]$ & $100(2)$ & reflections collected & 40145 \\
\hline crystal system & monoclinic & independent reflections & 5449 \\
\hline space group & $C 2 / c$ & $R_{\text {int }} / R_{\sigma}$ & $0.0393 / 0.0245$ \\
\hline$a[\AA]$ & $18.0553(17)$ & restraints/parameters & $0 / 280$ \\
\hline$b[\AA]$ & $13.6709(13)$ & GoF & 1.036 \\
\hline$c[\AA]$ & $22.639(2)$ & $R 1$ (all data) & 0.0361 \\
\hline$\beta\left[^{\circ}\right]$ & $97.149(2)$ & $R 1(I>2 \sigma(I))$ & 0.0281 \\
\hline$V\left[\AA^{3}\right]$ & $5544.6(9)$ & $w R 2$ (all data) & 0.0641 \\
\hline$Z$ & 4 & $w R 2(1>2 \sigma(I))$ & 0.0612 \\
\hline$\rho_{\text {calc }}\left[\mathrm{g} \mathrm{cm}^{-3}\right]$ & 1.222 & diff. peak/hole $\left[\mathrm{e}^{-3}\right]$ & $0.536 /-0.241$ \\
\hline$\mu\left[\mathrm{mm}^{-1}\right]$ & 1.147 & $g 1 / g 2$ & $0.0236 / 8.3289$ \\
\hline
\end{tabular}




\subsubsection{4 [(tmeda) $\left.K\left\{\mathrm{Ph}_{2} \mathrm{PCH}_{2} \mathrm{~S}\left(\mathrm{NSiMe}_{3}\right)_{2}\right\}_{2} \mathrm{Li}\right](35)$}

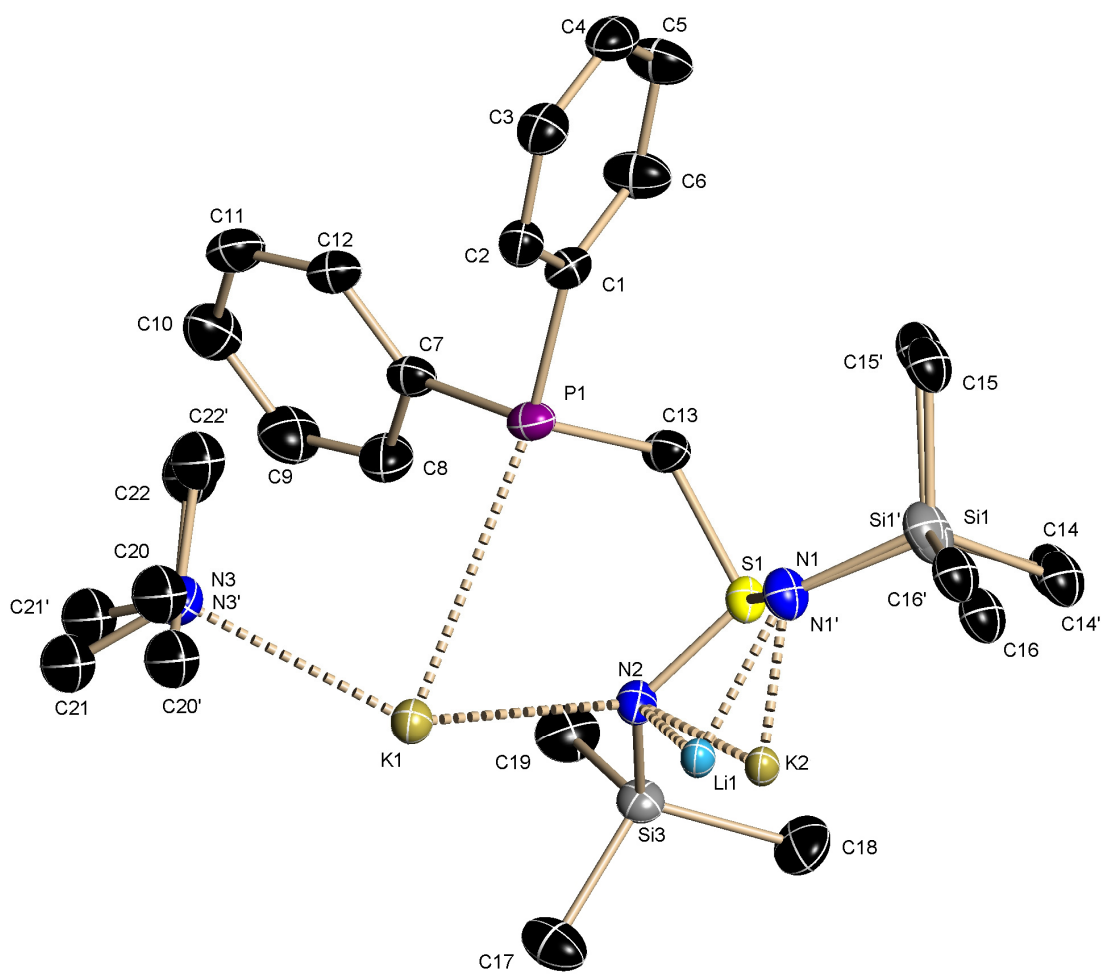

Asymmetric unit of 35 . The anisotropic displacement parameters are shown at the $50 \%$ probability level, hydrogen atoms are omitted for clarity. The TMEDA molecule is disorder over two sites with occupancy factors of 83 and $17 \%$, respectively. One $\mathrm{SiMe}_{3}$ group is disordered with occupancy factors of 50 and $50 \%$. The lithium cation is disordered with potassium with occupancy factors of 94 and $6 \%$, respectively. Because of insufficient crystal quality, the data is not satisfying. However, the unit cell presented here is the best solution.

\begin{tabular}{ll|ll}
\hline identification code & MMPEK26 & $F(000)$ & 2092 \\
empirical formula & $\mathrm{C}_{44} \mathrm{H}_{76} \mathrm{~K}_{1.06} \mathrm{Li}_{0.94} \mathrm{~N}_{6} \mathrm{P}_{2} \mathrm{~S}_{2} \mathrm{Si}_{4}$ & max./min. transmission & $0.9422 / 0.8605$ \\
molecular weight $[\mathrm{g} / \mathrm{mol}]$ & 975.50 & $\theta$ range $\left[^{\circ}\right]$ & $1.80-25.68$ \\
crystal size $[\mathrm{mm}]$ & $0.1 \times 0.1 \times 0.02$ & completeness to $\theta_{\text {max }}$ & 1.000 \\
temperature $[\mathrm{K}]$ & $100(2)$ & reflections collected & 39141 \\
crystal system & monoclinic & independent reflections & 5267 \\
space group & $C 2 / c$ & $R_{\text {int }} / R_{\sigma}$ & $0.0389 / 0.0228$ \\
$a[\AA]$ & $18.2492(11)$ & restraints/parameters & $10 / 280$ \\
$b[\AA]]$ & $13.4012(8)$ & GoF & 1.066 \\
$c[\AA]$ & $22.8301(14)$ & $R 1($ all data $)$ & 0.0585 \\
$\beta\left[^{\circ}\right]$ & $96.4140(10)$ & $w R 2($ all data $)$ & 0.0495 \\
$V\left[\AA^{3}\right]$ & $5548.4(6)$ & $w R 2(I>2 \sigma(I))$ & 0.1199 \\
$Z$ & 4 & diff. peak/hole $\left[\mathrm{e} \AA^{-3}\right]$ & 0.1146 \\
$\rho_{\text {calc }}\left[\mathrm{g} \mathrm{cm}{ }^{-3}\right]$ & 1.168 & g1/g2 & $1.470 /-0.691$ \\
$\mu\left[\mathrm{mm}^{-1}\right]$ & 0.354 & & $0.0438 / 19.8298$ \\
\hline
\end{tabular}




\subsubsection{5 $\left[\mathrm{Ph}_{2} \mathrm{PCSN}(\mathrm{H}) t \mathrm{Bu}\right]_{2}$}

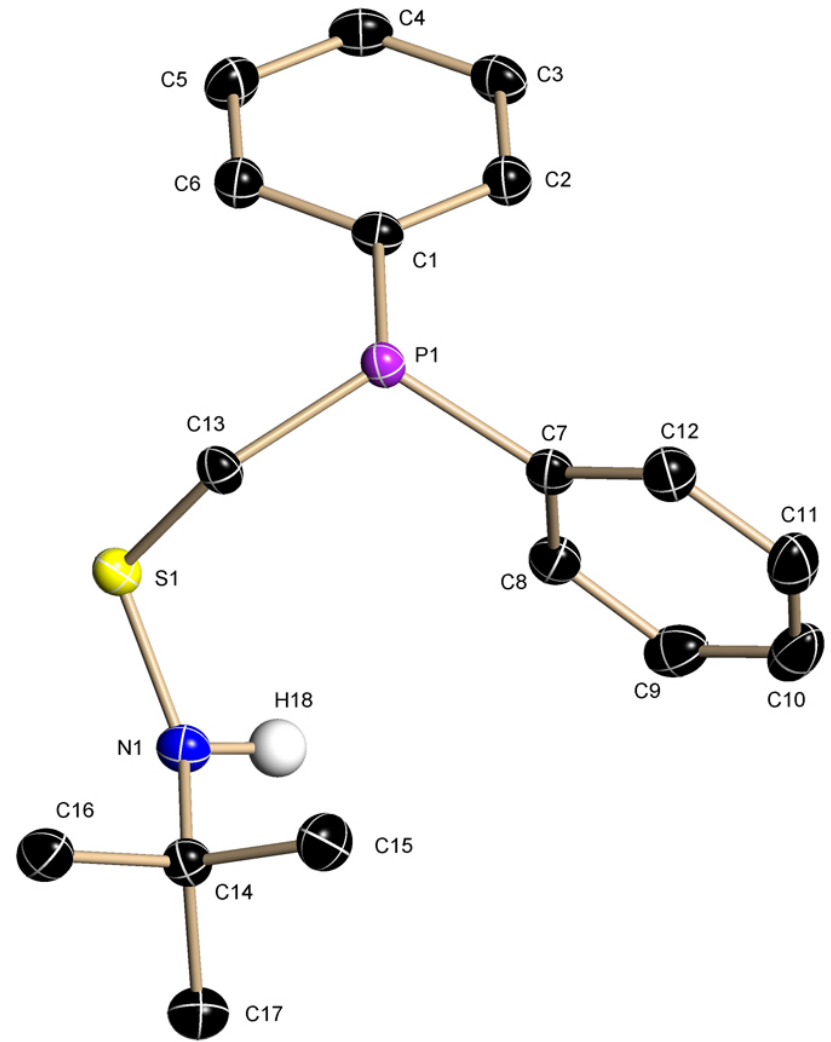

Asymmetric unit of $\left[\mathrm{Ph}_{2} \mathrm{PCSN}(\mathrm{H}) t \mathrm{Bu}\right]_{2}$. The anisotropic displacement parameters are shown at the $50 \%$ probability level, hydrogen atoms are omitted for clarity except for $\mathrm{H} 18$ which was freely refined using distance restraints.

\begin{tabular}{|c|c|c|c|}
\hline identification code & Falter & $\mu\left[\mathrm{mm}^{-1}\right]$ & 0.300 \\
\hline empirical formula & $\mathrm{C}_{34} \mathrm{H}_{40} \mathrm{~N}_{2} \mathrm{P}_{2} \mathrm{~S}_{2}$ & $F(000)$ & 320 \\
\hline molecular weight $[\mathrm{g} / \mathrm{mol}]$ & 602.74 & max./min. transmission & $0.9800 / 0.8349$ \\
\hline crystal size $[\mathrm{mm}]$ & $0.15 \times 0.08 \times 0.06$ & $\theta$ range $\left[{ }^{\circ}\right]$ & $2.11-26.80$ \\
\hline temperature $[\mathrm{K}]$ & $100(2)$ & completeness to $\theta_{\max }$ & 0.997 \\
\hline crystal system & triclinic & reflections collected & 23572 \\
\hline space group & $P \overline{1}$ & independent reflections & 3318 \\
\hline$a[\AA]$ & $9.4276(14)$ & $R_{\text {int }} / R_{\sigma}$ & $0.0496 / 0.0295$ \\
\hline$b[\AA]$ & $9.7367(14)$ & restraints/parameters & $1 / 203$ \\
\hline$c[\AA]$ & $10.5340(15)$ & GoF & 1.027 \\
\hline$\alpha\left[^{\circ}\right]$ & $68.924(2)$ & $R 1$ (all data) & 0.0538 \\
\hline$\beta\left[^{\circ}\right]$ & $89.615(2)$ & $R 1(1>2 \sigma(I))$ & 0.0389 \\
\hline$V\left[^{\circ}\right]$ & $61.767(2)$ & $w R 2$ (all data) & 0.1031 \\
\hline$V\left[\AA^{3}\right]$ & $779.1(2)$ & $w R 2(I>2 \sigma(I))$ & 0.0984 \\
\hline Z & 1 & diff. peak/hole $\left[\mathrm{e} \AA^{-3}\right]$ & $0.413 /-0.392$ \\
\hline$\rho_{\text {calc }}\left[\mathrm{g} \mathrm{cm}^{-3}\right]$ & 1.285 & $g 1 / g 2$ & $0.0455 / 0.5364$ \\
\hline
\end{tabular}




\subsubsection{MMP40}

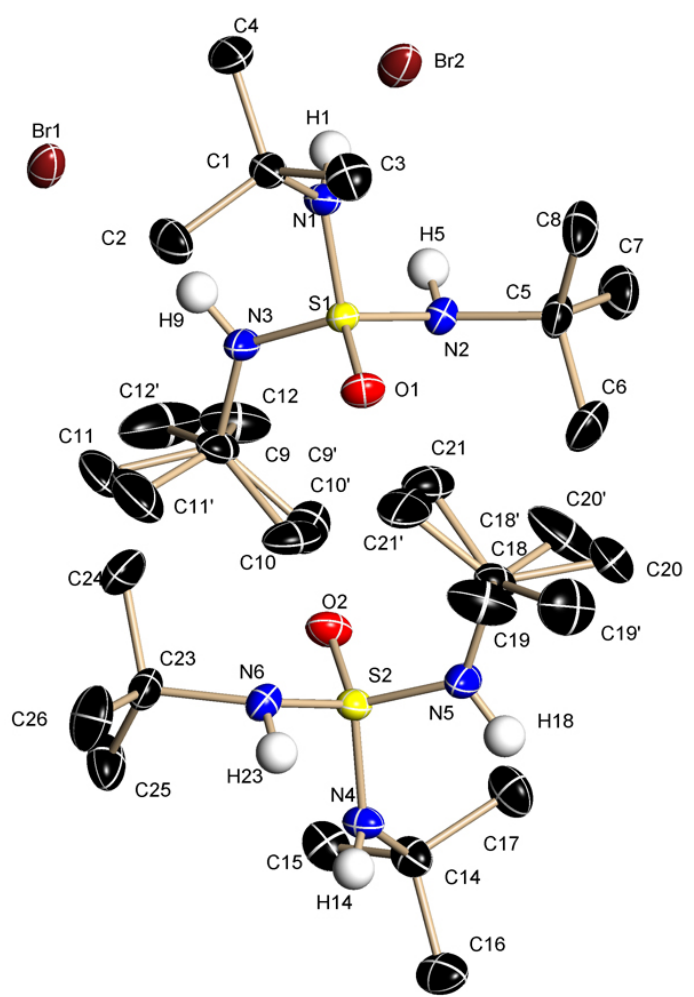

Asymmetric unit of MMP40. The anisotropic displacement parameters are shown at the $50 \%$ probability level, hydrogen atoms are omitted for clarity except for $\mathrm{H} 1, \mathrm{H} 5, \mathrm{H} 9, \mathrm{H} 14, \mathrm{H} 18$ and $\mathrm{H} 23$

which were freely refined using distance restraints. The tBu group on N3 is disordered with occupancy factors of 72 and $28 \%$, respectively. The tBu group on N5 is disordered with occupancy factors of 81 and $19 \%$, respectively. Both were refined using SAME, EADP and EXYZ.

\begin{tabular}{ll|ll}
\hline identification code & Smarties & $F(000)$ & 1456 \\
empirical formula & $\mathrm{C}_{12} \mathrm{H}_{30} \mathrm{BrN}_{3} \mathrm{OS}$ & max./min. transmission & $0.9703 / 0.7969$ \\
molecular weight $[\mathrm{g} / \mathrm{mol}]$ & 344.36 & $\theta$ range $\left[^{\circ}\right]$ & $1.72-27.10$ \\
crystal size $[\mathrm{mm}]$ & $0.2 \times 0.2 \times 0.1$ & completeness to $\theta_{\max }$ & 0.999 \\
temperature $[\mathrm{K}]$ & $100(2)$ & reflections collected & 93217 \\
crystal system & monoclinic & independent reflections & 7874 \\
space group & $P 21 / c$ & $R_{\text {int }} / R_{\sigma}$ & $0.0346 / 0.0147$ \\
$a[\AA]$ & $12.3613(7)$ & restraints/parameters & $18 / 429$ \\
$b[\AA]$ & $19.2447(12)$ & GoF & 1.034 \\
$c[\AA]$ & $16.0995(10)$ & $R 1($ all data) & 0.0265 \\
$\beta\left[^{\circ}\right]$ & $111.2920(10)$ & $R 1(/>2 \sigma(I))$ & 0.0234 \\
$V\left[\AA^{3}\right]$ & $3568.5(4)$ & $w R 2($ all data) & 0.0594 \\
$Z$ & 8 & $w R 2(/>2 \sigma(I))$ & 0.0582 \\
$\rho_{\text {calc }}\left[\mathrm{g} \mathrm{cm}^{-3}\right]$ & 1.282 & diff. peak/hole $\left[\mathrm{e} \AA^{-3}\right]$ & $0.573 /-0.343$ \\
$\mu\left[\mathrm{mm}^{-1}\right]$ & 2.417 & g1/g2 & $0.0299 / 1.504$ \\
\hline
\end{tabular}




\subsection{Service Structures}

\subsection{1 $\quad \mathrm{C}_{9} \mathrm{H}_{8} \mathrm{O}_{5}(\mathrm{MMPHB} 01)$}

This structure was a service measurement for the group of Prof. Tietze. ${ }^{[26]}$

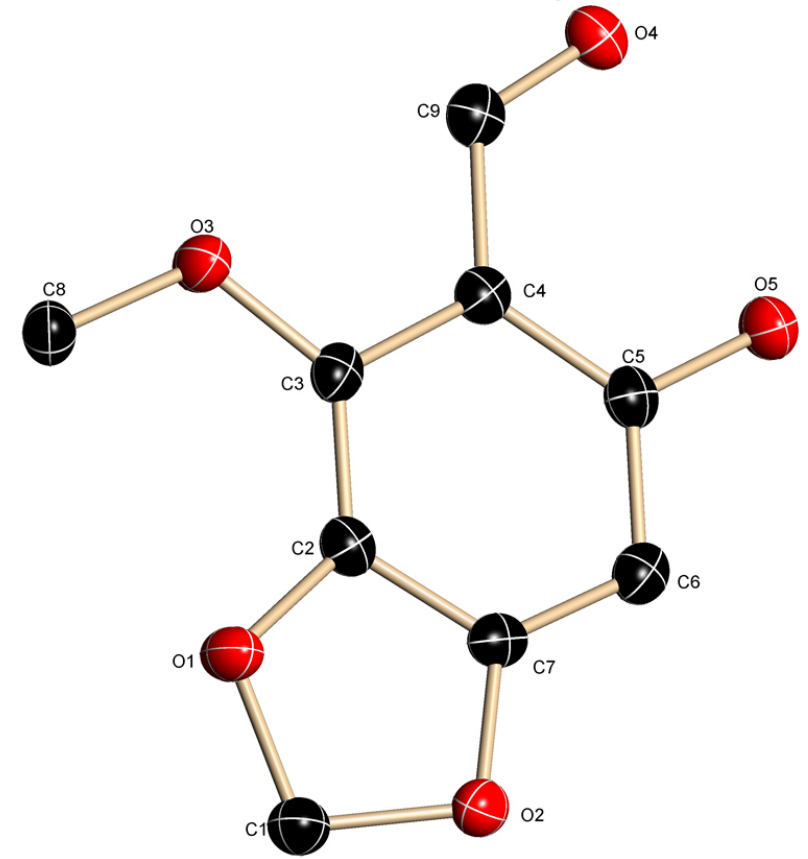

Asymmetric unit of $\mathrm{C}_{9} \mathrm{H}_{8} \mathrm{O}_{5}$. The anisotropic displacement parameters are shown at the $50 \%$ probability level, hydrogen atoms are omitted for clarity except for $\mathrm{H} 5$ which was freely refined using distance restraints.

\begin{tabular}{ll|ll}
\hline identification code & Zicke & $F(000)$ & 408 \\
empirical formula & $\mathrm{C}_{9} \mathrm{H}_{8} \mathrm{O}_{5}$ & max./min. transmission & $0.9422 / 0.7780$ \\
molecular weight $[\mathrm{g} / \mathrm{mol}]$ & 196.15 & $\theta$ range $\left[^{\circ}\right]$ & $2.04-25.34$ \\
crystal size $[\mathrm{mm}]$ & $0.2 \times 0.14 \times 0.01$ & completeness to $\theta_{\text {max }}$ & 0.996 \\
temperature $[\mathrm{K}]$ & $100(2)$ & reflections collected & 9944 \\
crystal system & monoclinic & independent reflections & 1439 \\
space group & $P 2_{1} / c$ & $R_{\text {int }} / R_{\sigma}$ & $0.0469 / 0.0299$ \\
$a[\AA]$ & $3.8332(14)$ & restraints/parameters & $0 / 129$ \\
$b[\AA]]$ & $12.639(5)$ & GoF & 1.035 \\
$c[\AA]]$ & $16.337(6)$ & $R 1($ all data $)$ & 0.0564 \\
$\beta\left[^{\circ}\right]$ & $96.283(7)$ & $R 1(>2 \sigma(I))$ & 0.0363 \\
$V\left[\AA^{3}\right]$ & $786.7(5)$ & $w R 2($ all data) & 0.0974 \\
$Z$ & 4 & $w R 2(1>2 \sigma(I))$ & 0.0892 \\
$\rho_{\text {calc }}\left[\mathrm{g} \mathrm{cm}^{-3}\right]$ & 1.656 & diff. peak/hole $\left[\mathrm{e} \AA^{-3}\right]$ & $0.189 /-0.188$ \\
$\mu\left[\mathrm{mm}^{-1}\right]$ & 0.138 & $\mathrm{~g} 1 / \mathrm{g} 2$ & $0.0473 / 0.3526$ \\
\hline
\end{tabular}




\subsubsection{HWOA019}

This was measured for $\mathrm{H}$. Wolf from our own group.

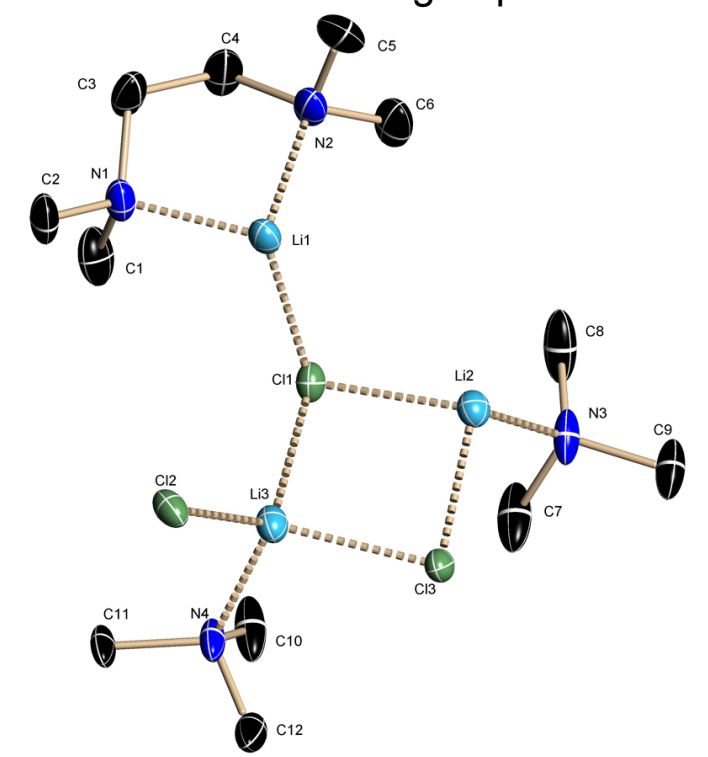

Asymmetric unit of HWOA019. The anisotropic displacement parameters are shown at the $50 \%$ probability level, hydrogen atoms are omitted for clarity.

\begin{tabular}{ll|ll}
\hline identification code & HWOA019 & $\mu\left[\mathrm{mm}^{-1}\right]$ & 0.441 \\
empirical formula & $\mathrm{C}_{12} \mathrm{H}_{32} \mathrm{Cl}_{3} \mathrm{Li}_{3} \mathrm{~N}_{4}$ & $F(000)$ & 384 \\
molecular weight $[\mathrm{g} / \mathrm{mol}]$ & 359.59 & max./min. transmission & $0.9422 / 0.8765$ \\
crystal size $[\mathrm{mm}]$ & $0.2 \times 0.2 \times 0.1$ & $\theta$ range $\left[^{\circ}\right]$ & $2.09-26.37$ \\
temperature $[\mathrm{K}]$ & $100(2)$ & completeness to $\theta_{\max }$ & 0.997 \\
crystal system & triclinic & reflections collected & 18917 \\
space group & $P \overline{1}$ & independent reflections & 4202 \\
$a[\AA]$ & $10.7463(8)$ & $R_{\text {int }} / R_{\sigma}$ & 0.0294 \\
$b[\AA]$ & restraints/parameters & 0.0230 \\
$c[\AA]$ & $11.1086(8)$ & GoF & 1.249 \\
$\alpha\left[^{\circ}\right]$ & $11.1472(9)$ & $R 1($ all data $)$ & 0.0455 \\
$\beta\left[^{\circ}\right]$ & $61.1730(10)$ & $R 1(>2 \sigma(I))$ & 0.0328 \\
$V\left[^{\circ}\right]$ & $74.626(2)$ & $w R 2($ all data $)$ & 0.1124 \\
$V\left[\AA^{3}\right]$ & $62.4420(10)$ & $w R 2(I>2 \sigma(I))$ & 0.0967 \\
$Z$ & $1032.03(14)$ & diff. peak/hole $\left[\mathrm{e} \AA^{-3}\right]$ & $0.357 /-0.266$ \\
$\rho_{\text {calc }}\left[{ }^{\circ} \mathrm{cm}^{-3}\right]$ & 2 & g1/g2 & $0.0651 / 0.2132$ \\
\hline
\end{tabular}

Other service structures that were measured for our own group can be found in the corresponding diploma theses. ${ }^{[227,228]}$ 


\section{REFERENCES}

[1] S. Trofimenko, J. Am. Chem. Soc. 1966, 88, 1842.

[2] a) J. P. Jesson, S. Trofimenko, D. R. Eaton, J. Am. Chem. Soc. 1967, 89, 3248; b) S. Trofimenko, J. Am. Chem. Soc. 1967, 89, 3170.

[3] S. Trofimenko, Chem. Rev. 1993, 93, 943.

[4] F. T. Edelmann, Angew. Chem. 2001, 113, 1704; Angew. Chem. Int. Ed. 2001, 40, 1656.

[5] M. Paneque, S. Sirol, M. Trujillo, E. Gutiérrez-Puebla, M. A. Monge, E. Carmona, Angew. Chem. 2000, 112, 224; Angew. Chem. Int. Ed. 2000, 39, 218.

[6] C. Slugovc, K. Mereiter, S. Trofimenko, E. Carmona, Chem. Commun. 2000, 121.

[7] Z. Hu, S. M. Gorun, Inorg. Chem. 2001, 40, 667.

[8] a) J. C. Calabrese, S. Trofimenko, J. S. Thompson, J. Chem. Soc., Chem. Commun. 1986, 1122; b) S. Trofimenko, J. C. Calabrese, J. S. Thompson, Inorg. Chem. 1987, 26, 1507.

[9] a) S. G. N. Roundhill, D. M. Roundhill, D. R. Bloomquist, C. Landee, R. D. Willett, D. M. Dooley, H. B. Gray, Inorg. Chem. 1979, 18, 831; b) J. S. Thompson, T. J. Marks, J. A. Ibers, J. Am. Chem. Soc. 1979, 101, 4180; c) J. S. Thompson, T. Sorrell, T. J. Marks, J. A. Ibers, J. Am. Chem. Soc. 1979, 101, 4193.

[10] D. L. Reger, J. R. Gardinier, W. R. Gemmill, M. D. Smith, A. M. Shahin, G. J. Long, L. Rebbouh, F. Grandjean, J. Am. Chem. Soc. 2005, 127, 2303.

[11] E. V. Mutseneck, S. Bieller, M. Bolte, H.-W. Lerner, M. Wagner, Inorg. Chem. 2010, 49, 3540.

[12] J. Bielawski, M. K. Das, E. Hanecker, K. Niedenzu, H. Nöth, Inorg. Chem. 1986, 25, 4623.

[13] S. Bieller, M. Bolte, H.-W. Lerner, M. Wagner, Chem. Eur. J. 2006, 12, 4735.

[14] T. A. Betley, J. C. Peters, Inorg. Chem. 2003, 42, 5074.

[15] A. A. Barney, A. F. Heyduk, D. G. Nocera, Chem. Commun. 1999, 2379.

[16] a) S. Trofimenko, J. Am. Chem. Soc. 1970, 92, 5118; b) H. Gornitzka, D. Stalke, Angew. Chem. 1994, 106, 695; Angew. Chem. Int. Ed. 1994, 33, 693; c) F. Breher, J. Grunenberg, S. C. Lawrence, P. Mountford, H. Rüegger, Angew. Chem. 2004, 116, 2575; Angew. Chem. Int. Ed. 2004, 43, 2521; d) A. Otero, J. Fernández-Baeza, A. Antiñolo, J. Tejeda, A. Lara-Sánchez, Dalton Trans. 2004, 1499; e) A. Hoffmann, U. Flörke, M. Schürmann, S. Herres-Pawlis, Eur. J. Org. Chem. 2010, 4136.

[17] D. Kratzert, D. Leusser, D. Stern, J. Meyer, F. Breher, D. Stalke, Chem. Commun. 2011, 47, 2931.

[18] W. H. Armstrong, A. Spool, G. C. Papaefthymiou, R. B. Frankel, S. J. Lippard, J. Am. Chem. Soc. 1984, 106, 3653. 
[19] N. Kitajima, K. Fujisawa, C. Fujimoto, Y. Moro-oka, S. Hashimoto, T. Kitagawa, K. Toriumi, K. Tatsumi, A. Nakamura, J. Am. Chem. Soc. 1992, 114, 1277.

[20] T. C. Higgs, C. J. Carrano, Inorg. Chem. 1997, 36, 291.

[21] K. Ruth, S. Tüllmann, H. Vitze, M. Bolte, H.-W. Lerner, M. C. Holthausen, M. Wagner, Chem. Eur. J. 2008, 14, 6745 .

[22] a) S. T. Prigge, A. S. Kolhekar, B. A. Eipper, R. E. Mains, L. M. Amzel, Science 1997, 278, 1300; b) S. T. Prigge, B. A. Eipper, R. E. Mains, L. M. Amzel, Science 2004, 304, 864.

[23] a) A. Otero, A. Lara-Sánchez, J. Fernández-Baeza, E. Martínez-Caballero, I. Márquez-Segovia, C. Alonso-Moreno, L. F. Sánchez-Barba, A. M. Rodríguez, I. López-Solera, Dalton Trans. 2010, 39, 930; b) S. Milione, F. Grisi, R. Centore, A. Tuzi, Organometallics 2006, 25, 266; c) S. C. Lawrence, B. D. Ward, S. R. Dubberley, C. M. Kozak, P. Mountford, Chem. Commun. 2003, 2880; d) G. Türkoglu, C. Pubill Ulldemolins, R. Müller, E. Hübner, F. W. Heinemann, M. Wolf, N. Burzlaff, Eur. J. Inorg. Chem. 2010, 2962.

[24] M. N. McCain, S. Schneider, M. R. Salata, T. J. Marks, Inorg. Chem. 2008, 47, 2534.

[25] a) E. E. Pullen, D. Rabinovich, C. D. Incarvito, T. E. Concolino, A. L. Rheingold, Inorg. Chem. 2000, 39, 1561; b) J. Grobe, R. Wehmschulte, B. Krebs, M. Läge, Z. Anorg. Allg. Chem. 1995, 621,583

[26] a) D. D. LeCloux, C. J. Tokar, M. Osawa, R. P. Houser, M. C. Keyes, W. B. Tolman, Organometallics 1994, 13, 2855; b) J. S. Fleming, E. Psillakis, J. C. Jeffery, K. L. V. Mann, J. A. McCleverty, M. D. Ward, Polyhedron 1998, 17, 1705; c) V. Chandrasekhar, B. Murugesapandian, Acc. Chem. Res. 2009, 42, 1047.

[27] A. Steiner, D. Stalke, Inorg. Chem. 1995, 34, 4846.

[28] M. A. Beswick, M. K. Davies, P. R. Raithby, A. Steiner, D. S. Wright, Organometallics 1997, 16, 1109.

[29] D. Leusser, J. Henn, N. Kocher, B. Engels, D. Stalke, J. Am. Chem. Soc. 2004, 126, 1781.

[30] J. Henn, D. Leusser, D. Ilge, D. Stalke, B. Engels, J. Phys. Chem. A 2004, 108, 9442.

[31] R. Fleischer, S. Freitag, D. Stalke, J. Chem. Soc., Dalton Trans. 1998, 193.

[32] R. Fleischer, S. Freitag, D. Stalke, Angew. Chem. 1996, 108, 208; Angew. Chem. Int. Ed. 1996, 35, 204.

[33] T. Schulz, D. Stalke, Chem. Eur. J. 2010, 2185.

[34] R. Fleischer, D. Stalke, Coord. Chem. Rev. 1998, 176, 431.

[35] C. Selinka, S. Deuerlein, T. Häuser, D. Stalke, Inorg. Chim. Acta 2004, 357, 1873.

[36] J. T. E. Meyer, T. Schulz, S. K. Pandey, D. Stalke, Inorg. Chem. 2010, 49, 2743.

[37] C. Selinka, D. Stalke, Z. Naturforsch., B: Chem. Sci. 2003, 58, 291.

[38] S. M. Deuerlein, PhD Thesis, Göttingen, 2007. 
[39] M. M. Meinholz, S. K. Pandey, S. M. Deuerlein, D. Stalke, Dalton Trans. 2011, 40, 1662.

[40] a) M. A. Casado, V. Hack, J. A. Camerano, M. A. Ciriano, C. Tejel, L. A. Oro, Inorg. Chem. 2005, 44, 9122; b) J. A. Camerano, M. A. Casado, M. A. Ciriano, C. Tejel, L. A. Oro, Chem. Eur. J. 2008, 14, 1897.

[41] a) R. G. Pearson, J. Am. Chem. Soc. 1963, 85, 3533; b) R. G. Parr, R. G. Pearson, J. Am. Chem. Soc. 1983, 105, 7512; c) R. G. Pearson, J. Am. Chem. Soc. 1985, 107, 6801.

[42] a) L. Lochmann, J. Pospíšil, D. Lim, Tetrahedron Lett. 1966, 257; b) M. J. Schlosser, J. Organomet. Chem. 1967, 8, 9.

[43] a) Y. Kondo, M. Shilai, M. Uchiyama, T. Sakamoto, J. Am. Chem. Soc. 1999, 121, 3539; b) T. Imahori, M. Uchiyama, T. Sakamoto, Y. Kondo, Chem. Commun. 2001, 23, 2450.

[44] A. Krasovskiy, P. Knochel, Angew. Chem. 2004, 116, 3396; Angew. Chem. Int. Ed. 2004, 43, 3333.

[45] a) P. C. Andrikopoulos, D. R. Armstrong, D. V. Graham, E. Hevia, A. R. Kennedy, R. E. Mulvey, C. T. O'Hara, C. Talmard, Angew. Chem. 2005, 117, 3525; Angew. Chem. Int. Ed. 2005, 44, 3459; b) R. E. Mulvey, Acc. Chem. Res. 2009, 42, 743.

[46] S. Merkel, D. Stern, J. Henn, D. Stalke, Angew. Chem. 2009, 121, 6468; Angew. Chem. Int. Ed. 2009, 48, 6350 .

[47] F. M. Piller, A. Metzger, M. A. Schade, B. A. Haag, A. Gavryushin, P. Knochel, Chem. Eur. J. 2009, 15, 7192.

[48] Available from Aldrich and Chemmetall $\mathrm{GmbH}$

[49] A. Krasovskiy, V. Krasovskaya, P. Knochel, Angew. Chem. 2006, 118, 3024; Angew. Chem. Int. Ed. 2006, 45, 2958.

[50] a) C. R. Hauser, H. G. Walker Jr., J. Am. Chem. Soc. 1947, 69, 295; b) F. C. Frostick Jr., C. R. Hauser, J. Am. Chem. Soc. 1949, 71, 1350.

[51] J. García-Álvarez, D. V. Graham, E. Hevia, A. R. Kennedy, J. Klett, R. E. Mulvey, C. T. O’Hara, S. Weatherstone, Angew. Chem. 2008, 120, 8199; Angew. Chem. Int. Ed. 2008, 47, 8079.

[52] E. Hevia, D. J. Gallagher, A. R. Kennedy, R. E. Mulvey, C. T. O'Hara, C. Talmard, Chem. Commun. 2004, 2422.

[53] W. Clegg, K. W. Henderson, A. R. Kennedy, R. E. Mulvey, C. T. O'Hara, R. B. Rowlings, D. M. Tooke, Angew. Chem. 2001, 113, 4020; Angew. Chem. Int. Ed. 2001, 40, 3902.

[54] A. R. Kennedy, J. Klett, R. E. Mulvey, D. S. Wright, Science 2009, 326, 706.

[55] P. Braunstein, F. Naud, Angew. Chem. 2001, 113, 702; Angew. Chem. Int. Ed. 2001, 40, 680.

[56] D. Hänssgen, H. Hupfer, M. Nieger, M. Pfendtner, R. Steffens, Z. Anorg. Allg. Chem. 2001, 627, 17.

[57] T. Schulz, Diploma thesis, Würzburg (GER), 2006. 
[58] R. Fleischer, D. Stalke, Organometallics 1998, 17, 832.

[59] D. Hänssgen, R. Steffens, Z. Anorg. Allg. Chem. 1983, 507, 178.

[60] H. H. Karsch, H. Schmidbaur, Z. Naturforsch. 1977, 32B, 762.

[61] L. M. Engelhardt, G. E. Jacobsen, C. L. Raston, A. H. White, J. Chem. Soc., Chem. Commun. 1984, 220.

[62] L. T. Byrne, L. M. Engelhardt, G. E. Jacobsen, W.-P. Leung, R. I. Papasergio, C. L. Raston, B. W. Skelton, P. Twiss, A. H. White, J. Chem. Soc., Dalton Trans. 1989, 105.

[63] L. Wang, E. Hauptman, L. K. Johnson, E. F. McCord, Y. Wang, S. D. Ittel, US6897275B2, 2005.

[64] a) G. C. Eberhardt, W. A. Butte, J. Org. Chem. 1964, 29, 2928; b) D. J. Peterson, J. Organomet. Chem. 1967, 8, 199.

[65] G. Fraenkel, W. R. Winchester, Organometallics 1989, 8, 2308.

[66] S. Blaurock, O. Kühl, E. Hey-Hawkins, Organometallics 1997, 16, 807.

[67] P. Rademacher, Strukturen Organischer Moleküle, VCH, New York, 1987.

[68] Cambridge Structural Database, v5.32, Cambridge Crystallographic Data Centre, Cambridge, 2010.

[69] a) D. Stalke, Proc. Indian Acad. Sci. 2000, 112, 155; b) J. K. Brask, T. Chivers, Angew. Chem. 2001, 113, 4082; Angew. Chem. Int. Ed. 2001, 40, 3960.

[70] W. Clegg, K. Izod, W. McFarlane, P. O'Shaughnessy, Organometallics 1998, 18, 3950.

[71] MestreNova, three-spin system ABC (C-P-P); A: v $=0$ ppm, $J_{A B}=18.3 \mathrm{~Hz}, J_{A C}=0 \mathrm{~Hz}, \mathrm{~B}: v=$ $1000 \mathrm{ppm}, J_{\mathrm{AB}}=18.3 \mathrm{~Hz}, J_{\mathrm{BC}}=8.6 \mathrm{~Hz}, \mathrm{C}: \mathrm{v}=1000.002 \mathrm{ppm}, J_{\mathrm{CA}}=0 \mathrm{~Hz}, J_{\mathrm{CB}}=8.6 \mathrm{~Hz}$.

[72] S. Deuerlein, D. Leusser, U. Flierler, H. Ott, D. Stalke, Organometallics 2008, 27, 2306.

[73] M. Hesse, H. Meier, B. Zeeh, Spektroskopische Methoden in der organischen Chemie, Thieme, Stuttgart, 2005.

[74] O. J. Scherer, R. Wies, Z. Naturforsch. 1970, 25b, 1486.

[75] A. M. Aguiar, G. W. Prejean, J. R. S. Irelan, C. J. Morrow, J. Org. Chem. 1969, 34, 4024.

[76] a) Z. Fei, N. Kocher, C. J. Mohrschladt, H. Ihmels, D. Stalke, Angew. Chem. 2003, 115, 807; Angew. Chem. Int. Ed. 2003, 42, 783; b) G. Schwab, D. Stern, D. Leusser, D. Stalke, Z. Naturforsch. 2007, 62b, 711; c) G. Schwab, D. Stern, D. Stalke, J. Org. Chem. 2008, 73, 5242.

[77] T. Chivers, M. Krahn, M. Parvez, G. Schatte, Chem. Commun. 2001, 1922.

[78] T. Chivers, M. Krahn, M. Parvez, G. Schatte, Inorg. Chem. 2001, 40, 2547.

[79] V. H. Gessner, C. Strohmann, J. Am. Chem. Soc. 2008, 130, 14412.

[80] a) D. Leusser, B. Walfort, D. Stalke, Angew. Chem. 2002, 114, 2183; Angew. Chem. Int. Ed. 2002, 41, 2079; b) B. Walfort, D. Stalke, Angew. Chem. 2001, 113, 3965; Angew. Chem. Int. Ed. 2001, 40, 3846.

[81] S. Freitag, W. Kolodziejski, F. Pauer, D. Stalke, Dalton Trans. 1993, 3479. 
[82] B. Walfort, A. P. Leedham, C. A. Russell, D. Stalke, Inorg. Chem. 2001, 40, 5668.

[83] J. C. Thomas, J. C. Peters, Inorg. Chem. 2003, 42, 5055.

[84] F. Eisenträger, A. Göthlich, I. Gruber, H. Heiss, C. A. Kiener, C. Krüger, J. U. Notheis, F. Rominger, G. Scherhag, M. Schultz, B. F. Straub, M. A. O. Volland, P. Hofmann, New. J. Chem. 2003, 27, 540.

[85] F. T. Edelmann, F. Knösel, F. Pauer, D. Stalke, W. Bauer, J. Organomet. Chem. 1992, 438, 1.

[86] T. Stey, D. Stalke in: Z. Rappoport, I. Marek (Eds.), The Chemistry of Organolithium Compounds, Wiley, New York, 2004.

[87] M. Müller, H.-W. Lerner, M. Bolte, Acta Cryst. 2008, E64, m803.

[88] a) A. R. Lepley, W. A. Khan, A. B. Giumanini, A. G. Giumanini, J. Org. Chem. 1966, 31, 2047; b) E. B. Pederson, J. Chem. Soc., Perkin Trans. 2 1977, 473; c) S.-I. Murahashi, T. Naota, Y. Tanigawa, Org. Synth. Col. 1984, 62, 39.

[89] D. Bojer, I. Kamps, X. Tian, A. Hepp, T. Pape, R. Fröhlich, N W. Mitzel, Angew. Chem. 2007, 119, 4254; Angew. Chem. Int. Ed. 2007, 46, 4176-4179.

[90] E. Weiss, Angew. Chem. 1993, 105, 1565; Angew. Chem. Int. Ed. Engl. 1993, 32, 1501.

[91] A. Streitwieser, Jr., J. E. Williams, Jr., J. M. McKelvey, J. Am. Chem. Soc. 1976, 98, 4778.

[92] E. Kaufmann, K. Raghavachari, A. E. Reed, P. v. R. Schleyer, Organometallics 1988, 7, 1597.

[93] a) F. M. Bickelhaupt, M. Solà, C. F. Guerra, J. Chem. Theor. Comput. 2006, 2, 965; b) E. Matito, J. Poater, F. M. Bickelhaupt, M. Solà, J. Phys. Chem. 2006, B110, 7189.

[94] E. Weiss, G. Henken, J. Organomet. Chem. 1970, 21, 265.

[95] H. J. Dietrich, J. Organomet. Chem. 1981, 205, 291.

[96] T. Kottke, D. Stalke, Angew. Chem. 1993, 105, 619; Angew. Chem. Int. Ed. 1993, 32, 580.

[97] C. Strohmann, V. H. Gessner, J. Am. Chem. Soc. 2007, 129, 8952.

[98] M. Schlosser, Organoalkali Reagents in Organometallics in Synthesis, A Manual. M. Schlosser (Ed.), John Wiley \& Sons: New York, 2002.

[99] H. Hope, P. P. Power, J. Am. Chem. Soc. 1983, 105, 5320.

[100] R. G. Pearson, J. Am. Chem. Soc. 1985, 107, 6801.

[101] S. Harder, J. Boersma, L. Brandsma, J. A. Kanters, W. Bauer, P. v. R. Schleyer, Organometallics 1989, 8, 1696.

[102] a) E. O. Stejskal, J. E. Tanner, J. Chem. Phys. 1965, 42, 288; b) E. O. Stejskal, J. Chem. Phys. 1965, 43, 3597.

[103] K. F. Morris, C. S. Johnson Jr., J. Am. Chem. Soc. 1992, 114, 3139.

[104] J. T. Edward, J. Chem. Educ. 1970, 47, 261.

[105] G. Kagan, W. Li, R. Hopson, P. G. Williard, Org. Lett. 2009, 11, 4818.

[106] I. Keresztes, P. G. Williard, J. Am. Chem. Soc. 2000, 122, 10228. 
[107] D. Li, I. Keresztes, R. Hopson, P. G. Williard, Acc. Chem. Res. 2009, 42, 270.

[108] All NMR studies on this system were conducted by Ann-Christin Pöppler, to whom I am very grateful.

[109] R. D. Thomas, M. T. Clarke, T. C. Young, J. Organomet. Chem. 1987, 328, 239.

[110] R. D. Thomas, M. T. Clarke, R. M. Jensen, T. C. Young, Organometallics 1986, 5, 1851.

[111] V. Snieckus, Chem. Rev. 1990, 90, 879; M. C. Whisler, S. MacNeil, V. Snieckus, P. Beak, Angew. Chem. 2004, 116, 2256; Angew. Chem. Int. Ed. 2004, 43, 2206.

[112] CRC Handbook of Chemistry and Physics (Ed. D. R. Lide), Taylor \& Francis, Boca Raton, 2006.

[113] a) H. Gilman, F. J. Webb, J. Am. Chem. Soc. 1940, 62, 987; b) H. Gilman, S. M. Spatz, J. Org. Chem. 1952, 17, 860; c) D. J. Peterson, H. R. Hays, J. Org. Chem. 1965, 30, 1939; d) S. V. Kessar, P. Singh, Chem. Rev. 1997, 97, 721.

[114] A. I. Shatenslitein, H. A. Gvozdera, Tetrahedron 1969, 25, 2749.

[115] a) D. J. Peterson, J. Organomet. Chem. 1970, 21, 63; b) D. J. Peterson, J. F. Ward, J. Organomet. Chem. 1974, 66, 209.

[116] a) T. Cohen, J. R. Matz, J. Am.Chem. Soc. 1980, 102, 6900; b) C. A. Broka, T. J. Shen, J. Am. Chem. Soc. 1989, 111, 2981; c) C. Strohmann, B. C. Abele, Angew. Chem. 1996, 108, 2514; Angew. Chem. Int. Ed. 1996, 35, 2378.

[117] R. E. Gawley, Q. Zhang, J. Org. Chem. 1995, 60, 5763.

[118] a) A. Hildebrand, P. Lönnecke, L. Silaghi-Dumitrescu, I. Silaghi-Dumitrescu, E. Hey-Hawkins, Dalton Trans. 2006, 967.

[119] C. Strohmann, V. H. Gessner, Angew. Chem. 2007, 119, 4650; Angew. Chem. Int. Ed. 2007, 46,4566 .

[120] C. Strohmann, V. H. Gessner, Angew. Chem. 2007, 119, 8429; Angew. Chem. Int. Ed. 2007, 46,8281 .

[121] H. H. Karsch, Chem. Ber. 1996, 129, 483.

[122] H. Ott, PhD thesis, Göttingen (GER), 2008.

[123] K. Izod, J. C. Stewart, W. Clegg, R. W. Harrington, Dalton Trans. 2007, 257.

[124] J. D. Smith, Adv. Organomet. Chem. 1998, 43, 267.

[125] M. A. Beswick, N. Choi, A. D. Hopkins, M. McPartlin, M. A. Paver, D. S. Wright, Chem. Commun. 1998, 261.

[126] D. Hoffmann, W. Bauer, P. v. R. Schleyer, U. Pieper, D. Stalke, Organometallics 1993, 12, 1193.

[127] U. Pieper, D. Stalke, Organometallics 1993, 12, 1201.

[128] G. Bai, H. W. Roesky, M. Noltemeyer, H.-G. Schmidt, Organometallics 2002, 21, 2789. 
[129] M. Herberhold, S. Gerstmann, W. Milius, B. Wrackmeyer, H. Borrmann, Phosphorus, Sulfur, Silicon Relat. Elem. 1996, 112, 261.

[130] a) D. Leusser, J. Henn, N. Kocher, B. Engels, D. Stalke, J. Am. Chem. Soc. 2004, 126, 1781; b) J. Henn, D. Leusser, D. Ilge, D. Stalke, B. Engels, J. Phys. Chem. A 2004, 108, 9442.

[131] T. Schulz, PhD thesis, Göttingen (GER), 2010.

[132] a) D. Olbert, H. Görls, D. Conrad, M. Westerhausen, Eur. J. Inorg. Chem. 2010, 12, 1791; b) H. Nöth, S. Rojas-Lima, A. Troll, Eur. J. Inorg. Chem. 2005, 10, 1895.

[133] a) H. Ott, U. Pieper, D. Leusser, U. Flierler, J. Henn, D. Stalke, Angew. Chem. 2009, 121, 3022; Angew. Chem. Int. Ed. 2009, 48, 2978; b) P. Macchi, Angew. Chem. 2009, 121, 5905; Angew. Chem. Int. Ed. 2009, 48, 5793.

[134] V. H. Gessner, C. Däschlein, C. Strohmann, Chem. Eur. J. 2009, 15, 3320.

[135] a) H. Yuge, T. K. Miyamoto, Inorg. Chim. Acta 2002, 329, 66; b) M. Montfort, I. Resino, J. Ribas, X. Solans, M. Font-Bardia, N. J. Chem. 2001, 25, 1577 ; c) sligthly modified: F. Voigt, A. Fischer, C. Pietzsch, K. Jacob, Z. Anorg. Allg. Chem. 2001, 627, 2337.

[136] A. W. Addison, T. Nageswara Rao, J. Reedijk, J. van Rijn, G. C. Verschoor, Dalton Trans. 1984, 1349.

[137] S. Sripothongnak, A. M. Pischera, M. P. Espe, W. S. Durfee, C. J. Ziegler, Inorg. Chem. 2009, 48,1293

[138] a) I. Cragg-Hine, M. G. Davidson, F. S. Mair, P. R. Raithby, R. Snaith, J. Chem. Soc., Dalton Trans. 1993, 2423; b) M. L. Cole, A. J. Davies, C. Jones, P. C. Junk, New J. Chem. 2005, 29, 1404.

[139] F. Pauer, D. Stalke, J. Organomet. Chem. 1991, 418, 127.

[140] P. C. Andrews, D. R. Armstrong, C. L. Raston, B. A. Roberts, B. W. Skelton, A. H. White, Dalton Trans. 2001, 996.

[141] P. B. Hitchcock, M. F. Lappert, P. G. Merle, Dalton Trans. 2007, 585.

[142] D. J. Peterson, J. H. Collins, J. Org. Chem. 1966, 31, 2373.

[143] J. W. F. L. Seetz, G. Schat, O. S. Akkerman, F. Bickelhaupt, J. Am. Chem. Soc. 1982, 104, 6848.

[144] C. Strohmann, Angew. Chem. 1996, 108, 600; Angew. Chem. Int. Ed. 1996, 35, 528.

[145] V. H. Gessner, S. Dilsky, C. Strohmann, Chem. Commun. 2010, 46, 4719.

[146] a) F. M. Mackenzie, R. E. Mulvey, J. Am. Chem. Soc. 1996, 118, 4721; b) X. Wei, Q. Dong, H. Tong, J. Chao, D. Liu, M. F. Lappert, Angew. Chem. 2008, 120, 4040; Angew. Chem. Int. Ed. 2008, 47, 3976.

[147] R. E. Mulvey, Chem. Soc. Rev. 1998, 27, 339. 
[148] C. Drost, C. Jager, S. Freitag, U. Klingebiel, M. Noltemeyer, G. M. Sheldrick, Chem. Ber. 1994, 127, 845 .

[149] M. B. Hursthous, M. A. Hossain, M. Motevdli, M. Sanganee, A. C. Sullivan, J. Organomet. Chem. 1990, 381, 293.

[150] A. R. Kennedy, R. E. Mulvey, R. B. Rowlings, J. Am. Chem. Soc. 1998, 120, 7816.

[151] a) A. R. Kennedy, R. E. Mulvey, R. B. Rowlings, Angew. Chem. 1998, 110, 3321; Angew. Chem. Int. Ed. 1998, 37, 3180; b) A. R. Kennedy, R. E. Mulvey, C. L. Raston, B. A. Roberts, R. B. Rowlings, Chem. Commun. 1999, 353; c) R. E. Mulvey, Chem. Commun. 2001, 1049.

[152] D. J. Gallagher, K. W. Henderson, A. R. Kennedy, C. T. O’Hara, R. E. Mulvey, R. B. Rowlings, Chem. Commun. 2002, 376.

[153] D. R. Armstrong, A. R. Kennedy, R. E. Mulvey, R. B. Rowlings, Angew. Chem. 1999, 111, 231; Angew. Chem. Int. Ed. 1999, 38, 131.

[154] A. J. Chalk, T. J. Hoogeboom, J. Organomet. Chem. 1968, 11, 615.

[155] R. Fleischer, D. Stalke, J. Organomet. Chem. 1998, 550, 173.

[156] a) S. Blair, K. Izod, W. Clegg, R. W. Harrington, Eur. J. Inorg. Chem. 2003, 3319; b) S. Blair, K. Izod, W. Clegg, Inorg. Chem. 2002, 41, 3886.

[157] A. Pape, M. Lutz, G. Müller, Angew. Chem. 1994, 106, 2375; Angew. Chem. Int. Ed. 1994, 33, 2281

[158] a) F. Pauer, J. Rocha, D. Stalke, Chem. Commun. 1991, 20, 1477; b) R. Fleischer, B. Walfort, A. Gbureck, P. Scholz, W. Kiefer, D. Stalke, Chem. Eur. J. 1998, 4, 2266.

[159] a) M. R. Crimmin, I. J. Casely, M. S. Hill, J. Am Chem. Soc. 2005, 127, 2042; b) M. R. Crimmin, A. G. M. Barrett, M. S. Hill, P. B. Hitchcock, P. A. Procopiou, Organometallics 2007, 26, 2953; c) M. R. Crimmin, A. G. M. Barrett, M. S. Hill, P. B. Hitchcock, P. A. Procopiou, Organometallics 2008, 27, 497.

[160] F. Buch, J. Brettar, S. Harder, Angew. Chem. 2006, 118, 2807; Angew. Chem. Int. Ed. 2006 45,2741

[161] W. E. Lindsell, F. C. Robertson, I. Souter, Eur. Polym. J. 1983, 19, 115.

[162] a) M. Kaupp, P. v. R. Schleyer, H. Stoll, H. Preuss, J. Chem. Phys. 1991, 94, 1360; b) M. Kaupp, P. v. R. Schleyer, J. Am. Chem. Soc. 1992, 114, 491.

[163] R. Fleischer, D. Stalke, Inorg. Chem. 1997, 36, 2413.

[164] G. Mösges, F. Hampel, M. Kaupp, P. v. R. Schleyer, J. Am. Chem. Soc. 1992, 114, 10880.

[165] a) S. Blair, K. Izod, W. Clegg, Inorg. Chem. 2002, 41, 3886; b) P. W. Roesky, Inorg. Chem. 2006, 45, 798; c) S. Datta, M. T. Gamer, P. W. Roesky, Dalton Trans. 2008, 2839.

[166] T. P. Hanusa, Chem. Rev. 1993, 93, 1023. 
[167] a) C. Eaborn, P. B. Hitchcock, K. Izod, Z.-R. Lu, J. D. Smith, Organometallics 1996, 15, 4783; b) H. Schumann, S. Schutte, H.-J. Kroth, D. Lentz, Angew. Chem. 2004, 116, 6335; Angew. Chem. Int. Ed. 2004, 43, 6208; c) S. Harder, Angew. Chem. 2004, 116, 2768; Angew. Chem. Int. Ed. 2004, 43, 2714.

[168] N. N. Greenwood, A. Earnshaw, Chemie der Elemente, 1. Aufl. (Nachdr.), VCH, Weinheim (GER), 1990.

[169] R. D. Shannon, Acta Cryst. 1976, A32, 751.

[170] K. Abdur-Rashid, T. Graham, C.-W. Tsang, X. Chen, R. Guo, W. Jia, D. Amoroso, C. Sui-Seng, WO2008141439A1, 2008.

[171] a) T. B. Marder, Angew. Chem. 2007, 119, 8262; Angew. Chem. Int. Ed. 2007, 46, 8116; b) F. H. Stephens, V. Pons, R. T. Baker, Dalton Trans. 2007, 2613.

[172] a) B. L. Small, M. Brookhart, A. M. A. Bennett, J. Am. Chem. Soc. 1998, 120, 4049; b) G. J. P. Britovsek, M. Bruce, V. C. Gibson, B. S. Kimberley, P. J. Maddox, S. Mastroianni, S. J. McTavish, C. Redshaw, G. A. Solan, S. Strömberg, A. J. P. White, D. J. Williams, J. Am. Chem. Soc. 1999, 121, 8728; d) C. Bianchini, G. Mantovani, A. Meli, F. Migliacci, F. Zanobini, F. Laschi, A. Sommazzi, Eur. J. Inorg. Chem. 2003, 1620.

[173] M. M. P. Grutters, C. Müller, D. Vogt, J. Am. Chem. Soc. 2006, 128, 7414.

[174] M. Takata, K. Kashiwabara, H. Ito, T. Ito, J. Fujita, Bull. Chem. Soc. Jpn. 1985, 58, 2247.

[175] a) M. Atoh, K. Kashiwabara, J. Fujita, Bull. Chem. Soc. Jpn. 1985, 58, 3492; b) M. Atoh, H. O. Sørensen, P. Andersen, Acta Chem. Scand. 1997, 51, 1169.

[176] J. Bennett, R. J. Doyle, G. Salem, A. C. Willis, Dalton. Trans. 2006, 4614.

[177] a) Y. A. Simonov, N. V. Gerbeleu, M. Gnadets, P. N. Bourosh, E. B. Koropchanu, O. A. Bologa, Koord. Khim. (Rus. J. Coord. Chem.) 2001, 27, 386; b) N. Bresciani-Pahor, M. Calligaris, L. Randaccio, P. J. Toscano, J. Chem. Soc., Dalton Trans. 1982, 1009; c) B. D. Gupta, K. Qanungo, R. Yamuna, A. Pandey, U. Tewari, V. Vijaikanth, V. Singh, T. Barclay, W. Cordes, J. Organomet. Chem. 2000, 608, 106; d) T. Yamada, Y. Ohashi, Bull. Chem. Soc. Jpn. 1998, 71, 2527.

[178] a) S. C. Bart, E. Lobkovsky, P. J. Chirik, J. Am. Chem. Soc. 2004, 126, 13794; b) S. C. Bart, E. J. Hawrelak, E. Lobkovsky, P. J. Chirik, Organometallics 2005, 24, 5518; c) Q. Knijnenburg, A. D. Horton, H. van der Heijden, A. W. Gal, P. Budzelaar, M. Henricus, WO2003042131, 2003; d) A. Mikhailine, F. Freutel, N. Meyer, R. H. Morris, P. O. Lagaditis, US20100145087A1, 2010.

[179] V. V. K. M. Kandepi, J. M. S. Cardoso, E. Peris, B. Royo, Organometallics 2010, 29, 2777.

[180] a) C. Bianchini, G. Mantovani, A. Meli, F. Migliacci, F. Zanobini, F. Laschi, A. Sommazzi, Eur. J. Inorg. Chem. 2003, 1620; b) B. L. Small, M. Brookhart, Macromolecules 1999, 32, 2120; c) T. 
M. Smit, A. K. Tomov, V. C. Gibson, A. J. P. White, D. J. Williams, Inorg. Chem. 2004, 43, 6511; d) M. W. Bouwkamp, E. Lobkovsky, P. J. Chirik, J. Am. Chem. Soc. 2005, 127, 9660.

[181] a) M. Tamura, J. K. Kochi, J. Am. Chem. Soc. 1971, 93, 1487; b) A. Fürstner, A. Leitner, Angew. Chem. 2002, 114, 632; Angew. Chem. Int. Ed. 2002, 41, 609; c) A. Fürstner, A. Leitner, M. Méndez, H. Krause, J. Am. Chem. Soc. 2002, 124, 13856.

[182] R. J. Trovitch, E. Lobkovsky, M. W. Bouwkamp, P. J. Chirik, Organometallics 2008, 27, 6264.

[183] C. Bolm, J. Legros, J. Le Paih, L. Zani, Chem. Rev. 2004, 104, 6217.

[184] C. Sui-Seng, F. Freutel, A. J. Lough, R. H. Morris, Angew. Chem. 2008, 120, 954; Angew. Chem. Int. Ed. 2008, 47, 940.

[185] a) R. Noyori, S. Hashiguchi, Acc. Chem. Res. 1997, 30, 97; b) T. Ikariya, A. J. Blacker, Acc. Chem. Res. 2007, 40, 1300.

[186] P. O. Lagaditis, A. A. Mikhailine, A. J. Lough, R. H. Morris, Inorg. Chem. 2010, 49, 1094.

[187] A. Kermagoret, F. Tomicki, P. Braunstein, Dalton Trans. 2008, 22, 2945.

[188] D. Benito-Garagorri, E. Becker, J. Wiedermann, W. Lackner, M. Pollack, K. Mereiter, J. Kisala, K. Kirchner, Organometallics 2006, 25, 1900.

[189] A. Murso, D. Stalke, Dalton Trans. 2004, 2563.

[190] V. Rautenstrauch, X. Hoang-Cong, R. Churlaud, K. Abdur-Rashid, R. H. Morris, Chem. Eur. J. 2003, 9, 4954.

[191] S. Gladiali, E. Alberico, Chem. Soc. Rev. 2006, 35, 226.

[192] G. Glatz, S. Demeshko, G. Motz, R. Kempe, Eur. J. Inorg. Chem. 2009, 1385.

[193] J. Volbeda, A. Meetsma, M. W. Bouwkamp, Organometallics 2009, 28, 209.

[194] B. Walfort, T. Auth, B. Degel, H. Helten, D. Stalke, Organometallics 2002, 21, 2208.

[195] a) D. Fenske, H. Krautscheid, S. Balter, Angew. Chem. 1990, 102, 799; Angew. Chem. Int. Ed. 1990, 29, 796; b) D. Fenske, J.-C. Steck, Angew. Chem. 1993, 105, 254; Angew. Chem. Int. Ed. 1993, 32, 238; c) J.-P. Lang, H. Kawaguchi, K. Tatsumi, Chem. Commun. 1999, 2315.

[196] D. Fenske, H. Krautscheid, M. Müller, Angew. Chem. 1992, 104, 309; Angew. Chem. Int. Ed. $1992,31,321$.

[197] S. Dehnen, D. Fenske, Chem. Eur. J. 1996, 2, 1407.

[198] a) P. Pyykkö, Chem. Rev. 1997, 97, 597; b) H. L. Hermann, G. Boche, P. Schwerdtfeger, Chem. Eur. J. 2001, 7, 5333.

[199] U. Englich, K. Hassler, K. Ruhlandt-Senge, F. Uhlig, Inorg. Chem. 1998, 37, 3532.

[200] G. W. Rabe, S. Kheradmandan, L. M. Liable-Sands, I. A. Guzei, A. L. Rheingold, Angew. Chem. 1998, 110, 1495; Angew. Chem. Int. Ed. 1998, 37, 1404.

[201] K. Izod, W. Clegg, S. T. Liddle, Organometallics 2001, 20, 367.

[202] W. Clegg, A. M. Drummond, R. E. Mulvey, S. T. Liddle, Chem. Commun. 1998, 2391. 
[203] D. R. Armstrong, W. Clegg, A. M. Drummond, S. T. Liddle, R. E. Mulvey, J. Am. Chem. Soc. 2000, 122, 11117.

[204] T. Gelbrich, T. L. Threlfall, S. Huth, E. Seeger, Polyhedron 2006, 25, 937.

[205] M. Westerhausen, S. Weinrich, G. Kramer, H. Piotrowski, Inorg. Chem. 2002, 41, 7072.

[206] D. llge, D. S. Wright, D. Stalke, Chem. Eur. J. 1998, 4, 2275.

[207] I. Ruppert, V. Bastian, R. Appel, Chem. Ber. 1975, 108, 2329.

[208] G. van Koten, A. J. Leusink, J. G. Noltes, J. Organomet. Chem. 1975, 85, 105.

[209] a) T. Tsuda, T. Hashimoto, T. Saegusa, J. Am. Chem. Soc. 1972, 94, 658; b) T. Greiser, E. Weiss, Chem. Ber. 1976, 109, 3142.

[210] a) W. Schlenk, J. Holtz, Ber. Dtsch. Chem. Ges. 1917, 50, 262; b) W. Schlenk, Die Methoden der Organischen Chemie in Die Methoden der Organischen Chemie (Ed. J. Houben), G. Thieme, Leipzig, 1924, p. 720.

[211] O. J. Scherer, G. Wolmershäuser, Z. Anorg. Allg. Chem. 1977, 432, 173.

[212] O. J. Scherer, R. Wies, Z. Naturforsch. 1970, 25b, 1486-1487.

[213] a) T. Kottke, D. Stalke, J. Appl. Crystallogr. 1993, 26, 615; b) D. Stalke, Chem. Soc. Rev. 1998, $27,171$.

[214] picture by Dr. Christian Kling

[215] T. Schulz, K. Meindl, D. Leusser, D. Stern, J. Graf, C. Michaelsen, M. Ruf, D. Stalke, J. Appl. Crystallogr. 2009, 42, 885.

[216] a) Bruker APEX v2.2-0, Bruker AXS Inst. Inc., Madison (WI, USA), 2007; b) Bruker APEX v2009.11-0, Bruker AXS Inst. Inc., Madison (WI, USA), 2009; c) Bruker APEX v2010.7-0, Bruker AXS Inst. Inc., Madison (WI, USA), 2010.

[217] a) SAINT v7.46A in Bruker APEX v2.2-0, Bruker AXS Inst. Inc., Madison (WI, USA), 2007; b) SAINT v7.68A in Bruker APEX v2009.11-0, Bruker AXS Inst. Inc., Madison (WI, USA), 2009; c) SAINT v7.68A in Bruker APEX v2010.7-0, Bruker AXS Inst. Inc., Madison (WI, USA), 2010.

[218] a) G. M. Sheldrick, SADABS 2008/1, Göttingen (GER), 2008; b) G. M. Sheldrick, SADABS 2008/2, Göttingen (GER), 2008.

[219] G. M. Sheldrick, XPREP in SHELXTL v6.12, Bruker AXS Inst. Inc., Madison (WI, USA), 2000.

[220] G. M. Sheldrick, Acta Crystallogr., Sect. A 2008, 64, 112; V. V. Zhurov, E. A. Zhurova, A. A. Pinkerton, J. Appl. Crystallogr. 2008, 41, 340

[221] W. Massa, Crystal Structure Determination, Springer, Berlin, 2004.

[222] P. Müller, Crystallogr. Rev. 2009, 15, 57.

[223] P. Müller, R. Herbst-Irmer, A. L. Spek, T. R. Schneider, M. R. Sawaya, Crystal Structure Refinement - A Crystallographer's Guide to SHELXL in IUCr Texts on Crystallography, Vol. 8 (Ed. P. Müller), Oxford University Press, Oxford (UK), 2006. 
[224] PLATON v1.081, University of Glasgow, Glasgow (UK), 2005.

[225] H. D. Flack, Acta Cryst. 1983, A39, 876.

[226] H. Böckemeier, PhD thesis, Göttingen (GER), 2011.

[227] E. Carl, Diploma thesis, Göttingen (GER), 2010 (EC50, EC99)

[228] R. G. Michel, Diploma thesis, Göttingen (GER), 2010 (RMA10, RMA16, RMA18, RMA23, RMA33) 